\title{
Identifikationspotenziale in den Psalmen
}

Emotionen, Metaphern und Textdynamik in den Psalmen 30, 64, 90 und 147

\section{Bonn University Press}




\section{V\&R unipress}

Open-Access-Publikation im Sinne der CC-Lizenz BY-NC-ND 4.0

(c) 2019, V\&R unipress $\mathrm{GmbH}$, Göttingen

ISBN Print: 9783847109808 - ISBN E-Lib: 9783737009805 


\section{Bonner Biblische Beiträge}

Band 183

herausgegeben von

Ulrich Berges und Martin Ebner 


\author{
Sigrid Eder
}

\title{
Identifikationspotenziale in den Psalmen
}

Emotionen, Metaphern und Textdynamik in den Psalmen 30, 64, 90 und 147

\section{V\&R unipress}

Bonn University Press 


\section{1 \\ universitätbonnl}

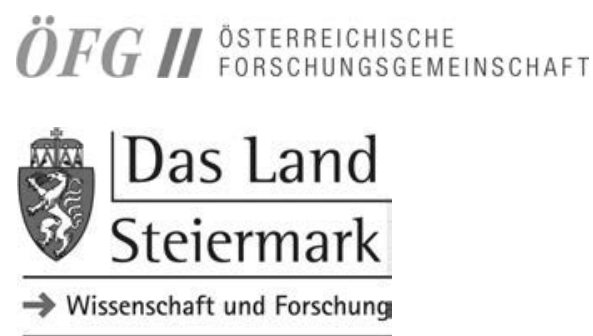

Bibliografische Information der Deutschen Nationalbibliothek

Die Deutsche Nationalbibliothek verzeichnet diese Publikation in der Deutschen

Nationalbibliografie; detaillierte bibliografische Daten sind im Internet über

http://dnb.d-nb.de abrufbar.

Veröffentlichungen der Bonn University Press

erscheinen im Verlag V\&R unipress GmbH.

Gedruckt mit freundlicher Unterstützung des Bischöflichen Fonds zur Förderung der Katholischen Privat-Universität Linz, der Österreichischen Forschungsgemeinschaft (ÖFG) und des Landes Steiermark.

2., veränderte Auflage

(C) 2019, 2018, V\&R unipress GmbH, Robert-Bosch-Breite 6, D-37079 Göttingen

Dieses Werk ist als Open-Access-Publikation im Sinne der Creative-Commons-Lizenz BY-NC-ND International 4.0 (»Namensnennung - Nicht kommerziell - Keine Bearbeitungen«) unter dem DOI 10.14220/ 9783737009805 abzurufen. Um eine Kopie dieser Lizenz zu sehen, besuchen Sie https://creativecommons.org/licenses/by-nc-nd/4.0/.

Jede Verwertung in anderen als den durch diese Lizenz zugelassenen Fällen bedarf der vorherigen schriftlichen Einwilligung des Verlages.

Vandenhoeck \& Ruprecht Verlage | www.vandenhoeck-ruprecht-verlage.com

ISSN 0520-5670

ISBN 978-3-7370-0980-5 


\section{Inhalt}

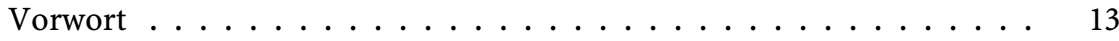

Abkürzungen $\ldots \ldots \ldots \ldots \ldots \ldots \ldots \ldots \ldots \ldots$

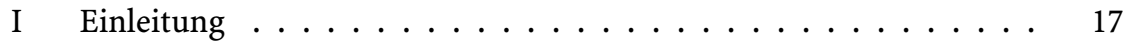

1 Hinführung zum Thema . . . . . . . . . . . . . . 17

2 Aktualität der Psalmen . . . . . . . . . . . . . . . . . 19

3 Forschungsfragen und Aufbau der Arbeit . . . . . . . . . . 22

4 (M)eine Hermeneutik des Psalmenlesens . . . . . . . . . . 23

4.1 Charakteristika der Psalmensprache . . . . . . . . . 23

4.1.1 Psalmen und Narrativität . . . . . . . . . . . . 23

4.1.2 Emotionale Qualität . . . . . . . . . . . . . . 25

4.1.3 Transformierender Charakter . . . . . . . . . . . 27

4.1 .4 Lyrisches Ich . . . . . . . . . . . . . . . . . . . . . . . . . . . 28

4.1.5 Psalmen als Gebrauchstexte . . . . . . . . . . . . 30

4.2 Lesende . . . . . . . . . . . . . . . . . . . . 32

4.3 Haltungen . . . . . . . . . . . . . 33

4.3.1 Empathiefähigkeit als anthropologische Konstante . . . 34

4.3.2 Weitere Haltungen in Bezug auf das Psalmenlesen . . . 36

5 Psalmenauswahl . . . . . . . . . . . . . . . . . 37

6 Forschungsstand . . . . . . . . . . . . . . . . . 39

6.1 Rezeptionsästhetische Zugänge . . . . . . . . . . . . . . 39

6.2 Emotionen $\operatorname{im~AT~\ldots .~.~.~.~.~.~.~.~.~.~.~.~.~.~} 42$

6.3 Lyrik und Narratologie . . . . . . . . . . . . . . . . . . . . . . . . . . . . 4

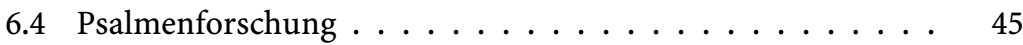

II Methodologische Grundlagen . . . . . . . . . . . . . 47

1 Von der Empathie zur Identifikation - eine Begriffsannäherung . 49

2 Identifikation in der Literaturwissenschaft . . . . . . . . . . . 52

3 Identifikation in der Psychologie . . . . . . . . . . . . . . 55 
4 Begriffsbestimmungen zur literarischen Identifikation . . . . . . 56

4.1 Werner Wolf . . . . . . . . . . . . . . 56

4.2 Els Adringa . . . . . . . . . . . . . . . . . . . . . 57

4.3 Suzanne Keen . . . . . . . . . . . . . . 58

4.4 Keith Oatley . . . . . . . . . . . . . . . . . . . . 60

4.5 Uri Margolin . . . . . . . . . . . . . . . . . . . 60

5 Zusammenschau und Begriffsableitung . . . . . . . . . 62

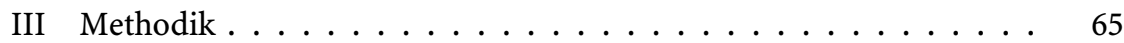

1 Inhalt . . . . . . . . . . . . . . . . . 65

2 Emotionen und Textelemente, die Emotionen auslösen . . . . . . 67

2.1 Emotionen: Der Versuch einer begrifflichen Bestimmung . . 67

2.2 Emotionen beim Lesen . . . . . . . . . . . . . 70

2.2.1 Explizite und implizite Emotionen . . . . . . . . 70

2.2.2 A-emotions und F-emotions . . . . . . . . . . . 72

2.2.3 Metaphern und Emotionen . . . . . . . . . . . . . 76

2.3 Methodisches Vorgehen . . . . . . . . . . . . . . . . 81

3 Perspektiven und Textdynamik ............ 83

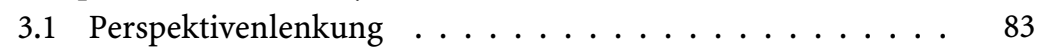

3.2 Deixis . . . . . . . . . . . . . . 86

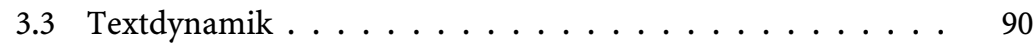

3.3.1 Übergänge und Verbformen . . . . . . . . . . . . 91

3.3.2 Zeitfaktor beim Lesen: Parallelismus und weitere

Stilmittel . . . . . . . . . . . . . . . 94

IV Textanalyse Psalm $30 \ldots \ldots$. . . . . . . . . . . . 99

1 Inhalt . . . . . . . . . . . . . . . . . . 100

1.1 Stimmen und Rederichtungen . . . . . . . . . . . . 102

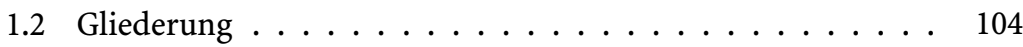

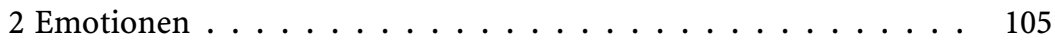

2.1 Vers 1: Überschrift . . . . . . . . . . . . . . . 105

2.2 Vers 2: Jubel, Befreiung und keine Schadenfreude . . . . . 107

2.3 Vers 3: Hilfeschrei und Heilung . . . . . . . . . . . . 111

2.4 Vers 4: Vom (sozialen) Tod zurück ins Leben . . . . . . . . . 112

2.5 Vers 5: Musik, Gesang und Lob für JHWH . . . . . . . . . . 117

2.6 Vers 6: Zorn und Wohlgefallen, Weinen und Jubelgeschrei . 118

2.7 Vers 7: Selbstsicherheit . . . . . . . . . . . . . . . 124

2.8 Vers 8: Kraft und Erschrecken . . . . . . . . . . . . . 125

2.9 Vers 9: Gottesanruf . . . . . . . . . . . . . . . . . . . . . . . . . . . 127

2.10 Vers 10: Verhandeln mit Gott . . . . . . . . . . . 129 
2.11 Vers 11: Erhörbitte um Hilfe . . . . . . . . . . . . . . . 132

2.12 Vers 12: Von der Trauerklage hinein in den Freudentanz . . 133

2.13 Vers 13: Gotteslob . . . . . . . . . . . . . . . . . . . . . 137

3 Perspektiven und Textdynamik . . . . . . . . . . . . . . . . . . . . . . . . . 139

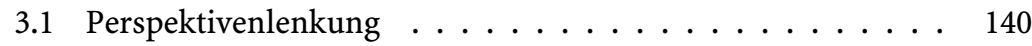

3.2 Textdynamik . . . . . . . . . . . . . . . . . . . . 142

3.2.1 Erste Minierzählung V2-4 . . . . . . . . . . . . . . . . . . . . . . . . . . . . 145

3.2.1.1 Struktur . . . . . . . . . . . . . . . . . . . . . . . . . . . . . . . . . . . . . .

3.2.1.2 Übergänge . . . . . . . . . . . . . . . . . . . . . . . . . . . . . . . . . . 146

3.2.2 Zwischenabschnitt V5-6 . . . . . . . . . . . . . . . 147

3.2.3 Zweite Minierzählung V7-13 . . . . . . . . . . . . . . 148

3.2.3.1 Struktur . . . . . . . . . . . . . . . . . . . . . . . . . 152

3.2.3.2 Kommunikationsebenen . . . . . . . . . . . 155

3.2.3.3 Übergänge . . . . . . . . . . . . . . . . . . . . . . . . . . . . . . . . . . . . . . . . . . .

4 Zusammenschau und Auswertung . . . . . . . . . . . . . . . . . 157

4.1 Emotionen . . . . . . . . . . . . . . . . . . . . . . . . . 158

4.2 Textdynamik und Perspektivenlenkung . . . . . . . . . . 161

4.2.1 Räume und Bewegungen . . . . . . . . . . . . . . . 163

4.2 .2 Zeitebenen . . . . . . . . . . . . . . . . . . . . . . . . . . . . . . 163

4.2 .3 Parallelismen . . . . . . . . . . . . . . . . . . . . . . . . . . . . . . . . . . . . . 164

5 Identifikationspotenziale in Psalm $30 \ldots \ldots 6$

5.1 durch Inhalte . . . . . . . . . . . . . . . . 166

5.2 durch Emotionen . . . . . . . . . . . . . 168

5.3 durch Perspektivenlenkung und Textdynamik . . . . . . 171

V Textanalyse Psalm $147 \ldots \ldots \ldots \ldots$. . . . . . . . . . . . . . . . . . . . . . . . 177

1 Inhalt . . . . . . . . . . . . . . . . . . 177

1.1 Rederichtungen, Themen und Zeitachse . . . . . . . . . . . 179

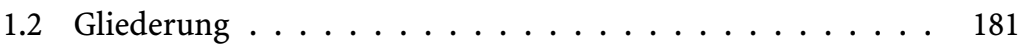

2 Emotionen .............................. 183

2.1 Vers 1: Lobaufforderung und -begründung . . . . . . . . 183

2.2 Vers 2: Göttliches Bauen und Sammeln . . . . . . . . . . . . . 186

2.3 Vers 3: Göttliches Heilen . . . . . . . . . . . . . . . . 188

2.4 Vers 4: JHWH und der Kosmos . . . . . . . . . . . . . . . 191

2.5 Vers 5: Göttliche Größe . . . . . . . . . . . . . . . . 193

2.6 Vers 6: Göttliches Aufrichten und Erniedrigen . . . . . . . . 194

2.7 Vers 7: Aufruf zum Lobpreis . . . . . . . . . . . . . . . . . . . . . . . . . . 197

2.8 Vers 8: Gott und die Schöpfung . . . . . . . . . . . . . . . . 198

2.9 Vers 9: Göttliches Füttern . . . . . . . . . . . . . . . . . . . . . . . . . . . . . . 201

2.10 Vers 10: Göttliche Ablehnung . . . . . . . . . . 201 
2.11 Vers 11: Göttliches Wohlgefallen . . . . . . . . . . . 202

2.12 Vers 12: Lobaufforderung an Jerusalem . . . . . . . . . . 205

2.13 Vers 13: Göttliche Stärke und göttlicher Segen . . . . . . . . 205

2.14 Vers 14: Göttliche Sicherheit und Sättigung . . . . . . . . . 208

2.15 Vers 15: Göttliches Wort . . . . . . . . . . . . . . . . 210

2.16 Vers 16: Schnee und Asche . . . . . . . . . . . . . . . . . . 210

2.17 Vers 17: Eis und Kälte . . . . . . . . . . . . . . . . . . . . . . . . . . . . 212

2.18 Vers 18: Wort und Geist Gottes . . . . . . . . . . . . . 214

2.19 Verse 19-20: Göttliches Wort für Israel . . . . . . . . . . 216

3 Perspektiven und Textdynamik . . . . . . . . . . . . . . . . 218

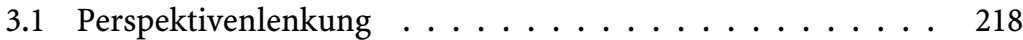

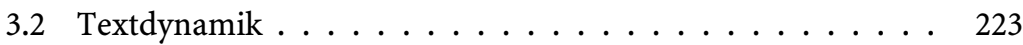

3.2.1 Erste Szene V1-6 . . . . . . . . . . . . . 226

3.2.1.1 Parallelismen . . . . . . . . . . . . . . . . . . . 228

3.2.1.2 Räume und Zeiten . . . . . . . . . . . . 229

3.2 .2 Zweite Szene V7-11 . . . . . . . . . . . . . . . . . . 230

3.2.2.1 Übergänge und Struktur . . . . . . . . . . . . . . . . . 230

3.2.2.2 Parallelismen . . . . . . . . . . . . . . . . . 233

3.2.3 Dritte Szene V12-20 . . . . . . . . . . . . . . . . 233

3.2.3.1 Parallelismen und Struktur . . . . . . . . . 234

3.2.3.2 Räume und Zeiten . . . . . . . . . . . . . . . . . . . . . . . 237

3.2.3.3 Übergänge . . . . . . . . . . . . . . . . . . . . . . . . . . . . . . . . . . . . . . . . . .

4 Zusammenfassung und Auswertung . . . . . . . . . . . . . . . 240

4.1 Inhalt . . . . . . . . . . . . . . . 240

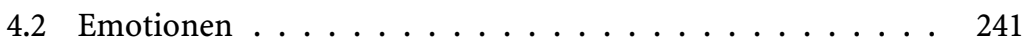

4.3 Perspektiven und Textdynamik . . . . . . . . . . . . . 243

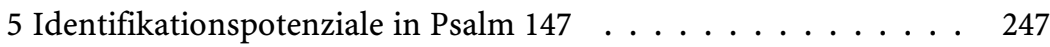

5.1 durch Emotionen . . . . . . . . . . . . . . 247

5.2 durch Perspektivenlenkung und Textdynamik . . . . . . . 248

5.3 durch Inhalt . . . . . . . . . . . . . . . 249

VI Textanalyse Psalm $90 \ldots \ldots \ldots \ldots \ldots \ldots$

1 Inhalt . . . . . . . . . . . . . . . . . . . 253

1.1 Rederichtungen und Themen . . . . . . . . . . . . 253

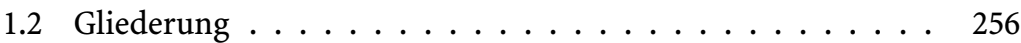

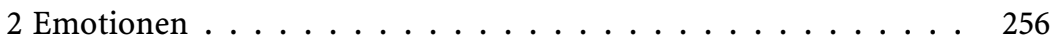

2.1 Vers 1: Unsere Zuflucht ist Gott . . . . . . . . . . . . 258

2.2 Vers 2: Gott und Schöpfung . . . . . . . . . . . . . . . . 260

2.3 Vers 3: Zurück zum Staub? . . . . . . . . . . . . . 263

2.4 Vers 4: Tausend Jahre sind ein Tag . . . . . . . . . 265 
2.5 Verse 5-6: Wie Schlaf und Gras . . . . . . . . . . . . . . 266

2.6 Vers 7: Göttlicher Zorn . . . . . . . . . . . . . 271

2.7 Vers 8: Verborgene Schuld . . . . . . . . . . . . . . 273

2.8 Vers 9: Dahinschwinden .............. 275

2.9 Vers 10: Mühevolle Lebenszeit . . . . . . . . . . . . . . . . 276

2.10 Vers 11: Göttliche Zorneskraft . . . . . . . . . . . . 278

2.11 Vers 12: Weise Zeitbetrachtung . . . . . . . . . . . . 280

2.12 Vers 13: Wie lange noch? . . . . . . . . . . . . . . . . 282

2.13 Vers 14: Lebensfreude . . . . . . . . . . . . . . . . . . . . . . . . . . 284

2.14 Vers 15: Ausgleichende Gerechtigkeit . . . . . . . . . . 286

2.15 Vers 16: Göttlicher Glanz . . . . . . . . . . . . . . . . . . . 287

2.16 Vers 17: Segenswunsch . . . . . . . . . . . . . . . . 288

3 Perspektiven und Textdynamik . . . . . . . . . . . . . . . . 290

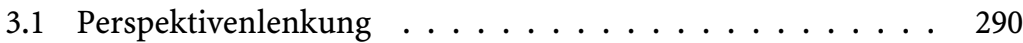

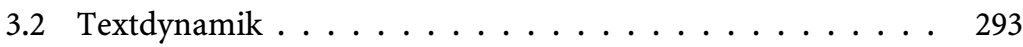

3.2.1 Erster Gedankenspot V1-6 . . . . . . . . . . . . . . . . . 293

3.2.1.1 Zeiterfahrungen . . . . . . . . . . . . . . . 295

3.2.1.2 Räume und Handlungen . . . . . . . . . . . . . . 296

3.2.1.3 Übergänge . . . . . . . . . . . . . . . . . . . . . . . . . . . . . . . . 297

3.2.1.4 Parallelismen . . . . . . . . . . . . . . . . . . . . . . . 298

3.2.2 Zweiter Gedankenspot V7-12 . . . . . . . . . . . . . . . . . . . . . . . . . 399

3.2 .2 .1 Übergänge . . . . . . . . . . . . . . . . . . . . . . . . . . . . . . . . . . . . . . . .

3.2 .2 .2 Verben . . . . . . . . . . . . . 302

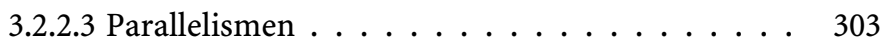

3.2.3 Dritter und vierter Gedankenspot V13-17 . . . . . . . 304

3.2 .3 .1 Verben . . . . . . . . . . . . . . . . 306

3.2.3.2 Zeiten und Räume . . . . . . . . . . . . . . . . . . . . . . . . . . . . . 307

3.2.3.3 Übergänge . . . . . . . . . . . . . . . . . . . . . . . . . . . . . . . . . . . . . . . . . . .

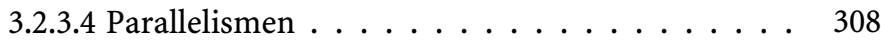

4 Zusammenschau und Auswertung . . . . . . . . . . . . . . . . . 310

4.1 Inhalt ...................... 310

4.2 Emotionen ............................... 312

4.3 Perspektiven und Textdynamik . . . . . . . . . . . . . 315

5 Identifikationspotenziale in Psalm $90 \ldots . . \ldots 321$

5.1 durch Inhalte . . . . . . . . . . . . . . . . . . . . . . 321

5.2 durch Emotionen . . . . . . . . . . . . . . . . . 323

5.3 durch Perspektivenlenkung und Textdynamik . . . . . . . 324 
VII Textanalyse Psalm $64 \ldots \ldots$. . . . . . . . . . . . . . . . . . 329

1 Inhalt . . . . . . . . . . . . . . . . . . . . . . . . . . . 329

1.1 Sprechstimme und Struktur . . . . . . . . . . . . . . . 330

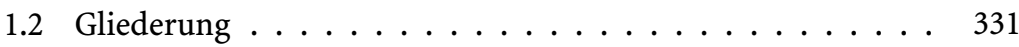

2 Emotionen . . . . . . . . . . . . . . . . . . 332

2.1 Vers 1: Auf David hin . . . . . . . . . . . . . . . . 332

2.2 Vers 2: Erhörungsbitte . . . . . . . . . . . . . 333

2.3 Vers 3: Versteck erbeten . . . . . . . . . . . . . . . . 335

2.4 Vers 4: Lebensgefährliche Worte . . . . . . . . . . . . . 337

2.5 Vers 5: Unvermuteter Beschuss . . . . . . . . . . . . 339

2.6 Vers 6: Feindlicher Hochmut . . . . . . . . . . . . . . 341

2.7 Vers 7: Verkehrte Gedanken . . . . . . . . . . . . . . 343

2.8 Vers 8: ... und Gott greift ein . . . . . . . . . . . . . . 344

2.9 Vers 9: Straucheln . . . . . . . . . . . . . . . . . . . 346

2.10 Vers 10: Reaktion und Erkenntnis . . . . . . . . . . . 347

2.11 Vers 11: Freude und Zuflucht . . . . . . . . . . . . . . . . . . 348

3 Perspektiven und Textdynamik . . . . . . . . . . . . . . 350

3.1 Perspektivenlenkung . . . . . . . . . . . . . 350

3.2 Textdynamik . . . . . . . . . . . . . . . . 353

3.2.1 Charakterisierung . . . . . . . . . . . . . . . . 354

3.2.1.1 Feindliche Übeltäter . . . . . . . . . . . . . . 355

3.2.1.2 Gottheit Israels . . . . . . . . . . . . . . . . 356

3.2.1.3 Lyrisches Ich . . . . . . . . . . . . . . . 357

3.2.1.4 Alle Menschen . . . . . . . . . . . . . . . . . 358

3.2.2 Handlungen . . . . . . . . . . . . . . . . . . . 359

3.2 .3 Zeiten und Räume . . . . . . . . . . . . . . . . . 360

3.2.4 Parallelismen . . . . . . . . . . . . . . . . . . . . 361

3.2 .5 Übergänge . . . . . . . . . . . . . . . . . . . . . 363

4 Zusammenfassung . . . . . . . . . . . . . . . 364

4.1 Inhalt und Emotionen . . . . . . . . . . . . . . . . . 364

4.2 Textdynamik . . . . . . . . . . . . . . . . . 365

5 Identifikationspotenziale in Psalm 64 . . . . . . . . . . . 366

5.1 durch Emotionen, Aufbau, Textdynamik und

Perspektivenlenkung . . . . . . . . . . . . . 366

5.2 durch Inhalt, Analogiebildung und Kontraste . . . . . . . 367

VIII Ergebnisse . . . . . . . . . . . . . . . . . 371

1 Narratologische Analysekriterien und Psalmen . . . . . . . . . 371

1.1 Bewegungen in Raum und Zeit . . . . . . . . . . . . . 371

1.2 Charakterisierung . . . . . . . . . . . . . . . 373 
2 Emotionen ........................... 375

2.1 Bildersprache und Emotionen . . . . . . . . . . . . . 375

2.2 Emotionsfelder . . . . . . . . . . . . . . . . . . . . . . . . . 378

2.3 Zuordnung der Emotionen . . . . . . . . . . . . . . . . 382

2.4 Doppelte Emotionalität . . . . . . . . . . . . . . . . 383

3 Identifikationspotenziale . . . . . . . . . . . . . . . . . . . . 384

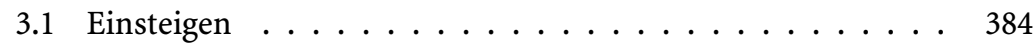

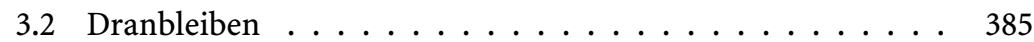

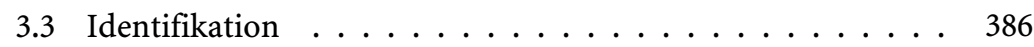

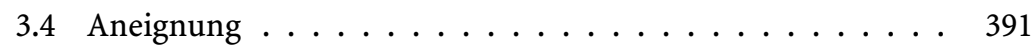

4 Standpunktbestimmung und Ausblick . . . . . . . . . . . 391

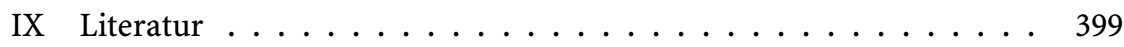

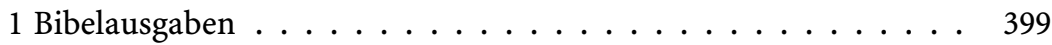

2 Sekundärliteratur und Hilfsmittel . . . . . . . . . . . . . . . . . . . . . . . . . . . . 400

3 Internetadressen . . . . . . . . . . . . . . . . . 420

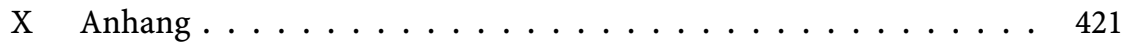

1 Arbeitsübersetzung Psalm $30 \ldots . . \ldots 421$

2 Arbeitsübersetzung Psalm 147-1. Variante . . . . . . . . . . . . . . . . 422

3 Arbeitsübersetzung Psalm 147-2. Variante . . . . . . . . . . . . . . . . . . . . . . . . . 423

4 Arbeitsübersetzung Psalm $90 \ldots . . \ldots$. . . . . . . . . . . . . . . . . . . . . . . . . 424

5 Arbeitsübersetzung Psalm $64 \ldots$. . . . . . . . . . . . . . . 425

Bibelstellenregister . . . . . . . . . . . . . . . . 427 
Open-Access-Publikation im Sinne der CC-Lizenz BY-NC-ND 4.0

(c) 2019, V\&R unipress GmbH, Göttingen 


\section{Vorwort}

Die vorliegende Arbeit stellt die leicht überarbeitete Fassung meiner Habilitation da, welche ich im Rahmen der vom Österreichischen Forschungsfonds (FWF) geförderten Elise-Richter-Stelle vollendet habe. Sie wurde im Mai 2016 an der Katholischen Privat-Universität Linz (KU) unter dem Titel »Identifikationspotenziale in den Psalmen. Über die Wirkung von Emotionen, Metaphern und Textdynamik in den Psalmen 30, 64, 90 und 147 auf gegenwärtige Lesende» approbiert.

Für die Übernahme der Habilitationsgutachten danke ich Susanne GillmayrBucher, Marianne Grohmann und Johannes Schnocks, ebenso Ulrich Berges und Martin Ebner für die Aufnahme in die Reihe »Bonner Biblische Beiträge« und Oliver Kätsch für die Verlagsbetreuung.

Am Institut für Bibelwissenschaften des Alten und Neuen Testamentes der KU habe ich Raum gefunden, im Rahmen des dortigen offenen, respektvollen und inhaltsreichen Diskurses die wissenschaftlichen Anliegen meiner Arbeit weiter zu entwickeln und abzuschließen. Dieser Arbeits-, Forschungs- und Suchprozess wurde von zahlreichen Gesprächen begleitet. Aus bibelwissenschaftlicher Perspektive danke ich hierfür Irmtraud Fischer, Barbara Schmitz und Johannes Schiller, außerdem der ESWTR-AT-Fachgruppe - unter anderem Johanna Erzberger, Uta Schmidt und Michaela Geiger -, den TeilnehmerInnen des biblischen Forschungsseminars an der KU Linz - unter anderem Christoph Niemand, Werner Urbanz, Michael Zugmann, Elisabeth Birnbaum, Franz Hubmann, Sarah Artner und Johannes Marböck - sowie den TeilnehmerInnen des Arbeitskreises der Rezeption alttestamentlicher Texte (AKRAT), unter anderem Marianne Grohmann und Agnethe Siquans.

Während meines Forschungsaufenthalts an der Catholic University of Leuven hat sich Pierre van Hecke viel Zeit genommen, meinen Ansatz kennenzulernen und gemeinsam mit mir in die Geheimnisse der Auslegung metaphorischer Sprache einzutauchen. Ihm und den TeilnehmerInnen an der Leuven Old Testament Study Group, in welcher ich meine Arbeit im internationalen Rahmen präsentieren durfte, sei herzlich gedankt, unter anderem Eibert Tigchelaar, Brian 
Doyle, Bénédicte Lemmelijn, Johan de Joode und Elisabeth Hernitschek. Dorothea Erbele-Küster, die mich durch ihre Dissertation für meine Arbeit inspirierte, konnte ich im Rahmen meines Forschungsaufenthalts in Belgien "wiederentdecken«. Für ihr großes Interesse und die anregenden Gespräche über die Konzeption meines Habilitationsprojekts sei ihr an dieser Stelle herzlichst gedankt.

Aus theologischer Perspektive gilt der Forschungsplattform des Mittelbaus der KU ein großer Dank für die Rückmeldungen, hier vor allem Andreas Telser (Systematische Theologie) und Anita Schwantner (Pastoraltheologie). Da diese Arbeit starke literaturwissenschaftliche Züge trägt, konnten aus den Gesprächen mit Werner Wolf, Robert Vellusig sowie Mieke Bal und Ansgar Nünning im Rahmen der von Irmtraud Fischer an der Universität Graz organisierten MeisterInnenklasse wertvolle Impulse gewonnen werden.

Susanne Gillmayr-Bucher stand mir von Anbeginn der Arbeit an mit Rat und Tat zur Seite. Für zahlreiche Forschungsgespräche, kritisch-wertschätzende Rückmeldungen sowie vor allem für ihre unbändige Neugier und Offenheit neuen Ansätzen in der Bibelwissenschaft gegenüber und ihre Motivationskraft gilt ihr ein herzliches Dankeschön. Meiner Projektmitarbeiterin Magdalena Lass danke ich herzlich für ihre kompetente Arbeit. Ein großer Dank gilt Ilse Müllner für ihre wertvollen Rückmeldungen in Bezug auf die Publikation dieser Arbeit, Gerlinde Baumann für das Lektorat im Rahmen der Publikationsvorbereitungen sowie Patrick Marko für die Erstellung des Registers. Die Drucklegung der Habilitation wurde dankenswerter Weise vom Bischöflichen Fonds zur Förderung der KU Linz sowie vom Land Steiermark und der Österreichischen Forschungsgemeinschaft unterstützt.

Renate Wieser ist nicht nur unersetzlich, was das Korrekturlesen angeht. Ohne sie wären die vielen freud- und lustvollen, aber oft auch mühsam erlebten Stunden im Rahmen dieses Forschungsprozesses anders verlaufen. Der promovierten Pastoraltheologin und Habilitandin am Institut für Praktische Theologie an der Universität Wien sei hier auf das Herzlichste für ihre Freundschaft, ihre große theologische Kompetenz und faszinierende Weite im Denken und Forschen sowie für ihr nie enden wollendes Interesse an aktuellen Themen und Fragestellungen der Theologie gedankt. 


\section{Abkürzungen}

akt. aktiv

atl. alttestamentlich

Dipl. Diplomarbeit

d. h. das heißt

dt. Deutsch

ePP enklitisches Personalpronomen

hi. Hifil

hit. Hitpael

Imp. Imperativ

Inf.abs. Infinitiv absolutus

Inf.constr. Infinitv constructus

Jh. Jahrhundert(s)

lat. lateinisch

lyr. lyrisch

LXX Septuaginta

m. E. meines Erachtens

MT Masoretentext

ni. Nifal

P. Person

pas. Passiv

pi. Piel

po. Polel

PK Präfixkonjugation (yiqtol)

pl. Plural

Ptz. Partizip

q. Qal

sg. Singular

SK Suffixkonjugation (qatal)

S. E. Sigrid Eder

u. a. und andere

V Vers oder Verse 
W-PK Waw-Präfixkonjugation $=$ Konsekutivform der Präfixkonjugation $=$ Narrativ = wayyiqtol

W-SK Waw-Suffixkonjugation = Konsekutivform der Suffixkonjugation

Waw+PK Präfixkonjugation + Waw

z. B. zum Beispiel 
... fiel mitten im Singen der Psalmen der Schauer des Mitlebens auf ihn, und er schrie auf.

Peter Handke, Am Felsenfenster morgens 1982-1987

Die Psalmen der Hebräischen Bibel bergen in ihrer kraftvollen, anziehenden, tröstenden, kunstvoll-schönen und zugleich teils irritierenden Art eine ungeheure Vielfalt an Erfahrungsräumen. Sie vermögen es, heutigen LeserInnen diese Räume immer wieder neu zugänglich zu machen, indem sie den Abstand zwischen damals und heute mit schierer Leichtigkeit überbrücken. Die unendliche Weite dieser poetischen Texte und die tiefe menschliche Dimension sind ebenso faszinierend wie die Lebensechtheit und Lebensnähe, die geprägt sind vom intensiven Ringen um die Zuneigung Gottes. „Das ist die existenzielle Dimension der Psalmen schlechthin: Sie feiern das Leben als Geschenk Gottes, sie protestieren gegen alles, was das so verstandene Leben bedroht, und sie erinnern Gott selbst daran, dass er die Fürsorge für dieses Leben übernommen hat. « ${ }^{1}$ So können die Verse der Psalmen beim Psalmenlesen und -beten in das je eigene Leben fallen und damit einen Resonanzraum schaffen, der es ermöglicht, dass sich die Lesenden und Betenden selbst hineinbegeben in die Textwelt und daraus existenzielle Bedeutung gewinnen.

\section{$1 \quad$ Hinführung zum Thema}

Durch die Geschichte der Textauslegung hindurch, die ja bereits in der Bibel selbst beginnt, haben Menschen zu allen Zeiten und Epochen in je unterschiedlichen Kontexten bis zum heutigen Tag die Psalmen gelesen, gebetet, ausgelegt, über sie nachgedacht, sie meditiert, mit ihnen in kreativer, wissenschaftlicher und spiritueller Weise gearbeitet und gelebt. ${ }^{2}$ "Blickt man in die

1 Zenger, "Du thronst auf den Psalmen Israels«, 19f.

2 Der Psalter spielt in der christlichen Tradition eine zentrale Rolle: Er ist nicht nur jenes atl. Buch, das im NT am häufigsten aufgegriffen wurde (vgl. Weber, Werkbuch 3, 248), sondern dient der frühen Kirche neben der Verkündigung und Ausformulierung des Christusglaubens bereits im urkirchlichen Gottesdienst (Eph 5,19) sowie dem frühen Mönchtum in Form des Stundengebets. Vgl. Sieben, Schlüssel zum Psalter, 10f. Einen kurzen Einblick in die jüdische 
Geschichte der Rezeption der biblischen Bücher, so wird deutlich, dass die Psalmen seit ihrer Entstehung das am häufigsten rezipierte Buch aller biblischen Bücher ist. Sie blieben während aller Jahrhunderte stets aktuell. ${ }^{3}{ }^{3}$ Die folgenden Stimmen aus dem 4., 16., 20. und 21. Jhdt. der Rezeptionsgeschichte der Psalmen, die die jeweilige Aktualität, die Lebensnähe, das Mitschwingen und das SichBergen in den Texten betonen, sollen dies verdeutlichen:

So hält bereits Athanasius von Alexandrien in seinem Brief an Marcellinus, der im 4. Jh. n. Chr. verfasst wurde, fest: »Wer diese Psalmen liest, wird zerknirscht, wie jemand, der selber so redet, er wird durch die Worte dieser Lieder in die gleiche innere Stimmung versetzt, wie wenn es seine eigenen persönlichen wären. [...] Ich bin der Ansicht, dass in den Worten dieses Buches das ganze menschliche Leben, sowohl die geistlichen Grundhaltungen als auch die jeweiligen >Bewegungen « und Gedanken umfasst und enthalten sind. Nichts kann darüber hinaus im Menschen gefunden werden [...].« 1528 schreibt Martin Luther in seiner zweiten Vorrede zum Psalter: „Daher kommt's auch, dass der Psalter aller Heiligen Büchlein ist, und ein jeglicher, in welcherlei Sache er ist, Psalmen und Worte drinnen findet, die sich auf seine Sache reimen und ihm so eben sind, als wären sie allein um seinetwillen so gesetzt, dass er sie auch selbst nicht besser setzen noch finden kann noch wünschen mag. « ${ }^{5}$ Und nur wenige Jahre später formuliert Johannes Calvin im Vorwort zu seinem Psalmenkommentar (lat. 1557): "Mit gutem Grund nenne ich gewöhnlich das [Psalmen]buch eine Aufgliederung aller Teile der Seele. Denn jede Regung, die jemand in sich empfindet, begegnet als Abbild in diesem Spiegel. Ja, hier hat uns der Heilige Geist alle Schmerzen, Traurigkeit, Befürchtungen, Zweifel, Hoffnungen, Sorgen, Ängste, Verwirrungen, kurzum alle Gefühle, durch die

Tradition bietet Weber, Werkbuch 3, 263-266. Bezüglich einer größeren Auswahl aus der jüdischen wie christlichen Wirkungs- und Rezeptionsgeschichte verweist er auf die Studien von Gillingham, Susan: Psalms Through the Centuries: Volume One, Blackwell Bible Commentaries, Oxford 2008.

3 Gillmayr-Bucher, Die Psalmen, 17. Darüber hinaus haben die Psalmen zu einer großen Anzahl an Neu- und Nachdichtungen, Vertonungen und Liedern sowie Bildern angeregt. Vgl. Weber, Werkbuch 3, 262; ebenso Witte, Schriften, $421 \mathrm{f}$. In ihrem Beitrag über die Psalmentraditionen in der deutschsprachigen Lyrik des 20. Jh. einschließlich der Übersetzungen aus anderen Sprachen hält Irmgard Ackermann fest: »Sie [die Psalmentraditionen] machen jedenfalls deutlich, welche Spannweite die Psalmengattung bereitstellt und wie sehr es sich bei der Psalmendichtung nicht um historische und auf die heutige Situation nicht mehr zutreffende Lyrik handelt. Sie beweisen stattdessen die Offenheit der Psalmengattung für die Außenperspektive und ihre Anpassungsfähigkeit an sich wandelnde Situationen.« Ackermann, Psalmendichtung, 195.

4 Zitiert nach Zenger, »Du thronst auf den Psalmen Israels«, 16. Er verweist auf die Übersetzung bei Sieben, Athanasius, 157-173 sowie Reemts, Schriftauslegung, 29-31.

5 Bornkamm, Luthers Vorreden, 68. 
Menschen innerlich hin und her geworfen werden, lebensnah vergegenwärtigt. $\ll^{6}$

Äußerst bekannt und prominent ist die Aussage Rainer Maria Rilkes, der am 4. Januar 1915 an seinen Verleger schreibt: »Ich habe die Nacht einsam hingebracht in mancher inneren Abrechnung und habe schließlich beim Schein eines nochmals entzündeten Weihnachtsbaumes die Psalmen gelesen, eines der wenigen Bücher, in denen man sich restlos unterbringt, mag man noch so zerstreut und ungeordnet und angefochten sein. ${ }^{7}$ Knapp hundert Jahre später formuliert dazu Manfred Oeming: "Dieser Aspekt, dass sich jeder Mensch in den Psalmen >restlos unterbringt $\iota$, diese existentielle >Anwendbarkeit ist ein wesentlicher Grund für die hohe Gegenwartsbedeutung des Psalters. ${ }^{8}$ Demgemäß kann für das 21. Jh. mit Susanne Gillmayr-Bucher festgehalten werden: »Die Psalmen bilden so gleichsam eine Folie, auf der die Gegenwart der LeserInnen immer wieder verstanden werden kann. ${ }^{9}$

\section{$2 \quad$ Aktualität der Psalmen}

Psalmen sind offenbar für viele suchende Menschen Begleiter auf ihrem Lebensweg. Gerade also an den Psalmen scheint die Zeit zwischen ihrer Produktion, der Zeit der Redaktion und der Zeit der Rezeption nahezu spurlos vorüber gegangen zu sein; die Psalmen sind zeitlos und werden zu jeder Zeit und in den jeweiligen Kontexten immer wieder neu rezipiert und aktualisiert. »Das ist in der Tat die faszinierende Eigenart der Psalmen: Es sind Gebete und Lieder aus einer lange vergangenen Zeit, und doch sind es Worte, die über die Jahrhunderte hinweg bis heute unmittelbar anrühren. ${ }^{10}$ So formuliert Erich Zenger die Aktualität der Psalmen. Paul Deselaers spricht in diesem Zusammenhang von der

6 Zitiert nach Weber, Werkbuch 3, 274 bzw. Busch, Eberhard u. a. (Hg.): Der Psalmenkommentar. Eine Auswahl, Calvin-Studienausgabe 6, Neukirchen-Vluyn 2008, 21-23.25.

7 Rilke, Briefe, 247.

8 Oeming, Das Buch der Psalmen, 47.

9 Gillmayr-Bucher, Die Psalmen, 18. Ähnlich Lämmlin, Lust am Wort, 15: „Sie bilden keine objektiven Sinngebilde, denen ich als Rezipient gegenüberstehen würde, vielmehr bilden sie die Basis für eine Lektüre, in der daraus ein Sinngebilde entsteht, dass mein individuelles Selbst-, Welt- und Gottesverständnis davon betroffen, verändert und darin integriert wird.«

10 Zenger, Der Psalter, 548. Erich Zenger zitiert in einem seiner zahlreichen Beiträge zu den Psalmen den Atheisten Milan Machovec, der von einer phantastischen Aktualität der Psalmen spricht. Vgl. Zenger, „Du thronst auf den Psalmen Israels«, 20. Martin Fritz hält hinsichtlich der Aktualität der gesamten bibelhebräischen Poesie fest, dass bereits Robert Lowth (17101783) in seinen "Vorlesungen über die heilige Poesie der Hebräer" versucht hat, »eine erlebnisorientierte Schriftlektüre zu etablieren, bei der die alttestamentliche Poesie als Schatz archetypischer religiöser Erfahrung zur Geltung kommt, die sich durch sprachliche Mitteilung je und je aufs Neue zu aktualisieren vermag.» Fritz, Von der heiligen Poesie, 110. 
"weit verzweigten Ausstrahlungskraft ${ }^{11}$ der Psalmen, die praktische Theologin Uta Pohl-Patalong von deren Wirkkraft und davon, dass sie »offensichtlich nicht ıverbraucht $\iota$, sondern [...] lebendig [bleiben] und [...] Menschen immer wieder neu an[sprechen]. ${ }^{12}$

Wie kommt es dazu? Welche Eigenarten und Charakteristika der alttestamentlichen Psalmen führen dazu, dass der Abstand zwischen damals und heute scheinbar gegen Null geht? Woher stammt bzw. wie passiert diese faszinierende Unmittelbarkeit, die den Psalmen bzw. dem Psalmenlesen gleichsam wie einem Wesenszug inhärent ist? Worin liegt also der Reiz der Psalmenlektüre in der jeweiligen Gegenwart?

Eine Antwort darauf ist jene, dass sich die LeserInnen, BeterInnen und AuslegerInnen mit den in den Psalmen geschilderten Erfahrungen, Situationen, Bitten, Aufforderungen und Dankeshymnen identifizieren können: »Wie wohl kein anderes biblisches Buch bieten die Psalmen die Möglichkeit, dass Menschen sich in ihnen wiederfinden. ${ }^{13}$ Die LeserInnen "gehen mit «, weil sie an die in diesen Liedern erzählten Erfahrungen anknüpfen, sich in ihnen bergen können, weil sie sich in sie hineindenken und -fühlen können und sich daher mit dem in den Texten geschilderten Geschehen identifizieren, ${ }^{14}$ sie können sich in ihrer jeweiligen biographischen Situation angesprochen fühlen und für ihre je eigene Situation Kraft schöpfen und Mut gewinnen. Erich Zenger formuliert das so: »Gewiss, nicht alle Psalmen sind in gleicher Weise poetisches Kunstwerk, aber in irgendeiner Weise eignet ihnen allen jene dichterische Kraft, die nicht nur den Verstand, sondern die emotionale, personale Mitte der Psalmenbeterinnen und Psalmenbeter anspricht und zur Identifikation, zum Widerspruch und zum >Weiterschwingen herausfordert. ${ }^{15}$ Er spricht später auch von der »Identifikationskraft der Psalmen ${ }^{16}$ aufgrund der Tatsache, dass in den Psalmen ver-

11 Deselaers, Wiederentdeckung, 11.

12 Pohl-Patalong, Zugänge, 137. Ähnlich Füglister, Psalmengebet, $149 \mathrm{f}$.

13 Pohl-Patalong, Zugänge, 52. Van Grol, Emotions, 76 vermerkt zu Ps 6 und insgesamt zu den Psalmen: "Obviously, the text was not written to inform us. [...] Maybe, these texts were written to involve us."

14 Die Psalmen stehen »dann einer Vielzahl von Menschen als Klagen und Bitten zur Verfügung, mit denen sie ihr eigenes konkretes Erleben identifizieren können.« Wälchli, Gottes Zorn, 151. „Weil in den Psalmen Menschen zu Wort kommen, die genauso unsicher und auch begeisterungsfähig sind wie wir, ist es einfach, sich mit ihnen zu identifizieren [...].« Gerstenberger, Arbeitsbuch Psalmen, 8. Ähnlich Notker Füglister, der die poetische Wirkung lyrischer Texte und im Besonderen die der Psalmen unter den drei Stichworten »Kommunikation", "Identifikation" und "Evokation« entfaltet. Unter der Kategorie "Identifikation" betont er vor allem das Verschmelzen des lyrischen Ich mit dem lesenden Ich (vgl. dazu mehr in I Einleitung 4). Vgl. Füglister, Psalmengebet, $51 \mathrm{f}$.

15 Zenger, »Du thronst auf den Psalmen Israels«, 21.

16 Zenger, »Du thronst auf den Psalmen Israels«, 21. 
dichtetes Leben zur Sprache komme. ${ }^{17}$ Auch Egbert Ballhorn verweist im Rahmen der Pragmatik des Psalters auf Identifikationsangebote für Lesende: "Mit den vielfältig unterschiedlichen Leseweisen und fiktionalen Betergestalten bietet der Psalter seinen Leserinnen und Lesern Konkretionsmodelle und Identifikationsmöglichkeiten an, die nicht streng gegeneinander abgrenzbar sind, sondern - ganz bewusst - unscharf bleiben und ineinander übergehen können. « ${ }^{18}$ Es sind also die vielfachen Identifikationsmöglichkeiten in ihrer hohen Intensität, die u. a. den Reiz der Psalmenlektüre ausmachen und die "Erfolgsgeschichte» der Psalmen in deren Rezeption bestätigen. »Der literarische Erfolg eines Werkes scheint u. a. mit dem Angebot solcher Identifikationsmöglichkeiten zusammenzuhängen. Es ist denkbar, dass dabei weniger der Umfang als die Qualität oder Intensität der Identifikationsmöglichkeiten über die Wirkungsdauer und Wirkungsbreite eines Werkes entscheiden. ${ }^{19}$ Als kanonische Texte, die als normativ und formativ für die entsprechenden Rezeptionsgemeinschaften gelten, werden biblische Texte zu allen Zeiten aktualisiert. So entspringt der Identifikationsgedanke einer Grundintention biblischer Texte. ${ }^{20}$ Ilse Müllner hält in Bezug auf das identifikatorische Lesen fest, dass »jede theologische (im Unterschied zur religionsgeschichtlichen) Lektüre in eine Verhältnisbestimmung des biblischen Texts zu den jeweiligen LeserInnen der Gegenwart eintreten muss. « ${ }^{21}$

17 Zenger, »Du thronst auf den Psalmen Israels«, $21 \mathrm{f}$ : Weil die Psalmen verdichtetes Leben sind, kann sich jede und jeder in ihnen wiederfinden - im klagenden Nein zum Leid und zur Gewalt, in der sehnsuchtsvollen Gott-Suche mitten in Krankheit, Zweifel, Einsamkeit und inmitten von Anfeindung und Hass, aber auch im beglückten Dank für erfahrene Hilfe durch Menschen und durch das Geschenk der Gottesnähe sowie schließlich im selbst- und interesselosen Rühmen des (trotz allem) gütigen und barmherzigen Gottes.«

18 Ballhorn, Pragmatik, 244. Vgl. ebd., 256.

19 Schönau / Pfeiffer, Einführung, 55.

$20 »$ Dass Angebote zur Identifikation und Mitwirkung ganz fehlen, kann man sich bei biblischen Geschichten eigentlich nicht vorstellen." Seybold, Poetik der erzählenden Literatur, 283. Zur Aneignung theologischer Inhalte durch die Identifikation mit biblischen Texten vermerkt Christian Link: „Wir können uns durch das Medium einer erzählten Geschichte noch in die uns fremdeste Ereigniskonstellation hineinziehen lassen. Jedes Drama und jeder gute Film lebt von dieser Leistung der Sprache. Es ist deshalb völlig unerheblich, ob die Geschichten vom Barmherzigen Samariter (Lk 10,25-37) oder vom Verlorenen Sohn (Lk 15,11-32) in einem historischen Sinn tatsächlich stattgefunden haben oder nicht, wenn uns nur die Identifikation mit den dort handelnden Akteuren gelingt, sodass wir deren Perspektive - wenigstens auf Zeit - übernehmen können. So schaffen sie eine offene Gesprächssituation, in der überlieferte theologische Inhalte die Chance einer freien, weil selbstevidenten Aneignung bekommen.« Link, Die Theologie vor der »linguistischen Wende«, 139.

21 Müllner, Wie sind wir gemeint?, 17. 


\section{Forschungsfragen und Aufbau der Arbeit}

Die Psalmen bieten also Identifikationspotenziale an, die eine anhaltende Rezeption ermöglichen. Wie die bisherigen Ausführungen gezeigt haben, ist der Identifikationsgedanke in Bezug auf die Psalmen breit belegt. Ein Forschungsdesiderat stellt hingegen dar, wie dieser genau funktioniert bzw. woran er festzumachen ist. Welche Elemente bieten die Texte des Psalters, dass sich LeserInnen mit den Psalmen identifizieren? Welche Textstrategien sind in diesen poetischen Texten angelegt, die $u$. a. verdichtetes Leben thematisieren und damit LeserInnenidentifikation ermöglichen? Basierend auf dem Ausgangspunkt der faszinierenden Unmittelbarkeit der Psalmen, denen der Wesenszug der Vergegenwärtigung durch Identifikationsmöglichkeiten inhärent ist, gehe ich demnach in dieser Arbeit folgenden Forschungsfragen nach:

Welche Aspekte von Identifikation kommen in den Psalmen zum Tragen, und durch welche Textelemente werden sie ermöglicht? Wie können sich LeserInnen mit den Psalmen identifizieren? Ziel der Arbeit ist es, den Identifikationsbegriff zu klären, diesen für die Analyse der Psalmen methodisch zu operationalisieren und dadurch Textstrategien zu eruieren, die LeserInnenidentifikationen ermöglichen. Dies geschieht in folgenden Schritten:

Zunächst werden im weiteren Verlauf von Kapitel I die hermeneutischen Voraussetzungen dieser Arbeit dargelegt; das Kapitel endet mit der Begründung der Psalmenauswahl und dem Einordnen der Arbeit in den aktuellen Forschungsstand. Kapitel II (Methodologische Grundlagen) skizziert den Weg entlang der historischen Entwicklung des Begriffs "Identifikation« bis zur Identifikation mit literarischen Texten und der Ableitung der Begrifflichkeit für diese Studie. In Kapitel III (Methodik) wird die Operationalisierung des Identifikationsbegriffs für die Anwendung auf die Psalmen anhand der Analysekriterien "Inhalt« bzw. "Analogiebildung«, »Emotionen" und »emotionale Wirkung" sowie "Perspektivenlenkung " und »Textdynamik» durchbuchstabiert. Die sich aus diesen Kategorien ableitenden Fragestellungen werden in den anschließenden Textanalysen auf die Ps 30, 147, 90 und 64 (Kapitel IV-VII) angewendet. Die Analyseergebnisse werden im Schlusskapitel (Kapitel VIII) konzentriert dargestellt und mit einem Ausblick versehen. Das Literaturverzeichnis (Kapitel IX) sowie die Arbeitsübersetzungen der vier Psalmen im Anhang (Kapitel X) runden die Arbeit ab. Basierend auf dem Forschungsdesiderat und aufgrund der Konzentration auf die Forschungsfragen nach textuellen Identifikationspotenzialen ist in dieser Arbeit weder eine Gesamtexegese der $\mathrm{zu}$ analysierenden Psalmen noch eine Befragung und Untersuchung empirischer LeserInnen zu erwarten. Vielmehr wird die Leseerfahrung schriftkundiger Psalmlesender in den Blick genommen, die wissenschaftlich verantwortet lesen. 


\section{$4 \quad$ (M)eine Hermeneutik des Psalmenlesens}

Im folgenden Abschnitt kommen die hermeneutischen Prämissen dieser Arbeit zur Darstellung. Diese Ausführungen orientieren sich an den beiden Grundsatzfragen »Was lese ich? « und »Wie lese ich? «. Zunächst geht es dabei darum, was Psalmen sind und welche Merkmale sie auszeichnen, und des Weiteren darum, welche Psalmen aus welchem Grund zur Analyse ausgewählt wurden. In der Frage »Wie lese ich?« werden das »Wie» hinsichtlich der Haltungen beim Lesen näher charakterisiert sowie das »Ich« in Bezug darauf, wer mit dem lesenden Ich gemeint ist. Das Kapitel schließt damit, die Arbeit in den aktuellen Forschungsstand einzuordnen.

\subsection{Charakteristika der Psalmensprache}

Die in dieser Arbeit zugrunde gelegte Hermeneutik schließt zunächst an bekannte und ausführlich besprochene Charakteristika der Psalmen an, wonach die Psalmen kunstvolle Poesie sind, die sich durch verdichtete Sprache (in wenigen Worten wird Vielfaches ausgedrückt), einen Reichtum an Sprachbildern (Metaphern, Vergleichen etc.), eine Vielfalt an Lebens- und Glaubensthemen sowie durch Dialogizität (Psalmen gelten als textgewordene Dialoge) auszeichnet. ${ }^{22}$ Darüber hinaus sind für die Hermeneutik dieser Arbeit drei weitere Aspekte relevant, nämlich (1) die Narrativität und (2) der Formularcharakter der Psalmen, dem das Konzept des Thoughtwriting zugrunde gelegt werden kann, sowie (3) die emotionale Qualität der Psalmen. Ausführungen zum transformierenden Charakter der Psalmenlektüre und zum lyrischen Ich als textuellem Identifikationspotenzial runden das Kapitel über die Charakteristika der Psalmensprache ab.

\subsubsection{Psalmen und Narrativität}

Die Psalmen sind in erster Linie Gedichte, Gebete und poetische Kunstwerke. Sie werden in dieser Arbeit u. a. mit Hilfe narratologischer Analysekriterien untersucht (vgl. III Methodik und IV-VII Textanalysen). Inwiefern können diese poetischen Texte überhaupt mit Kategorien aus der Erzähltextanalyse erschlossen werden? Es stellt sich hierbei die Frage, wie Narrativität zu denken und zu definieren ist. Laut Wolf Schmid, »Elemente der Narratologie«, sind das Vorhandensein einer Erzählstimme bzw. einer vermittelnden Erzählinstanz und eine

22 Vgl. Weber, Werkbuch 3, 22-24.230-235; Marböck, Psalmen, 607-609; Zenger, Psalmen, $1036 \mathrm{ff}$ und Eder, Sehnsucht, 74-79. 
Ereignisfolge bzw. Zustandsveränderung konstitutiv für das, was narrativ, d. h. in erzählender Form darlegend genannt wird. ${ }^{23}$ Beide Elemente, nämlich Ereignisse einerseits und das lyrische Ich oder Wir als Erzählstimme andererseits, sind im Psalter vorhanden. Roy Sommer beschreibt die Grundvoraussetzungen von Narrativität folgendermaßen: "Zu den weithin akzeptierten und weitgehend miteinander kompatiblen Voraussetzungen von Narrativität zählen erstens die temporale und/oder kausale bzw. logische Verknüpfung von mindestens zwei erzählten Ereignissen, zweitens die Existenz einer vermittelnden Erzählinstanz, die das Erzählte selektiert, strukturiert und organisiert und die das Aussagesubjekt des Erzählakts darstellt, und drittens die Erfahrungsbezogenheit der E.[Erzählung], die sich in Abgrenzung zu argumentierenden oder wissenschaftlichen Texten an den kognitiven Schemata von Menschen orientiert. ${ }^{24}$ Die drei Aspekte (1) der Verknüpfung von mindestens zwei Ereignissen, (2) der Erzählinstanz sowie (3) der Erfahrungsbezogenheit sind in den Psalmen vorhanden. Daneben lassen sich darin zeitlich organisierte narrative Sequenzen finden, sogenannte Minierzählungen (short stories, vgl. IV Textanalyse Psalm 30), ${ }^{25}$ ebenso auch längere erzählende Passagen wie etwa jene in den Geschichtspsalmen (Ps 78, 105; 106; 135; 136). Daher trifft die Definition der Narration als eines kommunikativen Aktes, in dem eine Ereigniskette durch eine bestimmte Erzählinstanz und aus einer bestimmten Perspektive geschildert wird, auch auf den Großteil der Psalmen zu. ${ }^{26}$

Robert Alter spricht in seiner »Art of Biblical Poetry« im Kapitel »From Line to Story« von einem narrativen Impuls in poetischen Texten. ${ }^{27}$ Er veranschaulicht

23 Vgl. Schmid, Narratologie, 1-10.

24 Sommer, Erzählung, 163.

$25 \mathrm{Zu}$ den Kurzgeschichten zählen laut Seybolds Einteilung nach dem Umfang und gemessen am Maß einer (durchschnittlich großen) Kolumne (= eine Seite BHS) all jene Texte im AT, die bis zu einer Kolumne bzw. drei Minuten »lang« sind: z. B. Gen 11,1-9; 18,1-16;32,23-33; Jos 5,13-15. Hierzu zählen auch die meisten Psalmen, wobei viele Psalmen auch länger sind als eine Kolumne. Vgl. Seybold, Poetik der erzählenden Literatur, 41. Zu den Erzählungen in Versform zählt Seybold neben Ri 5, Jona 2 sowie Theophanietexten und vereinzelten Abschnitten aus der prophetischen Literatur die Geschichtspsalmen 78; 105; 106 und die Individualpsalmen Ps $18 ; 40,2-5 ; 64 ; 69 ; 109$. Auswahlkriterien für das Erheben von Erzählungen in Versform sind seines Erachtens: (1) eine kettenbildende Mehrzahl von Narrativformen, die eine Ereignisfolge anzeigt; (2) dass die Ereignisfolge in der Vergangenheit liegt; und (3) zusätzliche Signale, die auf die Erzählfunktion des Textes hindeuten. Vgl. Seybold, Poetik der erzählenden Literatur, 211.

26 Vgl. Hühn / Sommer, Narration, 1. Hühn, Geschichten, 80: „Erzählen ist ein kommunikativer Akt, in dem eine zeitlich organisierte Kette von Geschehenselementen in einem sprachlichen Medium vermittelt (oder repräsentiert) und in eine kohärente, sinnhafte Abfolge-Struktur transformiert wird, und zwar durch eine sprachliche Vermittlungsinstanz (einen Erzähler) sowie aus einer bestimmten - räumlichen, zeitlichen, ideologischen etc. - Perspektive (der des Erzählers und/oder einer oder mehrerer handelnden Figuren)."

$27 »$ Recognizing the operation of such a narrative impulse in the poems may help us see their 
seine Ausführungen über narrative Strategien in biblischer Lyrik mit unterschiedlichen Beispielen aus poetischen Texten (z. B. 2 Sam 22; Joël 2 und Ri 5), in denen er die nach vorne gerichtete narrative Bewegung durch in den Parallelismen miteinander verbundene Handlungen herausarbeitet. ${ }^{28}$ Die im Methodenteil dieser Arbeit ausgewiesene und in den Textbeobachtungen analysierte Intensivierung und Spezifizierung eines Gedankens in den Psalmversen durch die Stilfigur des Parallelismus geht teils auch mit einer zeitlichen Bewegung Hand in Hand (Ereignisse, die aufeinander folgen; Ursache und Wirkung etc.). Narrative Elemente innerhalb der Parallelismen können darüber hinaus auch dazu genutzt werden, im Rahmen der Charakterisierung von Figuren die Zunahme von deren Stärke - z. B. jener der Gottheit oder der Feinde (vgl. VII Textanalyse Psalm 64) - zu demonstrieren..$^{29}$ Aufgrund der Definitionen der Narrativität und der narrativen Impulse in den Parallelismen ist es daher durchaus möglich, die Kategorie des Narrativen transgenerisch auch auf die Psalmen als poetische Texte anzuwenden. ${ }^{30}$

\subsubsection{Emotionale Qualität}

Emotionen spielen in der Analyse von Identifikationspotenzialen eine entscheidende Rolle (vgl. II Methodologische Grundlagen und III Methodik). So gilt es an dieser Stelle, kurz darzulegen, dass Emotionen auch für das Psalmenbuch selbst eine relevante Größe sind.

Van Grol bezeichnet den Psalter als das emotionalste Buch der Bibel. ${ }^{31}$ Grogan spricht davon, dass die antiken Verfasser und die modernen Lesenden durch gemeinsame Emotionen verbunden sind. Dies ist gerade beim Lesen des Psalmenbuches der Fall, das die gesamte Bandbreite an menschlichen Gefühlen in ihren Höhen und Tiefen, Freuden und Sorgen umfasst. ${ }^{32}$ Frank Matheus geht in

liveliness more fully, may help us understand the links in modes of expression between the typical non-narrative poems and the occasional poems with explicit narrative materials." Alter, Art, 31.

28 Vgl. Alter, Art, 46.

29 Vgl. Alter, Art, 58.

30 »Deswegen ist es zulässig und fruchtbar, das (im Unterschied zur unterentwickelten Lyriktheorie und -methodik) hoch differenzierte Instrumentarium der Narratologie zur Spezifizierung von Gedichtanalysen zu nutzen.« Hühn, Geschichten, 79.

31 Vgl. van Grol, Emotions, 70. Ebenso Ridderbos, Die Psalmen, 112: „Niemand wird leugnen wollen, dass in den Psalmen tiefempfundene Emotionen wiedergegeben werden. [...] Es werden heftige Emotionen wiedergegeben, ihre Formgebung aber unterliegt der Kontrolle der ordnenden Vernunft."

32 »Ancient writers and modern readers share many common emotions. This is why we can still read ancient literature and find it engaging with our feelings and many of our human concerns. This is true of Scripture and nowhere more so than in the book of Psalms, which 
seiner Studie über Tempus und Aspekt im biblisch-hebräischen Verbalsystem im letzten Kapitel auf die Psalmen ein, die er im Rahmen der Nomenklatur der Sprechaktanalyse als Expressiva bezeichnet. In Bezug auf die Psalmen hält er fest: »[...] sie transportieren in erster Linie Emotionen und sind Ausdruck der Gefühlslage der Betenden, die in ihrer Freude und Not oft selbst im Mittelpunkt der Betrachtung liegen und so eine charakterisierte Situation schaffen. ${ }^{33}$ Die bisherigen Ausführungen zusammenfassend bringen die Psalmen eine große Fülle an Emotionen zum Ausdruck. Dies kann auf Seiten der Lesenden bewirken, dass eigene Emotionen hervorgerufen werden. »[Die Dichtung] leiht den in uns schlummernden Gefühlen - der stillen Trauer etwa oder der einer geheimen Sehnsucht - jene Stimme, ohne die unser Innerstes und Tiefstes ungesagt und unsagbar und damit unaktualisiert bliebe. Mit anderen Worten: durch die Dichtung kommt der Mensch zu sich. [... Die Psalmen] wecken das, was in uns vorhanden ist: unsere Sehnsucht und unsere Trauer, unser Glauben, Hoffen und Lieben. ${ }^{34}$

Den ästhetisch-religiösen Charakter nicht nur der Psalmen, sondern der atl. Poesie insgesamt hat bereits Robert Lowth unter dem Begriff »Erhabenheit» nachgezeichnet. Martin Fritz hält in seiner Studie über Lowth' Ausführungen dazu fest: "In der Wechselbeziehung von Erleben und Gestalten sind von den alttestamentlichen Dichtern die tiefsten, tief-religiösen Antriebe und Bewegungen der menschlichen Seele in Sprache gefasst worden, und darum vermögen ihre Schöpfungen beim Leser auch nach Hunderten von Jahren die entsprechenden Schichten des Gemüts wachzurufen. ${ }^{35}$

So vermögen gerade die Psalmen aufgrund ihrer Dichte an unterschiedlichen Emotionen, je eigene Emotionen wachzurufen, und sie geben die Möglichkeit, diese sprachlich zu fassen zu bekommen und auszudrücken. "Oft haben wir wenige Worte, die Vielfalt einer Emotion auszudrücken, die ganz persönlichen Facetten von Freude und Trauer und Ohnmacht und Angst. Sprache zu lernen für die eigenen Empfindungen kann mit Psalmen geschehen, mit Gebetstexten, mit eigenem kreativem Ausdruck. Mich vor Gott zu wissen erlaubt mir, eigene Emotionen ansehen zu können. ${ }^{36}$ Die Psalmen bürgen also für eine hohe emotionale Qualität: Sie berühren das volle Spektrum an Emotionen und geben dadurch Lesenden die Möglichkeit, ihre je eigenen Emotionen darin zu finden und diese mit Hilfe der Psalmenworte auch ausdrücken zu können.

touches the full range of human emotion in all its heights and depths, its joys and sorrows.» Grogan, Psalms, 1.

33 Matheus, Zeit, 395.

34 Füglister, Psalmengebet, $52 \mathrm{f}$.

35 Fritz, Von der heiligen Poesie, 107.

36 Kohler-Spiegel, Emotionen, 12. 


\subsubsection{Transformierender Charakter}

Psalmen und deren Nachdichtungen sind im Unterschied zu anderen Liedern und Gedichten "gerichtete» Texte: Sie sind durch die Orientierung auf eine transzendente Kraft, auf das Ausgerichtetsein auf das göttliche Du bestimmt. Psalmen sind Gespräche mit und zu Gott und haben daher existenziellen Charakter. "Sie ermöglichen einen veränderten Weltzugang und ein neues Gottesverhältnis. Sie bilden nicht Welt ab, vielmehr eröffnen sie vielfältige neue Bezüge auf diese. ${ }^{37}$ Dieses Ausgestreckt- bzw. Ausgerichtetsein auf ein größeres Ganzes und dessen heilende Nähe können im Leseprozess der Psalmen transformierend wirken: „Sie können und wollen so rezitiert bzw. gesungen werden, dass sie das, was sie sprachlich zum Ausdruck bringen, in den Betern selbst bewirken. In ihrer poetischen Komposition sind sie meist so ausgelegt, dass sie einen Gebetsweg bzw. einen Gebetsprozess bilden, durch den sie die Beter so verwandeln wollen, dass das sprechende Ich am Ende des Psalms ein anderes Ich ist als am Anfang des Psalms. ${ }^{38}$ Oder anders gesagt: "Im und mit dem Psalmengespräch findet eine heilvolle Transformierung statt oder wird zumindest angebahnt: Der (Nach-)Sprechende erfährt Gottes rettende Hilfe, die Wiederherstellung von schalom (Heil, Würde, Frieden, Glück) und die (Neu-)Integrierung in die Gemeinde. $\varkappa^{39}$ Dies zu erfahren, sich auf die Texte existenziell einzulassen und darin etwa Geborgenheit, Angenommensein und Trost zu erleben sowie die eigene Erfahrungswirklichkeit zu überschreiten, bleibt den LeserInnen vorbehalten, zumal mit dieser persönlichkeitsverändernden Wirkung laut Ralf Schneider »ein Bereich berührt [wird], der so persönlich ist, dass er sich dem wissenschaftlichen, intersubjektiven Zugang in besonderem Maße versperrt. ${ }^{40}$ Die Aneignung der Texte verbleibt also auf Seite der LeserInnen und ist mittels einer Textanalyse nicht zu erheben. Was am Text allerdings nachvollzogen werden kann, ist die Einstellungs- und Verhaltensänderung in Bezug auf das sprechende Ich bzw. Wir. In diesem Zusammenhang wird vom sogenannten Darbietungsereignis gesprochen, das in poetischen Texten häufig anzutreffen ist: „D. h. Gedichte führen vielfach performativ, im Präsens, einen Bewusstseinsprozess vor, innerhalb dessen der Sprecher eine entscheidende Veränderung in seiner Einstellung oder in seinem Wissen durchläuft. ${ }^{41}$ Dies ist auch in den Psalmen der Fall, weshalb

37 Erbele-Küster, Lesen, 184.

38 Zenger, Der Psalter, 549.

39 Weber, Werkbuch 3, 235. Ebenso van Grol, Emotions, 80 in Bezug auf die Leserkonstruktion des idealen bzw. textinternen Lesers: »The ideal or text-internal reader is supposed or invited to identify with the central character, and to perform the emotional transformations of the supplicant himself or herself."

40 Schneider, Grundriß, 132.

41 Hühn, Geschichten, $84 \mathrm{f}$. 
folglich durch den Mitvollzug der Veränderung im literarischen Ich/Wir auch eine Erneuerung im eigenen Leben stattfinden kann.

\subsubsection{Lyrisches Ich}

Ein Großteil der Psalmen wird von der Sprechinstanz des lyrischen Ich bzw. Wir bestimmt. Im Rahmen der Textanalyse werden folgende Begriffe synonym für diese Sprechinstanz verwendet: lyrisches Ich/Wir, betendes Ich/Wir, BeterIn und PsalmistIn. Wer aber ist nun das lyrische Ich in den Psalmen $?^{42}$ Je nach theoretischen Annahmen können die literaturwissenschaftlichen Positionen in drei Gruppen eingeteilt werden: ${ }^{43}$ (1) Das lyrische Ich wird in engem Zusammenhang mit dem jeweiligen Autorenkonzept gesehen. Es kann der Autor oder die Autorin sein, also die geschichtliche Person, die den poetischen Text verfasst hat (empirischer Autor). Lyrisches Ich und empirisches Ich sind in diesem Ansatz identisch. Das lyrische Ich kann aber auch Träger allgemeingültiger Aussagen sein. Es wird zwar vom empirischen Autor kreiert, ist dabei aber nicht identisch mit dem Autor/der Autorin. (2) Es kann zudem eine Instanz im Text sein, die das Gedicht äußert, also das sprechende Subjekt. Das lyrische Ich des Textes kann damit eine fiktive Person sein, eine Figur also, welche die Dichterin/der Dichter erfunden hat und in ihrem/seinem Namen sprechen lässt. Das Ich kann daher auch als narrative Figur betrachtet und dementsprechend analysiert werden, was in den Textanalysen dieser Arbeit der Fall sein wird. ${ }^{44}$ (3) Die dritte Gruppe bestimmt das Konzept des lyrischen Ich aufgrund rezeptionsästhetischer Überlegungen. In Anlehnung an Wolfgang Isers Begriff der Leerstelle geht es beim lyrischen Ich um eine Leerdeixis bzw. Ich-Deixis (zum Begriff der Deixis vgl. III Methodik 3.2), die von den Lesenden durch Imagination und Identifikation gefüllt wird. So ist das Ich im Gedicht semantisch unterdeterminiert, eigenschaftslos und als Pronomen ein leeres Zeichen, das erst durch den Gebrauch einer/eines Sprechenden gefüllt wird. Das lyrische Ich wird damit zum RollenIch, welches offen für die Aneignung durch die Lesenden ist. So wird das lyrische Ich zur Leserin/zum Leser, die/der das Gedicht nachspricht.

42 Einen informativen Überblick über die heterogene Verwendungsgeschichte des Begriffs "lyrisches Ich" sowie über die unterschiedlichen Positionen und Argumente der BefürworterInnen sowie der Ablehnenden des unterschiedlich bestimmten Konzepts bieten Borkowsi / Winko, Wer spricht das Gedicht?, 45-60. Sie entwickeln darüber hinaus ein eigenes Modell der Sprechinstanz im Gedicht, wobei sie zwischen einem textinternen Sprecher (Sprecher 1) und einem textexternen Sprecher (Sprecher 2) sowie zwischen drei verschiedenen Kontexten unterscheiden.

43 Vgl. Borkowsi / Winko, Wer spricht das Gedicht?, 46-48.

44 "I propose instead to consider the figure who appears in the first person singular in the psalms rather as a character in a narrative, and so to examine the ways in which $s / h e$ is presented, imagined, addressed.« McConville, Happiness, 91. 
Heinz Schlaffer formuliert dies pointiert folgendermaßen: »Wer ist das Ich im Gedicht? - Jeder, der es spricht. ${ }^{45}$ Mit dem lyrischen Ich ist damit auch ein Identifikationspotenzial gegeben. ${ }^{46}$

$\mathrm{Da}$ sich die vorliegende Arbeit als rezeptionsästhetisch versteht (vgl. I Einleitung 6), wird die Betrachtung des lyrischen Ich als lesendes Ich auch in den Textanalysen verfolgt und ausgewertet. Blickt man auf die Bestimmung des lyrischen Ich in den Psalmen, dann ist dieser Ansatz anschlussfähig. So konstatiert Notker Füglister das Ineinander von empirischem und lesendem Ich: »Das Ich des Lesers verschmilzt nicht nur mit dem Ich des Dichters, sondern irgendwie mit dem Ich aller Leser: es entsteht das, was man das dichterische Über-Ich nennen möchte. ${ }^{47}$ Das Ich der Psalmen wird schon früh kollektiv verwendet ${ }^{48}$ und geht damit über einen individualisierten Gebrauch hinaus. „Wenn ein altorientalischer Dichter [...] >Ich sagt [...], meint er ein allgemeines, inklusives, kollektives Ich [...], er begreift in einem Ich zugleich auch die andern ein; aus ihm spricht nicht nur das isolierte Individuum, sondern viel mehr der Mensch von einer umfassenderen Basis aus als der des Individuums. In der Fülle der Erfahrungen, von denen er spricht, transzendiert er das auf sich geworfene, atomisierte Individuum. ${ }^{49}$ Die Offenheit des lyrischen Ich für die Aneignung durch die jeweils Lesenden gilt auch für das lyrische Wir. ${ }^{50}$ Daneben weist Ulrike Bail darauf hin, dass das Ich in den Psalmen keinem bestimmten Geschlecht zuzuordnen ist. Sie geht vom lyrischen Ich der Klagelieder aus, das geschlechtlich nicht differenziert ist, und dehnt ihre Aussage auf den gesamten Psalter aus: »Bezogen auf das literarische Ich sind die Psalmen genderneutral, und so können sich Männer und Frauen gleichermaßen die Worte der Psalmen leihen, als wären es die ihren, sich in ihnen aussprechen und bergen: Erst im Lesen bekommt das literarische Subjekt des Psalms sein Geschlecht. ${ }^{51}$ Und so kann jüngst mit Stephen Dawes

45 Schlaffer, Die Aneignung von Gedichten, 38. In seinem Werk »Geistersprache« formuliert Heinz Schlaffer dazu: »Jeder, der ein Gedicht nachspricht, übernimmt dessen Ich. Gerade weil es weder bekannt noch beschrieben ist, kann an seine Stelle das aktuell anwesende Ich des Lesers oder Sprechers treten - freilich nicht dessen konkrete, einmalige Persönlichkeit, sondern das abstrakte allgemeine Ich, das allen Menschen zusteht. « Schlaffer, Geistersprache, 117.

46 "Another device inviting the worshiper to identify with the sentiments of the psalm is the use of the first person." Wenham, Psalms, 60.

47 Füglister, Psalmengebet, 50. Ähnlich Braulik, Rezeptionsästhetik, 531, der im Rahmen der Psalmenmeditation und -rezitation von der "Identifikation des Psalmierenden mit dem Psalm bzw. dessen Ich« spricht.

48 Vgl. Dawes, The Psalms, 55.

49 Von Rad, Der 90. Psalm, 268.

50 »Wichtiger ist die Feststellung, dass das sich äußernde Wir eine grundsätzlich offene Größe bleibt, weil sie innerhalb der Texte nicht definiert wird.« Ballhorn, Pragmatik, 242.

51 Bail, Gendering Laments, 171. Für die Psalmen und im Besonderen für die in ihnen dargestellten Körperbilder konstatiert sie eine "geschlechtsneutrale Sprache» (S. 175). 
festgehalten werden:»[...] the readers are able to appropriate the $>$ $\ll$ of any of the psalms for themselves and so make a psalm their own. Thus the $>\mathrm{I}<$ of a psalm is everyone or anyone who chooses to be the $>\mathrm{I} \iota$ of the text $[\ldots] . \star^{52}$ Die Sprechinstanz des lyrischen Ich/Wir in den Psalmen gilt damit als ein Textelement, welches den Lesenden ein Identifikationspotenzial eröffnet.

\subsubsection{Psalmen als Gebrauchstexte}

Wie Ulrike Bail ausgeführt hat (s. o.), sind die Psalmen auch dazu da, dass sich die Lesenden diese uralten Worte leihen können, um durch sie ihre aktuellen Anliegen vor Gott zu tragen. Die Psalmen sind also Gebrauchstexte und dienen als Gebetsvorlagen. ${ }^{53}$

Kendall Walton stellt in seinem Artikel das Konzept des "Thoughtwriting" vor. Dieses lässt sich mit dem Gedanken verknüpfen, dass Psalmen als Gebrauchstexte und Vorlagen verwendet wurden sowie für die musikalische Aufführung bestimmt waren, was an den Überschriften mit diversen Aufführungsanweisungen noch erkennbar ist (z. B. »für den Chorleiter« oder »dem Musikverantwortlichen«; "nach der Weise/Melodie«; »auf/zu Saitenspiel« etc.). ${ }^{54}$ Walton beschreibt das Konzept in Anlehnung an jene, die Reden (speeches/speechwriters) für andere schreiben, folgendermaßen: »By thoughtwriters I shall mean writers who compose texts for others to use in expressing their thoughts (feelings, attitudes). The texts thoughtwriters compose are thoughtwritings. I shall argue that poets are often plausibly regarded as thoughtwriters, and their poems as thoughtwritings. Music and music making can frequently be understood in an analogous way..$^{55}$ "GedankenschreiberInnen « sind also jene Personen, die Texte für andere verfassen, damit diese in den komponierten Texten ihre Gedanken, Gefühle und Einstellungen zum Ausdruck bringen können. Dies geschieht in Analogie zum Redenschreiben. Walton bemerkt Ähnlichkeiten zwischen Lyrik und Musik und verweist dafür auf die Verschränkungen der Geschichte dieser beiden Künste wie auch auf die Tatsache, dass Klang und Rhythmus für beide wichtig sind. Daneben geht es in beiden Kunstrichtungen um den Ausdruck von Gefühlen. ${ }^{56}$ Er vergleicht dabei

52 Dawes, The Psalms, 55. Dagegen hält Gerleman, Der »Einzelne«, 47f. fest, dass in den durch die Überschrift David zugeschriebenen Psalmen das lyrische Ich mit David gleichzusetzen ist.

53 Zum Selbstverständnis der Psalmen als Gebrauchstexte vgl. auch Erbele-Küster, Lesen, 2.

54 »In der Antike wurden nicht nur lyrische Texte, sondern Versdichtung allgemein, Epen genauso wie Dramen gesungen - vom Einzelinterpreten oder vom Chor. Begleitet wurden sie von Saiteninstrumenten, z. B. von der Lyra oder Leier; im alten Ägypten auch von Harfe, Laute, Trommel usw., " vermerkt Horn, Theorie der literarischen Gattungen, 19.

55 Walton, Thoughtwriting, 455.

56 Die Gemeinsamkeiten zwischen Musik und Lyrik hebt Horn, Theorie der literarischen Gat- 
das lyrische Ich eines Gedichts mit einer »musical personae«: "Just as narrators in literary works express beliefs, attitudes, intentions, emotions, by means of the words of the text, musical personae express emotions (feelings, attitudes) by means of the sounds (or >gestures $\triangleleft$ ) of the music. ${ }^{57}$ Walton hält fest, dass Gedichte Phrasen, Sätze und Paraphrasen beinhalten, welche die Lesenden bei Bedarf gebrauchen und sozusagen »ausborgen « können. Die Worte sind also dafür da, dass die Lesenden sie benutzen. Dies ist unabhängig davon, was der Dichter/die Dichterin beim Schreiben beabsichtigt hat und auch davon, welche Absichten die Lesenden dem Dichter/der Dichterin unterstellen. Für die Lesenden ist es allerdings nicht immer möglich, die Ideen und Einstellungen, die in einem Gedicht zum Ausdruck gebracht werden, zu akzeptieren und damit die Worte der Dichtung in uneingeschränkter Weise zu gebrauchen. ${ }^{58}$

Wichtig ist ebenso die Funktionsweise des »thoughtwriting«. Das bedeutet, dass lyrische Texte und Musik dazu dienen können, dass sich Lesende und Hörende die Wörter ausborgen und aneignen, unabhängig davon, ob der Künstler/die Künstlerin dies beabsichtigt oder nicht. ${ }^{59}$ Warum lädt Poesie in besonderer Weise dazu ein, das Konzept des Thoughtwriting dahinter zu vermuten? Weil bei lyrischen Texten die Betonung eher darauf liegt, wie etwas ausgedrückt wird und weniger, was damit gesagt wird.$^{60}$ Beim Lesen poetischer Texte führen wir sie gleichsam bereits auf. Gedichte werden rezitiert und auswendig gelernt, was bei Erzählungen und Romanen weniger der Fall ist. Außerdem tragen Reime, die Anordnung in Verse, der Rhythmus - bei den Psalmen der Parallelismus membrorum - und die Lautmalerei dazu bei, sich Gedichte leichter zu merken als andere sprachliche Formen. Auch bei der Musik ist dies der Fall: Melodien merkt man sich relativ leicht, und sie können auch dazu verwendet werden, die Gedanken und Gefühle der Zuhörenden auszudrücken. ${ }^{61}$ Zusammenfassend lässt sich festhalten, dass Lesende und Hörende oftmals Wörter, die sie in lyrischen Texte und in Melodien bzw. in weiterem musikalischen Material finden, dazu gebrauchen, ihre eigenen Absichten, Gedanken und

tungen, 19 hervor, »sind doch beide tendenziell gefühlsbetont, expressiv, von Seele zu Seele sprechend."

57 Walton, Thoughtwriting, 459.

58 Dies trifft bei den Psalmen vor allem auf die sogenannten Fluch- und Rachepsalmen zu. Zur Lesart dieser vgl. u. a. Zenger, Ein Gott der Rache; Eder, Gewalt sowie Kapitel VII Textanalyse Psalm 64.

59 »Pure cases of thoughtwriting are probably rare, maybe even nonexistent. But it seems to me that the thoughtwriting function of a poem is sometimes by far the more important one. It may be important to the reader, and intended to be so by the poet, even if somewhere in the reader's experience there is an implicit, if not explicit, imagining of or recognition of a sserious` speaker.« Walton, Thoughtwriting, 466.

60 Vgl. Walton, Thoughtwriting, 468.

61 Vgl. Walton, Thoughtwriting, 470. 
Gefühle auszudrücken. Diese Texte dienen damit als von »GedankenschreiberInnen « formulierte und komponierte Gebrauchstexte. ${ }^{62}$

\subsection{Lesende}

Die Lesende der dieser Arbeit zugrunde gelegten theoretischen Literatur sowie der ausgewählten Psalmen bin selbstverständlich ich selbst. Ich stelle mich als im Christentum verwurzelte katholische Theologin mitteleuropäischer Provenienz damit in die Reihe der (wenigen) ExegetInnen, die ihren Ausgangspunkt, nämlich jenen bei sich selbst als reale bzw. empirische LeserInnen, transparent machen. ${ }^{63}$ Es gilt an dieser Stelle daran zu erinnern, "dass jede Aussage über einen Text die Aussage eines realen Lesers ist, dessen Behauptungen von Anfang an von seiner Standortgebundenheit, seiner Subjektivität und seinem Weltwissen beeinflusst sind. ${ }^{64}$ Die Aussagen, die ich im Leseprozess über die Psalmen mache, sollen anhand der Analysekriterien - die sich deduktiv entlang der Forschungsfrage nach textuellen Identifikationspotenzialen, nach der Begriffsgeschichte und -bestimmung von literarischer Identifikation und nach der entsprechenden methodischen Operationalisierung des Begriffs für die Textanalyse ableiten lassen - nachvollziehbar gemacht werden (vgl. die folgenden Kapitel II Methodologische Grundlagen und III Methodik). Die aus der jeweiligen Textanalyse entwickelten Beobachtungen bringe ich - vermittels der Literatur - mit jenen zahlreicher ExegetInnen ins Gespräch, die sich ebenso mit dem jeweiligen Thema bzw. Psalm beschäftigt haben. Damit wird ein Resonanzraum geschaffen, in welchem die je eigenen Beobachtungen in den Kreis vieler eingeordnet und intersubjektiv geteilt werden, sodass übergreifende Erkenntnisse formuliert werden können. Dies ist vor allem in Bezug auf die Analyse von Emotionen und noch mehr auf jene der emotionalen Wirkung von großer Relevanz, zumal sich hier die Analysierenden nicht wie distanzierte Lesende verhalten können, sondern selbst Teil des Analyseprozesses sind. ${ }^{65}$ Ich schließe mich daher dem Ansatz

62 "Poetry and music are strikingly similar in their propensity to function as thoughtwriting.» Walton, Thoughtwriting, 473.

63 David Clines tut dies ebenso, indem er in seinem als reader-response gestalteten Beitrag zu Beginn festhält: "Let me first speak of the reader that I am. « Clines, World, 80.

64 Richter, Wirkungsästhetik, 534.

65 Dieses Vorgehen lehnt sich an jenes von Sabine Schouten in ihrer theaterwissenschaftlichen Dissertation mit dem Titel »Sinnliches Spüren« an. Sie geht der Frage nach, wie Atmosphären im Theater erzeugt werden und richtet dabei den Blick auf das Dazwischen von Darstellung, also Inszenierung (werkästhetisch) einerseits und Wahrnehmung, also die Reaktionen der ZuschauerInnen (rezeptionsästhetisch) andererseits. Sie arbeitet mit dem Begriff der atmosphärischen Einfühlung bzw. des atmosphärischen Wahrnehmens und geht in ihrer Analyse von den eigenen Erfahrungen und Beobachtungen aus, wie ausgewählt besuchte Theater- 
Amy Cottrills bzw. ihrer Analyse von Affekten und Emotionen in Ri 3-5 an; sie geht von ihren eigenen Beobachtungen, von denen ihrer Studierenden und - durch das Heranziehen von Literatur - von denen anderer ExegetInnen aus. Eine Vergleichbarkeit dieser Beobachtungen mit jenen von antiken LeserInnen ist nicht gegeben. ${ }^{66}$ Schlussendlich ist für das wissenschaftliche Arbeiten an biblischen Texten in Erinnerung zu rufen: »In der Exegese, beim Übersetzen gibt es keine Objektivität - wissenschaftliche Redlichkeit zeigt sich darin, das eigene Vorverständnis und die Entscheidungskriterien offen zu legen. $\aleph^{67}$ Mit der Darlegung der Forschungsfrage, der Hermeneutik, der methodologischen Grundlagen und der Methodik sollen die Analysekriterien, die sich durch die Herleitung aus entsprechender theoretischer Literatur herauskristallisieren, sowie die eigenen Beobachtungen in den Textanalysen, die mit meinen GesprächspartnerInnen aus der Exegese in einen Dialog gebracht werden, transparent und nachvollziehbar gemacht werden.

\subsection{Haltungen}

Für den Analyseprozess von Identifikationspotenzialen sind bestimmte Haltungen unumgänglich, damit Erstere auch ihre Wirkung erzielen können. Es geht zunächst darum, die Texte als Gegenüber in ihrer Aussage- und Wirkkraft ernst zu nehmen und ihnen diese auch zuzutrauen. ${ }^{68}$ Für den Analyseprozess gilt, die Texte als Gegenüber auf Augenhöhe ernst zu nehmen. »Textinterpretation ist nicht bloße Gegenstandserkenntnis, sondern Kommunikation und Reflexion. Die sog. `Gegenstände` reden selber. Sie sind keine Objekte, sondern Subjekte.

stücke auf sie wirken. Diese bringt sie dann methodisch reflektiert mit jenen anderer TheaterbesucherInnen und deren offensichtlichen Reaktionen im Zuschauerraum (Weinen, Lachen etc.) in Zusammenhang. In ihrer Arbeit kann sich die Analysierende also nicht ausschließen, sondern ist Teil des Analyseprozesses. Vgl. Schouten, Sinnliches Spüren, 112. Dies trifft auch auf diese Arbeit zu.

66 »For the most part, my analysis of the affective potential of Judges is based on the experience of modern readers; I use my own experience as a reader of these texts, as well as those of my students and other interpreters, as reflected in their published comments. I do not assume similarity between ancient and modern physical responses to these stories. No one can know for sure the affective response of ancient readers and hearers." Cottrill, Reading, 431.

67 Janssen, »Ich ermutige euch«, 6. Ebenso Risse, Gut ist es, 17: »Da es keine >objektiveく Exegese gibt, sondern die Auslegung immer auch von den Interessen des Exegeten beeinflusst wird, sollte dieser sich seiner besonderen Interessen selbst klar sein, damit er weiß, bei welchen Fragen er in erhöhtem Maße kritisch sein muss. Auch für den Leser kann es hilfreich sein, wenn er darüber informiert wird.»

68 »Wenn ich den Texten eine Kraft und eine Wirkung auf Menschen heute zutraue, wird die Chance zumindest größer, dass ich diese entdecken und erfahren kann." Pohl-Patalong, Zugänge, 40. 
Besser: jeder Text ist Ausdruck menschlichen Subjekts. Im Lesen kommuniziere ich mit ihm. Und genau darin liegt der Sinn der Beschäftigung mit alten Texten. " ${ }^{69}$ Zentral ist bei der Frage nach den Identifikationspotenzialen in den Texten, dass sie auf Seite der LeserInnen auch wirken können. Das erfordert auf LeserInnenseite Empathiefähigkeit. $^{70}$

\subsubsection{Empathiefähigkeit als anthropologische Konstante}

Sich in andere Menschen und in ihre Lage hineinzuversetzen, sich in sie hineinzudenken und einzufühlen, sich mit ihnen zu identifizieren, gehört zu den grundlegenden Fähigkeiten der Menschen. Dadurch können Menschen die Gedanken und Gefühle anderer Menschen nachvollziehen oder miterleben. ${ }^{71}$ Dieses Phänomen - Freude und Ängste, Hoffnungen und Enttäuschungen, Schmerz und Hunger von Anderen wie eigene Gefühle zu empfinden und die Gedanken anderer nachzuvollziehen - wird mit den oft synonym verwendeten Begriffen Einfühlungsvermögen, Empathiefähigkeit oder auch Identifikation bezeichnet. Einfühlungsvermögen ist demzufolge eine anthropologische Kategorie, und das Fehlen von Empathie kann als ein Zeichen von Unmenschlichkeit betrachtet werden. ${ }^{72}$ Basis für die Empathie ist die menschliche Fähigkeit zum Wahrnehmen und Erkennen. Dabei wird beim Empathisieren erstens ein Ausdrucksverhalten jener Person, in die sich jemand hineinversetzt, wahrgenommen und zweitens die Lage jener Person erkannt. ${ }^{73}$ Erlebt werden Empathien, als ob sie eigene Reaktionen wären. Empathie ist somit ein Als-ob-Erlebnis: »Eigen sind die Reaktionen zwar, die eine jeweilige Empathie ausmachen, doch genuin eigen sind sie in der Tat nicht, weil wir beim Empathisieren fremde Ein- und Vorstellungen sozusagen übernehmen dadurch, dass wir sie in uns (ähnlich) reproduzieren. ${ }^{74}$ Empathie läuft fast immer unbewusst ab, ist aber bewusstseinsfähig. Empathische Reaktionen können als Resonanzphänomene bzw. als Echo beschrieben

69 Schweizer, Biblische Texte, 26. Ebenso Erbele-Küster, Lesen, 1.

70 »Nun gehört es gerade zum Wesen expressiver Texte, Gefühle zu äußern, Gefühle, die in Worte gefasst werden. Diese auf- und anzunehmen, verlangt von der Empfängerseite ein hohes Maß an Empathie. Erspürt er die transportierten Emotionen, heißt das noch nicht, dass er die Aussage oder Grammatik versteht [...].« Matheus, Zeit, 404. Ebenso Feagin, Imagining Emotions, 53: „Empathy requires sidentifying with someone, which requires being able to feel as they would $[\ldots] . . "$

71 Vgl. Hermanns, Empathie, 127. Die Fähigkeit, sich einzufühlen, eignen sich heranwachsende Menschen zusammen mit anderen Kompetenzen wie Erinnern, Denken, Verstehen und Konzeptualisieren an. Vgl. Fontius, Einfühlung, 124.

72 Vgl. Keen, Empathy, 6. Ähnlich Fontius, Einfühlung, 122, der an dieser Stelle anführt, dass das Fehlen von Empathie als Grundlage von sozialen Spannungen, Konflikten, Gewalt und Krieg gilt.

73 Vgl. Hermanns, Empathie, 142.

74 Hermanns, Empathie, 145. 
werden: »Wo sich Empathie ereignet, da gibt es ein echohaftes Nach- und Mitvollziehen der Gefühle, Gedanken usw. eines Anderen. ${ }^{75}$ Die Frage jedoch, warum und wie genau Empathie in den Körpern und Hirnen der Menschen funktioniert, kann bislang nur mit theoretischen Spekulationen über die Physiologie des menschlichen Körpers beantwortet werden, auch wenn in diesem Zusammenhang in der Neurologie immer wieder der Begriff »Spiegelneuronen « begegnet, der jenes System im menschlichen Gehirn bezeichnet, das für das »automatische« Teilen von Gefühlen zuständig ist. ${ }^{76}$

Empathisieren ist demnach eine psychische oder mentale Reaktion auf andere Wesen, die im Sich-Ausbilden oder Haben von Gedanken, Emotionen etc. analog zu denen besteht, die das Gegenüber hat, auf das reagiert wird. ${ }^{77}$ Dabei können Menschen nie direkt erfahren, was andere empfinden, sondern sich dies immer nur vorstellen. Die Aktivierung der je eigenen Vorstellungskraft und das Imaginieren sind damit wesentliche Bestandteile der Empathie.

Empathie wird in erster Linie mit Gefühl verbunden. Dies ist beim Empathisieren ein elementares Moment, wenngleich zum entwickelten Empathisieren auch das Nach- bzw. Mitvollziehen von Gedanken sowie das Begreifen der Wollensbestrebungen und Wünsche anderer Personen zählt. Man spricht daher nicht nur von emotiven, sondern ebenso von kognitiven und volitiven Empathien. $^{78}$

Die Empathiefähigkeit ist notwendig für das Existieren von menschlicher Gemeinschaft und Gesellschaft, oder anders gesagt: »Der Mensch braucht daher Empathie, er wäre ohne sie gar kein gesellschaftliches Wesen, sondern ein monadenhaft autistisch sozial isoliertes. ${ }^{79}$ Das Vermögen, empathisch zu sein, ist demnach die Voraussetzung für jegliche Sozialbeziehung, und da Kommunikation ein soziales Phänomen ist, setzt das menschliche Sprachvermögen Empathiefähigkeit voraus. Menschen können Sprache durch die Fähigkeit des SichHineinversetzens in den jeweils Anderen, den man verstehen will, erfassen. Demzufolge muss in jeder menschlichen Kommunikation Empathie beteiligt

75 Hermanns, Empathie, 143.

76 Vgl. Keen, Empathy, 14. Ob die Spiegelneuronen, die Mitte der 1990er Jahre im Gehirn von Makaken entdeckt wurden, und der darauf folgende Nachweis von mit dem Affenhirn analogen menschlichen Gehirnaktivitäten einen direkten Beleg für komplexe empathische Reaktionen des Menschen darstellen, bleibt offen. Vgl. zu diesem Bereich aus der Hirnforschung ausführlicher Curtis, Einführung, 13-16.21.23 sowie Hermanns, Empathie, 146-152.

77 Zillmann, Empathy, 136 sieht dementsprechend das Gemeinsame aller Definitionsversuche von Empathie als "process by which persons respond emotionally to the emotions of others, and do so with some degree of affinity between witnessed emotion and their emotional reaction to it."

78 »Human empathy clearly involves both feeling and thinking«, bemerkt dazu Keen, Empathy, 27.

79 Hermanns, Empathie, 145f, der sich an dieser Stelle auf einen Hinweis von Werner Holly beruft. 
sein. ${ }^{80}$ Im Bereich der Phonetik wird dies durch folgendes Argument gestützt: "Das Erkennen und Verstehen von Sprachlauten (und, so kann man hinzufügen, Silben, Wörtern, Sätzen und Texten), d. h. von sprachlichen Gesten, besteht essenziell in deren echohaftem Nach- und Mitvollziehen. ${ }^{81}$ Sprachverstehen geschieht somit in der Folge eines - automatischen und echohaften - inneren empathischen Mitsprechens, bei dem sich Hörende in die jeweiligen Sprechenden mitfühlend hineinversetzen. Verstehen meint dabei nicht nur das Verstehen von Worten, sondern auch von Absichten, von Handeln und Denken. Daher ist Sprachverstehen nicht nur ein Handlungsverstehen und Rollenverstehen, sondern ein Personverstehen. ${ }^{82}$

In der Linguistik wird für Empathie, falls diese dort überhaupt zur Sprache kommt, hauptsächlich der Begriff »Perspektive« bzw. »Perspektivenübernahme« verwendet. Dieser Ausdruck meint die Sichtweise, mit der Personen, Gegenstände und Sachverhalte wahrgenommen werden. Perspektiven gehen zudem über die Bedeutung eines »Blickwinkels« hinaus und bezeichnen ebenso zum Teil Einstellungen und Haltungen, die durch soziale Rollen, Gruppenzugehörigkeiten etc., aber auch durch punktuelle Ereignisse festgelegt werden. Dass Kommunikation trotz dieser Perspektivenvielfalt funktioniert, ist immer wieder erstaunlich, und dies zeigt, dass Sprechende und Zuhörende fähig sein können, sich in andere Menschen hineinzuversetzen, die Welt mit deren Augen zu betrachten und sie zum Teil ähnlich wie sie zu erleben. ${ }^{83}$

\subsubsection{Weitere Haltungen in Bezug auf das Psalmenlesen}

In der Diskussion mit einem Kollegen vom Fach Fundamentaltheologie kam eine interessante Frage auf: Ist es, damit die Psalmen ihre Wirkmacht entfalten können, notwendig, dass die Lesenden den Rezeptions- und Glaubensgemeinschaften des Juden- oder Christentums angehören? Zwingend ist dies nicht, zumal die Psalmen nicht nur als vertraute Texte wirken, sondern auch als Sprachschule dafür gelten können, wie eine direkte Kommunikation mit Gott aussehen kann (vgl. V Textanalyse Psalm 147). »In manchen Lebenssituationen erweist sich die Kraft der biblischen Texte vor allem darin, dass sie Sprachhilfe leisten, wenn uns die eigenen Worte fehlen oder aber wenn unsere Fantasie und Sprachkraft nicht reicht, um tiefe Erfahrungen auszudrücken. Dies gilt besonders für die Psalmen. ${ }^{84}$ Eine grundsätzliche Offenheit, die sich der Frage nach Transzendenz und der Begegnung mit dem Göttlichen nicht verschließt, ist al-

80 Vgl. Hermanns, Empathie, 156.

81 Hermanns, Empathie, 158.

82 Vgl. Hermanns, Empathie, 163.

83 Vgl. Hermanns, Empathie, $160 \mathrm{f}$.

84 Pohl-Patalong, Zugänge, 137. Ähnlich Füglister, Psalmengebet, $149 \mathrm{f}$. 
lerdings notwendig; und darüber hinaus die Bereitschaft, sich trotz der offensichtlichen - kulturellen, sprachlichen und zeitlichen - Fremdheit dieser altorientalischen Texte auf das Textgeschehen einzulassen. In diesem Zusammenhang spricht Notker Füglister von der »richtigen Disposition « des Psalmenlesens als »jene[r] Empfangsbereitschaft und Beweglichkeit, Disponibilität und Sensibilität, die ohne innere Ruhe und Gelöstheit nicht denkbar ist. ${ }^{85}$ Er betont daneben auch die Offenheit und das Eingestelltsein auf die "richtige Wellenlänge ${ }^{86}$ der Psalmen und ergänzt dies noch um den je eigenen inneren Reichtum: "Schließlich hängt die dichterische Evokation in ihrer Tiefe und Kraft vom inneren Reichtum des Angesprochenen ab. Es kann ja nur das in mir geweckt und aktualisiert werden, was bereits irgendwie in mir vorhanden ist. Je reicher ich innerlich bin, desto größer ist deshalb die Wirkung, die ein Gedicht auf Grund seiner Evokationsmacht auf mich hat. [...] Sich richtig disponieren bedeutet demnach vor allem: innerlich reich werden und ansprechbar bleiben. $"{ }^{87}$ Sich und sein Leben den Texten gegenüber zu öffnen, ist demnach ebenso wichtig wie die Bereitwilligkeit, sich selbst von den Texten in Frage stellen zu lassen. ${ }^{88}$

\section{Psalmenauswahl}

Die Kriterien der Textauswahl müssen mit der Forschungsfrage nach Identifikationspotenzialen konform gehen. Es gilt, Texte auszuwählen, an denen sich die theoretischen Prinzipien festmachen und methodisch operationalisieren lassen. Identifikation mit literarischen Texten hat mit der Übernahme von im Text vorgezeichneten Perspektiven zu tun (vgl. II Methodologische Grundlagen). Daher ist die Perspektive das Hauptkriterium, nach welchem die Psalmen in dieser Arbeit ausgewählt werden. Für das exemplarische Analyseverfahren legt sich damit das formale Kriterium der dominanten Ausrichtung der Sprechrichtung in Kombination mit der Sprechinstanz (lyrisches Ich/Wir) nahe, da so eine Unterschiedlichkeit der Perspektiven vorhanden ist. Außerdem ist beabsichtigt, möglichst unterschiedliche Psalmen auszuwählen, damit verschiedenste Erfahrungen, Situationen und Inhalte thematisiert sind. Auch die literarische Stellung innerhalb des Psalters bzw. in den fünf Büchern der Psalmen ist relevant, und desgleichen auch die Überschriften, die zwar redaktionell sind, aber bereits LeserInnenlenkungen beinhalten.

85 Füglister, Psalmengebet, 56.

86 Füglister, Psalmengebet, 57.

87 Füglister, Psalmengebet, 58. Zu weiteren Haltungen in Bezug auf das Psalmenlesen vgl. Witzenrath, Am Abend Weinen, 474-477.

88 Vgl. dazu auch die Ausführungen zur feministischen Hermeneutik sowie die weiteren Haltungen des Interesses, der Neugier und Wissbegierde bei Eder, Frauen und Männer, 15-21. 
Psalmen zeichnen sich durch mehrere Sprechrichtungen und durch Sprechrichtungswechsel aus. Es gilt daher, nach Texten zu suchen, die so etwas wie eine dominante Sprechrichtung aufweisen. Mit den unterschiedlichen Perspektiven sind die Objekte gemeint, die die Sprechinstanz in den Blick nimmt. Wovon erzählt das lyrische Ich/Wir? Von sich selbst (Ich/Wir), einem Du, einem Er/Sie/ Es etc.? Es geht hier um die grammatikalische und syntaktische Ausrichtung, d. h. um die Frage, ob der Psalm eine Mehrzahl an Ich-Du-Aussagen, Er-Ihr-Aussagen, Wir-Aussagen oder Sie-Aussagen beinhaltet. Von den 150 Psalmen habe ich die folgenden Psalmen ausgewählt, die auch in dieser Reihenfolge analysiert werden:

\begin{tabular}{|c|c|c|c|c|}
\hline $\begin{array}{l}\text { Dominante } \\
\text { Sprech- } \\
\text { richtung }\end{array}$ & \begin{tabular}{|l|} 
Psalm \\
Sprechinstanz \\
zentraler Aspekt \\
\end{tabular} & Themen & $\begin{array}{l}\text { Literarische } \\
\text { Position im } \\
\text { Psalter } \\
\end{array}$ & Überschrift \\
\hline Ich-Du & $\begin{array}{l}\text { Ps } 30 \\
\text { lyr. Ich } \\
\text { Lobdank }\end{array}$ & $\begin{array}{l}\text { Freude, Dankbarkeit, } \\
\text { göttliche Rettung aus } \\
\text { Todesnot, Selbst- } \\
\text { sicherheit, Wandel } \\
\text { der Klage in Tanz } \\
\text { durch JHWH, Lob- } \\
\text { preis }\end{array}$ & Erstes Buch & $\begin{array}{l}\text { Ein Psalm. Ein } \\
\text { Lied zur Ein- } \\
\text { weihung des } \\
\text { Hauses. Im } \\
\text { Geiste Davids. }\end{array}$ \\
\hline Er-Ihr & $\begin{array}{l}\text { Ps } 147 \\
\text { lyr. Wir } \\
\text { Lob Gottes }\end{array}$ & $\begin{array}{l}\text { JHWHs Heilstaten an } \\
\text { Israel und an bzw. in } \\
\text { der Schöpfung, Lob- } \\
\text { preis }\end{array}$ & Fünftes Buch & $\begin{array}{l}\text { Keine Über- } \\
\text { schrift }\end{array}$ \\
\hline Wir & $\begin{array}{l}\text { Ps } 90 \\
\text { lyr. Wir } \\
\text { Volksklage inkl. } \\
\text { weisheitliche Re- } \\
\text { flexion über Zeit } \\
\text { und Vergäng- } \\
\text { lichkeit }\end{array}$ & $\begin{array}{l}\text { Zeit und Ewigkeit } \\
\text { Gottes vs. Lebens- } \\
\text { dauer, Vergänglich- } \\
\text { keit und Sterblichkeit } \\
\text { der Menschen, Zorn } \\
\text { Gottes, Bitte um } \\
\text { Weisheit, Zuneigung } \\
\text { und Unterstützung } \\
\text { Gottes für den Be- } \\
\text { stand menschlichen } \\
\text { Tuns }\end{array}$ & Viertes Buch & $\begin{array}{l}\text { Ein Gebet. Im } \\
\text { Geiste Moses, } \\
\text { des Mannes } \\
\text { Gottes. }\end{array}$ \\
\hline Sie (pl.) & \begin{tabular}{|l} 
Ps 64 \\
lyr. Ich \\
Klage gegen \\
Feinde
\end{tabular} & $\begin{array}{l}\text { Schutz, Verschwö- } \\
\text { rung gefährlicher } \\
\text { Feinde, Eingreifen } \\
\text { Gottes, Fall der Fein- } \\
\text { de, Zuflucht und } \\
\text { Freude bei JHWH }\end{array}$ & Zweites Buch & $\begin{array}{l}\text { Für den Chor- } \\
\text { leiter. Ein } \\
\text { Psalm. Im Geis- } \\
\text { te Davids. }\end{array}$ \\
\hline
\end{tabular}

Diese vier Psalmen wechseln zwischen lyrischem Ich und Wir als Sprechinstanz ab und präsentieren, von dieser Sprechinstanz ausgehend, die verschiedenen Perspektiven Ich-Du (Ps 30), Er-Ihr (Ps 147), Wir (Ps 90) und Sie pl. (Ps 64). Des Weiteren verkörpern sie unterschiedliche Lebens- und Glaubensthemen (s. o.) 
wie auch verschiedene literarische Positionen im Buch der Psalmen (erstes und zweites bzw. viertes und fünftes Buch). Zudem tragen sie diverse Überschriften. Und letztlich sind es auch jene Psalmen, die mich ansprechen und in deren unterschiedlichen Versen ich mich selbst je nach Kontext und Lebenssituation wiederfand bzw. wiederfinde.

\section{Forschungsstand}

Basierend auf dem rezeptionsästhetischen Ansatz versuche ich mit dieser Arbeit, einen Beitrag zur Erforschung textueller Wirkungssignale in Bezug auf das Identifikationsphänomen zu leisten. Im Zuge dieser Analyse (siehe II Methodologische Grundlagen und III Methodik) sind weitere Erkenntnisse hinsichtlich der Analyse von Emotionen und der Bildersprache in den Psalmen sowie der Anwendung narratologischer Analysekriterien auf lyrische Texte für die Psalmenforschung zu erwarten. Im Folgenden werden der aktuelle Stand der eben genannten Forschungsbereiche kurz skizziert sowie Forschungsdesiderata ausgewiesen.

\subsection{Rezeptionsästhetische Zugänge}

Diese Arbeit ist der Rezeptionsästhetik verpflichtet, die besagt, dass das Lesen eines Textes ein aktives Geschehen zwischen Text und LeserIn ist, und dass es die Lesenden sind, die dem Text Sinn und Bedeutungen zukommen lassen, die wiederum wandelbar sind. ${ }^{89}$ Der Leseprozess gestaltet sich innerhalb der Begegnung zwischen LeserIn und Text. »Beide sind aber nicht allein, beide haben ihre Welt. Die Lesenden haben ihre Kultur, ihre Biographie, ihre Sozialisation, ihre Emotionen und die jeweilige Lesesituation. Der Text hat die Entstehungs-

89 Vgl. Utzschneider, Zur vierfachen Lektüre, 284. Ebenso Pohl-Patalong, Zugänge, 32: »Insofern ist die Bibel ein Buch, das den Menschen und seine Lebenserfahrungen braucht, um verstanden zu werden. Das gilt zunächst für jedes Buch - denn wir können Texte nicht san sich verstehen, sondern immer nur aus unserer persönlichen Perspektive heraus. Erst im Wechselspiel zwischen Text und Mensch erschließt sich ein möglicher Sinn und erst in der persönlichen Auseinandersetzung findet Verstehen statt.« Vgl. dazu die grundlegenden Werke zur Rezeptionsästhetik bei Iser, Akt des Lesens, und Warning, Rainer (Hg.): Rezeptionsästhetik. Theorie und Praxis, München 1975. Für bibelwissenschaftliche Werke mit rezeptionsästhetischem Zugang siehe Nißlmüller, Thomas: Rezeptionsästhetik und Bibellese. Wolfgang Isers Lese-Theorie als Paradigma für die Rezeption biblischer Texte, Philosophie und Theologie 25, Regensburg 1995; Erbele-Küster, Lesen, und Brockmöller, Katrin: Eine Frau der Stärke - wer findet sie? Exegetische Analysen und intertextuelle Lektüren zu Spr 31,10-31, BBB 147, Berlin u. a. 2004. 
welt, er birgt in sich die jeweiligen Erfahrungen uns unbekannter Menschen, die ihre Fragen, ihre Lebenssituation und Kultur in den Texten eingeschrieben haben. ${ }^{90}$ Diesen Ansatz aufnehmend sind im Bereich der Psalmenforschung u. a. folgende rezeptionsorientierte Studien $\mathrm{zu}$ nennen: Dorothea Erbele-Küster entwickelt in ihrer Dissertation ein rezeptionsästhetisches Verständnis des Psalmenbuches in der Perspektive eines »betenden Lesens«. Sie fokussiert die Psalmenlektüre auf die anthropologische Dimension mit der Art und Weise, «wie sich für den Leser und die Leserin bei der Beschäftigung mit den Texten Möglichkeiten der Welterschließung und Weltgestaltung eröffnen. Es sind die Texte selbst, die Interaktionsprozesse anlegen. ${ }^{91}$ Ihr Ansatz, der den Wirkungssignalen nachgeht, die eine anhaltende Rezeption der Psalmen ermöglichen, basiert auf dem Lesekonzept Wolfgang Isers, welches um den Gesichtspunkt ästhetischer Erfahrung von Hans Robert Jauß und der Betonung des informierten Lesers sowie der Rezeptionsgemeinschaft bei Stanley Fish und um weitere Ansätze des reader-response-criticism erweitert wird. Anhand vielfältiger Einzelanalysen unterschiedlicher Psalmverse, in die auch Methoden und Ergebnisse der historisch-kritischen Exegese einfließen, zeigt sie auf, dass beispielsweise narrative Psalmüberschriften als erste Leseanweisungen gelten und David darin als impliziter Leser und Beter des Psalms vorausgesetzt wird. Er wird zur Leserfiktion und stellt in weiterer Folge ein offenes Identifikationsangebot für Lesende dar. Darüber hinaus erörtert Erbele-Küster, wie Leerstellen »als Sprachgeschenk« (S. 173) die Mitwirkung der Lesenden evozieren sowie die Möglichkeit, sich mit den je eigenen existenziellen Erfahrungen in den Texten zu bergen. Sie weist nach, dass der Wechsel zwischen Aussagen in der 1.P. und allgemein formulierten Aussagen in der 3.P. sowie der Numeruswechsel Möglichkeiten zur Identifikation schaffen und wie die Darstellung der Feinde den Lesenden eine Negativfolie vor Augen hält, zur Abgrenzung gegenüber diesen und damit zur Identifikation mit dem betenden Ich einlädt. Im Schlusskapitel wird in der Zusammenschau der Forschungsergebnisse die Perspektive einer literarischen Anthropologie der Psalmen entworfen, die zur ästhetischen Erfahrung und damit zum betenden Lesen hinführt. Die Faszination der Wirkkraft der Psalmen sowie die Suche nach Wirkungssignalen aufnehmend, verfolge ich die Frage nach textuellen Identifikationspotenzialen in den Psalmen. Diese Forschungsfrage wird anhand der Begriffsklärung von literarischer Identifikation durch die Kategorien Inhalt, Perspektiven, Textdynamik und Emotionen bzw. emotionale Wirkung konkretisiert und an vier Psalmen beispielhaft angewandt. Dabei werden Erkenntnisse aus der Dissertation von Erbele-Küster aufgenommen, und ihr Begriff der ästhetischen Erfahrung durch die Untersuchung

90 Rapp, Mut, 14.

91 Erbele-Küster, Lesen, 2. 
verschiedener Arten von Emotionen wird weiterentwickelt. In dieser Arbeit wird - wie in der Dissertation von Dorothea Erbele-Küster - versucht, ausgehend von einzelnen Versen bzw. Psalmen Aussagen über den gesamten Psalter zu treffen. In den folgenden leserorientierten Studien stehen dagegen einzelne Psalmen im Mittelpunkt: Donald K. Berry verfolgt in seiner Studie zu Psalm 18, in der er sich nach Textkritik, Form- und Gattungskritik und poetisch-rhetorischer Analyse (Anordnung der Strophen, Wiederholungen, Leitwörter, Klang, Themen etc.) bis zur leserorientierten Analyse vorarbeitet und sich dabei auch der Sprechakttheorie und Fishs Lesemodell bedient, den Gedanken einer zweifachen Vermittlungsmöglichkeit zwischen gegenwärtig Lesenden und einstigen RezipientInnen des Psalms: So kann sich der/die heutige LeserIn in die Glaubenswelt des Alten Israel einfühlen und darin den Psalm zwar nicht in derselben, aber doch in ähnlicher Weise erfahren wie sein bzw. ihr israelitischer Vorgänger, oder aber wie der Israelit im Gottesdienst im Kontext des öffentlichen Gebets an der Aufführung des Psalms teilhaben. ${ }^{92}$ Eberhard Bons präsentiert in seiner synchron-leserorientierten Analyse von Psalm 31 eine Fülle von Einzelbeobachtungen zu Syntax und Semantik von Ps $31 .^{93}$ Sein Schwerpunkt liegt dabei auf der synchronen Analyse; die Ausschilderung der LeserInnenorientierung bleibt demgegenüber vage. Ulrike Bail geht in ihrer intertextuellen Studie zu Ps 6, Ps 55 und 2 Sam 13 von den Psalmüberschriften als innerbiblischen Verbindungen zwischen erzählenden und poetischen Texten aus und bezieht die Lesenden durch das Verschränken von Intertextualität und Rezeptionsästhetik mit ein. Dabei bieten die Texte selbst potenzielle referenzielle Wörter an. Die Verknüpfungen zwischen den Texten entstehen im Leseprozess und ereignen sich damit im Rezeptionsvorgang. ${ }^{94}$ So können Lesende die individuellen Klagepsalmen mit Texten über sexuelle Gewalt gegen Frauen ins Gespräch bringen: „Wo die Texte der Gewalt gegen Frauen schweigen, sprechen die Klagepsalmen der Einzelnen. $"{ }^{95}$ Wie Ulrike Bail nehme ich die Mitarbeit der LeserInnen an der Sinnkonstruktion der Texte ernst und versuche - analog zu den in ihrer Arbeit ausgewiesenen Anknüpfungssignalen -, Wirkungssignale in Bezug auf meine Forschungsfrage im Text zu erheben.

92 Vgl. Berry, The Psalms and their Readers, 136f. Er betont zudem den Unterschied zwischen dem aktuellen leisen und individuellen Lesen und dem einstigen lauten öffentlichen Vortragen der Psalmen. Zur Kritik an der Studie Berrys siehe Erbele-Küster, Lesen, $43 \mathrm{f}$.

93 Vgl. Bons, Psalm 31.

94 Vgl. Bail, Gegen das Schweigen klagen, 109.

95 Bail, Gegen das Schweigen klagen, 215. 


\subsection{Emotionen im AT}

Im Identifikationsprozess mit literarischen Texten spielen Emotionen eine wichtige Rolle. In der atl. Bibelwissenschaft ist Emotionsforschung ein junges, aufstrebendes Gebiet, das im Trend gegenwärtiger Forschung liegt. ${ }^{96}$ Bisher ist der Blick auf ausgewählte Emotionen, einzelne atl. Bücher oder kleinere Überblicksbeiträge gerichtet. ${ }^{97}$ Eine Gesamtkonzeption des Emotionalen im AT fehlt. ${ }^{98}$ Der derzeitige Forschungsschwerpunkt im Bereich der Emotionsforschung liegt auf der Semantik und den expliziten Manifestationen von Emotionen an der Textoberfläche. ${ }^{99}$ Die Erforschung impliziter Emotionen sowie die Unterscheidung zwischen A- und F-emotions (siehe III Methodik) ist m. W. bisher noch in keinem atl. veröffentlichten Beitrag erfolgt und stellt ebenso in Bezug auf die Emotionsanalyse lyrischer Texte allgemein ein Forschungsdesiderat dar. ${ }^{100}$ Vor diesem Hintergrund leistet diese Arbeit u. a. einen Beitrag zur Erforschung von Emotionen in den Psalmen. ${ }^{101}$ Diesen widmet sich auch der Beitrag von Harm van Grol mit demselben Titel. ${ }^{102}$ Sein Ausgangspunkt ist das Forschungsdesiderat einer Landkarte der Emotionen in den Psalmen. Dazu leistet er einen Beitrag, indem er die auf Menschen bezogenen Emotionen in Ps 6

96 Vgl. dazu das Heft von Biblical Interpretation 22 (2014), das sich der »affect theory« und der "analysis of emotions in biblical studies" widmet.

$97 \mathrm{Zu}$ Emotionen im Hld vgl. die Habilitationsschrift von Melanie Peetz (Peetz, Emotionen). Zu Emotionen im Sprüchebuch vgl. Yoder, Objects; Überblicke bieten neben Wagner, Emotionen, und Schroer / Staubli, Biblische Emotionswelten, auch Gillmayr-Bucher, Emotion, sowie dies., Rauchende Nase. Einzelne Emotionen sind in kürzeren oder längeren Beiträgen untersucht worden: Schuld, Schande, Depression und Wut bei Kruger, On Emotions; Wut und Liebe bei Van Wolde, Sentiments; Liebe bei Fischer, »die Liebe«; Angst bei Kruger, Cognitive Interpretation; Zorn bei Wagner, Emotionen in alttestamentlicher und verwandter Literatur; Wut in der Genesis bei Schlimm, Fratricide; Tränen und Emotionen bei Collins, Physiology; Emotionen im Zusammenhang mit dem Herz und den Innereien bei Smith, Heart; Trost bei Van Dyke Parunak, Survey; Emotionen im Zusammenhang mit den Gewaltakten an Eglon und Sisera in Ri 3-5 bei Cottrill, Reading; Trauer und Freude bei Anderson, A Time to Mourn. Zu Emotionen in Verbindung mit antiken jüdischen Gebeten in und aus der Zeit des zweiten Tempels siehe Reif / Egger-Wenzel, Ancient Jewish Prayers and Emotions.

98 Vgl. Wagner, Emotionen, 44.

99 Vgl. dazu das derzeitige Projekt von Andreas Wagner zu Emotionen im AT und zu den Emotionen Gottes. Zur Erforschung von Körperbildern und -konzepten und deren $\mathrm{Zu}$ sammenhang mit Emotionen gibt es im AT eine breitere Forschungsgeschichte als insgesamt zu Emotionen im AT. Zu Körperbildern in den Psalmen vgl. z. B. Bester, Körperbilder; Gillmayr-Bucher, Zunge, und dies., Body Images.

$100 »$ Nach welchen Mechanismen, in welchen Formen und auf welchen sprachlichen Ebenen Emotionen in literarischen Texten implizit artikuliert werden, ist weitgehend unerforscht.» Winko, Kodierte Gefühle, 48.

101 Freude, Freiheit und Gerechtigkeit in den Psalmen sind von McConville, Happiness, untersucht worden, physisch erlebte Freude in den Psalmen von Abart, Lebensfreude.

102 Vgl. van Grol, Emotions, 69-102. 
und die emotionale Welt Gottes im 5. Psalmenbuch (Ps 107-150) analysiert. Bei der Präsentation von Emotionen in den Psalmen differenziert er zwischen drei Ebenen: (1) Benennen, z. B. »unser Gott ist leidenschaftlich«; (2) Beschreiben, dies geschieht in der Rede der 3.P. sowie (3) Ausdrücken, und zwar durch Ausdrücke des sprechenden Ich/Wir und vollzogen in der Rede der 1. und 2.P., z. B. durch Ausrufe, Interjektionen und Fragen. Van Grol ordnet den überwiegenden Teil der Psalmgattungen - wie die Klagelieder des Einzelnen und des Volkes, die Vertrauenslieder, die Danklieder und die Hymnen - der dritten Ebene zu. Die Emotionen in diesen Psalmen implizieren Bewegung und Dynamik, indem der Psalm von einer Emotion zur nächsten führt. So ist z. B. in den Klageliedern die Bewegung von Traurigkeit und Trauer hin zur Freude offensichtlich. Für die Klassifikation der Emotionen verwendet er Parrotts Liste von Emotionen mit den sechs Primäremotionen Liebe, Freude, Überraschung, Wut, Traurigkeit und Angst sowie weiteren 25 Sekundäremotionen. ${ }^{103}$ In seiner Emotionsanalyse von Ps 6 kombiniert er die Charakterisierung der wesentlichen Figuren (JHWH, das lyrische Ich als zentrale Figur sowie die Feinde) mit der literarischen Textentwicklung und beschreibt die emotionale Welt des lyrischen Ich mit den Emotionen Angst, Schuldgefühl, Wut, Gefühl der Ablehnung, Trauer, Irritation, Hoffnungslosigkeit und Vertrauen. Danach gibt er einen Überblick über die Emotionen Gottes im fünften Psalmenbuch. Gott ist im Psalter Subjekt von nur wenigen Emotionen. Gottes Emotionen haben dabei einen relationalen Charakter, insofern sie dazu dienen, die Beziehung der Gottheit zu Israel, zum lyrischen Ich und zur kultischen Gemeinde zu qualifizieren. Die emotionale Welt Gottes in den Psalmen 107-150 kann den Emotionen Liebe und Freude zugeordnet werden, denn nur ein Mal ist vom Zorn Gottes die Rede. Wie van Grol versuche auch ich in dieser Arbeit, unterschiedliche Ebenen von Emotionen auszumachen. Dabei arbeite ich mit den Konzeptionen der expliziten und impliziten Emotionen sowie der A-emotions und F-emotions (vgl. III Methodik). Des Weiteren werde ich die Emotionen im Zusammenhang mit der Charakterisierung von Figuren und mit der Textdynamik erheben und die Emotionen anhand der Liste von Plutchik einordnen (vgl. die Kategorisierung der Emotionen bei Plutchik, Wagner u. a. in III Methodik).

Andreas Wagner weist in einem Artikel, in dem er Körperkonzepte und Emotionen Gottes in den Psalmliedern des evangelischen Gesangsbuchs mit jenen in den atl. Psalmen ins Gespräch bringt, auf oft beleuchtete und viel diskutierte Unterschiede zwischen anthropologischen Begriffen des AT (leb, nefesch etc.) und heutigen Konzeptionen von Herz und Seele etc. hin und betont eindrücklich die Unterschiedenheit zwischen dem Körper-Emotions-Verhältnis

103 Vgl. http://en.wikipedia.org/wiki/Contrasting_and_categorization_of_emotions [abgerufen am 30.4.2015]. 
in den Psalmen gegenüber neuzeitlich-westlichen Konzepten. ${ }^{104}$ Eingedenk dieser Differenz wird in den hier vorgelegten Textanalysen der emotionale Gehalt hebräischer Begriffe, wo nötig, im Unterschied zur heutigen Konzeption thematisiert. Beispielsweise ist das Verb »trösten « im AT viel weniger emotional konnotiert als im heutigen deutschen Sprachgebrauch.

Emotionen können auch durch die vielfältigen Sprachbilder und vor allem durch die metaphorische Rede der Psalmen evoziert werden, worauf in den Textanalysen ein besonderes Augenmerk gelegt wird. Diese Arbeit stellt damit auch einen Beitrag zur Metaphernforschung in den Psalmen dar - ein Forschungsbereich, der sich großer Beliebtheit erfreut und eine Vielzahl an Publikationen aufweist. ${ }^{105}$

\subsection{Lyrik und Narratologie}

Im Zuge meiner Analyse treffen narratologische Analysekategorien auf die poetischen Texte der Psalmen (siehe III Methodik und IV-VII Textanalysen). Der Forschungsbereich "Lyrik und Narratologie» ist inzwischen kein unbekannter mehr, auch wenn sich die Anzahl der biblischen Arbeiten diesbezüglich in Grenzen hält. Es gibt sowohl im literatur- und kulturwissenschaftlichen Bereich als auch in der atl. Wissenschaft Versuche, lyrische Texte mit narratologischen Analysekategorien zu untersuchen, um das klassische Methodenrepertoire der Untersuchung poetischer Texte (Stichwort: Stilfiguren, Bildersprache etc.) zu erweitern und so über die Gattungsgrenzen hinaus zu neuen Erkenntnissen zu gelangen. ${ }^{106}$ Im AT stechen dabei die Studien von Stefan Fischer und Yvonne Thöne zum Hld heraus. ${ }^{107}$ Stefan Fischer arbeitet in seiner Habilitation mit den Kategorien "Handlung" und »Darstellung« und mit den damit verbundenen Fragestellungen nach Zeit, Modus, Stimme, Fokalisierung, Ort und Raum sowie Figuren. Yvonne Thöne legt den Schwerpunkt ihrer Dissertation auf den $\mathrm{Zu}$ -

104 Wagner, Konturen Gottes, 280.

105 An dieser Stelle können nur einige wenige Titel genannt werden. Prominent sind die Sammelbände von Van Hecke, Metaphor sowie Van Hecke / Labahn, Metaphors; des Weiteren Gillmayr-Bucher, Zunge; Gillmayr-Bucher, Body Images; Gillmayr-Bucher, Die Psalmen; Nielsen, Variety; Grohmann, Fruchtbarkeit; Brown, Theology of Metaphor; Grund, "Die Himmel erzählen « und Bester, Körperbilder.

106 Für die Literaturwissenschaft konstatiert Simone Winko im Jahr 2003:»Die Erkenntnis, dass lyrische Texte sich mit narratologischen Mitteln sinnvoll und ergiebig beschreiben lassen, setzt sich langsam auch in der deutsch-sprachigen Lyrikforschung durch.« Winko, Kodierte Gefühle, 137. Dem Zusammenhang von Lyrik und Erzähltextanalyse widmen sich aus literatur- und kulturwissenschaftlicher Perspektive u. a. Müller-Zettelmann, Lyrik und Narratologie; Nünning / Nünning, Produktive Grenzüberschreitung; Schönert, Lyrik und Narratologie; Hühn / Sommer, Narration sowie Bleumer / Emmelius, Lyrische Narrationen.

107 Vgl. Fischer, Hohelied und Thöne, Liebe. 
sammenhang von Raum und Geschlecht mit den damit verknüpften Kategorien des Ortes und Raumes, der Figuren, Erzählstimme und Handlungen. In einem Beitrag zu den Psalmen führt sie eine narratologische Analyse zu Ps 55 mittels der Kategorien Inhalt, Rederichtungen, Zeit, Raum und Figuren (lyrisches Ich; Gottheit; Gruppe der Feinde) durch. ${ }^{108}$ Die Autorin konstatiert in puncto Narratologie und Lyrik ein Forschungsdesiderat bezüglich alttestamentlicher Texte: »Die Analyse mit den Methoden der [...] Narratologie lässt beispielsweise in den Psalmen, weisheitlichen oder prophetischen Texten spannende Einsichten erwarten. $"{ }^{109}$ Während in der Psalmenforschung im Zusammenhang mit Narrativität vor allem die Frage nach der Geschichte Israels in den Psalmen, ${ }^{110}$ nach narrativen Elementen innerhalb des Parallelismus ${ }^{111}$ (vgl. III Methodik) sowie nach dem Erzählzusammenhang zwischen einzelnen Psalmen, Psalmengruppen und innerhalb des gesamten Psalters (»story of the Psalter«) im Rahmen der kanonischen Exegese von Bedeutung sind, ${ }^{112}$ nicht aber die Anwendung narratologischer Analysekriterien auf die Psalmenanalyse, wird sich in dieser Arbeit zeigen, ob sich damit neue Erkenntnisse gewinnen lassen.

\subsection{Psalmenforschung}

In der aktuellen Psalmenforschung ${ }^{113}$ lässt sich diese Arbeit den werkzentrierten Zugängen zuordnen. Diese nehmen im Wissen um das historische Gewachsensein der Texte die kanonische Endgestalt des Psalms, wie sie uns derzeit im MT vorliegt, als Ausgangspunkt. Verzichtet wird hierbei aufgrund der entsprechenden Forschungsanliegen auf Rückfragen nach dem literarhistorischen Wachstum sowie nach dem soziokulturellen Kontext der Entstehung, der historischen Einordnung, des Sitzes im Leben, des Kults etc. Vielmehr steht das Zusammenspiel sprachlicher und literarischer Elemente mit den Fragen nach Semantik, individueller Struktur, innerbiblischen Textverweisen, Aussageabsichten, in-

108 Vgl. Thöne, Stay.

109 Thöne, Liebe, 56. Vgl. dazu Eder, »Neige, JHWH, dein Ohr!«, 187-216.

110 Vgl. z. B. Nasatu, Historical Narrative.

111 Vgl. z. B. Ibita, »O Israel«.

112 Vgl. z. B. Wallace, The Narrative Effect; ders., The Narrative Effect of Psalms 84-89. Er verweist auf die Werke von Wilson, Gerald H.: The Editing of the Hebrew Psalter, SBLDS 76, Chico / Kalifornien 1985 und DeClaissé, Nancy L.: Reading from the Beginning: The Shaping of the Hebrew Psalter, Macon / Georgia 1997.

113 Einen informativen Überblick über die Psalmenforschung bieten Kuntz, Continuing the Engagement; außerdem unter anderem Seybold, Zur neueren Psalmenforschung; Zenger, Psalmenexegese, 17-65; Gillmayr-Bucher, Die Psalmen, 17-69 sowie Radebach-Huonker, Opferterminologie, 5-30. Verwiesen sei hier auf die 182 Seiten umfassende Bibliographie zum Psalmenbuch von Weber, Beat: Bibliographie zu Psalmen und Psalter, die ständig aktualisiert abrufbar ist unter https://bienenberg.academia.edu/BeatWeber. 
haltlichen Komponenten sowie der theologischen Relevanz für heute ebenso im Mittelpunkt wie die poetische Gestaltung der Psalmen, die schon immer großes Interesse auf sich gezogen hat. Seit den 1970er Jahren konnten diesbezüglich verschiedene Ansätze aus Literaturwissenschaft, Linguistik, ästhetischer Stilistik und Rhetorik, der Sprechakttheorie, aber auch der Motiv- und Symbolforschung für die Psalmenanalyse furchtbar gemacht werden. Dabei steht das Interesse daran im Zentrum, was die hebräische Poesie kennzeichnet, wobei insbesondere der Parallelismus membrorum und die Bildersprache und hier besonders die metaphorische Rede im Fokus stehen. Im vorliegenden Werk wird, ausgehend von der Endgestalt, die Textbetrachtung einzelner ausgewählter Psalmen in den Mittelpunkt gestellt. Hierbei werden Kriterien aus der Analyse poetischer Texte (Parallelismus membrorum, Sprachbilder, Rhythmus, Melodie und Klang) mit narratologischen Analysekategorien (Stimme, Raum, Bewegung, Zeit, Figuren, Perspektiven), mit der Analyse von Emotionen sowie mit jenen Parametern aus der historisch-kritischen Exegese verbunden, die textkritische, syntaktische und semantische Fragestellungen sowie Übersetzungsfragen in den Blick nehmen. Auf der Ebene der Hermeneutik wird - ausgehend von rezeptionsästhetischen Überlegungen - der Leseprozess als sinnstiftender Begegnungsraum zwischen Text und Lesenden betrachtet. Gegenwärtig ist die Psalmenforschung von folgenden Tendenzen geprägt: (1) von der kanonischen Psalterexgese; (2) von der Zunahme linguistischer und struktureller Analysen, die hebräische Poesie betreffend; (3) von der Auseinandersetzung mit den Psalmen-Schriftrollen vom Toten Meer; (4) von einer großen Anzahl unterschiedlicher hermeneutischer Zugänge; vom Nebeneinander (5) stark sprachwissenschaftlich orientierter Studien; (6) religionsgeschichtlicher Vergleiche und (7) thematischer Zugänge (z. B. zu Feind, Opfer, Geburt etc.) sowie (8) vom Ausbau und der Präzisierung klassischer form- und gattungskritischer Zugänge. Vor diesem Hintergrund ist die vorliegende Arbeit jenem endtextorientierten Forschungsansatz zuzuordnen, der den Text in literaturwissenschaftlicher Weise betrachtet sowie in der von der Forschungsfrage geleiteten Einzeltextanalyse Methoden aus der Emotionsanalyse, der Narratologie, der Analyse poetischer Texte sowie der historisch-kritischen Exegese miteinander verbindet, die Einmaligkeit des poetischen Kunstwerks herausstellt und die Mitwirkung der Lesenden bei der Textauslegung ernst nimmt. ${ }^{114}$

$114 \mathrm{Zu}$ den aktuellen Trends in der Psalmenforschung vgl. ausführlicher Howard, The Psalms. 


\section{Methodologische Grundlagen}

Die Frage nach Identifikationspotenzialen impliziert die Darlegung sowohl der Definition als auch der methodischen Operationalisierung (siehe dazu III Methodik) des Identifikationsbegriffs für die Psalmenanalyse. Beides ist bis dato für die Analyse lyrischer Texte in der Exegese noch nicht geschehen. Daher werden im Folgenden - nach der begrifflichen Abgrenzung zur auktorialen Wirkungsabsicht sowie zur historischen Rezeption - wichtige Stationen der Begriffsgeschichte dargelegt, beginnend bei der Empathie über die Einfühlung (wobei der Schwerpunkt auf der Philosophie liegt) bis zur Identifikation in der Literaturwissenschaft. Danach kommen neuere Identifikations-Modelle zur Darstellung, aus welchen die hier zugrunde gelegte Bestimmung von Identifikation abgeleitet wird.

Gefragt wird in der vorliegenden Arbeit nach Identifikationspotenzialen in literarischen Texten. Der Differenzierung von Roy Sommer zufolge geht es dabei um das textuelle Wirkungspotenzial. Sommer unterscheidet zwischen (1) der auktorialen Wirkungsabsicht, auch AutorInnenintention genannt, (2) dem textuellen Wirkungspotenzial und (3) der historischen Wirkung literarischer Texte bzw. der Rezeption des zeitgenössischen Lesepublikums. ${ }^{115}$ Zum Rezeptionsbegriff hält er fest: »Während Aussagen über das Wirkungspotential fiktionaler Texte auf Annahmen bezüglich der Semantisierung von Erzählverfahren beruhen und somit stets auch vom Text her begründet sind, ist die [historische] Wirkung ein Phänomen aus den Bereichen der Literaturvermittlung, -verarbeitung und -rezeption. [...] Gegenstand historischer Rezeptionsforschung ist sowohl die

115 Vgl. Sommer, Funktionsgeschichten, 322.326. "Literatur ist (abgesehen von Tagebüchern und Arbeitsnotizen) auf Wirkung angelegt, sie findet ihre Daseinsberechtigung in der Rezeption durch das Lesepublikum. [...] Denn der primäre Impuls eines schaffenden Subjekts ist der Wunsch nach Kommunikation mit einem realen oder phantasierten Objekt, nicht der Wunsch, Objekt der Analyse zu werden. Der Dichter will gehört, nicht durchschaut werden. Und der primäre Impuls des Lesers ist `Erfahrungshungerı, das Verstehen kommt später.» Schönau / Pfeiffer, Einführung, 35. 
Aufnahme eines Werkes durch das breite Lesepublikum als auch seine Bewertung durch die zeitgenössische Literaturkritik. ${ }^{116}$

Beim Wirkungspotenzial, dem ich in dieser Arbeit nachgehe, handelt es sich um eine "vom Text her begründbare Annahme über die möglichen Effekte der narrativen Strategien, die den nacherzählbaren Inhalt eines literarischen Textes strukturieren und organisieren und damit für den Sinn entscheidend sind. ${ }^{117} \mathrm{Ob}$ die tatsächliche Wirkung auch eintritt, ergibt sich im Leseprozess und liegt bei den Lesenden. ${ }^{118}{ }$ Erst im Leseprozess wird in Abhängigkeit von den spezifischen Voraussetzungen der Leser ein bestimmter Teil des Wirkungspotentials realisiert und in einer Lesart konkretisiert, während andere Möglichkeiten der Interpretation verworfen werden. ${ }^{119} \mathrm{Ob}$ ein im Text eindeutiges Potenzial auch faktisch in Funktion tritt, hängt also von der Wechselwirkung mit dem konkreten Leser/ der konkreten Leserin ab. ${ }^{120}$ "Wirkungspotentiale können wiederum (müssen aber nicht) tatsächlich Auswirkungen auf den Leser haben, d. h. sie >realisieren sich unter Umständen in Wirkungsergebnissen oder -effekten. ${ }^{121}$

Identifikationspotenziale sind also textuelle Wirkungspotenziale. Nach welchen Kategorien sollen diese nun erhoben werden? Ein Blick in die Begriffsgeschichte von Identifikation und auf die Begriffsbestimmungen sowie deren $\mathrm{Zu}$ sammenschau dient als Voraussetzung, dies im anschließenden Methodenkapitel zu klären. Das menschliche Phänomen des Sich-Hineinversetzens in andere Personen bzw. (Kunst-) Gegenstände wird mit Einfühlung, Empathie oder Identifikation benannt. Die Funktionsweisen dieser Begriffe im Hinblick auf literarische Texte sind daher jene heuristischen Analysekategorien, die es in diesem Kapitel zu beschreiben gilt. Es will (historische) Grundlagen und theoretisches Basiswissen sowie die Bedeutung von Identifikation, Empathie und Einfühlung vor allem im Zusammenhang mit Literatur klären.

116 Sommer, Funktionsgeschichten, 331.

117 Sommer, Funktionsgeschichten, 328. Schon 1978 hat Heiner Willenberg nach Variablen für Wirkungsanalysen gefragt, also nach isolierbaren stilistischen, semantischen oder strukturellen Qualitäten in Texten, die als Identifikationspotenziale ausgewiesen werden könnten, und ist zu dem Schluss gekommen: »Wenn man den Blick auf den Textbereich erzählender oder dramatische Literatur richtet [...], dann existieren wenig überprüfbare Aussagen." Willenberg, Psychologie, 24.

118 »Aussagen über die Funktionen und Wirkungen literarischen Lesens gehen über die Beschreibung und Interpretation der literarischen Texte selbst hinaus. Sie beziehen sich auf die Leser dieser Texte, auf den >realen Leser also [...]. Die Frage, ob dem literarischen Lesen im Allgemeinen oder dem Lesen ausgewählter literarischer Texte tatsächlich die angenommenen Funktionen und Wirkungen zukommen, lässt sich nur durch die empirische Untersuchung von Lektüreprozessen und ihren Wirkungen beantworten.« Schreier, Textwirkungen, 193.

119 Sommer, Funktionsgeschichten, $330 \mathrm{f}$.

$120 \mathrm{Vgl}$. Groeben, Leserpsychologie 2, 222.

121 Groeben, Leserpsychologie 2, 223. 


\section{Von der Empathie zur Identifikation - eine Begriffsannäherung}

Aufgrund der Fähigkeit der Menschen, sich intellektuell und emotional mit imaginären Welten und deren BewohnerInnen $\mathrm{zu}$ verbinden, wird narrative Empathie am Knotenpunkt zwischen Ästhetik, Psychologie und Philosophie verortet. ${ }^{122}$ Aus diesen drei wissenschaftlichen Disziplinen ist der Empathiebegriff für die Anwendung in der Literaturwissenschaft hervorgegangen, in der er nun vor allem mit »Identifikation« wiedergegeben wird.

Der Begriff »Empathie» ist die Lehnübersetzung von »Einfühlung», die von Theodor Lipps eingeführt wurde. In der englischen Sprache ist »empathy» als Neologismus entstanden. ${ }^{123}$ Als Äquivalent des deutschen Ausdrucks »Einfühlung« vom amerikanischen Psychologen Edward B. Titchener verwendet, tritt der Ausdruck dort im Jahre 1909 als Kunstwort in gedruckter Form auf. ${ }^{124}$ Der Begriff wurde in weiterer Folge in der französischen Sprache als »empathie» nachgewiesen und sodann aus dem amerikanischen Englischen ins Deutsche mit "Empathie« rückübersetzt. ${ }^{125}$ In der deutschen Sprache können die Begriffe "Empathie« bzw. »Einfühlung« in bestimmten Fällen mit einem Teil-Bedeutungsfeld von Identifikation übereinstimmen ${ }^{126}$, wobei auf die Unterscheidung zwischen der Identifikation, die eine enge Beziehung der Lesenden zu einer literarischen Figur bis hin zur Verschmelzung meint, und der Einfühlung, in der es darum geht, eigene Gefühle in leblose Gegenstände der Natur hineinzulegen, verwiesen wird. ${ }^{127}$

In der Psychologie, Psychoanalyse und Psychotherapie steht der Begriff "Empathie» an prominenter Stelle und wird hier meist hinsichtlich der emotionalen Übereinstimmungen bei zwischenmenschlichen Erlebnissen gebraucht. ${ }^{128}$ Der empathische Prozess ist für jede psychotherapeutische Beziehung relevant, und der Begriff "Empathie» wird dabei so verwendet, wie ihn die deutschen Ästhetiker Friedrich Theodor Vischer (1807-1887) und sein Sohn Robert Vischer (1847-1933) ursprünglich entwickelt und verstanden haben. ${ }^{129}$ Die beiden vom naturwissenschaftlichen Denken beeinflussten Philosophen entfalten ihre Theorie im Rahmen der Betrachtung des Schönen in der Natur und legen damit den Grundstein für eine Theorie der Einfühlung. Entscheidend ist

122 Vgl. Keen, Empathy, 34.

123 Vgl. Curtis, Einführung, 11.

124 Vgl. Titchener, Lectures, 21.

125 Vgl. Hermanns, Empathie, 128; Fontius, Einfühlung, 121.

126 Vgl. Fontius, Einfühlung, 126.

127 Vgl. Fontius, Einfühlung, 122.

128 Vgl. Curtis, Einführung, 11. Zur Bedeutung der Empathie in der Psychologie und des Identifikationsbegriffes bei Sigmund Freud vgl. Loch, Identifikation, 137-144. Zur Identifikation bzw. Empathie in der Psychoanalyse siehe Fontius, Einfühlung, $123 \mathrm{f}$.

129 Vgl. Fontius, Einfühlung, 124. 
dabei, dass sie das Schöne nicht als einen Gegenstand, sondern als einen Akt bzw. ein Ineinander von mehreren Akten kennzeichnen. Die ästhetische Wahrnehmung ist durch die aktive und umformende Bewusstseinstätigkeit des Menschen zu erklären, und das Schöne existiert gar nicht unabhängig vom Bewusstsein der Betrachtenden. So ist das Empfinden eines Sonnenuntergangs als ahnungsvolle Beleuchtung, des Funkelns der Sterne am Himmel als erhaben oder einer Landschaft als anmutig durch dieses Tun des Menschen, durch diese Art der Betrachtung zu erklären. ${ }^{130}$

Die Natur ist nach Friedrich Theodor Vischer nicht beseelt. Die Beschauenden des Schönen versetzen sich mittels des Aktes der Einfühlung in das Unbeseelte so hinein, als ob sie mit ihrer Lebenskraft und Seele selbst darin wären. ${ }^{131}$ Dieses unbewusste Versetzen des eigenen Körpers und auch der Seele in die Objektform, diese Eintragung der Menschenseele in Unpersönliches, wird mit dem Begriff der Einfühlung benannt. ${ }^{132}$ Einfühlung ist also eine "Aktualisierung des Schönen in der Form, die eine symbolische Übertragung unserer Emotionen in jene Form beinhaltet ${ }^{133}$. Im Prozess der Einfühlung verbinden sich die beobachteten $\mathrm{Ob}$ jekte mit dem eigenen Gefühl. Charakteristisch für die Einfühlung ist also die emotionale Verbindung mit einer äußeren Erscheinung, die dann zustande kommt, wenn die Beobachtenden ihr eigenes Leben in die leblose Form projizieren.

Der Kunsthistoriker Robert Vischer verknüpft die philosophische Betrachtungsweise des Naturschönen durch seinen Vater mit Ergebnissen aus der experimentellen Psychologie des deutschen Physiologen, Philosophen und Psychologen Wilhelm Wundt (1832-1920), der als Begründer der Psychologie als eigenständige Wissenschaft gilt. Von ihm entlehnt der Ästhetiker Vischer den Begriff »Ähnlichkeit« und meint damit eine Übereinstimmung zwischen einem betrachteten Objekt und dem physiologischen Effekt auf die Betrachtenden. ${ }^{134}$ Einfühlung ist daher die Dynamik, mit der ein Kunst- bzw. Naturobjekt die Beobachtenden körperlich und emotional berührt und sie ähnliche Gefühle erfahren lässt. Robert Vischers Beitrag zur Einfühlungsästhetik liegt demnach darin, die Körperlichkeit der Wahrnehmung in den Mittelpunkt zu stellen: „Es handelt sich überhaupt um den ganzen Körper; der ganze Leibmensch wird ergriffen. Denn in Wahrheit gibt es ja keine strikte Lokalisierung in demselben. Jede betonte Empfindung führt daher schliesslich entweder zu einer Steigerung oder Schwächung der allgemeinen Vitalempfindung. « ${ }^{135}$ Einfühlung ist nach

130 Vgl. Fontius, Einfühlung, 130.

131 Vgl. Fontius, Einfühlung, 131.

132 Vgl. Fontius, Einfühlung, $130 \mathrm{f}$.

133 Curtis, Einführung, 20.

134 Vgl. Curtis, Einführung, 23.

135 Vischer, Ueber das optische Formgefühl, 11. 
Robert Vischer die emotionale Verbindung mit einer äußeren Erscheinung. Sie tritt dann ein, wenn die Beobachtenden ihr eigenes Leben in die leblose Form übertragen. Dies ist eine Art Ergänzung, die durch die Annahme der Abwesenheit von Leben in leblosen Gegenständen eintritt und daher zu einer Verlebendigung jener Objekte führt. ${ }^{136}$ Robert Vischer sagt dazu: »Ich traue also der leblosen Form mein individuelles Leben $\mathrm{zu}$, wie ich dasselbe mit Recht einem persönlichen, lebendigen Nichtich zutraue. Nur scheinbar behalte ich mich selbst, obgleich das Objekt ein Anderes bleibt. Ich scheine mich ihm nur anzubequemen und anzufügen, wie Hand in Hand sich fügt und dennoch bin ich heimlicher Weise in dieses Nichtich versetzt und verzaubert. $"{ }^{137}$ Diese Neigung zur verlebendigenden Einfühlung begründet der Philosoph mit dem »Wesen des Gefühls« als dessen Motor: »Das Gefühl ist objektiver als die Empfindung, schwingt sich ungleich energischer über die eigene Haut hinaus mit einem Nichtich zusammen. ${ }^{138}$

Theodor Lipps (1851-1914) war Lehrstuhlinhaber für Systematische Philosophie an der Universität München. Ihm ist es zu verdanken, dass der aus dem Verhältnis des Menschen zur Natur entwickelte Begriff „Einfühlung« mit psychologischen Erkenntnissen kombiniert und auf den kunstphilosophischen Bereich bezogen wird. Damit wird dessen Anwendung erheblich erweitert. ${ }^{139}$ Der Philosoph beschäftigt sich zu seiner Zeit mit Fragen, die heute der Psychologie zugeordnet werden, und konstatiert eine grundsätzliche menschliche Fähigkeit zur Einfühlung, die auf einer involuntären, instinktiven Mimikry an das Andere fußt. Damit wird die Neigung zum automatischen Miterleben bzw. inneren Nachahmen bei der Betrachtung von anderen bezeichnet, also z. B. das leichte Schaukeln oder Wippen bei der Beobachtung von TänzerInnen. ${ }^{140}$ Lipps konstatiert zunächst die Einfühlung in leblose Gegenstände und kommt erst später auf die Einfühlung in einen Menschen zu sprechen. Bei ihm stehen sowohl Lebewesen als auch Dinge als Objekte der Einfühlung gleichberechtigt nebeneinander. Er beschreibt Empathie als inneres Nachahmen und konzentriert sich dabei vor allem auf die Dynamik des Lebens und die Lebenskraft. ${ }^{141} »$ Im Akte der Einfühlung selbst ist mein Gefühl des Strebens und Tuns von dem in die Dinge eingefühlten Streben nicht geschieden. Die `Einfühlung`besteht ja eben in der Identität beider, oder in der Identifizierung meiner und des Objektes. " ${ }^{142}$ Für

136 Vgl. Curtis, Einführung, 24.

137 Vischer, Ueber das optische Formgefühl, 20.

138 Vischer, Ueber das optische Formgefühl, 28.

139 Vgl. Fontius, Einfühlung, 131 f. Die Expansion des ästhetischen Begriffs der Einfühlung lässt sich bis in die Biologie hinein nachverfolgen.

140 Vgl. Curtis, Einführung, 13.

141 Vgl. Curtis, Einführung, 16.

142 Lipps, Grundlegung, 182. 
Lipps gilt die Einfühlung als ein Grundbegriff der Ästhetik. ${ }^{143}$ Durch die Verbreitung des Begriffs in neue Bereiche geht allerdings die semantische Einheit weitgehend verloren, und schon 1912 spricht der deutsche Phänomenologe Moritz Geiger (1880-1937), der zuvor Student von Theodor Lipps und Wilhelm Wundt war, von vier verschiedenen Bedeutungen von Einfühlung: (1) Einfühlung als das theoretische Erklärungsmodell für das Entstehen unseres Wissens vom anderen Menschen; (2) Einfühlung als Nacherleben; (3) Einfühlung als Mitgehen mit anderen Menschen; sowie (4) Einfühlung als Quelle ästhetischen Genusses. ${ }^{144}$

\section{Identifikation in der Literaturwissenschaft}

In der Kunst stößt das Einfühlungsprinzip als Relationsbegriff, mit dem die Interaktion zwischen KünstlerInnen, Kunstwerk und BetrachterInnen als zusammengehöriger Prozess beschrieben wird, nur vereinzelt auf Interesse. Demgegenüber findet dieses Prinzip in der Literaturwissenschaft ab 1970 breite Anwendung, hier allerdings beinahe ausschließlich unter dem Begriff "Identifikation $\ll .{ }^{145}$ Das Lesen literarischer Texte ist eine Interaktion zwischen Text und LeserInnen. Demnach kann man innerhalb des Leseprozesses den Schwerpunkt auf den Text oder aber auch auf die Lesenden lenken. Mit Blick auf die LeserInnen lässt sich festhalten: »Wenn wir [...] Romane lesen, sind wir an den Schicksalen der Hauptpersonen affektiv ১beteiligt‘, wir erleben für sie und mit ihnen Freude, Liebe, Hoffnung und Enttäuschung, Leid und Trauer, und wir machen uns mit ihnen Bilder ihrer Lage, ihrer Chancen und Gefahren. $\aleph^{146}$ Lesende können sich demnach mit literarischen Figuren oder mit in literarischen Texten geschilderten Situationen identifizieren. Dabei wollen sich die Lesenden im Text wiedererkennen und sich doch unterscheiden können. Dies wird durch die Fiktionalität des Textes garantiert. ${ }^{147}$

Der geistigen Geburtsstunde des Einfühlungsbegriffs in Bezug auf Literatur und Drama nachgehend, trifft man auf den Dichter, Theoretiker und Dramatiker Gotthold Ephraim Lessing (1729-1781). Er spricht vom »feinen Mitschwingen unserer Seele bei allem, was der tragische Held erlebt, ${ }{ }^{148}$ misst diesem jedoch nur eine zweitrangige Bedeutung zu. Dadurch bringt er eine Vorstellung von »Einfühlung« zur Darstellung, auch wenn er den Begriff nicht wortwörtlich verwen-

143 Vgl. Fontius, Einfühlung, 121.

144 Vgl. Fontius, Einfühlung, 132f.

145 Vgl. Fontius, Einfühlung, 124.126.

146 Hermanns, Empathie, 129.

$147 \mathrm{Vgl}$. Jauß, Ästhetische Erfahrung, $253 \mathrm{f}$.

148 Zitiert nach Petsch, Einleitung, 52. 
det. $^{149}$ Auf der Suche nach Erklärungsmöglichkeiten dafür, wie diese Anteilnahme am Leiden anderer zustande kommt, analysiert der schottische Moralphilosoph Adam Smith (1723-1790) in seiner Theory of Moral Sentiments 1759 jene Bewusstseinsvorgänge, die beim Anblick eines leidenden Menschen ausgelöst werden, und lässt keinen Zweifel daran, dass die ästhetische Erfahrung des Mitleidens oder Mitfühlens mit dem Helden im Roman oder in der Tragödie zur Voraussetzung seiner ethischen Theorie gehört. ${ }^{150}$ Der Theorie von Smith zufolge, der als Entdecker der Empathie gilt, folgen Lesende und ZuschauerInnen bei den Erzählungen, die sie hören, den Romanen, die sie lesen, oder den Dramen, die sie sehen, nicht nur empathisch dem Sprechen des Erzählers, sondern ebenso einfühlend dem Handeln und den Widerfahrnissen der Helden der Geschichten. Alle möglichen Emotionen werden dabei mittels der Phantasie in Bezug auf diejenige Person entwickelt, deren Schicksal erzählt wird, sodass die empathisch erzeugten Gefühle zu deren Gefühlen passen. Die erzählte Angelegenheit wird folglich per Empathie zur je eigenen gemacht, so als ob die Lesenden und ZuschauerInnen ZeugInnen eines wirklichen Geschehens wären, auf das sie empathisch reagieren. ${ }^{151}$ Empathie löst daher Erlebnisse aus, die Fritz Hermanns "Texterlebnisse ${ }^{152}$ nennt. Demnach wären alle fiktionalen Texte inklusive der Gedichte als Erlebnisangebote zu betrachten, die von den Lesenden in dem Maße angenommen oder auch nicht angenommen werden, wie sie sich auf den jeweiligen Text einlassen. Dabei handelt es sich nicht nur um emotive, sondern auch um kognitive und moralische Erlebnisse. ${ }^{153}$

Der russische Semiologe sowie Literatur- und Kulturtheoretiker Michail Bachtin $^{154}$ (1895-1975) hat die Einfühlungstheorie weiterentwickelt, indem er sie neu formuliert hat. Er versteht Einfühlung nur als Anfangsphase, nicht jedoch als Endzweck der ästhetischen Tätigkeiten. Lesende müssen zunächst erleben, was der Held des Romans erlebt, sie müssen seinen Platz einnehmen, gleichsam mit ihm verschmelzen. Am Beginn also steht die Einfühlung. Die entscheidende ästhetische Erfahrung beginnt für Bachtin jedoch nicht mit diesem Vorgang des Einswerdens mit dem Helden, sondern erst in der Rückbesinnung auf das eigene Ich, nämlich erst dann, wenn die Lesenden auf einen Platz außerhalb des Leidenden zurückkehren und das Material der Einfühlung gestalten, indem sie es

149 Vgl. Fontius, Einfühlung, 126. Ähnlich Curtis, Einführung, 19.

150 Vgl. Fontius, Einfühlung, 128. Adam Smith verwendet für diese ästhetische Erfahrung allerdings die Bezeichnung "sympathy«, die auf Umwegen als "Sympathie» in die deutschsprachige Linguistik und Sprachtheorie gelangt ist. Dort ist der Ausdruck heute so gut wie nicht mehr anzutreffen. Vgl. dazu Hermanns, Empathie, $128 \mathrm{f}$.

151 Vgl. Hermanns, Empathie, 164.

152 Hermanns, Empathie, 164.

153 Vgl. Hermanns, Empathie, 164.

154 Vgl. Grübel, Michail M. Bachtin. 
ergänzen und vollenden. ${ }^{155}$ "Wie der Therapeut nach der Identifikation mit den Gefühlen eines Patienten das Vermögen aufbringen muss, das Ich vom Nicht-Ich zu trennen, um sich ein Bild über den Patienten zu machen, so postuliert Bachtin die Distanznahme als unverzichtbares Moment, wenn ästhetische Erfahrung ihre Möglichkeiten ausschöpfen soll. ${ }^{156}$

Auch für den deutschen Literaturwissenschafter Hans Robert Jauß (19211997) war diese Distanzierung ein wesentliches Element innerhalb seiner Theorie der ästhetischen Erfahrung, zu der er 1976 ein fünfteiliges Schema der Identifikation mit dem Helden vorgelegt hat. Er integriert dabei den für alle ästhetischen Erfahrungen unverzichtbaren Akt der Distanznahme und schildert die Identifikation als prozesshaftes Geschehen: "Denn weder das bloße Aufgehen in einer Emotion, noch die völlig abgelöste Reflexion über sie, sondern erst die Hin-undHer-Bewegung, das immer neue Sich-Abheben aus der fingierten Erfahrung, das Erproben seiner selbst am vorgestellten Schicksal des andern, macht das eigentümliche Vergnügen am Schwebezustand einer ästhetischen Identifikation aus. ${ }^{157}$ Jauß unterscheidet zwischen assoziativen, admirativen, sympathetischen, kathartischen und ironischen Identifikationen mit dem Helden, wobei unter diesen fünf Primäreinstellungen die auf Aristoteles zurückgeführten admirative und sympathetische Identifikationen von zentraler Bedeutung sind. Unter der sympathetischen Identifikation, die für diese Arbeit wichtig ist, "soll der ästhetische Affekt des Sich-Einfühlens in das fremde Ich verstanden werden, der die bewundernde Distanz aufhebt und den Zuschauer oder Leser durch seine Rührung hindurch zur Solidarisierung mit dem leidenden Helden führen kann. ${ }^{158}$ Jauß' Vorstellung von Identifikation besteht also in einem Gleichgewicht zwischen einem Zuviel und einem Zuwenig an Distanz zwischen RezipientIn und Werk, zwischen Abstand und Symbiose. Lesende können durchaus während des Leseprozesses unterschiedliche Einstellungen wie Staunen, Erschütterung, Angst, Freude etc. durchlaufen und diese auf die unterschiedlichen Figuren und Situationen im Text beziehen; sie sind aber auch immer wieder fähig, sich von den Figuren zu lösen und eine Position der Reflexion einzunehmen. ${ }^{159}$

155 Vgl. Fontius, Einfühlung, 133.

156 Fontius, Einfühlung, 134.

157 Jauß, Ästhetische Erfahrung, 254.

158 Jauß, Ästhetische Erfahrung, 271. Zur Rezeption des Ansatzes von Jauß in der Exegese vgl. Erbele-Küster, Lesen, 19-27 sowie Mayordomo-Marín, Den Anfang hören, 51-65.

159 Groeben, Leserpsychologie 2, 210. 


\section{Identifikation in der Psychologie ${ }^{160}$}

Im allgemeinpsychologischen Bereich trägt der Begriff »Identifikation« die Hauptbedeutung »Erkennen« bzw. „Wiedererkennen«. So bedeutet das Verb »identifizieren: aus innerer Überzeugung ganz mit etwas oder mit jemandem übereinstimmen, sich mit etwas oder jemandem emotional gleichsetzen und deren Ideale und Motive als die eigenen übernehmen. ${ }^{161}$ Identifikation ist einerseits ein völlig normaler Vorgang im Rahmen eines jeden Entwicklungsprozesses, kann aber auch als Abwehrmechanismus betrachtet werden. In lang andauernden Beziehungen werden oft unbewusst oder bewusst Einstellungen, Eigenschaften und auch Verhaltensweisen vom jeweils Anderen übernommen, sodass hier von gegenseitigen Identifikationen gesprochen werden kann. "Die Fähigkeit zu kurzfristigen I.en kann Ausdruck einer flexiblen, offenen, lernfähigen Persönlichkeit sein, sie ist die Basis der Empathie und der Vorstellungskraft. ${ }^{162}$ In der Psychoanalyse wird als Identifikation ein Vorgang bezeichnet, der die Übernahme bzw. Assimilation von Verhaltensweisen, Einstellungen und Normen sowie Motiven und Persönlichkeitseigenschaften eines sogenannten "Modells" beschreibt. Eingeführt und geprägt hat den Begriff in diesem Sinne Sigmund Freud, der dem Terminus mehrere Bedeutungen zuschreibt. Eine Bedeutung von Identifikation besteht darin, dass sich das Subjekt in Übereinstimmung mit einem Muster (Beispiel: Sohn - Vater) verhält. Freud benutzt den Identifikationsbegriff für Prozesse, die einerseits von einem Subjekt durchgeführt werden, andererseits dieses Subjekt selbst auch betreffen. Dabei handelt es sich um unabsichtlich und unbewusst ablaufende Vorgänge. ${ }^{163}$

160 Vgl. Loch / Prinz, Identifikation, 138-144 sowie Müller, Identifikation, $186 f$.

161 Müller, Identifikation, 186.

162 Müller, Identifikation, 187.

163 Die Psychoanalytische Literaturwissenschaft widmet sich der unbewussten Kommunikation im Lese- und Rezeptionsprozess und versucht, mit den therapeutischen Kategorien der "Übertragung« bzw. »Gegenübertragung« die Einstellungen der LeserInnen zum Werk zu erfassen. Vgl. dazu Schönau / Pfeiffer, Einführung, 50-53. Übertragung ist ein Aspekt, der in allen zwischenmenschlichen Beziehungen zum Tragen kommt und bedeutet, dass sich in diesen Beziehungen - oftmals unbewusst - Erwartungen, Gefühle und Einstellungen aus ähnlichen früheren Beziehungen wiederholen; meist sind dies die Beziehungen zu den Eltern. Gegenübertragung ist nun die gefühlsmäßige Reaktion des Analytikers/der Analytikerin auf die Übertragung des Klienten/der Klientin. In der Psychoanalytischen Literaturwissenschaft wird die Beziehung zwischen Text und LeserIn als eine Form der Gegenübertragung aufgefasst. Vgl. dazu auch die Konzeption bei Keitel (III Methodik 2.2.3). 


\section{Begriffsbestimmungen zur literarischen Identifikation}

In der Literaturwissenschaft wird unter Identifikation allgemein der "Vorgang der ästhetischen Erfahrung, bei dem sich der Rezipient in ein bestimmtes, durch emotional aufgeladene Nähe charakterisiertes Verhältnis zu Figuren (auch Empathie) oder anderen Textelementen setzt ${ }{ }^{164}$, verstanden. Damit ist Identifikation eine aktive Form der Beteiligung der Lesenden an den in den Texten dargestellten Situationen, Figuren oder Handlungsverläufen. ${ }^{165}$ Durch diese persönliche Beteiligung in Form von Projektion und Identifikation wird der Abstand zwischen den Lesenden und der Erzählfigur überbrückt. ${ }^{166}$

\subsection{Werner Wolf}

Unter Bezug auf den psychologischen Identifikationsbegriff unterscheidet Werner Wolf zwei Arten von Identifikation: (1) Die affektiv-normative Identifikation "meint das spielerische Sich-Einlassen auf die werkimmanenten Normen und gegebenenfalls ihre figuralen Vertreter [...] im Einklang mit werkseitiger Sympathielenkung. ${ }^{167}$ Diese Beschreibung des Identifikationsprozesses nimmt die drei Charakteristika des psychologischen Identifikationsbegriffs insofern auf, als erstens eine weitgehend reduzierte - aber immer noch vorhandene - Distanz zum Identifikationsobjekt vorherrscht, zweitens Textpersonen im Mittelpunkt stehen und drittens eine auf die Zeit der Lektüre und auf die Vorstellung der Lesenden beschränkte Persönlichkeitsveränderung, wenn auch an der Oberfläche bleibend, angenommen wird. ${ }^{168}$ (2) Die perspektivische Identifikation ist Voraussetzung für die ästhetische Illusion und ist stark bezogen auf den Übergang von der Vorstellung hin zum Sich-Hineinversetzen in die Textwelt: »Damit narrative Vorstellung zur erlebnishaften `Teilnahme`, ja zum Miterleben (nicht nur in einem zeitlich dynamischen Sinn) wird und so die Stufe der Illusionierung erst eigentlich erreicht, ist perspektivische Identifikation nötig. Identifikation in dieser Schattierung bedeutet in einem weiten Sinn die Übernahme eines textuell vorgezeichneten Perspektivzentrums (eines point of view sowohl in konkreträumlicher als auch in zeitlicher Hinsicht) durch den Leser. Indem der Leser sich

164 Scholz / Burgdorf, Identifikation, 339. Dick Schram formuliert Identifikation in Bezug auf Erzählungen folgendermaßen: »Identifikation bezieht sich dann im literarischen Bereich sowohl auf das Aufgehen des Lesers in der Erzählfigur als auch auf die Übernahme von Eigenschaften der Erzählfigur durch den Leser.« Schram, Norm, 137.

165 Vgl. Schram, Norm, 140.

166 Vgl. Schram, Norm, 141.

167 Wolf, Ästhetische Illusion, 109.

168 Vgl. Wolf, Ästhetische Illusion, 110. 
mit diesem Perspektivzentrum identifiziert, wird er in seiner Vorstellung notwendig Teil der Fiktionswelt. « ${ }^{169}$ Diese Definition lässt sich wiederum mit den Merkmalen des psychologischen Identifikationsbegriffs verbinden: Zunächst beschreibt das Einnehmen eines Blickpunktes innerhalb der erzählten Welt eine große Nähe und zugleich eine verminderte Distanz, zweitens werden dabei häufig Perspektiven von Erzählfiguren übernommen und drittens kann der/die Lesende, indem er/sie auf die textuelle Lenkung eingeht, im »Rollenspiel« kurzzeitig jemand anderes werden. ${ }^{170}$

\subsection{Els Adringa}

Els Andringa entwirft einen Begriff von Identifikation, der an die Psychologie - genauer gesagt an die Psychoanalyse - anknüpft, sich aber auch mit der Idee der perspektivischen Identifikation verbinden lässt: »Wenn es dem Subjekt gelingt, in den vom Text hervorgerufenen Vorstellungen Teile der in ihm gereiften Vorstellungsebenen wiederzuerkennen und wenn es von dort aus motiviert wird, sich auf das fiktive Geschehen einzulassen, Handlungen und Interessen gleichsam von den im Text vorgegebenen perspektivischen Möglichkeiten aus zu verfolgen, findet Identifikation statt. $«{ }^{171}$ Dabei weist die Autorin auf die Zweistufigkeit des vielschichtigen und komplexen Identifikationsprozesses hin: Die erste Stufe, die sie als kognitiv bezeichnet, betrifft die Wahrnehmung und Einordnung neuer Inhalte, die durch das Vergleichen mit vorhandenen Imaginationsebenen und die Bezugnahme darauf sowie durch das Wiedererkennen bestimmter Gemeinsamkeiten entstehen. "Die zweite Stufe besteht in der mentalen und emotionalen Beteiligung an der fiktiven Handlung auf der Grundlage des Wiedererkennens. ${ }^{172}$ Bei ihrer Begriffsbestimmung geht es damit einerseits um Wiedererkennung von Vorstellungsinhalten - und damit um Analogiebildung ${ }^{173}$ zwischen dem Textgeschehen und der Erfahrungswelt der Lesenden - und um das Einordnen neuer Inhalte. Andererseits ist die Perspektivenlenkung des

169 Wolf, Ästhetische Illusion, 110.

170 Vgl. Wolf, Ästhetische Illusion, 111.

171 Andringa, Wandel, 38. Sie legt diesen Begriff ihrem Lesemotivationsexperiment zugrunde, in dem sie konkrete LeserInnen zu ihrem Identifikationsverhalten hinsichtlich der in ausgewählten Textfragmenten erzählten Welt befragt hat.

172 Andringa, Wandel, 38.

173 Hardmeier, Textwelten, 213 spricht in diesem Zusammenhang von der Analogisierbarkeit mit aktuellen Problemsituationen der Erzählgegenwart: „Dabei geht es um den Grad der Korrelierbarkeit von Wissens-, Erfahrungs- und Problemperspektiven von Erzähler und Adressaten in der Erzählgegenwart mit der erzählten Geschichte und ihren kognitiven Strukturelementen sowie darum, wie der Erzähler diese Identifikationsangebote gestaltet.» Ebd., 214. 
Textes zentral. Sie ermöglicht es, dass sich Lesende aktiv auf das Textgeschehen einlassen und sich emotional daran beteiligen.

\subsection{Suzanne Keen}

Suzanne Keen ${ }^{174}$ liefert mit ihrer Zusammenstellung unterschiedlicher Hypothesen zur narrativen Empathiebildung auch entscheidende Elemente für das Identifikationsphänomen, zumal sie Empathie und Identifikation in ihren Ausführungen teilweise synonym verwendet. Sie definiert narrative Empathie folgendermaßen: "the sharing of feeling and perspective-taking induced by reading, viewing, hearing, or imagining narratives of another's situation and condition. ${ }^{175}$

Empathie für fiktionale Charaktere und Situationen scheint nur wenige bzw. minimale Elemente von Identität, Situation und Gefühl zu benötigen und nicht notwendigerweise komplexe oder realistische Darstellungen und Charakterisierungen. ${ }^{176}$ Für die Figurendarstellung genügen einfache Merkmale zur Identifizierung wie etwa ein Name, eine wiedererkennbare Situation sowie implizite Gefühle (vgl. III Methodik). ${ }^{177}$ Keen hält darüber hinaus fest, dass Charakteridentifikationen auch dann zur Empathie einladen, wenn sich die literarische Figur von der konkreten Leserin/dem konkreten Leser in allen möglichen Formen und Weisen unterscheidet. ${ }^{178}$ Dabei ist wichtig, dass ungewöhnliche und hervorstechende Repräsentationen im literarischen Text den Weg zu einem empathischen Lesen öffnen und dieses dadurch begünstigen. Wenn der Text allerdings zu unverständlich ist, behindert das erschwerte Verstehen die Empathie eher. ${ }^{179}$

Keens nächste These bezieht sich darauf, welche Art von Emotionen im Zusammenhang mit Identifikation stehen: Lesende identifizieren sich leichter mit Charakteren, die sich in einem negativen emotionalen Status befinden, wie etwa in einer Situation des Leides, der Trauer oder der Angst. ${ }^{180}$ Es geht darum, dass tiefe innere existenzielle Ängste etc. geweckt werden, auch wenn sich die Situa-

174 Vgl. Keen, Empathy, 169-171. Weitere textuelle Elemente in Bezug auf narrative Empathiebildung sind bei Müllner, Gewalt, 46-68; Pusch, Weibliches Schicksal, 109-128 sowie Schram, Norm, 137-141 angeführt.

175 Keen, Narrative Empathy, 1. Auch bei Hartvigsen, Prepare, 77 sind Empathie und Identifikation eng miteinander verschränkt. Hartvigsen betrachtet Identifikation als Unterkategorie der Empathie.

176 Vgl. Keen, Empathy, 12.

177 Vgl. Keen, Empathy, 69.

178 Vgl. Keen, Empathy, 70.

179 Vgl. Keen, Empathy, $87 \mathrm{f}$.

180 Ähnlich Levinson, Emotion, 29. 
tion von LeserInnen und literarischen Figuren unterscheidet: »Texts eliciting readers' deeply held fears seem especially successful in provoking empathy. ${ }^{181}$ Eventuell trägt der fiktionale Charakter von Literatur dazu bei, dass gerade negative Emotionen zugelassen werden können, die sonst in der "realen Welt« aus sozialen oder persönlichen Gründen vermieden werden. In der fiktionalen Welt ist es also möglich, das auszuprobieren und zu erleben, was im »echten Leben« nicht möglich ist, ohne dass bestimmte Konsequenzen folgen. ${ }^{182}$ Das Lesen literarischer Texte bietet demnach die Möglichkeit, über den Alltag hinausgehende Erfahrungen als eine Art »Probehandeln« in der Phantasie durchzuspielen, und, sollten die Erfahrung zu unangenehm werden, jederzeit auszusteigen. ${ }^{183}$ Der fiktionale Charakter der literarischen Texte beraubt die LeserInnen einiger Schutzschilde, welche die Empathie in der realen Welt hemmen können; d. h. die Fiktion deaktiviert den Argwohn der Lesenden und öffnet den Weg für eine leichtere Empathie. ${ }^{184}$ Das gilt auch für das Er- und Durchleben von Emotionen: »In fiction, we see but are not seen, and this allows a certain freedom of emotion. ${ }^{185}$ Das Anhaltende einer fiktionalen Situation - die nie wirklich vorbei ist, weil sie sich nie wirklich ereignet - kann damit zu einer empathischen Bindung führen. ${ }^{186}$

Schlussendlich übersteigt Empathie historische und kontextuelle Unterschiede, weil Empathie über diese hinausgeht. ${ }^{187}$ Dies ist gerade für die Psalmen, die von der Gegenwart durch einen großen zeitlichen, historischen, kulturellen und sprachlichen Abstand getrennt sind, von zentraler Bedeutung. Dadurch, dass in diesen poetischen Texten Identifikationspotenziale angelegt sind, die je nach Disposition und Offenheit der Lesenden wirksam werden können, wird diese immense Kluft so verringert, dass sie sich gegen Null bewegt. Durch die

181 Keen, Empathy, 71.

182 Vgl. Oatley / Gholamain, Emotions, 267. Ebenso Keitel, Von den Gefühlen, 9f: „Beim Lesen erschließen sich neue Welten mit fremden Normen und unbekannten Spielregeln. Damit ein literarischer Text erfaßt werden kann, müssen erlernte Reaktionsmuster außer Kraft gesetzt oder zumindest eingeklammert werden. Je weiter man sich von dem, worin man befangen ist, zu distanzieren vermag, desto erfolgreicher wird man mit dem anderen, das einem im Text begegnet, interagieren. Solche Interaktionen eröffnen die Möglichkeit, ungewohnte Formen von Weltzuwendung $\mathrm{zu}$ erproben und Konsequenz entlastet durchzuspielen. Sanktionen von seiten des Textes sind nicht zu befürchten. Ein durch Sprache strukturiertes Imaginäres erweitert den intellektuellen Horizont." Ähnlich Groeben, Leserpsychologie 2, 213: So ist "gerade die emotionale (hier in Form der identifikatorischen) Beteiligung des Lesers am Werk Bedingung der Möglichkeit von Erfahrung, über eingeschliffene (auch ideologische) Lebensstrukturen hinaus."

183 Vgl. Groeben, Leserpsychologie 2, 213.

184 Vgl. Keen, Empathy, 28f.

185 Oatley / Gholamain, Emotions, 270.

186 Vgl. Keen, Empathy, 79.

187 Vgl. Keen, Empathy, 80. 
Identifikationsmöglichkeit mit den Psalmen ist diesen die genannte Unmittelbarkeit gleichsam eingeschrieben. Suzanne Keen weist noch darauf hin, dass die Fähigkeit eines Romans, die Empathie der Lesenden zu wecken, sich über die Jahre hinweg ändern kann. So kann es sein, dass der Roman die ErstleserInnen anspricht, weitere Generationen jedoch nicht mehr. ${ }^{188}$ Das Faszinierende an den Psalmen ist jedoch gerade das Phänomen, dass sie über die Zeiten hinweg Menschen angesprochen haben und damit durch alle Epochen hindurch rezipiert worden sind.

\section{$4.4 \quad$ Keith Oatley}

Keith Oatley geht in seinem Beitrag zur Theorie der Identifikation vom Alltagsgebrauch des Identifikationsbegriffs im Sinne der Wiedererkennung und Nachahmung bzw. Nachbildung aus und präsentiert vier Textelemente, ohne die eine Identifikation für die Lesenden nicht möglich ist: ${ }^{189}$ (1) Ziele eines Protagonisten und Übernahme dieser Ziele durch die Lesenden: »The central process is that the reader runs the actions of the character on his own planning processes, taking on the character's goals, and experiencing emotions as these plans meet vicissitudes. ${ }^{190}$ (2) Vorstellungswelt: Bereitstellen von konkreten Details für das Erstellen eines mentalen Modells bzw. eines Denkmodells einer imaginierten Welt; (3) Sprechakte in Richtung auf die Lesenden als Relation zwischen Autor und Lesenden; und (4) Potenzial für eine konstruktive Integration unterschiedlicher Elemente: »Finally, the reader or member of the theatre audience must become an integrating centre of different streams of information, and the text must make this possible. $\aleph^{191}$

\subsection{Uri Margolin}

In seinem äußerst interessanten Beitrag zur LeserInnenbindung an Figuren in erzählenden Texten entfaltet Uri Margolin ein fünfstufiges Verfahren, dessen dritte Stufe er mit dem Begriff »Identifikation« bezeichnet. ${ }^{192}$ Der Autor legt seiner Studie, wie auch Werner Wolf, den spielerischen bzw. »Als-ob«-Charakter der fiktionalen Welt zugrunde ("game world«). Die erste Stufe ist der Einstiegsbereich in die erzählte Welt der Texte. Ich als Lesende trete in die Textwelt

188 Vgl. Keen, Empathy, 74.

189 Vgl. Oatley, Taxonomy, $69 \mathrm{f}$.

190 Oatley, Taxonomy, 66.

191 Oatley, Taxonomy, 70.

192 Zum Folgenden vgl. Margolin, Predicates, 411-413. 
bzw. Spielwelt ein und stelle mir vor, dass sowohl die Figuren als auch ich als Zuschauende bzw. Lesende existieren. Die zweite Stufe beinhaltet die Reaktion bzw. emotionale Antwort auf die Figuren und deren Einstellungen. Das können Mitleid oder Angst, Sorge, Sympathie oder Bewunderung für die Charaktere, aber auch Abneigung und Antipathie sein. Auf alle Fälle gibt es hier noch eine klare Trennung zwischen der Figur als fiktionalem Element und den Lesenden. In der dritten Stufe, die Margolin »Identifikation« oder auch mentale Nachbildung (»mental simulation«) nennt, wird der je eigene Gefühlszustand der Lesenden ausgeklammert und zurückgestellt und für eine bestimmte Zeit der geistige Zustand oder auch die Aktivitäten der Figur (z. B. Emotionen, Einstellungen, Ziele, Wünsche etc.) übernommen; etwa nach dem Motto »dein Leid ist mein Leid." Es geht darum, die Perspektive von anderen zu übernehmen und sich in diese hineinzudenken und hineinzufühlen. "In the context of fiction reading, mental simulation [= identification] implies adopting a perceptual, cognitive or affective perspective of the character which may be different from any perspective we have ever had before. ${ }^{193}$ Diese Perspektivenübernahme wird auch als imaginäre Rollenübernahme bezeichnet und durch die Fokalisierung gelenkt. »One elementary common form of readerly character simulation is focalization, where we are made to perceive (see, hear, taste) things as the character does [....$~ «{ }^{194}$ Die Identifikation mit einer literarischen Figur kann soweit gehen, dass das eigene Selbstverständnis von Leben und Welt erweitert und verändert wird in dem Sinne, dass wir das werden, was wir betrachten. Auf der vierten Stufe lösen identifikatorische Textelemente Erinnerungen und Emotionen im autobiographischen Gedächtnis der Lesenden aus, sodass die Lesenden diese Erfahrungen und Emotionen nochmals erleben können. ${ }^{195}$ Nach Abschluss des Leseprozesses er-

193 Margolin, Predicates, 411. Ernst van Alphen bezeichnet diese Form der Identifikation in Anlehnung an Kaja Silverman als »heteropathetic identification«: »Here, the self doing the identification takes the risk of - temporarily and partially - >becoming` (like) the other. This is both exciting and risky, enriching and dangerous, but at any rate, affectively powerful. [...] when we identify with the inner states or ethical dilemmas of a narrator or character, we are no longer reading signs to which we have to attribute meaning but we are living and experiencing them. We go through them: they are no longer just someone else's inner struggles read at a distance." Van Alphen, Affective Operations, $28 \mathrm{f}$.

194 Margolin, Predicates, 412. Siehe auch den Identifikationsbegriff im Film bei Tan, FilmInduced Affect, 24: »Identification occurs when the viewers imagine > what it is like to be the protagonist . Identification in a literal sense is characterized by the viewers' experience of the very same emotion that the character is imagined to have."

195 Darauf verweist auch Keith Oatley: »In art an emotion in the present is mediated by reliving an emotion from the past. [...] An original event can be re-experienced, but with a difference. The literary vehicle allows us to experience it at a best aesthetic distance - this distance is the continuum between outer and inner modes. [...] At the right distance an emotional event that was overwhelming can be recognized, experienced, assimilated; or an event from which we had cut ourselves off in pain can come alive, so that its significance and rami- 
folgt die fünfte Stufe, die als Transfer in die Lebenswelt beschrieben wird. Es ist nämlich gar nicht selten, dass Lesende die Art des Sprechens bestimmter fiktionaler Charaktere, das Outfit oder den gesamten Lebensstil übernehmen. ${ }^{196}$

\section{$5 \quad$ Zusammenschau und Begriffsableitung}

Die dargelegten Begriffsbestimmungen haben gezeigt, dass literarische Identifikation als ein Sich-Hineinversetzen in die Textwelt verstanden wird, das zugleich Resonanz (Vorstellungen, Erfahrungen, Wissen, Emotionen etc.) auslöst. Dafür ist es zunächst notwendig, dass Lesende überhaupt in die Textwelt einsteigen. Dies geschieht durch das Vorhandensein einer Bühne der erzählten Welt, die in wenigen wichtigen Elementen die Ausgangssituation des Textes auf eine Weise beschreibt, dass sich Lesende orientieren können (minimal elements: Suzanne Keen; konkrete Details: Keith Oatley). Dabei ist wichtig, dass den Lesenden einerseits die Möglichkeit der Wiedererkennung gegeben ist, welche durch Vergleich und Analogiebildung zwischen Textwelt und der je eigenen Erfahrungswelt hergestellt wird (Els Adringa). Andererseits ist Neues und Fremdes ebenso stimulierend (Suzanne Keen), dabei sollte eine Ausgewogenheit zwischen bekannten und vergleichbaren Elementen einerseits und neuen andererseits herrschen (Keith Oatley).

Nach den inhaltlichen, für die Identifikation relevanten Textelementen folgt nun der wichtige Schritt, dass diese bei den Lesenden Emotionen zum Schwingen bringen, also die emotionale Beteiligung aktiviert wird. Dies kann als emotionale Antwort auf die Figuren und deren Einstellungen sowie auf Situationen im Text geschehen (Uri Margolin). »Eigentliche« Identifikation findet dann statt, wenn es gelingt, die im Text vorgezeichneten Perspektiven mitsamt den damit verbundenen Zielen, Wünschen und Einstellungen zu übernehmen (Uri Margolin, Keith Oatley, Werner Wolf, Suzanne Keen). »Identifikation« mit literarischen Texten definiere ich im Anschluss hieran als die aktive Übernahme von im Text vorgezeichneten Perspektiven. Diese Perspektivenübernahme gelingt umso besser, je konkreter (nicht detaillierter) und »interessanter« bzw. »aktueller« die dargestellten Szenen und Inhalte sind (minimal elements und Analogiebildung), je mehr emotionale Wirkung ein Text ausübt (emotionale Beteiligung und emo-

fications can be comprehended, connections made, so that integration with the self can occur.« Oatley, Taxonomy, 63.

196 Heute wären dies etwa Bekleidungseuphorien, die z. B. Star Trek oder Harry Potter ausgelöst haben. Keith Oatley verweist auf die tragischen Suizide, die auf das Buch "Die Leiden des jungen Werthers« von Johann Wolfgang von Goethe im 18. Jh. folgten. 
tionale Resonanz auf Seiten der LeserInnen $)^{197}$ und je leichter die Anbindung an die Bewegungen des Textes gelingt (Perspektivenlenkung, Textdynamik).

197 "Lachen und Weinen bilden die extremen Pole eines Kontinuums an möglichen emotionalen Reaktionsweisen auf literarische Texte. Zwischen diesen beiden Endpunkten liegt ein breites Spektrum von affektiven Zuständen.« Keitel, Von den Gefühlen, 12. 
Open-Access-Publikation im Sinne der CC-Lizenz BY-NC-ND 4.0

(c) 2019, V\&R unipress GmbH, Göttingen 


\section{Methodik}

In diesem Kapitel wird der Weg von der theoretischen Exposition über die methodische Operationalisierung zur praktischen Textanalyse dargestellt. Für den Terminus der Identifikation gilt es, hinsichtlich der Deduktion von der Methodologie zur Methodik die Vielfalt der methodischen Herangehensweise im Blick zu haben, um dem Forschungsthema gerecht zu werden: »Im allgemeinen besteht Konsens darüber, dass Identifikation ein Phänomen ist, an das mit verschiedenen, einander ergänzender Methoden herangegangen werden kann und muss. « ${ }^{198}$ Dies aufnehmend wird hier an die Bestimmung des Begriffs »Identifikation « mit literarischen Texten erinnert als aktive Übernahme von im Text vorgezeichneten Perspektiven, die umso besser gelingt, je konkreter und »interessanter" die dargestellten Szenen und Inhalte sind, je mehr emotionale Wirkung ein Text ausübt und je leichter die Anbindung an die Bewegungen des Textes gelingt (Perspektivenlenkung, Textdynamik). Die Textanalyse wird demnach anhand der drei Analysekategorien »Inhalt", "Emotionen « und »Perspektiven « und der sich daraus ableitenden Methodenschritte durchgeführt, die im Folgenden dargestellt werden. Im Rahmen der Textanalysen, die in den anschließenden Kapiteln zur Darstellung gelangen, werden an schwierigen bzw. zentralen Stellen exegetische Informationen zu Semantik, Syntax und Textkritik inkl. Übersetzungsvarianten für das bessere Verstehen des Textes herangezogen.

\section{Inhalt}

Ein erster Schritt ist jener, der banal klingen mag, es aber nicht ist: Die LeserInnen müssen sich von Inhalt und Themen sowie von den in den Texten geschilderten Erfahrungen in irgendeiner Form angesprochen fühlen, damit sie das Geschilderte als interessant empfinden und Analogien zu eigenen Möglichkeiten und zum eigenen Leben entdecken: »[E]inen Text aufzunehmen, bedeutet, sich

198 Schram, Norm, 154. 
ihm in einem Prozeß anzunähern und langsam in ihn hineinzugehen. Zum ersten Schritt bei diesem Rendezvous gehört das Aufleuchten des Interesses, in dessen Schein die sprachliche Oberfläche durchschaubar wird. Allmählich dringt der Sehende in die Zentren der inhaltlich emotionalen Struktur ein, und es entfaltet sich ihm der Blick einer Hauptperspektive. ${ }^{199}$ Als Basis für den Identifikationsprozess sind daher die Inhalte der erzählten Welt ausschlaggebend. Suzanne Keen spricht in diesem Zusammenhang von "minimal elements", die vorhanden sein müssen, damit sich Lesende überhaupt auf das Textgeschehen einlassen (vgl. II Methodologische Grundlagen). Ihrer Ansicht nach sind nur wenige Elemente von Identität, Situation und Gefühl notwendig, nicht aber komplexe Charakterisierungen. ${ }^{200}$ Auch müssen fiktionale Charaktere keine menschlichen Wesen sein, um zur Identifikation einzuladen. Somit soll die Bühne der erzählten Welt einfach, aber klar dargelegt sein. Darauf aufbauend kann Analogiebildung im Leseprozess entstehen, indem das Gelesene mit der eigenen Erfahrungswelt laufend in Beziehung gesetzt wird. Dabei sollen in den erzählten Situationen mindestens zum Teil gegenwärtige Themen und Problemkonstellationen erkennbar sein. ${ }^{201}$ In der Textanalyse werden daher Fragen nach Inhalt, Kommunikationsstruktur und Darstellung der Szenen gestellt. Es erfolgt ein thematischer Überblick mit anschließender Analyse der Sprechrichtungen sowie der Gliederung des Textes in Spots bzw. Gedankenspots, Szenen und Minierzählungen. Unter einem Spot - einem Begriff aus der Beleuchtung, der u. a. im Rahmen des Theaters oder Films gängig ist - verstehe ich jene eine "Fläche« innerhalb eines Textes, die sich mehr oder weniger scharf von der nächsten abgrenzen lässt. ${ }^{202} \mathrm{Um}$ zu einem detaillierten Textverständnis zu gelangen, wird damit nacheinander auf abgrenzbare Teile des Textraums »das Licht« bzw. der Blick gerichtet. Die Gliederungskriterien für den gesamten Psalm werden im Kontext der jeweiligen Textanalyse benannt. Bei der Auswertung der Identifikationspotenziale wird danach gefragt, ob die minimalen Elemente der Bühne der erzählten Welt vorhanden sind und ob und wie aufgrund der geschilderten Thematik aktuelle Bezüge und damit Analogiebildung ermöglicht wird. Für das Identifikationspotenzial gilt: Je konkreter die Bühne der erzählten Welt dargestellt wird und je mehr aktuelle Themen der Text aufgreift, je größer also die

199 Willenberg, Psychologie, 21.

200 Vgl. Keen, Empathy, 69. Ähnlich Jeffries, The Role of Style, 77.83, die von den Koordinaten Zeit, Figur und Ort in Texteröffnungen als einem »full deictic field« spricht (S. 77).

201 Vgl. Hardmeier, Textwelten, 211. Ähnlich Müllner, Gewalt, 65: „Die LeserInnenlenkung in bezug auf Empathie mit repräsentierten Charakteren setzt Gemeinsamkeiten zwischen erzählten Charakteren und realen Personen voraus."

202 Vgl. Duden, 766, wo auf den Begriff »Spot« als Abkürzung für »Spotlight« verwiesen wird. Dies bezeichnet einen auf einen Punkt gerichteten Scheinwerfer, der dabei die Umgebung im Dunkeln lässt. 
Möglichkeit zur Analogiebildung ist, desto höher ist das Identifikationspotenzial.

Den Punkt »Inhalt" abschließend ist noch das Element des Interesses zu beachten: »Identifikation wird erleichtert, wenn der latente oder manifeste Inhalt des Werkes an die Interessen des Lesers anschließt und die Erzählfiguren eine gewisse Übereinstimmung mit ihm besitzen; völlige Übereinstimmung zwischen Erzählfiguren und Leser ist jedoch nicht unbedingt notwendig. ${ }^{203}$ Interesse ist eine Dimension, die in erster Linie von der Interessenslage der jeweiligen Lesenden abhängig und daher in einer Textanalyse schwer zu erfassen ist. Es kommt also darauf an, welche Inhalte und Themen die Lesenden gerade aufgrund ihrer je eigenen biographischen Situation interessieren oder eben nicht. Andererseits wird Interesse als Emotion betrachtet und kann dementsprechend analysiert werden. Damit sind wir bereits bei der nächsten Analysekategorie »Emotionen« angelangt.

\section{Emotionen und Textelemente, die Emotionen auslösen}

Im folgenden Unterkapitel wird geklärt, was Emotionen sind, welche Ebenen und Komponenten Emotionen beinhalten und wie diese innerhalb literarischer Texte analysiert werden können. Dazu werden verschiedene Zugänge zum Thema »Emotionen beim Lesen « vorgestellt und daraus im abschließenden Punkt die für das methodische Verfahren in der Textanalyse wesentlichen Elemente herausgearbeitet.

\subsection{Emotionen: Der Versuch einer begrifflichen Bestimmung}

In den Emotionstheorien herrscht Uneinigkeit darüber, wie Emotionen zu definieren sind. ${ }^{204}$ Gemeinsam ist den Ansätzen jedoch, dass »Emotion « ein subjektives Erleben ist, das durch neurophysiologische Erregung bzw. eine körperliche Reaktion, durch eine kognitive Bewertungskomponente (Denken) sowie durch ein interpersonales Ausdrucksverhalten geprägt ist. Es gibt dabei Versuche, zwischen den Begriffen "Emotion«, "Gefühl» sowie "Affekt» zu differenzieren: „Gefühle beschreiben den Zustand, den Menschen innerlich empfinden, wenn sie etwas fühlen. Der Begriff Emotion wird dagegen als theoreti-

203 Schram, Norm, 140.

204 Daneben wird darüber debattiert, in welchem Ausmaß Emotionen kulturell determiniert sind, ob es jenseits der Dichotomie von Denken und Fühlen so etwas wie einen Vorrang des einen gegenüber dem anderen gibt und wie und nach welchen Kriterien Emotionen klassifiziert werden können. Zu diesen Debatten siehe Miall / Kuiken, Feeling, 222. 
sches Konstrukt verwendet, das sich aus vier Komponenten zusammensetzt: dem subjektiven Gefühl, seinem Ausdruck, den physiologischen Veränderungen und dem spontanen Handlungsimpuls. ${ }^{205}$ Emotion ist eine Bewegung, ein komplexer Prozess, ein psychophysisches Phänomen. So wird z. B. bei der Emotion »Angst « Erschrecken erlebt (subjektives Erleben), das Herz beginnt zu rasen, der Puls schlägt höher (körperliche Reaktion), man wird blass, der Mund ist vor Entsetzen geöffnet, Zittern stellt sich ein (physiologische Veränderungen bzw. Ausdruck des Erlebten). Zugleich setzt das Denken inklusive der Bewertung der Situation als angstauslösend ein. Dem folgt ein etwaiger Handlungsimpuls wie z. B. Weglaufen, Schreien, Sich-Verstecken. Das Gefühl ist dabei nur ein Bestandteil der Emotion, nämlich das subjektiv emotionale Erleben. ${ }^{206}$ Diese Komponenten der Emotion zeigen auch, dass Emotion nicht ohne Kognition auskommt und damit Denken und Fühlen weitestgehend zusammengehören. ${ }^{207}$ Denken, Überzeugungen und Vorstellungsarbeit sind Teil der Emotion. Auf literarische Texte angewandt bedeutet dies: »When texts invite readers to feel [...], they also stimulate readers' thinking. ${ }^{208}$

Und der Affekt? Während der Begriff einerseits als zusammenfassende Bezeichnung für Emotionen, Haltungen und Stimmungen verwendet wird, werden Affekte andererseits als nicht mehr bewusst kontrollier- und steuerbare Emotionen betrachtet: ")Affekt ` beschreibt einen Zustand starker emotionaler Erregung, der das Verhalten leitet. « ${ }^{209}$

205 Bender, Heiliger Zorn, 300. Ebenso Greule, Empor die Herzen!, 321. Dieser spricht von folgenden vier Komponenten der Emotion: 1. subjektive Erlebniskomponente, 2. neurophysiologische Erregungskomponente, 3. kognitive Bewertungskomponente, 4. interper-

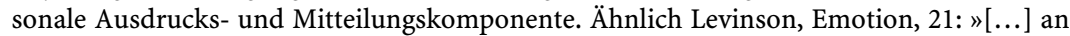
emotion is best thought of as bodily response with a distinctive physiological, phenomenological, and expressive profile, one that serves to focus attention in a given direction, and that involves cognition to varying degrees and at various levels."

206 Vgl. Winko, Kodierte Gefühle, 73.

207 »Ein Ergebnis neuerer Hirnforschung [...] lautet, dass das Denken nicht unabhängig von emotionalen Prozessen verläuft.« Winko, Kodierte Gefühle, 71. Ebenso Carroll, Art, 196f. Er führt einige Beispiele zur Illustration des Zusammenhangs zwischen Emotion und Kognition an. Vgl. auch Feagin, Imagining Emotions, $50 \mathrm{ff}$.

208 Keen, Empathy, 28.

209 Kohler-Spiegel, Emotionen, 8. Ernst van Alphen verweist dabei auf die soziale Dimension von Affekten. Diese entstehen im Inneren eines Menschen, können aber auch von außen kommen. Sie können dabei von einer anderen Person oder auch von einem Kunstwerk oder literarischen Text hervorgerufen werden. »They come from an interaction with objects, an environment, or other people. Because of its origin in interaction, one can say that the transmission of affect is social in origin, but biological and physical in effect.« Van Alphen, Affective Operations, 23. Er unterscheidet zwischen Affekt und Gefühl, wobei er Emotionen und Gefühle synonym verwendet. 
Was zählt eigentlich zu den Emotionen ${ }^{210}$ Es gibt eine lange Diskussion darüber, ob Freude, Überraschung, Traurigkeit, Angst, Ekel und Zorn mit Charles Darwin als Basisemotionen gelten sollen. ${ }^{211}$ Von diesen Primäremotionen wird angenommen, dass sie sehr früh erworben werden oder gar angeboren sind; sie zählen zum anthropologischen Bestand des Menschen und manifestieren sich kulturübergreifend entweder in gleicher Mimik oder in unterschiedlichen körperlichen Ausdrucksformen. Es gibt verschiedene Vorschläge für Kataloge von Emotionen, die sich meist voneinander unterscheiden. Zu nennen ist hier zunächst das Modell der Grundemotionen, die von Robert Plutchik in acht Begriffspaaren benannt werden. Dieses dreidimensionale Kategorisierungsschema geht von der Intensität der Emotion aus. Der Klassifizierungsversuch wird als Kegel dargestellt, wobei die Emotionen zur Spitze hin immer weniger intensiv werden: ${ }^{212}$ 1. Ekstase / Freude / Gelassenheit; 2. Kummer / Traurigkeit / Schwermütigkeit; 3. Umsicht bzw. Wachsamkeit / Erwartung bzw. Antizipation / Interesse; 4. Verwunderung / Überraschung / Verstörtheit; 5. Abscheu / Ekel / Langeweile; 6. Verehrung / Vertrauen / Akzeptanz; 7. Wut / Ärger bzw. Groll / Verdruss; 8. Panik / Angst / Besorgnis.

Wagner führt ebenso eine differenzierte Liste von Emotionen im Deutschen an: »Angst und Furcht - Eifersucht - Empörung - Ekel - Glück und Freude Hass - Liebe - Mitleid und Sympathiegefühle - Neid - Scham und Peinlichkeit Schuld - Stolz - Trauer und Niedergeschlagenheit - Verachtung, Achtung, Respekt - Zorn, Wut, Ärger. ${ }^{213}$ Die diesen und weiteren Katalogen gemeinsamen Elemente sind Freude, Zorn, Furcht und Ekel; uneins ist man sich dagegen bei Trauer, Überraschung, Abneigung, Zuneigung, Scham; und keinerlei Einigkeit besteht bei Schuld, Lust, Interesse und Unruhe. Daraus lässt sich das folgende Fazit ziehen: Einige Emotionen scheinen prototypischer und elementarer zu sein als andere, doch selbst für diese (Freude, Furcht, Wut, Ekel) gilt, dass der Ausdruck kulturell variabel ist. ${ }^{214}$ Daneben wird in den Emotionstheorien festgehalten, dass nicht alle Emotionen adäquat benannt werden können. ${ }^{215}$ So gibt es

210 Vgl. Winko, Kodierte Gefühle, 76.

211 Vgl. dazu Kohler-Spiegel, Emotionen, 8f. Ebenso Greule, Empor die Herzen!, 321.

212 Vgl. Plutchiks Rad der Emotionen in: http://de.wikipedia.org/wiki/Robert_Plutchik [abgerufen am 30.4. 2015].

213 Wagner, Emotionen, 13.

214 Silvia Schroer und Thomas Staubli beziehen sich auf die bei Carroll Ellis Izard (vgl. Izard, Carroll E.: Die Emotionen des Menschen, Weinheim $\left.{ }^{3} 1994\right)$ genannten zehn kulturübergreifenden Emotionen Interesse, Leid, Widerwillen, Freude, Zorn, Überraschung, Scham, Furcht, Verachtung und Schuldgefühl. Vgl. Schroer / Staubli, Biblische Emotionswelten, 44. Diese zehn Emotionen werden auch in altorientalischen Texten beschrieben. Der Unterschied zwischen heutigen und damaligen Lebenswelten liegt in der Art und Weise, wie Emotionen zum Ausdruck gebracht, wahrgenommen und gedeutet werden.

215 So ist zum Beispiel die Emotion Geborgenheit, die über die Aspekte Sicherheit, Schutz und 
z. B. keinen geeigneten Ausdruck für jene Emotionen, die evoziert werden, wenn wir Babys oder Jungtieren begegnen. Auch in der Textanalyse zeigt sich diese Schwierigkeit bei der Benennung von Emotionen. Wenn im Rahmen der Emotionsanalyse in den ausgewählten Psalmen keine adäquate Emotion benannt werden kann, diese aber dennoch mitschwingt, wird deshalb in den Textanalysen allgemein auf die Emotionen hingewiesen, die mit den entsprechenden Aspekten (z. B. Sicherheit, Gewalt etc.) verbunden sein können.

\subsection{Emotionen beim Lesen}

Im Folgenden werden jene Ansätze beschrieben, die für die Textanalyse in dieser Arbeit von Relevanz sind. Im letzten Punkt dieses Unterkapitels werden die Methodenschritte der unterschiedlichen für die Analyse herangezogenen Ansätze zusammenfassend dargestellt.

\subsubsection{Explizite und implizite Emotionen}

Simone Winko hat sich mit Emotionen in der Dichtung auseinandergesetzt. Ihr Ausgangspunkt lautet, dass Emotionen durch verschiedene Vorgaben kulturell geprägt sind. Infolgedessen spricht sie von kulturellen Codes bzw. von der Codierung und Decodierung von Emotionen. Damit das Verstehen von Emotionen in Gedichten gelingt, müssen Lesende die Codes identifizieren: »Leser müssen eigene remotionale Muster`, gebildet aus lebensweltlich und/oder literarisch angeeigneten Erfahrungen, einbringen, um emotionale Situationen, Verhaltensweisen oder Aussagen auf der fiktionalen Ebene eines literarischen Textes sowie emotionsbezogene Formen zu verstehen. ${ }^{216}$ Durch dieses Code-Wissen darüber, in welchen Situationen Emotionen entstehen, wie sie sich entwickeln und wie sie angemessen auszudrücken sind, funktioniert dann das Codieren wie das Decodieren der literarischen Gestaltung von Emotionen. Emotionen gelten als soziale und kulturelle Konstrukte.

Dabei ist die Sprache ein Medium der Codierung von Emotionen. ${ }^{217}$ Schließlich geht es bei der Betrachtung von Emotionen in Texten immer um die

Unverletzlichkeit hinausgehend auch jene der Ruhe, des Friedens und der Wärme umfasst, kaum in andere Sprachen übersetzbar. Vgl. dazu http://de.wikipedia.org/wiki/Geborgenheit [abgerufen am 18.5.2015]. Daneben verfügt nicht jede Sprache über die genau gleichen Ausdrucksmittel für Emotionen. Für weitere Benennungen und Klassifizierungen von Emotionen siehe u. a.http://en.wikipedia.org/wiki/Contrasting_and_categorization_of_emo tions [abgerufen am 30.4.2015].

216 Winko, Kodierte Gefühle, 141.

217 »Emotionen werden vielmehr als 'kodiert aufgefasst, und die Art und Weise, wie sie in 
sprachliche Gestaltung und Darstellung von Emotionen: «Literarische Texte können selbst jedoch nun einmal keine Affekte haben. Affekte können in ihnen benannt, thematisiert oder als Befindlichkeiten von Figuren dargestellt, von Autoren als eigene Befindlichkeit mit literarischen Texten ausgedrückt oder bei Lesern durch literarische Texte hervorgerufen oder hervorzurufen versucht werden. ${ }^{218}$ Emotionen werden also in Texten durch Sprache ausgedrückt. Dieser sprachliche Ausdruck ermöglicht es, dass Emotionen analysierbar werden. Dabei gilt, dass sprachlich ausgedrückte Emotionen bestimmten kulturellen und sozialen Regeln und Konventionen unterliegen: "Auch der Emotionsausdruck ist konventionalisiert; körpersprachlich durch Mimik, Gestik und Haltung geäußerte Emotionen müssen anderen verständlich sein, um eine angemessene Reaktion zu erhalten, und für die Verbalisierung von Emotionen gilt dasselbe. ${ }^{219}$ In der sprachlichen Darstellung von Emotionen differenziert Simone Winko zwischen der Thematisierung von Emotionen (was wird dargestellt?) und der Präsentation von Emotionen (wie wird es dargestellt?). ${ }^{220}$

In der vorliegenden Arbeit geht es um die Thematisierung von Emotionen in den Psalmen. Dabei werden unter Rekurs auf Winkos Differenzierung Emotionen grob in explizite und implizite eingeteilt. Werden Emotionen im Text thematisiert - wenn z. B. der Erzähler oder die Figuren über eigene Emotionen oder die anderer sprechen, oder aber abstrakt darüber reflektiert wird -, dann sind dies explizite textuelle Manifestationen von Emotionen. Von impliziten Emotionen wird dann gesprochen, wenn Emotionen indirekt ausgedrückt werden, etwa vermittelt durch Sprachbilder (vor allem Metaphern), durch das Verhalten der Figuren, durch die Handlung des Textes, durch die Situationen, in denen Figuren handeln oder die sie hervorrufen, oder durch Objekte und wie diese beschrieben werden bzw. wie mit diesen umgegangen wird. ${ }^{221}$

Abschließend sind die Emotionen zuzuordnen. Dies geschieht ausgehend von der Frage, welcher Instanz im Text sie zugeschrieben werden: Die Zuordnung kann zu einer Sprecherinstanz (Narrator; lyrisches Ich/Wir etc.) oder einer Figur erfolgen, wobei dabei die Emotionen so präsentiert werden, als wären es jene der Figur oder Sprechstimme. Daneben können Emotionen »subjektfrei« dargestellt werden und kommen daher ohne Zuordnung aus. Dies ist vor allem bei jenen

literarischen Texten thematisiert und präsentiert werden, partizipiert an solchen kulturellen Kodes und formt sie zugleich mit.« Winko, Kodierte Gefühle, 14.

218 Anz, Kulturtechniken, 213. Er verwendet hier den Begriff »Affekt« als Synonym für »Emotion".

219 Winko, Kodierte Gefühle, 82.

$220 »$ Um die Thematisierung von Emotionen zu analysieren, reicht es in der Regel aus, auf zwei sprachliche Formen zurückzugreifen: auf die expliziten Benennungen [...] und den bildlichen Typ impliziter Emotionsvermittlung [...].» Winko, Kodierte Gefühle, 136.

221 Vgl. Winko, Kodierte Gefühle, 47. 
Emotionen der Fall, die eng mit der bildlichen Rede verknüpft sind und durch Sprachbilder evoziert werden. ${ }^{222}$

In bibelwissenschaftlich-alttestamentlicher Hinsicht haben Andreas Wagner und Susanne Gillmayr-Bucher die sprachsystematischen Codierungen emotionaler Aspekte durchbuchstabiert. ${ }^{223}$ Für die bei Simone Winko genannten impliziten Emotionen sind nach Wagner und Gillmayr-Bucher Ausrufe (Weh! Ach!), die Wortwahl sowie syntaktische Ausdrucksmittel wie Aufforderungen, Verdoppelungen, Fragen und Auslassungen sowie elliptische Äußerungen zu nennen. Für die expliziten Emotionswörter, die die inhaltlich-thematischen Bezeichnungen des Erlebens wiedergeben, wird im AT der Schwerpunkt auf die Gefühlswörter wie Gefühlsverben (lieben, hassen etc.), verba dicendi (schwören, fluchen, schreien, klagen etc.) und Gefühlssubstantive (Freude, Angst etc.) gelegt. ${ }^{224}$ Andreas Wagner betont ebenso wie Simone Winko, wie wichtig sprachliche Bilder wie Metaphern, Vergleiche oder Allegorien sind, um Emotionen zu transportieren. Susanne Gillmayr-Bucher verortet den Ausdruck von Emotionen im AT in körperlichen Reaktionen (z. B. zittern als Ausdruck von Angst und Schrecken), Mimik und Gestik (z. B. Trauergesten als Ausdruck der Trauer), Affektlauten (seufzen, weinen etc.), verbalisierungsbegleitenden Manifestationen wie Sprechtempo, Stimmlage etc. sowie in verbaler Thematisierung wie Weherufen, Wortwahl, begrifflichen Erlebens- und Emotionsbenennungen und explizite Emotionsbeschreibungen. ${ }^{225}$

\subsubsection{A-emotions und F-emotions}

Keith Oatley differenziert in seiner Taxonomie der emotionalen Reaktionen beim Lesen zwischen sogenannten »internen" und »externen« Emotionen. Dabei geht es um Folgendes: Bei der emotionalen Resonanz auf Literatur kann unterschieden werden zwischen einer Person, die außerhalb des Werkes bleibt und einer, die das Werk »betritt«. Das Bild für den ersten Fall ist das einer Person und eines Objektes, z. B. einer Person und eines Buches oder einer Person und der Kinoleinwand. Der zweite Fall bezieht sich auf Lesende, die in die vom Künstler/ von der Künstlerin entworfene Welt eintreten. Es wird also zwischen drinnen und draußen unterschieden, und zwar mittels des Sprachbildes einer semipermea-

222 Vgl. Winko, Kodierte Gefühle, 137.

223 Vgl. Wagner, Emotionen, 28-47. Eine ausführliche Zusammenschau der beiden Ansätze von Andreas Wagner und Simone Winko bietet Artner, Emotionen in Psalm 90, $121 \mathrm{f}$.

224 In Bezug auf Verben der Gefühlsäußerung hält Wagner fest: »[...] das Aussprechen einer Gefühlsäußerung hat sicher auch etwas >Konstituierendes`, das Gefühl wird durch das Aussprechen klar, mitteilbar, verstehbar, irgendwie manifest.« Wagner, Emotionen, 124.

225 Vgl. Gillmayr-Bucher, Emotion, 282-285. Dies., Rauchende Nase, $22 \mathrm{f}$. 
blen (d.h. halbdurchlässigen) Membran. ${ }^{226}$ Semipermeabel wird sie deshalb genannt, weil man nicht alle, sondern nur einige Charakteristika der je eigenen Persönlichkeit in die andere Welt hineinträgt. Auf die literarischen Künste übertragen werden die Emotionen, die entstehen, wenn sich Lesende mit dem Text konfrontieren, als die Emotionen außerhalb der Membran angesehen: die Freude beim Lesen allgemein, die Befriedigung der Neugierde, die Spannung, wie es weitergeht. Dagegen gelten als Emotionen, die innerhalb der erzählten Welt entstehen, diejenigen, die durch die Handlungsabläufe oder Charaktere der Erzählung hervorgebracht werden und beim Eintauchen in die erzählte Welt entstehen. Diese Trennung von innen und außen ist nicht als Dichotomie, sondern als Kontinuum zu begreifen. ${ }^{27}$ Die internen und externen Emotionen können mit Tan auch als A- und F-emotions bezeichnet werden. A-emotions sind jene Emotionen, die beim Betrachten des Kunstwerks - in unserem Fall im Leseprozess - ausgelöst werden. A-emotions sind Emotionen, die sich auf das Kunstwerk als Artefakt beziehen (Artefact-based emotion) und z. B. Freude oder Bewunderung für das Werk beinhalten. Sie werden auch ästhetische Emotionen genannt. F-emotions dagegen sind Emotionen, die sich auf Elemente der fiktionalen Welt beziehen (Fiction-based emotion). Hier sind die Lesenden ganz in die Textwelt involviert; sie stellen sich vor, an die Stelle der Erzählfigur zu treten, und erleben dabei ähnliche Emotionen. ${ }^{228}$ Innerhalb der F-emotions spielt auch Identifikation eine große Rolle: "Diese so genannten Fiktionsemotionen beinhalten empathische und sympathetische Reaktionen bezüglich der handelnden Charaktere, die sich z. B. in der Identifikation mit einem Helden ausdrücken, aber auch durch Gefühle von Spannung, Angst oder Ärger, die durch bestimmte

226 Vgl. Oatley, Taxonomy, 54f. »The worlds inside literary membranes are like our familiar world, but also unlike it. [...] To experience emotions in this way, the reader must enter through the pores of the membrane. With each new book or drama it is as if he or she comes to live (in part and for a limited time) within one of these sequestered worlds. As entrants into such worlds, in them but not of them, we can experience emotions in three ways, in terms of sympathy, memories and identification.« (S. 61) Der Autor greift mit diesem Bild der semipermeablen Membran, die jede Art sozialer Interaktion umgibt, eine Idee von Goffman, Erving: Encounters: Two Studies in the Sociology of Interaction, Indianapolis 1961, auf.

227 Vgl. Oatley, Taxonomy, 55.

228 "We could call emotion related to (aspects of) the artefact `Artefact-based emotion<, and emotion stimulated by (elements of) the fictional world /Fiction-based emotion/. A-emotion include enjoyment, admiration, wonder (as when a spectacle looks technically impossible), and others. « Tan, Film-Induced Affect, 13. Auch Kneepkens und Zwaan arbeiten mit der Unterscheidung zwischen F- und A-emotions. Sie differenzieren ihrerseits die F-emotions noch stärker, und zwar einerseits in Emotionen, die eher auf die Lesenden selbst und die Aktivierung der je eigenen emotionalen Erfahrungen bezogen sind, und andererseits in solche, die sich auf andere bzw. Anderes in der Textwelt beziehen. Kneepkens / Zwaan, Emotions, 132. 
Handlungsabfolgen evoziert werden. ${ }^{229}$ Die A- und F-emotions werden hauptsächlich in Erzähltexten verortet. In der vorliegenden Arbeit wird die Unterscheidung und Erhebung von A-emotions und F-emotions nun auf lyrische Texte angewandt. "Obwohl sich diese Taxonomie auf die Rezeption narrativer Texte bezieht, sollte sie auch in Bezug auf lyrische Texte ihre Gültigkeit haben. « $^{230}$ Die Klassifizierung der A- und F-emotions kann also auch auf Poesie übertragen werden. In dieser Studie werden - da die Unterscheidung zwischen A- und Femotions nicht immer eindeutig und der Übergang fließend ist - auch jene Emotionen als A-emotions bezeichnet, die nicht nur durch den Text als Gesamtes ausgelöst werden, sondern die im Rahmen der Textlektüre bzw. des Leseprozesses in der Textwelt aufgebaut werden, ohne dass die Lesenden sich voll und ganz in das Erzählte involvieren, z. B. die Emotion der Bewunderung und des Staunens aufgrund der Rede von der Größe Gottes in Ps 147,4-5.

Aus der literaturwissenschaftlichen Analyse erzählender Texte in Bezug auf Emotionen ist noch festzuhalten, dass die emotionale Relation zwischen Figuren und Lesenden bis dato nicht geklärt ist. So können Leser- und Figurenemotion identisch sein, indem die Lesenden sich ganz in die Situation, Gedanken- und Gefühlswelt der Figur hineinversetzen; etwa nach dem Motto »dein Leid ist mein Leid " (vgl. den Identifikationsbegriff bei Margolin in Kapitel II Methodologische Grundlagen). Auf Figuren bezogene Emotionen müssen aber auch nicht identisch sein mit den Emotionen der Lesenden. Wenn ich von einer Figur lese, die verliebt oder eifersüchtig ist, dann muss ich nicht gleichzeitig verliebt oder eifersüchtig sein. Meist sind nämlich auf Figuren bezogene Emotionen komplementär zu den Emotionen der Lesenden: "Das Weinen einer fiktiven Figur provoziert (komplementär dazu) das karitative Mitleid des Rezipienten. ${ }^{231} \mathrm{Zu}$ einer Parallelisierung von Figuren- und LeserInnenemotionen kann es aber auch kommen, wenn die Lesenden nicht auf die Figur selbst reagieren, sondern auf die Situation, die die Figur durchlebt. ${ }^{232}$

229 Lüdtke, Frage, 121.

230 Lüdtke, Frage, 121.

231 Mellmann, Gefühlsübertragung?, 115. Zur emotionalen Reaktion auf Figuren in Erzähltexten siehe auch Hartvigsen, Prepare, 75-80.

232 Vgl. Mellmann, Gefühlsübertragung?, 115f. Die Autorin weist zudem darauf hin, dass sich Lesende aufgrund ihrer Empathiefähigkeit durchaus vorstellen können, wie sich die Figur fühlt, und unterscheidet dann zwischen der Vorstellung, wie es sich anfühlt (beispielsweise gelassen oder traurig zu sein) und dem tatsächlichen Sein und Erleben (von Gelassenheit und Traurigkeit). Es geht also bei Mellmann um die Frage, ob ein Unterschied besteht zwischen der Vorstellung, eine bestimmte Emotion zu haben - diese Vorstellungsarbeit wird ja durch Kunstwerke, Filme, Texte etc. angeregt -, und dem eigentlichen Erleben der Emotion in der Wahrnehmung dieser. Mehr dazu siehe bei Feagin, Imagining Emotions, 5457. 
Nach diesen Bemerkungen zur literaturwissenschaftlichen Perspektive ist nun ein Blick auf empirische Daten über LeserInnenemotionen $\mathrm{zu}$ werfen: David Miall und Don Kuiken ${ }^{233}$ entfalten in ihrer Auswertung der empirischen Untersuchung der emotionalen Reaktion auf eine Kurzgeschichte vier verschiedene Arten von Emotionen, die im Leseprozess entstehen. Diese vier Ebenen sind nicht scharf voneinander abgrenzbar und können in einem Lesemoment auch gleichzeitig entstehen: (1) Bewertende Emotionen wie etwa Zufriedenheit, Genuss und Vergnügen, die sich dann einstellen, wenn ein Buch oder ein Film allein zur Unterhaltung gelesen oder angesehen wird; dies sind Emotionen, die Vergnügen und Spannung erzeugen, damit weitergelesen wird; sie haben nichts mit jenen Gefühlen zu tun, die durch die Textwelt evoziert werden. ${ }^{234}$ (2) Narrative Emotionen hinsichtlich spezifischer Aspekte der fiktionalen Welt (Handlungen, Figuren) sowie Empathie mit einer Figur. (3) Ästhetische Emotionen sowie Faszination und Interesse als Antwort auf formale Elemente wie Aufbau, Rhetorik oder Stil oder auch auf das Berührtsein durch eine passende Metapher. Stellt sich diese Emotion ein, dann wird der Leseprozess verlangsamt, die Lesenden bleiben aufgrund einer gewissen Unsicherheit und Nachdenklichkeit länger am Text, d. h. dass sie sich länger mit dem Text beschäftigen. Miall und Kuiken verweisen darauf, dass diese ästhetischen Emotionen auch A-emotions genannt werden (siehe oben). (4) Emotionen, die die Persönlichkeit der Lesenden verändern: Diese stellen sich nur bei einem bestimmten Teil der LeserInnen ein und führen dazu, dass diese durch die Lektüre einen veränderten Zugang zur eigenen Lebenswelt erhalten.

David Miall und Don Kuiken beziehen sich in ihrer Klassifizierung der Emotionen beim Lesen auch auf die Emotion des Interesses, welches hier bereits im ersten Unterkapitel (III Methodik 1) als Identifikationspotenzial erwähnt wurde. Jenseits der Tatsache, dass Interesse stark an die Biographie der jeweiligen Lesenden geknüpft ist, ist Interesse auch als Textstrategie zu eruieren. »Die Interessenlage dürfte sich so lange mit der des Gedichtes decken (bzw. im Leseakt zu dieser hinaufgezogen werden), wie die vom Leser erforderte Mühe durch emotionale Ereignisse sbelohnt « wird. $" 235$ Aus dem Bereich des Films wird Interesse als Basisemotion bezeichnet und sowohl als A-emotion als auch als Femotion definiert: "Interest, then, is the basic emotion in film viewing. We can define interest as an inclination to spend attention on the film, to watch it intensely, and engage in active processing in response to promising prospects [...]. Interest is an anticipatory emotion, such as desire, hope and fear. In con-

233 Zum Folgenden siehe Miall / Kuiken, Feeling, 223-225.

234 Auch wenn dies hier als Einstiegsebene dargestellt wird, bemerkt Anz, Kulturtechniken, 234 trocken: »Vermutlich ist der Lustgewinn sogar das dominante Motiv, sich durch Literatur emotionalisieren $\mathrm{zu}$ lassen.»

235 Mellmann, Emotionalisierung, 220. 
trast to these last two emotions, which have specific events as their objects, the film as a whole is the target of interest. Interest is both an A- and an F-emotion. The viewer appraises promise of knowledge of the final state of affairs in the fictional world, as well as of further development and completion of stylistic patterns and motives. The action tendency, an urge to watch, has both the fictional world and the film portraying it as its object. ${ }^{236}$

Interesse und Aufmerksamkeit sind auch für das "Dranbleiben « an Texten bedeutsam. ${ }^{237}$ Der Autor/die Autorin literarischer Texte trägt durch die Gestaltung seines/ihres Textes dazu bei, dass die Lesenden ihre Aufmerksamkeit auf den Text richten. Dies geschieht durch die Art und Weise, wie er/sie die Textelemente anordnet und etwa diese in den Vordergrund, jene aber in den Hintergrund rückt. Ein solchermaßen vorfokussierter Text zieht unsere Aufmerksamkeit zu bestimmten Details hin, und er stimuliert dabei eine emotionale Antwort, die uns an den Text bindet. Doch die Fokussierung im Text reicht alleine nicht aus, um eine emotionale Reaktion bei den Lesenden hervorzurufen. Dazu ist es notwendig, dass die Erzählung bestimmte Interessen, Einstellungen, Anliegen und Bedenken über die Figuren und Geschehnisse der erzählten Welt nach und nach »einträufelt». Diese funktionieren dann wie Wünsche in vielen Emotionen des Alltags und wenn diese zu den Konzeptionen des vorfokussierten Textes hinzugefügt werden, dann wird durch die Kombination eine emotionale Reaktion hervorgerufen: »Emotional involvement with a narrative depends upon the combination [...] of a conception of the situation [prefocused text] along with some relevant concerns, preferences and desires. Together, these provide necessary and sufficient conditions for an emotional response to the text to take hold in such a way that the reader, viewer, or listener becomes emotionally focused [...]. $\aleph^{238}$ Interesse hat also neben (1) dem Inhalt auch (2) mit der emotionalen Gestaltung des Textes zu tun und wird (3) durch die Textdynamik, wie etwa im Spannungsaufbau eines Psalms, textuell sichtbar. Interesse ist damit jenes Element, das alle drei Analysekategorien (Inhalt, Emotionen und Textdynamik) verbindet.

\subsubsection{Metaphern und Emotionen}

Identifikation und Empathie mit literarisch Dargestelltem hat in erster Linie etwas mit Emotionen zu tun, wie dies bereits dargestellt wurde. «Die Gefühle beim Lesen werden durch Strukturen im Text ermöglicht, hervorgebracht und

236 Tan, Film-Induced Affect, 16.

237 Zum Folgenden vgl. Carroll, Art, 201-206.

238 Carroll, Art, 206. 
(zumindest ansatzweise) auch gelenkt. « $^{239}$ Diese Erkenntnis legt Evelyne Keitel ihrer Habilitationsschrift mit dem Titel »Von den Gefühlen beim Lesen« zugrunde. Sie geht von der Annahme aus, dass Lesevorgänge auf verschiedenen Ebenen stattfinden, und sieht es daher als Notwendigkeit, für ihre Frage nach der Rolle von Gefühlen ${ }^{240}$ beim Lesen ein Modell zu entwickeln, das die Methoden der modernen Literaturwissenschaft um die Methoden der Psychoanalyse ergänzt. Dabei unterscheidet sie eine Ebene der kognitiven Texterfassung von einer Ebene der unbewussten Texterfassung, womit einerseits die Gegebenheiten des Textes und andererseits das menschliche Subjekt mit seiner Körperlichkeit, seinen Gefühlen und seiner Subjektivität ihren theoretischen Ort finden. ${ }^{241}$ Das Unbewusste $^{242}$ ist nach Keitel beim Lesen maßgeblich beteiligt und auf beiden genannten Ebenen unterschiedlich stark präsent. Daneben treten auf beiden Ebenen Gefühle auf. Jene Emotionen, die beim Lesen auf der Ebene der kognitiven Texterfassung ausgelöst werden, sind abhängig von der Form des literarischen Textes und somit von bestimmten Wirkungsstrategien. Auch können sie bewusst oder unbewusst sein. Auf der Ebene der unbewussten Texterfassung zeigt sich die Interaktion mit dem Text in diffusen, unspezifischen Gestimmtheiten. ${ }^{243}$ Auf jeder Ebene gibt es zudem Elemente, die sich methodisch nicht fassen lassen, weil sie kontingent sind und teilweise zufällig auftreten. Dennoch hält Keitel fest: "Sowohl der kognitive Lektüreprozess und die emotionale Reaktion auf ihn als auch die nicht kognitiv vermittelten, unbewußten Gestimmtheiten beruhen auf der Vermittlungsleistung von Sprache. Beide Ebenen von Texterfassung und die in ihnen involvierten Dimensionen einer affektiven Beteiligung am Lesen sind dem Text eingeschrieben. Sie werden konditioniert durch Sprachstrukturen, durch konkrete Merkmale im literarischen Text.. ${ }^{244}$

239 Keitel, Von den Gefühlen, 10.

$240 »$ Gefühle werden stimuliert durch einen Reiz (einen Vorstellungsinhalt, ein Objekt) auBerhalb des Kontinuums zwischen Körper und Sprache, und sie manifestieren sich in je unterschiedlichen Anteilen entweder in Sprach- oder in Körperreaktionen (oder in beiden). Aber sie lassen sich nicht reduzieren auf ihren äußeren Ausdruck, sei er sprachlich, sei er körperlich, denn sie sind gerichtet. Sie verweisen zurück auf die Gegebenheit jenseits von Körper und Sprache, durch die sie hervorgerufen wurden. Problematisch für den Versuch, Gefühle zu definieren, ist, dass ein Gefühl nicht etwa an einem bestimmten Ort entsteht, sondern durch dynamische Prozesse, genauer: durch die Verschiebung von psychischen Energien.« Keitel, Von den Gefühlen, 18. Zur weiteren Beschreibung des Begriffs »Gefühl« und dessen Komplexität siehe ebd., 18-36.

241 Vgl. Keitel, Von den Gefühlen, 35.

242 Keitel bezieht sich dabei auf das Konzept eines sprachlich vermittelten, intersubjektiv vergleichbaren Unbewussten nach Lacan. Vgl. Keitel, Von den Gefühlen, 46.131-140. Nach Lacan gilt die Sprache als eigentlicher Ort des Unbewussten. Die Sprache strukturiert das Unbewusste wie auch umgekehrt das Unbewusste die Sprache gestaltet. Das Unbewusste bildet sich erst durch das Lernen von Sprache und ist ein Konstrukt.

243 Vgl. Keitel, Von den Gefühlen, 70.

244 Keitel, Von den Gefühlen, 46f. 
Diese konkreten textuellen Elemente benennt Keitel mit den rhetorischen Figuren Metapher und Metonymie. Dies sind also die Knotenpunkte im Text, an denen sich die beiden Ebenen der Texterfassung verdichten. Im Leseprozess haben sie eine zweifache Funktion: Einerseits sind sie kognitiv erfassbar, und andererseits stimmen sie mit den unbewussten Prozessen von Verdichtung und Verschiebung überein. ${ }^{245}$ "Ein Wort kann ersetzt werden durch eines, das ihm ähnlich ist, oder es kann verschoben werden auf eines, das ihm nahe steht bzw. an es angrenzt. Die Äquivalenz zwischen beiden, dem Ursprünglichen und dem Ersetzenden, liegt nicht in der Substanz, sondern in der Funktion: Beide können potentiell dieselbe Position innerhalb eines Sprechaktes einnehmen. Und sie sind kognitiv rezipierbar. Ihrer Struktur nach aber entsprechen Metapher und Metonymie bestimmten, im Unbewußten ablaufenden, psychischen Prozessen: der Verschiebung und Verdichtung ebenso wie der Umsetzung von Gedanken in visuelle Bilder und Symbole. ${ }^{246}$ Darüber hinaus sind sie vom jeweiligen Kontext abhängig, in dem bestimmte Begriffe "wörtlich« verwendet werden, damit der übertragene Gebrauch des Wortes als Metapher bzw. Metonymie erkannt werden kann. ${ }^{247}$

Auf der Ebene der unbewussten Texterfassung ist danach zu fragen, ob das Unbewusste des Lesers mit dem sprachlich bzw. semiotisch verfassten Unbewussten des Textes in Interaktion treten kann. Die Kommunikation zwischen zwei unbewussten Systemen wird in der Psychoanalyse mit dem Konzept der Übertragung und Gegenübertragung benannt. Übertragung ist die Wiederholung einer Gefühlsbeziehung aus der Vergangenheit im Verhältnis zu neuen, anderen Menschen in der Gegenwart. Bei dieser Übertragungsbeziehung wird einer Person - im Falle der Psychoanalyse dem Therapeuten/der Therapeutin eine bestimmte Autorität zugesprochen. In Form der Gegenübertragung kann der Psychotherapeut/die Psychotherapeutin auf den Patienten/die Patientin reagieren. Dieses Modell wird nun auf die Interaktion zwischen Text und LeserIn übertragen. Dabei sind immer beide Momente, also Übertragung und Gegenübertragung, gleichzeitig im Spiel, sie sind ineinander verflochten und miteinander vernetzt. Ein zentraler Aspekt der Übertragungs- und Gegenübertragungsreaktionen besteht darin, dass diese oft in Emotionen enthalten sind, die der Analytiker/die Analytikerin spürt, d. h. dass die Kommunikation zwischen zwei unbewussten Systemen spürbar ist und sich in Gefühlen und Gestimmtheiten manifestiert. ${ }^{248}$ Emotionen beim Lesen kommen also auch durch das Phänomen der Übertragung und Gegenübertragung zustande. Da dieses Phä-

245 Vgl. Keitel, Von den Gefühlen, 49.

246 Keitel, Von den Gefühlen, 47.

247 Vgl. Keitel, Von den Gefühlen, 114.

248 Vgl. Keitel, Von den Gefühlen, 182. 
nomen allerdings mittels literaturwissenschaftlicher Methoden der Textanalyse nicht zu erheben ist, beschränke ich mich bei der Rezeption von Keitels Ansatz darauf, die Wichtigkeit der Analyse metaphorischer Sprache im Rahmen der Emotionsforschung aufzunehmen.

Eine Metapher ist ein Sprachbild, das zwei verschiedene Vorstellungsbereiche (Bildempfänger/tenor/focus, z. B. Gott; Bildspender/vehicle/frame, z. B. mein Fels; vgl. Ps 18,3), die im Alltagsgebrauch nichts gemeinsam haben, miteinander in Beziehung setzt, wodurch neue Verständnisweisen entstehen. ${ }^{249}$ Der metaphorische Sinn schafft demnach eine Nähe zwischen Bedeutungen, die einander vorher fremd waren. ${ }^{250}$ Betrachtet man die Metapher mit Hilfe der Interaktionstheorie, so kommt es bei einer Metapher zu einer Wechselwirkung zweier Vorstellungen bzw. Vorstellungskomplexe, die eine neue Sinndimension eröffnet. ${ }^{251}$ Zentral ist bei der Erkennung und Benennung von Metaphern die Tatsache, dass es keine eindeutigen grammatischen Verfahren gibt, um eine Metapher als solche zu kennzeichnen. Demzufolge hängt es von den Lesenden ab, ob sie eine metaphorische Äußerung als solche identifizieren oder nicht. ${ }^{22}$ Die Mitarbeit der Lesenden ist also bei der Metaphernanalyse unumgänglich. Darüber hinaus erhält eine Metapher nur in einer entsprechenden Situation, einem gesamten Satz oder in einem bestimmten Kontext ihren Sinn.

Emotionen spielen eine große Rolle in metaphorischen Aussagen, die sowohl Emotionen zum Ausdruck bringen als auch bei den Lesenden Emotionen wachrufen und sie in den Text mit hineinnehmen: ${ }^{253}$ "Aus dem Zusammenspiel von Hervorhebung einer Wertvorstellung und emotionaler Beteiligung der Hö-

249 Vgl. Gillmayr-Bucher, Zunge, 197. Mittlerweile gibt es eine große Fülle von Literatur zu Metapherntheorien, die im Einzelnen nicht aufgeführt werden können, da dies den Umfang der Arbeit sprengen würde. Einen Überblick über die unterschiedlichen theoretischen Entwürfe, ausgehend von Aristoteles bis zur Blendingtheorie, die Pierre van Hecke auf biblische Texte angewandt hat, findet sich bei Liebert, Metaphernforschung. An dieser Stelle sei nur noch auf den etablierten Forschungsbereich der Analyse von Metaphern in den Psalmen und damit u. a. auf folgende Werke verwiesen: Van Hecke / Labahn, Metaphors; Van Hecke, Metaphor; Grohman, Fruchtbarkeit; Riede, Netz; Nielsen, Variety; Gillmayr-Bucher, Die Psalmen.

250 Vgl. Ricœur, Funktion, 51.

251 Vgl. Black, Metapher, 68-77.

252 Vgl. Beckmann, Grammatik, 93. Dennoch bereitet es den Lesenden nach Susanne Beckmann keine allzu großen Schwierigkeiten, Metaphern zu erkennen und sie als solche zu deuten. Zur Identifikation von Metaphern vgl. auch die Pragglejaz Group, Method, sowie Steen, Linguistic Form.

$253 \mathrm{Zu}$ Not- und Rettungsaussagen in den Psalmen vermerkt Susanne Gillmayr-Bucher: »Die metaphorische Sprache und die darin zum Ausdruck gebrachte Erlebniswirklichkeit erlaubt den LeserInnen die Not, wie auch die Rettung emotional nachzuvollziehen." GillmayrBucher, Zunge, 206. Zum Phänomen der »Gefühlsübertragung» im Rahmen der Überlappung und Wechselwirkung zwischen den Vorstellungsbereichen innerhalb der metaphorischen Rede vgl. Koppe, Sprache, 119. 
rerInnen intensiviert metaphorische Sprache die Verbindung von RezipientIn und Text und trägt somit dazu bei, eine intime Beziehung zwischen LeserIn und Text aufzubauen. ${ }^{254}$ Metaphern interagieren also nicht nur innerhalb der sprachlichen Äußerungen, sondern auch mit den Lesenden. Dabei eröffnen sie den Lesenden die Möglichkeit, sich selbst im metaphorischen Sprachbild wiederzufinden und äquivalente Ausdrücke für die je eigene emotionale Situation zu finden. ${ }^{255}$ Durch metaphorische Rede wird damit ein Identifikationspotenzial für LeserInnen geschaffen, indem Metaphern Leerstellen und Lücken dahingehend lassen, wie ihre Bedeutung im Detail interpretiert werden soll. So geben sie den Lesenden die Möglichkeit, sich selbst mit jener Bedeutung zu identifizieren, die genau und individuell zur jeweiligen Lebenssituation passt. ${ }^{256}$

In der vorliegenden Arbeit werden in den Textanalysen sowohl bildliche Rede (z. B. Ps 30,2.4), Metaphern (z. B. Ps 30,12) und Personifikationen (z. B. Ps 30,6.10; $90,4 ; 147,12.15)$ als auch Vergleiche ${ }^{257}$ (z. B. Ps 64,4; 90,4-5.9; 147,16-17) analysiert. Durch das Sprachbild der Personifikation werden nichtlebende Wesen wie Abstrakta, Ideen oder Gegenstände mit Handlungsweisen und Eigenschaften ausgestattet, die ansonsten nur Lebewesen (Menschen, Tieren) zugeschrieben werden. ${ }^{258}$ Es tritt das Phänomen der Vermenschlichung ein. Personifikationen gelten als Sonderform der Metapher; sie zählen zu den am häufigsten verwendeten Metaphern. Grammatikalisch werden sie durch Substantive (z. B. die Inflation frisst unsere Profite auf; "die Gegenstände sehen mich kommen ${ }^{259}$ ), durch Adjektive bzw. Adverbien (z. B. eifersüchtige Bäume, geprügelte Tage ${ }^{260}$ ) sowie durch Verben (z. B. die Zeit heilt alle Wunden; die Hügel tanzen; das Leben hat mich betrogen) realisiert. ${ }^{261}$ Sie tragen nicht nur zur Anschaulichkeit und

254 Gillmayr-Bucher, Zunge, 200. Ebenso MacCormac, Cognitive Theory, 160.

255 Vgl. Labahn, Wild Animals, 69-72. Auf den Zusammenhang zwischen Emotionen und sprachlichen Bildern - insbesondere Metaphern - sowie auf die Imaginationsarbeit der Rezipierenden beim Lesen verweist auch Peetz, Emotionen, 31.337.361.439.

256 Vgl. Labahn, Wild Animals, 94.

257 Vgl. Seybold, Poetik der Psalmen, $195 \mathrm{ff}$.

258 Vgl. die Definition im bibelwissenschaftlichen Bereich bei Dodson, Personification, 40: Personifikation bedeutet "the attribution of human traits to an inanimate object, abstract idea or impersonal being which is used with action verbs most commonly employed to describe the action of a person.« Dodson unterscheidet weiter zwischen Metapher, Allegorie, Anthropomorphismus, Prosopopoia und Hypostase; Letztere ist für ihn »a figure which stands between a personification and an independent being, more than a personification but not quite an autonomous power.» Die »Frau Weisheit» wäre demnach als Hypostase zu bezeichnen.

259 "Ausreisegedicht» von Domin, Gesammelte Gedichte, 254. Ebenso: »Eine unordentliche Reihe von Tagen steht Schlange vor meiner Tür« aus: »Bedrohung«, ebd., 258.

260 »Kalender« von Domin, Gesammelte Gedichte, 251.

261 Auf die Betonung des Prädikats innerhalb der Verbpersonifikation verweist Bloomfield: Of all the grammatical signs of personification it seems to me that the use of animate verbs and predicates is the most characteristic and important, [except perhaps in dialogue or debate]. 
Lebendigkeit von Sprache bei, sondern auch dazu, dass sich Menschen gerade mit diesen Sprachbildern identifizieren. Doch aus welchem Grund? Die menschliche Darstellung von leblosen Gegenständen und Abstrakta in einer Personifikation evoziert auf Seiten der RezipientInnen das gesamte Repertoire menschlicher Erfahrungen. Durch die Darstellung als Personifikation werden menschliche Erfahrungen freigesetzt: "We are people. We know a lot about ourselves. And we often make sense of other things by viewing them as people too. ${ }^{262}$ Diese Analogiebildung mit menschlichen Wesen ist somit ein hervorstechendes Merkmal von Personifikationen innerhalb der metaphorischen Sprache. $^{263}$

\subsection{Methodisches Vorgehen}

Im Rahmen der Emotionsanalyse werden Textstrategien untersucht, die an die LeserInnenemotionen appellieren. Von den dargestellten Ansätzen folge ich der Analyse expliziter und impliziter Emotionen (Simone Winko), der Analyse metaphorischer Sprache (Keitel u. a.) sowie jener von A-emotions und F-emotions (Tan). In einem ersten Schritt werden dabei Textelemente aufgespürt, die Emotionen enthalten und als explizite Emotionswörter ausgewiesen werden können. Die lexikalische Benennung von Emotionen kann in Form von Substantiven, Adjektiven oder Verbformen erfolgen, z. B. Freude, ängstlich, sehnsuchtsvoll, sich fürchten. Im Rahmen der Analyse dieser textuellen Manifestationen von Emotionen wird jeder einzelne hebräische Begriff, der emotional konnotiert ist oder sein könnte, auf der Ebene der Semantik auf seinen emotionalen Gehalt im Bibelhebräischen hin befragt. Dabei kommen für die Benennung der Emotionen die in der Begriffsbestimmung von Emotion genannten Kataloge von Plutchik, Wagner etc. zur Anwendung. In bestimmten Fällen gilt es, die Spannung zwischen den Auffassungen und Bestimmungen von Emotionen im Bibelhebräischen und in heutigen Sprachen aufzuzeigen und auszuhalten. ${ }^{264}$

The stress in most personification allegory is on the action." Bloomfield, Grammatical Approach, 65.

262 Turner, Death, 21. Zur Betrachtung der Personifikation als ontologische Metapher und zu weiteren Beispielen von Personifikationen im Englischen vgl. Lakoff / Johnson, Metaphors We Live By, $33 \mathrm{f}$.

$263 »$ When we personify we bring events like death down to human scale so as to understand them concretely as personified agents analogous to human beings." Dodson, Personification, 49. Zur ausführlichen Diskussion der theoretischen Grundlagen des Personifikationsbegriffs und zur Analyse von Verbpersonifikationen im Psalter vgl. Eder, Do Justice and Peace Really Kiss Each Other?, 388-394.

264 Andreas Wagner verweist dabei auf die unterschiedlichen Körperkonstruktionen und deren 
Danach erfolgt die Analyse der impliziten Emotionen. Dies sind Ausdrücke und Phrasen, die keine Emotionswörter beinhalten, sondern erst durch den Kontext des Verses oder des gesamten Psalms als emotional konnotiert gelten. ${ }^{265}$ Dabei sind potenziell alle sprachlichen Formen von Bedeutung. Im Zentrum der Analyse der impliziten Emotionen steht die Betrachtung der Bildersprache mit Schwerpunkt auf metaphorischer Sprache (Metaphern, Personifikationen, Vergleich). Dabei werden vor allem die Semantik der bildspendenden und bildempfangenden Bereiche sowie die Interaktion zwischen den beiden genauer untersucht. ${ }^{266}$ Ebenso sind Syntax, Ko- und Kontext der Phrasen zu berücksichtigen, durch die implizite Emotionen evoziert werden. Anschließend erfolgt die Auswertung unter der Frage, wem die expliziten und impliziten Emotionen im Text - sofern dies eruierbar ist - zugeschrieben werden. Dann wird der Blick auf die dritte Ebene der Emotionsanalyse gerichtet, nämlich auf jene Emotionen, die im Leseprozess ausgelöst werden; wie bereits erläutert (siehe III Methodik 2.2.2), werden diese Emotionen auch als A-emotions bezeichnet. Hier wird der eigene Befund mit den Betrachtungen der vielen KommentatorInnen des Psalmenbuches und jener ExegetInnen, die sich zu den jeweiligen Psalmen geäußert haben, ins Gespräch gebracht (vgl. Kapitel I Einleitung 4.2). Über die bisher genannten Begriffe hinaus kommen in der Analyse noch zwei weitere zur Anwendung: Emotionalität und Emotionalisierung. Unter Emotionalität verstehe ich die Quantität an geschilderten Emotionen, unter Emotionalisierung das Gepacktwerden durch die Emotionalität des Texts. Für das Identifikationsphänomen gilt: Je höher Emotionalität und Emotionalisierung sind und je breiter das Spektrum der unterschiedlichen im Text thematisierten Emotionen, desto höher ist das Identifikationspotenzial.

Ausdruck in Metaphern im Bibelhebräischen und im Deutschen. Vgl. Wagner, Emotionen, 98.

265 Melanie Peetz differenziert in ihrer Emotionsanalyse des Hld zwischen emotional konnotierten und denotierten Termini und betont, dass es sich beim Ausdruck von Emotionen im Text um ein Zusammenspiel mehrerer Textmerkmale handelt. Jenseits der Termini, die direkt oder indirekt auf Emotionen verweisen, spielen somit auch weitere sprachliche Mittel wie Bildersprache (Metaphern und Vergleiche), Sprechakte sowie die Gestaltung der Lautebene durch Rhythmus, Melodie und Klang eine Rolle. Vgl. Peetz, Emotionen, $31 \mathrm{f} .436 \mathrm{ff}$. Dies ist in der Analyse der impliziten Emotionen in dieser Arbeit berücksichtigt worden.

266 Bei der Metaphernanalyse folge ich dem methodischen Vorgehen von Zimmermann, Metapherntheorie. Ruben Zimmermann entfaltet in seinem äußerst informativen Artikel die Art und Weise, wie Metaphern anhand der Syntax bzw. der formalen Struktur der Metapher, der Semantik und der Pragmatik der Metapher methodisch transparent analysiert werden können. Da in dieser Arbeit die Analyse der Metaphern ein Analyseaspekt unter vielen ist und die Ausführungen von Ruben Zimmermann zur Metaphernanalyse sehr umfangreich gehalten sind, muss hier eine Schwerpunktsetzung erfolgen (siehe oben). 


\section{Perspektiven und Textdynamik}

»Die Lenkung des Blicks der LeserInnen hat großen Einfluss auf deren Wahrnehmung der AktantInnen und birgt ein hohes Identifikationspotential. Der Zugang zur Perspektive einzelner AktantInnen ist für die Bewertung des Geschehens und hinsichtlich der Sympathie für die einzelnen AktantInnen von höchster Bedeutung. ${ }^{267}$ Im Anschluss an diese Gedanken Ilse Müllners lässt sich also sagen, dass Perspektivierungsstrukturen in Texten wesentlich dazu beitragen, ob und wie Lesende sich mit der Textwelt identifizieren können. Daher wird in der Textanalyse der jeweilige Psalm hinsichtlich seiner Perspektivenlenkung befragt: Wer sieht? Was wird von welchem Standpunkt bzw. welcher Wahrnehmungsinstanz aus in den Blick genommen? Welche Formen von Perspektiven bzw. Fokalisierungen (intern; extern; doppelt etc.) sind auszumachen? Wohin und worauf wird die Perspektive gelenkt (nach oben, nach unten; auf das göttliche Du, auf die Unterdrückten, auf das Volk Israel, auf die Feinde etc.)? Wie nah oder wie fern gestaltet sich der "Zoom» der Kameraeinstellung im Text? Was steht im Vordergrund und was im Hintergrund? Sind kontrastierende Elemente auszumachen? Was wird ausgeblendet und nicht in den Blick genommen? Sind die Perspektivenwechsel abrupt oder für die Lesenden nachvollziehbar gestaltet?

\subsection{Perspektivenlenkung}

Unter Perspektive verstehe ich die »Repräsentation von etwas für jemanden von einer gegebenen Position aus. Dabei wird dieses etwas, ein Objekt, eine Person, ein Sachverhalt, ein Ereignis, eine Handlung [...] nur in einem oder mehreren seiner Aspekte für ein Individuum relevant, nicht als Ganzes, und es wird so für (einen) Adressaten zu einem bestimmten Zweck verbalisiert. ${ }^{268}$ Von einem bestimmten Standpunkt aus wird also zu einem bestimmten Zeitpunkt auf einen Gegenstand geblickt, wodurch eine Teilansicht auf diesen entsteht. ${ }^{269}$ In literarischen Texten - und vor allem in Erzähltexten - wird dabei von Fokalisierung gesprochen. Diese bezeichnet »die virtuelle Wahrnehmungsinstanz, von deren raum-zeitlichen Koordinaten aus all das, was in einer Erzählung

267 Müllner, Gewalt, 57.

268 Sandig, Perspektivierung, 37.

269 Dabei kann dasselbe Individuum denselben Gegenstand auch aus verschiedenen Perspektiven betrachten. Perspektivität ist daher auch immer potenzielle Multiperspektivität, insofern die Möglichkeit, ein Objekt oder einen Sachverhalt auch anders betrachten zu können, Voraussetzung für die Erkenntnis der je eigenen Perspektivität ist. Vgl. Sandig, Perspektivierung, 39 . 
vorkommt, >gesehen`, >gehört ‘ etc. wird. « ${ }^{270}$ Innerhalb einer Erzählung kann die Darstellung aus verschiedenen Blickwinkeln erfolgen. Für die Perspektiven in den Psalmen gelten - die Perspektiven aus der Narratologie aufnehmend und erweiternd - die folgenden vier Punkte: (1) Der Blickwinkel kann an den Blickwinkel einer Figur gebunden sein. Dies ist innerhalb eines Textes dann gegeben, wenn die Figur selbst spricht, und wird als interne Fokalisierung bzw. Ich-Perspektive bezeichnet. (2) Der Blickwinkel ist der einer außenstehenden Erzählinstanz (externe Fokalisierung). Meist wird die Perspektive einer Figur von einer Erzählinstanz berichtet, d. h. die Wahrnehmung der Figur, ihre Perspektive, wird aus der Perspektive der Erzählinstanz geschildert. (3) Doppelte Fokalisierung herrscht dann vor, wenn der externe Fokussator gemeinsam mit einem internen wahrnimmt. So blicken die LeserInnen beispielsweise auf eine Textperson, die wiederum selbst ihren Blick auf eine andere Person lenkt. Dies ist etwa in 2 Sam 11,2 der Fall. Hier sehen wir zum einen David, und zum anderen sehen wir, wie David Batseba sieht. Die Lesenden können die Frau nur sehen, indem sie an Davids Blick partizipieren. ${ }^{271}$ (4) AdressatInnenperspektive (Imperative an AdressatInnen).

Bei Erzählungen werden die Lesenden automatisch in die Position der Erzählinstanz und damit in die jeweilige Erzählsituation hineinversetzt. Oder anders gesagt: "Das fokussierende Subjekt nimmt einen in dieser Hinsicht privilegierten Status ein, da die LeserInnen faktisch gezwungen werden, die anderen AktantInnen und die erzählten Ereignisse durch die Brille des Fokussators zu betrachten. ${ }^{272}$

Für die Perspektivenlenkung innerhalb literarischer Texte gilt: »Offenbar gibt es neben der Präferenz für fokalisierte Erzählungen auch eine für Fokalisierungsverläufe, die menschliche Bewegungsabläufe imitieren. Mit anderen Worten: Eine bewegliche Wahrnehmungsinstanz ist ১besser als eine statische, und eine quasi linear fortschreitende Wahrnehmungsinstanz ist >besser als eine wild zwischen mikroskopischer und All-Perspektive umherspringende. ${ }^{273}$ Für das Identifikationspotenzial im Rahmen der Perspektivenlenkung ist demnach eine dynamische Wahrnehmungssituation, $d$. h. eine sich in der Zeitdimension verändernde Wahrnehmungssituation »besser" als eine statische. Je konkreter und deutlicher die Perspektivenlenkung ausfällt, desto leichter ist Identifikation möglich. Eine ausdifferenzierte Wahrnehmungsfunktion ist Voraussetzung für

270 Mellmann, Emotionalisierung, 106. Fokalisierung bedeutet »die virtuelle Erfahrungsinstanz, deren quasi $>$ stellvertretende` Informationsaufnahme wir im Imaginationsprozeß mitvollziehen « (ebd).

271 Vgl. Müllner, Gewalt, 59.

272 Müllner, Gewalt, 68.

273 Mellmann, Emotionalisierung, 108. 
die optimale Wirkung emotionaler Reize. ${ }^{274}$ "Eine distinkte Wahrnehmungssituation, wie sie durch die Darstellung einer Ereignisabfolge (Dynamisierung) oder durch die Fokussierung einzelner Wahrnehmungsdetails (Konkretisierung) gegeben ist, läßt dem Leser allein schon durch die Textmenge, die eine solche Ausführlichkeit produziert, genügend Zeit zur Vorstellungsbildung. Eine distinkte Wahrnehmungssituation bringt automatisch eine zeitdeckende bis zeitdehnende Darstellung mit sich, d. h. sie zwingt den Leser, für die kognitive Decodierung der sprachlichen Informationsdarbietung ungefähr so viel Zeit aufzuwenden, wie er für die Wahrnehmung einer entsprechenden sinnlichen Informationsdarbietung bräuchte. ${ }^{275}$

Identifikation mit literarischen Texten basiert $u$. a. auf einer entsprechenden Perspektivenlenkung und hat vor allem mit einer Perspektivenübernahme zu tun. Mit dieser alleine ist es aber nicht getan. Es geht dabei auch um die Übernahme von Zielen, Plänen und Intentionen, die im Text vorgezeichnet sind. ${ }^{276} \mathrm{Im}$ Falle der Psalmen kann sich das auf die Übernahme der Intentionen des betenden Ich/Wir in seinem Bitten, Klagen und Jubeln, seinem Sich-Ausweinen, Freuen und Anklagen, in seiner Verwünschung der Feinde oder in seinen dringenden Appellen, die Gottheit zum Eingreifen zu bewegen, beziehen. Oder anders gesagt: Wir akzeptieren die in der Textwelt wahrnehmbaren Pläne und Ziele. Für die Psalmen ist in dieser Hinsicht festzuhalten, dass diese selbst auf ein Ziel hin angelegt sind: "Sie wollen etwas. Sie wollen etwas erreichen. [...] sie sind immer wieder darauf aus, bestimmte Effekte zu erzielen. [...] Die Psalmisten haben eine Überzeugung, ein Bewusstsein, ein Gefühl usw.; sie wollen es zum Ausdruck bringen, es an andere herantragen. ${ }^{277}$ Die Psalmen, die meist zu oder über Gott sprechen, wollen demnach bei Gott etwas erreichen, und sie laden gleichzeitig die HörerInnen und LeserInnen ein, dies mitzuvollziehen. ${ }^{278}$ Können Lesende an die im Psalm geschilderten Erfahrungen nicht anknüpfen, weil sie ihnen fremd sind, so ist doch die Möglichkeit gegeben, im Rahmen einer empathischen Perspektivenübernahme diese Erfahrungen stellvertretend für das lyrische Ich/Wir nachzuvollziehen.

274 Vgl. Mellmann, Emotionalisierung, 222.

275 Mellmann, Emotionalisierung, 218f.

276 Vgl. Mellmann, Emotionalisierung, 109.

277 Ridderbos, Die Psalmen, 109.

$278 »$ Wie aus diesen Bemerkungen hervorgeht, wollen die Psalmisten mit ihren Gedichten zwar Eindruck auf Gott machen, aber sie bedienen sich zu diesem Zweck [...] derselben Mittel, mit denen sie auch versuchen würden, auf einen Menschen, etwa den König, Eindruck zu machen. Zumindest von den Liedern des Lobes und Dankes kann gesagt werden, dass sie auch von Menschen gehört werden sollten. Die Psalmisten wollen, dass auch andere, indem sie sehen und hören, was die Dichter erfahren haben, von Ehrfurcht und Vertrauen zu Jahwe erfüllt werden [...] und in das Loben und Danken einstimmen.» Ridderbos, Die Psalmen, 110. 


\subsection{Deixis}

Welche Elemente einer Textstruktur tragen dazu bei, dass Lesende im Lektüreprozess bzw. in ihrer Perspektive gelenkt werden? Wie kommt eine Fokussierung der Lesenden und Hörenden im Psalm auf die jeweiligen Textelemente zustande? Welche sprachlichen Aspekte beinhalten eine Perspektivenlenkung bzw. einen empathischen Perspektivenwechsel? Es sind jene Elemente und Aspekte, die unter dem Begriff »Deixis« zusammengefasst werden können. "Ein besonders auffälliger Fall von dauernd praktizierter Empathie im Bereich sprachlichen Verstehens ist das Verstehen von Deixis. [...] Das Gelingen dieses Wechselspiels der Personalpronomen beruht nicht auf Übersetzung. Das Verstehen sämtlicher Pronomen [...] verlangt eine Fähigkeit zum empathischen Perspektivenwechsel. ${ }^{279}$

"Deixis» (griech. "auf etwas hinweisen«, "zeigen«) ist ein sprachwissenschaftlicher Fachbegriff, der eigentlich innerhalb von mündlichen Kommunikationssituationen Verwendung findet. Der Terminus bezeichnet einen Verweis auf eine Komponente einer Sprechsituation und stellt damit eine direkte Beziehung zum Situationskontext her. Durch diese Verweise ist es für Sprechende und Hörende möglich, eine Aussage auch ohne explizite Erwähnung aller notwendigen Namen, Gegenstände, Orts- und Zeitangaben zu verstehen. ${ }^{280}$ "Deiktisch sind jene Ausdrücke, die auf die personellen, temporalen oder lokalen Charakteristika der Sprechsituation verweisen, z. B. ich - du, jetzt - dann, hier da. $\aleph^{281}$ Das heißt, dass diese Wörter keine eigene, für sich selbst stehende Information beinhalten, sondern sprecherInnen- und kontextabhängig sind, sich auf nicht-explizierte Angaben (Personen, Ort, Zeit) beziehen und von den KommunikationspartnerInnen automatisch richtig aufgefüllt werden. ${ }^{282}$ Unter den Deixiskategorien wird unterschieden zwischen einer Personaldeixis, einer Raum- oder Lokal- bzw. Ortsdeixis und einer Zeit- oder Temporaldeixis. Zur Personaldeixis zählen alle deiktischen Elemente einer Sprache, die einen Bezug

279 Hermanns, Empathie, 162.

280 »Using pointers, it is possible for speaker und hearer to situate an utterance without explicitly mentioning all characterizing features. The pointing words are mostly pronouns and various adverbial expressions; all such grammatical expressions compose a system of deixis, the Greek word for pointing." Waltke / O'Connor, Biblical Hebrew Syntax, 235. Verwiesen wird dabei auf bereits Bekanntes (rückwärts bzw. anaphorisch), auf neu zu Erwartendes (vorwärts bzw. kataphorisch) und auf die Kommunikationssituation selbst (deiktisch). Vgl. Schneider, Grammatik, 231.

281 Dürr / Schlobinski, Deskriptive Linguistik, 294.

282 Vgl. Mehling, Heute hier, 41 sowie Linke, Linguistik, 178 und Köller, Perspektivität, 475: »Da der Origopunkt der Rede sprecherbezogen ist, verschiebt er sich notwendigerweise bei jedem Sprecherwechsel. Entsprechende Umorientierungen vollziehen die Sprachteilnehmer in der Regel aber problemlos." 
zu einer Person oder zu einem Objekt herstellen wie z. B. Demonstrativpronomen (dieser, jene), Personalpronomen (ich, du), der unbestimmte und bestimmte Artikel, Possessivpronomen (mein, dein etc.) und Relativpronomen. Während Ausdrücke, die sich auf die 1. und 2.P. (sg. und pl.) beziehen, als deiktisch betrachtet werden, sind jene, die sich auf die 3.P. beziehen, entweder deiktisch oder anaphorisch. ${ }^{283}$ Dabei kommt gerade der Ich-und-Du-Deixis eine große identifikatorische Kraft zu. ${ }^{284}$ Zur Raumdeixis zählen bestimmte Lokaladverbien (hier, dort, diesseits, jenseits etc.), Prä- und Postpositionen, lokale Nomina sowie einige Verben der Bewegung (wie z. B. kommen, gehen, fallen, sinken/steigen, senken/heben etc.). Die Temporaldeixis beinhaltet Temporaladverbien, (jetzt, heute, morgen, damals etc.), zeitdeiktische Ausdrücke (Tag, Jahr, Stunde, Woche etc.) sowie Tempus bzw. Tempusformen. ${ }^{285}$ Zentral ist bei jeder Form von Deixis die Lenkung des Fokus: »Mithilfe von d[eiktischen] Ausdrücken bewirkt ein Sprecher in seiner Sprechhandlung eine Fokussierung der Aufmerksamkeit des Hörers auf einzelne Aspekte eines für den Sprecher und Hörer gemeinsamen Bezugsraums, dem Verweisraum. ${ }^{286}$ Die letzte Instanz und der absolute Bezugspunkt ist dabei der Sprecher/die Sprecherin selbst. ${ }^{287}$

Verwendet wird die Deixis im Rederaum bzw. Sprechzeitraum (Rededeixis), Textraum (Textdeixis) und im Vorstellungsraum (Deixis am Phantasma) ${ }^{288}$ Für die vorliegende Arbeit ist die Deixis im Textraum von Relevanz. Im Unterschied zum Kommunikationsgeschehen im Sprechzeitraum sind Texte aus der jeweiligen Sprechsituation entbundene sprachliche Einheiten. Das bedeutet, dass der Textraum durch die Lesenden im Leseprozess zunächst einmal als solcher kon-

283 Anaphorisch betrachtet Shin Tanaka die Rede in der 3. P.: "Die grammatische Kategorie `Person` beruht auf der interpersonalen Beziehung in der Sprechsituation, d. h. die Personen werden differenziert, je nachdem, wo sie in Bezug auf den deiktischen Raum zu platzieren sind: Die erste Person und die zweite Person, der Sprecher und der Adressat, sind in der Sprechsituation verankert. Allein die dritte Person wird symbolisch, d. h. durch Benennung der Eigenschaft, oder anaphorisch determiniert.« Tanaka, Deixis, 47. Deiktisch wird die 3.P. dagegen bei Waltke / O'Connor, Biblical Hebrew Syntax, 235 aufgefasst.

$284 »$ Both $>$ I and $>$ you<, then, are perceived by theorists as having immersive, identificationinducing powers." Macrae, You and I, 65.

285 Vgl. Mehlich, Heute hier, $52 \mathrm{ff}$.

286 Ehlich, Deixis, 132.

287 Der Bezugspunkt wird nach Karl Bühler auch als hic-nunc-ego-origo bezeichnet. Diese HierJetzt-Ich-Origo ist der Nullpunkt des Bezugssystems, von dem aus auf etwas gezeigt wird. Vgl. Bühler, Sprachtheorie, 102ff. »Diesen Origopunkt der Wahrnehmung von etwas können wir auch als Sehepunkt einer bestimmten sprachlichen Objektivations- bzw. Wahrnehmungsperspektive bestimmen. In räumlicher Hinsicht wird dieser Origopunkt durch das Zeigwort hier, in zeitlicher Hinsicht durch das Zeigwort jetzt und in personaler Hinsicht durch das Zeigwort ich fixiert. « Köller, Perspektivität, 475. Diese sprachlichen Verweiswörter haben analog zu Gesten die Funktion, unsere Aufmerksamkeit in eine bestimmte Richtung zu lenken. Vgl. Köller, Perspektivität, 475.

288 Vgl. Ehlich, Deixis, 132. 
stituiert werden muss. Die wesentlichen Komponenten der Deixis im Sinne der Steuerung der Rezeption bleiben dabei erhalten: „Wenn innerhalb eines Textes Teile der deiktischen Ausdrucksklasse verwendet werden, wird auch mit ihnen eine Orientierungshandlung vollzogen. [...] Der Autor bewegt den Leser dazu, seine Aufmerksamkeit innerhalb des Textraums zu fokussieren. ${ }^{289}$ Ehlich bezeichnet den Einsatz von deiktischen Prozeduren beim literarischen Erzählen als hervorragendes Mittel der Lenkung der Rezeption durch den Autor: «Dieses Verfahren, das sich der deiktischen Prozedur bedient, könnte man als ıZoomEffekt bezeichnen: durch die unterschiedliche Aufmerksamkeitslenkung seines Adressaten holt der Sprecher die propositionalen Gegenstände näher heran, oder er gibt, in der Form der Totale, lediglich die allgemeinen Charakteristika mehrerer solcher Elemente an. ${ }^{290}$

Konrad Ehlich ist den Verwendungen der Deixis im sprachlichen Handeln innerhalb des Bibelhebräischen in einer ausführlichen zweibändigen Studie nachgegangen, wobei er sich in dieser seiner Dissertation hauptsächlich mit der Problematik der Differenzierung von Anaphorik und Deixis auseinandersetzt. ${ }^{291}$ Er kommt dabei zu dem Schluss, dass es sich bei Anaphorik und Deixis um zwei verschiedene Referenzprozeduren handelt. So dient die Deixis der Neufokussierung und die Anaphorik der Fokusaufrechterhaltung. ${ }^{292}$ Bei den Funktionen der Deixis verweist er mehrmals auf die bereits erwähnte ausdrückliche Fokussierung der Aufmerksamkeit der LeserInnen und HörerInnen. ${ }^{293}$

Deixis wird in verschiedenen Sprachen ${ }^{294}$ auf unterschiedliche grammatikalische und syntaktische Weise konstruiert, und dabei spielen die Pronomen eine entscheidende Rolle. Diese Fürwörter stehen "für« etwas und sind damit »Platzhalter bzw. Ersatzformen für sprachliche Einheiten. ${ }^{295}$ Im Bibelhebräischen gelten Personalpronomen, Demonstrativpronomen, Interrogativprono-

289 Ehlich, Prozeduren, 120.

290 Ehlich, Deixis 1, 481.

291 Vgl. Ehlich, Deixis 1.2.

292 Vgl. Tanaka, Deixis, 27.

293 Vgl. Ehlich, Deixis 2, 740.

294 Auf die Übersetzungsproblematik der Deixis verweist Köller, Perspektivität, 476: «Die sprachlichen Mittel für die Raum-, Zeit- und Personendeixis sind in den verschiedenen Sprachen naturgemäß unterschiedlich ausgebildet, was bei Übersetzungen natürlich große Probleme aufwirft. [...] Wenn die räumlichen, zeitlichen und personalen Verweisungsmittel der Sprache emotionale, wertende und soziale Implikationen haben, dann ergeben sich ebenfalls schwer lösbare Übersetzungsprobleme."

295 Köller, Perspektivität, 477. Über den Zusammenhang zwischen den traditionellen lateinischgriechischen Ausdrücken für die Pronomen (Demonstrativpronomen, Personalpronomen, Possessivpronomen etc.) und der Deixis informiert Ehlich, Prozeduren, 113f. Durch den Begriff der Deixis (Zeigfeld) wird die Sprechsituation einbezogen und damit eine Konzeption erweitert bzw. abgelöst, bei der isolierte sprachliche Ausdrücke klassifiziert und kategorisiert werden, wie das bei der Analyse von Pronomen der Fall ist. 
men, ${ }^{296}$ Relativpronomen sowie der Artikel als deiktisch. ${ }^{297}$ Zur Personaldeixis im Bibelhebräischen zählen demnach die selbstständigen und unselbstständigen Personalpronomen, ${ }^{298}$ die Pronominalsuffixe an Substantiven oder Präpositionen, Demonstrativpronomen, ${ }^{299}$ Relativpronomen, Interrogativpronomen und Personalsuffixe sowie -präfixe am Verb und auch der Artikel. Diese Elemente werden im Rahmen der Textanalyse untersucht. Für die selbstständigen Personalpronomen ist die Verstärkung des Fokus ein bekanntes Thema in den Grammatiken des Bibelhebräischen. Das betrifft vor allem selbstständige Personalpronomen, die vor oder nach einem finiten Verb stehen. ${ }^{300}$ Die Temporaldeixis wird entsprechend ihrer Temporalobjekte (gestern, heute; Jahr, Tag etc.) ausgewiesen, für die Lokaldeixis sind Lokaladverbien (hier, dort etc.) sowie Verben der Bewegung zentral.

Für die Identifikation im Text gilt: Je deutlicher und klarer die Perspektivenlenkung ist und je näher diese die LeserInnen an den Text heranholt, umso höher ist das Identifikationspotenzial. Für die Deixis bedeutet das: Je dichter das Netz an deiktischen Textelementen ist, desto leichter ist Identifikation möglich. $^{301}$

296 »Fragepronomen (wer, was, welcher, wen usw.) dienen dazu, unsere Aufmerksamkeit auf unbekannte Akteure oder Gegenstände von Handlungen und Vorgängen zu richten, weshalb sie natürlich auch dazu verwendet werden können, die Vorstellungsgrößen zu erfragen, die in Aussagesätzen die Rolle von Subjekten oder Objekten übernehmen (Was hat er gestohlen?).« Köller, Perspektivität, 481.

$297 »$ The personal pronouns are deictics: the first-person singular pronoun points to the speaker (the plural points to a group the speaker belongs to), the second-person singular points to the hearer, and third-person pronouns point to anything or anyone else. Most other pronouns are also deictics, be they demonstrative (e.g., , this book ), interrogative (e.g., , who are you? ), indefinite (e.g., , whoever he sends, goesı), or relative (e.g., , The book that / which I read is good ).« Waltke / O'Connor, Biblical Hebrew Syntax, 235.

298 Vgl. Waltke / O’Connor, Biblical Hebrew Syntax, 235.292.

299 Auf den starken deiktischen Charakter der Demonstrativpronomen und deren Einteilung in einen Nähe (hier)- bzw. Fernebereich (da, dort) verweisen Waltke / O'Connor, Biblical Hebrew Syntax, 306. Vgl. ebenso Gzella, Althebräisch, 73. Anders Joüon / Muraoka, Grammar, 498, wo zwischen Nah- und Ferndeixis nicht unterschieden wird: »Hebrew does not distinguish between the demonstrative of the near object (this one) and the demonstrative of the far object (that one)."

300 »Independent pronoun added to a finite verb. Since a finite verb by itself indicates the person, it can be said that, whenever a verb occurs with a pronoun referring to its subject, some extra nuance is intended. Generally speaking, the addition of a pronoun gives some special prominence to the person or persons indicated by it, comparable to a close-up focus in photography. [...] The pronoun can precede or follow the verb, apparently without any difference in meaning; in most cases it precedes.« Joüon / Muraoka, Grammar, 505.507.

301 Vgl. dazu die Funktion deiktischer Elemente in Erzähltexten bei Furrow, Listening Reader, $375: »[\ldots]$ the more deictics in a narrative passage, the stronger the link with the reader [...].» 


\subsection{Textdynamik}

Auf die Wichtigkeit einer dynamischen Wahrnehmungssituation wurde bereits unter dem Punkt »Perspektivenlenkung« (siehe oben III Methodik 3.1) verwiesen. Im Rahmen der Textdynamik wird nun das Augenmerk darauf gelegt, ob und wie es gelingt, mit der Figur im Text - im Falle der Psalmen mit dem sprechenden Ich/Wir - mitzugehen und sich deren Perspektiven anzuschließen. Aus der Analyse von Figuren im Film ist bekannt: "Die raumzeitliche Anbindung suggeriert, dass Figur und Zuschauer dieselbe Situation wahrnehmen und einen Bedeutungs- und Wahrnehmungsraum teilen, der ihnen ähnliche Möglichkeiten der Wahrnehmung, des Denkens, Fühlens und Handelns bietet. ${ }^{302}$ Für die Identifikation ist demnach das Mitgehen mit der Figur des Textes und die Nähe zu dieser entscheidend sowie das Teilen von deren Gedanken, Ideen, Stimmungen, Emotionen und Handlungen im Text. ${ }^{303}$ Um diese raum-zeitliche Anbindung an die Figur zu erörtern und auszuweisen, wird auf die Textuntersuchung mittels narratologischer Analysekategorien zurückgegriffen. In der Textanalyse werden also Figuren, Zeit, Räume und Bewegungen, Handlungen sowie Subjekt- und Objektpositionen untersucht. ${ }^{304}$ Dass diese Analysekategorien aus der Erzähltextanalyse auch auf die Psalmen als poetische Texte angewandt werden können, wurde bereits in Kapitel I Einleitung 4.1.1 ausgewiesen. Des Weiteren werden - sofern vorhanden - short stories (Minierzählungen) innerhalb des jeweiligen Psalms analysiert. Da die Reihenfolge der Textelemente die Perspektive der Lesenden lenkt, wird danach gefragt, welche Elemente wann zum Einsatz kommen und was wie verklammert, ein- bzw. ausgeleitet wird. ${ }^{305}$ Bei der Analyse der Figuren (dem lyrischen Ich/Wir, der Gottheit oder den Feinden) wird darauf geachtet, inwieweit eine Introspektion in diese und damit der Einblick in das kognitive und emotionale Innenleben möglich sind. Dies lässt sich auf narrative Weise durch direkte Rede ausdrücken. Diese gilt als bevorzugter Ort, an dem die Gefühls- und Gedankenwelt der Figuren den Lesenden zugänglich gemacht wird. ${ }^{306}$ Der direkten (oder auch erlebten) Rede ist Unmittelbarkeit

302 Eder, Die Figur im Film, 638.

303 Jens Eder unterscheidet fünf Arten imaginativer Nähe zu einer Figur: raum-zeitliche Nähe, kognitive Nähe durch Verstehen und Perspektivenübernahme, soziale Nähe durch Vertrautheit, Ähnlichkeit und Gruppenzuordnung, parasoziale Interaktion und emotionale Nähe. Vgl. Eder, Die Figur im Film, 638.

304 Zur narratologischen Analyse atl. Texte vgl. u. a. Müllner, Zeit; Müllner, Gewalt; Schmidt, Zentrale Randfiguren; Gillmayr-Bucher, Erzählte Welten; Eder, Frauen und Männer.

305 »In der poetischen Gestalt eines Psalms wird die Erlebnisabfolge nicht wie in einer Erzählung linear, d. h. temporal und kausal, dargestellt. Psalmen sind vielmehr hochgradig strukturierte Gebilde, die in zyklisch-repetierender Weise erschlossen werden.« Weber, Psalm 30, 40.

306 Vgl. Müllner, Gewalt, 54. 
eigen. Die direkte Rede ist damit zeitdeckend, d. h. Erzählzeit und erzählte Zeit fallen zusammen. Gleichzeitigkeit stellt sich ein und die Lesenden haben keine andere Möglichkeit, als "stehen zu bleiben « und in die jeweilige Perspektive der sprechenden Figur zu schlüpfen. „Das Wiedergeben von Gedanken in der erlebten Rede ist sonderbarerweise die unmittelbarste Form der Wiedergabe von Gedanken. Es entsteht ein Band zwischen dem Erzähler und der Erzählfigur und damit zwischen dem Leser und der Erzählfigur. Die Wiedergabe von Gedanken in der erlebten Rede verringert die Distanz zwischen der Erzählfigur und dem Leser optimal und ist ein wichtiges Mittel für Identifikation. ${ }^{307}$ Die direkte Rede mit der Möglichkeit der Innensicht einer Figur, im Falle der Psalmen hauptsächlich jener des lyrischen Ich/Wir, birgt demnach ein großes Identifikationspotenzial mit dem lyrischen Ich/Wir. Bei den Psalmen ist im Rahmen der direkten Rede zu unterscheiden zwischen an textinterne und an textexterne AdressatInnen gerichtete Rede; Letztere etwa an die Öffentlichkeit oder Gemeinde (z. B. Ps 30,5 oder Ps 147,1.7.20). Eine direkte Rede an textexterne AdressatInnen holt die Lesenden näher an den Text heran: »Jede direkt wiedergegebene Rede in der Erzählung gibt die Möglichkeit zur Identifikation mit den Personen der Erzählung. Das kann der Sprecher selbst sein, der Adressat oder ein Beobachter der Szene. ${ }^{308}$

\subsection{1 Übergänge und Verbformen}

Im Rahmen der Textdynamik ist neben der Ebene des Mitgehens mit der Figur (Analyse der Figuren, der Räume und Bewegungen, der Zeitangaben und Zeiträume sowie der Subjekt- Objekt-Konstellationen) auch jene Ebene essentiell, die die Lesenden im Textgeschehen hält und ein Hinausfallen aus dem Leseprozess verhindert. Daher wird gefragt, wie die Übergänge innerhalb der Verse sowie zwischen den Versen und den einzelnen Szenen bzw. Minierzählungen gestaltet sind: Gibt es abrupte Übergänge oder Asyndesen? ${ }^{309}$ Gibt es fließende Übergänge, die die einzelnen Halbverse, Verse und Szenen mehr oder weniger harmonisch miteinander verbinden? Wenn ja, wie werden sie grammatikalisch bewerkstelligt?

307 Walravens 1980, 183, zitiert nach Schram, Norm, 153.

308 Seybold, Poetik der erzählenden Literatur, 283.

309 »Unter Asyndese pflegt man die Erscheinung zu verstehen, dass in auffallender Weise zwischen zwei oder mehr Wörtern, Ausdrücken oder (kurzen) Sätzen ein Bindewort fehlt. Im AT, namentlich in den poetischen Texten, kommt es vielfach vor, dass verschiedene Aussagen unvermittelt nebeneinandergestellt werden. Bei den hier gemeinten Fällen handelt es sich nicht so sehr um ein auffälliges Fehlen eines Bindewortes, sondern es verhält sich wohl so, dass der Zuhörer, der Leser selbst herausfinden muss, welcher Art die Verbindung zwischen den betreffenden Aussagen ist.« Ridderbos, Die Psalmen, 107. 
Durch Konjunktionen, Relativpronomen, den Artikel, Stichwortverbindungen o. a.?

An dieser Stelle sind auch die Verbformen zu nennen, durch die Handlungen auch miteinander verbunden werden können. Diethelm Michel ist 1960 dem Zusammenhang zwischen den SK- und PK- bzw. W-PK-Formen in den Psalmen nachgegangen und zu dem Ergebnis gekommen, dass die genannten Formen zunächst einmal keine eindeutigen Zeitstufen (Vergangenheit, Gegenwart, Zukunft etc.) ausdrücken. ${ }^{310}$ Nach Michel stellt die SK-Form eine eigenständige, punktuell und absolut gesetzte sowie eigengewichtige Handlung dar und führt autonome Fakten an. Die PK-Form dagegen wird von Michel als Folgehandlung betrachtet, die relativ und von einem anderen Sachverhalt abhängig ist und diesen fortführt. ${ }^{311}$ Die W-PK-Form ist noch enger an die vorangehende Handlung geknüpft. ${ }^{312}$

Diese eindeutig scheinenden Ergebnisse, die für den einen oder anderen Psalm zutreffen können (vgl. IV Textanalyse Psalm 30), werden in neueren Ansätzen jedoch kritisch betrachtet. Frank Matheus hält in seiner Studie über Tempus und Aspekt im biblisch-hebräischen Verbalsystem zunächst fest, dass es sich bei biblischen Texten im linguistischen - nicht jedoch im theologischen Sinn immer um vergangene und abgeschlossene Ereignisse und Sachverhalte handelt. Bei der Rezeption biblischer Texte, deren Wirkungsgeschichte und Auswirkungen bis heute reichen, erwartet Lesende zunächst die Vergangenheit. ${ }^{313}$ Matheus unterscheidet zwischen vier temporalen Komponenten: (1) Topikzeit oder Textzeit als Zeit im Text, als die Zeitspanne, die in der Äußerung beschrieben wird; (2) Situationszeit (oder -zeiten) als die Zeit, in der ein Ereignis mit seinen einzelnen Bestandteilen tatsächlich stattfindet; ${ }^{314}$ (3) Äußerungszeit als Zeit der Textverfassung, die die Niederschrift meint, und (4) Rezeption als Zeit der Texterfassung. Während die Zeit der Niederschrift und die Rezeption auBerhalb des Textes liegen, kann die Situationszeit sowohl innerhalb des Textes als auch außerhalb liegen. ${ }^{315}$ Die zeitliche Lage eines Textes ergibt sich aus dem

310 Vgl. Michel, Tempora, 41. Zustimmend dazu auch Matheus, Zeit, 421.

311 Vgl. Michel, Tempora, 21f.126. Die PK kann dabei durativ, modal und iterativ sowie als Ausdruck des Begehrens verwendet werden. Matheus, Zeit, 278 sieht hingegen in der PK weder eine Abfolge noch einen Fortschritt oder eine Verkettung von Ereignissen.

312 Vgl. Michel, Tempora, 137.

313 Vgl. Matheus, Zeit, 97.

314 „Situationszeit(en): die einzelnen mit der Textwelt verbundenen Bestandteile einer Ereignisstruktur oder ihrer Summe. Beispiele: einen Brief schreiben, sich die Zähne putzen - es wird alles getan, was dazu gehört, um einen Brief zu schreiben oder sich die Zähne zu putzen, wobei die Ereignisstruktur durchaus je unterschiedlich sein kann." Matheus, Zeit, 11.

315 Vgl. Matheus, Zeit, 68-90. 
Zusammenspiel von Topikzeit, der Ereignisstruktur und den dazu gehörenden Situationszeiten. ${ }^{316}$

Frank Matheus differenziert in seiner Analyse des hebräischen Verbalsystems zwischen Verbformen in der erzählten Welt (erzählende Texte) und jenen in der besprochenen Welt (besprechende Texte). Letztere gliedert er, den Kategorien aus der Sprechakttheorie folgend, in Assertiva, Direktiva, Kommissiva, Deklarativa und Expressiva, wobei er die Psalmen der letzten Kategorie zuordnet. Bereits in seiner Einleitung zur gesamten Studie verweist er mit Ps 57,2 auf die Problematik der Übersetzung in die geeignete Zeitstufe und damit auf das sogenannte Tempusproblem in den Psalmen, die sich einer klaren Typisierung des hebräischen Verbalsystems zu entziehen scheinen. ${ }^{317}$ So sind gerade in den Psalmen die Strukturen SK und PK austauschbar, »sodass eine genaue Zuordnung allein durch die Verbformen kaum gelingt. $\aleph^{318}$ Nach Matheus wird daher die Zeitstruktur gerade in den expressiven Texten der Psalmen durch eine genaue Analyse der Topik- und Situationszeiten gewonnen, wobei die Grundfunktionen der Konjugationen durchaus bestehen bleiben. ${ }^{319}$ Eine exakte Beobachtung der Zeitstrukturen mit Hilfe der genannten Analysekategorien Topikzeit und Situationszeiten kann im Rahmen dieser Arbeit zwar nicht geleistet werden. Allerdings werden die folgenden Elemente, die sich zur Klärung vieldiskutierter Fragen der Übersetzung in die »adäquate« Zeitstufe (Ps 90; 64) als hilfreich erweisen, für die Textanalyse herangezogen:

Bei besprechenden Texten ist zentral, dass der sich äußernde Mensch selbst der Bezugspunkt ist: »Das textemittierende Subjekt ist der Angelpunkt, von dem aus gesehen Dinge in der Zeit geschehen. Sind es in erzählenden Texten die Ereignisse selbst, die ihre Dynamik in der betrachteten Zeit entfalten (moving events), so steht hier der Mensch im Mittelpunkt, der sich durch seine Äußerungen in der Zeit bewegt und sein Gegenüber an der Reise teilnehmen lässt (moving ego). « ${ }^{320}$ Für den Wechsel in den Narrativ und die unterschiedlichen Übersetzungen, wie dies etwa in Ps 64,8ff der Fall ist, gilt damit, dass das sprechende Ich in den Modus des Erzählens wechselt und die Ereignisse, von denen es berichtet, von seiner Perspektive aus gesehen in der Vergangenheit liegen. ${ }^{321}$

316 Vgl. Matheus, Zeit, 78 .

317 Vgl. Matheus, Zeit, $13 \mathrm{f}$.

318 Matheus, Zeit, 421.

319 Vgl. Matheus, Zeit, 421.

320 Matheus, Zeit, 274.

321 »Welche Zeitlage- oder -ablaufverhältnisse im Text existieren, ergibt sich allein aus der spezifischen Zeitstruktur einer Proposition und dem Kontext, in den sie gerät. Lediglich gegenüber dem Rezipienten signalisiert waw-PK Abgeschlossenheit und Vergangenheit und damit den Modus bzw. die Gesprächshaltung >Erzählenı. Die waw-PK lässt die Rezipierenden erkennen, dass die geschilderten Ereignisse zum Äußerungszeitpunkt der Vorwelt 
Die SK kann in der besprochenen Welt als Teil der Topikzeit auf Vergangenes oder aber Gegenwärtiges verweisen. ${ }^{322}$ Dies wird vor allem in Ps 90,7-10 sichtbar. Soll im Bibelhebräischen in besprechenden Texten ein Vergangenheitsbezug hergestellt werden, dann wird das mit der SK bewerkstelligt: »Auch das Hebräische kennt eine spezielle Form für den Vergangenheitsbezug eines moving ego; es ist die Suffixkonjugation «. ${ }^{323}$ Liest man diese als Perfekt-Implikatur, so verweist sie auf Ereignisse und eine Situationszeit, die vor der Topikzeit liegt. Die Ereignisse der Situationszeit(en) wirken bis in die Topikzeit nach. ${ }^{324}$ Dies kann für Ps 90,7-10 zutreffen. Für Ps 90 gilt jedoch wie für alle anderen Psalmen auch, dass bei der Übersetzung der einzelnen Verse immer auch der Kontext eine Rolle spielt. Es ist daher sinnvoll, zu überlegen, welche (Zeit-) Dimensionen vor bzw. nach dem jeweiligen Vers eröffnet werden und wie sich diese in den Gesamtduktus des Psalms einfügen.

Für das Identifikationspotenzial in Bezug auf die Textdynamik gilt: Je leichter die raum-zeitliche Anbindung an die Figuren im Text, vor allem an das lyrische Ich/Wir gelingt, umso größer ist das Identifikationspotenzial. Je harmonischer die Übergänge zwischen den einzelnen Versen und Szenen gestaltet sind, umso leichter ist es, im Leseprozess zu bleiben. Noch besser ist es, wenn dieser durch den Spannungsaufbau noch zusätzlich intensiviert wird, weil dadurch das Interesse am Text bestehen bleibt.

\subsubsection{Zeitfaktor beim Lesen: Parallelismus und weitere Stilmittel}

Nach Katja Mellmann ist die emotionale Wirkung eines Textes und damit die Möglichkeit der Identifikation umso höher, je mehr Zeit Lesende für ihre Vorstellungsarbeit verwenden können bzw. müssen. Dieser für die Imagination notwendige Zeitaufwand wird durch die Textbeschaffenheit bestimmt. ${ }^{325}$ Für die Psalmen sind hinsichtlich des Zeitfaktors beim Lesen nicht nur die Sprachbilder und Leerstellen von Bedeutung, die eine produktive Eigenleistung der Lesenden verlangen - wenn Lesende sich selbst ein Bild machen müssen, ist mehr Zeit notwendig -, sondern auch die Parallelismen. Dieses in der altorientalischen Dichtung bevorzugte Stilmittel der Wiederholung verlangsamt den Leseprozess und bewirkt, dass die Lesenden länger bei einem Gedanken bleiben (müssen). Hierdurch wird dem geäußerten Sachverhalt Nachdruck verliehen: »Es scheint, dass noch die drängendsten Gebetsrufe und verzweifelsten Klagen - man muss

angehören.« Matheus, Zeit, 147. Die W-PK macht auch keine Aussage über eine abgeschlossene oder nicht abgeschlossene Handlung.

322 Vgl. Matheus, Zeit, 401.

323 Matheus, Zeit, 274.

324 Vgl. Matheus, Zeit, 402.

325 Vgl. Mellmann, Emotionalisierung, 58. 
sagen: zumindest bei der Aufzeichnung - sich des Parallelverses bedienen. Und natürlich hatte diese Form den Vorteil, das Beklagte, Erbetene, Gepriesene durch Wiederholung mit Nachdruck vorzubringen oder nachzuvollziehen. ${ }^{326}$

Die Kompositionstechnik, in der zwei Sätze einander auf unterschiedliche Weise zugeordnet sind, aktiviert Denkvorgänge, unterstreicht und verstärkt Sinnaussagen und eröffnet eine breitere und tiefere Perspektive auf ein- und dieselbe Sache. ${ }^{327}$ "Im Hintergrund steht dabei die - für unser modernes und westliches Denken eher fremde - Einsicht, dass sich die Realität eigentlich nie mit einer einzelnen Aussage abbilden lässt, sondern dass es darauf ankommt, eine Sache aus (mindestens) zwei Perspektiven oder auch durch die Hinzusetzung ihres Gegenteils zu beleuchten. ${ }^{328}$ Unterschieden wird u. a. zwischen synonymen, synthetischen und antithetischen Parallelismen. ${ }^{329}$ Beim synonymen Parallelismus variiert die sprachliche Gestaltung beider Sätze nur leicht, und zwar durch Beibehaltung bzw. Wiederholung der gleichen Aussage. Dadurch entsteht der Eindruck des Festhaltens der Aussage, ihrer Vertiefung und Verstärkung. Es geht darum, sich der Aussage länger zu widmen oder sich dem Aussagekern schrittweise zu nähern. Im synthetischen (ergänzend, weiterführend) Parallelismus ist der Gedanken- und Aussagefortschritt deutlich erkennbar. Im zweiten Satz wird der angefangene Gedanke weitergeführt, meist im Sinne einer Steigerung zu einem neuen Gedanken hin. Beim antithetischen Parallelismus ist der Inhalt der beiden Glieder entgegengesetzt. Der zweite Satz steht im Gegensatz zum ersten. Durch Kontraste und Entgegensetzungen bleibt eine Aussage nicht eindimensional stehen, sondern sie wird mehrschichtig und plastisch. Robert Alter spricht im Zusammenhang mit dem Parallelismus von einer Sinnbewegung, die auf Steigerung, Intensivierung, Fokussierung, Spezifizierung und Konkretisierung bis hin zur Dramatisierung ausgerichtet ist. ${ }^{330}$ Daher wird im Rahmen der

326 Seybold, Poetik der Psalmen, 98f. Ridderbos, Die Psalmen, 43 spricht davon, dass die Dichter mittels des Stilprinzips der Wiederholung ihren Zuhörenden »eine bestimmte Vorstellung, einen bestimmten Gedanken gleichsam einhämmern« wollen.

327 Vgl. Seybold, Poetik der Psalmen, 85. „Parallelism in turn has the function of emphasis since its repetitive nature underlines what is said; while it also gives a broader or deeper perspective by providing >stereo vision. « Botha, Strategy, 71.

328 Schnocks, Psalmen, 13.

329 Damit folge ich der Unterscheidung von Robert Lowth, der den Begriff im 18. Jh. erstmals ausführlich behandelt hat. Seitdem wurde der Parallelismus weiter ausdifferenziert und laufend erweitert. Vgl. dazu Horst, Kennzeichen, 100, und Seybold, Poetik der Psalmen, 85. Hinsichtlich des synthetischen Parallelismus, welcher bei Lowth als Restkategorie für die Fälle gilt, die sich weder in den synonymen noch den antithetischen Parallelismus einordnen lassen, stellt sich die Frage, welche Elemente noch als Parallelsetzung zu betrachten sind. Vgl. Seybold, Poetik der Psalmen, 86.

330 Vgl. Alter, Art, 20. Auf die dynamische Dimension des Parallelismus verweist Wagner, Parallelismus, 252. Er führt im Rahmen der zentralen noetischen Leistungen des Parallelismus neben der Plastizität und Bi- bzw. Multiperspektivität auch jene der Dynamik in- 
Analyse der Parallelismen neben dem Zeitfaktor auch die Art und Weise der Steigerung bzw. Spezifizierung und Konkretisierung der Gedanken und Sachverhalte erkundet, indem folgenden und ähnlichen Fragen nachgegangen wird: Erfährt der Vers in der zweiten Aussagehälfte eine Dynamik, indem eine Bewegung vom Allgemeinen zum Speziellen bzw. Konkreten, vom Wörtlichen zum Bildlichen, von der Weite in die Nähe, von größeren räumlichen und zeitlichen Einheiten zu kleineren, von außen nach innen oder von oben nach unten feststellbar ist? Sind Wiederholungen auszumachen, und wenn ja, wie sind diese zu deuten? Oder ist von einer statischen Synonymität zu sprechen?

Weitere Stilmittel, die u.a. in der poetischen Analyse zur Anwendung gelangen, sind Inklusion, Leitwörter, Kontraste und last but not least Klangmalerei, Rhythmus und onomatopoetische Gestaltung. Unter Inklusion ist zu verstehen, dass es zwischen dem Anfang und Ende eines Gedichts oder eines seiner Teile einen Zusammenhang gibt (z. B. Ps 30; Ps 90). ${ }^{331}$ Unter einem Leitwort wird ein Wort oder Wortstamm verstanden, der sich innerhalb einer Textstruktur sinnreich wiederholt. Die Bedeutung des Textes wird durch das Folgen der Leitwörter verdeutlicht (z. B. Loben in Ps 30). ${ }^{332}$ Kontraste können als Identifikationspotenziale wirken (vgl. VII Textanalyse Psalm 64), da sie durch die Abgrenzung gegen die einen (Feinde) gleichzeitig zur Identifikation mit dem anderen (Gerechten) einladen. ${ }^{333}$

Schlussendlich gilt der Blick dort, wo dies auffällig ist, der rhythmischen Gestaltung durch Metrum, Klangfarbe und Lautmalerei, die als A-emotions ihre Wirkungen entfalten (z. B. Ps 147).

Für das Identifikationsphänomen ist an dieser Stelle festzuhalten: Es ist umso höher, je offensichtlicher Parallelismen den Psalm prägen und die Lesenden durch diese Kompositionstechnik eingeladen werden, länger am Text zu bleiben und durch Konkretisierung, Intensivierung und Dynamisierung tiefer in die

nerhalb des Denkens an und spricht dabei von einer »Eröffnung eines Erkenntnisraumes, in dem sich das Verstehen hin und her bewegen kann und das damit eine dynamische Dimension hat.«

331 Vgl. Ridderbos, Die Psalmen, 35.

332 Vgl. Ridderbos, Die Psalmen, 20. Ebenso Watson, Hebrew Poetry, 267.

333 »Wenn ein Autor zwei oder mehr Wörter oder Aussagen mit entgegengesetztem Inhalt dicht nebeneinander gebraucht, können wir von einer Antithese, der Stilfigur des Gegensatzes, des Kontrastes, sprechen. Bei der Behandlung der Stilfigur des Gegensatzes, des Kontrastes in den Psalmen ist zweierlei zu beachten. Zunächst muss berücksichtigt werden, dass der Mensch im allgemeinen für die Wirkung des Gegensatzes, des Kontrastes empfänglich ist. Eine Farbe fällt besonders auf, sticht besonders hervor, wenn sie von anderen, mit ihr kontrastierenden Farben umgeben ist. [...] Sodann ist zu bedenken, dass der Stoff, den die Psalmen behandeln, reich an Gegensätzen ist. Die Psalmen sprechen von Gerechten und Gottlosen, von Segen und Fluch, von göttlicher Bewahrung und göttlicher Strafe, von Glück und Unglück, von Not und Errettung, von dem Handeln des großen, heiligen Gottes und dem des nichtigen, sündigen Menschen.« Ridderbos, Die Psalmen, 53. 
Textwelt einzutauchen. Durch rhythmische und klangliche Gestaltung kann das Identifikationspotenzial nochmals erhöht werden.

So weit zum Methodenkapitel. Die darin erörterten zentralen Analyseschritte werden zu Beginn des folgenden Kapitels - und damit vor der ersten Textanalyse - nochmals ausgewiesen. 
Open-Access-Publikation im Sinne der CC-Lizenz BY-NC-ND 4.0

(c) 2019, V\&R unipress GmbH, Göttingen 


\section{Textanalyse Psalm 30}

Die Untersuchungen von Ps 30; 147; 90 und 64 folgen zunächst dem Inhalt, der Kommunikationsstruktur, der Gliederung und den Aussageabsichten des Psalms einschließlich der Analogiebildungsmöglichkeiten (vgl. III Methodik 1). Daran schließt sich die Vers-für-Vers-Analyse an. Hier werden zunächst wesentliche syntaktische, semantische und textkritische Fragestellungen erörtert sowie Übersetzungsvarianten dargelegt. Danach erfolgt die Analyse explizit und implizit ausgedrückter Emotionen (F-emotions und A-emotions). Auch die Frage nach der emotionalen Quantität und Diversität sowie der Zuordnung der Emotionen zu den entsprechenden HandlungsträgerInnen wird geklärt (vgl. III Methodik 2). Danach erfolgt die Analyse der Perspektivenlenkung, wobei der Schwerpunkt auf der Fokalisierung (intern, extern, doppelt oder AdressatInnenperspektive), der Nähe und Distanz (Zoom-Effekt) sowie der Deixis (vgl. III Methodik 3) liegt. Zum Abschluss der Analyse werden die Textdynamik (Figuren, Raum/Bewegungen, Zeit, Handlungen), der Spannungsaufbau, die Übergänge, die Parallelismen (synonym, synthetisch und antithetisch) und deren Dynamik (Konkretisierung, Spezifizierung, Intensivierung etc.) sowie weitere Stilelemente (Rhythmus, Klang etc.) genauer betrachtet. Die Ausführungen zu den einzelnen Unterpunkten (1 Inhalt; 2 Emotionen; 3 Perspektiven und Textdynamik) gestalten sich je nach Psalm unterschiedlich lang, je nach dem, wieviele Hinweise daraus für das Identifikationspotenzial gewonnen werden können. Jedes Analysekapitel endet mit einer Zusammenschau und Auswertung sowie der Erhebung von Identifikationspotenzialen, die im Schlusskapitel der Arbeit (vgl. VIII Ergebnisse) nochmals ausdifferenziert werden.

Von den hermeneutischen Prämissen ist aus rezeptionsästhetischer Perspektive die Mitwirkung der Lesenden mit den entsprechenden Haltungen im Leseprozess (vgl. I Einleitung 4.2 und 4.3) bei der Textanalyse, insbesonders bei der Betrachtung der emotionalen Wirkung, von Relevanz, darüber hinaus die Möglichkeit, im lyrischen Ich/Wir des Psalms das lesende Ich zu entdecken. Dass Psalmen als Gebrauchstexte gelten - hier ist an das Konzept des Thoughtwriting zu erinnern - wird im Besonderen bei der Analyse von Ps 30 bedeutsam. Die 
Anordnung der Textanalysen entspricht dem Auswahlkriterium der unterschiedlichen Perspektiven (vgl. I Einleitung 5: Ich-Du: Ps 30; Er-Ihr: Ps 147; Wir: Ps 90; Sie: Ps 64).

\section{$1 \quad$ Inhalt}

Psalm 30 (zur Arbeitsübersetzung siehe X Anhang) erzählt von mehrmaliger Todesgefahr und dem wiederholten Rettungshandeln Gottes und kulminiert in der umfassenden Erfahrung der Wandlung des/der Notleidenden durch JHWH hin zu Freude und Tanz. Gerahmt wird dieses Danklied nach der Errettung aus Todesnot durch das Loben Gottes, das am Beginn, in der Mitte und am Ende des Psalms erwähnt wird. Aus der Perspektive der überstandenen Not und des dankbaren Lobpreises heraus verfasst, erscheint das erlittene tiefe Leid in einem besonderen Licht und wird in einem umfassenden Sinn in den Gang des Lebens eingeordnet. ${ }^{334}$

Der Psalm beginnt mit der Selbstaufforderung zum Rühmen JHWHs, das mit der Errettung begründet wird (V2). ${ }^{335}$ Dies führt zu einem ersten Rückblick, in dem der/die BeterIn von seinem/ihrem Geheiltwerden durch JHWH spricht (V34). Die Gruppe der Frommen bzw. Vertrauten JHWHs werden sodann in den Dank mit einbezogen (V5). Der/die Beterin bringt damit seine/ihre Erfahrung in die Gemeinschaft ein, gibt dieser infolgedessen Anteil an seiner/ihrer Rettung und fordert gleichzeitig ihre Mitbeteiligung am Dank. Dieser liegt in der persönlichen Erfahrung begründet, dass JHWHs Wohlgefallen und Gunst ein Leben lang Bestand haben - im Kontrast zum göttlichen Zorn, der nur einen Augenblick andauert (V6). Ein erneuter, zweiter Rückblick (V7-V12) führt über die einzelnen Stationen von Sicherheit und Glück (V7-8a), Gefahr (8b), Hilferuf (V9.11) und argumentativer Auseinandersetzung (V10) zur Erfahrung der Verwandlung (V12) sowie zum erneuten Dank (V13). ${ }^{336}$

Die Gliederung des Psalms erfolgt nach den Gliederungskriterien der abgeschlossenen Gedankengänge bzw. thematischen Einheiten sowie der Zeitachsen und dem Sprechrichtungswechsel. So ergeben sich vier Teile (V1; V2-4; V5-6; V7$\left.13^{337}\right)$. Nach der Überschrift in V1 setzt das lyrische Ich in der Ich-Form ein (2a)

334 Vgl. Kraus, Psalmen, 390; Janowski, Konfliktgespräche mit Gott, 270.

335 Vgl. Witzenrath, Am Abend Weinen, 467.

336 Der Psalm weist große intertextuelle Bezüge zu Jes 38 auf (vgl. dazu Craigie, Psalms 1-50, 251), steht mit Ps 6 in Verbindung, welcher ebenso häufig als Krankheitspsalm gelesen wird, und weist die größte Gemeinsamkeit mit dem Wortschatz von Ps 18, Ps 31 und Jona 2 auf. Siehe Witzenrath, Am Abend Weinen, 463.

337 Damit schließe ich mich der Gliederung von Kraus, Psalmen, 386 an: V1 Überschrift; V2-4 Lobpreis auf Jahwe, der den Beter aus Krankheit und Scheol errettete; V5-6 Aufruf zum 
und erzählt von der erfahrenen Rettung (2b-4). In V5-6 erfolgt ein Themenwechsel sowie ein Wechsel der Rederichtung. Ist in den vorhergehenden Versen von vergangenen Taten JHWHs und des betenden Ich die Rede (Ich-Du-Beziehung), so wird nun die Öffentlichkeit in Form der Getreuen JHWHs in den Blick genommen (Ihr), und zwar in der Sprechsituation des Hier und Jetzt. Den Imperativen pl. (V5) und der Rede über JHWH in der 3.P. (6a.b) folgen allgemein formulierte Aussagen (6c.d). Nach diesem dritten Teil (V5-6) setzt mit V7 ${ }^{338}$ wieder eine Ich-Rede ein (Sprechrichtungswechsel), die in V13 endet. Der vierte Teil des Psalms beginnt mit der Erzählung von der einstigen Sicherheit des lyrischen Ich (Themenwechsel) und blickt abermals zurück in die Vergangenheit der Not, der Gottferne, der Verhandlung mit und der Verwandlung durch Gott bis hin zur daraus folgenden Feststellung des immerwährenden Lobes Gottes (Gegenwart bzw. Zukunft) in V13. Dieser letzte Vers des Psalms schließt sich aufgrund seiner Anlage als Konsekutivbzw. Finalsatz nahtlos an den narrativen Teil (V7-12) an und beschließt damit zugleich den Psalm. Die V10-11 können als direkte Rede innerhalb des erzählenden Abschnittes von V7-12 betrachtet werden. Nach der Überschrift, die noch keinen inhaltlichen Aspekt des Psalms benennt, ist mit 2a der Beginn des Psalms knapp gehalten, während der Schluss (V13) ausführlich ist. Beide Verse sind aufeinander bezogen, da beide das Loben Gottes zum Thema haben: Während 2a aus einer Selbstaufforderung und dem Gottesnamen im Vokativ besteht, nimmt 13c die Aussage aus 2a in Variation auf und erweitert sie um eine Apposition (mein Gott) und um eine Zeitangabe (auf ewig).

Somit ist das Leitwort, das auch strukturierende Momente beinhaltet, das Verb ידה (loben): »V. 2-4 beginnen mit der Äußerung des Vorsatzes, Jahwe zu loben [hier wird das Loben allerdings mit der Wurzel רום thematisiert], v. 5 f. mit der Aufforderung zum Lobe Jahwes, v. 7-13 schließen mit der Äußerung des Vorsatzes, Jahwe zu loben. [...] Als Grund des Lobens, so können wir sagen, gibt der Autor dreimal die Erzählung seiner Not und Errettung an, siehe v. 2a $\beta-4.6$. 7-13a. In v. 6 denkt er speziell an das, was ihm selbst widerfahren ist, spricht jedoch in allgemeinen Wendungen; dieser Aussage schließt sich denn auch die an ידה verwendet. $^{340}$

Lobpreis an alle Frommen und bekenntnisähnliche Erklärung; V7-13 Schilderung der Heilung und Hilfe mit abschließendem Lobpreis. Ebenso Loader, Psalm 30, 293f: V1: Superscription; V2-4: Quasi-Hymn; V5-6: Interjunction; V7-13: „Story«. Der Psalm wird durchaus auch in zwei Phasen (V2-6; 7-13) eingeteilt; vgl. Ridderbos, Die Psalmen, 84. Zu weiteren Gliederungen von Psalm 30 vgl. Ridderbos, Die Psalmen, 223 Anm. 2. In zwei große Teile (I Danklied des Einzelnen V2-6; II Rückblick auf die Not V7-13) mit kleineren Untergruppen gliedert auch Janowski, Konfliktgespräche mit Gott, 269.

$338 »$ The conspicuous and quasi-redundant $w a^{a a} n i$ at the beginning of v.7 indicates a break." Fokkelman, Major Poems, 122.

339 Ridderbos, Die Psalmen, 223. Zur Position des Schlüsselwortes »loben« in Ps 30 ergänzt 


\subsection{Stimmen und Rederichtungen}

In V1 tritt mit der Überschrift eine anonyme Sprechstimme in Aktion. In V2-4 wird vom lyrischen Ich gesprochen. V5 wechselt mit der Anrede an die Frommen die Sprechrichtung hin zur AdressatInnenperspektive. Von V7-13 an übernimmt wiederum das lyrische Ich die sprechende Rolle. Innerhalb des Textes ist zwar ein Wechsel der Sprechrichtung in Bezug auf die Gottesanrede (Ich-Du), die Aussagen über Gott (Er-Ich) und die Anrede an die Gruppe der Frommen (Ihr) auszumachen, ein klarer Sprecherwechsel ist allerdings nicht festzustellen, wodurch sich die Annahme einer durchgehenden Sprechstimme des lyrischen Ich ergibt.

Das dialogische Setting dieses Psalms ist offensichtlich. Dabei ist diese Rede in ein Danklied (Toda; תiָֹדה) gegossen, was sich aus den Verweisen auf die entsprechende Textgruppe erschließen lässt. ${ }^{341}$ Christof Hardmaier sieht gerade in der Diskursdynamik der Toda einen elementaren Kristallisationspunkt biblischer Theologie. So konstituiert sich gerade im Diskursgeschehen und Prozess der Toda die Beziehung zwischen Gott und Mensch immer wieder neu und "gibt sich zugleich weiter. ${ }^{342}$ Die Weitergabe dieser Gott-Mensch-Beziehung im Diskursgeschehen ist den Psalmen gleichsam als Wesenszug inhärent. So dient gerade auch das im Psalm 30 textlich festgehaltene Gespräch mit, zu und über Gott als Gebrauchstext bzw. Formular ${ }^{343}$ für einstige und heutige Lesende: »Doch wird

Craigie, Psalms 1-50, 252: «At each point in the psalm, the expression of praise is rooted in the memory of recent deliverance from death and of the removal of tears and grief.« Zum Leitwortcharakter von ידה bemerkt Ridderbos, Die Psalmen, 224: „Das Schlüsselwort dieses Psalms, ידה, ist auch das Schlusswort."

340 Dabei ist diesem Loben in 10c mit dem Vorverweis auf V13 und dem Rückverweis auf V2 eigene Aufmerksamkeit zu schenken: »Man beachte vor allem v. 10 und v. 13a: In seiner Not führt der Dichter an, v. 10, dass das Loblied auf Jahwe ausbleiben wird, wenn ihm nicht geholfen wird; und in v. 13a heißt es: Jahwe hilft, weil sein Lob ständig erklingen muss (rauf dass`). In diesem Licht muss auch v. $2 \mathrm{~b}$ gesehen werden: wird der Dichter nicht gerettet, so haben seine Feinde, die zugleich die Feinde Jahwes sind, Grund zu jubeln; das aber tut der Ehre Jahwes Abbruch.« Ridderbos, Die Psalmen, 224.

341 Psalm 30 wird gattungskritisch als Danklied eines aus Todesgefahr Genesenen (vgl. Weber, Werkbuch 1, 150), als Lobdank, als Danklied des Einzelnen, in dem sich Gebet (zu Gott) und Bezeugung (gegenüber der Gemeinde) verbindet (vgl. Weber, Psalm 30, 33), als Danklied und Bekenntnis (»Psalm 30 is a textbook example of a thanksgiving or testimony psalm.» Goldingay, Psalms 1, 424), als individuelles Danklied mit hymnischen Zügen (vgl. Groß / Reinelt, Das Buch der Psalmen, 172.) etc. betrachtet. Anders Wilson, Psalms, 514, der Ps 30 in die Klagelieder einreiht:»[Ps 30] is a lament or plea for deliverance.« Zur Literarkritik siehe z.B. Kraus, Psalmen, 386; Spiekermann, Heilsgegenwart, 257. Zum Bezug der zị zum möglichen Kult und zum rituellen Rahmen vgl. Janowski, Konfliktgespräche mit Gott, 284294. Ebenso Weber, Psalm 30, 45. Fohrer, Psalmen, 224 verortet den Sitz im Leben von Ps 30 im nachexilischen Tempelgottesdienst.

342 Hardmeier, Systematische Elemente, 339.

$343 \mathrm{Zu}$ den Psalmen als Gebrauchstexte bzw. Formulare vgl. Kapitel I Einleitung 4.1.5. 
zu bedenken sein, dass der Psalm nicht ein Einzelschicksal schildert, sondern als Formular denjenigen gedient hat, die ein den umfassenden Gebets- und Dankaussagen entsprechendes Rettungsgeschehen erlebt haben und nun im Bereich des Heiligtums Jahwe danken. In diesem Formular konnte sich manches Lebensschicksal unterbringen und finden: In der Erkenntnis und Aussage der Tiefe der Not und im Bekenntnis des Dankes für die erfahrene Rettung. ${ }^{344}$ Durch dieses Charakteristikum der Gebetsvorlage kann Psalm 30 auch heutigen LeserInnen in ihren tiefen Nöten, in ihren Auseinandersetzungen mit Gott sowie auch in Phasen der vermeintlichen Selbstsicherheit und des Glücks und schließlich in jenen des Übergangs und der Verwandlung durch Gott hin zu Lebensfreude und Jubelrufen ein Formular bieten, indem sie in diese uralten Worte ihre ganz aktuellen Anliegen hineinlegen und vor Gott bringen können.

Auffällig sind in Ps 30 die vielfachen direkten Anreden an JHWH (7x) und die dichte Beziehungskonstellation zwischen dem betenden Ich und der Gottheit (Ich-Du). Festzuhalten ist daher, dass »das `Du welchem das >Ich ` des lobenden und dankenden Beters gegenübersteht. ${ }^{345}$ Nur V5-6 fallen mit den Imperativen pl. und der Rede über Gott in der 3.P. aus diesem Rahmen. ${ }^{346}$

Neben der Gottheit werden einzig noch die Getreuen bzw. Frommen direkt angeredet. Neben der signifikanten Rederichtung zu JHWH hin ist deshalb eine zweite hin zu einer Öffentlichkeit festzustellen. Sehr oft wird die Gottheit Israels mit ihrem Eigennamen angeredet: In V2-4 erfolgt dies drei Mal nacheinander: JHWH (2a), JHWH, mein Gott (3a) und JHWH (4a). In V5f entfallen die Vokative an JHWH, dagegen wird über JHWH gesprochen. In V7-13 sind direkte Anreden an JHWH (8a; 9a) und an Adonaj (9b) offensichtlich. In V11 steht JHWH im Vokativ zwei Mal dicht nebeneinander (11a.b), und in V13 erscheint nochmals JHWH, mein Gott. Insgesamt kommt der Gottesname in Psalm 30 zehn Mal vor, davon sieben Mal in Form von JHWH, zwei Mal in der verstärkten Form als JHWH, mein Gott und ein Mal als Adonaj. ${ }^{347}$ Die vielen direkten Anreden an Gott

344 Kraus, Psalmen, 388. »Ps 30 diente zunächst und vor seiner Eintextung in den Psalter als Buch aller Wahrscheinlichkeit nach als `Formular` für die rituell-liturgische Begehung der >Toda am Heiligtum, « vermerkt Weber, Psalm 30, 36. Ähnlich Fohrer, Psalmen, 224: »Gewiss ist das Lied sehr persönlich gehalten, tatsächlich aber geht es um einen Fall, der wohl recht häufig war und für den man es als feststehendes Formular verwendete."

345 Spieckermann, Heilsgegenwart, 255.

346 Zusammenfassend gilt: "2a-4b; $7 \mathrm{a}-13 \mathrm{c}$ sind durch die ePP der 1. und 2. ps zusammengehalten. $5 \mathrm{ab}$ und 6a-d entfallen die ePP der 1. und 2. ps sg. Das ePP 3.ps in 6ab ist auf den Vok Jahwe in 5 a rückbezogen. Jahwe wird also nicht an-, sondern in der 3. ps besprochen. $5 \mathrm{ab}$ ist an Menschen addressiert. 6a-d liegt kein auf Menschen bezogenes ePP vor. Somit bewegt sich 2a-4b; 7a-13c zwischen Jahwe und dem Beter; 5ab zwischen dem Beter und den Frommen; 5b; 6ab ist im ePP 3.ps, 5a in der PV auf Jahwe Bezug genommen." Witzenrath, Am Abend Weinen, 462.

347 Vgl. Ridderbos, Die Psalmen, 224. 
(V2, V3, V4, V8, V9, V11, V13) unterstreichen den Charakter einer »eminent persönlichen Rede, ein[es] Gebet[s] zu Jahwe. ${ }^{348}$ Sie verleihen dem Psalm nicht nur den Charakter der Eindringlichkeit, sondern bewirken auch eine Entschleunigung des narrativen Fortgangs. Die direkten Anreden bewirken eine Form der Unmittelbarkeit, die es den Lesenden erleichtert, in die Perspektive des lyrischen Ich zu schlüpfen. Aber nicht nur die (zeitdeckenden) direkten Reden des Psalms ermöglichen das Involvieren der LeserInnen in das Textgeschehen. In Bezug auf die zweite Rederichtung an die Öffentlichkeit (V5f) ist hinsichtlich der Involviertheit festzuhalten: »Hier ist die Stelle des Gedichts, an der der Hörer und Leser aufgefordert wird, sich das Vorgetragene nicht bloß passiv-kühl ıanzuhören', sondern sich von der gleichen Begeisterung erfassen zu lassen. Der Dichter fordert seinen Hörer und Leser auf, das zu tun, was an sich schon jedes Gedicht bei seinem Hörer und Leser erreichen will: sich seine Gefühle und Stimmungen zu eigen zu machen. ${ }^{349}$

\subsection{Gliederung}

\begin{tabular}{|l|l|l|l|l|}
\hline Vers & Themen & Zeitachse & Sprechstimme & Sprechrichtung \\
\hline 1 & $\begin{array}{l}\text { Lied, Hauseinweihung, } \\
\text { David zugehörig }\end{array}$ & $\begin{array}{l}\text { anonyme } \\
\text { Sprechstimme }\end{array}$ & \\
\hline $2-4$ & $\begin{array}{l}\text { Selbstaufforderung } \\
\text { zum Lob; erfahrene } \\
\text { Rettung }\end{array}$ & $\begin{array}{l}\text { Jetzt (PK); } \\
\text { Rückblick (SK; } \\
\text { W-PK) }\end{array}$ & lyr. Ich & $\begin{array}{l}\text { Ich-Du (JHWH) } \\
\text { bzw. Du-Ich }\end{array}$ \\
\hline 5-6 & $\begin{array}{l}\text { Aufforderung zum } \\
\text { Lob; Zorn Gottes vs. } \\
\text { Wohlgefallen; Weinen } \\
\text { und Jubel }\end{array}$ & Jetzt (Imp.; PK) & $\begin{array}{l}\text { lyr. Ich oder } \\
\text { Sprechstimme }\end{array}$ & $\begin{array}{l}\text { Ihr; über JHWH } \\
\text { in der 3.P. }\end{array}$ \\
\hline $7-13$ & $\begin{array}{l}\text { Selbstsicherheit; Zu- } \\
\text { wendung JHWHs vs. } \\
\text { Gottferne; } \\
\text { Verhandlung mit Gott, } \\
\text { Hilfeschrei; } \\
\text { Verwandlung durch } \\
\text { JHWH; Immerwähren- } \\
\text { des Gotteslob }\end{array}$ & $\begin{array}{l}\text { Rückblick (SK; } \\
\text { PK; W-PK); } \\
\text { Zukunft (PK) }\end{array}$ & lyr. Ich & $\begin{array}{l}\text { Ich-Du bzw. } \\
\text { Du-Ich }\end{array}$ \\
\hline
\end{tabular}

348 Witzenrath, Am Abend Weinen, 462.

349 Krinetzki, Psalm 30, 351. 


\section{Emotionen}

Bei der Analyse der Emotionen (siehe III Methodik 2) werden zunächst explizite Emotionswörter in den Blick genommen. Zwei weitere Elemente der Emotionsanalyse sind die Untersuchung der Bildersprache sowie die der impliziten Emotionen, wobei hier vor allem die Syntax eine Rolle spielt.

\subsection{Vers 1: Überschrift}

Ein Psalm. Ein Lied zur Einweihung des Hauses. Im Geiste Davids.

Die Überschrift ${ }^{350}$ hat mit dem Psalm, der als Danklied für die individuelle Errettung aus Todesnot bezeichnet werden kann, inhaltlich nichts gemeinsam. Sie verweist auf jene Situation, in der das Lied vorgetragen wurde, und kann, dem biblischen Erzählzusammenhang entsprechend, mit Situationen aus dem Leben Davids in Verbindung gebracht werden. Diskutiert wird u. a., worauf sich der Begriff בִּיָּ (Haus; Tempel) ${ }^{351}$ bezieht. Wäre damit der Tempel gemeint, bliebe zu fragen, um welchen es sich hier handeln sollte.

Die Verwendungssituation ist das Chanukkafest, das an die Wiedereinweihung des Tempels durch Judas Makkabäus 164/63 v. Chr. erinnert (1 Makk 4,52ff; 2 Makk 10,1 ff; Joh 10,22 verweist auf das Tempelweihfest). ${ }^{352}$ Ps 30 wird beim Chanukkafest seit einem nicht genau festlegbaren Zeitpunkt liturgisch verwen-

350 Zur Überschrift von Ps 30 vgl. Herkenne, Das Buch der Psalmen, 126f; Cohen, The Psalms, 85; Terrien, The Psalms, 282 und Oeming, Das Buch der Psalmen, 180. In der Psalmenforschung besteht weitgehend Konsens darüber, dass die Psalmüberschriften nachträglich zum Psalmkorpus hinzugefügt wurden, und zwar im Sinne einer »midraschischen Interpretation «, die eine erste Leserichtung vorgibt.

351 Oeming stellt in seinem Kommentar die Frage, ob das Haus als Metapher für den Körper steht und infolgedessen der gesamte Psalm als Lied über die Neuschaffung bzw. Wiederherstellung eines kranken Körpers gedeutet werden sollte. Vgl. Oeming, Das Buch der Psalmen, 182. Goldingay, Psalms 1, 425 verweist darauf, dass der Inhalt des Textes besser auf die Einweihung eines individuellen Hauses zu beziehen ist (Dtn 20,5) als auf einen Tempel. Am häufigsten wird חִ חִגָָּּה laut Wilson, Psalms, 514 mit der Einweihung des Altars in Verbindung gebracht (vgl. mit Num 7,10.11.84.88 und $2 \mathrm{Chr} 7,9$ ).

352 Eventuell ist der Psalm aus einer individuellen Erfahrung heraus verfasst und erst danach dem Tempelweihfest liturgisch zugeordnet worden. Vgl. dazu Kraft, Strophic Structure, 84. Ähnlich McCann, Psalms 795. Hupfeld, Die Psalmen, 458 verweist auf das Chanukkafest, das wzugleich als Dankfest für die unerwartete Errettung von der drückenden Syr. Oberherrschaft, die unter Antiochus Epiphanes die nationale Existenz Israels u. den Bestand seiner Religion zu vernichten drohte [gilt]; in 2Macc. wird noch besonders die schnelle Umwandlung der äußersten Not in die größte Freude hervorgehoben. Dies gibt befriedigende Erklärung darüber, warum grade unser Ps (vgl. bes. V. 6 und 12) an diesem Fest gesungen zu werden pflegte." 
det, was der Talmudtraktat Soferim 18,2/42a bestätigt. ${ }^{353}$ Nach der Mischnah (Bikkurim 3,4; Dtn 26,1-11) wird der Psalm auch bei der Darbringung der Erstlingsfrüchte gelesen. ${ }^{354}$

Versucht man, für den Vermerk der Hauseinweihung sowie für den Eintrag לִדְָוד (für/von David) eine Verbindung zum im AT erzählten Leben Davids herzustellen, dann legen sich 2 Sam 24 // 1 Chr 21-22 als Verweisstellen nahe. ${ }^{355}$

Durch die Angabe לִ לָזְו werden 73 Psalmen des Psalters David zugeordnet. ${ }^{356}$ Die Hebräische Bibel bietet bei 13 Psalmen zusätzlich Situationsangaben, die mit dem Leben Davids in Verbindung stehen. ${ }^{357}$ Mit diesen biographischen Angaben wird eine Verbindung zum Leben Davids hergestellt, wie es in den Samuelbüchern erzählt wird. Diese Angaben dienen als Identifikationsangebote: Die LeserInnen können sich mit David in der jeweiligen Lebenssituation, meist in einer Krise oder Verfolgung, identifizieren und somit den Psalm im Geiste Davids lesen. Durch die narrativen Psalmüberschriften werden die Betenden aufgefordert, die Haltung des betenden Ich des Psalms zu übernehmen. So wie David in seiner Not zu Gott schrie und erhört wurde, so kann es jede und jeder Betende tun. ${ }^{358}$

353 Vgl. Hossfeld / Zenger, Die Psalmen 1, 187.

354 Vgl. Craigie, Psalms 1-50, 253.

355 In 2 Sam 24,25 baut David für JHWH einen Altar und opfert darauf Brandopfer und Heilsopfer, sodass die Pest von Israel abgewehrt wird. In der Parallelstelle $1 \mathrm{Chr} 21,28-30$ sowie 1 Chr 22,1 wird davon erzählt, dass David an diesem Ort, an dem der Altar gebaut wurde, das Haus Gottes errichten lässt. Zum chronistischen Davidbild und zur Idee, David als Initiator des Kults zu betrachten, sowie zur Verbindung von $1 \mathrm{Chr} 21$ und Ps 30 vgl. Erbele-Küster, Lesen, 64-66.

356 »Wer den Psalter in die Hand nimmt und das Gespräch mit Gott sucht, wird in ein Gespräch mit David verwickelt. Die Auseinandersetzung mit David charakterisiert den Psalter.» Butting, Erbärmliche Zeiten, 46.

357 Z. B. Ps 3,1: Ein Psalm. Von/für David. Als er vor seinem Sohn Abschalom floh (Bezug auf 2 Sam 15f).

358 Vgl. Erbele-Küster, Lesen, 61. Butting, Erbärmliche Zeiten, 88, spricht in diesem Zusammenhang davon, dass sich Lesende als David verkleiden. In Bezug auf Ps 51 hält sie fest: "Psalm 51 liest sich wie die Reaktion auf die Gerichtsreden in Psalm 50: In Reaktion auf Gottes Gerichtsreden verkleiden wir uns als David und machen uns gemeinsam auf den Weg der Umkehr.« Als Ausführungen über David liest Gillis Gerlemann die David zugeordneten Dank- und Klagepsalmen des Einzelnen im Psalter: "Gleichviel wer sie gedichtet hat, sie sind von Anfang an darauf angelegt, als Aussagen über David gelesen zu werden. [...] Uns unbekannte Dichter haben in selbstbiographisch stilisierten Liedern David besungen. Die Psalmen sollen nicht als Quellen zur Geschichte Davids, sondern als Zeugnisse eines konventionierten Davidbildes bewertet werden.« Gerlemann, Der »Einzelne«, 47. Zur Funktion der Psalmüberschriften als erste Leseanweisung für Lesende im aktuellen Rezeptionsprozess und zu David als Identifikationsfigur in der Konzeption der impliziten LeserInnenrolle vgl. Erbele-Küster, Lesen, 54.61 ff.107: »Der im Text implizite Leser und Dichter David hat ersten Lesern in den Jahrhunderten um die Zeitenwende neue Rezeptionsmöglichkeiten eröffnet und gibt darüber hinaus nachfolgenden Lesern und Leserinnen Leseanweisung.» Zur Dekonstruktion und Neugestaltung der Figur Davids im Psalter und zur politisch-messianischen Dimension der Davidfigur vgl. Butting, Erbärmliche Zeiten, 46-50. 
Auch wenn Emotionen in der Überschrift nicht auszumachen sind, werden die Lesenden durch diese in dreifacher Weise gelenkt: Der Psalm kann als individuelles Danklied nach einer Noterfahrung, als Danklied einer Gemeinde bzw. Gemeinschaft nach verschiedenen Noterlebnissen und Befreiungserfahrungen in der Geschichte sowie als Danklied Davids gelesen werden. Damit bietet es drei unterschiedliche Identifikationsmöglichkeiten für Lesende an. So wenig emotionaler Gehalt in der Überschrift vorhanden ist, so deutlich kommt dieser in den folgenden Versen zum Ausdruck.

\subsection{Vers 2: Jubel, Befreiung und keine Schadenfreude}

2a Ich will dich hochheben, JHWH,

$2 b$ denn $d u$ hast mich herausgeschöpft

$2 c$ und hast meine Feinde sich nicht freuen lassen über mich.

Befragt man V2 auf seinen emotionalen Gehalt, so ist dieser bereits im ersten Wort

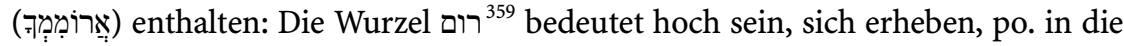
Höhe bringen, emporheben (Ps 27,5), einen Baum hochwachsen lassen (Ez 31,4), Wellen auftürmen (Ps 107,25), ein Gebäude aufrichten. Im po. wird das Erhöhen auf Personen übertragen und bedeutet dann »loben, preisen«, wobei Objekt des Lobens immer JHWH oder dessen Name ist (Ex 15,2; Jes 25,1; Ps 30,2; 34,3; 99,5.9; $107,32 ; 118,28 ; 145,1) .{ }^{360}$ In 2 a hebt nun das lyrische Ich JHWH in die Höhe, wodurch eine Form des Preisens und der Verehrung zum Ausdruck kommt. Dies ist keineswegs emotionslos zu begreifen: Der »hymnische Preis kennzeichnet [...] die rekstatische Ergriffenheit des Ichs, das zu dem göttlichen Du raufsingt‘. Man geht deshalb wohl nicht fehl, wenn man die Selbstaufforderung des Sängers zur `Erhebung` Jahwes (2a) [...] als Ausdruck der Entschlossenheit und Bereitschaft des Willens zu einem preisend-rekstatischen ‘ Aufschwung des ganzen inneren Wesens (13a) hinauf in göttliche Höhen deutet [...]." ${ }^{361}$ Das Verb רום involviert demnach eine Bewegung hinauf in die Höhe und weg vom sprechenden Ich. Diese Bewegung steht im Kontrast zur nachfolgenden, die das Hinaufziehen (דלה) von unten in Richtung des sprechenden Ich beschreibt. ${ }^{362}$

Die Begründung der Selbstaufforderung zur preisenden Erhöhung Gottes liegt in der Erfahrung des Gerettetwerdens, die in 2c mittels des Zeitworts »herausschöpfen« erzählt wird. Das Verb דלה ist Teil der reichhaltigen Bildersprache des

359 Vgl. Stähli, רום, 753-761. Die Wurzel kommt im AT 189x im Bibelhebräischen und 4x im Bibelaramäischen vor, davon $25 \mathrm{x}$ im po. und hiervon wiederum $13 \mathrm{x}$ in den Psalmen.

360 Vgl. Firmage / Milgrom / Dahmen, רום, 428.

361 Krinetzki, Psalm 30, 347.

362 Vgl. Wilson, Psalms, 515. 
Psalms und hat damit auch eine übertragene Bedeutung. Das hier verwendete seltene Verb דלהI (vgl. nur noch Spr 20,5;26,7 und Ex 2,16.19), das mit "schöpfen" wiedergegeben werden kann, aber auch mit "retten" in der Bedeutung von »entnehmen«, »losmachen", "herausziehen" und »emporheben«, ${ }^{363}$ hängt eng mit dem Nomen דִ̣ zusammen. der aus Leder besteht und dessen Öffnung durch ein Holzkreuz offengehalten wird. Das Verb דלה I in der Bedeutung schöpfen kommt, wie oben erwähnt, in Ex 2 vor. Es ist dies die Erzählung von der Begegnung des Mose mit den Töchtern Jitros, die am Brunnen Wasser schöpfen und die Tränkrinnen füllen, um die Herde des Vaters zu tränken. Hier wird anschaulich, dass sich das Verbum דלה I auf die Handlung bezieht, bei der ein im Brunnen oder Zisternenschacht mit Wasser gefüllter Eimer am Seil hochgezogen wird, um ihn in die Tränkrinnen zu entleeren. Martin Buber übersetzt an dieser Stelle »denn du hast mich heraufgewunden." Hinter dem Bild des Herausschöpfens, Hinaufziehens und Heraufwindens schimmern auf Seiten des lyrischen Ich die Tiefendimensionen der Angst und Enge, auf Seiten des Rettenden dessen kraftvolles, verlässliches "Anpacken « durch:»[...] as one would pull a person in danger of drowning out of the raging water with the aid of a rope. ${ }^{364}$ Sicherheit, Verlässlichkeit und Vermögen sind hier auf Seiten der Gottheit zu verbuchen.

An die Thematik des Herausschöpfens und Gerettetwerdens schließt sich jene der nicht vorhandenen (Schaden-) Freude der Feinde an. Die Gegner bzw. Feinde (יㅏㅄ wörtlich als Ptz: die mich Anfeindenden) des sprechenden Ich sind in Ps 30 nicht näher beschrieben. Ein klares Bild dieser Opponenten fehlt daher. Ein Feind ist biblisch betrachtet immer einer, der von außen angreift. Dabei kommt die Form xist in allgemein formulierten Abschnitten vor, wie hier in den Psalmen oder in den Klgl. ${ }^{365}$ In diesen Büchern ergibt sich ein sehr komplexes Bild der Feinde, die sich als Bedränger (Ps 27,2; 74,10; 81,15 u. a.) bzw. Hasser und Verfolger (Ps 18,18.41; 21,9 u. a.) auf keine eindeutige Kategorie festlegen oder exakt einordnen lassen. ${ }^{366} \mathrm{Im}$ Hinblick auf die Emotionalität ist der Hochmut der

363 Vgl. Hupfeld, Die Psalmen, 454.

364 Wilson, Psalms, 515.

365 Vgl. Ringgren, איב, 231-234. In den Individualpsalmen finden sich 37 Belege für. Vgl. Ringgren, איב, 233.

366 Folgende Feind-Bestimmungen sind nach Beat Weber in den Psalmen erkennbar: Feinde im engeren und weiteren Beziehungsfeld wie in der Familie und im Freundeskreis, Feinde als Chiffre, als Zeichen für das Böse schlechthin, Feinde als Zweitverursacher der Not neben z. B. der Krankheit oder der Gottferne, Feinde im militärischen Sinn sowie politische und strukturelle Feindmächte. Vgl. Weber, Werkbuch 3, 118 sowie Kapitel VII Textanalyse Psalm 64. »Das Wesentliche ist nicht die genaue Beschreibung der Feinde, sondern die theologische Einordnung ihres Wirkens als widergöttlich und chaotisch."Ringgren, איב, 234. Auf die Verbindung von Feinden und Freunden im Zusammenhang mit Krankheit verweist Craigie, Psalms 1-50, 253: »The psalmist's basic problem had been a sickness which took him to 
Feinde erwähnenswert. Anmaßende und prahlende Worte, Lästerungen und Verderbtheit sind Charakteristika der Feinde: Sie erheben sich (Ps 13,3), tun groß (Klgl 1,9), höhnen und schmähen (Klgl 2,17), sperren den Mund auf (Klgl 2,16; 3,46), knirschen mit den Zähnen (Klgl 2,16) und freuen sich (Klgl 2,17). Interessant ist in Ps 30, dass sich die Feinde nicht freuen (vgl. auch Ps 41,12). ${ }^{367}$ Eine einheitliche Bestimmung der Identität der Feinde ist nicht möglich. In irgendeiner Weise dürfte in Psalm 30 allerdings auch von Krankheit die Rede sein, nachdem der Prozess der Heilung angesprochen wird. Dabei wird allerdings nicht klar, „ob die Feinde die Krankheit des Beters verursacht haben oder sich nur über sein Unglück [nicht!] freuen. ${ }^{368}$ Nach Beat Weber sind hier die Feinde "die Nutznießer der Notlage des Sprechenden, dann auch Spötter und Gleichgültige. Die Gotteshilfe hat ihre Schadenfreude durchkreuzt (2[c]). Die bleibende Freude ist nun - man beachte den Stichwortbezug zwischen 2[c] und $12[\mathrm{c}]$ - beim Geretteten. ${ }^{369}$ Die Feinde können hier auch als Chiffre für die gesamte Lebenswelt stehen, die als feindlich aufgefasst wird, oder für die persönlichen Ängste des betenden Ich. ${ }^{370}$ Der Feind könnte an dieser Stelle auch die Macht des Todes bzw. der Tod selbst in seiner personifizierten Form sein, der allerdings dieses Mal nicht triumphiert hat. ${ }^{371}$ Auf alle Fälle kommt איא im weiteren Verlauf nicht mehr vor, wohl aber die Freude, die in V12 auf das betende Ich selbst bezogen wird.

Mit dem letzten Verb des Verses, der Wurzel שמחה, wird erstmals ein explizites Emotionswort verwendet. Denn in Psalm 30 fällt die Quantität der Emotionen auf: »Der reichliche Gebrauch von Verben der Gemütsbewegung, die Jahwe oder Menschen attribuiert werden, geben dem Psalm ein von Gefühlen belebtes Kolorit. ${ }^{372}$ שממח (erfreuen, sich freuen lassen) ist eine Gemütsbewegung und daher von Emotionalität durchdrungen. ${ }^{373}$ Vermutet wird, dass sich der Begriff von der

death's door; in that crisis, even friends became enemies, for they assumed that the sickness was a divine judgment on the sick person. « In ähnlicher Weise argumentiert Anderson, A Time to Mourn, 94, indem er das betende Ich in eine Zeit des Klagerituals verortet: »In a period of mourning, one expects sympathy, not antagonism. Friend or kinfolk are expected to share the ritual state of the grieved individual (Job 2:11-13). To fail to show solidarity in such a situation [...] was to declare oneself an enemy rather than a covenantal partner."Auf die Schadenfreude der Feinde über die Krankheit des/der Psalmisten/Psalmistin bezieht sich ebenso Grogan, Psalms, 82: "So his enemies would gloat over him, not because of their own actions but because of his death through illness."

367 »Die von Gott scheidenden Mächte können nicht triumphieren.« Kraus, Psalmen, 387.

368 Ringgren, איב, 234.

369 Weber, Psalm 30, 41.

370 Vgl. Zenger, Mit meinem Gott, 91.

371 Vgl. Alonso Schökel / Carniti, Salmos 1, $472 \mathrm{f}$.

372 Witzenrath, Am Abend Weinen, 460.

373 Die Wurzel שמח ist im AT 154x belegt, wobei sie in konzentrierter Form - 52x - in den Psalmen begegnet (vgl. Abart, Lebensfreude, 22. Zu diesen und den folgenden Ausfüh- 
konkreten Bedeutung "strahlen« als Ausdrucksseite der Freude herleiten lässt (Ps 19,9; Spr 15,30). Im Kontrast zum berichtenden Lob (הלל hitp. und ידה hi. vgl. V13), das in strukturierten Aussagen artikuliert wird und in einem gewissen zeitlichen Abstand zum Erlebten erfolgt, ist שמח eine spontane und elementare Äußerung der Freude. Diese Freude entbehrt der Zurückhaltung; der betreffende Mensch ist fast überschwänglich und kann auch außer sich geraten. Der Freudenschrei oder Jubelruf gilt als maßgebliche Äußerung der Freude (1 Kön 1,39). Das Substantiv שִׁמְחָה (vgl. V12), welches meist als Abstraktum für »Freude» verwendet wird, kann auch für das Freudengeschrei stehen bzw. die im Augenblick erlebte konkrete Freude zum Ausdruck bringen (Gen 31,27; 1 Sam 18,6; Ps 137,3 u. a.). רנן (vgl. das Substantiv רִּנּ - Jubel - in V6) zeugt ebenso von einer impulsiven, unmittelbaren Reaktion der Freude. Solche Freudenlaute werden u. a. auch bei Freudenfesten geäußert, eventuell auch in Freudenliedern. ${ }^{374}$ Hier in V2 wird שמח mit der Präposition ? konstruiert. Damit wird auf die Person hingewiesen, auf deren Kosten man sich freut bzw. eben nicht freut. Auf diese Weise ist eine andere Art von Freude, nämlich die Schadenfreude ${ }^{375}$ über das Unglück eines anderen, bereits sprachlich gekennzeichnet: Diese Freude über den Schaden des Gegners wird hier von Gott verhindert (bzw. an anderen Stellen geahndet vgl. dazu Ez 25,6; 35,15; 36,5; Spr 17,5).

Zum Abschluss der Analyse von V2 ist hinsichtlich der Emotionen festzuhalten: Es finden sich Ergriffenheit, Ekstase und Entschlossenheit, die sich in der Selbstaufforderung des Hochhebens JHWHs äußern und dem lyrischen Ich zugeschrieben werden. Ebenso werden Emotionen der Verehrung und des Respekts geäußert, die mit dem Preisen und Erhöhen JHWHs verbunden sind. Dem Sprachbild des Herausschöpfens sind die Emotionen der Angst und Unsicherheit sowie das Gefühl der Enge wegen des dunklen Abgrunds auf Seiten des lyrischen Ich inhärent. Auf Seiten der Gottheit finden sich Verlässlichkeit und jene Emotionen, die im Zusammenhang mit Sicherheit, Kraft und Vermögen stehen, wie z. B. Umsicht und Wachsamkeit. Den Feinden als Bedrängern, Verfolgern und Hassern kann Hochmut zugeschrieben werden, wobei diese Emotion in diesem Vers nicht konkret zum Ausdruck gebracht wird. Die Feinde können für die Ängste des lyrischen Ich und die Todesmacht schlechthin stehen - eine Deutung, die sich gut in das Textverständnis fügt. Das Abstraktum Freude, das als

rungen vgl. Ruprecht, שמח, שמחת, 828-835. Laut Vanoni, 809 findet sich der Wortstamm 158x in der Hebräischen Bibel.

374 Vgl. Vanoni, שמש, 813.

375 Ruwe, Die Psalmen, 44 übersetzt V2:»Ich erhebe dich ADONAI, weil du mich emporgezogen und meine Feinde nicht in der Schadenfreude über mich gelassen hast.« Davon, dass sich die Feinde nicht freuen bzw. jubeln sollen, sprechen u. a. auch 2 Sam 1,20; Jes 14,29; Mi 7,8; Ps 35,19.24.26; Ps 38,17. 
spontaner Ausdruck konkreter Erlebnisse der Freude und des Glücks gilt, wird vor allem in V12 relevant. Hier in V2 verweist das Verb auf die Schadenfreude.

\subsection{Vers 3: Hilfeschrei und Heilung}

3a JHWH, mein Gott, ich schrie um Hilfe zu dir

$3 b$ und $d u$ hast mich geheilt.

Die Anrede "JHWH, mein Gott" beinhaltet eine verdoppelte Anrede des Adressaten. Hierin kann eine Form von Dringlichkeit ihren Ausdruck finden, die sich in der Semantik der Wurzel שוע fortsetzt. ${ }^{376}$ Mit wוע werden vor allem die Not eines Einzelnen und dessen Hilfeschrei zu Gott in akuten Notsituationen ausgedrückt. ${ }^{377}$ Als Reaktion auf Negativerfahrungen ist mit einer lautlichen Äußerung im Sinne eines Ausstoßens von Schreien zu rechnen, wobei der Adressat der Äußerung fast durchgängig JHWH ist. In den Psalmen sind zwei Verwendungskontexte von שוע auszumachen: Einerseits wird vom Schreien um Hilfe in Rückblicken auf erlebte Not gesprochen. Das geschieht hier in V3, wo ebenso die Erfahrung der Heilung genannt wird. Andererseits wird die aktuelle Not in Form von gerade vollzogenen Klagen durch den Hilferuf vor JHWH gebracht (Ps 5,3; 28,2;39,13 u. a.). Das Verb שוע wird nur in jenen Texten verwendet, die das Klagen des Einzelnen beschreiben und nicht das des Volkes. Die Einzelklage fällt dabei heftig aus. Auch Flehen und Weinen werden synonym zum Hilfeschrei verwendet. Hinter der Notsituation und dem Hilfeschrei stehen damit Leid und Elend, mit denen implizit die Emotionen der Niedergeschlagenheit, der Besorgnis und des Kummers verbunden werden können.

רפא Nach dem Hilfeschrei wird von Heilung erzählt. Die südsemitische Wurzel bedeutet flicken, ausbessern, zusammennähen ${ }^{378}$ und erweckt hier in $3 \mathrm{~b}$ die Assoziation von JHWH als Arzt. ${ }^{379}$ Die Wurzel mit der Grundbedeutung »wiederherstellen, ganz/heil machen ${ }^{380}$ bezieht sich in den meisten Fällen auf Heilung von Verletzungen und Krankheiten aller Art. Dahinter steht die Annahme, dass das Fehlen von Heilung qualvoll und bei schweren Wunden tödlich sein kann. Im Zusammenhang mit dem Heilen von Wunden und Verletzungen kann dieses Heilen im metaphorischen Sinn auch als Bild für den schlimmen Zustand eines Volkes betrachtet werden und daher für Verletzungen und Schäden eines

376 Verdoppelungen sind laut Andreas Wagner (vgl. III Methodik 2) Ausdrucksmöglichkeiten von Emotionen.

377 Vgl. Hausmann, שוע, 1187-1191.

378 Vgl. zu den folgenden Ausführungen, wenn nicht anders angegeben, Stoebe, ארפ, 803-809.

379 Vgl. Witzenrath, Am Abend Weinen, 459 und Keel, Die Welt der altorientalischen Bildsymbolik, 177.

380 Vgl. Brown, רפ, 619. 
Volkes oder Landes stehen (vgl. dazu die prophetische Literatur, z. B. Hos 5,13; Jer 30,13.17; 33.6). Im Zusammenhang mit Jer 17,14 kann das Heilen hier auch die Wiederherstellung des seelischen Gleichgewichts bedeuten. ${ }^{381}$

In V3 ist die Heilung verbunden mit dem in V4 erzählten Abstieg in die Unterwelt bzw. Zisterne und dem Errettetwerden daraus. Das Leid muss somit dementsprechend schwer empfunden und erlebt worden sein. ${ }^{382}$ Heilung ist immer mehr als ein medizinisch nachvollziehbarer körperlicher Vorgang. Es geht um das Verlangen nach umfassender Errettung, die nur durch JHWH vollbracht werden kann. ${ }^{383}$ Durch das Heilen zeigen sich also nicht nur die erlösende Dimension Gottes, sondern auch dessen Emotionen des Mitgefühls und der Zuneigung.

Vielfach wird in Bezug auf Ps 30 wie auch auf Ps 6; 88 und Jes 38 von Krankheitsklagen gesprochen, wobei »Krankheit ein Ort in der Todeszone [ist], beeinflusst und beherrscht bereits von den Gesetzen der Unterwelt. ${ }^{384}$ Das Geheiltwerden kann an dieser Stelle andeuten, dass das betende Ich krank oder verwundet war. Der Psalm berichtet jedoch in weiterer Folge von keinem physischen Gebrechen und lässt die Verbindung mit anderen Formen der Gesundung und Wiederherstellung offen, die das Verb ebenso andeuten kann (Ps 147,3: Er heilt, die gebrochenen Herzens sind.). ${ }^{385}$

Durch die doppelte Anrede wird die Dringlichkeit deutlich, die sich als implizite Emotion durch den gesamten Psalm zieht. Weitere Emotionen, die im Vers verankert sind, sind jene, die mit dem Hilfeschrei in akuter Not verbunden sind, wie etwa Niedergeschlagenheit, Sorge und Kummer. Diese werden dem lyrischen Ich zugeschrieben. Mit dem Heilen als umfassendem Ganzwerden - nach dem sich das lyrische Ich in einem schlimmen Zustand der Verletzung, der Verwundung, des Schmerzes, der Angst und der Unsicherheit sehnt - können auf Seiten der Gottheit die Emotionen des Mitgefühls und der umfassenden Zuneigung verortet werden.

\subsection{Vers 4: Vom (sozialen) Tod zurück ins Leben}

4a JHWH, du hast heraufgeholt aus dem Totenreich meine Lebenskraft, $4 b$ du hast mich zum Leben gebracht weg von meinem Hinabsteigen zur Zisterne.

381 Vgl. Herkenne, Das Buch der Psalmen, 127.

382 Vgl. Brown, 622.

383 Vgl. Brown, רפר 624.

384 Seybold, Poetik der Psalmen, 268.

385 Vgl. Goldingay, Psalms 1, 426. 
V.4 ist wie V2.3 geprägt von metaphorischer Redeweise, die unterschiedliche Emotionen evoziert. Markant ist darin vor allem das Totenreich. שְׁאוֹ gilt als verwildeter, unwirtlicher Raum; es kann auch als Öde oder Unland bezeichnet werden und ist damit das Gegenstück zur Erde, und es steht als unterste Gegend in Kontrast zu den Himmeln als oberstem Bereich des Kosmos. ${ }^{386}$ Die שִׁאוֹ ist die "Unheilssphäre der Un-Welt, d[ie] das Leben verschlingende Unterwelt. “ ${ }^{387}$ Tiefe und Abgrund, Kraftlosigkeit, undurchdringliches Dunkel, Verwesung, der angesammelte Staub, Schweigen und Vergessenheit sind jene Charakteristika, die in den Psalmen dem Totenreich zugeschrieben werden. ${ }^{388}$ Die Scheol kann auch einen psychosozialen Zustand der Schwachheit, Krankheit, Gefangenschaft, Rechtsnot, Angst usw. bedeuten und somit wie hier in V4 bereits vor dem physischen Tod ins Leben hineinragen. ${ }^{389}$ Des Weiteren kann zwischen einer Unterwelt als Bereich des Todes "mitten im Leben« bzw. einer Unterwelt der Lebenden (V4) und einer Unterwelt der Toten (V10) unterschieden werden. ${ }^{390}$ Aus der Unterwelt der Lebenden ist durchaus Rettung möglich, aus jener der Toten nicht mehr (vgl. Analyse zu V10).

Wenn sich nun die sprudelnde Lebensenergie und Leidenschaft steht und den ganzen Menschen unter dem Aspekt des Verlangens und Begehrens, der Sehnsucht und des

386 Vgl. Gerlemann, לשָׁ, 838-841.

387 Kraus, Psalmen, 388. Im Jahr 1911 klingt der Vers so: "Jahwe, du hast heraufgeholt aus der Hölle meine Seele«, Schlögl, Die Psalmen, 40.

388 Vgl. Keel, Die Welt der altorientalischen Bildsymbolik, 53.55.59. Ebenso Riede, Jenseitsvorstellungen (AT), 2.

389 "His condition had been so serious that he actually thought of himself as already in Sheol.» Cohen, The Psalms, 85. Ähnlich Craigie, Psalms 1-50, 253: »The meaning of $v 4 a$ is not that the psalmist had died and been restored to life; rather, he had been so close to death that it was as if he were already dead, and from that grave situation he had been rescued by God's act of healing."

390 Vgl. Eberhardt, JHWH und die Unterwelt, 222-229 unter Aufnahme der Rede Barths vom partiellen Aufenthalt im Totenreich. Vgl. Barth, Errettung, 93f. Ähnlich Riede, Jenseitsvorstellungen (AT), 2.

391 Die נֶֶֶ ist das Organ, durch das die Luft in die Lungen strömt, sodass an ihr das Leben hängt. נְפְּ ist somit die Kehle, der Rachen, der ganze Hals wie auch die Luft- und Speiseröhre. Als Sitz der elementaren Lebensbedürfnisse (atmen, begehren) steht נֶֶֶ auch als Synonym für Leben und Atem. Im Bibelhebräischen werden mit Organen gleichzeitig auch Fähigkeiten und Tätigkeiten verbunden. Davon ausgehend ist נֶפֶׁ die nicht zu stillende Gier (Koh 6,9), der Sitz des Geschmacksinns (Spr 27,7), des Weiteren der Atem (Gen 35,18), die Kraft des Begehrens und des sehnsüchtigen Verlangens - gerade auch hinsichtlich der Gottesbeziehung (Dtn 6,5) -, Ausdruck der verschiedenen Gefühlszustände des Menschen sowie das Leben selbst (Spr 8,35f) und auch die einzelne Person (Lev 23,30). Auch die

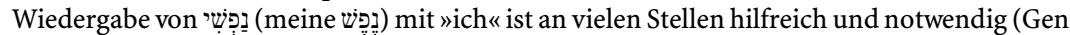
19,19f; 1 Kön 20,32; Jes 1,14; Ps 3,3 etc.) Zur detaillierten Darlegung von נֶֶפ vgl. Wolff,

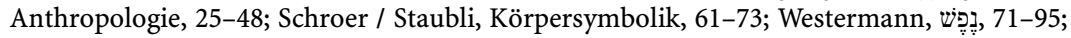

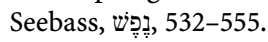


Wünschens wie auch seiner Verletzlichkeit mit einschließt, im Totenreich befindet, so »ist in der Sicht der Psalmen schon 'tot`, wer keine Lebenskraft und keinen Lebensmut mehr hat. Er bedarf, dass der Gott des Lebens ihn ins Leben zurückruft. ${ }^{392}$ Denn der Tod ist eine in das Leben hineinreichende Macht und nicht einfach das Aufhören des Lebens. So ist alles schwere Leid Angriff des Todes. Die Erfahrung des Todes macht primär der lebende und nicht der sterbende Mensch. Die Erfahrung der Macht des Todes ist Todesangst. "Der aus schwerem Leid Erlöste versteht sein wiedergeschenktes Leben als Befreiung aus dem Tod. ${ }^{393}$

Die Nefesch wird also in eine neue Umgebung gebracht, die nicht genannt, aber in Verbindung mit $4 \mathrm{~b}$ mit Leben und Lebendigkeit konnotiert ist. Das eingeschränkte, geminderte Leben des/der Psalmisten/in wird somit wieder zu einem erfüllten Leben. ${ }^{394}$ Ausgedrückt wird dieses Hochholen der Nefesch aus dem Totenreich mittels der Wurzel עלה, die insgesamt 890 Mal im AT vorkommt. Von seiner Grundbedeutung her beschreibt das Verb eine Bewegung von unten nach oben, von einer niedriger liegenden Gegend zu einer höheren, ein Vorankommen zu einem höheren Ziel hin. עלה kommt hier im hi. vor. Das ist auch in Ex 32,7; 33,1 und Num 14,13 der Fall, wo die Exodustradition benannt und damit deutlich von einem Befreiungshandeln durch das Hinaufführen gesprochen wird. Wie das Heilen in 3b impliziert auch das Heraufholen der Nefesch aus der Scheol neue Lebensmöglichkeiten. Im Kontrast dazu steht das Hinabsteigen (ירד). In 4b ist vom eigenen Hinabsteigen in die Zisterne (Qere analog zu V10) bzw. von den in die Zisterne Hinabsteigenden (Ketib) die Rede, aus deren Gruppe bzw. Schar das betende Ich herausgenommen wird bzw. von deren Gruppe es sich deutlich abgrenzt. ${ }^{396}$

Auf die Verwendung von עלה als Gegenüber des Verbs רד ירד, das - wie hier in V4 das Hinabfahren in die Totenwelt bezeichnet, weist vor allem Wehmeier hin. ${ }^{397}$

392 Weber, Werkbuch 1, 151. Von einem Nicht-Land, einer Nicht-Welt, vom Verlust der Handlungsfähigkeit und des Subjektseins sowie von der passiven Schattenexistenz spricht im Zusammenhang mit der Scheol in Ps 30,2 Marti, Die Psalmen, 82.

393 Witzenrath, Am Abend Weinen, 469.

394 Vgl. Baumgart, Vom Tod mitten im Leben, 104.

395 Vgl. Fuhs, עלה, 89. Allgemein wird im AT der Weg von Ägypten nach Kanaan bzw. Etappen auf dem Weg dorthin (z. B. Ex 13,18; Num 20,19; 32,11; Ri 11,13.16; 19,30), der Weg aus der Wüste nach Kanaan (z. B. Ex 33,1; Num 13,17; Dtn 1,21.26.41) sowie der Weg hinauf zum Tempel in Jerusalem als Hinaufsteigen bezeichnet.

396 An dieser Stelle verweist der textkritische Apparat der BHS auf ein Ketib: מִּיוּרִִּ (Ptz.m.pl. »weg von denen, die hinabsteigen«). Qere gilt: Inf.constr.q. + Suffix 1.P.sg.: Vor meinem Hinabsteigen/Abstieg in die Grube bzw. damit ich nicht in die Grube stiege. Hupfeld, Die Psalmen, 455 verweist an dieser Stelle auf die zweimalige Verwendung der Präposition מִ̣ :מ̣ aus zuerst vom Ort, aus dem er gezogen, dann von der Gemeinschaft derer, die sich dort befinden, aus der er entnommen wird."

397 Vgl. Wehmeier, עלר wird zudem für die Reise von Palästina nach Ägypten verwendet 
»Die `religiöse Topographie` von Ps 30 kennt neben dem Bereich des `Unten`, der Tiefe, Nachtschwärze und Isolierung, als Gegenpol ein `Oben`, wohin Gott

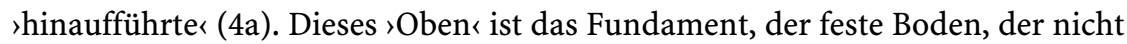
wankt (vgl. 7b). Es sind erhobene, dem Himmel nahe Orte: ‘feste Berge ( $8[b]$ ), v. a. aber der `Zion`, der Jerusalemer Tempelberg. Er ist in Ps 30 explizit nicht genannt, darf aber als Ort der Darbringung dieses Lobdanks vorausgesetzt werden. ${ }^{398}$ Wo auch immer dieses Oben sein mag: Mit Sicherheit kann festgehalten werden, dass die Rettungserfahrung in V4 als räumlicher Vorgang dargestellt wird. ${ }^{399}$

Synonym zum Heraufholen der Nefesch aus dem Totenreich (Ps 49,16) in 4a steht - in $4 \mathrm{~b}$ und damit chiastisch formuliert - das Zum-Leben-Bringen in Kontrast zum Hinabsteigen in die Zisterne. Dabei beschreibt $4 \mathrm{~b}$ den Ort der tiefen Verlassenheit mit dem Bild eines Grabes bzw. einer Zisterne (ר) (ר). ${ }^{400} \mathrm{Zis}$ ternen sind in den Boden geschlagene Hohlräume, in denen in der Winterzeit Regenwasser gesammelt und für den Sommer gespeichert wird. Sie gelten als dunkle, Furcht einflößende Orte und besitzen vor allem im Gegensatz zur Quelle, die lebendiges, fließendes, klares Wasser zu Tage fördert, ein eher negatives Image, weil sie schließlich nur abgestandenes Wasser enthalten. Typisch für die Zisterne im metaphorischen Sprachgebrauch sind auch ihre Aspekte Rissigkeit und Unzuverlässigkeit.

Zisternen, die in ihren Erscheinungsformen dem Grab ähnlich sind, haben auch als Gefängnisse gedient. An ein Entkommen aus diesen finsteren Löchern, deren Boden nicht nur mit abgestandenem Wasser bedeckt ist, sondern auch mit Schlamm, ist nicht zu denken. Wie die in V10 genannte Grube, aus der es kein Herauskommen gibt und die für Tiefe und Enge steht, ist רiֹ neben dem im V4 dargestellten Totenreich ein Bildausdruck für Grab oder Unterwelt und bezeichnet die Sphäre der Todesgefahr sowie den Eingang in die Totenwelt. ${ }^{401}$

»Mit diesen Begriffen [Zisterne, Grube, Totenreich] assoziieren sich Momente wie Tiefe, Versinken, Überflutetwerden, Dunkelheit, Gefangensein, Schreckenserstarrung (vgl. 8[d]), Isolierung und anderes mehr, die sich in leib-seelischen Symptomen ausprägen (können) und neben der Gottverlassenheit auch soziale Isolierung bis hin zu Auflösungserscheinungen der Persönlichkeit zeitigen

(z. B. Gen 12,10; 26,2; 42,2), für das Hinabsteigen vom Gebirgsland in die Wüste (z. B. Num 14,45; 1 Sam 25,1), in niedriger gelegene Städte wie Gilgal (1 Sam 10,8), für das Verlassen einer Stadt (1 Sam 9,27; Rut, 3,3.6), für das Herabsteigen zu einem Brunnen (z. B. Gen 24,16.45) sowie zu einem Fluss (z. B. Ex 2,5).

398 Weber, Psalm 30, 38.

399 Vgl. Janowski, Konfliktgespräche mit Gott, 274.

400 Vgl. Koenen, Wasserversorgung.

401 Vgl. Keel, Die Welt der altorientalischen Bildsymbolik, $60 \mathrm{f}$. 
(können).«02 In ähnlicher Weise beschreibt Erich Zenger die metaphorische Sprache des Psalms, die Todesgefahr zum Ausdruck bringt: »Die Metaphern sind einerseits so konkret und plastisch, dass die ganze Dramatik von Angst und Ausweglosigkeit lebendig wird. Andererseits sind sie so offen und unbestimmt, dass sie für viele konkrete Situationen stehen, in denen Menschen sich der Macht des `Todes ausgeliefert sehen [...]: wo und wie immer das Leben eines Menschen gestört und bedroht wird [...], ist die (chaotische) Macht des Todes am Werk und hat die Scheol (die Unterwelt) ihre Greifarme ausgestreckt. ${ }^{403}$ Leo Krinetzki spricht im Zusammenhang mit den in V4 erwähnten Bildern vom Gefühlseindruck des Schaudervollen und Unheimlichen auf HörerInnen und LeserInnen. ${ }^{404}$

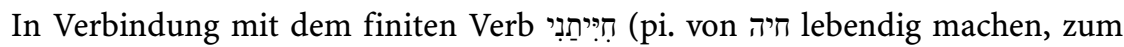
Leben bringen, am Leben erhalten, neu beleben) und mit der synonymen Aussage in 4a sowie im Kontrast zu den Todesorten und zum Hinabsteigen dorthin ist hier von einer doppelten Emotionalität zu sprechen: In die Perspektive der befreienden Errettung, Erleichterung und Freude über das Wieder-lebendig-Sein und über das Erhalten neuer Lebenskraft und neuen Lebensmutes werden die dunklen Räume eingebettet, die mit Todesangst, Isolation, Enge, Einsamkeit und Gefährlichkeit konnotiert sind. In der Zusammenschau der Bewegung innerhalb des Sprachbildes dominiert dabei die »semantische Stärke« der Verben der Bewegung, die JHWH zugeschrieben werden. Diese steht damit über den Räumen, die schweres Leid thematisieren. In Bezug auf die Gottheit ist dabei, wie bereits in V3, machtvolle Stärke festzuhalten. Georg Fohrer formuliert das so: „Was hat Gottes Erhabenheit bewirkt? Sie hat den Beter der Todesnot entrissen, wie die starke Hand des Retters einen Ertrinkenden aus den todbringenden Fluten zieht. So hat Gott ihn aus der Unterwelt hinaufgezogen (V. 4).«05 Der im Leseprozess Unheimliches und Schaudern auslösende V4 ist, wie bereits erwähnt, geprägt von einer doppelten Emotionalität: Werden mit der bildlichen Rede von der Scheol und Zisterne Emotionen der Angst, Kraftlosigkeit, Todesgefahr, des Gefangenseins, der Ausweglosigkeit und generell der Gottverlassenheit thematisiert, so sind mit der Nefesch, dem Zum-Leben-Bringen und dem Heraufholen Aspekte der Errettung und Befreiung verbunden, die mit den Emotionen der Leidenschaft und Erleichterung sowie mit Vitalität, Lebendigkeit und Rettung verknüpft sind. Dies erfährt im Psalm das lyrische Ich. Dennoch wirken die Emotionen, die aufgrund des Sprachbildes hervorgerufen werden, m. E. auch subjektfrei. Mit der Handlung Gottes sind jene Emotionen verbunden, die Befreiungsstärke und Erhabenheit ausdrücken.

402 Weber, Psalm 30, 38.

403 Zenger, Mit meinem Gott, 90.

404 Vgl. Krinetzki, Psalm 30, 354.

405 Fohrer, Psalmen, 225. 


\subsection{Vers 5: Musik, Gesang und Lob für JHWH}

5a Singt/spielt für JHWH, ihr seine Getreuen

$5 b$ und lobt zum Gedenken seiner Heiligkeit.

Der Psalm verlässt nun die Ich-Du-Perspektive und nimmt mittels der Imperative die Öffentlichkeit bzw. Gemeinde in den Blick. Diese Aufforderung zum Lob an die Gemeinde einschließlich einer Begründung steht parallel zur Selbstaufforderung des/der PsalmistIn in $2 a^{406}$ Dabei bringt das betende Ich nicht nur seine Rettungserfahrung in die Gemeinschaft ein, sondern holt gleichzeitig die Gemeinschaft in seine Erfahrung hinein. Das betende Ich involviert die Öffentlichkeit in seine Dankbarkeit, indem seine Aufgabe auch die Aufgabe der Öffentlichkeit wird; die AdressatInnen sollen an seiner Erfahrung partizipieren: ${ }^{407}$ »Die Adressaten kommen mit ins Spiel, handeln und leiden mit, werden Teil der Begebenheit. ${ }^{408}$ Die Imperativformen sind damit ein weiteres Textelement, durch das die Lesenden in das in der Textwelt geschilderte Geschehen einbezogen werden. ${ }^{409}$ Dabei ist ein freudiger Aufbruch wahrnehmbar. Bei dieser Öffentlichkeit geht es um einen "Kreis von Menschen, dem der Lobdank aus dem Munde des einzelnen zu Ohren kommt, der darüber hinaus jedoch selbst im Diskursgeschehen aktiv werden soll. « ${ }^{410}$ Die Aufgabe der Öffentlichkeit besteht zuallererst im singenden Lobpreis Gottes. זמר verbindet zwei Aspekte, die kaum mit nur einem Wort zu übersetzen sind: Es geht dabei um Singen und Spielen זמgleich, um eine Tätigkeit, die sowohl instrumental als auch vokal ist. ${ }^{411}$ kommt ausschließlich im pi. vor. In 15 von 45 Belegen handelt es sich - wie in der Imperativform in V5 - um einen Aufruf zum Lobpreis. Das Verb steht im Kontext von weiteren Zeitwörtern des kultischen Lobpreisens, die das Singen (שיר V1) und Loben (ידה V5.10.13) einerseits sowie das Jubeln (רנן V6), Jauchzen (רוע Ps 47,2; 60,10; 81,2 u. v. a. m.) und Sich-Freuen (שמח V2.12) andererseits benennen. Das Singen und Spielen gilt in allen Fällen JHWH (V5 לַיהוזה), und es wird als Sache der Frommen angesehen, diesen fröhlichen Auftrag auszuführen (V5 חָדִיד). Die Gottheit soll damit geehrt und erfreut werden. ${ }^{412}$

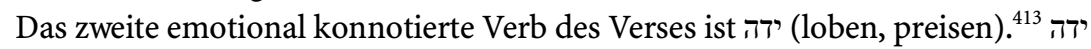
ist die preisende Antwort auf ein Handeln und kann als berichtendes Gotteslob

406 Vgl. Fohrer, Psalmen, 226.

407 Vgl. Loader, Psalm 30, 297.

408 Seybold, Poetik der erzählenden Literatur, 283.

409 Vgl. Wenham, Psalms, 156.

410 Hardmeier, Systematische Elemente, 344.346.

411 Vgl. Barth, זמר, 603-612.

412 Vgl. Barth, זמר 611.

413 Eine charakteristische Häufung von ידה lässt sich mit 67 Vorkommen in den Psalmen finden. $\mathrm{Zu}$ diesen und den folgenden Ausführungen vgl. Westermann, ידה , 674-682. 
beschrieben werden. Diese Antwort ist eine spontane Reaktion auf ein Ereignis, meist auf die Wende des Leides, d. h. auf das helfende und befreiende Handeln Gottes (vgl. dazu V13). ${ }^{414}$ Dabei ist im Vergleich zu הלל pi. (beschreibendes Gotteslob bzw. festlicher Jubel) »mit $j d h$ hi. primär das Einstimmen des Einzelnen in das Gotteslob gemeint, hinter dem der aus einer eigenen Erfahrung kommende Entschluss steht. « ${ }^{415}$ Hier in V5 begegnet ידה in der Imperativ-Form hi.m.pl. Es wird an dieser Stelle mit dem Imperativ von הלל (lobet!) mehr oder weniger gleichgesetzt. Beiden Verben ist die Funktion gemeinsam, das Loben in Bewegung zu setzen. Umso interessanter erweisen sich jene vier Stellen (Ps 6,6; 30,10; 88,11; Jes 38,18f), in denen Aussagen über das Loben getätigt werden. Inhaltlich haben sie alle gemeinsam, dass die Toten JHWH nicht loben. Dabei wird ידה als Motiv eingesetzt (vgl. dazu V10), um Gott zum Eingreifen zu bewegen und Rettung herbeizuführen. Wenn die Toten also JHWH nicht loben, dann umso mehr die Lebenden - das Gotteslob gehört daher zum erfüllten und heilen Dasein. Im Gegensatz dazu wird im Totenreich weder gelobt noch an Gott gedacht (זכר Ps 6,6).

Die Lesenden werden durch die mittels der Imperative geäußerte AdressatInnenperspektive von V5 aufgefordert, die Erfahrungen des lyrischen Ich mitzuvollziehen und ins Textgeschehen einzusteigen. Im Blick auf die Emotionen ist festzuhalten, dass das Singen und Spielen Freude machen und der Gottheit Freude bereiten soll. Die Emotion der Freude bestimmt also V5. Sie soll allerdings erst evoziert werden und ist noch nicht präsent. Mit dem Loben ist jene Aktion verbunden, das Lob in Bewegung zu setzen und in das Lob einzustimmen.

\subsection{Vers 6: Zorn und Wohlgefallen, Weinen und Jubelgeschrei}

$6 a$ Denn ein Augenblick in seinem Zorn-

$6 b$ (ein) Leben (lang) in seinem Wohlgefallen.

$6 c$ Am Abend übernachtet Weinen,

$6 d$ aber zum Morgen hin (gilt): lauter Jubel.

Wird in V5 zum Lobpreis Gottes aufgerufen, so wird nun in V6 der Anlass dafür angegeben, warum JHWH gepriesen werden soll. Die Angabe des Grundes erfolgt zunächst in 6a.b mit Blick auf Gott, in 6c.d mit Blick auf den Menschen. ${ }^{416}$ Von einer konkreten Rettungstat wie in V2-4 wird dabei nicht erzählt, vielmehr geht es in $6 a \cdot b^{417}$ um allgemeine Aussagen über das Geheimnis des Wirkens Gottes.

414 Vgl. Westermann, ידי, 676.

415 Westermann, ידה, 677.

416 Vgl. Krinetzki, Psalm 30, 355.

417 Zur grammatikalisch ungewöhnlichen Satzform 6ab siehe ausführlich Jenni, Psalm 30,6a, 105-120. 
Der Vers besitzt die Form eines antithetischen Parallelismus. Er enthält eine

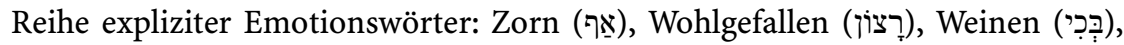
lauter Jubel (רְנָָּּ). Auch mit der Personifikation »Weinen bleibt (über Nacht)« ist ein Bildwort gegeben, das einen emotionalen Gehalt besitzt. ${ }^{418}$

Dabei werden Zorn und Wohlgefallen der Gottheit zugeschrieben. Hinter dem Zorn verbirgt sich die Nase (אַ) als Geruchsorgan. Metaphorisch wird ַָ ebenso im Sinne von Entschlossenheit (»starke Nase») und Hochnäsigkeit (»hohe Nase») gebraucht wie im Sinne von Zorn (»entbrannte Nase« Gen 30,2; Ex 11,8; Ri 9,30; Ps 124,3). Dabei ist von der »entbrannten Nase«, die die Vorstellung vom zornigen Schnauben transportiert (Ijob 32,2: Da entbrannte die Nase Elihus ...), im AT viel häufiger die Rede als von den anderen beiden übertragenen Bedeutungen der Hochnäsigkeit und Entschlossenheit. Am häufigsten wird dabei der Zorn Gottes bzw. dessen Nase erwähnt; das ist hier in V6 und an weiteren 167 Stellen der Fall. ${ }^{419}$ "Gottes Zorn entbrennt, wenn seine lange Nase, sprich sein >Langmut erschöpft ist. [...] Grund für den Zorn Gottes ist immer ein geschichtliches Ereignis, das Gottes Pläne, nämlich den Schutz des Lebens, zunichte macht. « ${ }^{420}$ Dabei ist der Zorn als Teil der Weltzuwendung JHWHs zu betrachten. Auch kann er vernichtende Dimensionen aufweisen: „Einerseits können Einzelne wie das Volk eigenes Leiden als Wirkung dieses Zornes benennen, andererseits kann der vernichtende Zorn zur Rettung vor den bedrohlichen Feinden angerufen werden. $" ~{ }^{421}$ In den Psalmen begegnet der Zorn Gottes meist im Zusammenhang mit der Erfahrung des Leidens und des Unheils, wobei die Leidens- bzw. Unheilserfahrung als Erfahrung des zornigen Handelns JHWHs oder als Heilsabwesenheit Gottes gedeutet wird. ${ }^{422}$

418 Übersetzungsvarianten von 6a.b sind folgende: »Einen Augenblick sind wir in seinem Zorn, ein Leben lang in seinem Wohlgefallen« oder "Nur einen Augenblick lebt man in seinem Zorn, ein Leben lang in seinem Wohlgefallen" (Fohrer, Psalmen, 223) bzw. mit einem semantischen Unterschied in Bezug auf das Subjekt: »Denn ein Augenblick (vergeht) in seinem Zorn, ein Leben in seiner Huld.« (Hupfeld, Die Psalmen, 451). In ähnliche Richtung geht die Wiedergabe bei Alonso Schökel / Carniti, Salmos 1, 466: «Un instante dura su cólera, toda la vida su favor« (Ein Augenblick dauert sein Zorn, das ganze Leben sein Wohlgefallen. Übersetzung S.E.).

419 Vgl. Sauer, ఇֵ, 223.

420 Schroer / Staubli, Körpersymbolik, 106. Nach Wälchli, Gottes Zorn, 32, spricht der Psalter nach den Büchern der Prophetie und dem dtr. Geschichtswerk am häufigsten vom Zorn Gottes. Er verweist auf 49 Verse, die Gottes Zorn mit unterschiedlichsten Begriffen (S. 29f) thematisieren, wobei in 27 Psalmen ein Mal oder mehrere Male vom Zorn Gottes gesprochen wird (S. 36).

421 Wälchli, Gottes Zorn, 95. Er unterscheidet drei unterschiedliche Weisen des Sprechens über Gottes Zorn im Psalter: 1. Leiden als Zorneserfahrung ohne Grund; 2. Leiden als Zorneserfahrung aufgrund einer Schuld - dazu zählt er Ps 30,6 - und 3. Hoffen auf den Zorn JHWHs zur Rettung vor Feinden. Vgl. Wälchli, Gottes Zorn, 88.96.

422 Vgl. Wälchli, Gottes Zorn, 86. Er liest V6 als redaktionelle Eintragung mit weisheitlichlehrhafter Tendenz und kommt zu folgendem Schluss: „Demnach ist die Erwähnung des 
Der Zorn Gottes in V6 folgt der Lobaufforderung in V5. Dieser Zorn kann mit der Erfahrung der Todesnähe aus V2-4 in Verbindung gebracht werden, aber auch eine allgemeine Aussage im Rahmen der biblischen Gottesrede darstellen. Dadurch lassen sich mit seiner Hilfe verschiedene Aspekte der Glaubenserfahrungen Israels zum Ausdruck bringen. Auf alle Fälle zeugt die Thematisierung des göttlichen Zornes von einem lebendigen, leidenschaftlichen Gott, der mit der Welt direkt in Beziehung steht. Gott setzt sich der Welt nicht nur aus und wird dadurch zum Wutschnauben gereizt, sondern er setzt sich auch für die Welt ein. ${ }^{423}$

Im Kontrast zum kurzen Moment (רֶגֵ Augenblick, kurze Dauer, kleine Weile, $\mathrm{Nu})^{424}$ des Zornes Gottes, der in V6 weder erklärt noch begründet wird, ${ }^{425}$ steht

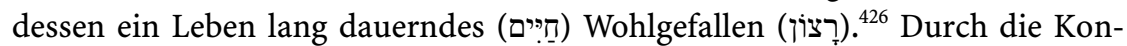
notationen des Gernhabens, der Liebe, des Gefallens sowie der Lust und des Begehrens wird der emotionale Gehalt von רָ רצון offensichtlich - und dies nicht zuletzt durch die zeitliche Ausdehnung: Währt der Zorn Gottes in seiner Mehrdimensionalität der Leidenschaftlichkeit sowie der Zerstörung nur einen

Zornes Gottes hier nicht primär als Erfahrung der Krankheit zu verstehen, sondern als sekundäre Deutung des Geschehens. Gottes Zorn wird zur Entschlüsselung des Zusammenhanges von falscher Selbstsicherheit und Krankheit verwendet und zugleich in den Gegensatz zum Erbarmen Gottes gerückt, das um vieles grösser erscheint als der Zorn" (S. 50). Diachron betrachtet ist dieser Schluss nachvollziehbar, synchron jedoch müsste dann die Erwähnung des Zorns in V6 als Prolepse zu V7 gelesen werden. Auf S. 144 verweist Stefan Wälchli auf Oppositionsworte zum Zorn: »Gegenbegriffe zum Zorn sind allerdings immer wieder das Erbarmen und die Güte bzw. Gnade Gottes. Durch das Erbarmen wird der Zorn begrenzt, wegen seiner Reue und seines Erbarmens fällt sich Gott sozusagen selber in den zornig erhobenen Arm.«

423 Vgl. Wälchli, Gottes Zorn, 150.

$424 \mathrm{Zu}$ רֵֶ als Begriff, der u. a. in den Vorstellungsbereich des göttlichen Strafgerichts fällt, vgl. Witzenrath, Am Abend Weinen, 464. Dahood, Psalms 1, 182 ordnet den Begriff in den Bereich des Verderbens und der Verdammnis ein und sieht ihn in Ps 6,11 und Num 26,12 - an beiden Stellen geht es im Zusammenhang mit רִ ư um Vernichtung bzw. Zugrundegehen - mit einem Todesort konnotiert. Dementsprechend lautet seine Übersetzung von V6: "For death is in his anger, life eternal in his favor" (S. 181).

425 »Ps 30,6 ist nicht behauptet, dass Jahwes Zorn Reaktion auf des Menschen Schuld ist. Die Frage nach dem Ursprung des Unheils und Bösen ist hier nicht behandelt.« Witzenrath, Am Abend Weinen, 470.

426 Das Nomen רצִ רצו kommen verhältnismäßig oft in den Psalmen der Hebräischen Bibel vor, und zwar jeweils 13x (Verb im q.). Das Hauptwort kann mit Gefallen, Wohlgefallen, Wohlwollen, Güte, Huld, Gnade, Gunst, Liebe, Einvernehmen und an manchen Stellen auch mit Wille, Wunsch, Lust und Begehren (Ps 40,9; 145,19) wiedergegeben werden. Die Wurzel רצה besitzt die Grundbedeutung: Wohlgefallen, Gefallen an jemandem oder an etwas haben; etwas gut finden, wohlgefällig betrachten, gern haben, lieben, wollen. Synonyme dazu sind begehren, wünschen, erwählen, lieben, segnen, Gefallen finden. Vgl. dazu Barstad, רצה, 640-652. Nach Diedrich / Scholtissek, Gnade, 859 steht der Begriff am deutlichsten für die Freiheit der Zuwendung Gottes zum Menschen. Wohlgefallen kann hier auch den Willen bzw. die Willkür zum Ausdruck bringen. 
Augenblick, so ist im deutlichen Kontrast dazu mit der göttlichen Güte und dem Wohlwollen JHWHs ein Leben lang zu rechnen.

Im Anschluss daran folgen in 6c.d allgemeine Aussagen die dunkle Seite des Weinens sowie die helle Seite des Jubels betreffend. Die Wurzel בכה wird im AT häufig verwendet. ${ }^{427}$ Weinen wird vor allem im Kontext der Trauer und Klage sowie der Angst und Bedrückung erwähnt. Als Zeichen des Schmerzes des/der Klagenden ist sie eine Form des emotionalen Ausdrucks von Tod, Zerstörung und Verwüstung - vor allem angesichts von Kriegsereignissen - sowie Ausdruck von Trauer über Abschied und Verlust. Bei starken Gefühlsregungen bricht spontan Weinen aus, so z. B. bei Erschütterung (Gen 42,24; 43,30; Ijob 2,12), Trauer über einen schlimmen Vorfall (Gen 27,38; Ri 11,37) oder bei Kränkung (1 Sam 1,7f.10). Geweint wird auch im Kult, in der Totenklage (vgl. Gen 23,2; 2 Sam

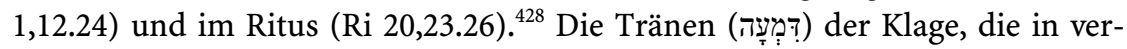
schiedene poetische Bilder aufgenommen werden (Ps 42,4;56,9;80,6), können die Bitte und das Rufen zu Gott unterstreichen. Gegenbild zu den Tränen und damit Kontrastbegriff zum Weinen ist der Jubel (רָָּּה)); das ist hier in V6 der Fall und - ganz besonders deutlich ausgedrückt - in Ps 126,5f. Dort allerdings ist der

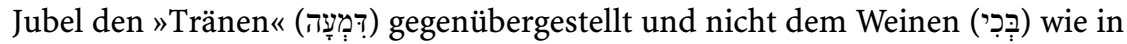

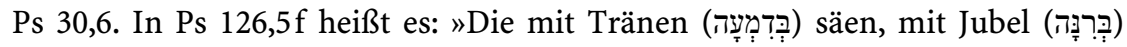
werden sie ernten. Einer der weinend geht, den Samenbeutel tragend, der kommt

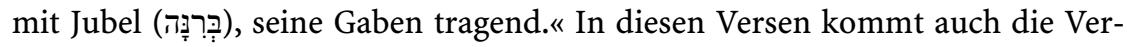
heißung zum Ausdruck, dass Klagen und Weinen ein Ende haben werden (ebenso Jes 25,8; 30,19; 65,19). Neben dem bereits erwähnten Weinen aufgrund von Not, Schmerz und Trauer können auch Tränen der Freude und Rührung fließen (Gen 29,11; 42,24; 45,2.14f). ${ }^{429}$

In V6 ist davon die Rede, dass das Weinen übernachtet bzw. die Nacht verbringt לין לין beginnt am Abend und endet am Morgen. Nicht nur Gemeinschaften, Personen, tote Körper sowie Tiere und andere Lebewesen können übernachten, sondern auch Zustände und Eigenschaften (Ijob 19,4: mein Irrtum/ meine Verfehlung; Ijob 41,14: Stärke; Jes 1,21: Gerechtigkeit; Ps 25,13: seine nefesch und hier V6: Weinen). Das Zeitwort setzt eine Form des Unterwegsseins bzw. Wanderns voraus. ${ }^{431}$ לין wird im q. mit den drei Schwerpunkten »die Nacht

427 Und zwar stets im q. (außer in Jer 31,15 und Ez 8,14). Das Substantiv iִ iִ in der Bedeutung "Weinen« kommt hingegen insgesamt 30x vor, als Subjekt allerdings nur 5x: Jer 3,21; 31,15; 48,5; Est 4,3 und hier in V6.

428 Vgl. Stolz, בכה, 313-316.

429 Vgl. Bester, Weinen (AT).

430 Der textkritische Apparat der BHS erwägt an dieser Stelle die Streichung des Zeitwortes metri causa. Diesem Vorschlag folgen einige Kommentatoren, u. a. Spieckermann, Heilsgegenwart, 253, der das Zeitwort als Glosse betrachtet, da es »den konzentrierten Nominalstil des Verses stört."

431 Vgl. Oikonomou, לין, 562-567. 
über bleiben «, »übernachten« und "wohnen« wiedergegeben. ${ }^{432}$ Hupfeld sieht hinter der Phrase das Bild eines am Abend in der Herberge einkehrenden Wanderers. ${ }^{43}$ Das Weinen scheint also vorerst unterwegs zu sein, bleibt über Nacht und zieht dann weiter, bevor zum Morgen hin lauter Jubel ausbricht, bzw. sodass dann morgens lautstark gejubelt werden kann. ${ }^{434}$ So kommt dem statisch anmutenden V6, der hauptsächlich mit Nominalsätzen konstruiert ist, durch das einzige Verb לין doch eine Form von Bewegung zu. John Goldingay übersetzt das Verb mit "take up lodging" und ergänzt: "In a vivid metonymy the suppliant pictures the weeping as lying down to sleep for the night instead of the weeper doing so. ${ }^{435}$ Er unterstreicht damit das Bild des personifizierten Weinens: Anstelle des/der Weinenden ist es das Weinen selbst, das sich zum Schlafen hinlegt. Die Personifikation gilt als Sonderfall metaphorischer Sprechweise (siehe III Methodik 2.2.3). Durch die Kombination und Überlappung der beiden Bereiche »Weinen" und "Übernachten" können neue Bedeutungszusammenhänge entstehen. Dabei ist das Moment der Bewegung festzuhalten. Hier ist keine Statik zu finden. Weinen als Ausdruck des Schmerzes und der Trauer angesichts eines Verlustes oder einer tiefen Not stellt sich vor allem über Nacht ein, in der Zeit der Dunkelheit und des Unheils. Weinen geht jedoch vorbei, wenn der Morgen kommt. Weinen nähert sich, kehrt ein, wohnt für eine Zeit lang und zieht dann wieder weiter. Oft wird die finite Verbform יִ יָיז als Prädikat für beide Stichen gedeutet: Am Abend kehrt Weinen ein, und am Morgen ist der Freudengesang zu Gast. ${ }^{436}$ Dabei ist zu bedenken, dass sich לין schwerpunktmäßig auf das Übernachten bezieht, das mit dem Morgen ohnehin vorüber ist. Das Verb evoziert die Frage nach einem Ort (wo findet die Übernachtung statt?). Darüber hinaus könnte nach weiteren handelnden Subjekten und Objekten gefragt werden: Übernachtet das Weinen allein? Bei wem übernachtet das Weinen? In V6 sind Abend (עָרֶב) und Morgen (כָּקָר) nochmals spezifisch konnotiert und auch mit zwei unterschiedlichen Präpositionen (כִ bzw. ?ִ) versehen. Dem Weinen am Abend steht der Jubel zum Morgen hin bzw. bis zum Morgen gegenüber. Der Jubel scheint also schon vor dem Morgen einzusetzen und sich zum Morgen hin »mitzubewegen«. Der Nacht als Zeit der Dunkelheit, des Unheils und des Unglücks wird in diesem Vers kontrastreich der Morgen als Zeit des Lichts und des Heils gegenübergestellt. ${ }^{437}$

432 KAHAL, 271.

433 Vgl. Hupfeld, Die Psalmen, 458.

434 Vgl. Cohen, The Psalms, 86.

435 Goldingay, Psalms 1, 429.

436 Vgl. z. B. Krinetzki, Psalm 30, 355.

437 Vgl. Witzenrath, Am Abend Weinen, 465f. Ebenso Hossfeld / Zenger, Die Psalmen 1, 189. Keel, Die Welt der altorientalischen Bildsymbolik, 67 ordnet ebenso den zeitlichen Bereich der Nacht der Grenze zur Totenwelt zu, so wie dies auch für bereits analysierte räumliche 
Der Vers schließt freudig, und zwar mit der Erwähnung lauten Jubels: Beim Substantiv רנה handelt es sich um eine lautstarke Äußerung, um ein lautes Schreien, welches inhaltlich zunächst noch unbestimmt ist, in der Mehrzahl der Vorkommen jedoch - wie hier in Ps 30 - mit dem parallel gebrauchten Wortfeld der Freude verbunden ist. In wenigen Fällen kann es aber auch für Klage- und Gebetsrufe (vgl. Ps 17,1; 61,2; 88,3; 106,44; 119,169; 142,7) stehen. ${ }^{438}$ Es handelt sich hier um lautstarke Freudenkundgebungen, welche in der Mehrzahl der Belegstellen im Zusammenhang mit dem Gotteslob Verwendung finden. Gejubelt wird darüber, dass JHWH in einer Notsituation durch sein rettendes Handeln geholfen hat. ${ }^{439}$ Dabei bricht der Jubel spontan aus. ${ }^{440}$ Die Begründungen für das Schreien vor Freude sind - neben der gerade erwähnten Erfahrung der Heilstaten Gottes für einen Einzelnen oder für das Volk - vielschichtig; es hat den Anschein, dass eine exakte Konkretisierung bewusst vermieden wird, "um so möglichst vielen das Einstimmen in das jubelnde Loben JHWHs angesichts seines bereits erfahrenen Handelns zu ermöglichen. « ${ }^{441}$

Zur Erinnerung: V5-6 sind im Stil der AdressatInnenperspektive gehalten, die sich durch Inhalt und Sprechrichtungswechsel deutlich von V2-4 abheben. Gerade diese Zugewandtheit an eine wie auch immer geartete Öffentlichkeit kann neben den zahlreichen explizit ausgedrückten Emotionen im Text eine weitere emotionale Wirkung erzielen, indem die Emotionen aus dem Inneren des/der Sprechenden auf die Zuhörenden übergehen, damit diese in den Lobpreis einstimmen: »Although these lines [...] seem to have the flavor of an interpolation

Bereiche (Zisterne, Totenwelt, Grube etc.) gilt. »In der Nacht erscheinen Krankheit und jegliches Übel viel schlimmer als tags, und die Dichter der Klagelieder erzählen, wie sie die ganze Nacht unter Tränen und Seufzen wachgelegen haben $(6,7 ; 30,6 ; 77,6)$. Die Welt ist vergangen und der Beter mit seinem Schmerz, der ins Unermeßliche wächst, allein.» (S. 67). Ähnlich Hupfeld, Die Psalmen, 458, der stichwortartig formuliert: »[...] der Abend (wie sonst die Nacht), als die Zeit der einbrechenden ängstl. Finsternis, für das Einkehren des Leids, der Morgen, als wiederkehrendes Licht, für die Wiederkehr der Freude.« Zur thematisch geprägten Vorstellung der Hilfe Gottes am Morgen vgl. Janowski, Rettungsgewissheit, $180-188$.

438 Die Hauptanzahl der Belegstellen für die Wurzel רנן (53x) und für das Substantiv רנה (33x) findet sich in den Psalmen. Jutta Hausmann präsentiert folgende Zählung: »Schwerpunkte für den Gebrauch von rnn im Zusammenhang mit freudigen Aussagen, wobei $r n n$ wohl im Sinne von `jubeln, jauchzen $>$ o. ä. verstanden werden kann, sind die Psalmen (34mal) und das Buch Jesaja (20mal, davon 9mal DtJes).« Hausmann, רנן, 539. Laut Abart, Lebensfreude, 135 kommt die Wurzel רנן in den Psalmen insgesamt $42 \mathrm{Mal}$ vor und wird davon $6 \mathrm{Mal}$ als Ausdruck von Klage, $36 \mathrm{Mal}$ als Ausdruck von Freude verwendet.

439 Vgl. Ficker, רנון, 781-786.

440 Vgl. Abart, Lebensfreude, 250.

441 Hausmann, רנן, 540. So geht auch Ps 30 über ein spezifisches Ereignis, welches einen Einzelnen betrifft, hinaus: »Ps 30,6 spricht vom Jubel angesichts der Errettung aus Krankheit, wobei diese aber auch wieder über das individuelle Moment hinaus erweitert wird, indem die Frommen angesichts der Erfahrung des Beters zum Lob aufgefordert werden (v. 5). Das Einzelschicksal wird so zum Paradigma.« Hausmann, 544. 
because they depart from the intensely personal character of the rest of the poem, it may be that the author intended that at this point the pent-up emotion in the soul of the speaker overflows to demand that every one join with him in his praises. $\aleph^{42}$

Zusammenfassend lässt sich in Bezug auf den emotionalen Gehalt des Verses Folgendes festhalten: $\mathrm{Zu}$ den explizit ausgedrückten Emotionen zählt der göttliche Zorn, der kurz ist und die Dimensionen der Zerstörung sowie jene der Leidenschaft, Zuwendung und Gerechtigkeit besitzt. Ein weiteres explizites Emotionswort ist jenes der lang anhaltenden göttlichen Güte, die mit Wohlgefallen, Gernhaben, Zuneigung und Lieben verbunden ist. Sowohl der Zorn als auch die Zuneigung werden der Gottheit zugeschrieben. Hinter dem Weinen als Ausdruck von Zerstörung, Tod, Schmerz und Abschied stehen die Emotionen der Erschütterung, der tiefen Betroffenheit und Trauer, die sich zur Abend- bzw. Nachtzeit einstellt, welche als dunkle Zeit der Gefahr und des Unheils gilt. Mittels der Personifikation des wandernden Weinens (vgl. III Methodik 2.2.3), welches abends einkehrt, über Nacht bleibt und morgens weiterzieht, kann das menschliche Erfahrungsrepertoire durchweinter Nächte, die beim Eintreten des ersten Tageslichts enden und gegen Morgen hin immer heller und leichter werden, sodass sich tagsüber gar Freude einstellen kann, evoziert werden. Dadurch können sich die Lesenden besser in den Text hineindenken und -fühlen. Der Vers endet mit dem expliziten Emotionswort des Jubels, der mit dem Morgen als Zeit von Licht und Heil in Verbindung steht. Diese weisheitliche Reflexion über allgemein menschliche Erfahrungen kann, analog zu Ps 90,3-6 (siehe Kapitel VI Textanalyse Psalm 90), dazu anregen, die je eigenen persönlichen Erfahrungen mit diesen in allgemeiner Rede (3.P.) gehaltenen zu vergleichen und zu prüfen, $o b$ diese auch für die persönliche Existenz zutreffen. Dadurch können Lesende in das Textgeschehen involviert werden. Interessant ist die Tatsache, dass in diesem Vers weniger die durch die expliziten Emotionswörter thematisierten Emotionen zur Identifikation einladen (vgl. dazu auch die Analyse zu Ps 90), sondern vielmehr jene, die durch die metaphorische Rede evoziert werden.

\subsection{Vers 7: Selbstsicherheit}

7a Ich aber, ich habe gesagt in meiner Sicherheit:

$7 b$ Nicht werde ich ins Wanken gebracht auf ewig.

Bezüglich des emotionalen Gehalts ist in V7 auf indirekte Anspielungen in Verbindung mit der Semantik zu verweisen. So geht es zunächst um Sicherheit.

442 Kraft, Strophic Structure, 83. 
Dabei begegnet das althebräische hapax legomenon שָׁלו biblisch-aramäisch in der Bedeutung »Nachlässigkeit» in Dan 6,5; Esr 4,22 und 6,9. ${ }^{443}$ Es kann gemäß der Wurzel שלה (q. Ruhe haben) ${ }^{444}$ sowohl mit positiven Konnotationen (Ruhe, Sicherheit) ${ }^{445}$ als auch mit negativen (Selbstsicherheit, Selbstgenügsamkeit) wiedergegeben werden. Könnte also שָׁלו zunächst eine relativ neutrale Sorglosigkeit bezeichnen, wofür sich vom entsprechenden Adjektiv

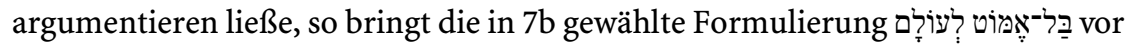
allem mit dem Zusatz »in Ewigkeit« eine Form der Überheblichkeit zum Ausdruck. ${ }^{447}$ Für שָׁלו kann damit festgehalten werden: "Im vorliegenden Kontext hat die Bezeichnung einen Stich in Richtung 'Selbstsicherheit, Selbstgenügsamkeit, Überheblichkeit $\_.{ }^{448}$ Es geht also darum, auf wen man Vertrauen gründet - auf sich selbst oder auf JHWH. ${ }^{449}$ Verstärkt wird die Deutung der sich selbst gegebenen Sicherheit - im Gegensatz zur Sicherheit, die in JHWH gegründet ist durch die viermalige direkte Bezugnahme auf das lyrische Ich: Ich aber (וָאָנִי), ich

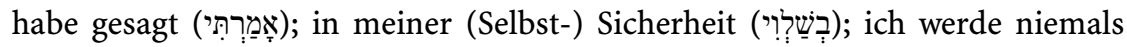
wanken (אֶּוֹט). Sorglose Selbstsicherheit zeichnet übrigens die Toren aus (Spr

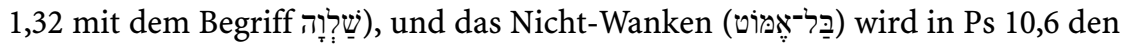
Gottlosen in den Mund gelegt. In Ps 62,7 wankt der/die PsalmistIn deshalb nicht, weil Gott ihm/ihr Fels, Burg und Hilfe ist.

Durch die Analyse der Syntax und Semantik kann die Selbstbezogenheit des lyrischen Ich in V7 deutlich gemacht werden. Hinsichtlich der Emotionen ist der Vers von Selbstsicherheit und Selbstüberschätzung geprägt, die in Überheblichkeit und Stolz ausarten und bis zur Torheit führen können.

\subsection{Vers 8: Kraft und Erschrecken}

8 a JHWH, in deinem Wohlgefallen

$8 b$ hast du aufgestellt für meinen Berg eine Kraft.

443 Vgl. Müller, Psalm 30, 195.

444 KAHAL, 607.

445 Vgl. »ruhige Zufriedenheit« bei Hardmeier, Systematische Elemente, 342 sowie »sicheres, sorgloses Glück« bei Kraus, Psalmen, 385.387.

446 Vgl. die relativ seltenen Vorkommen des Adjektivs שָָׁׁ (ungestört, sorglos) in Jer 49,31; Ez 23,42; Sach 7,7; Ps 73,12; Ijob 16,12; 20,20; 21,32; 1 Chr 4,40.

447 Vgl. Müller, Psalm 30, 196. Von einer »ewigen Selbstverständlichkeit« spricht in Zusammenhang von V7 Zenger, Theophanien, 418.

448 Weber, Psalm 30, 42. Miller, Die Psalmen, 62 übersetzt 7a folgendermaßen: »Ich prahlte einst in meinem Wohlergehen." Müller, Psalm 30, 198 spricht von »hybrider Selbstüberhebung«, Herkenne, Das Buch der Psalmen, 128 vom Sicherheitswahn bzw. davon, sich in seinem Glück zu sonnen.

449 Vgl. Jacobson, »Many are Saying«, 62. 
8c Du hast dein Angesicht verborgen,

$8 d$ ich war erschrocken.

Neben syntaktischen Schwierigkeiten, die das Verständnis der Aussageabsicht von $8 \mathrm{~b}$ erschweren - die Phrase »du hast aufgestellt für meinen Berg eine Kraft« meint wahrscheinlich einen festen Standort ${ }^{450}$ - begegnet hier wieder das bereits aus V6 bekannte רִצוֹ, welches das Wohlgefallen sowie die Gnade und Zuwendung Gottes, das Gernhaben und Lieben impliziert und damit emotional sehr positiv konnotiert ist. ${ }^{451}$ Mit dem Erschrecken als Reaktion auf das Verbergen des Angesichts Gottes in 8c.d wird eine dazu eindeutig im Kontrast stehende Emotion zum Ausdruck gebracht. Das Angesicht Gottes (פָָּ ) steht für göttliche Nähe und Zuwendung sowie für die schützende und wohlwollende Gegenwart Gottes. Das Gesicht ist ja der »Ort« der Wahrnehmung, der Kommunikation und damit der Beziehungsaufnahme und Beziehungspflege schlechthin. ${ }^{452}$ "Insgesamt geht es in der Rede von Gottes Angesicht selten um den anatomischen Körperteil im engen Sinn, sondern um die Gegenwart JHWHs, seine Nähe oder Hinwendung in positiver oder negativer Absicht. [...] Im Hintergrund der zentralen Erwähnung des göttlichen Antlitzes steht [...] vor allem in den Psalmen vermutlich die altorientalische Vorstellung, dass die Begegnung mit JHWH analog zur Begegnung mit einem König konnotiert ist. ${ }^{453}$ Diese Beziehungsaufnahme mit Gott

450 Vgl. Kraus, Psalmen, 389. "You made me more stable than the mighty mountains« bei Dahood, Psalms 1, 181. Von der Festigkeit des Glücks spricht Miller, Die Psalmen, 63: „Du hattest ja, o Herr, in deiner Huld mein Glück gefestigt.» Nach Alonso Schökel / Carniti, Salmos 1, 471 symbolisiert der Berg Stabilität und Höhe.

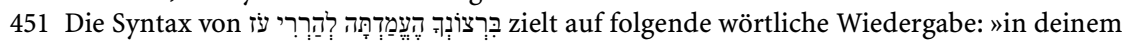
Wohlgefallen hast du hingestellt meinem Berg Stärke.« Dabei gilt Vgl. Spieckermann, Heilsgegenwart, 253. Ein Überlieferungsfehler wird konstatiert und der Versuch unternommen, die ursprüngliche Lesart zu rekonstruieren. Weitere Übersetzungsversuche sind u. a. folgende: »hattest du mich auf einen hohen Fels gestellt« (LUT); "hattest du mich auf feste Berge gestellt« (ELB); »stelltest du mich auf den schützenden Berg« (EIN); »hast du meinem Berg Stärke verliehen« (BigS), ähnlich Ruwe, Die Psalmen, 44: "hattest du meinem Berg eine Macht hingestellt" und Zenger, Theophanien, 420: »hattest du Kraft / Festigkeit als Berg für mich hingestellt.» Eine Deutung bietet Michel, Tempora, 67. Nachdem in V7 der Hochmut des betenden Ich dargestellt wurde, muss seines Erachtens an dieser Stelle nun JHWHs Eingreifen geschildert werden. Er deutet die Stelle mit »du hast meinem Hochmut eine Grenze gesetzt.» Gegenteilig ist die Deutung von Ludwig Wächter: Mit der Übersetzung »hast du mir schützende Berge hingestellt«, »ergibt sich die Aussage, dass der Beter sich durch Jahwes Schutz umgeben fühlt. Es wäre hier Ps 125,2 zu vergleichen, der das gleiche Bild bringt: Jerusalem - Berge umhegen es -; es umhegt Jahwe sein Volk. « Wächter, Psalmstellen, 65. Als Bildwort deutet die Stelle Goldingay, Psalms 1, 424: »Apparently this is a way of saying, ,You established me with the strength of a mountain."«

452 Vgl. Weber, Werkbuch 3, 109.

453 Baumann, Das göttliche Geschlecht, 224. Auch Fohrer, Psalmen, 227 nimmt an dieser Stelle auf den König Bezug: »Wenn der König in der Gerichtssitzung sein Gesicht verbarg und verhüllte, dann bedeutete es das Todesurteil für den Verbrecher. In anderen Fällen bedeutete 
und damit dessen erfahrbare Nähe werden durch das Verbergen des Angesichts negiert. $8 \mathrm{c}$ wird deshalb als Entzug der Gnade und Gottverlassenheit gedeutet. ${ }^{454}$ Ist also die Begegnungsmöglichkeit verstellt und damit die göttliche Zuwendung nicht erfahrbar, sondern nur noch die Gottferne - was auch immer der Grund בהל dafür sein mag -, so setzt Erschrecken ein (Ps 104,29). Hinter der Wurzel (erschrecken) stehen die Bedeutungen »eilen«, "sich plötzlich und erregt bewegen« sowie »atemlos sein « ${ }^{455}$ Das Hauptwort steht für ein plötzliches, unerwartetes oder bedrohliches Ereignis und beschreibt in vielen Fällen jenen Schrecken, בהל der den befällt, der sich dem Göttlichen gegenübergestellt weiß. Das Verb wird mit jenen Verben synonym verwendet, die der Emotion "Angst « zuzuordnen sind. Erich Zenger beschreibt בהל mit »schreckensstarr [sein], d. h. zutiefst lebensunfähig, sozusagen krank bis in die Knochen hinein.« ${ }^{456}$

Hinsichtlich der Emotionen stehen das göttliche Wohlgefallen und die damit verbundene Zuwendung sowie Halt und Beständigkeit für das lyrische Ich durch den festen Standort im Gegensatz zum Verbergen des Angesichts. In 8c.d ist darauf zu schließen, dass die Beziehungsaufnahme mit der Gottheit verwehrt und damit keine Begegnung und Kommunikation möglich ist. Implizit werden damit hier auf Seiten der Gottheit der Entzug der Gnade und Abwendung, auf Seiten des lyrischen Ich Gottverlassenheit und damit einhergehend die Emotion der Einsamkeit evoziert. Infolgedessen tritt für das lyrische Ich durch das plötzliche Erschrecken Angst ein, die bis zur Todesfurcht reichen kann.

\subsection{Vers 9: Gottesanruf}

9a $\mathrm{Zu}$ dir, JHWH, rief ich

$9 b$ und zu Adonaj flehte ich um Erbarmen:

Zunächst fällt das zweifache Rufen zur Gottheit ins Auge. ${ }^{457}$ Dies ist ein Mal direkt (9a) und ein Mal erzählend (9b) präsentiert, was auf eine gewisse Dringlichkeit hinweist, womit implizit eine Emotion zum Ausdruck gebracht wird.

es, dass er einem Höfling seine Gunst entzog und ihn ins Elend verstieß. So ist es dem Beter ergangen."

454 Vgl. Krinetzki, Psalm 30, 356f. In Ps 51,11 bittet das betende Ich Gott darum, er möge sein Antlitz angesichts seiner großen Schuld verbergen bzw. abwenden. Im Gegensatz dazu ist alleine schon die Zuwendung, das Zuhören Gottes positiv konnotiert, zumal die Abwendung und Nicht-Kontaktaufnahme JHWHs mit den Menschen unheilvoll ist. Zur Rede vom Angesicht JHWHs in den Psalmen vgl. im Detail Hartenstein, Das Angesicht JHWHs, 213-261.

455 Vgl. Otzen, בהל, 521.

456 Hossfeld / Zenger, Die Psalmen 1, 190.

457 In V9 werden sowohl JHWH als auch Adonaj für die Bezeichnung der Gottheit Israels verwendet. Dazu bemerken Joüon / Muraoka, Grammar, 510: »In the sacred namẹ the 
קרא (rufen, zurufen, ausrufen, anrufen, berufen; z. B. Ps 28,1; Joël 1,19) dient zur Kommunikationsaufnahme und hat die Grundbedeutung »durch den Laut der Stimme die Aufmerksamkeit jemandes auf sich ziehen, um mit ihm in Kontakt zu kommen. ${ }^{458}$ Das Anrufen JHWHs ist mit unterschiedlichen Bedeutungsnuancen versehen, die vom jeweiligen Kontext bzw. von den parallel verwendeten Verben abhängen. Hier in V9 kann aufgrund der Parallelsetzung mit חנן von einem Hilferuf gesprochen werden. ${ }^{459}$ Die Kommunikationsaufnahme durch das Rufen soll die Distanz überbrücken und die Entfernung zum Gesprächspartner überwinden. Diese Form der Kontaktaufnahme wird unter anderem - wie hier in V9 - mittels der Präposition אֶ konstruiert. ${ }^{460}$ Auf Formulierungen mit dem Verb קרא sind in den Psalmen mehrere Reaktionen auszumachen: Einerseits folgt auf das Rufen nach bzw. zu Gott die unmittelbare Reaktion Gottes in Form einer Antwort (z. B. Ps 3,5; 118,5; 138,3), des Neigens des Ohres (z. B. Ps 116,2) oder des Erlösens (z. B. Ps 81,8). Andererseits kann die Anrufung Gottes mit einer Bitte um Erhörung und Eingreifen zunächst auch unbeantwortet bleiben (Ps 22,3). Parallel zu קרא steht das zweite Verb des Verses, חנן. Diese Wurzel bedeutet im hitp. sich jemandes Gunst erflehen, um Erbarmen flehen, und sie wird unter anderem - ebenso wie קרל - mit der Präposition gebildet (vgl. neben hier in V9 Gen 42,21; Dtn 3,23; 1 Kön 8,33.47; 2 Kön 1,13; Ps 142,2; Ijob 8,5; 2 Chr 6,37). ${ }^{461}$ Das Substantiv חֲk akzentuiert in besonderer Weise die Zuneigung, die Gunst, das Gnädigsein dessen, der diese Gunst gewährt. Auf Seiten der Empfangenden bezeichnet das Wort die "Lieblichkeit» bzw. "Anmut «. ${ }^{462}$ Dann ist es ein Terminus für Schönheit und bezeichnet die Qualität, die jemand oder etwas hat. ${ }^{463}$

Bezüglich des emotionalen Gehalts wird mit dem wiederholten Rufen die Dringlichkeit verdeutlicht, die durch die Syntax des Verses implizit ihren Ausdruck findet. Es geht dabei um die Kontaktaufnahme mit JHWH, wodurch die Distanz (vgl. V8) überwunden und die Erfahrung von Nähe wieder möglich werden soll. Die Kontaktaufnahme mit JHWH ist mit dem Wunsch verknüpft, dass die Emotionen der Zuneigung und des Erbarmens seitens der Gottheit für das lyrische Ich wieder erfahrbar werden mögen.

Lord, the 1st pers. possessive suffix has weakened and even no value.« Viele masoretische

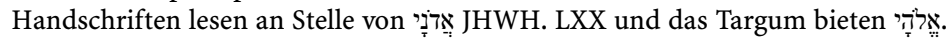

458 Labuschagne, קרא, 668. Als »rufen zu JHWH« kommt die Wurzel 89x vor, davon 47x in den Psalmen.

459 Vgl. Labuschagne, קרא, 673.

460 Vgl. Hossfeld / Kindl, קרא, 120.

461 GES, 373. Vgl. V11.

462 Vgl. Diedrich, Gnade, 859.

463 Vgl. Freedman / Lundbom, חנן, 23. 


\subsection{Vers 10: Verhandeln mit Gott}

10a Was für ein Gewinn (ist) an meinem Blut,

$10 b$ wenn ich in die Grube hinabsteige?

10c Wird dich loben Staub,

10d wird er erzählen von deiner Treue?

Durch die Fragen, die in Anklageform an JHWH gerichtet sind und die Auseinandersetzung mit der Gottheit in drastischer Weise zum Ausdruck bringen, klingt bereits in der Syntax eine Form der Empörung und eine Dichte von Emotionen an, die durch die Semantik, die Bildersprache und den Kontext des Verses verstärkt werden: „Wie der Ausruf von 10a.b von einer heftigen Gemütsbewegung, dem Schmerz, so zeugt die rein rhetorische Doppelfrage von 10c.d von dem Bestreben des Dichters, Gott den Widersinn seines drohenden Todes besonders eindringlich (synonymer Parallelismus) und mit der nötigen Klarheit vor Augen zu stellen. Die grammatische Konstruktion steht ganz im Dienste des Anliegens der Klagegebete, Gott zum helfenden Einschreiten zu bewegen. ${ }^{464}$ Mit den in dieser ersten Frage gewählten Begriffen wird somit die Deutlichkeit der Konfrontation ebenso offensichtlich wie die existenzielle Bedeutsamkeit des erwünschten Eingreifens Gottes.

10a.b dürften sich auf das Sterben beziehen. Dabei gilt רֶֶֶּ (Vorteil, Gewinn; Gen 37,26; Ri 5,19; 1 Sam 8,3; Ps 119,36; Spr 28,16) als Terminus technicus der Wirtschaftssprache und weist eindrucksvoll auf eine Gewinn- und Verlustrechnung sowie auf die Größe des Verlustes hin. ${ }^{465}$ In der Frage von 10a, die an die Gottheit gerichtet ist, wird mit dem Begriff בֶֶֶּ der Verhandlungscharakter des Kommunikationsgeschehens verstärkt. דָָ (Blut) kann unter anderem auf eine gewalttätige Handlung bzw. auf einen »vorzeitige[n], durch höhere Gewalt (z. B. Seuche) herbeigeführte[n] Tod ${ }^{466}$ verweisen. Sehr nahe zu ${ }^{2}$ (ạ (an meinem Blut)

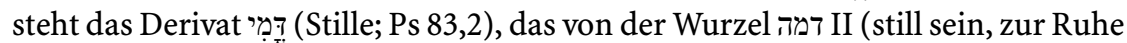
kommen, stumm sein, schweigen müssen) abgeleitet wird. Interessant ist, dass

464 Krinetzki, Psalm 30, 358. Witzenrath, Am Abend Weinen, 461 verweist ebenso auf die von den Fragen in 10a.c.d ausgehende Eindringlichkeit, die den Adressaten, also die Gottheit Israels, überzeugen sollen. Auf die Rhetorik der Klage gegen Gott und deren Funktion, Emotionen zum Ausdruck zu bringen, beziehen sich Dale Patrick und Kenneth Diable: "What is the rhetoric of accusation directed against God? Obviously it is expressive of emotion, a way of clearing the air, so to speak, similar to a fight in a personal relationship." Patrick / Diable, Persuading The One, 28.

465 Vgl. Seybold, Poetik der Psalmen, 268.

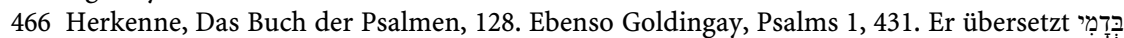
(durch mein Blut) mit »in my being killed « und fährt fort:»[...] which would often point to violent death and suggests the kind of danger coming from an injury that could have led to death rather than an illness." Auf die Dimension der Zerstörung weist ebenso Wilson, Psalms, 518 mit der Übersetzung »in my destruction« hin. 
das semantisch ähnlich gelagerte Verb דמם (schweigen, sich still halten) in V13 aufgenommen wird. Die NIV gibt daher die Phrase in V10 mit »what is gained if I am silenced « wieder. Mit dem Blut wird auf einen gewaltsamen Tod hingewiesen, mit der Stille auf den Todesort selbst. Die Räume des Todes wurden bereits in den vorhergehenden Versen angesprochen. So war schon in V4 vom Hinabsteigen (ירד) die Rede. Nun wird vom Hinabsteigen in die Grube (שֵָׁ) gesprochen, was ein weiteres Bild für den Todesraum ist. ${ }^{467}$ שֵ bezeichnet die Grube, in der das Wild gefangen wird, und steht im übertragenen Gebrauch für ein nicht näher genanntes Unheil, das dem Menschen bereitet wird. Aus der Grube gibt es kein Entrinnen. Die Tiefe und Enge der Grube verweisen auf das Grab und die Unterwelt (vgl. V4; ebenso Ps 55,24). ${ }^{468}$ "Zisterne, Gefängnis und Fallgrube sind von ihrer Form her geeignet, als Fallen zu wirken, die alles Lebendige verschlingen [...]. Auf Grund ihrer äußeren Form werden sie sich gegenseitig und alle drei zusammen dem Grab assoziiert. « ${ }^{469}$

In der Verhandlung mit der Gottheit wird hier in V10 darauf hingewiesen, welchen Nutzen oder Gewinn es bringt bzw. was das Leben noch wert ist, wenn der/die PsalmistIn dem Tode so nahe ist, dass er/sie Gott nicht mehr loben kann. »Dabei wird neben den Hilfsappellen auch eine Überzeugungsrhetorik ansichtig im Sinne von: Was hilft es dir, mein Gott, wenn ich endgültig vom Tod überwunden werde? Du verlierst so nur einen auf dieser Welt, der dir lobdankt und deine Treue bekennt. « ${ }^{470}$ Die Gottheit wird damit zum Handeln aufgefordert und ihr Eingreifen wird verlangt, was durch den Kontext des Rufens um Erbarmen in V9 und der Bitte um Erhörung und Hilfe in V11 noch verstärkt wird.

Der in diesem Vers genannte Staub, dem es im Gegensatz zu lebenden Menschen nicht möglich ist, JHWH zu loben, kann das Material sein, aus dem der Mensch entsteht und in das der/die Tote wiederum zerfällt (Gen 3,19; Koh 3,20; 12,7); es kann aber auch jener Staub sein, der die Unterwelt anfüllt (Jes 26,19; Ps 22,30; Ijob 17,16;20,11; 21,26). ${ }^{471}$ Dahood übersetzt mit »slime«, weil dies besser

467 Vgl. zu den folgenden Ausführungen Wächter,

468 Keel, Die Welt der altorientalischen Bildsymbolik, 57 verweist an dieser Stelle auf die Wiedergabe von der Beter Jahwe gegenüber argumentiert: Was gewinnst du damit ..., dass ich zur Verwesung hinabsteige, preist dich der Staub? Kündet er von deiner Treue? (Vgl. auch 55,24 >die Grube der Verwesung $)$."

469 Keel, Die Welt der altorientalischen Bildsymbolik, 63. Er spricht in weiterer Folge von diesen Räumen als »Chiffren [...] für die Enge und Verlorenheit, die den Israeliten jederzeit und überall bedrängten und zu Jahwe hindrängten, der angesichts solcher Bedrohungen allein festen Halt gewähren konnte« (S. 63).

470 Weber, Psalm 30, 42. Ähnlich argumentiert Hardmeier, Systematische Elemente, 345, indem er feststellt, »dass JHWH mit jedem, der dem Tode anheimfällt, selbst einen für ihn besonders kostbaren Zeugen verlieren würde.« Ähnlich Kuckhoff, Psalm 6, 252, der darauf verweist, »dass Gott sich selbst schadet, wenn er den ihn lobenden Beter sterben lässt.»

471 Vgl. Müller, Psalm 30, 198. 
zum nordwestsemitischen Motiv passe, das die Unterwelt als einen Ort voller Schlamm, Lehm, Matsch bzw. Schmutz und Dreck beschreibe. ${ }^{472}$ In Ps 113,7 wird

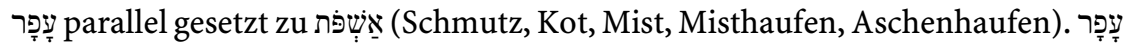
hat demnach die Konnotation eines amorphen Materials; es kann das Material selbst (Schlamm, Matsch, Staub, Lehm etc.) bezeichnen, aber auch den Ort, an dem dies sich vorzugsweise befindet. Damit ist dann jener Todesraum gemeint, der neben der genannten Enge und Unbeweglichkeit auch als ein Ort der Stille gilt.

Das Loben und Preisen (ידה) Gottes hingegen (vgl. Analyse zu V5) gehört zur Grundaufgabe des Menschen und damit in den Bereich des Lebendigen. Den Toten ist dieses Loben nicht möglich: »Nicht die Toten, deren Blut zu pulsieren aufhört und die zu Staub verfallen, können auf dieser Erde bezeugen, dass Gott die Quelle des Lebens ist, sondern die Lebendigen. Vor allem die, die real erfahren haben, dass das Leben ein Geschenk ist, weil es ihnen an der Schwelle des Todes wiedergegeben wurde. ${ }^{473}$ Im Todesraum wird JHWH nicht mehr gelobt (vgl. die gleiche Argumentation in Ps 6,6; 88,11f; 115,17; Jes 38,18f). ${ }^{474}$ An dieser Stelle ist festzuhalten, dass sich in Ps 30 unterschiedliche Auffassungen zur Unterwelt und zur Grube finden. Werden die Begriffe Totenreich (4a), Zisterne (4b) und Grube (10b) im Psalter häufig synonym verwendet, so stehen in Psalm 30 das Totenreich und die Zisterne (V4) für den Tod mitten im Leben, die Grube (V10) dagegen für das Ableben bzw. den Tod am Lebensende. ${ }^{475}$

Mit V10 wird der klare Gegensatz zwischen dem Schweigen im Todesraum (V4; V10) und dem Lobpreis JHWHs (V2.5.13) zum Ausdruck gebracht. Die angeführte Argumentation "wird von den Betern gleichsam wie ein letzter Strohhalm aufgegriffen, um es als Argument ihrem Gott vorzulegen, in dem Sinne, dass er sich am meisten selbst schade, wenn er den Verlust eines Verehrers an die Scheol nicht verhindere. ${ }^{476}$

Die Personifikation von עָ פָָּ als Subjekt des Lobens und Erzählens bewirkt zunächst eine Vermenschlichung des Staubes: Nur lebendige Menschen können

472 Vgl. Dahood, Psalms 1,184.

473 Zenger, Die Nacht wird leuchten, 92f. »Wird dich wohl meine Asche preisen ...» bei Miller, Die Psalmen, 63.

$474 »$ Allen Stellen liegt die Vorstellung zu Grunde, dass nach dem Tod, in der Unterwelt, es nicht mehr möglich ist, JHWHs zu gedenken, ihn zu preisen oder ihn zu verkündigen, weil - nach verbreiteter Auffassung - dort, am Ort des `Vergessens (Ps 88,13) und der `Stille` (Ps 115,17), die Beziehung zu JHWH selbst aufgehört hat, wie ja auch ein freies und lautes Sprechen nicht mehr möglich ist.« Seybold, Poetik der Psalmen, 267.

475 Vgl. die Analyse von V4 und Baumgart, Vom Tod mitten im Leben, 104.

476 Seybold, Poetik der Psalmen, 267. Ebenso Hossfeld / Zenger, Die Psalmen 1, 190. Der Tod würde JHWH nicht nur keinen Gewinn bringen, sondern im Gegenteil sogar schädlich sein (vgl. in ähnlicher Weise Ps 88, 11-13; 115,17; Jes 38,18f; Sir 17,27f; Bar 2,17f). Ähnlich Loader, Psalm 30, 299: "It will be to God's detriment if a faithful human individual dies.» Vgl. ebenso Charney, Persuading God, $21 \mathrm{f}$. 
Gott loben und von seiner Treue kundtun. Im Psalter gehört es zutiefst zum Menschsein dazu, die Gottheit zu loben und von ihren Taten zu sprechen. Die Personifikation von עָ עָפָר verknüpft insofern zwei als unvereinbar geltende Bereiche: עָכָָּ ist ohne Gestalt und gehört hier in V10 in den Bereich des Todes, der sich durch Schlamm, Morast und Finsternis auszeichnet, aber auch der Ort der absoluten Stille ist. ידה (loben) und נגד (erzählen, sagen, mitteilen, berichten)

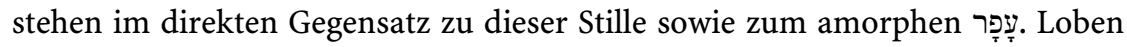
und berichten können nur gestalthafte Lebewesen. In der überlappenden $\mathrm{Zu}$ sammenschau der beiden Bereiche "Staub« und "Erzählen/Loben« ergibt sich neben dem immensen Kontrast (עָ פָָר gestaltlos, Schlamm, Stille, Finsternis, Unbeweglichkeit, Angst im Gegenüber zu נגד עי ביה in Verbindung mit Gestalt, Sprechen, Helligkeit, Bewegung, Freude) das Bild des sich auflösenden Lobes: Die Treue Gottes zerfällt und wird nicht mehr vermittelt, von den Heilstaten Gottes wird nicht mehr erzählt, sie zerfallen zu Asche, werden zu Morast und Schlamm. Insgesamt hätte also JHWH einen deutlichen Verlust zu verzeichnen und keinen Gewinn, wenn es zum Hinabsteigen in die Grube käme. Dieser Verlust zeichnet sich nicht nur durch das Verlieren eines Menschenwesens aus, sondern ebenso durch das Unterbrechen des die Heilstaten Gottes vermittelnden Erzählflusses (»wird er erzählen von deiner Treue?«).

Die durch die Syntax unter anderem ausgedrückte Emotion der Empörung durchzieht den Vers, der im Klage- und Anklagestil gehalten ist und mittels einer Überzeugungsrhetorik auf die Dramatik und den Verlust für die Gottheit hinweist, der mit dem drohenden Tod des/der Betenden einhergehen würde. Neben der Todesmetaphorik (Blut, Grube, Staub) wird in der Personifikation des lobenden Staubes der krasse Gegensatz zwischen Leben (loben, erzählen, bewegen, Helligkeit) und Tod (still sein, Staub, Schlamm, Dunkelheit) sichtbar, indem sich das Lob auflöst und das Erzählen im Schlamm erstickt. Durch die Personifikation erhält der Todesraum (Grube, Staub) deutlichere Konturen: Er gilt damit auch als Ort des Verstummens und der Stille, in dem alles Lebendige verschlungen und die Lebendigkeit eliminiert wird. Der Vers zielt mit aller Vehemenz darauf $\mathrm{ab}$, gar nicht erst an diesen Ort zu gelangen.

\subsection{Vers 11: Erhörbitte um Hilfe}

11a Höre, JHWH, und sei mir gnädig,

$11 b$ JHWH, sei mir Hilfe. 
Die syntaktische Konstruktion des Verses, der aus zwei Vokativen an JHWH und drei Imperativen besteht, deutet auf ein drängendes Bittgesuch hin. ${ }^{477}$ Am Beginn steht die Bitte um das Hören der Gottheit, die parallel zum Rufen in V9 konstruiert ist und hier wie dort die Kommunikationsaufnahme mit Gott und den Wunsch nach entsprechender Resonanz signalisiert. Der Gebrauch von שמע in den Psalmen zeigt, dass das "Hören« JHWHs an einigen Stellen bereits ein »Erhören« (Ps 22,25; 28,6; 31,23; 54,4 u. ä.) ${ }^{478}$ ist. Dieses Erhören wird im folgenden V12 durch die Verwandlung eingelöst.

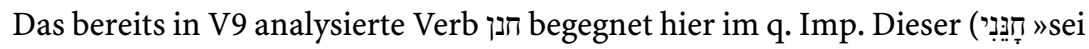
mir gnädig«) kommt nur in den Psalmen vor. Hinter der Bedeutung »gnädig sein, Gunst bezeigen« steckt Aktivität: Es geht um den aktiven Gnadenerweis und um die aktive Annahme: »Gnädig sein bedeutet, den Armen zu helfen, die Hungrigen zu speisen, die Bedrängten vor Vernichtung und Tod zu retten. $"{ }^{479}$ Mit der Bitte um Gnade wird gleichzeitig Gottes Zuneigung erbeten. Der Wunsch um Zugewandtheit zum betenden Ich (? " „ü̈r mich") in Form des helfenden Eingreifens (עזר) der Gottheit beschließt V11, auf den mit V12 ein relativ abrupter Wechsel der Thematik erfolgt.

Hinsichtlich der Emotionen wird durch die Syntax und Semantik die Unruhe des lyrischen Ich und dessen dringende Bitte um Antwort, Zuneigung und um helfendes Eingreifen seitens der Gottheit deutlich. Mit dem Gnadenerweis und dem Helfen wird die göttliche Zuwendung thematisiert.

\subsection{Vers 12: Von der Trauerklage hinein in den Freudentanz}

12a Verwandelt hast du meine Trauerklage in einen Tanz für mich,

$12 b$ geöffnet hast du mein Trauergewand

$12 c$ und mich umgürtet mit Freude.

Der Vers beginnt mit dem Verb הפך, das mehrfach mit »verwandeln « wiedergegeben wird und hier ein vollständiges Umwenden im übertragenen Sinn beschreibt. ${ }^{480}$ In V12 bezeichnet הפך eine völlige Umkehrung des Bestehenden und

477 Kuckhoff, Psalm 6, 169 ordnet die Bitten an Gott im Psalter der Kategorie der asymmetrischen Bitten zu, mit welchen Betende Gott um etwas bitten, das ihre Fähigkeiten übersteigt. Gott kann der jeweilgen Bitte entsprechen, muss es aber nicht. Die Freiheit des Adressaten ist damit ein Charakteristikum dieser Bitten, ebenso die Appellfunktion: »In der Anrede Gottes meint der Imperativ immer eine wirkliche Bitte im Sinne eines Appells an die Freiheit des Angesprochenen."Kuckhoff, Psalm 6, 170.

478 Vgl. Michel, Tempora, 63.

479 Freedman / Lundbom, חנן, 25.

480 Vgl. Baader, Wortkunde, 768; HALAT 1, 243; Lisowsky, Konkordanz, 428. הפך kann ״wenden «, "auf die andere Seite legen " (2 Kön 21,13), »auf den Kopf stellen«, »umstürzen« (Hag 2,22), »umwerfen" (Ri 7,13) bzw. »sich umwenden, um- und zurückkehren« (1 Sam 10,9) 


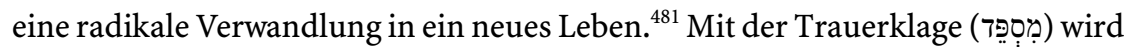
auf die rituelle Totenklage ${ }^{482}$ bzw. Trauerfeier Bezug genommen (Gen 23,2; Gen 50,10; 1 Kön 13,29 u. a.). Im Rahmen dieser Trauerklage werden ritualisierte Zeichen der Trauer, unter anderem das Zerreißen von Kleidern und das Anlegen von Trauergewändern bzw. Sacktüchern (שָ vgl. unten und 2 Sam 3,31), gesetzt. Dabei kommt es zu Gesten und Ausrufen des Schmerzes. ${ }^{483}$ In Opposition zu diesem Klageritual steht der Tanz, der als bewegter Ausdruck der Freude gilt: "When the Bible speaks of joy, that joy is not just >down in my heart ‘ but also in my feet, my legs, my whole body. In other words, the typical expression of joy in the Bible is dancing. ${ }^{484}$ In Ps 30,12 ist der Tanz "Ausdruck überbordender Lebensfreude und wird als solcher bildhaft der Klage gegenübergestellt (Jer 31,13; Klgl 5,15; Ps 30,12; Koh 3,4; vgl. noch Mt 11,17 par Lk 7,32). « ${ }^{485}$ Wenn die Gottheit nun die Trauerklage in einen Tanz verwandelt, ist von einer großen Veränderung die Rede, von einer totalen Wende, und zwar hin zum Guten, zu mehr Leben. Der sich in Not, Verlassenheit und Trauer befindende Mensch wird durch Gott bewegt, verändert und schließlich verwandelt. Dabei sind die Bewegung und die Dynamik festzuhalten, denn aus dem Trauerritus mit vielfältig tradierten und »einstudierten« Gesten wird ein spontaner Freudentanz.

Der Raum der Klage wird mit dem Kleidungsstück des Trauer- bzw. Bußgewandes (שِ kenntlich gemacht. שַׁק bezeichnet zunächst einen rauen, groben Stoff, der aus Ziegenhaar gewebt wurde, schwarz aussah und zu verschiedenen Zwecken verwendet wurde. ${ }^{486}$ Dabei geht der Verwendung des schweres Unheil voraus. Gehalten wurde das Gewand durch einen Gürtel. Man trug es auf der bloßen Haut und setzte es dabei, wie oben bei der Trauerklage beschrieben, als Teil einer rituellen Handlung ein. ${ }^{487}$ Das Ablegen des Gürtels

bedeuten. Vom vollständigen Wandeln sprechen Dtn 23,6; Ps 41,4; Ps 66,6; Ps 78,44; Ps 105,29 sowie Ps 114,8.

481 Vgl. Krinetzki, Psalm 30, 359. Von einem genau umgekehrten Geschehen (הפך ni. inf.) berichtet auch das Buch Ester (Est 9,1). Außerdem heißt es im Buch des Propheten Amos: "Und ich verwandle eure Feste in Trauer und all eure Gesänge in Totenklage und bringe auf alle Hüften Sacktuch und auf jeden Kopf eine Glatze« (Am 8,10; ELB). In Klgl 5,15 wird ebenso von der gegenteiligen Verwandlung berichtet, als Jerusalem zerstört wurde: »Die Freude unseres Herzens hat aufgehört, in Trauer ist unser Reigen verwandelt« (ELB).

482 »This makes a link with the death-like nature of the suppliant's experience.» Goldingay, Psalms 1, 432.

$483 »$ Das vom Stamm spd gebildete Verbum und Nomen bezeichnet im AT also einen Komplex von Äußerungen großen Schmerzes, der vorwiegend aus dem Gestus des auf die Brust Schlagens und aus mehr oder weniger durch Herkommen standardisierten oder auch spontanen Klagerufen und Klagelauten besteht.« Scharbert, 7פO, 905.

484 Limburg, Psalms, 95.

485 Schroer, Tanz, 779.

486 Vgl. Thiel,

487 "Das Tragen des rauen, harten, auf der Haut kratzenden und schabenden Stoffstückes stellte einen Selbstminderungsritus dar, der zu einem Ensemble von Trauer- und Bußriten gehörte. 
bzw. Gewandes wird mit »öffnen« bzw. »entgürten« (פתח) ausgedrückt. Das Kleidungsstück ist Zeichen für Not, Trauer und Unheil sowie für die psychische und physische Desintegration des Notleidenden. ${ }^{488}$ Oder anders gesagt: "Die rituelle Funktion des śaq hat ihn zu einem Zeichen für Unheil, Trauer und Not werden lassen. Ein solch metaphorischer Gebrauch findet sich in Ps 30,12, wo der Psalmist die Wendung seiner Not in Freude darstellt. ${ }^{489}$ Als Bild für die Lebenswende steht das Öffnen: »... du hast geöffnet mein Trauergewand und mich umgürtet mit Freude« (V12). ${ }^{490}$ Die Sprache dieses Verses ist figurativ. ${ }^{491}$ Die Schwere und das Dunkel der Klage und Trauer werden gelöst, und der betende Mensch wird anstelle dessen in die Leichtigkeit, Schönheit und Buntheit der Freude gekleidet. ${ }^{492}$ Die Freude (שְְִׁחזה) ist ein weiterer bereits bekannter Begriff aus V2. Dort geht es darum, dass die Feinde nicht schadenfroh sind. «Nicht haben die Feinde den Jubel letztgültig für sich reklamieren können (vgl. שמח pi. in V.2), sondern Jahwe hat ihnen die שְְִׁחָה $>$ Freude entrissen und gürtet damit den Geretteten (V.12), wie er [JHWH] sich selbst in Ps 93,1 als König mit ע >Macht gürtet. « ${ }^{493}$ Vom Umgürten mit Kraft, Macht und Stärke (חָיָ) spricht auch Ps 18,40 // 2 Sam 22,40: »du hast mich mit Kraft umgürtet (vgl. auch 1 Sam 2,4). Auch hier gibt es, wie in Ps 30, »ein ähnliches Schwanken zwischen der Bezeichnung einer

Damit reagierte man auf den Tod eines nahestehenden Menschen, aber auch auf eingetretenes oder drohendes Unheil anderer Art.« Thiel, wָ, 851.

488 Vgl. Hossfeld / Zenger, Die Psalmen 1, 190.

489 Thiel, Trauer und der Buße in das allgemeine Bewußtsein der Deutschen bis hin zur Bildung der geflügelten Wendung in Sack und Asche büßenヶ.« Ebd., 855.

490 Vgl. Herkenne, Das Buch der Psalmen, 129: Der Gürtel ist als Strick zu betrachten, der fest an den Körper gebunden wurde. Von daher ergeben sich die Ausdrücke lösen bzw. losmachen, öffnen oder ausziehen. Das Gegenteil dazu ist das Umgürten oder Anziehen. »Zogst mir aus meinen Bußsack, gürtetest mich mir Freude« bei Schlögl, Die Psalmen, 40.

491 Vgl. Cohen, The Psalms, 87. Hossfeld / Zenger, Die Psalmen 1, 186, sprechen von »Metaphern für die Veränderung des Lebensgefühls."

492 An das Anlegen eines Kleidungsstückes denkt dabei Oeming, Das Buch der Psalmen, 181: "Das Sackgewand der Trauer wird abgelegt und durch ein schönes Festgewand ersetzt." Ebenso Müller, Psalm 30, 198. Ähnlich Rogerson / McKay, Psalms 1-50, 135: »He has exchanged beating the breast in lamentation for the festive dance, and has replaced clothing of penitence and mourning, my sackcloth, with the festal garments of joy.« Anderson, A Time to Mourn, 48 verweist an dieser Stelle auf den literarischen Kontext v. a. des Gilga-

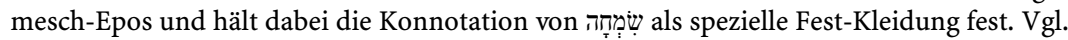
dazu ebenso Groß / Reinelt, Das Buch der Psalmen, 175: „Überschwengliche Freude erfüllt den Beter. Anstelle des Trauergewandes hat Gott selbst ihm das Festkleid angezogen.« Noch anthropomorpher beschreibt Goldingay, Psalms 1, 432 die Stelle: »Now it is as if Yhwh personally undid the ties on the sackcloth, like a parent undressing a child, and put over the shoulders something bright and festal, the clothing for a wedding rather than a funeral. The psalm actually refers to joy rather than joyful clothing (no doubt both would apply), and this makes for a link between the beginning and end of the line as this joy replaces mourning.» Zum Freudengewand vgl. Jes 61,3.

493 Spieckermann, Heilsgegenwart, 261. 
inneren Bewegung und der eines Kleidungsstücks, dessen Wahl die Bewegung ausdrückt. [...] der Ausdruck kriegerischen Kraftgefühls ist dagegen das Anlegen des $[\ldots]>$ Hüftschurzes $\_.{ }^{494}$ Ps 65,7 spricht ebenso vom Umgürtetsein mit Macht bzw. Stärke. Anstelle des Anlegens eines Trauergewands drückt die Metapher »du hast mich mit Freude umgürtet» die Wende zur überschäumenden Lebensfreude aus. Dabei ist analog zu den Parallelstellen des Umgürtens das Bekräftigende und Schützende des Bildwortes festzuhalten (Ps 18,33). Wenn also im Rahmen der Metapher der Begriff »Freude« mit dem »Umgürten « interagiert, kommen damit die Konnotationen von Schutz und Kraft, Halt und Beständigkeit, die das Umgürten impliziert, sowie Leichtigkeit, Festlichkeit und Buntheit, die die Freude ausmacht, zum Vorschein. Um die Körpermitte wird demnach die Freude gelegt, die das dunkle raue Trauergewand ablöst. In all dem ist die totale Gegenwart, ja erfahrbare Nähe Gottes für das lyrische Ich hervorzuheben - genau diese Nähe, die in den Versen davor stark vermisst und sehnlichst erbeten wurde. An der Textoberfläche wird dies durch die Possessiv- und Personalpronomen in der 1.P.sg. (mein; für mich; siehe dazu unten Deixis) sowie mittels des göttlichen $\mathrm{Du}$ als Subjekt ausgedrückt. Inhaltlich erhält hier die Gottheit sehr anthropomorphe Züge (verwandeln, öffnen, umgürten). Die Nähe Gottes geht sogar (fast) bis zur Berührung (öffnen, umgürten). Mit dem Ablegen des rauen Trauergewands und der Teilnahme am Reigentanz wird der innere Prozess der Verwandlung von Klage und Trauer in Dank und Freude auch nach außen hin sichtbar. ${ }^{495}$

V12 endet mit der positiv konnotierten שְְִׁ und und deren tiefer emotionaler Dimension: »Freude ist die unmittelbare Reaktion auf die Rettung des in seiner Existenz Bedrohten, worauf das berichtende Lob zurückschaut (Ps 30,12;

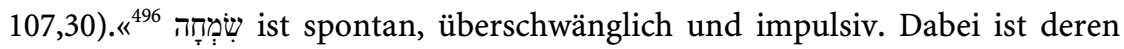
Ausdruck als Bewegung relevant: »Die Freude äußert sich in Sprüngen (Jer 50,11), Klatschen (Ez 25,6), Tanzen, Geschrei und Singen. Bevorzugter Ort der Freude ist das Fest. « ${ }^{497}$ Und so verwandelt Gott selbst »die Buß- und Trauerklage über die tödliche Bedrohung des Beters [...] in einen Freudentanz über die Entmachtung des Todes und die wiedererlangte Lebensfülle. ${ }^{498}$ Während die Trauerklage und

494 Müller, Psalm 30, 198. Zum Hüftschurz vgl. 2 Kön 1,8.

495 Vgl. Fohrer, Psalmen, 228.

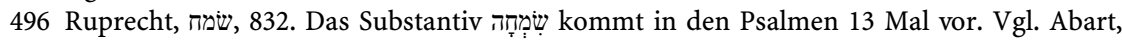
Lebensfreude, 22. Christine Abart geht in ihrer Dissertation über die physisch erlebte Freude im Buch der Psalmen schwerpunktmäßig jenen Psalmversen und deren Kontexten nach, welche die körperlich erfahrene Freude, vor allem im Zusammenhang mit Körperbildern, zum Ausdruck bringen. Psalm 30 wird dabei nicht behandelt.

497 Vanoni, שמח, 814.

498 Hossfeld / Zenger, Die Psalmen 1, 190. »Reigen` erinnert an Tänze bei fröhlichen Anlässen (vgl. 2 Sam 6,14) und steht hier metonymisch für Jubel, wie `Trauerkleid für Trauer.» Herkenne, Das Buch der Psalmen, 128. 
das Trauergewand Teil eines fest strukturierten Trauerrituals sind, zeugen - auf der Ebene der Textoberfläche chiastisch und antithetisch dazu konstruiert - der Tanz und die Freude von impulsiver Spontanität.

Wie bereits aus V4 bekannt, ist auch dieser Vers geprägt von der sogenannten doppelten Emotionalität. Stehen Trauerklage und Trauergewand für die erfahrene Not und das Leid, für die Emotionen der Trauer und Traurigkeit, so wird im Bild des Öffnens des Trauergewandes und des Umgürtetwerdens mit Freude die innere Wandlung und Wende hin zur Lebensfreude und Lebensfülle sichtbar und spürbar: An die Stelle der Trauer tritt die Emotion der überschäumenden Lebensfreude. Die Metapher impliziert darüber hinaus Spontanität, Leichtigkeit, Sicherheit, Schutz und Kraft, Halt und Bestand sowie Buntheit und Bewegung. Im körperlichen Ausdruck bzw. Handlungsimpuls, der ja Bestandteil einer Emotion ist (vgl. III Methodik 2) und hier als Tanz ausgewiesen ist, wird die Freude intensiviert. Schlussendlich kann das lyrische Ich die Emotion der göttlichen Zuwendung, die bereits ersehnt wurde, »hautnah« erfahren.

\subsection{Vers 13: Gotteslob}

13a Damit dich besinge Ehre

$13 b$ und nicht verstumme,

13c JHWH, mein Gott, auf ewig will ich dich loben.

Der Schlussvers zieht die Konsequenz aus dem davor Erlebten, vor allem aus der in V12 erzählten Wandlung von der Trauer zur Freude. Das bereits aus V5 bekannte Verb spielen/musizieren/singen (זמר) begegnet hier abermals, allerdings nicht in der Imperativform, sondern im pi. PK. Subjekt ist dabei Dieser Begriff kann mit »Ehre, Ruhm, Pracht, Herrlichkeit, Reichtum und Glanz« und Ähnlichem wiedergegeben werden sowie als Bezeichnung der Seele dienen. Die Personifikation "damit dich besinge Ehre« sorgt im Text für Unklarheit, was die textkritischen Varianten zu lösen versuchen. Die LXX fügt an כָָּ das Suffix der 1.P.sg. (meine Ehre) an. Im textkritischen Apparat vorgeschlagen wird zudem "meine Leber" (כְבְדי) als Sitz seelischer Empfindungen. Daraus ergeben sich unter anderem folgende Übersetzungsmöglichkeiten für כָָָּּּ: ich (LUT), meine Seele (ELB); mein Herz (EIN); Schönheit (BigS), mein Innres (Krinetzki), das Ehren (BUBER). Strittig ist ebenso die syntaktische Zuordnung des Nomens, das sowohl auf Gott als auch auf den/die Psalmisten/Psalmistin bezogen werden kann. Der Bezug auf Gott erweist sich allerdings als schwierig, da dann nicht klar

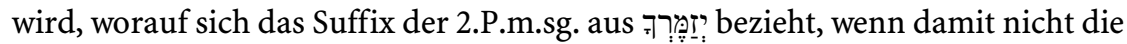
Gottheit gemeint ist. Einen weiteren Übersetzungsvorschlag bietet dazu Christof 
Hardmeier: »damit man für dich musiziert (zu deiner) Ehre und nicht schweigt. (499 $^{499}$

Inhaltlich sind die Übersetzung mit "Ehre« und die Bezugnahme auf das lyrische Ich insofern nachzuvollziehen, als nach der erzählten Wandlung des betenden Ich in V12 nun dessen »Ehre« wiederhergestellt ist, »und so muss auch der Mund beteiligt sein im Lobdank. Die Selbstachtung findet damit beredten Ausdruck in der Gottesachtung. ${ }^{500}$ Die Personifikation »damit Ehre dich besinge und nicht verstumme« steht im deutlichen Gegensatz zur Personifikation des lobenden Staubes in V10. Tritt dort der Todesraum als Ort des Verstummens und der Stille deutlich hervor, so wird hier im Schlussvers der Raum des Klanges, des Singens und des immerwährenden Lobens eröffnet, das nicht schweigt und verstummt. Und so endet der Psalm mit dem schon aus V5.10 bekannten Verb des Lobens (ידי), das die spontane preisende Antwort auf Gottes Heilshandeln sowie das Gotteslob bezeichnet. Der sich durch Bewegungen von unten nach oben auszeichnende Psalm wird durch das Lob an JHWH verklammert. Am Beginn steht das Hochheben bzw. Loben Gottes (V2), wonach der betende Mensch seiner Gottheit dafür dankt, dass er aus seiner Not gerettet wurde, so wie man einen Schöpfeimer aus einem tiefen und engen Brunnen herauszieht. Am Ende des Psalms zieht der/die BeterIn die Konsequenz aus der Erfahrung der Heilung, indem er/sie einen immerwährenden Jubel und Dank an Gott anstimmt: "Denn der Lobpreis Gottes, in dem sich die Selbstmächtigkeit und Selbstverabsolutierung des Menschen relativiert, bringt zum Ausdruck, was der Kern der Gottesbeziehung ist: die Zuwendung des barmherzigen Gottes, der vom Tod errettet und ins Leben führt. ${ }^{501}$ Das Lob soll laut V13 nicht verstummen bzw. nicht stillstehen, starr sein, sich nicht still halten (דמם I) ${ }^{502}$ Die Wurzel kann auch mit "aufhören, etwas zu tun« wiedergegeben werden, aber auch folgende Bedeutungen tragen: vor Schrecken starr werden, leise jammern, schweigen, sich still halten sowie vertilgt werden, umkommen (ni.). ${ }^{503}$ Der Vers endet mit der For-

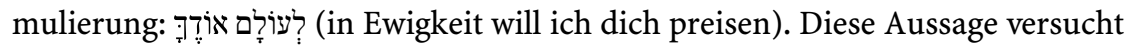
»nicht nur dem durch Rettung und Dank neu begründeten Gottesverhältnis des Betenden Kontinuität zu verleihen, sondern das Gotteslob zugleich zeitlich ins

499 Hardmeier, Systematische Elemente, 342. Mit dem unpersönlichen »man « übersetzt ebenso Ruwe, Die Psalmen, 45: „damit man dich in Ehre besinge«.

500 Weber, Psalm 30, 41. Ebenso Müller, Psalm 30, 199: »[...] die Verminderung oder Vernichtung der kābôd des Betenden bedauern die Klage- und Bittpsalmen des einzelnen in Ps 4,3; 7,6 (vgl. Hi 19,9); nach der Rettung wäre es umgekehrt die `Ehre ‘ des Betenden, die nun [...] das Lob JHWHs vermehrt.« Ähnlich Janowski, Konfliktgespräche mit Gott, $281 \mathrm{f}$.

501 Janowski, Konfliktgespräche mit Gott, 266.

502 Vgl. KAHAL, 117. Anders Goldingay, Psalms 1, 432. Er sieht in V13 die Weiterführung des Kontrastes zwischen Trauerklage und Freudentanz bzw. Musik und übersetzt das Verb, ausgehend von דמם II (wehklagen, heulen), mit "and not wail«.

503 Vgl. GES, 165. 
Unendliche auszudehnen: der Augenblick wird zum Ein-für-Allemal. " ${ }^{504} \mathrm{Hat}$ sich Gott in V12 ganz nah dem/der PsalmistIn zugewandt, so wendet sich nun der/die PsalmistIn so lange wie möglich Gott zu.

Der Psalm endet mit dem Lob der Gottheit, das als preisende Antwort auf die erfahrene Lebenswende - im Gegensatz zum Verstummen - auf Unendlichkeit hin ausgedehnt wird. Das Lob ist mit den Emotionen der Freude und Dankbarkeit auf Seiten des lyrischen Ich verbunden. Der Gegensatz zwischen dem Lob Gottes, dem Raum des Klanges und des Preisens einerseits und dem Raum der Stummheit und Stille andererseits wird erneut eröffnet (vgl. V10).

\section{Perspektiven und Textdynamik}

In der folgenden Darstellung steht neben der Beschreibung der Parallelismen und der Eruierung der Dynamik des Textes die Analyse der Perspektivenlenkung im Mittelpunkt (vgl. dazu detaillierter die Ausführungen in Kapitel III Methodik 3). $\mathrm{Zu}$ beachten ist dabei, dass in der Poesie - im Gegensatz zur Prosa - die Fokalisierung meist stabil bleibt. ${ }^{505}$ Dies bedeutet, dass es keine eindeutige "Kameraführung" gibt, wie diese in Filmen vorhanden ist und für die Analyse von Erzähltexten adaptiert werden kann. Die Kamera wird also, bildlich gesprochen, in poetischen Texten nicht an andere weitergegeben, wie dies in Erzählungen der Fall sein kann, in denen das Geschehen aus unterschiedlichen Blickwinkeln (Narrator, Textpersonen etc.) erzählt wird. In poetischen Texten dagegen geht die Perspektive meist von einer Wahrnehmungsinstanz aus und bleibt auch überwiegend bei dieser, wobei die "Kameraführung" hier eher in Bezug auf Nähe (Zoom) vs. Distanz oder Liebe zum Detail vs. Allgemeinaussagen variieren kann. Da allerdings viele Psalmen als Ich- bzw. Wir-Erzählungen betrachtet werden können und vor allem Ps 30 von narrativen Passagen lebt, die in der weiteren Untersuchung als Minierzählungen analysiert werden, können an dieser Stelle die Arten der Fokalisierung aus der Narratologie (externe, interne, doppelte Fokalisierung bzw. AdressatInnenperspektive) für die Analyse der Perspektivenlenkung herangezogen werden.

504 Müller, Psalm 30, 199.

505 Zum unfokalisierten Erzählen in poetischen Texten vgl. Mellmann, Emotionalisierung, 107. 


\subsection{Perspektivenlenkung}

In der Überschrift von V1 ist eine externe Fokalisierung gegeben. V2-4 sind intern fokalisiert, indem aus der Ich-Perspektive von einem $\mathrm{Du}$ (JHWH) und einem Sie (Feinde) erzählt wird. Hier wird das Rettungshandeln aus der Sicht des/der Geretteten mittels der Innensicht dargestellt. Mit V5 erfolgt ein deutlicher »Kameraschwenk« nach außen auf die ZuschauerInnen. Im Fall von Ps 30 werden damit die AdressatInnen, d. h. die Frommen bzw. Getreuen JHWHs, in den Blick genommen. Es erfolgt eine Öffnung hin zur AdressatInnenperspektive, wodurch jene, die draußen stehen, mittels der Imperative pl. in das Geschehen hinein geholt werden, welches in V2-4 aus der Innenperspektive heraus erzählt wurde. Während in V2-4 Sprecher- und Wahrnehmungsinstanz zusammenfallen, gehen diese in V5-6 auseinander: Es ist nicht deutlich erkennbar, wer spricht. Während V5 klare AdressatInnen aufweist, ist V6 neutral formuliert. Mit V7 wird die interne Fokalisierung wieder aufgenommen, die bis zum Schlussvers 13 durchgehalten wird. Ab V8 sind abermals - wie zuvor in V2-4 - Ich-Du bzw. Du/ JHWH-Ich-Konstellationen auszumachen, wobei ein Mal das Ich stärker betont wird und ein Mal das Du. Vom Fokus her könnte man V12-13 als Weitwinkeleinstellung bezeichnen: "Weitwinkel-Einstellung. Es wird nochmals der ganze Prozess von der Not bis zur Wiederherstellung in den Blick genommen und dabei die `Wende`, die überraschend und unerwartet zuteil wurde, besonders gewichtet. Es sind tiefgründige Worte, die in ihrem Gehalt zwischen innerem Empfinden und äußerem Ausdruck schillern. ${ }^{506}$

Die Fokalisierung in Ps 30 kann dementsprechend folgendermaßen zusammengefasst werden: V1.6: extern; V5: AdressatInnenperspektive; V2-4.713: intern. Blickt man genauer auf diese Einteilung, so zeigen sich die Konstruktionen der Perspektive durch die Verwendung deiktischer Elemente deutlicher, genauer gesagt durch die Verwendung der Personaldeixis. Zur Erinnerung an die Funktion der Deixis (vgl. III Methodik 3.2) sei an dieser Stelle Konrad Ehlich zitiert: »Die deiktische Prozedur ist ein sprachliches Mittel, um eine Fokussierung der Aufmerksamkeit des Hörers auf ein bestimmtes Objekt zu erreichen. Die Anapher dagegen vermittelt dem Hörer die Kontinuität einer vorgängigen Fokussierung. ${ }^{507}$ Die Personaldeixis wird im Deutschen unter anderem mittels Personalpronomen, Relativpronomen und Interrogativpronomen sowie Artikel konstruiert, im Hebräischen mittels der Suffixe und Präfixe an Verben, Substantiven und Präpositionen sowie durch Relativ- und Interrogativpronomen und Artikel (vor allem bei Ps 147). Dabei zeichnet sich

506 Weber, Psalm 30, 41.

507 Ehlich, Deixis 2, 775. 
die interne Perspektive in Ps 30 (V2-4; V7-13) durch die Häufung der Personaldeixis (kursiv) aus:

\begin{tabular}{|c|c|}
\hline Vers & Deixis \\
\hline $2 \mathrm{a}$ & Ich will dich hochheben \\
\hline $2 \mathrm{~b}$ & $d u$ hast mich herausgeschöpft \\
\hline $2 c$ & hast die, die mich anfeinden, sich nicht freuen lassen über mich \\
\hline $3 a$ & mein Gott, ich schrie um Hilfe zu dir \\
\hline $3 \mathrm{~b}$ & $d u$ hast mich geheilt \\
\hline $4 \mathrm{a}$ & $d u$ hast heraufgeholt aus dem Totenreich meine Lebenskraft \\
\hline $4 \mathrm{~b}$ & $d u$ hast mich zum Leben gebracht; weg von meinem Hinabsteigen \\
\hline $7 \mathrm{a}$ & Ich aber, ich habe gesagt in meiner Sicherheit \\
\hline $7 \mathrm{~b}$ & Nicht werde $i c h$ ins Wanken gebracht auf ewig \\
\hline $8 \mathrm{a}$ & in deinem Wohlgefallen \\
\hline $8 \mathrm{~b}$ & hast $d u$ aufgestellt für meinen Berg eine Kraft \\
\hline $8 \mathrm{c}$ & $D u$ hast dein Angesicht verborgen \\
\hline $8 \mathrm{~d}$ & da war ich erschrocken \\
\hline $9 \mathrm{a}$ & $\mathrm{Zu}$ dir, JHWH, rief $i c h$ \\
\hline $9 \mathrm{~b}$ & zu Adonaj flehte ich um Erbarmen \\
\hline $10 \mathrm{a}$ & Was für ein Gewinn ist an meinem Blut \\
\hline $10 \mathrm{~b}$ & durch mein Hinabsteigen in die Grube? \\
\hline $10 \mathrm{c}$ & Wird (Fragepartikel ד̣) dir lobdanken Staub \\
\hline $10 \mathrm{~d}$ & wird (Fragepartikel n̦) er erzählen von deiner Treue? \\
\hline $11 \mathrm{a}$ & sei mir gnädig \\
\hline $11 \mathrm{~b}$ & sei eine Hilfe für mich \\
\hline $12 \mathrm{a}$ & $D u$ hast verwandelt meine Trauerklage in einen Tanz für mich \\
\hline $12 \mathrm{~b}$ & $d u$ hast geöffnet mein Trauergewand \\
\hline $12 \mathrm{c}$ & mich umgürtet mit Freude \\
\hline $13 \mathrm{a}$ & Damit dich besinge Ehre \\
\hline $13 \mathrm{c}$ & mein Gott, auf ewig will ich dir lobdanken \\
\hline
\end{tabular}

Dieser nahe Fokus verweist auf die Intensität der Auseinandersetzung mit Gott. Diese Nähe ist auch im Rückblick sowie durch die direkten Anreden an Gott gegeben. In der externen Perspektive von V5-6 sind sehr wohl Verweiszeichen vorhanden, allerdings sind diese als anaphorisch anzusehen. V6 verweist mittels der anaphorischen Bezüge zurück auf die Gottheit in V5. Durch die direkte Anrede an die AdressatInnen wird der Fokus zwar in V5 nach außen gelenkt, dieses Außen wird aber an die Ereignisse herangeholt.

Auffällig ist, dass zwar konkrete Situationen geschildert, diese aber nicht im Detail dargestellt werden. So wird von einer Todesnot und der Errettung daraus 
mehrfach berichtet, nicht jedoch, worin diese bestand. Die offene Sprache des Psalms ist mit ihren Bildern so konkret und bestimmt wie notwendig, um sich die Rahmenbedingungen vorstellen zu können, und gleichzeitig so offen und unbestimmt wie möglich, damit diese Bilder stets neu von den Lesenden selbst gefüllt werden können. So werden in Ps 30 die generellen Umstände der Todesgefahr nicht genannt. Auch das feindliche Gegenüber in $2 c$ wird nicht näher charakterisiert und bleibt daher schemenhaft. Die Umstände und Art der Befreiung werden ebenfalls nicht angegeben, die Verben der Hilferufe des/der Betenden sind sehr allgemein gehalten: שוע (3b: um Hilfe schreien), קרא (9a: rufen), חנן (9b: um Erbarmen flehen, 11a: um Gehör und Gnade bitten). Ins Auge fällt die metaphorische Redeweise in Bezug auf Gefährdung und Errettung, Trauer und Freude: Der/die Gefährdete wird herausgezogen (2b) bzw. aus der Scheol heraufgeführt (4a) und damit der Tiefe des Totenreiches entrissen. Heilen (3b) kann sowohl im eigentlichen Sinn als auch im übertragenen Sinn verstanden werden. Eine Vielfalt von Bildern spricht vom Sterben (mitten im Leben) und vom Totsein: Blut (10a), Staub (10c), Hinabsteigen in die Grube (10b). Die Freude wird als Metapher dargestellt mit äußerer Wahrnehmung des Tanzes, die Trauer mit ebenso äußerem sichtbarem Zeichen des Trauergewandes (V12). Der Umschwung von der Trauer in die Freude wird mit dem Ausziehen des Trauergewandes und dem »Anlegen« der Freude konstatiert (12b). ${ }^{508}$

Bei der Darstellung fällt weiter ins Auge, dass in diesem Dialog mit Gott die Gottheit selbst nicht zur Sprache kommt. Das ist für den gesamten Psalter nichts Ungewöhnliches, denn JHWH wird ja meist aus der Perspektive eines sprechenden Ich oder Wir angerufen, oder es werden Sachverhalte in Du-Reden vorgetragen bzw. über JHWH in der dritten Person erzählt.

\subsection{Textdynamik}

Im Folgenden wird die Textdynamik im Sinne einer raum-zeitlichen Anbindung an eine Figur ermittelt. Durch diese Anbindung wird suggeriert, dass die Lesenden dieselben Situationen wie die Textpersonen wahrnehmen. Dies kann als weiteres Identifikationspotenzial im Text dienen (vgl. III Methodik 3.3). ${ }^{509}$ Dabei

508 Vgl. Witzenrath, Am Abend Weinen, 476f.

509 Für die Textdynamik poetischer Texte können u.a. auch Klang und Rhythmus sowie Metrum und Stichen analysiert werden (vgl. dazu die Analyse zu Ps 147). Da dies in Ps 30 kein hervorstechendes Merkmal ist, wird an dieser Stelle auf einschlägige Literatur verweisen: Zum Rhythmus von Ps 30 vgl. Seybold, Die Psalmen, 126. Krinetzki, Psalm 30, 348 spricht von einem tänzerisch anmutenden Rhythmus: »Man merkt es dem Rhythmus an, dass der Dichter nicht mehr unter den Anfechtungen der einstigen Not zu leiden hat, sondern auch von dieser mit tänzelnd-leichter Überlegenheit zu künden vermag. So kommt eine Span- 
steht die Analyse von Ereignisfolgen mittels der narratologischen Analysekategorien Figuren, Handlungen, Raum/Bewegungen und Zeit im Mittelpunkt. Im Hinblick auf die Textdynamik werden außerdem die Verbformen beschrieben und die Übergänge und Verbindungen zwischen den einzelnen Ereignissen ermittelt. In einem dritten Schritt werden die Parallelismen in Ps 30 charakterisiert. Dies dient neben der näheren Beschreibung des jeweiligen Themas und dessen Variation, Weiterführung, Intensivierung, Konkretisierung oder Kontrastierung dazu, den Faktor Zeit aufzunehmen, der ausschlaggebend dafür ist, wie lange im Leseprozess beim Gedanken des Textes geblieben werden kann bzw. soll. Der Zeitfaktor ist ja nach Katja Mellmann (vgl. III Methodik 3.3.2) entscheidend für die Stärke des literarischen Stimulus bzw. für das emotionale Auslösepotenzial.

\subsubsection{Erste Minierzählung V2-4}

In Ps 30 sind zwei kleine Erzählungen ${ }^{510}$ auszumachen, die das Mitgehen mit einer Figur ermöglichen, die im Fall von Ps 30 im lyrischen Ich besteht. Die erste Minierzählung ist in V2-4 zu finden. ${ }^{511}$ Sie ist für ihre Kürze reich an Bewegung.

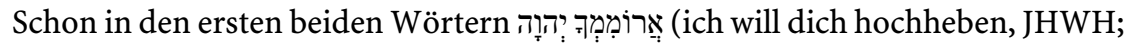
PK po. mit implizitem Kohortativ) wird die Beziehung festgelegt, die in den folgenden Versen der Minierzählung (und im gesamten Psalm) vorherrschend sein wird: Ein Ich will ein Du, genauer JHWH, hochheben, hochleben lassen, preisen. Dabei drückt die Verbform im PK ein Begehren aus und wird meist modal übersetzt. ${ }^{512}$

nung zustande zwischen dem Inhalt mit seinen trüben Bildern von Tod und Grab und dem vom Jubel der Erhörung beseelten Rhythmus, der alle Not verklärt.« Auf Seite 352 bezieht sich Krinetzki auf die durch die Vokale erzeugte Klangfarbe von Ps 30.

510 Auf das narrative Moment in Ps 30 wird mehrmals hingewiesen. Vgl dazu z. B. Goldingay, Psalms 1, 433: Psalm 30 »tells a story, [...] links the story with issues of life and death, tells the story again when once does not seem enough.« Erich Zenger spricht von zwei Danksagungserzählungen (V3-4; V7-12) mit je individuellem Profil. Vgl. Hossfeld / Zenger, Die Psalmen 1, 186. Aufgrund des thematischen Zusammenhangs zähle ich, anders als Zenger, V2 ebenso zur Minierzählung. 2a liefert dazu mit der Selbstaufforderung den Auftakt, während mit der Begründung in 2b bereits ein erzählendes Element einsetzt, das JHWHs Taten in der Vergangenheit beschreibt. James Luther Mays spricht von einem »basic report of prayer and deliverance» in V2, der der "longer narrative« in V6-12 vorangeht. Mays, Psalms, 139.

511 Dabei lässt sich der Textabschnitt V2-4 von der Überschrift in V1, die Nomen aneinanderreiht und ganz andere Themen aufweist, sowie vom imperativischen Hymnus in V5, der von der Vergangenheitsperspektive der Rettungserzählung zurück ins Hier und Jetzt der Sprechsituation führt, abgrenzen und als eigene kleine Erzählung (Mini-Erzählung bzw. short story) analysieren. Zur Textabgrenzung siehe auch die Gliederungskriterien unter IV Textanalyse Psalm 301 Inhalt.

512 Vgl. Michel, Tempora, 153. 
Nach dem Auftakt in 2a können 2b.c als synthetischer Parallelismus klassifiziert werden. $2 c$ führt den Rettungsgedanken aus $2 b$ insofern weiter, als mit der Nicht-Schadenfreude der Feinde ein weiterer Gedanke hinzukommt. Von der vertikalen Bewegung in $2 \mathrm{~b}$ von unten nach oben (herausschöpfen) wird in $2 \mathrm{c}$ nun der Blick auf das Umfeld des lyrischen Ich (horizontal) und damit auf das feindliche Gegenüber gelenkt, das allerdings nicht näher beschrieben wird (ganz anders verhält es sich in Ps 64). In V3 ist ebenso ein synthetischer Parallelismus auszumachen, der die inhaltliche Komponente des Verses verstärkt: Der nicht näher charakterisierte Hilfeschrei - eine neues Element des Psalms - wird durch das Moment der Heilung weitergeführt, das an das rettende Herausschöpfen von 2b anknüpft. Somit bleibt der Hilfeschrei nicht ohne Reaktion. Im Gegenteil: JHWH greift ein, der Hilfeschrei bewirkt etwas, nämlich Heilung, Ganzwerden, Zusammengeflicktwerden. In V3 liegt damit eine narrative Sequenz vor. Die beiden Gedanken des Hilfeschreiens und des Geheiltwerdens sind sowohl semantisch durch die gedankliche Weiterführung in Form des synthetischen Parallelismus als auch syntaktisch durch die Konjunktion ? miteinander verbunden: Auf den Hilfeschrei folgt eine Heilung, oder anders gesagt: Der Heilung wird ein Hilfeschrei vorangestellt. Diese scheinbar kausale Tatsache ist in den Psalmen keineswegs eine Selbstverständlichkeit. Anrufe an Gott können auch ohne Antwort und Reaktion bleiben (Ps 22,2f; 88,2), und der Zusammenhang von Schreien und Heilen wird nur hier in Ps 30,3 erwähnt.

In V4 geht es um die Wiedererlangung der verlorenen Lebenskraft aus der Tiefe der Notsituation, statt in eine ähnliche Situation der Tiefe hinabzusteigen. Der Vers beginnt abermals mit einem Vokativ, mit dem die Gottheit im Hier und Jetzt der Sprechsituation angesprochen wird. "In v.3 ist [...] eine Beziehung zwischen Rufen und Heilen ausgedrückt. V.4 geht nun weiter auf diese Heilung ein und stellt ihre Bedeutung fest, verweilt gewissermaßen reflektierend bei ihr. Ein Fortschritt in der Handlung ist sicherlich nicht vorhanden. ${ }^{513}$ V4 intensiviert und dramatisiert damit 3b. Im synonymen Parallelismus von V4 wird anhand zweier Aussagen dasselbe Phänomen des »Wieder-ins-Leben-Zurückkommens« im Kontrast zum Verlust der Lebenskraft zum Ausdruck gebracht. Beide Stichen zeichnen sich durch bildliche Rede aus. Dabei stehen sich die Verben עלה (hinaufsteigen 4a) un שִאוֹל (Totenreich

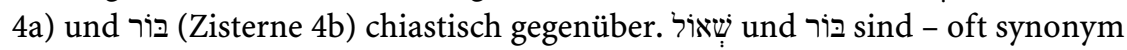
wie hier - Bezeichnungen für die Sphäre des Todes. Im Gegensatz dazu wird das Leben des betenden Ich benannt, ein Mal ausgedrückt mit נַפְּשִי (meine Lebenskraft/Seele; ich) und ein Mal mittels des Verbs חִייתנִ (pi. du hast mich zum Leben gebracht, lebendig gemacht). In beiden Aussagen des Verses geht es darum, nach einer tiefen, nicht näher spezifizierten Not (Krise, Krankheit etc.) die Vitalität

513 Michel, Tempora, 18. 
wiederzuerlangen im Kontrast zu den unwirtlichen Sphären des Totenreiches, in dem keine Lebendigkeit möglich ist. Durch die Konstruktion des synonymen Parallelismus - der an den Heilungsgedanken in 3b anknüpft (der wiederum an das rettende Element in 2b anschließt) und diesen in V4 bildlich ausleuchtet, wodurch eine Intensivierung und Dramatisierung des Rettungsgedankens erfolgt - können Lesende länger am Gedanken der Wiedergewinnung des Lebens nach einer Todeserfahrung bleiben.

\subsubsection{Struktur}

Thematisch steht die Errettung aus Todesgefahr (2b; 3b; V4) im Mittelpunkt, die durch die Selbstaufforderung zum Lob (2a) gerahmt und mit der Schadenfreude gegenüber den Feinden (2c) sowie mit dem Hilfeschrei (3a) versehen ist. In dieser ersten Minierzählung kann von drei Akteuren (JHWH als Du; Ich; Feinde) gesprochen werden, wobei die Feinde weder näher charakterisiert werden noch im weiteren Textverlauf wieder vorkommen. Zeitangaben sind nicht auszumachen, die Erzählung ist also nicht an bestimmte Zeiten gebunden und somit zeitlos, wiewohl durch die Aspekte der Verben Zeitenfolgen auszumachen sind (siehe

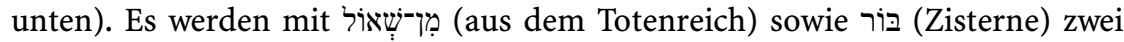
Räume genannt, die im Zusammenhang mit der Rettungserfahrung des betenden Ich und mit Bewegungen stehen. Dabei wird jeweils die Präposition (ִ̣ (von weg; aus) gesetzt: aus dem Totenreich bzw. weg von meinem Hinabsteigen (Qere) bzw. weg von jenen, die in die Zisterne hinabsteigen (Ketib). Diese Präposition bringt den ausschließenden Charakter bzw. den Gegensatz zwischen der lebensförderlichen Handlung des Heraufholens bzw. Zum-Leben-Bringens einerseits und jener des Abstiegs in den lebensgefährlichen Ort der Zisterne nochmals stärker zum Ausdruck. Anhand dieses Kontrastes wird die Alternative zwischen Leben und Tod (im Leben) noch einmal stärker verdeutlicht. Der Gegensatz zeigt auf, wie viel das Lebenkönnen und Lebendigsein angesichts des Wissens um die Todesräume zählt. Blickt man auf die Subjekte und deren Handlungen, dann ergibt sich folgendes Bild:

\begin{tabular}{|l|l|l|l|}
\hline Vers & Subjekt & Handlung & Objekt \\
\hline 2a & Ich & hochheben רום PK po. & dich \\
\hline 2b & Du & herausschöpfen דלה SK pi. & mich \\
\hline 2c & Du & $\begin{array}{l}\text { nicht freuen lassen } \\
\text { pi. }\end{array}$ & Feinde; über mich \\
\hline 3a & Ich & schreien שוע SK pi. & zu dir \\
\hline 3b & Du & heilen W-PK q. & mich \\
\hline 4a & Du & heraufholen על SK hif. & meine Lebenskraft \\
\hline 4b & Du & zum Leben bringen Si. & $\begin{array}{l}\text { mich; weg von meinem Hinab- } \\
\text { steigen }\end{array}$ \\
\hline
\end{tabular}


Die Analyse bringt den direkten Kontakt zwischen dem betenden Ich und JHWH zum Ausdruck, ohne dass nennenswerte Objekte dazwischenstünden (Subjekt Objekt; Ich - Du bzw. Du - Ich). Dabei wird das lyrische Ich zwei Mal mit Kommunikationsverben in Verbindung gebracht. Alle weiteren Handlungen führt JHWH aus. Auf Seiten Gottes ist mit den Handlungsverben ein reges Eingreifen gegeben, und es fällt auf, wie aktiv die Gottheit dargestellt wird: JHWH packt zu, greift an, setzt konkrete Aktionen. Insgesamt fallen die Bewegungen von unten nach oben (hochheben, herausschöpfen, heraufholen) sowie die von oben nach unten (hinabsteigen) ins Auge. Bei den Bewegungen nach unten sind Räume angegeben. Es gibt also eine konkrete Verortung des »Abstiegs«. Die Bewegung nach oben ist mit der Gottheit verbunden. ${ }^{514}$

\subsubsection{2 Übergänge}

Das betende Ich beginnt in 2a mit der Selbstaufforderung zum Lob Gottes. Grund des Lobens ist der mit ’כִ eingeleitete Kausalsatz, der die folgenden Ereignisse in der Vergangenheit (SK) einleitet, nämlich die Rettung aus tiefer Not im Angesicht

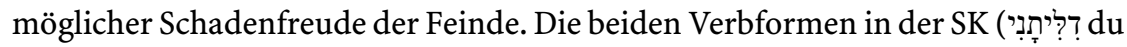

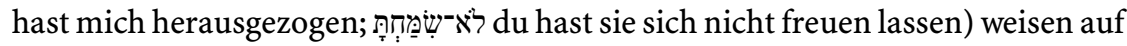
einzelne Handlungen hin, auf die das betende Ich zurückblickt. Die beiden Ereignisse werden durch die Konjunktion ? miteinander verbunden. Die Verneinung erweist sich dabei als negative Explikation und führt daher weder die Handlung weiter, noch würde von einer Folge berichtet. ${ }^{515}$ Von der anfänglichen Gegenwartsperspektive bzw. dem Hier und Jetzt der Sprechsituation aus, die durch die PK und die kohortative Bedeutung der Verbform sowie den Vokativ gegeben ist, wird mittels einer Rückblende eine Perspektive in die Vergangenheit konstruiert. Die Lesenden können mit der Sprecherinstanz mitgehen und zurückblicken in die Vergangenheit der erfahrenen Rettung. Deshalb ist mit der direkten Anrede an die Gottheit in 3a - wie bereits am Beginn von V2 - eine zeitdeckende Gegenwartssituation gegeben, die durch die doppelte Anrede (JHWH, mein Gott) verstärkt wird. Das betende Ich erzählt von einem Hilfeschrei in der Vergangenheit (SK) und einer erfolgten Heilung (W-PK). Zusammengehalten werden die beiden Ereignisse durch die in der W-PK konstruierte Verbform, die darauf verweist, dass die Sprechstimme in den Modus des Erzählens wechselt (vgl. III Methodik 3.3.1). Auffällig ist, dass 2a und 3a an erster Stelle vom Handeln des lyrischen Ich und erst danach vom Tun JHWHs sprechen. ${ }^{516}$

514 Vgl. Krinetzki, Psalm 30, 348.

515 Zur Explikation durch die SK-Form in jener Konstruktion, die zu einer vorherigen Handlung eine Erklärung hinzufügt, vgl. Michel, Tempora, 95-98.

516 Vgl. Witzenrath, Am Abend Weinen, 454. 
Da eine thematische Vielfalt nicht festzustellen ist, lebt die Erzählung vielmehr von den Handlungen und den mit den Bewegungen in Verbindung stehenden Räumen, sowie darüber hinaus vom Wechsel zwischen dem Hier und Jetzt der Sprechsituation und den Rückblicken. Dieser Wechsel zwischen der Jetzt-Perspektive und der Vergangenheitsperspektive ist allerdings weder sprunghaft noch chaotisch gestaltet. Die Handlungen in der Vergangenheit werden durch die Konjunktionen כִ כִ (2b), ? (2c) und die W-PK-Form 3b verbunden, wodurch die Minierzählung im Fluss gehalten wird.

\subsubsection{Zwischenabschnitt V5-6}

Nach der ersten Minierzählung (V2-4) folgt der hymnische Abschnitt V5-6, der aus der Einladung zum Lobpreis (5a.b) und der entsprechenden Begründung (6a.b) besteht. Das lyrische Ich tritt in diesen Versen zurück und ist erst ab V7 wieder präsent.

Der synonyme Parallelismus von V5 beendet die erste Minierzählung (2b-4b),

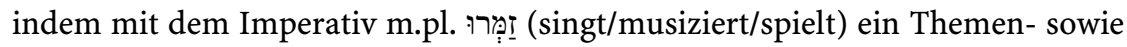
Sprechrichtungswechsel stattfindet. Mit den Wurzeln זמר זמר שמר wird das Loben

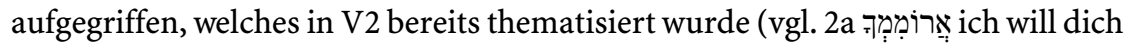
hochheben, preisen). Textintern angeredet werden die הַחִידים Vertrauten oder Getreuen Gottes. Neben dem Themen- und Sprechrichtungswechsel ist auch ein Zeitensprung ersichtlich: Bewegen sich die Verben der V2-4

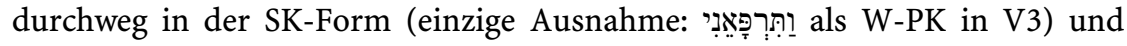
deuten damit auf abgeschlossene, vergangene Ereignisse hin, so wird jetzt mit dem Imperativ Gegenwärtiges aktiviert. Beide Sätze sind auf das Loben ausgerichtet; beide beginnen mit einem Imp.m.pl., und der zweite Satz verstärkt den Gedanken des Lobens und Preisens Gottes insofern, als der Zweck des Preisens ausgeführt wird: »zum Gedenken seiner Heiligkeit.« Die Lesenden werden durch die beiden Sätze in V5 in der Konstruktion des Parallelismus länger am Lobgedanken gehalten, wobei das vokale und instrumentale Singen und Spielen (5a) variiert wird mit dem Lobdanken (5b) und der Nennung des Zwecks. Im antithetischen Parallelismus des nachfolgenden V6 hingegen findet sich weniger eine intensive Beschäftigung mit einem einzigen Gedanken als vielmehr die Plastizität und Mehrdimensionalität mehrerer Themen durch die Verwendung kontrastiver

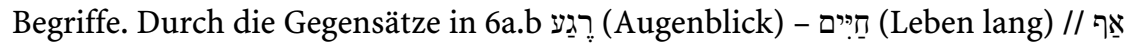
(Zorn) - רָצוֹן (Wohlgefallen), die JHWH zugeschrieben werden, wird das Gottesbild im Verhältnis zum Menschenbild näher charakterisiert. Hier ist es vor allem die Dichte der expliziten Emotionswörter, die die Verskonstruktion ausmacht. Auch die in 6c-d weitergeführten Kontraste עֶרֶ (Abend) - בֶּר (Morgen)

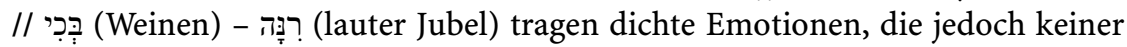
Sprechinstanz zugeschrieben, sondern subjektfrei dargestellt werden, perso- 
nenneutral formuliert sind und Ähnlichkeiten zu weisheitlichen Aussagen aufweisen ${ }^{517}$ Im kunstvoll gestalteten V6 sind die semantischen Oppositionen augenfällig: Die Zeitangaben in 6a.b (Augenblick; Leben lang) unterscheiden sich durch Kürze und Länge, jene in 6c.d (Morgen, Abend) durch Anfang und Ende des Zeitraums. Antithetisch geschildert werden die Haltungen JHWHs, die in 6a.b erwähnt werden: Der Zorn ist Ausdruck der Erfahrung der Abwendung JHWHs, das Wohlgefallen die Erfahrung der göttlichen Zuwendung. Infolgedessen stehen sich die in $6 c$.d genannten Äußerungen von Trauer und Freude des Menschen, Weinen und Jubel oppositionell gegenüber. Die Kürze wird dem Zorn JHWHs zugeordnet, die Dauer seinem Wohlgefallen, das Weinen dem Abend und der Jubel dem Morgen. ${ }^{518}$ Bei all diesen oppositionellen Begriffen fällt auf, dass 6a.b. von Abstrakta bestimmt wird, die in der Personifikation des übernachtenden Weinens von $6 \mathrm{c}$ ihre bildliche Verdeutlichung erfahren.

\subsubsection{Zweite Minierzählung V7-13}

Mit V7 setzt die zweite Minierzählung ein, die bis V13 reicht. Diese beginnt mit einem Sprechrichtungswechsel. Zudem tritt das lyrische Ich, das in V5-6 nicht vorkommt, nun in V7 in betonter Stellung auf: "Ich aber, ich sagte in meiner Sicherheit.«Im synthetischen Parallelismus von V7 führt wiederum der zweite Satz den Inhalt des ersten Satzes weiter, indem die Äußerung durch einen Gedanken aus dem Inneren des lyrischen Ich prolongiert wird. Auf die Einleitung in die direkte Rede durch das metakommunikative Verb des Sprechens in 7a folgt in $7 \mathrm{~b}$ die direkte Rede selbst. Innerhalb dieses synthetischen Parallelismus wechselt damit der Blick von außen nach innen. Thema des Verses ist die Sicherheit bzw. Selbstsicherheit oder Sorglosigkeit des lyrischen Ich. Dabei wird das "Ich» in 7a durch die mehrmalige Erwähnung hervorgehoben: אִ (selbstständiges Personal-

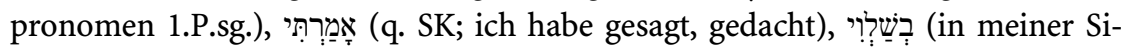
cherheit). Der/die PsalmistIn wiegt sich in zufriedener Sorglosigkeit und vertraut allein auf sich. Der Fokus liegt auf dem »Ich«. Die Selbstsicherheit wird durch den Begriff שָׁ zum Ausdruck gebracht und durch die Erweiterung in Form des

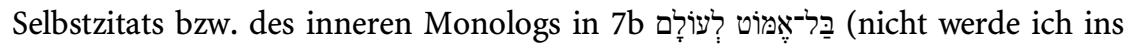
Wanken gebracht auf ewig) konkretisiert und damit deutlich verstärkt. Im Kontrast dazu wird die Sicherheit des Menschen in anderen Psalmversen auf die Unter-

517 Oeming, Das Buch der Psalmen, 181 bezeichnet V6 als »einen allgemeinen theologischen Lehrsatz, der das Wesen Gottes beschreibt. Gott hat sozusagen zwei Seiten, eine dunkle Nachtseite, in der sein Zorn losbricht und Krankheit und Leid über den Menschen bringt, und eine helle Tagseite, die Krankheit vertreibt und Leben schenkt. In Gott überwiegt bei Weitem die Lichtseite.« Der Zusammenhang zwischen göttlichem Zorn und menschlicher Krankheit geht m. E. jedoch aus dem Psalm nicht explizit hervor.

518 Vgl. Witzenrath, Am Abend Weinen, 455. 
stützung Gottes zurückgeführt (Ps 16,$8 ; 55,23 ; 62,3.7$ ) und nicht auf menschliche Stärken oder auf sich selbst. Die hier in V7 ausgedrückte Selbstsicherheit führt im darauffolgenden V8 zum Erschrecktwerden durch die Gottferne.

Nach der unklaren Textstelle 8b können 8c.d als synthetischer Parallelismus betrachtet und analysiert werden, wobei V8 einen inhaltlichen Gegensatz enthält: 8a-b erzählen von der Zuwendung Gottes, $8 \mathrm{c}$ spricht von der Gottferne. ${ }^{519}$ Diese wird durch das Verbergen des Angesichts Gottes zum Ausdruck gebracht. 8d führt das Thema des Abwendens Gottes weiter, indem die Reaktion des betenden Ich darauf geschildert wird: das Erschrocken- bzw. Erstarrtsein. Im synthetischen Parallelismus von $8 \mathrm{c}$.d erzählt das lyrische Ich also zunächst in $8 \mathrm{c}$ von einer Tat Gottes und in $8 \mathrm{~d}$ von der Konsequenz, die sich als Folgehandlung für das lyrische Ich ergibt (Ursache - Wirkung). Stilistisch gesehen ist hier von einer Asyndese zu sprechen, da die beiden Aussagen relativ unvermittelt aufeinander folgen und kein Bindewort vorhanden ist. ${ }^{520}$ Mit V7-8 werden Themen eingeführt, die im Psalm bislang noch nicht erwähnt wurden: Bisher ging es um das Loben (2a.V5), die Rettung und die Wiedergewinnung neuen Lebens bzw. neuer Lebenskraft (V3-4) sowie um die in weisheitliche Aussagen gekleideten Aspekte von Gottes Zorn und Güte bzw. von Weinen und Jubel auf Seiten des Menschen. Nun treten mit der vermeintlichen menschlichen Selbstsicherheit und der Erfahrung der Abwesenheit Gottes inklusive der Reaktion des Erstarrtseins neue Aspekte zu Tage. Doch schon im darauffolgenden V9 begegnet dem/der Lesenden wieder ein bereits vertrauter Gesichtspunkt, und zwar jener der direkten Zuwendung und des Rufens zu Gott. Im synonymen Parallelismus von V9 ist offensichtlich, wie sehr sich die Konstruktion der beiden Sätze ähnelt: Es wird die gleiche Präposition verwendet (אֶ), ebenso der Gottesname JHWH in paralleler Konstruktion mit dem Ersatznamen Adonaj sowie die Verben rufen (קרא) (חנן), die auch synonym gebraucht werden. Der einzige Unterschied besteht in Bezug auf den Gottesnamen und dessen Anrede: Wird in 9a JHWH im Vokativ angesprochen, so steht in 9b Adonaj als Dativobjekt, welches mit einer Präposition eingeleitet wird. Beide Personalformen sind in der PK formuliert. Das Rufen zu Gott wird damit nicht nur durch die Konstruktion des synonymen Parallelismus, sondern auch durch den Aspekt der Unabgeschlossenheit und des Anhaltenden der Handlung intensiviert. Die PK-Formen weisen auf einen iterativen Gebrauch hin: Das Rufen zu Gott und das Flehen um Erbarmen geschieht immer wieder, ist daher als kaum unterbro-

519 In Bezug auf das lyrische Ich bemerkt Craigie, Psalms 1-50, 254 an dieser Stelle: »He had indeed been prosperous and upright, like the mighty mountains, not for anything he had done, but simply because of divine favor. The moment God turned his face away, disaster struck."

520 Vgl. Ridderbos, Die Psalmen, 106. Ebenso Craigie, Psalms 1-50, 254. 
chenes Schreien zu Gott zu betrachten. Hier verstärkt der Parallelismus den Nachdruck und die Bestimmtheit, die in den Versen liegen. ${ }^{521}$

Thema des nächsten Verses (V10) ist jener Verlust, den Gott davontragen muss, wenn Menschen gestorben sind bzw. sich in Räumen der Kommunikationslosigkeit mit Gott und mit anderen befinden, sodass sie JHWH nicht mehr loben können. Formal ist der Vers in drei rhetorische Fragen gegliedert. Von diesen drei Interrogativsätzen beginnt der erste mit einem Fragewort (זָ̦) und die zwei nachfolgenden mit einer Interrogativpartikel (nָ). Diese in Form rhetorischer Fragen ausgedrückte Argumentation in der Verhandlung mit Gott wird in den Psalmen öfter dazu verwendet, um JHWH zum Eingreifen zu bewegen (z. B. Ps 6,6; 88,11-13). 10c-d führen dabei in einem synonymen Parallelismus den Gedanken der Absurdität des Ertrages für Gott aus dem Totsein des Menschen aus dem synthetischen Parallelismus von 10a.b weiter. V10 insgesamt kann als Sequenz betrachtet werden, welche die Aussageabsicht sukzessive konkretisiert.

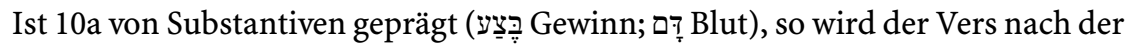
Infinitivkonstruktion ( PK weitergeführt (ידה loben 10c) und vollendet (נגד erzählen 10d). Der synthetische Parallelismus beginnt also mit Abstrakta und führt zu konkreten Handlungen hin, die - auch angesichts der Personifikationen des lobenden und erzählenden Staubs (vgl. Versanalyse zu V10) - zur Konkretisierung und Verlebendigung der dargestellten Situation beitragen. Es geht damit um das Ringen nach Leben und Lebendigkeit angesichts des drohenden Todes. Sich in der Grube, im Grab, im Totenreich zu befinden, kann mit Abbruch der Kommunikation mit Gott und Beziehungslosigkeit gleichgesetzt werden. Gerade in diesem Raum der Kommunikationslosigkeit wird durch den Staub, der lobt und erzählt, das Paradoxon der Situation noch deutlicher: Staub gehört in die Sphäre des Todes, doch nur Lebendige können JHWH loben und von seinem treuen Eingreifen in die Geschichte erzählen.

In V10 begegnen bekannte Begriffe: das Loben (ידה) aus V5 sowie das Hinabsteigen (ירד) aus V4. Der Kontrast zwischen Leben und Tod bzw. das unmittelbare Nebeneinander dieser beiden Bereiche machen den Vers aus: So ist von $\square$ ד̦ (Blut) die Rede, das sowohl als Sitz des Lebens gilt (Gen 9,4; Lev 17,11.14; Dtn 12,23) als auch mit dem Tod, insbesondere mit Mord (Gen 4,10; 9,5; Jos 2,19) verbunden werden kann, denn Blutverlust bedeutet den Verlust des Lebens und damit den Tod. ${ }^{522}$ Das Hinabsteigen in die Grube bedeutet das Betreten der Todessphäre. Demnach beschreiben 10c-d die Todessphäre ausführlicher, indem der Staub erwähnt wird, mit dem Verben der Kommunikation verbunden werden - jene Kommunikation, die im Bereich des Todes nicht möglich ist. Die Lesenden

521 Vgl. Krinetzki, Psalm 30, 357.

522 Vgl. Kampling, Blut, $82 \mathrm{f}$. 
werden nicht nur durch die Variation des Themas (Leben - Tod bzw. Todessphäre), durch die stufenweise Konkretisierung und sukzessive Verlebendigung der Situation, sondern auch durch die Anzahl der Wörter gezwungen, länger am Vers und damit am Gedanken zu bleiben: V10 besteht aus zehn Wörtern und ist - etwa im Unterschied zum vorhergehenden V9 mit nur sechs Wörtern - in diesem Textzusammenhang ein langer Vers, der entsprechend hohe Aufmerksamkeit der Lesenden auf sich zieht.

V11 bewegt sich zwischen einem synonymen und einem synthetischen Parallelismus. Das bereits aus V3.9 bekannte Thema des Rufens zu Gott um Hilfe wird hier in den Schlussversen nochmals aufgegriffen. Neu sind hier in V11 im Vergleich zu den Formulierungen der SK und vor allem der PK-Formen aus V3.9, die von vergangenen Ereignissen erzählen, die Imperative in Verbindung mit den direkten Gottesanreden. Diese drücken die Dringlichkeit des erbetenen Eingreifens noch deutlicher aus, als dies zuvor der Fall ist. Die beiden Sätze 11a.b sind grammatikalisch ähnlich aufgebaut und unterscheiden sich lediglich in der Syntax: 11a: Imp.q.m.sg. - Gottesname - Imp.q.m.sg. + Suffix 1.P.sg.; 11b: Gottesname Imp.q.m.sg. - Ptz.q.m.sg. - Präp. + Suffix 1.P.sg. Somit sind in beiden Sätzen Imperative, Gottesname und die Suffixe der 1.P.sg. vorhanden. Es geht in V11 um das erbetene Zuhören Gottes, also die Wahrnehmung der Notsituation des betenden Ich, um die göttliche Zuwendung (חנן q. gnädig sein) und Hilfe (עזר) Ptz.q.m.sg.). Durch die Bitte um das Hören Gottes wird dessen Wahrnehmungsfähigkeit aktiviert, mit der Bitte um Hilfe das Handeln Gottes erbeten. Synthetisch betrachtet, kann ein Dreischritt erschlossen werden: JHWH wird zunächst zur Wahrnehmung (hören) aufgefordert, dann wird seine Zuwendung (sei mir gnädig) erbeten und am Schluss seine konkrete Hilfe (sei ein Helfender) angesprochen.

Thema des vorletzten Verses, V12, ist die Verwandlung durch JHWH hin zu neuem Leben bzw. zu Leben in Freudenfülle, ausgedrückt wiederum mittels eines synonymen Parallelismus, der viele Gegensätze enthält. Die Verwandlung wird in 12a konstatiert, dann in 12b.c plastisch ausgeschmückt und an den Kontrast-

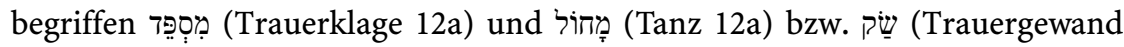
12b) und שִמְחָָה (Freude 12c) explizit gemacht. JHWH verwandelt die Trauer des betenden Ich in bewegte Freude. Mittels des synonymen Parallelismus wird die allgemeine Aussage aus 12a in 12b.c spezifiziert. Wird in 12a der Wandel durch Substantive (Trauerklage; Tanz) beschrieben, so wird diese abstrakte Formulierung durch die bildliche Rede in 12b.c, die unter anderem anthropomorphe Züge trägt (Trauergewand öffnen; mit Freude umgürten), entfaltet und ausgebreitet. Im synonymen Parallelismus von V12 wird die Bedeutung der Rede vom Wandel der Trauerklage in einen Freudentanz durch die metaphorische Rede, die weitere Aspekte und Emotionen freisetzt (siehe Analyse zu V12), intensiviert, wodurch 
die Lesenden länger am Text verweilen und durch das Sprachbild tiefer in die Aussageabsicht eintauchen können.

Der Psalm 30 abschließende synonyme Parallelismus von V13 nimmt das Lobthema wieder auf, von dem in 2a.5a.b.10c bereits die Rede war, und führt es weiter in Richtung Preisung Gottes durch alle Zeiten hindurch bis in Ewigkeit

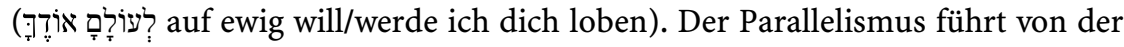
Personifikation der singenden bzw. musizierenden Ehre hin zum Loben Gottes durch das lyrische Ich selbst. Auf diesem Weg des fortschreitenden Gotteslobes vom Abstraktum zum betenden Ich werden die Lesenden kurz gestoppt: Mit der negierten Form des Verstummens wird das, was bereits in V10 als drohendes Szenario mit der Personifikation des lobenden Staubes im Todesraum - der unter anderem durch Verstummen und absoluter Stille gekennzeichnet ist - entworfen wurde, nochmals eingespielt.

Das Thema des Lobens und Preisens Gottes sowie der Danksagung durchzieht den Psalm und wird am Ende nochmals intensiviert. ${ }^{523}$ Beginn und Ende eines Gedichtes prägen sich bei den Lesenden intensiver ein als andere Textabschnitte. Gerade der Schluss ist zentral, da er beim inneren Nachklingen des Gedichts eher in Erinnerung bleibt. Die Lesenden werden hier in Ps 30 am Ende dazu angehalten, nach der Rettung aus Todesnot, der Erfahrung scheinbarer sicherer Zufriedenheit, Verhandeln mit und Schreien zu Gott und der abschließenden Wandlung hin zum guten und freuderfüllten Leben mit dem lyrischen Ich in das Lob Gottes einzustimmen.

\subsubsection{Struktur}

Als Figuren sind wiederum das lyrische Ich (V7.8d.V9.10b.13c), JHWH (Du; 8b.c.V11-12) sowie zwei weitere Subjekte auszumachen: der Staub und die Ehre treten als Personifikationen auf (V10.13). Dabei ist, wie bereits in der ersten Minierzählung, das Beziehungsgeschehen zwischen Ich und Du wichtig. Auffällig ist im Vergleich zur ersten short story - die Themenvielfalt, die innerhalb dieses Beziehungsgeschehens artikuliert wird: Sie reicht von der menschlichen Selbstsicherheit über das göttliche Wohlgefallen, Kraft und Stärke bis hin zur Gottferne und die darauffolgende Reaktion des Erschrecktseins. Nach dem Hilfeschrei zu Gott erfolgt die Verhandlung mit der Gottheit über den Nutzen des Hinabsteigens in den Todesraum. Daran schließt sich die Bitte um Wahrnehmung und Hilfe an. Auf die Verwandlung durch JHWH wird das immerwährende Lob Gottes in Aussicht gestellt, das im Gegensatz zum Verstummen steht. Die Themen wechseln

523 »Bei Ps 30 kann von Inklusion gesprochen werden, und zwar nicht so sehr der Wiederkehr von (v. 2) in v. 12 und von >Jahwe, mein Gottı (v. 3) in v. 13 wegen, sondern vielmehr deswegen, weil v. 13b inhaltlich auf v. 2a zurückgreift; ebenso wie bei Ps 21 kann hier von einem circulus gloriosus gesprochen werden.« Ridderbos, Die Psalmen, 37. Vgl. ebenso Weber, Werkbuch 1, 150. 
dabei nicht sprunghaft. Einem Thema werden mehrere Gedanken und Zeilen gewidmet, wie dies die Analyse der Parallelismen bereits gezeigt hat. Darüber hinaus werden sie im Spannungsaufbau des Plots entwickelt und weitergeführt. Blickt man nun noch auf die Räume, so fallen zwei völlig entgegengesetzte Räume ins Auge: הַ, der Berg, der in die Höhe ragt und mit Beständigkeit konnotiert ist (8b), steht oppositionell zu שַָָׁ, der Grube, die die Tiefe, Falle und Enge darstellt (10b). So kontrastreich die Räume, so identisch die Zeitangaben, die mit Bezug auf den jeweiligen Textkontext - intratextuell betrachtet - wiederum doch im Gegensatz zueinander stehen: Das Temporalobjekt לְעוְָֹם (auf ewig 7b, 13c) rahmt die zweite Minierzählung. Inhaltlich steht das Nicht-Wanken auf ewig mit Bezug auf die eigene Selbstsicherheit (7a) und weniger auf das Vertrauen in Gott im Kontrast zum ewigen Lob Gottes (13c), das von der Selbstbezogenheit weg hin zum transzendenten Gegenüber führt. Jenseits der identischen Zeiträume ist noch auf die differenzierte Wahrnehmung der Zeitebenen im gesamten Psalm hinzuweisen, die Hardmeier unterstreicht. Er spricht von einer gegenläufigen Verschränkung der Zeitebenen im gesamten Text, sieht in 2a.V5-6 sowie 13b Gegenwart bzw. Gegenwart und Zukunft ausgedrückt und hält an dieser Stelle fest: »Das betende Ich vollzieht den Lobpreis als performativen Akt im Hier und Jetzt der Gebetsäußerung. Dabei fasst das abschließende Lobgelübde die weitere Zukunft der Gottesbeziehung ins Auge. Demgegenüber werden im Innern des Psalms ringförmig drei Vergangenheitsebenen angesprochen. ${ }^{524}$ Diese drei Vergangenheitsebenen (Vg1, $\mathrm{Vg} 2, \mathrm{Vg} 3)^{525}$ kennzeichnet er folgendermaßen:

Vg1: 2b.c; V3-4; V12.13a: Diese Verse begründen den Lobpreis mit dem Rückblick auf die erfahrene Rettung.

Vg2: 3a; V9-11: Diese Verse greifen hinter die Rettungserfahrung zurück. Dabei wird das Flehen (Bittgebet) nochmals in Erinnerung gerufen.

Vg3: V7-8: Der Mittelteil des Psalms bildet die letzte Vergangenheitsebene, die hinter das Bittgebet zurückgreift. Inhaltlich erstrecken sich diese Verse von den guten Zeiten (Selbstsicherheit) ${ }^{526}$ bis hin zur Gottesferne.

Kehren wir nun nach dem Kurzexkurs zu den unterschiedlichen Zeitebenen des Textes zurück zur zweiten Minierzählung. Die Analyse der Subjekte, Objekte und Handlungen lässt sich folgendermaßen darstellen:

524 Hardmeier, Systematische Elemente, 343.

525 Vgl. Hardmeier, Systematische Elemente, 342. Diesem Modell folgen Janowski, Konfliktgespräche mit Gott, 271-274 und Weber, Psalm 30, 37.

526 Mit dem Selbstzitat über die Selbstsicherheit unterstreicht der/die PsalmistIn, dass der Stolz bzw. die Selbstüberheblichkeit in einer anderen Zeitstufe ausgesprochen wurde. Es war jene Zeit, in welcher er/sie sich selbst mehr vertraute als Gott. Vgl. dazu Jacobson, "Many are Saying", 62 . 


\begin{tabular}{|c|c|c|c|}
\hline Vers & Subjekt & Handlung & Objekt \\
\hline $7 \mathrm{a}$ & Ich & $\begin{array}{l}\text { sagen אמר } \\
\text { SK q. }\end{array}$ & in meiner Sorglosigkeit \\
\hline $7 \mathrm{~b}$ & Ich & $\begin{array}{l}\text { nicht ins Wanken gebracht wer- } \\
\text { den, wackeln מַּל מוט } \\
\text { PK nif. }\end{array}$ & \\
\hline $8 \mathrm{a}$ & $\mathrm{Du}$ & & in deinem Wohlgefallen \\
\hline $8 \mathrm{~b}$ & $\mathrm{Du}$ & $\begin{array}{l}\text { עמד עמד } \\
\text { SK hif. }\end{array}$ & $\begin{array}{l}\text { für meinen Berg } \\
\text { Stärke/Kraft }\end{array}$ \\
\hline $8 c$ & $\mathrm{Du}$ & $\begin{array}{l}\text { herbergen סתר } \\
\text { SK hif. }\end{array}$ & dein Angesicht \\
\hline $8 \mathrm{~d}$ & Ich & $\begin{array}{l}\text { sein, werden, wurde היה } \\
\text { SK q. } \\
\text { erschreckt בהל } \\
\text { Ptz. nif. }\end{array}$ & \\
\hline $9 a$ & Ich & $\begin{array}{l}\text { rufen קרא } \\
\text { PK q. }\end{array}$ & zu dir \\
\hline $9 b$ & Ich & $\begin{array}{l}\text { um Erbarmen flehen חנן } \\
\text { PK hitp. }\end{array}$ & zu Adonaj \\
\hline $10 \mathrm{a}$ & Gewinn & & an meinem Blut \\
\hline $10 \mathrm{~b}$ & (Ich) & \begin{tabular}{|l|} 
hinabsteigen ירד \\
Inf.constr.q.+Suffix1.P.sg.
\end{tabular} & in die Grube \\
\hline $10 \mathrm{c}$ & Staub & $\begin{array}{l}\text { loben ידה } \\
\text { PK hif. }\end{array}$ & \\
\hline $10 \mathrm{~d}$ & $\begin{array}{l}\text { Er } \\
\text { (Staub) }\end{array}$ & $\begin{array}{l}\text { erzählen } \\
\text { PK hif. }\end{array}$ & deine Treue \\
\hline $11 \mathrm{a}$ & $\mathrm{Du}$ & $\begin{array}{l}\text { hören שמע Imp.q.m.sg. } \\
\text { Impädig sein חנן } \\
\text { gnaffix 1.P. } \\
\text { Imp.q.m.sg. + Suffix }\end{array}$ & $\operatorname{mir}$ \\
\hline $11 \mathrm{~b}$ & $\mathrm{Du}$ & \begin{tabular}{|l} 
sein היה.sg. \\
Imp.q.m.sg. \\
helfen עזר \\
Ptz.
\end{tabular} & für mich \\
\hline $12 \mathrm{a}$ & $\mathrm{Du}$ & $\begin{array}{l}\text { הפך verwandeln } \\
\text { SK q. }\end{array}$ & $\begin{array}{l}\text { meine Trauerklage } \\
\text { in einen Tanz } \\
\text { für mich }\end{array}$ \\
\hline $12 \mathrm{~b}$ & $\mathrm{Du}$ & $\begin{array}{l}\text { öffnen, ausziehen, lösen, able- } \\
\text { gen, befreien פתח SK pi. } \\
\text { umgürten אזר SK } \\
\text { W-PK pi. }\end{array}$ & $\begin{array}{l}\text { mein Trauergewand } \\
\text { mich } \\
\text { Freude }\end{array}$ \\
\hline $13 a$ & Ehre & $\begin{array}{l}\text { singen, spielen זמר } \\
\text { PK pi. }\end{array}$ & Dich \\
\hline $13 \mathrm{~b}$ & (Ehre) & $\begin{array}{l}\text { nicht verstummen, schweigen } \\
\text { למג + למם } \\
\text { PK q. }\end{array}$ & \\
\hline
\end{tabular}


(Fortsetzung)

\begin{tabular}{|l|l|l|l|}
\hline Vers & Subjekt & Handlung & Objekt \\
\hline $13 \mathrm{c}$ & Ich & $\begin{array}{l}\text { loben, danken, } \\
\text { PK hif. }\end{array}$ & \\
\hline
\end{tabular}

Neben der Häufung von Kommunikationsverben fällt auf, dass diese zweite Minierzählung durch folgende Elemente Einblick in das Innere und somit in die Gedanken des lyrischen Ich gewährt: 7a: in meiner Sicherheit habe ich gesagt bzw. gedacht oder erwogen; 8d erschrocken sein als emotionaler Ausdruck; rhetorische Fragen (V10) und direkte Anreden (Imperative) an Gott (V11), die die Dringlichkeit des Anliegens zum Ausdruck bringen.

V7-13 lebt von der reichen, abwechslungsreichen Gestaltung der Themen, Verbformen und rhetorischen Mitteln. Formal ist folgender Aufbau möglich: Selbstzitat (7b), ${ }^{527}$ Bitte um Hilfe (V9; V11), Argumentation in Form von Fragen (V10), Verwandlungsbericht (V12), Conclusio (V13). Bezüglich der Textdynamik fällt der Wechsel zwischen erzählenden Teilen (V7-9; 12-13) und direkter Rede (Imperative, Fragen V10-11) auf. Mehrere Zustandsveränderungen, die ja gerade die Narrativität der Textstelle V7-13 ausmachen (vgl. I Einleitung 4.1.1), sind festzuhalten: Die Ereignisse handeln von Sicherheit, gehen dann weiter über Erschrecken (plötzliche Angst), Hilfeschrei, Todesnot vor Augen, Bitte und Verwandlung bis zur Konsequenz daraus in Form des ewigen Gotteslobes. Hier sind eine Dramaturgie und ein Spannungsaufbau auszumachen. Nach jedem Vers stellt sich die Frage, wie es nun weitergeht. Das Interesse wird wach gehalten, es bleibt spannend: Hält die Selbstsicherheit in V7 an? Was passiert nach der Abwendung Gottes und dem Erschrockensein in V8? Wird Gott die Bitten erhören (V9.11)? Ist die Verhandlungstaktik in V10 überzeugend? Schließlich löst sich die Spannung in der Klimax des Psalms (V12) mit der Wandlung der Klage in Freude und Tanz. Mit V13 kommt die Erzählung zur Ruhe. Ein »runder Schluss« ist damit gegeben. ${ }^{528}$

\subsubsection{Kommunikationsebenen}

In diese Erzählung ist, wie bereits erwähnt, eine direkte Rede eingebettet (V1011), die mit dem Verb des Rufens in V9 eingeleitet wird. Dementsprechend kann die Erzählung auch folgendermaßen eingeteilt werden: V7-8: Ich-Erzähler; V9:

527 Vgl. Witzenrath, Am Abend Weinen, 454. Selbstzitate der PsalmistInnen haben in den Psalmen vor allem die Funktion, vergangene Ereignisse zu erzählen, um die gegenwärtige Argumentation des jeweiligen Psalms zu unterstützen. Vgl. dazu Jacobson, »Many are Saying«, 61.

528 Blickt man auf die Abfolge der Ereignisse in V7-13, dann ist mit Loader festzuhalten »The chronology of the little narrative is therefore: negative change - substantiated plea - positive change.« Loader, Psalm 30, 295. 
Redeeinleitung des Ich-Erzählers; V10-11: direkte Rede an Gott: drei Fragen + drei Imperative; V12: Ich-Erzähler; V13: Schlusssatz/Konsequenz des Ich-Erzählers aus der Erzählung. In der direkten Rede fallen die PK-Formen ins Auge, die meist in der Vergangenheit wiedergegeben werden. ${ }^{529}$ Dabei wird die Anrufung JHWHs im Rahmen von V9-11 mehrheitlich als Zitierung der einst formulierten Not-Klage betrachtet. ${ }^{530}$ Anders sieht das an dieser Stelle z. B. Beat Weber, der neben V10-11 ebenso V9 präsentisch übersetzt und die PK-Formen als gegenwärtige Klage sieht. ${ }^{531}$ Auf den iterativen und durativen Aspekt der PK macht in diesem Zusammenhang Diethelm Michel aufmerksam: "Der Psalmist will nicht ein Faktum berichten, sondern einen Zusammenhang zwischen seinem Rufen und dem Nicht-Hören Jahwes angeben: Jedesmal, wenn er ruft, antwortet Jahwe nicht. Die impfa. bezeichnen also ein korrespondierendes Eintreten. ${ }^{532}$ Auf die in V9-11 ausgedrückte Prozesshaftigkeit, die Wiederholung, das Immerwieder-versuchen wird mehrfach hingewiesen. ${ }^{533}$

In V7-11 fallen also durch die direkten Reden und rhetorischen Fragen die Kommunikation bzw. die Verhandlung und Argumentation ins Auge. Gott wird als abwesend empfunden, und die Kommunikation, d. h. die Imperative und Fragen, scheinen die Distanz zur Gottheit zu überbrücken. Rede überwindet also Distanz. Das Anrufen Gottes ist deshalb notwendig, weil die Nähe und Zuwendung nicht erfahren wird (V8). Erst in V12 werden der direkte Kontakt und das konkrete Eingreifen und Handeln Gottes durch die Verwandlung des betenden Ich greifbar. ${ }^{534}$ Hier zeigen sich Analogien zur ersten Minierzählung in V2-4: Auch dort wird vom direkten Eingreifen Gottes durch die Rettung aus Todesnot erzählt.

\subsubsection{3 Übergänge}

Die Erzählung beginnt in 7a mit der Konjunktion ? (aber, und) und dem selbstständigen Personalpronomen der 1.P.sg. אֶנְ (ich) betont »kräftig" und bettet das im Rückblick getätigte Selbstzitat in $7 \mathrm{~b}$ mittels des metakommunikativen Verbs אמר als Redeeinleitung in den Erzählverlauf ein. 8a stellt mit dem

529 Vgl. z. B. Michel, Tempora, 81.

530 Vgl. Hardmeier, Systematische Elemente, 343.

531 Vgl. Weber, Werkbuch 1, 150. Ebenso in der Präsensform übersetzen V9 Ketter, Die Psalmen, 43 sowie Spieckermann, Heilsgegenwart, $255 \mathrm{f}$; für Letzteren handelt es sich »eigentlich um Klage in actu und nicht um Rückblick auf Klage im Kontext des Dankliedes«. Auch Zenger, Theophanien, 418 plädiert dafür, die beiden Präfixkonjugationen in V9 präsentisch zu übersetzen.

532 Michel, Tempora, 82.

533 Vgl. z. B. Weber, Psalm 30, 42.

534 »In v. 12 kehrt der Dichter zur Schilderung der Errettung zurück, typisch sind wieder die unverbundenen VS mit perfektischen Prädikaten, die aufzählend aneinanderreihen.» Michel, Tempora, 67. 
Vokativ, also der direkten Anrede an JHWH, einen Bezug zum Hier und Jetzt der Sprechsituation her, bevor wieder die Vergangenheitsperspektive eingenommen wird und eine Aneinanderreihung von Ereignissen in der SK geschildert wird. Dabei wird innerhalb dieser asyndetischen Reihe von Ereignissen (für meinen Berg eine Kraft aufstellen עמד, dein Angesicht verbergen סתר, erschrocken sein היה) der Übergang von der Aktion des Verbergens des Angesichts hin zum Erschrecktsein als plötzlich bzw. abrupt charakterisiert, was auch mit der Semantik des Partizips נִבְָה (überraschtes Erstarrt- bzw. Schreckensstarrsein) zu tun haben kann. In 9a wird abermals mit dem Vokativ an das Hier und Jetzt der Sprechsituation erinnert, bevor mit den durch die Konjunktion ? in Verbindung stehenden Verben des Rufens (חנן, קרא) die direkte Rede in V10-11 eingeleitet wird. Während der Übergang von $11 \mathrm{~b}$ zu 12a durchaus unerwartet sowie auch wieder abrupt $\mathrm{t}^{535}$ von Statten geht, ist der letzte Vers von Psalm 30 durch die Konjunktion לִֵַ, die einen Folgesatz einleitet, mit dem Gesamt der Erzählung verbunden. Auch wenn mitunter abrupte Übergänge zu verzeichnen sind, lädt die zweite Minierzählung V7-13 vor allem durch den narrativen Charakter, die lebendige Gestaltung und den darin enthaltenen Spannungsaufbau zum Mitgehen ein: "Narrative thanksgiving: by being told the story, the readers are drawn into the praying individual's plight - we can identify, that is, participate. This means that we are drawn into the psalm's world and become associated with the second person plural already spoken earlier (v 5). It also means that we become witness to the self-assurance and the fear of the psalmist. We become aware of how easy it is to develop a false sense of security when one never has to feel pain and fear. ${ }^{536}$

\section{$4 \quad$ Zusammenschau und Auswertung}

Im Folgenden werden die Ergebnisse aus den Analysen zu Emotionen, Perspektiven und Textdynamik gebündelt. Daran schließt sich eine Auswertung in Bezug auf den Anteil an Emotionen und Handlungen an, der jeweils der Gottheit und dem lyrischen Ich zuzuordnen ist. Aus Zusammenfassung und Auswertung werden Tendenzen für die abschließende Eruierung von Identifikationspotenzialen hergeleitet.

535 Vgl. Ridderbos, Die Psalmen, 78.

536 Loader, Psalm 30, 299. 


\subsection{Emotionen}

V2 bringt die Emotionen der Freude und Erleichterung implizit zum Ausdruck. Die Freude sowie die Entschlossenheit sind im Kontext des Hochhebens und Preisens JHWHs, das als ekstatischer Aufschwung betrachtet werden kann, zu eruieren, also die Erleichterung aus dem Herausgeschöpftwerden. Durch die kohortative Bedeutung von רום wird die Freude syntaktisch verstärkt. Das Herausschöpfen selbst impliziert das Dunkel und die Tiefe eines Schachtes. Daneben werden mittels des Bildes des Schöpfeimers - als einem Schweben über dem Abgrund - Unsicherheit sowie Angst ausgedrückt. Diese Emotionen werden dem lyrischen Ich zugeschrieben. Auf Seiten JHWHs sind Stärke, Sicherheit und Verlässlichkeit auszumachen. Schon hier ist eine Form dessen auszumachen, was ich als doppelte Emotionalität bezeichne: In der preisenden Freude und Erleichterung über die erfahrene Rettung schwingt das Dunkel, die Tiefe und die (Todes-) Furcht noch mit, welche in V4 nochmals aufgegriffen wird. Bei der Erwähnung der Feinde können das Moment der Bedrängung und Verfolgung sowie die Todesangst mitgedacht werden. Das explizite Emotionswort der Freude - hier in der verneinten Verbform - drückt Schadenfreude aus, im weiteren Textverlauf kommt die Freude als tiefe Emotion und spontane Äußerung, einem Freudengeschrei gleich, nochmals an prominenter Stelle vor (vgl. die Klimax in V12).

Die Verdoppelung der Anrede in V3 stellt die Dringlichkeit und akute Notsituation des Geschilderten deutlich vor Augen. Dem darauffolgenden Schreien, das - im Rückblick formuliert - als Hilferuf auf eine erlebte Not bzw. als eine Reaktion auf eine Negativerfahrung betrachtet wird, folgt die Erfahrung der Heilung. Dahinter können Verletzungen und Krankheiten aller Art stehen, die schlimm, qualvoll und tödlich enden können. Dieses schwere Leid impliziert die Emotionen der Trauer, der Angst, des Kummers und der Niedergeschlagenheit. Heilung bezieht sich daraufhin auf eine umfassende ganzheitliche Rettung, die allein durch die Gottheit vollzogen werden kann. Dieser können dabei die Emotionen des Mitgefühls und der umfassenden Zuneigung zugeschrieben werden.

Der wiederholten Anrede an JHWH in V4 folgt die Erleichterung, die im erzählten Befreiungshandeln mitschwingt. Dabei impliziert die Bewegung von unten nach oben (עלה) das Heraufkommen der Lebenskraft in die Helle des Lebens im Kontrast zur Scheol als Raum der Not, der Gefahr, der Furcht und der Todesangst. In der Erleichterung schwingt dabei die dunkle Seite noch mit, hier kann man wiederum von einer doppelten Emotionalität sprechen: einerseits die freudige Erleichterung, andererseits die leidvolle Not, Angst, Enge, Isolation, Ausweg- sowie Kraftlosigkeit. Der Kontrast zwischen oben und unten - und somit der Gegensatz zwischen Freude und Angst - wird durch das Bild vom 
Hinabsteigen in die Grube weiter verstärkt. Hier wird die Bewegung von oben nach unten, weg vom Leben und von der Lebendigkeit hinab in das Dunkel, das Unzuverlässige und Furchteinflößende der Zisterne geschildert. Erleichterung, Vitalität und Lebensfreude sowie Furcht und Todesangst bestimmen den emotionalen Gehalt dieses Verses. Was die Emotionen betrifft, ist V5 thematisch »einseitiger« gelagert. Die beiden Imperative, welche die Getreuen bzw. Frommen oder Vertrauten JHWHs zum singenden und musizierenden Lob auffordern, verstärken die Emotionen, die Freude und das Verbreiten von Freude beinhalten. Darüber hinaus werden diese Freude und die preisende Antwort auf die erfahrene Lebenswende ausgedehnt und die Öffentlichkeit mit einbezogen, sodass von einer Aufbruchsstimmung gesprochen werden kann - das Lob Gottes soll in Bewegung gebracht werden, gehört es doch zu einem erfüllten Dasein dazu. Die Emotionen der Freude, des Aufbruchs und der Dankbarkeit werden den AdressatInnen zugeschrieben bzw. von ihnen erwartet und eingefordert.

V6 ist einer der Verse des Psalms mit den meisten und semantisch stärksten expliziten Emotionswörtern, die mitsamt ihren Konnotationen in die vier großen Bereiche (1) Zorn, (2) Wohlgefallen und Gernhaben, (3) Leid und Schmerz sowie (4) Jubel eingeteilt werden können. Der Vers lebt von kontrastiven Aussagen, die mit Hilfe des antithetischen Parallelismus plastisch dargestellt werden. Im Gegensatz zum kurzen Moment des Zorns bzw. des göttlichen Wutschnaubens, das dann entbrennt, wenn Gottes Geduld erschöpft und seine Pläne zum Schutz des Lebens zunichte gemacht werden, stehen das Wohlwollen, das Gefallen und die Liebe Gottes, die ein Leben lang dauern. Der Zorn bringt den Aspekt der Zerstörung und Vernichtung ins Spiel, zeugt aber andererseits auch von der tiefen Leidenschaft Gottes. Einen weiteren Gegensatz stellen das abendliche Weinen, das starke Emotionen angesichts von Vernichtung, Verlust, Trauer und Abschied ausdrückt, und das morgendliche Jubeln dar. Dabei sind der Abend bzw. die Nacht als eine Zeit des Unheils und des Leids, der Morgen jedoch mit Sonne, Wärme und Licht als eine Zeit des Heils zu betrachten. Der Übergang vom Weinen am Abend zum morgendlichen Jubeln wird durch das Zeitwort »übernachten « markiert. Dies bricht die Statik in V6 auf und mündet in eine Bewegung, die in gellenden Freudenkundgebungen ihren Abschluss findet. Das personifizierte Weinen, das über Nacht bleibt, kann das menschliche Erfahrungsrepertoire manch durchweinter Nächte evozieren, die mit Tagesanbruch enden. Dann zieht auch das Weinen weiter, sodass sich anschließend sogar Freude einstellen kann.

In V7 ist von Sorglosigkeit und Zufriedenheit ebenso die Rede wie von Selbstsicherheit, Überlegenheit, Stolz und Selbstgenügsamkeit, die dem lyrischen Ich zugeschrieben werden. In V8 begegnet das bereits aus V6 bekannte explizite Emotionswort Wohlgefallen wieder. Dieses Gernhaben von Seiten JHWHs, oft auch mit Gnade, Gunst und Huld übersetzt, wird mittels der Erwähnung seines Angesichts fortgesetzt. כְָָָ impliziert die Nähe, Zuwendung und schützende 
Gegenwart Gottes, die allerdings verborgen bleibt. Das wiederum wird als unerwartetes Ereignis des Schreckens erfahren, womit ein zweites explizites Emotionswort (erschrocken) eingespielt wird. Nach dem lauten Jubel in $6 \mathrm{~d}$ und der verstärkten Selbstsicherheit in 7a setzt somit nach dem Wohlgefallen und der Kraft bzw. Stärke, die für das lyrische Ich Halt bedeuten, in 8a.b plötzlich Schrecken ein. Dieser impliziert Angst und Erstarrtsein. Das Verbergen des Angesichts wird als Gottferne, Kälte und Dunkelheit empfunden. Auf Seiten des lyrischen Ich lässt sich die Emotion der Einsamkeit feststellen. Sie ergibt sich aus der Abwendung und dem Kommunikationsentzug der Gottheit. Daraufhin erfolgt in V9 der Hilfeschrei zu Gott, wobei das verdoppelte Rufen "zu dir « und der synonyme Parallelismus den Eindruck der Dringlichkeit verstärken. Während mit קרא eine Form der Kontaktaufnahme beschrieben wird, kann durch die parallele Gestaltung mit חנן davon ausgegangen werden, dass es sich um einen Hilferuf handelt, der um die Zuneigung und das Erbarmen der Gottheit bittet. Der Hilferuf wird in V10 in Form einer direkten Rede an JHWH ausgeführt, in der Empörung mitschwingt. Dieses Verhandeln mit JHWH mit dem Ziel, er möge eingreifen und die Notsituation des betenden Ich angesichts des drohenden Lebensverlustes und Hinabsteigens in den Angst- und Todesraum der Grube verhindern, wird durch die Überzeugungsrhetorik der Fragen, die darin gewählten Begriffe, die eine Gewinn- bzw. Verlustrechnung implizieren, sowie das aufs Spiel gesetzte gesamte Leben thematisiert und schlussendlich durch die Personifikation des lobenden und erzählenden Staubes emotional verstärkt. Grube steht ebenso wie Zisterne und Scheol aus V4 für einen Todesraum, gefüllt mit Dreck und Schlamm und gekennzeichnet von Enge und Gefangenschaft. Die Emotion der Todesangst ist in V10 ebenso präsent wie die Freude, die dem Loben Gottes inhärent ist, jedoch durch den Staub als Subjekt nicht zur Geltung kommen kann. Denn Staub gehört in die Todesnähe und Freude zu den Lebendigen. Soll der Staub von Gott und dessen Treue erzählen, wird dies in Staub und Asche enden, im Morast erstickt werden und nicht zur Glaubensweitergabe führen. Lebendigkeit würde zunichte gemacht, absolute Stille stellte sich ein.

Während V11 die dringende Bitte um das Zuhören und das helfende Eingreifen sowie den aktiven Gnadenerweis Gottes ausdrückt, sind in diesem Vers auf emotionaler Seite ebenso Zuwendung und Zuneigung auszumachen, die JHWH zugeschrieben werden. V12 markiert m. E. den Höhepunkt des Psalms. Der Vers hat die radikale, plötzliche Wende durch Gott von der Verzweiflung der Not und der Trauer, der Lebensbedrohung sowie des Schmerzes hin zur überschäumenden Lebensfreude zum Inhalt. Er ist durch die bereits benannte doppelte Emotionalität (Trauer, Klage, Schwere, Dunkel / Freude, Tanz, Leichtigkeit) geprägt, die dem lyrischen Ich zugeschrieben werden kann. Diese doppelte Emotionalität wird durch die Bildersprache konkretisiert, und zwar vor allem mittels der Metapher des Umgürtens mit Freude, das die schützende, bestär- 
kende und Halt gebende Funktion dieser Handlung ebenso zum Ausdruck bringt wie die Erleichterung, die Festfreude und Buntheit nach dem befreienden Ablegen des schweren, dunklen Trauergewandes. Dieses Öffnen und Umgürten durch die Gottheit beinhaltet göttliche Nähe, Berührung und die Zuwendung Gottes, die lange ersehnt wurde. Aus der rituellen Totenklage wird ein spontaner Freudentanz. Emotionen finden ihren Ausdruck in Gesten, Riten und Ritualen ebenso wie in Bewegung; innere Bewegtheit wiederum drückt sich in Emotion aus. Diese ist auch im Schlussvers V13 vorhanden, in dem im Kontrast zum spontanen Besingen (ידה), mit dem das preisende Gotteslob bezeichnet wird, das verneinte Verstummen bzw. Stillstehen (דמם) steht. Wie in V10 wird hier erneut eine Personifikation ins Spiel gebracht: die musizierende Ehre. Der Gegensatz zwischen dem freudigen Gotteslob und dem Schweigen verstärkt im abschließenden Satz des Verses das ewig anhaltende Loben Gottes. Der Dank und Jubel und damit die Emotion der immerwährenden Freude sollen nicht aufhören, sondern für ewig gelten.

\subsection{Textdynamik und Perspektivenlenkung}

Die erste Minierzählung (V2-4), deren Ereignisse einerseits mittels Konjunktionen verbunden (V2.3), andererseits asyndetisch gestaltet sind (V4), markiert einen ersten Rückblick, in dem die erfahrene Rettung im Vordergrund steht. In der zweiten Minierzählung (V7-13), die als zweiter Rückblick gestaltet ist, holt das lyrische Ich weiter aus und reflektiert dabei die Zeit vor der Gefährdung. Außerdem werden die Stadien des Glücks und Unglücks aufgezählt, vom Auf und $\mathrm{Ab}$ des Lebens berichtet und alles auf JHWH zurückgeführt. ${ }^{537}$ In dieser zweiten Minierzählung ist durch die Darstellung des Selbstzitats (V7), der starken expliziten Emotionswörter, die auf das lyrische Ich bezogen sind (8d.9b), sowie der implizit ausgedrückten Emotionen von V11 eine deutliche Introspektion erkennbar: »Während es im ersten Teil des Psalms stärker um den äußeren Vorgang der Rettung ging (`der Tote darf wieder leben`), zielt dieser zweite Teil auf die innere Dimension des Geschehens. ${ }^{538}$ Dabei ist der zweite Teil als eine Erzählung inklusive direkter Rede mit hoher Dynamik und thematischer Variation gestaltet. Auffallend sind die Gegensätze, die mit V6 beginnen, sowie die plötzlichen und vielfachen Veränderungen, die das betende Ich durchlebt. ${ }^{539}$

Hinsichtlich der Charakterisierung der Textpersonen ergibt sich mit Blick auf die Verben beider Minierzählungen folgendes Bild: Das betende Ich wird dabei in

537 Vgl. Witzenrath, Am Abend Weinen, 468.

538 Zenger, Mit meinem Gott, 89.

539 Vgl. Ridderbos, Die Psalmen, 225. 
erster Linie durch die Kommunikationsverben רום (hochheben, preisen 2a), שוע (schreien 3a), אמר (sagen 7a), קרא (rufen 9a), רנן (um Erbarmen flehen 9b) und ידה (loben, danken 13c) charakterisiert, wodurch der Rede- und Gesprächscharakter des Psalms deutlich zum Vorschein kommt. Mit dem Erschrecktsein (היה בהל 8d) ist eine Innensicht gegeben. Das Loben (ידה 13c) beendet den Kreis der Bewegung des lyrischen Ich, der mit dem Hochheben (רום 2a) beginnt. Im Gegensatz zu den Kommunikationsverben, die unter anderem die Gottheit zum Eingreifen bewegen sollen, fallen die vielen Aktionsverben ins Auge, die mit dem Du der Gottheit verbunden sind: דלה (herausschöpfen 2b), רפא (heilen 3b), עלה (heraufholen 4a),

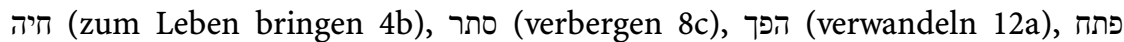
(öffnen, ausziehen 12b), אזר (umgürten 12b). Gott wird also nicht nur um sein Eingreifen gebeten, er handelt auch tatsächlich.

Auf der Ebene der Semantik sind die genannten Bewegungsverben, die mit der Gottheit verbunden sind, gleichzeitig mit einer Art von Wandlung bzw. Wende verbunden. So geht es beim Herausschöpfen (2b), Heraufholen (4a) und ZumLeben-Bringen (4b) um eine Bewegung von der Tiefe der Not in die Höhe des Lebens, beim Heilen (3b) um die Wende von Not (»Krankheit») in Gesundheit, beim Verbergen (8c) um das Verdecken eines ansonsten sicht- und erfahrbaren Gegenstandes oder Wesens, dessen Status damit in jenen der Abwesenheit bzw. Ferne verwandelt wird, beim Verwandeln (12a) um eine totale Wende, in diesem Fall von der Trauer zur Freude, beim Öffnen (12b) um das Ausziehen und Ablegen eines Kleidungsstückes und beim Umgürten (12c) darum, dass ein neues Gewand erhalten bzw. dadurch Bestärkung erfahren wird. Diese Mehrdimensionalität des Themas »Wandel«, das nicht allein auf V12 beschränkt bleibt, haben bereits eine Reihe von Exegeten festgehalten und in unterschiedlicher Weise beschrieben. So konstatiert Beat Weber für Ps 30 eine dreifache Wende: (1) von der Trauer zum Jubel; (2) von der Isolation zur ganzheitlichen Integration; sowie (3) bezüglich der Einstellung: weg von der Selbstsicherheit und Selbstgenügsamkeit (V7) hin zu einem Lebensstil der Dankbarkeit gegenüber Gott. ${ }^{540}$ Bernd Janowski siedelt den in Ps 30 erzählten Wandlungsprozess auf den drei Ebenen (1) des Raumes, (2) der Zeit und (3) der Emotionen an: "Die Lebenswende vollzieht sich für den bedrängten Beter also als räumlicher Übergang von der Scheol zum Tempel (Ps 116,3.8.9.19), als zeitlicher Umbruch vom Abend zum Morgen (Ps 30,6) und als emotional-affektiver Wechsel vom Weinen zum Jubel (Ps 30,6) bzw. von der Trauerklage zum Reigentanz (Ps 30,12). ${ }^{541}$

Die Perspektivenlenkung zeichnet sich durch den Wechsel zwischen interner (V2-4; 7-13) und externer (V5-6) Fokalisierung aus. Im Rahmen der internen Fokalisierung ist ein dichtes Netz an deiktischen Elementen auszumachen, hier

540 Vgl. Weber, Psalm 30, 46.

541 Janowski, Konfliktgespräche mit Gott, 280. 
vor allem in der Form von Personal- und Possessivpronomen. ${ }^{52}$ Durch die Deixis, die als Zoom-Effekt wirkt (vgl. III Methodik 3.2), werden die Lesenden näher an das Textgeschehen herangeholt. Die Nähe zum Text wird auch durch die erzählten Inhalte evoziert. Diese sind zwar konkret und nachvollziehbar, gehen aber nicht ins Detail und eröffnen damit den Lesenden Raum und Zeit, die je eigenen Erfahrungen mit dem Text in Verbindung zu bringen.

\subsubsection{Räume und Bewegungen}

Die Bewegungen in Ps 30 fallen bereits bei der ersten Kontaktaufnahme mit dem Text ins Auge. Auf die mehrfach dargestellte Bewegung von unten (Zisterne, Scheol, Grube, Grab, Staub) nach oben (Berg, zu JHWH hin) weisen mehrere Kommentatoren hin. ${ }^{543}$ Die wellenartigen Auf- und Abwärtsbewegungen dienen als Umschreibung von Not (hinabsteigen $4 \mathrm{~b} .10 \mathrm{~b}$ ) und Rettung (herausschöpfen $2 \mathrm{~b}$; heraufholen $4 \mathrm{a}$ ). Die Rettungsbewegungen von unten nach oben spiegeln sich dabei in der Bewegung des Gotteslobes (hochheben) wider. Auf weitere Bewegungen weist Mays hin: "The movement from divine anger to sovereign pleasure in verse $5 a$ is correlated with the opposite movement from divine pleasure to displeasure in verse 7 . The alternation of weeping and joy in verse $5 b$ anticipates the move from mourning to gladness in verse 11 . The danger of the silencing of praise by death (v. 9) is resolved when the soul breaks silence with praise (v. 12). ${ }^{544}$ Eine ansteigende Bewegung in Ps 30 vermerken ebenso Luis Alonso Schökel und Cecilia Carniti, wenn sie sich auf den Übergang vom Tod zum Leben, von der Krankheit zur Gesundheit, vom Leid zum Genuss sowie vom Abend auf den Morgen beziehen. Sie sprechen von einer positiven Bewegung, einer Bewegung der Befreiung. Alles löst sich ins Gute auf. Der Tod hat den Sieg nicht besungen, der wieder lebendige betende Mensch aus Ps 30 wird für immer ein Loblied auf Gott singen. ${ }^{545}$

\subsubsection{Zeitebenen}

Während eine Reihe von Räumen genannt wird, bleiben die Zeitangaben dürftig:

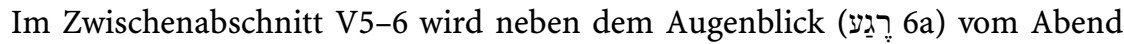

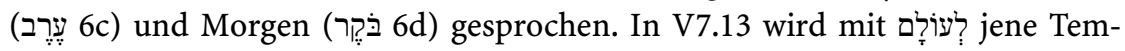
poralangabe im Text genannt, die zwei Mal wortgleich vorkommt. In V7 bezieht sich diese auf das betende Ich, in V13 wird die Zeitangabe auf das Loben Gottes

542 Vgl. dazu die Tabelle über die Personaldeixis oben unter 3.1 in diesem Kapitel.

543 Vgl. Weber, Werkbuch 1, 150.

544 Mays, Psalms, 139.

545 Vgl. Alonso Schökel / Carniti, Salmos 1, 472. 
bezogen, wodurch ein inhaltlicher Kontrast zwischen der Selbstbezogenheit des Menschen und dem Bezug zur Gottheit gezeichnet wird. ${ }^{546}$ Ps 30 lebt aufgrund deren geringer Anzahl weniger von den Zeitangaben im Text, sondern vielmehr von den Zeitachsen, die durch die Handlungen hergestellt werden. Dabei zeichnet sich der Text durch den Wechsel zwischen Ausblick, dem Hier und Jetzt der Sprechsituation sowie Rückblenden aus. ${ }^{547}$

\subsubsection{Parallelismen}

Ps 30 lebt von der Abwechslung zwischen synthetisch (V2.3.7.8.10) und synonym (V4.5.9. 11.12.13) gestalteten Parallelismen (Ausnahme V6: antithetisch), die die Intention verfolgen, den auszusagenden Inhalt zu verstärken bzw. diesen in Nuancen weiterzuführen, mit der Folge, dass die Lesenden für eine gewisse Zeit beim Gedanken des Verses verweilen (können bzw. müssen). Neben dem Zeitfaktor werden die analysierten inhaltlichen Verfeinerungen nochmals kurz genannt, die sich durch das Stilmittel des Parallelismus eröffnen: Der synthetische Parallelismus von V2 führt von einer vertikalen Bewegung hinüber in eine horizontale, der ebenso synthetisch gestaltete V3 hat eine narrative Sequenz zum Inhalt: Nach der Aussage (Hilfeschrei; Ursache) wird die Reaktion bzw. Folgehandlung Gottes (Heilung; Wirkung) genannt. Der synonyme Parallelismus von V4 intensiviert und dramatisiert die erzählte Rettungserfahrung. Der ebenso synonym gestaltete V5 verstärkt die Lobaufforderung durch die Angabe des Zweckes. Der antithetische Parallelismus von V6 eröffnet mit seinen Polen und Gegensätzen in Bezug auf das Gottesbild (kurzer Zorn; lange Güte) sowie auf das Menschenbild (Weinen am Abend; Jubel am Morgen) Plastizität und Mehrdimensionalität, in denen sich die Lesenden wiederfinden sowie den Weg und die Verbindungspfade zwischen den großen Kontrasten mit den je eigenen Gedanken füllen können. Darüber hinaus werden in V6 Substantive durch die bildliche Rede der Personifikation verdeutlicht und lebendig gemacht. Im synthetischen Parallelismus von V7 wird der Blick von außen nach innen gerichtet, im ebenso synthetisch gestalteten V8 folgt auf die Tat Gottes die Reaktion des Menschen (siehe dazu in umgekehrter Reihenfolge V3). Der synonyme Parallelismus von V9, dessen Stichen nahezu identisch formuliert sind, bringt durch die Wiederholung die Eindringlichkeit des Gebets zum Ausdruck. V10 ist eine Sequenz, die eine stufenweise Konkretisierung der Aussageabsicht beinhaltet und, ausgehend von Abstrakta, über den Inf. constr. zu finiten Verben führt. Ebenso ist durch die

546 An dieser Stelle verweist Weber, Werkbuch 1, 151 darauf, dass »das verneinte לעולם der Selbstüberhebung in 7b (^niemals mehrı) zum positiven לעולם der Hingabe und des Lobpreises im Schlusskolon 13b („für immerı) )korrigiert` [wird] «.

547 Zur Verschänkung der Zeitebenen im Psalm siehe die differenzierte Darstellung unter 3.2.3. 
bildliche Rede der Personifikation eine Verlebendigung der Aussage auszumachen. Der Parallelismus von V11, der ebenso von Dringlichkeit geprägt ist, hat den Dreischritt Wahrnehmung - Zuwendung - Hilfe zum Inhalt. Im synonymen Parallelismus von V12 wird der Wandel vielfältig zum Ausdruck gebracht: Die allgemeine Aussage wird plastisch ausgeschmückt, Substantive werden durch metaphorische Sprache entfaltet, auf eine eher abstrakt gehaltene Formulierung folgt die Bilderrede. Es kommt damit zu einer Intensivierung und Konkretisierung der Aussageabsicht. Der abschließende synthetische Parallelismus von V13 führt von der Personifikation zum lyrischen Ich mit einem Kurzstopp beim Nicht-Verstummen.

Zur Konklusion: Die Lesenden sind durch die Kompositionsstruktur des Parallelismus, die Ps 30 durchzieht, eingeladen, beim jeweiligen Gedanken innezuhalten, die Dynamik des jeweiligen Parallelismus auf sich wirken zu lassen, den narrativen Sequenzen sowie der Konkretisierung und Dynamisierung nachzugehen und die Intensivierung in sich aufzunehmen. Diese wird vor allem durch die Sprachbilder erzielt, in welche sich die Lesenden hineinbegeben und welche sie mit den je eigenen Erfahrungen füllen können (vgl. III Methodik 2.2.3).

Auffällig sind in Ps 30 die zahlreichen Gegensätze, die nicht nur in V6 geschildert werden: Zorn - Wohlgefallen; Augenblick - Leben (lang); Weinen Freude; Abend - Morgen; dazu kommen diverse weitere Gegensatzpaare: V2: hochheben - herausziehen; V3: um Hilfe schreien - geheilt werden; V4: Totenreich - Lebenskraft; zum Leben bringen - in die Zisterne hinabsteigen; V7: Sicherheit - V8: Entsetzen; V7: Berg - V4: Grab/V10: Grube; V12: Trauerklage Tanz; Trauergewand - Freude; V13: besingen/dankend preisen - verstummen/ still sein. ${ }^{548}$ Die kontrastreiche Erzählweise eröffnet durch die oppositionelle Bipolarität Räume der Plastizität, die den jeweils angesprochenen Gedanken vertiefen und erweitern.

548 Vgl. dazu die antithetischen Konstruktionen, die Alonso Schökel / Carniti, Salmos 1, 470 herausgearbeitet haben: Leben / Scheol; Leben / Zisterne; Zorn / Wohlgefallen; Augenblick / ein Leben lang; am Abend / am Morgen; entgürten / umgürten; Weinen / Jubel; nicht wanken / schreckensstarr; Wohlgefallen / das Angesicht verdecken; Klage / Tanz; Trauergewand / Freudenfest; singen / schweigen. Die AutorInnen erkennen in Ps 30 deshalb zwei semantische Achsen, die sich an den Gegensatzpaaren Aufstieg / Abstieg und Schweigen / Singen orientieren. 


\section{Identifikationspotenziale in Psalm 30}

\section{1 durch Inhalte}

In Bezug auf die Frage nach den im Methodenteil erörterten mininal elements (vgl. III Methodik 1) - also dem Vorhandensein einer erzählten Bühne, welche die Basis für LeserInnenidentifikation schafft - ist in Bezug auf Psalm 30 festzuhalten, dass diese gegeben sind: Es gibt eine (beinahe) durchgehende Sprechstimme in Form des lyrischen Ich, das seine Rettungserlebnisse mit JHWH und das daraus folgende Lob kund tut. Dabei sind eindeutige Themen, ein Aufbau und Klarheit in der Darstellung erkennbar - oder anders gesagt: »Der Gang ist einfach und sachgemäß. ${ }^{549}$ Ein Wechsel der Rederichtungen sowie eine Abwechslung zwischen bekannter und neuer Thematik sind auszumachen - beide sind allerdings nicht sprunghaft gestaltet und damit für die Lesenden gut nachvollziehbar.

\begin{tabular}{|l|l|}
\hline Vers & Thema \\
\hline 1 & $\begin{array}{l}\text { Bestimmung des Psalms als eines Sprechgesangs mit Saitenspielbegleitung } \\
\text { (רín:); Hauseinweihungslied; für/von/im Geiste Davids = Bezugnahme auf } \\
\text { David }\end{array}$ \\
\hline 2 & $\begin{array}{l}\text { Selbstaufforderung zum Lob JHWHs nach Rettung; keine (Schaden)Freude der } \\
\text { Feinde }\end{array}$ \\
\hline 3 & Hilfeschrei des betenden Ich; Heilung durch JHWH \\
\hline 4 & JHWH ermöglicht Leben nach der Erfahrung der Todesnähe \\
\hline 5 & Aufruf an die Frommen zu Lobdank und Musik für JHWH \\
\hline 6 & $\begin{array}{l}\text { Gegensatz zwischen Zorn JHWHs und seinem Wohlgefallen; Gegensatz zwi- } \\
\text { schen Weinen am Abend und Freude am Morgen }\end{array}$ \\
\hline 7 & Selbstsicherheit \\
\hline 8 & Wohlgefallen und Kraft versus Abwesenheit Gottes \\
\hline 9 & Rufen und Flehen zu Gott um Erbarmen \\
\hline 10 & $\begin{array}{l}\text { Anfrage an Gott, inwieweit Lob an ihn möglich ist, wenn Subjekte des Lobens } \\
\text { tot sind }\end{array}$ \\
\hline 11 & Bitte um Zuhören, Hilfe und Gnade JHWHs \\
\hline 12 & Verwandlung durch Gott: Klage wird zum Tanz und Trauer zur Freude \\
\hline 13 & Lob Gottes in musikalischer Form; Selbstaufforderung zum Lob Gottes \\
\hline
\end{tabular}

Gemäß der geschilderten Inhalte und Erfahrungen kann eine Analogiebildung erfolgen, wie dies in methodischer Hinsicht den Inhalt betreffend für Identifi-

549 Hupfeld, Die Psalmen, 451. Ähnlich und deshalb auf die Bewegung in Ps 30 bezugnehmend Alonso Schökel / Carniti, Salmos 1, 469: "El salmo tiene movimiento y tiene lógica» (Der Psalm weist Bewegung auf und hat eine Logik. Übersetzung S. E.). 
kation notwendig ist (vgl. III Methodik 1). So können sich gegenwärtige BeterInnen mit dem Text identifizieren und sich gleichzeitig neue Dimensionen durch ihn eröffnen lassen. Menschen, die großer Not entkommen sind und die aus tiefem Leid gerettet wurden, können sich in Ps 30 wiederfinden; ebenso jene, die mit dem Thema der vermeintlichen Selbstsicherheit und Unfehlbarkeit vertraut sind. Und auch jene, die den Wandel von der Trauer zum Freudentanz Gott zuschreiben, der ihnen in dieser Situation ganz nahe gekommen ist. Menschen, die mit dem Leben ringen und mit Gott hadern, finden Anknüpfungspunkte im Psalm. "Der Psalm kann auch einen in Schmerz Verstummten oder sich selbst Beklagenden dahin führen, dass er sich im Gebet zu Gott öffnet und aus seiner Selbstzentriertheit herausfindet. Der Psalm kann auch zur Distanz zum Schmerz und zu sich selbst führen. Ps 30 kann also den Beter, der sich dieses vorgegebene Gebet anzueignen versucht, über sich hinaus zu etwas Neuem führen. «50 $^{550}$

Dabei wird die Möglichkeit, Ps 30 mit der eigenen Erfahrungswelt in Beziehung zu setzen, durch den Formularcharakter des Psalms unterstrichen. So gelten Psalmen - wie bereits dargelegt (vgl. I Einleitung 4.1.5) - als Gebrauchstexte, die dazu dienen, dass Menschen sich die Aussagen des Textes zu den je eigenen machen bzw. sich die Worte ausborgen und aneignen. Dies wird durch die Konzeption des »Thoughtwriters" unterstrichen, die jener des »Speechwriters« ähnelt. Als Speechwriter werden jene Personen bezeichnet, die Reden für andere schreiben (vgl. I Einleitung 4.1.5). Die Idee des "Thoughtwriters" von Kendal Walton besagt, dass Gedichte Phrasen, Sätze und Paraphrasen beinhalten, welche die Lesenden (wenn sie das wollen) gebrauchen und sozusagen ausborgen können. Dies ist, wie bereits bekannt, auch den Psalmen attestiert worden. Walton nimmt Ps 23 als ein Beispiel auf: „So I will say that poets sometimes serve not exactly as speechwriters, but as thoughtwriters. (By >thoughts I include not just intellectual ideas, but any feelings, emotions, sentiments, attitudes, etc. that might be expressed by means of words). If I agree with the sentiments expressed by the words of a poem or find them especially apropos on a particular occasion, I might recite the entire poem, seriously asserting (if only to myself) those sentiments. Think of a person who, finding herself in a tight spot, recites the twentythird Psalm. ${ }^{551}$ Psalm 30, der insbesondere als Formular für die Toda gilt, kann als Gebetsvorlage für heutige BeterInnen dienen, die sich in den dort erzählten Beziehungskonstellationen mit Gott sowie in den Themen der tiefen Not, Errettung aus Todesgefahr, des Hilfeschreis zu Gott, der totalen Verwandlung und des Lobes Gottes wiederfinden. Auf den Zeugnischarakter des Psalms und auf dessen Relevanz in der Gegenwart weist Christof Hardmeier hin: "Aufs Ganze gesehen gewinnt das Glaubenswissen von der Heilsmächtigkeit und rettenden

550 Witzenrath, Am Abend Weinen, 476.

551 Walton, Thoughtwriting, 462. 
Zugewandtheit JHWHs [...] durch das Zeugnis des Geretteten [für die Öffentlichkeit] eine neue, leibhaftige Gegenwartsrelevanz trotz bitterster Gegenerfahrung in Todesnot. Der oder die geheilte BeterIn sind dafür der lebendige Erweis. Durch ihre Person kommen Glaube und Erfahrung im Lobpreis authentisch zur Deckung.. ${ }^{552}$ Die Aneignung des Psalms kann im individuellen oder kollektiven Rahmen erfolgen, in Momenten der Stille und Besinnung, gerade aber auch in Formen von Festen und Feiern. Für den Prozess der Aneignung spielt das lyrische Ich des Textes eine entscheidende Rolle (vgl. I Einleitung 4.1.4): »Weil die Übernahme der Ich-Formel feierlich begangen wird, hebt sich das Ich, das die Formel nachspricht, als wären es seine eigenen Worte, aus der alltäglichen Empirie heraus. Jetzt, und nur jetzt, ist es frei vom individuellen Namen, von besonderen Charakterzügen, von kontingenten Umständen. Daher passt das formelhafte sich für alle Namen, Charaktere und Umstände. Eben diese Verbindung von Eigenschaftslosigkeit (frei von ...) und Wesentlichkeit (frei für ...) kennzeichnet das ılyrische Ich..${ }^{553}$

\section{2 durch Emotionen}

Psalm 30 zeichnet sich durch eine hohe Dichte an Emotionen aus. Die Analyse hat gezeigt, dass keine expressiven Ausdrücke wie z. B. »ach" oder »wehe« vorhanden sind. Statt dessen werden die Emotionen deskriptiv durch explizite Emotionswörter zum Ausdruck gebracht sowie durch implizite Emotionen, also durch solche, die durch die Syntax, die Bildersprache und im Leseprozess freigesetzt werden. Dabei ist eine große Vielfalt an Emotionen auszumachen. Dominant ist dabei die Emotion der Freude, die durch Spontanität im Singen, Musizieren und lauten Jubel sowie in der Bewegung ihren Ausdruck findet. Im starken Kontrast dazu stehen die Emotionen der Todesangst. Beide im Gegensatz zueinander stehende Bereiche von Emotionen - also Freude, Erleichterung, Vitalität, Dankbarkeit einerseits sowie Angst, Unsicherheit, Engegefühl, Kraftlosigkeit, Niedergeschlagenheit, Isolation, Ausweglosigkeit, Trauer und Verzweiflung andererseits - werden dem lyrischen Ich zugeschrieben. Hier ist von einer doppelten Emotionalität zu sprechen: Aus der Perspektive der Freude über die befreiende Rettungserfahrung heraus sind die »dunklen" Emotionen der Todesangst, die vielfach in metaphorischer Sprache ihren Ausdruck finden, mitteilbar und auch aushaltbar. Weitere Emotionen, die dem lyrischen Ich zugeschrieben werden, sind jene der Selbstgenügsamkeit bzw. Selbstsicherheit, der Dringlichkeit in Bezug auf das Eingreifen Gottes, der Empörung im Verhandeln mit Gott

552 Hardmeier, Systematische Elemente, 346.

553 Schlaffer, Die Aneignung von Gedichten, 48. 
sowie des Erschreckt- bzw. Erstarrtseins aufgrund der Gottferne, die als Einsamkeit erlebt werden kann. Das Umgürtetwerden mit Freude lässt neben Leichtigkeit und frohem Mut auch Schutz, Bestärkung und Halt durchschimmern. Auf Seiten JHWHs sind als implizite Emotionen Stärke, Sicherheit und Verlässlichkeit sowie Mitgefühl anzuführen, aber auch Abwendung ist auszumachen, durch explizite Emotionswörter die Zuneigung, das Hinwenden und das Wohlgefallen, aber auch der Zorn und die damit verbundene vernichtende Dimension sowie die Leidenschaft JHWHs, die dahinter steht. Die Tatsache, dass der Gottheit Israels gerade in den Klageteilen des Psalms Emotionen wie Empörung und Dringlichkeit zugetragen werden, zeigt die Sensibilität und Offenheit JHWHs für die gerechte Sache des/der Betenden. ${ }^{54}$ Subjektfrei werden menschliche Erfahrungen und Emotionen vor allem durch die metaphorische Sprache - insbesondere durch die Personifikationen des übernachtenden Weinens (V6), des lobenden Staubs (V10) und der musizierenden Ehre (V13) freigesetzt: Durch das Weinen werden Abschied, Schmerz, Trauer sowie großes Leid thematisiert, und durch den lauten Jubel wie durch die musizierende Ehre kommt gellende Freude zum Ausdruck. Der im Todesraum verortete lobende Staub evoziert das Verstummen und das Zu-Ende-Gehen aller Lebendigkeit. Ganz anders dagegen werden die Lesenden und Zuhörenden eingebunden: Die AdressatInnen bzw. die Öffentlichkeit werden mit den Emotionen der Dankbarkeit und der Verbreitung der Freude durch Lob verknüpft. Diese Vielfalt an Emotionen, welche sich relativ klar eruieren lassen und nicht diffus zwischen den Zeilen aufblitzen, lässt sich auch darin ausmachen, dass von den 97 hebräischen Wörtern des Psalms 33 emotional konnotiert sind (wobei Phrasen aus zwei oder mehreren Wörtern, die als Bildwort oder implizit Emotionen ausdrücken, als eine Emotion gezählt werden). Oder anders gesagt: Es ist nicht nur jeder Vers (V1 ausgenommen) emotional besetzt, sondern sogar jedes dritte Wort drückt explizit oder implizit eine Emotion aus. Für Lesende bedeutet das, dass durch diese Bandbreite an genannten Emotionen ein hohes Identifikationspotenzial vorhanden ist: Die je eigenen Emotionen - seien es die der Freude, aber auch die der Angst und Verzweiflung - können einen Platz finden, sind aufgehoben bzw. können auch hervorgerufen werden, je nachdem, in welchem biographischen Kontext sich die Lesenden gerade befinden. Hinsichtlich der Dichte an Emotionen und der quantitativen Einschätzung der Emotionalität eines Textes sei

554 In Bezug auf das Artikulieren von Emotionen in der Klage halten Dale Patrick und Kenneth Diable für das Alte Israel fest: »Worshippers all through history have experienced crisis and despair, yet rarely have they indulged themselves in accusation against God. The fact that ancient Israel did so suggests a particular dynamic in their piety, one that expected YHWH to be sensitive to the just cause of the supplicant, to be subject to emotions like pity and guilt, defending his honor but not overly concerned with his majesty." Patrick / Diable, Persuading the One, 28. 
nochmals an Katja Mellmann erinnert (vgl. auch III Methodik 3.3.2): „Das emotionale Auslösepotential bestimmter Textelemente, die `Stärke` des literarischen Stimulus, ist desto höher, (a) je mehr Merkmale der Reiz enthält, die fest verdrahtete (`angeborene`) emotionale Auslöseschemata bedienen, (b) je mehr emotionsauslösende Merkmale der Reiz pro Zeiteinheit darbietet (Schemakongruenz) und (c) je mehr Zeit der Leser auf die begleitende Imaginationsarbeit verwendet bzw. durch die Textbeschaffenheit zu verwenden herausgefordert ist (Zeitfaktor). ${ }^{555}$

Zudem ist an dieser Stelle auf die grundsätzliche Funktion von Gebeten hinzuweisen, die darin besteht, dass sie bei Gott etwas erreichen wollen: "In principle, prayer should be the purest form of persuasive speech. The supplicant seeks to persuade God to intervene on his or her behalf [...]. ${ }^{556}$ Hier schließt sich der Gedanke der Intention bzw. Spannung eines Textes und die dadurch evozierten Emotionen der Lesenden an. Gerade in der zweiten Minierzählung konnten eine aufsteigende Dynamik und ein Spannungsaufbau festgestellt werden. Dabei gilt Spannung in Bezug auf literarische Texte selbst als Emotion: "Suspense is an emotion, one that in fictions generally involves an event where some outcome that we regard to be morally righteous is improbable. ${ }^{557}$ Durch die bereits mehrfach konstatierte emotionale Erzählweise sowie durch die Rhetorik wird unter anderem die Dramatik bzw. Spannung des Textes aufgebaut, die nicht nur zum Weiterlesen und Dranbleiben einlädt, sondern auch dazu, mit den Zielen des lyrischen Ich mitzugehen und sich in die Situation einzufühlen (siehe unten Anm. 559). An dieser Stelle kann von einer Belohnung durch emotionale Ereignisse gesprochen werden (vgl. III Methodik 2.2.2). ${ }^{558}$

Implizit und explizit dargestellte Emotionen im Text können also auf Seiten der Lesenden Emotionen evozieren. Eine weitere Möglichkeit der emotionalen Beteiligung der Lesenden besteht darin, dass durch die im Text vorhandene vorfokussierte Erzählweise eine Haltung des Interesses in den Lesenden erzeugt wird, die den Anliegen, Wünschen und Plänen der fiktionalen Gestalten folgt. Demzufolge reicht also für eine emotionale Beteiligung nicht allein die Perspektivierung eines Textes aus. ${ }^{559}$ Es geht vielmehr um Aufmerksamkeit und Interesse. Dieses Interesse (vgl. III Methodik 2.2.2) an dem in narrativen Texten

555 Mellmann, Emotionalisierung, 58.

556 Patrick / Diable, Persuading the One, 31. Vgl. ebenso Ridderbos, Die Psalmen, 109.

557 Carroll, Art, 202.

558 Vgl. Mellmann, Emotionalisierung, 220.

559 »Die imaginationsgenerierende $>$ Rollenübernahme erschöpft sich in der Praxis also nicht schon mit einer reinen Perspektivenübernahme, in der wir uns von einem simulierten Erfahrungsablauf leiten lassen, sondern umfasst eine Art Zielvorgaben- oder Mentalitätsübernahme, in der wir unsere eigene kognitive Verarbeitung der simulierten Erfahrung durch die Informationsverarbeitung eines `Textsubjekts` leiten lassen.» Mellmann, Emotionalisierung, 109. 
Erzählten übernimmt die Funktion von Wünschen, wodurch in Kombination mit dem Inhalt des Textes eine emotionale Reaktion evoziert wird: »That is, in addition to being criterially prefocused, the narrative must instill certain concerns about the fictional characters and events in the reader, viewer, or listener. These concerns function like the desires in many everyday emotions, and when added to the mental content or conception derived from the criterially prefocused text, the combination, all things being equal, should elicit an emotional response in accordance with the criteria features of the situation that the text has made pertinent for attention. $" 560$

Je stärker also das Interesse der Lesenden am Text geweckt wird und je intensiver sie den Plänen, Wünschen und Intentionen des lyrischen Ich in Ps 30 nachgehen können, desto größer ist das Identifikationspotenzial. Hinzu kommt die emotionale Erzählweise: Je deutlicher die Absichten und Inhalte des Psalms mit Emotionen verstärkt werden, desto größer ist das Identifikationspotenzial. Dies ist besonders in Psalm 30 der Fall.

\section{3 durch Perspektivenlenkung und Textdynamik}

Die Analyse der Textdynamik hat gezeigt, dass Ps 30 nicht nur in einzelnen Stationen und Szenen, gleichsam Vers für Vers, gelesen werden kann, sondern auch als ein Text, der aus zwei Erzählungen besteht, die ineinander und miteinander dynamisch verbunden sind. An dieser Stelle sei an den Ansatz von Robert Vellusig zur Sinnenhaftigkeit der Poesie verwiesen. Vellusig hebt die prinzipielle Vergegenwärtigungsleistung von literarischen Texten durch das Vorstellungsvermögen der Lesenden hervor: "Poetische Geschichten sind, wie gesagt, als Folge einzelner Bildvorstellungen organisiert - und sie verlangen vom Leser, dass er die verbale Sequenz seinerseits in eine phrasierte Bilderfolge rückübersetzt. Sie stimulieren die Imagination, und sie können dies, weil die mentale Repräsentation von Worten immer schon die unterschiedlichsten Empfindungen und Handlungen wachzurufen imstande ist, die mit einem Objekt oder einer Kategorie von Objekten zusammenhängen. ${ }^{561}$ Demzufolge steigen Lesende »automatisch« in Erzählungen ein und leben mit diesen mit: »Poetische Geschichten lesend, erleben wir uns - die Erlebnisdimension unseres Lebens im Spiegel imaginierter Personen - und ihres Erlebens - wieder. Wir tun dies und wir können dies tun, weil uns unsere je individuellen Erinnerungen auch als intuitives Wissen über Strukturen der Erfahrung zur Verfügung stehen. « ${ }^{56}$

560 Carroll, Art, 204.

561 Vellusig, Die Sinnenhaftigkeit der Poesie, 365.

562 Vellusig, Die Sinnenhaftigkeit der Poesie, 367. 
Die beiden Erzählungen in Ps 30 sind unterschiedlich gestaltet, wobei die erste Minierzählung weniger eine Abwechslung in der Thematik und im Handlungsfortschritt als vielmehr klare Aktionen durch Bewegungsverben und eigenständig gesetzte Handlungen in Verbindung mit emotional stark konnotierten Räumen aufweist. Die zweite Minierzählung hingegen ist durch mehrere Redeebenen grammatikalisch sowie thematisch abwechslungsreich gestaltet. Bezüglich der Zeitachse weisen beide short stories Gegenwarts- und Vergangenheitsbezüge auf, wobei der Schlussvers einen Ausblick formuliert. Dieser Wechsel zwischen der Jetztsituation und Rück- sowie Ausblicken zeugt von einer dynamischen Sprechbzw. Wahrnehmungssituation. An dieser Stelle sei (vgl. III Methodik 3.1) an Folgendes erinnert: Je dynamischer die Wahrnehmungssituation, d. h. die sich in der Zeitdimension verändernde Wahrnehmungssituation, desto leichter ist LeserInnenidentifikation möglich. ${ }^{563}$ Diese dynamische Wahrnehmungssituation ist in Ps 30 sowohl durch die verschiedenen Zeitachsen als auch durch die unterschiedlichen Raumebenen gegeben. Für das Mitgehen mit dem lyrischen Ich sind neben den Bewegungen in der Zeit auch jene zwischen den Räumen von Bedeutung (vgl. III Methodik 3.3). ${ }^{564}$ Durch die klar geschilderten Auf- und Abwärtsbewegungen können Lesende nicht nur mit dem lyrischen Ich mitgehen und sich zeitlich sowie räumlich an das Textgeschehen binden, sondern auch das eigene Auf und $\mathrm{Ab}$ des Lebens mit dem Text verknüpfen. Dadurch wird ein weiteres Identifikationspotenzial geschaffen.

Aus der Narratologie ist bekannt, dass es für Lesende leichter ist, sich mit Textpersonen zu identifizieren, von denen mehr und detaillierter erzählt wird. Je mehr Informationen der Text über die jeweilige Erzählfigur durch Handlungszuweisungen, Beschreibungen und Sprechakte bietet, desto größer ist das Identifikationspotenzial. Ps 30 zeichnet sich durch das Beziehungsgeschehen zwischen dem lyrischen Ich und der Gottheit Israels aus. Diese beiden ProtagonistInnen werden durch ihre jeweiligen Handlungen und Gedanken charakterisiert, während die weiteren Figuren (die Feinde 2c, die Frommen 5a) oder auch das Weinen (6c), der Staub (10c.d) und die Ehre (13a) als Subjektpositionen nicht näher spezifiziert werden. JHWH wird durch sein tatkräftiges Eingreifen, durch sein heilendes Rettungs- und Befreiungshandeln, seine Wandlungskraft, sein Wohlgefallen und seine Zuneigung gegenüber dem betenden Ich, aber auch durch seinen Zorn und seine Verborgenheit und Abwendung sowie seine berührende Nähe charakterisiert. Vom lyrischen Ich erzählt Ps 30 in mehrfacher Hinsicht: Zunächst sind es die Handlungen des Lobens und Dankens, des Rufens und Bittens um Hilfe, die das lyrische Ich charakterisieren. Des Weiteren findet sich eine Introspektion (V7). Die Zeitachsen der Jetztsituation sowie des mehr-

563 Vgl. Mellmann, Emotionalisierung, 222.

564 Vgl. Eder, Die Figur im Film, 638. 
fachen Rückblicks und des Ausblicks stehen ebenso in enger Verbindung mit dem lyrischen Ich wie die im Psalm geschilderten Todesräume: Scheol (4a) und Grube (10b), der Raum der Klage und der Trauer (V12), der Berg (V8) sowie die mit erfülltem Leben verbundenen Begriffe Kraft (8b), Tanz und Freude (V12). Eine Identifikation mit dem lyrischen Ich ist somit aufgrund der Quantität an Information möglich.

Hinsichtlich der Textdynamik lassen die Konjunktionen die Übergänge fließend erscheinen, während Asyndese und abrupte Übergänge die Lesenden auffordern, während des Lesens die Verbindungen selbst zu schaffen. Einem »Hinausfallen« der Lesenden aus dem Text wird insofern gewehrt, als die plötzlichen Übergänge nicht derart abrupt und unverständlich ausfallen, dass das Herstellen von Zusammenhängen im Leseprozess völlig unmöglich wäre. Die (beinahe) durchgehende Erzählstimme des lyrischen Ich, die auch Innenperspektiven gewährt und emotional erzählt, führt die Lesenden gleichsam durch die Ereignisse. Durch diese Empathielenkung - wie dies in der Narratologie genannt wird - ist ein intensives Mitgehen mit dem Text möglich.

An dieser Stelle sei an den Ansatz von Heinz Schlaffer erinnert, der das grammatische Ich des Gedichts mit dem konkreten lesenden Ich identifiziert. So ist durch das lyrische Ich im Text einerseits eine weitere Identifikationsmöglichkeit für Lesende gegeben, andererseits wird das lyrische Ich durch die lesende Person »konkretisiert « (vgl. I Einleitung 4.1.4): »Da das ১ich des Gedichts weder benannt noch beschrieben ist, liegt es nahe, dass an seine Stelle das einzig anwesende >ich tritt: das des Lesers, der das Gedicht laut oder leise, vor sich hin oder in sich hinein spricht. Wer immer also das Gedicht spricht oder nachspricht, sei es der Dichter selbst, der Sänger, der Rezitator oder der Leser, gewährt der grammatischen Person des Pronomens durch seine körperliche Präsenz Festigkeit und Identität, die freilich selbst nur eine fiktive Festigkeit und auch nur eine formale Identität ist. ${ }^{565}$ Auf die Psalmen bezogen heißt dies, dass das lyrische Ich für die Lesenden offen ist: »Die Lebensgeschichte des Ich der Psalmen lädt ein zur admirativen Identifikation, indem die Rettungserfahrung für alle zugänglich gemacht wird. $\aleph^{566}$

Auch die direkten Anreden an JHWH bzw. an die Öffentlichkeit sind als weitere Möglichkeit der Identifikation zu nennen. Die an die Gottheit Israels gerichteten Vokative, die in Ps 30 sowohl in Qualität (JHWH, mein Gott) als auch in Quantität (10x) konzentriert vorkommen, beinhalten durch die zeitdeckende, immer wieder ins Hier und Jetzt der Sprechsituation zurückführende Dimension Potenziale für Lesende, indem sie nicht nur die Eindringlichkeit des Gebets vor Augen führen, sondern auch dessen Unmittelbarkeit zur Darstellung bringen.

565 Schlaffer, Die Aneignung von Gedichten, 41.

566 Erbele-Küster, Lesen, 112. 
Zudem lädt die zweite Rederichtung an die Öffentlichkeit die Lesenden zum Mitund Nachvollzug des Gesagten ein. So können die im Text gezeichneten Beziehungskonstellationen (Ich - Du - mich), verstärkt durch die Vielzahl deiktischer Elemente, ein Angebot für LeserInnen sein, sich in diese hineinzuversetzen.

Die hauptsächlich in Form von Parallelismen geschilderten Themen und Erfahrungen können durch diese parallele Konstruktion intensiv »erlebt« werden, da durch die Wiederholung der Aussagen eine Vertiefung der Gedanken erreicht wird. ${ }^{567}$ Wie die Analyse gezeigt hat, erfolgt durch das Stilmittel des Parallelismus eine Konkretisierung und Intensivierung bis hin zur Dynamisierung und Dramatisierung des Gedankens, welches für die Lesenden die Möglichkeit schafft, länger am Textgeschehen zu bleiben, das Erzählte auf sich wirken zu lassen und in die Sprachwelt des Psalms einzusteigen sowie die je eigenen Erfahrungen in den Text einzuschreiben.

In Bezug auf die Perspektivenlenkung ist klar geworden, dass zwar konkrete Erfahrungen und Situationen sowie nachvollziehbare Inhalte geschildert werden, die genauen Einzelheiten jedoch nicht benannt werden. Eine bestimmte Unschärfe macht somit gerade den Reiz von Ps 30 aus. Dorothea Erbele-Küster spricht im Zusammenhang der Beschreibung der Notsituationen von Leerstellen, die sowohl den vielschichtigen Erfahrungen des lyrischen Ich gerecht werden als auch eine bewusste Offenheit für die jeweiligen Lesenden und deren Noterfahrungen darstellen. ${ }^{568}$ Durch diese Offenheit des Textes wird ein Auslegungsspielraum eröffnet, der als Voraussetzung für die Identifikation mit dem Text betrachtet werden kann. ${ }^{569}$ Diese Identifikation wird durch die interne Fokalisierung und das damit verbundene dichte Netz an deiktischen Elementen erhöht.

567 Zur Erinnerung hier nochmals die erzählten Inhalte: So spricht der synthetische Parallelismus von $2 \mathrm{bc}$ von der Rettungserfahrung und der Schadenfreude der Feinde, welche nicht eingetreten ist. Der synthetische Parallelismus von V3 erzählt von der Heilung nach einem Hilfeschrei und schließt damit inhaltlich an V2 an. Die Parallelismen von V4.5 sind synonym ausgerichtet: V4 erzählt vom Wieder-ins-Leben-Kommen nach einer dem Tode ähnelnden Erfahrung im Anschluss an V2-3, V5 fordert zum Loben und Musizieren für JHWH auf. Aus der Reihe der synonymen und synthetischen Parallelismen fällt V6 als antithetischer Parallelismus heraus. Die Abfolge der Parallelismen weiterführend spricht der synthetische Parallelismus von V7 von Sicherheit und ewigem Nicht-Wanken, der ebenso synthetische Parallelismus von 8cd von der Reaktion des Erschreckens, nachdem sich Gott abgewandt hat. Der synonyme Parallelismus von V9 verstärkt das Rufen zu JHWH. Der synthetische Parallelismus von 10ab stellt die Frage nach Gewinn und Verlust durch das Ableben. Diese Frage wird im synonymen Parallelismus von 10cd weitergeführt und verdichtet. V11 schwankt zwischen einem synonymen und einem synthetischen Parallelismus, der das erbetene Zuhören und eingreifende Helfen Gottes verdeutlicht (vgl. V9). V12.13 sind synonym gestaltet. Die Verwandlung durch Gott in V12 wird dort ebenso in zwei Aussagen geschildert wie das Besingen und Loben Gottes auf ewig in V13.

568 Vgl. Erbele-Küster, Lesen, 142.145.

569 "Die unspezifische Sprache bei den Lexemen für den Hilferuf, die Unbestimmtheitsstellen bei der Nennung der Feinde, die metaphorische Redeweise bei der Nennung/Beschreibung 
Ps 30 bietet eine strukturierte Bühne der erzählten Welt und eröffnet durch den dargestellten Inhalt, durch den Analogiebildung möglich ist, ebenso Identifikationspotenziale wie durch die dynamische Darstellungsweise in Form von zwei Minierzählungen, durch die Charakterisierung der Textpersonen sowie die Perspektivenlenkung, die das raum-zeitliche Mitgehen mit dem lyrischen Ich ermöglicht. Die emotionale Erzählweise und emotionale Wirkung, die Vertiefung der Themen durch die Parallelismen, die direkten Anreden und die dargestellten Beziehungskonstellationen sowie die offene metaphorische Sprache können ebenso Potenziale bieten, durch die sich Lesende mit der im Text dargestellten Welt identifizieren können. Aus dieser Fülle von Identifikationsangeboten ist das höchste Potenzial dort auszumachen, wo hohe bzw. doppelte Emotionalität, deiktische Dichte, aktueller Inhalt und spannende Erzähldynamik aufeinandertreffen, wie dies in $2 b-4 b$ und $8 c-12 c$ gegeben ist.

von Todesgefahr und Rettung, Trauer und Freude, Sterben und Totsein, die bildhaft konkrete Ausdrucksweise bei der Übersetzung von Jahwes Zorn und seiner Huld, die in theologischer Tradition steht, das alles zeigt zunächst einen hohen poetischen Rang des Psalmtextes, der die erste Voraussetzung für sein Weiterwirken ist. Sodann eröffnet ein gewisses Maß an Unbestimmtheit, ebenso die metaphorische Sprache, dem Rezipienten die Möglichkeit, sich im Psalm wiederzufinden und Kongruenz zwischen sich und dem Psalm zu erfahren. Die poetisch metaphorische Sprache ist offen, aber nicht allgemein. Sie ist konkret und damit eindrücklich. Sie regt die Schaukraft des Menschen an. Die offene Unbestimmtheit, verbunden mit der bildlichen Eindrücklichkeit fordert die Kreativität des Beters heraus. Sie bewegt, ergreift und rührt.« Witzenrath, Am Abend Weinen, 476. Ähnlich Weber, Werkbuch 1, 151: »Die Sprache der Todesbedrohung im Psalm ist - wie vielfach in den Psalmen - offen für verschiedene Umstände und Situationen und damit geeignet für das Nachsprechen und -beten in unterschiedlichen Gefährdungen und Nöten.» 
Open-Access-Publikation im Sinne der CC-Lizenz BY-NC-ND 4.0

(c) 2019, V\&R unipress GmbH, Göttingen 


\section{Textanalyse Psalm 147}

\section{$1 \quad$ Inhalt}

Der Hymnus beschreibt und besingt JHWH und seine positiven Taten an Jerusalem und Israel, an elenden und gebeugten Menschen sowie JHWHs Aktivitäten an und in der Schöpfung. ${ }^{570} \mathrm{Im}$ Rahmen dieser Themengebiete begegnet im Text (zur Arbeitsübersetzung vgl. X Anhang) eine Vielzahl von Gottesbildern, die in der folgenden Analyse in männlichen wie weiblichen Übersetzungen ihren Ausdruck findet. ${ }^{571}$ So wird die Gottheit Israels in Ps 147 - neben den Bezeichnungen JHWH, Adonaj und "unser Gott« - dadurch charakterisiert, dass sie Jerusalem aufbaut (V2), als Ärztin, Hirtin und Trösterin wirkt (V2-3), als Schöpferin in ihrer Fürsorge (V8-9) und auch in ihrer Gefährlichkeit (V17) sowie als Leiterin des Volkes Israel (V18-19) tätig ist. Die unermessliche Größe Gottes (V4-5) wird genauso thematisiert wie seine Zugewandtheit zu denen, die arm sind (V6) und die auf Gott warten und vertrauen (V11). Im Gegensatz dazu wird der Umgang Gottes mit den Frevlern ebenso deutlich charakterisiert (Erniedrigen bis zum Boden 6b) wie seine Einstellung zu militärischer Stärke und Kraft der Menschen (kein Wohlgefallen V10). Neben den unterschiedlichen Gottesbildern tritt immer wieder Jerusalem/Israel ins Zentrum der Aufmerksamkeit. Hinter den Handlungen der Gottheit Israels, die Jerusalem aufbaut und sicher macht (V2-3; 13-14), steht die Erfahrung von Zerstörung, Krieg und Flucht. Gerahmt

$570 »$ Dabei folgen sich die Motive zu jenem Lobe in buntem Wechsel, teils sind sie entnommen dem Schaffen Gottes in der Natur, teils seiner Fürsorge für die Geschöpfe, teils seiner gnadenvollen Lenkung Israels sowohl in dessen äußerem Bestand wie in seiner inneren Geschichte.« Herkenne, Das Buch der Psalmen, 450.

571 Dies entspricht der theologischen Kenntnis, dass exklusiv männliche Gottesbezeichnungen in der Rede von Gott als der/die/das ganz Andere den biblischen Gottesbildern in ihrer Fülle nicht gerecht werden und dass der Gottesname JHWH, welcher die bleibende Fremdheit und das Geheimnis des Göttlichen selbst repräsentiert, jede Geschlechtlichkeit transzendiert. Vgl. dazu Bail / Crüsemann, Einleitung, 14-18; Keel, Gott weiblich, 10-18; Ebach, Gottes Name(n) u. v. a. m. Siehe dazu auch die beiden Übersetzungsvarianten von Ps 147 im Anhang. 
und strukturiert wird dieses »Beschreibungslied JHWHs« von der wiederholten Aufforderung zum Lob (V1.7.12.20). Diese Lobaufforderung kann als Gliederungsmerkmal herangezogen werden; der Psalm lässt sich somit in die drei Teile V1-6, 7-11 und 12-20 gliedern. ${ }^{572}$

Der Psalm trägt keine Überschrift und setzt nach dem Auftakt (Lobaufforderung in 1a inkl. Begründung in 1b.c) mit der Erzählung der Taten Gottes für Jerusalem ein (Er-Perspektive). Diese wird in V5 mit der Beschreibung des »Wesens" Gottes unterbrochen, in V6 jedoch weitergeführt. Mit der hymnischen Lobaufforderung in V7, die - im Gegensatz zu V1 - ohne Begründung (kein ’ִ̣) fortgeführt wird, und mit dem damit verbundenen Sprechrichtungswechsel (IhrPerspektive) beginnt ein neuer Textabschnitt, der die Taten Gottes im Bereich der Schöpfung stärker in den Blick nimmt (V8-9) und abermals die Charakterisierung des Gottesbildes (V10-11) zum Inhalt hat. Mit dem Lobaufruf in V12, der diesmal an ein Du gerichtet (Jerusalem 12a bzw. Zion 12b) und - wie in V1 begründet ist, werden in V12-20 erneut die Taten JHWHs an Jerusalem bzw. an der Schöpfung sowie am Volk Israel geschildert. Diese werden in 20a.b auf alle Nationen ausgeweitet. Der Psalm endet mit einem erneuten Lobaufruf (20c IhrPerspektive). ${ }^{573}$

$572 »$ The first section [V1-6] goes from Jerusalem to creation to restoring the weak. The second [V7-11] goes from creation to people who revere Yhwh. The third [V12-20] goes from Jerusalem to creation to Yhwh's revelation to Israel.« Goldingay, Psalms 3, 717. Selten herrscht in der exegetischen Literatur so viel Einigkeit über die Gliederung eines Psalms. Alle von mir konsultierten KommentatorInnen sprechen sich für die gleiche Strukturierung von Ps 147 aus.

573 Auch in der Frage der Datierung herrscht relative Einigkeit. So wird aufgrund von V2.3 sowie V12-14 auf die Heimkehr nach dem babylonischen Exil und die Folgezeit geschlossen. V13 wird auf die durch Nehemia initiierte Wiederherstellung der Stadtmauer Jerusalems bezogen (um 445). Der Psalm könnte nach der Vollendung des Mauerbaus durch Nehemia entstanden sein. Vosberg, Studien, 95. So wird der Psalm auf alle Fälle in nachexilische Zeit datiert (Ende des 5./4. Jh.). So z. B. Fohrer, Psalmen, 67; Schlögl, Die Psalmen, 226; Anderson, The Book of Psalms 2, 944; Cohen, The Psalms, 472; Herkenne, Das Buch der Psalmen, 450 und Allen, Psalms 101-150, 309. Weber, Werkbuch 2, 374 bezeichnet ihn als (spät)nachexilisch, Briggs / Briggs, Commentary, 534 sprechen davon, dass der Psalm in die Makkabäer-Zeit gehört. Brodersen, The End of the Psalter, 200.205, datiert den Text in den Zeitraum des 3. bis 2. Jh. v. Chr. Anders Dahood, Psalms 3, 344, der Ps 147 in das 6. Jh. datiert. Laut Weiser, Die Psalmen 2, 558 ist eine genaue Datierung von Ps 147 nicht möglich. 


\subsection{Rederichtungen, Themen und Zeitachse}

Eine durchgehende Sprechstimme, die aufgrund der Bezeichnung אֶלהֵינוּ (unser Gott) in 1b sowie אֶדוֹנֵינו (unser Adonaj) in 5a als lyrisches Wir ${ }^{574}$ ausgewiesen ist, nimmt in abwechselnder Reihenfolge das Beziehungsgeschehen zwischen JHWH und dem Volk Israel (V2-3.6-7.10-14.19-20) einerseits sowie zwischen JHWH und der Schöpfung (V4-5.8-9.15-18) andererseits in den Blick. Die auf die Gottheit bezogenen Personalsuffixe (unser Gott 1b, unser Adonaj 5a, dein Gott 12b) drücken dabei laut Siegfried Risse eine besondere Beziehung und Verbundenheit zwischen Israel und "seiner « Gottheit aus. ${ }^{575}$

Verschiedene Spots (zum Begriff »Spot« vgl. III Methodik 1) werden demnach auf den einen Gott in seiner Wirkmacht gerichtet. Unterbrochen werden diese Aussagen über JHWH (Er-Perspektive) mit direkten Anreden an ein Ihr bzw. Du (1a.7a.b.12a.b.20c mit AdressatInnenperspektive), die - wie bereits in der Analyse von Ps 30 aufgezeigt - zeitdeckend sind. Die AdressatInnen, die in 1a.7a.b.20c in der Pluralform angesprochen werden, bleiben unbestimmt, das in 12a.b angesprochene $\mathrm{Du}$ ist durch Jerusalem bzw. Zion konkretisiert. Nach Gordon Wenham sind es in diesem Text gerade die Imperative, durch welche die Lesenden in das Textgeschehen einbezogen werden. ${ }^{576}$ Die Rhetorik in Bezug auf die AdressatInnen enthält nach John Goldingay eine subtile Komplexität. ${ }^{577}$ So spricht das lyrische Wir im ersten und zweiten Teil des Psalms die Öffentlichkeit bzw. eine unbestimmte Gruppe in der 2.P.pl. an - und meint damit auch sich selbst. Dies geschieht dadurch, dass unmittelbar nach der Anrede der AdressatInnen in V1.7 die 1.P.pl. verwendet und damit aufgezeigt wird, dass es hier um ein »Wir" und um »unseren Gott" geht, zu dessen Lob die Angeredeten aufgefordert werden. Das sprechende lyrische Wir ist damit auch Teil der AdressatInnen. Im ersten Teil wird dann über JHWHs Heilstaten in der 3.P. gesprochen. Vermutlich befinden sich unter den EmpfängerInnen dieser Heilstaten (Jerusalem, die Verstoßenen Israels, die zerbrochenen Herzens sind, die Gebeugten) sowohl die AdressatInnen als auch das lyrische Wir des Psalms: "The rhetoric thus invites them to look at themselves from the outside, to see themselves being built up, healed, and restored even as they see the faithless being put down. ${ }^{578} \mathrm{Im}$ dritten Teil des Psalms wird - anders als zuvor - die Stadt (Jerusalem, Zion) in der 2.P.sg. angesprochen. Die AdressatInnen sind an dieser Stelle einerseits wiederum identisch mit konkreten Menschen, andererseits aber auch von ihnen

574 »Das Lied ist einer Gesamtheit in den Mund gelegt: >unser Gott $<$ (V. 1), >unser Herr (V. 5).» Fohrer, Psalmen, 66f.

575 Vgl. Risse, Gut ist es, 47.102 .

576 Vgl. Wenham, Psalms, 156.

577 Vgl. zum Folgenden Goldingay, Psalms 3, $717 \mathrm{f}$.

578 Goldingay, Psalms 3, 717. Ähnlich Ballhorn, Telos, 311. 
unterschieden, da eine Stadt immer mehr ist als die Summe ihrer gegenwärtigen BewohnerInnen. Indirekt werden nun diese derzeitigen EinwohnerInnen aufgefordert, Gott zu loben. Es sind jetzt die StadtbewohnerInnen, die den Psalm singen oder die zuhören, wenn dieser gesungen wird. In der Beschreibung der Erfahrung der Stadt können sie sich selbst sehen: »They are its children (v. 13). They are also the current embodiment of the Jacob-Israel of vv. $19-20 .{ }^{579}$ Das lyrische Wir bleibt also als durchgehende Sprechstimme bestehen, es wird aber laut Goldingay immer wieder mit hineingenommen in die Gruppe der AdressatInnen bzw. in die im Text durch JHWHs Heilstaten Begünstigten. ${ }^{580}$ Diese Subtilität in der rhetorischen Gestaltung des Psalms erleichtert den Lesenden durch das Ineinander von Sprechenden und Angesprochenen die Möglichkeit der Identifikation mit dem offenen lyrischen Wir einerseits sowie mit den im Text angesprochenen Personengruppen andererseits.

Die im Loblied entfalteten Taten und Aktivitäten Gottes (JHWH tritt ein für ...) lassen sich im Überblick folgendermaßen darstellen:

\begin{tabular}{|l|l|}
\hline Verse & Zuwendung Gottes/Objekte \\
\hline $2-3$ & Jerusalem/Israel \\
\hline $4-5$ & Schöpfung \\
\hline $6 ;$ allgemeine Formulierung & für Gebeugte, gegen Frevler \\
\hline $8-9$ & Schöpfung \\
\hline $10-11 ;$ allgemeine Formulierung & gegen Schnelle/Starke, für Gottesfürchtige \\
\hline $13-14$ & Jerusalem \\
\hline $15-18$ & Schöpfung \\
\hline 19 & Israel/Jakob \\
\hline 20 & jede Nation \\
\hline
\end{tabular}

Die Inhalte werden dabei hintereinander erzählt und - grammatikalisch betrachtet - in einer stringenten Gleichzeitigkeit dargestellt. Diese Gleichzeitigkeit lässt sich vor allem an der Vielzahl der Handlungen JHWHs festmachen, die in Partizipialformen geschildert werden (2a.3a.3b.4a.6a.6b.8a.8b.8c.9a.11a.14a.15a. 16a.17a.19a). Durch die Darstellung der Handlungen mittels Partizipien erhalten die Aussagen einen generellen, der Zeit enthobenen bzw. zeitlosen oder aber zu allen Zeiten gültigen Charakter. Zudem tauchen drei weitere substantivierte

579 Goldingay, Psalms 3, 718.

580 »Grund zum Lob haben im ganzen Psalm all diejenigen Menschen, die Gottes Taten positiv erfahren: `wir $\iota$, nämlich die zu >unserem Gott $\iota$ Gehörigen (V. 1, 5, 7), Jerusalem = Zion (V. 2, 12-13) und ihre Söhne (V. 13), Israel = Jakob (V. 2, 19), Betrübte (V. 3), Elende (V. 6) und Gottesfürchtige (V. 11).« Brodersen, Schöpfungsaussagen, 51. Sie kommt daraufhin zum Schluss, dass "mit den verschiedenen Bezeichnungen jeweils das Volk Israel gemeint ist» (S. 52). 
Partizipien auf (Versprengte/Verstoßene Israels 2b; die zerbrochenen Herzens sind 3a, die Wartenden 11b). Das Partizip ist damit die vorherrschende Verbform in Ps 147 und steht - mit Ausnahme der substantivierten Partizipien - immer an erster Stelle.

Die Darstellungsform durch die vielen Adjektive (gut 1b, angenehm, schön 1c, groß 5a, reich 5b) und das Adverb (schnell) in 15b verstärken den beschreibenden Stil des Psalms, der aus einer Jetzt-Perspektive heraus spricht. Diese wird durch die direkten Anreden an die AdressatInnen (1a.V7.V12.20c) deutlich hervorgehoben. Es lassen sich 14 Verbformen in der PK (2b.4b.9b.10a.b. 14b.15b.16b.17b.18a.18b:2x.20a.b) sowie eine in der W-PK (18a), aber nur vier in der SK (13a.b.20a.b) ausmachen, sodass keine zeitlich deutlich voneinander getrennten Passagen in der Vergangenheit oder mit Ausrichtung auf die Zukunft festzustellen sind. Für die Deutung der PK-Formen gilt ein generelles Verständnis: »Die Taten sind in der Vergangenheit wiederholt aufgetreten und pflegen sich in der Gegenwart zu wiederholen, daher ist auch zu erwarten, dass sie sich in der Zukunft wiederholen werden. In der Übersetzung wird für diese generellen Aussagen das deutsche Präsens verwendet. « ${ }^{581}$

\subsection{Gliederung ${ }^{582}$}

\begin{tabular}{|l|l|l|l|l|}
\hline Vers & Themen & Zeitachse & Sprechstimme & Sprechrichtung \\
\hline 1 & $\begin{array}{l}\text { Lobaufruf, Begrün- } \\
\text { dung und Verstärkung }\end{array}$ & Jetzt (Imp.) & lyr. Wir & Ihr \\
\hline
\end{tabular}

581 Brodersen, Schöpfungsaussagen, 33.

582 Weitere anschauliche Aufbauschemata bieten u. a. Risse, Gut ist es, 32, sowie Brodersen, Schöpfungsaussagen, 29. Auch wenn die LXX und Vg Ps 147 auf zwei Psalmen aufteilen (MT Ps 147, 1-11 = LXX Ps 146,1-11; MT Ps 147,12-20 = LXX Ps 147,1-9) und damit V12-20 als separaten Psalm anführen, besteht nur geringer Zweifel daran, dass die Masoreten Ps 147 als einen einzigen Psalm betrachtet haben. Zu den weiteren Unterschieden zwischen LXX und MT vgl. Brodersen, Schöpfungsaussagen, 23-26. Die ursprüngliche Einheit des Psalms wird demnach relativ selten in Frage gestellt. Vgl. Risse, Gut ist es, 15. 192; Goldingay, Psalms 3, 717; Allen, Psalms 101-150, 308; Stuhlmueller, Psalms 2, 214. „Der Psalm ist als wohlgegliederte Einheit zu verstehen « vermerkt Kraus, Psalmen, 1135. Ebenso Anderson, The Book of Psalms 2, 944 und Herkenne, Das Buch der Psalmen, 450. Strittig ist alleine, ob die Halleluja-Rufe in V1.20 originäre Bestandteile des Psalms sind oder nicht. Dafür sprechen sich u. a. aus: Sarna, Halleluja, 280; Schlögl, Die Psalmen, 227; Vosberg, Studien, 91; dagegen votiert u. a. Anderson, The Book of Psalms 2, 944. Die weitere literarkritische Diskussion bezieht sich darauf, ob auf Basis der LXX- und Vg-Version die Annahme eines Grundpsalms und dessen Fortführung berechtigt ist. Für diese Erweiterungshypothese sprechen sich u. a. Risse, Gut ist es, $192 \mathrm{f}$ und Lohfink, Lobgesänge, $115 \mathrm{f}$ aus. Sie gehen von einem Grundpsalm V2-11 sowie dessen Fortführung in V12-20 aus. Anders Leuenberger, Konzeptionen, 350, der von einem Grundpsalm V12-20b ausgeht, welcher um die Verse 1-11.20c bei der Einfügung in das Schlusshallel erweitert wurde. Hossfeld / Zenger, Psalmen 101-150, 827 
(Fortsetzung)

\begin{tabular}{|c|c|c|c|c|}
\hline Vers & Themen & Zeitachse & Sprechstimme & Sprechrichtung \\
\hline $2-6$ & $\begin{array}{l}\text { JHWHs aufbauende } \\
\text { und heilende Taten für } \\
\text { Jerusalem/Israel; Gott } \\
\text { als Schöpfer und des- } \\
\text { sen Größe und Macht; } \\
\text { Zuwendung JHWHs zu } \\
\text { Armen vs. Demütigung } \\
\text { der Frevler }\end{array}$ & Jetzt (Ptz.) & lyr. Wir & $\mathrm{Er}$ \\
\hline V7 & $\begin{array}{l}\text { Lobaufruf ohne Be- } \\
\text { gründung }\end{array}$ & Jetzt (Imp.) & lyr. Wir & Ihr \\
\hline V8-11 & $\begin{array}{l}\text { Die Gottheit als Schöp- } \\
\text { ferin und deren Für- } \\
\text { sorge für Natur und } \\
\text { Tiere; göttliches Wohl- } \\
\text { gefallen für die Gottes- } \\
\text { fürchtigen vs. Nicht- } \\
\text { Gefallen an mensch- } \\
\text { licher Kraft und } \\
\text { Schnelligkeit }\end{array}$ & Jetzt (Ptz.; PK) & lyr. Wir & $\mathrm{Er}$ \\
\hline V12 & $\begin{array}{l}\text { Lobaufruf mit Begrün- } \\
\text { dung }\end{array}$ & Jetzt/Imp. & lyr. Wir & $\mathrm{Du}$ \\
\hline $\begin{array}{l}\text { V13- } \\
20 \mathrm{~b}\end{array}$ & $\begin{array}{l}\text { JHWHs Taten der Si- } \\
\text { cherheit, des Schutzes } \\
\text { und des Sättigens für } \\
\text { Jerusalem; Gott als } \\
\text { Schöpfer und dessen } \\
\text { Gefährlichkeit (Schnee, } \\
\text { Reif, Eis); Gottes Wort } \\
\text { und Ordnungen für Is- } \\
\text { rael vs. Gottes Nicht- } \\
\text { Handeln an anderen } \\
\text { Völkern }\end{array}$ & $\begin{array}{l}\text { Jetzt/Ptz. + } \\
\text { PK + Rückblick } \\
\text { (SK) }\end{array}$ & lyr. Wir & Er \\
\hline $20 c$ & Lobaufforderung & Jetzt/Imp. & lyr. Wir & Ihr \\
\hline
\end{tabular}

nehmen ebenfalls an, dass der Psalm nicht von einem einzigen Autor stammt, und lesen ihn als Doppelhymnus. Für weitere Details in Bezug auf eine mögliche Uneinheitlichkeit vgl. Brodersen, Schöpfungsaussagen, 42. Hinsichtlich der vielfältigen intertextuellen Bezüge und Anspielungen sind vor allem Dtn 4, Jes 11,12; 40-66, Ps 33; 81; 104; 119; 136 sowie Ijob 37-39 zu nennen. Vgl. Grogan, Psalms, 226, und Sedlmeier, Jerusalem, 353. Zu einer detaillierten Aufschlüsselung der intertextuellen Bezüge, vor allem auch jener zu anderen Psalmen, vgl. Hossfeld / Zenger, Psalmen 101-150, $827 \mathrm{f}$ und Brodersen, The End of the Psalter, 179-186. 


\section{Emotionen}

In dieser Analyse werden zum einen die Emotionen in den Blick genommen und zum anderen Details zur Textkonstitution sowie weitere Aspekte und Themen des Verses herausgearbeitet. Ebenso werden semantische, syntaktische und textkritische Fragen besprochen, die zum besseren Verstehen des Textes und der unterschiedlichen Übersetzungsvarianten dienen.

\subsection{Vers 1: Lobaufforderung und -begründung}

1a Lobt JH!

$1 b$ Denn gut ist es, zu singen/spielen unserem Gott.

1c Ja, angenehm ist ein schöner Lobgesang.

V1 setzt mit einer Lobaufforderung im Imp.pi.m.pl. ein. ${ }^{583}$ Von den insgesamt 206 Vorkommen von הלל (rühmen, preisen) ${ }^{584}$ in der Hebräischen Bibel sind fast zwei Drittel in den Psalmen bzw. in Psalmmotiven anzutreffen. Das Verb kann den Vorgang des Rühmens zwischen Menschen sowie das Rühmen von Sachen bezeichnen; in der Mehrzahl der Fälle ist es allerdings die Gottheit, die gepriesen wird. Es handelt sich bei diesem imperativischen Lobaufruf um einen starken und drängenden Impuls, der das Rühmen und Loben in Bewegung setzen soll und zugleich »Ausdruck der zu Gott hin gewandten Freude ist. Man kann also den Ruf zum Loben Gottes im AT nicht hören, ohne darin eingeschlossen den Ruf zur Freude zu hören. ${ }^{585}$ Die Lobaufforderung steht fast immer in der Pluralform. Die einzigen beiden Singularformen kommen in Ps 146,1 (»lobe, meine Seele, JHWH«) und in diesem Psalm in V12 vor, wobei hier ein Kollektiv, nämlich Zion, angesprochen ist (»lobe deinen Gott, Zion«). Dies zeigt, dass das Gotteslob, das häufig von Musikinstrumenten begleitet wird (vgl. V7), seinen Ort in der Gemeinschaft hat. In V1 werden Gotteslob und Gott durch die enge syntaktische Verbindung des Lobaufrufes mit dem Gottesnamen in der Kurzform JH nahe aneinander gerückt: »Gotteslob gehört zum Dasein, es ist selbst eine Weise des Daseins. Wo es aufgehört hat, hat auch das eigentliche Leben aufgehört. [...] hll pi. ist zu Gott hingewandte, zu Gott hin singende Daseinsfreude. ${ }^{586}$

583 »Voll Freude über die Erwählung, die Israel widerfahren ist, ruft der Psalmist sein Volk zum Lobgesang.« Lamparter, Das Buch der Psalmen 2, 374.

584 Vgl. Ringgren, הלל, 434. Die Wurzel ist verwandt mit dem ugar. Jauchzen und dem akk. EinFreudenlied- Singen. Die liturgische Formel »Halleluja» kommt $23 \mathrm{Mal}$ in der Hebräischen Bibel vor, und zwar ausschließlich im Psalter. Vgl. Sarna, Halleluja, 280.

585 Westermann, הלל, 495.

586 Westermann, הלל 498. 
Die Aufforderung zum Loben JHWHs wird damit begründet, dass es gut (טוֹב) sei, die Gottheit sowohl vokal als auch instrumental (זמר) zu preisen. זמר ist ganz besonders dazu geeignet, die Freude des Lobpreises zum Ausdruck zu bringen (vgl. dazu die Analyse von Ps 30,5). ${ }^{587}$ An dieser Stelle ist kurz auf das Thema der Begründung und damit auf die beiden ’ִ̣-Partikeln in diesem Vers einzugehen. Die Partikel כִ̣ kann neben einer kausalen Bedeutung (denn, weil) auch eine affirmative, deiktische Funktion besitzen (fürwahr, gewiss, ja). Hier stellt sich die Frage, welcher Bedeutung die beiden Partikeln zuzuordnen sind, d. h. ob sie die Lobaufforderung begründen oder aber verstärken. Geht man von der Annahme aus, dass der Hallelujaruf nicht zum ursprünglichen Psalm gehört, sondern erst später als Rahmung hinzugefügt wurde, dann ergibt sich das Problem, dass es für einen Psalm ungewöhnlich oder sogar unmöglich ist, mit einem kausalen כִ̣ zu beginnen. Da ich den Text dergestalt in den Blick nehme, wie er uns im MT überliefert ist, verstehe ich den und übersetze das erste כִ kausal (denn). Diese Lobbegründung wird durch den zweiten כִ̣-Satz unterstrichen (affirmativ: ja). ${ }^{588}$ Weitere Lobbegründungen inhaltlicher Art erfolgen dann in V2-3. ${ }^{589}$ V4 wird ebenso als Lobbegründung verstanden. ${ }^{590}$ Die Deutung als zweimaliges affirmatives כִ̣ würde allerdings bereits in der Syntax den emotionalen Gehalt der Lobaufforderung und den Aspekt des freudigen Lobes unterstreichen.

Mit טוֹ begegnet das erste Adjektiv im Psalm, der sich - wie bereits erwähnt טוi ב bezeichnet allgemein jene Eigenschaften, die ein Objekt erstrebenswert machen.

587 Vgl. Risse, Gut ist es, 99.

588 Ebenso Weiser, Die Psalmen 2, 557 und Fokkelman, Major Poems, $317 \mathrm{f}$. Zwei Mal affirmativ lesen ELB; BigS; Hossfeld / Zenger, Psalmen 101-150, 824f; Kraus, Psalmen, 1134; Grogan, Psalms, 226; Allen, Psalms 101-150, 304f; Rogerson / McKay, Psalms 101-150, 179; Herkenne, Das Buch der Psalmen, 450; Dahood, Psalms 3, 343; Anderson, The Book of Psalms 2, 944; Ruwe, Die Psalmen, 214; Marti, Die Psalmen, 438; Sedlmeier, Jerusalem, 18-20 und Risse, Gut ist es, 52. Zunächst affirmativ und dann kausal lesen V1 Weber, Werkbuch 2, 373; Viviers, Psalm 147, 172; Limburg, Psalms, 495: "How good it is ...; for he is gracious." Zwei Mal kausal lesen Schlögl, Die Psalmen, 226; Ketter, Die Psalmen, 194; Hupfeld, Die Psalmen, 671; Stuhlmueller, Psalms 2, 212; Seybold, Die Psalmen, 537; Cohen, The Psalms, 472; Briggs / Briggs, Commentary, 533; Goldingay, Psalms 3, 715 und BUBER. כִ̣ bleibt unübersetzt bei ZUR, EÜ, Fohrer, Psalmen, 65; Groß / Reinelt, Das Buch der Psalmen, 431: "Gut ist es, unserem Gott zu singen; schön ist es, ihn zu loben."

$589 »$ Verses 2 and 3 provide reasons for praising the Lord. The reasons have to do with the delivering act of the Lord who is rebuilding the capital city, bringing in those who had been exiled, and healing broken bodies and broken hearts." Limburg, Quoth, 103.

590 »Verse 4 presents the Lord's work in nature as a second reason for praise. Limburg, Psalms, 497. Cohen, The Psalms, 472 führt vier Gründe an, Gott zu preisen: 1. die Zuwendung zu Israel durch die Wiederherstellung; 2. die großzügige Versorgung, die er für die Nahrung seiner Geschöpfe bereitgestellt hat; 3. seine Kontrolle der Naturgewalten; 4. seine Offenbarung für Israel. 
Das Adjektiv wird im täglichen Leben für Gegenstände, Handlungen oder Situationen hinsichtlich deren Zweckmäßigkeit angewandt und dabei mit »brauchbar«, »nützlich« und "günstig« wiedergegeben. ${ }^{591}$ Wird בiv auf Menschen bezogen, dann hebt das Adjektiv eine bestimmte Begabung bzw. eine besonders positive Eigenschaft hervor. ${ }^{592}$ Von den 559 Belegen von finden sich 68 in den Psalmen. Je nach Zusammenhang werden neben der Übersetzung "gut« zahlreiche andere Eigenschaftswörter für die Wiedergabe im Deutschen verwendet. ${ }^{593}$ So stellt $1 \mathrm{~b}$ fest, dass es gut, erfreulich und zweckmäßig ist, JHWH zu loben, gibt aber den Grund dafür nicht an. "Die Antwort auf die Frage nach dem Warum ist im ganzen Psalm zu suchen. Er preist Gottes Macht, Weisheit und Güte, mit denen er für die Schöpfung und für sein Volk und jeden einzelnen Menschen sorgt. Im Gotteslob realisiert der Mensch seine Zugehörigkeit zu diesem lebenschaffenden Gott. ${ }^{594}$

In 1c stehen gleich zwei Adjektive hintereinander. Mit dem ersten Adjektiv נִָעיכ (lieblich, wonnig, angenehm) wird im Psalm ein Begriff aus der Liebessprache verwendet. So findet sich das Eigenschaftswort ebenso in den Beschreibungen der Schönheit des Geliebten oder in Äußerungen über die erotische Liebe im Hld (z. B. Hld 1,16) wie im Rahmen der Freundschaftsbekundungen zwischen David und Jonatan (2 Sam 1,23). In metaphorischer Redeweise bezeichnet נִָעים die Köstlichkeit bzw. Schönheit des Landes Israel, z. B. in Gen 49,15. An dieser und an

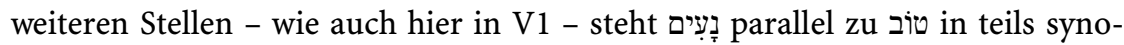
nymer Verwendung. folgende Adjektiv aus 1c, findet sich auch in der Liebesterminologie des Hld, wird diesmal allerdings für die Beschreibung der Geliebten verwendet (Hld 1,5.10;4,3).

Das Loben Gottes ist nicht nur angemessen, nützlich und notwendig, sondern ein ästhetisches Geschehen. So zeigt V1 durch die Verwendung der Adjektive, dass die Anmut und Schönheit des Lobpreises betont an den Anfang gestellt wird. $^{597}$

591 Vgl. Höver-Johag, בiv, 319.

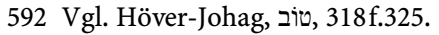

593 Stoebe, בטוֹ, 653: »Angenehm, erfreulich, befriedigend, wohlgefällig, günstig, brauchbar, zweckmäßig, recht, nützlich, reichlich, schön, wohlgestaltet, wohlriechend, freundlich, gütig, fröhlich, brav, wacker, wahr.»

594 Risse, Gut ist es, 46.

595 Vgl. Kronholm, נעָּ, $502 \mathrm{f}$.

596 Manche Kommentatoren betrachten die Form als Inf. pi. mit der fem.-Endung parallel

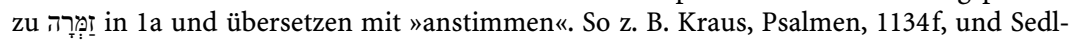
meier, Jerusalem, 18. Hossfeld / Zenger, Psalmen 101-150, 825 übersetzen mit »(ihn) mit Lob zu schmücken." «נָ wäre hier allerdings das einzige Vorkommen als Inf. pi., ansonsten tritt es immer als Adjektiv auf, kommt zehn Mal in der Hebräischen Bibel vor und zwar immer in der Bedeutung »schön«, "geziemend«. Vgl. dazu Risse, Gut ist es, 21.

597 Vgl. Kraus, Psalmen, 1136. 
V1 besticht durch den freudigen und zur Freude aufrufenden Charakter, der die Atmosphäre des gesamten Psalms bestimmt. ${ }^{598}$ Neben Freude und Fröhlichkeit als Emotionen kommen mit den Adjektiven aus der Liebessprache die Emotionen der Liebe, der Anmut und des Wohlgefühls sowie die Themen der Schönheit und Köstlichkeit in den Blick. Die Emotionen lassen sich nicht eindeutig zuordnen und werden daher subjektfrei geäußert.

\subsection{Vers 2: Göttliches Bauen und Sammeln}

\section{2a Aufbauend JHWH Jerusalem,}

$2 b$ die Verstoßenen Israels sammelt er.

2a zeichnet das Bild JHWHs als Erbauer bzw. Bauherrin Jerusalems. Mit der Verwendung des Ptz. בפּנ (aufbauend ${ }^{599}$ ) wird auf ein Geschehen hingewiesen, das noch nicht abgeschlossen, also noch im Gang ist; schließlich geht es auch um einen inneren Wiederaufbau. ${ }^{600}$ Es handelt sich dabei um ein kontinuierliches Sich-Kümmern um Jerusalem und dessen Entwicklung. ${ }^{601}$ Neben der handfesten und profanen Bedeutung des Aufbauens verweist Franz Sedlmeier auf den metaphorischen Gebrauch von בנה Rahmen einer theologischen Verwendung der Wurzel. ${ }^{602}$ Seine Untersuchung der Wurzel mit JHWH als Subjekt in der prophetischen Literatur sowie im Psalter ergibt, dass die allermeisten Aussagen an den Wiederaufbau nach dem Exil anknüpfen. Dies geschieht in Verbindung mit der Erwartung einer von JHWH bewirkten Wende zum Heil, wobei hier auch »Exil« im übertragenen Sinn gebraucht wird. In der Prophetie (Schwerpunkt: Jer und Jes) bezieht sich das "Bauen JHWHs" im übertragenen Sinn auf die Auferbauung des Volkes, den Aufbau der Gemeinde. Die im Buch der Psalmen analysierten Aussagen zeichnen JHWH als jenen Gott, »der das Gottesvolk von Grund auf erneuert und es in der Zukunft seiner endgültigen Bestimmung zu-

598 Vgl. Grogan, Psalms, 226.

599 Fohrer, Psalmen, 65 gibt den anhaltenden Aspekt des Ptz. hier in 2a mit »Der Herr erbaut Jerusalem von neuem« wieder. Ähnlich Miller, Die Psalmen, 252: „Neu baut der Herr Jerusalem." Auf ein andauerndes Aufbauen anstatt auf ein singuläres geschichtliches Ereignis verweist auch Anderson, The Book of Psalms 2, 945. Sedlmeier, Jerusalem, 45-64 und Goldingay, Psalms 3, 716, geben das Ptz. als Substantiv (»Bauherr« bzw. »the builder of Jerusalem«) wieder. Da es m. E. auf der Ebene der Semantik keinen wesentlichen Unterschied macht, ob das Ptz., das eine Zwischenstelle zwischen Nomen und finitem Verb einnimmt, in diesem Fall als Substantiv oder als Verb wiedergegeben wird, bleibe ich aufgrund der hohen Anzahl an Ptz., die in Ps 147 als Verb fungieren, bei der Wiedergabe als Prädikat.

600 Vgl. Hossfeld / Zenger, Psalmen 101-150, 830 und Sedlmeier, Jerusalem, 63 Anm. 72.

601 Vgl. Rogerson / McKay, Psalms 101-150, 181.

602 Vgl. Sedlmeier, Jerusalem, 81-175. 
führt. « ${ }^{603}$ Somit handelt es sich bei der gottgewirkten Auferbauung ebenso um eine innere Erneuerung, um Heil und Rettung. ${ }^{604}$

In $2 \mathrm{~b}$ werden die Verstoßenen bzw. Versprengten oder Vertriebenen Israels erwähnt, die JHWH wieder sammelt: »Hier treffen JHWH und die Versprengten, d. h. Einheit und Zerstreuung, Macht und Hilflosigkeit aufeinander. Damit ist ein Grundthema des Psalms angesprochen: JHWH sorgt für sein Volk, das auf ihn angewiesen ist. ${ }^{605}$ Das Verb כנס q. bezieht sich auf das Ansammeln bzw. Einsammeln unterschiedlicher Materialien wie z. B. Steine (Koh 3,5), Geld (Koh 2,8.26), Ernteerträge (Neh 12,44) oder Wassermassen (Ps 33,7). כנס kann auch das Ansammeln von Menschen bedeuten (1 Chr 22,2; Est 4,16). Im pi. kommt es nur hier vor sowie im Gerichtswort von Ez 22,21 und in Ez 39,28. An der letztgenannten Stelle bezeichnet das Verb den Übergang vom Gericht zum endgültigen Heil: »Die von Jahwe durchgeführte Sammlung ist als vollständige, alle und jeden Israeliten einschließende Rückkehr in das Wohnland Israels zu verstehen $[. ..] . \varkappa^{606}$

Die Wurzel נדז trägt die Bedeutung von wegstoßen, versprengen sowie stoßen. Die Belege in der Nifal-Form, in der das Verb hier erscheint (Ptz.ni.pl.constr.), zeigen an, dass נדח auf die Sprache der Viehzüchter verweist. Metaphorisch tritt das Bild von der versprengten Herde Israels hervor. Der Ausdruck »Versprengte Israels« kommt wortwörtlich nur hier in V2 sowie in Jes 11,12 und 56,8 vor. Er kann sich hier entweder auf die durch die Feinde Verbannten oder auch auf die von JHWH Abgeirrten beziehen. ${ }^{607}$ Hinter dem Sprachbild steht in erster Linie die Rolle JHWHs als fürsorglicher Hirte. JHWH kann entweder selbst verstoßen (נדח hi. Ez 4,13; Jer 8,3; Dtn 30,1) oder aber, wie hier in 2b, seine Hirtentreue bezeugen, indem er die Verstoßenen Israels sammelt. ${ }^{608}$ Hinter dem Verb נדח (verstoßen, verjagen, wegstoßen, flüchten etc.) kann somit eine Not- bzw. Gewaltdimension ausgemacht werden (vgl. die Belege vor allem in Jes 8,22; 11,12; 13,$14 ; 16,3 \mathrm{f} ; 27,13$ und die hohe Anzahl der Belege in Jer, z. B. Jer 8,3; 16,15; 23,2$3.8 ; 24,9 ; 27,10)$. Wenn nun JHWH als Hirte gezeichnet wird, der seine Leitungsaufgabe wahrnimmt und die Zerstreuten und Vertriebenen seines Volkes

603 Sedlmeier, Jerusalem, 173.

$604 »$ Es ist offensichtlich, dass die Erbauung Jerusalems nicht als vordergründiger materieller Vorgang verstanden sein will, sondern die Sammlung und Heilung des Gottesvolkes meint.» Sedlmeier, Jerusalem, 348.

605 Risse, Gut ist es, 33.

606 Sedlmeier, Jerusalem, 183.

$607 \mathrm{Vgl}$. Risse, Gut ist es, 109.

608 Vgl. Kronholm, חד, 254-258. Die »Zerstreuten Israels« werden an dieser Stelle mit Bezug auf Jes 11,12 und Jes 56,8 sowie Ez 39,28 oftmalig auf die aus dem Exil Heimkehrenden bezogen. Vgl. Fohrer, Psalmen, 68. "Jahwe hat Jerusalem wieder aufgebaut und die Exilierten in die Heimat zurückgebracht.» Kraus, Psalmen, 1136. Miller, Die Psalmen, 252 übersetzt mit »Israels verbannte Kinder«. 
Israel sammelt (כנס), ${ }^{609}$ dann bringt diese Handlung im Kontext der Rede von den Zerstreuten implizit die Emotion der Geborgenheit und des Sich-aufgehobenFühlens bei JHWH zum Ausdruck sowie die göttliche Fürsorge und die Emotion der Zuneigung. Hintergrund dafür bildet die »Erfahrung der Verlorenheit und Verwirrung des Volkes. ${ }^{610}$

Neben dem Thema des Aufbauens sowie der dahinterstehenden existenziellen Erneuerung und des Neuanfangs kommen in V2 die Emotionen der Geborgenheit und des Sich-daheim-Fühlens durch die göttliche Hirten-Aktivität des Sammelns ebenso zum Ausdruck wie die Themen des Schutzes und der Sicherheit, die in V13 wieder aufgenommen werden. Mit dem Ausdruck der "Verstoßenen Israels« wird die unheilvolle Not- bzw. Gewaltsituation angesprochen, die sich dahinter verbirgt.

\subsection{Vers 3: Göttliches Heilen}

$3 a$ Er heilend die zerbrochenen Herzens sind

$3 b$ und verbindend ihre schmerzenden Wunden.

In diesem Vers wird die Fürsorge JHWHs, die in V2 mit dem Aufbauen Jerusalems und dem Einsammeln der Versprengten Israels beginnt, fortgesetzt und gesteigert. V3 enthält deshalb gewichtige Aussagen über die Heilstaten und Heilstätigkeiten JHWHs: Die Gottheit heilt (רפא), und zwar jene, deren Herzen

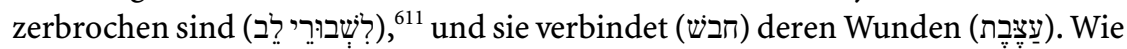
bereits in der Analyse von Ps 30,3 herausgearbeitet wurde, bedeutet רפָת ausbessern, flicken und zusammennähen sowie wiederherstellen, heilen und ganz machen, wodurch die Vorstellung von Gott als Arzt, Heiler und Erlöser evoziert wird. Die Wunden sitzen tief, und der Schmerz ist allgegenwärtig. ${ }^{612}$

Heilwerden meint dabei mehr als den körperlichen Vorgang des Gesundwerdens. Es bezieht sich gerade im Zusammenhang mit dem Bildwort des zerbrochenen Herzens auf eine umfassende Rettungstat, die nur Gott selbst vollbringen kann. Heilwerden bedeutet Lebenkönnen nach der Erfahrung einer

609 Weber, Werkbuch 2, 373 gibt die PK von כנס an dieser Stelle mit "versammelt er immer neu« wieder und betont damit den anhaltenden Aspekt der Handlung im Gegensatz zu einem einmaligen geschichtlichen Ereignis.

610 Sedlmeier, Jerusalem, 64. Inhaltlich wird damit auf die Heimholung der Exilierten aus dem babylonischen Exil angespielt, wodurch das Bild eines neuen Exodus entworfen wird. Vgl. Limburg, Quoth, 103 und Limburg, Psalms, 497.

611 Bei Weber, Werkbuch 2, 373 »die Zerbrochenen am Herzen«; die »Herzgebrochenen« bei Sedlmeier, Jerusalem, 18.

612 Ich folge aufgrund der semantischen Implikationen von עִֶֶּּ ("Schmerzen" sowie "Wunden«) der Übersetzung von Sedlmeier, Jerusalem, 18, »schmerzende Wunden«. 
tiefen Notsituation, auf die sich der metaphorische Ausdruck »für die, deren

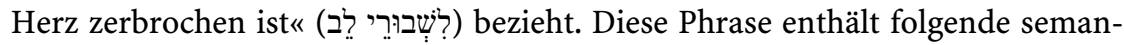
tische Implikationen: שבר I bedeutet brechen, zerbrechen, vernichten. Die Wurzel kann für das Zerbrechen von Gegenständen (z. B. Hölzer, Türen, Waffen, Knochen) ebenso verwendet werden wie für das Zerbrechen von Körperteilen: »Als Obj. des Zerbrechens ( $q a l, p i$ ) oder Zerbrochenseins (niph) gelten 32mal Teile des menschlichen oder tierischen Körpers (bes. Arm, Knochen, Zähne und - im metaphorischen Sinne - auch das Herz). ${ }^{613}$ Der Ausdruck »zerbrochenes Herz« bzw. "für die, deren Herz zerbrochen ist « gilt damit als Metapher. Welche Bedeutung ist dieser inhärent? Welche Assoziationen und Emotionen, Gedanken und Empfindungen setzt sie frei? Wird die Wurzel שבר I in einer metaphorischen Aussage mit לִ verbunden (Jes 61,1; Ps 34,19; 51,19), so ist das Brechen all dessen gemeint, wofür לֶ steht: innerste Gedanken, Pläne, Denken, Erinnern, Herz, Gefühl, Selbstbewusstsein, Verstehen, Charakter, Mut, Intention, "Leben« und auch Person. ${ }^{614}$ So wird etwa der Ausdruck in Ps 69,21 (»die Schande zerbricht mir das Herz«) als das Brechen bzw. Schwinden von Mut und Zuversicht betrachtet. ${ }^{615}$ Doch die Metapher, die aus jenem Neuen erwächst, das aus der Überlappung der beiden genannten Bereiche - שבר I und לֶב - hervorgeht (zur Interaktionstheorie vgl. III Methodik 2.2.3), lässt eine Intensität und Dynamik erahnen, die weit über die Bedeutung des Schwindens von Mut hinausgeht. Nachdem das Zerbrechen ein Auseinanderbrechen von Teilen bis hin zur Vernichtung bezeichnet und dies auf das Innere des Menschen (לב) und alles damit Zusammenhängende übertragen wird, sind hier große Destruktivität, Gewalt, Dunkelheit und Vernichtung impliziert. Das Innere des Menschen und all das, was ihn ausmacht, werden zerbrochen, so wie z. B. Knochen zertrümmert wer-

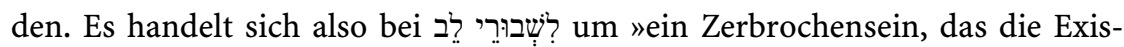
tenzmitte des Menschen betrifft «; $;{ }^{616}$ damit sind die so bezeichneten Menschen am Boden zerstört, ihre Lebenskraft und ihr Lebensmut sind völlig vernichtet und sie selbst von tiefer existenzieller Not getroffen. ${ }^{617}$ Sie sind von Entmutigung,

613 Knipping, שבר, 1029.

614 Vgl. Fabry, לֶ, 413-451. Goldingay, Psalms 3, 716 übersetzt an dieser Stelle mit »the broken in spirit«. Ebenso Rogerson / McKay, Psalms 101-150, 179.

615 Vgl. HALAT 4, 1303.

616 Risse, Gut ist es, 116.

617 נשברי־לב sie sind jene, die in eine Not geraten sind (Ps 34,18f.), es sind die Elenden (Ps 147,3; Jes 61,1), die Gefangenen und Gefesselten (Jes 61,1), jene, die von andern Schmach erleiden (Ps 69,21), es sind jene, die nicht am vollen Leben teilhaben." Bühlmann, Vom rechten Reden, 283. Vgl. die Verbindung von שבר in Jes 61,1; Jer 23,9; Ez ,69; Ps 34,19; 51,19 .»[Hiermit] ist das Volk zugleich in seinen einzelnen Gliedern gesehen« bei Sedlmeier, Jerusalem, 195. Häufig werden in Ps 147 jene, die zerbrochenen Herzens sind, auf die durch das Exil Betroffenen bezogen: "People both in Jerusalem and in exile had been broken in spirit and hurt, first by Jerusalem's fall and the exile itself, then by the ongoing broken-down 
Kummer und Niedergeschlagenheit gezeichnet. ${ }^{618}$ Dabei wird das Subjekt des Zerbrechens nicht genannt. Es ist also nicht bekannt, wer diese gewalttätige und ruinierende Tat begangen hat, wohl aber das Subjekt des Heilens: JHWH. ${ }^{619}$

Die schmerzvolle Erfahrung des Verletzt- und Zerstörtseins für die, deren Herz zerbrochen ist (3a), wird durch die Parallelsetzung mit ihren schmerzenden Wunden (3b) zusätzlich verstärkt. Eingebunden sind diese Phrasen mit den dunklen Assoziationen jedoch in die Aussagen des göttlichen Heilens und Verbundenwerdens (חבש umlegen, umbinden, verbinden). ${ }^{620} \mathrm{JHWH}$ handelt wie ein Hirte, der nicht nur seine Herde einsammelt (V2), sondern sich auch um die Wunden, Schmerzen, Nöte und Leiden seines Volkes kümmert, sich seiner annimmt, es versorgt und heilt. "Trost und Heilung ist damit den zerbrochenen Herzen widerfahren (V. 3). « ${ }^{621}$ Dabei sind mit עַצֶבֶת (Schmerzen, Wunden) nicht nur körperliche Leiden, sondern auch seelische Wunden gemeint. ${ }^{62}$ An dieser Stelle kann eine Verbindung zwischen der Darstellung der Gottheit als Ärztin für äußere Wunden und als Trösterin innerer Schmerzen ausgemacht werden. ${ }^{623}$ »Wenn Israel hier als versprengt [...], mut- bzw. kraftlos und verwundet [...] charakterisiert wird, klingen zwei Aspekte des Unheils an, dem JHWH ein Ende setzen will: Israel ist wie eine Herde, die einerseits ihrem Hirten weggelaufen ist und andererseits zugleich von wilden Tieren bzw. Räubern weggetrieben und verletzt wurde. Dieser Situation setzt JHWH ein Ende: Er sammelt die Versprengten, heilt die Verwundeten - und lässt sie wohnen im Schutzbereich seiner Stadt Jerusalem. $«{ }^{64}$ Die Tatsache, dass für die Darstellung der Taten Gottes Partizipien verwendet werden, macht die Taten des Heilens und Verbindens zu

state of city and community and by the ongoing pressures of life in exile.« Goldingay, Psalms 3,720 .

618 Vgl. Cohen, The Psalms, 472. "Eine Herzenswunde war Israels Mutlosigkeit und Heimweh im Exil« bei Herkenne, Das Buch der Psalmen, 451. »The heartbreak of exile (cf. 137:1-4) has been replaced by the healing comfort (cf. Hos 6:1; 7:1) of being home again « bei Allen, Psalms 101-150, 309. Seybold, Die Psalmen, 539: »die Brüche und Wunden sind seelischgeistige Traumata der wieder Vereinigten, wie aus dem Wort (לב) hervorgeht, und zwar der einzelnen (pl Suffix).«

619 »Woher das Leid rührt, wird nicht gesagt; ob es politische, wirtschaftliche oder soziale Ursachen hat, bleibt offen. Der Nachdruck liegt voll und ganz darauf, dass Gott heilen kann und will." Fohrer, Psalmen, 68.

620 »In der medizinischen Sprache bezeichnet $h b s ̌$ das Verbinden von Brüchen - eine Tätigkeit, die zur Sorge des Hirten für die Tiere seiner Herde gehört - (Ez 30,21, 34,4.16) und sonstigen Verletzungen (Jes 1,6; Ps 147,3; Hi 5,18 ...). Da das Verbinden immer auf Heilung gerichtet ist, kann das Verb auch die allgemeinere Bedeutung sheilen` annehmen (Jes 61,1).« Münderlein, חבר 727.

621 Lamparter, Das Buch der Psalmen 2, 374.

622 Vgl. Cohen, The Psalms, 472. Herkenne, Das Buch der Psalmen, 451 spricht von »(Seelen)wunden «.

623 Vgl. Brodersen, Schöpfungsaussagen, 55.

624 Hossfeld / Zenger, Psalmen 101-150, 830f. 
typischen Aktivitäten, die das Gottesbild in diesem Psalm prägen. ${ }^{625}$ Mit V2-3 kommt somit eine »Typisierung [... bzw.] Bündelung von Noterfahrung « ${ }^{626}$ zum Ausdruck. Es geht dabei um die Überwindung des Unheils, die in V13-14, in dem Heil in Fülle beschrieben wird, erfolgt ist. Und so kann auch das Lob JHWHs aus V1 über V2 hinweg bis zu V3 wirken und der Tatsache gelten, dass die Gottheit die Zerstreuten Israels sammelt, sie heilt und von ihrem Leiden befreit.

Der Vers kann durch die aus der Analyse von Psalm 30 bereits erwähnte doppelte Emotionalität charakterisiert werden. Da ist zunächst von Schmerzen, Wunden, dem Verletztsein, von Leid und Elend, existenzieller Not, Gewalt und Vernichtung, Entmutigung und Niedergeschlagenheit die Rede. Darüber aber stehen die göttliche Hinwendung und Zuwendung, das Verbunden- und Geheiltwerden, die Achtsamkeit des/der Heilenden. V3 wird auch dahingehend gedeutet, dass der Vers die Gefühle der Exilierten bei deren Rückkehr nach Jerusalem, das in Trümmern liegt, zum Ausdruck bringt. ${ }^{627} \mathrm{~V} 2-3$ sind insgesamt gekennzeichnet durch Not, Niedergeschlagenheit und Zerstreuung einerseits und andererseits durch die Emotionen der Geborgenheit und des Aufgehobenseins, der göttlichen Fürsorge und heilenden Zuneigung sowie das Thema des Neuanfangs. ${ }^{628}$

\subsection{Vers 4: JHWH und der Kosmos}

\section{$4 a$ Bestimmend eine Anzahl von Sternen, $4 b$ sie alle ruft er mit Namen.}

Der Vers bringt bildhaft zum Ausdruck, dass Gott nicht nur die Zahl der Sterne מנה kennt, sondern auch den Namen eines jeden einzelnen Sterns. ${ }^{629}$ Das Verb (abzählen, bestimmen) bezieht sich dabei auf ein zielgerichtetes Zählen bzw. auf ein genaues Abzählen. JHWH kennt und bestimmt die Anzahl der Sterne, wobei die Anzahl als genaues Ergebnis einer Zählung aufzufassen ist, die auf Vollständigkeit angelegt ist. ${ }^{630}$ (abzählend eine Zahl) stellt eine Hapaxlegomenon-Phrase dar. ${ }^{631}$ Diese bringt zur Sprache, dass sich die überragende

625 Vgl. Mays, Psalms, 443.

626 Sedlmeier, Jerusalem, 66f.

627 Vgl. Grogan, Psalms, 226.

628 »Die 1. Strophe (V1-6) hat tröstenden Charakter und setzt offensichtlich eine Notlage des Volkes voraus; denn Lob soll dem Gott gelten, der den Notleidenden hilft.« Fohrer, Psalmen, 68. Auf den tröstenden Charakter von V1-6 verweist auch Lamparter, Das Buch der Psalmen 2, 375.

629 Vgl. Alonso Schökel / Carniti, Salmos 2, 1651.

630 Vgl. Risse, Gut ist es, $129 \mathrm{f}$.

631 Vgl. Dahood, Psalms 3, 345. 
Macht und Größe Gottes beispielsweise in seiner Fähigkeit zeigt, die Sterne zu bestimmen und zu benennen. ${ }^{632}$ Was demnach für Menschen unmöglich ist (Gen 15,5), ist für Gott möglich. ${ }^{633}$ Überlegen ist die Gottheit Israels damit auch anderen Göttern. ${ }^{634}$ Dies unterstreicht nicht nur ihre Allmacht, sondern auch ihre Einzigkeit. ${ }^{635}$ Hinter dem jeweils neuen Bestimmen der Sternenanzahl - nicht in jeder Nacht ist dieselbe Anzahl von Sternen zu sehen - steht damit eher ein fortwährendes Walten Gottes in der Natur als ein ursprüngliches Schöpfungshandeln, das aber dahinter anklingt: »Die in Vers 4 zugrundeliegende Vorstellung ist demnach, dass JHWH allabendlich die Sterne herausführt, ihre Zahl zählt bzw. bestimmt und sie alle mit Namen ruft. Mitzuhören ist: JHWH hat diese Macht über die Sterne und dieses Wissen um die Sterne, weil er sie geschaffen hat. « ${ }^{636}$

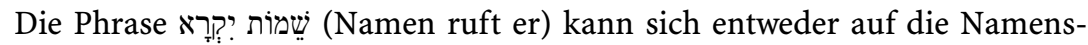
gebung beziehen, oder aber, was wahrscheinlicher ist, auf das Rufen der Namen, die bereits vorhanden sind. ${ }^{637}$ In jedem Fall werden damit die Verbundenheit Gottes mit der Schöpfung sowie seine persönliche Beziehung ausgedrückt. Das Weltall gehört dadurch zu Gott.

In V4 sind - im Gegensatz zu den vorhergehenden Versen - keine expliziten Emotionswörter zu finden. Allerdings sind implizite Emotionen aufzuspüren: Die Beschreibung der göttlichen Kenntnis der vielen für Menschen unzählbaren Sterne löst im Leseprozess Staunen und Bewunderung über die Macht und Größe Gottes aus, über die in V5 weiter nachgedacht wird. ${ }^{638}$ Die bildhafte Darstellung Gottes als Kenner der Sterne und deren Zahl und damit als Lenker des Univer-

632 Grogan, Psalms, 226 stellt an dieser Stelle einen Zusammenhang zwischen den Sternen und den Exilierten aus V2-3 her: JHWH kennt jeden einzelnen Exilierten. Ähnlich Vosberg, Studien, 93: »Dem `Rufen der Sterne entspricht das `Sammeln der Exilierten.» Die Sterne werden daneben als himmlisches Heer Gottes interpretiert. Vgl. dazu Alonso Schökel / Carniti, Salmos 2, 1650 mit Verweis auf Ex 12,41.51; Ri 5,20. Cohen, The Psams, 472, verweist darauf, dass Gott die Sterne zusammenruft bzw. einberuft, damit sie quasi auf Abruf zum Dienst erscheinen. Vgl. Jes 40,26.28. Dazu Lamparter, Das Buch der Psalmen 2, 375: »Ist doch das Heer der Sterne ein sichtbares Zeichen für die Allmacht und Treue des Herrn, sofern er sie herausführt mit starkem Arm, sie alle mit Namen nennt und keinen vergißt.» Des Weiteren gelten die Sterne wegen ihrer Unzählbarkeit als Bild für Segensverheißungen und Nachkommenschaft. Vgl. Sedlmeier, Jerusalem, 248.

633 Vgl. Anderson, The Book of Psalms 2, 945.

634 »To number the stars not only meant that Yahweh was supreme over the gods worshipped by other nations, but also that Yahweh directed the seasons of the year.« Stuhlmueller, Psalms 2, 215.

635 Vgl. Sedlmeier, Jerusalem, 247.

636 Risse, Gut ist es, 139.

637 Vgl. Risse, Gut ist es, 136. Herkenne, Das Buch der Psalmen, 451 drückt dies folgendermaßen aus: »Jahve weiß als Schöpfer genau Bescheid über die Zahl der für Menschen unzählbaren Sterne (Gn 15,5); er ruft sie sozusagen beim Namen, ein Beweis, dass er jeden Stern nach Wesen und Bestimmung kennt und sich um ihn kümmert. Ebensowenig wird einer aus seinem Volke von seiner liebevollen Fürsorge übersehen.»

638 Vgl. u. a. Risse, Gut ist es, 355. 
sums beeindruckt. Außerdem klingt das Thema der persönlichen Zuwendung und Fürsorge Gottes an, das dessen heilende Zuwendung aus V2-3 weiterführt und auf V8f vorverweist.

\subsection{Vers 5: Göttliche Größe}

5 a Groß ist unser Adonaj

$5 b$ und reich an Stärke,

$5 c$ für seine Klugheit gibt es keine Anzahl.

Das Thema der Größe Gottes aus V4 wird in V5 mittels einer theologischen Reflexion bildlos in einem Nominalsatz weitergeführt. Mit גָז (groß) begegnet im Psalm das nächste Adjektiv, das hier als Gottesprädikation gilt. Die Aussage, dass Gott groß ist, begegnet vor allem in hymnischen Texten der Zionstradition (z. B. Ps 48,2; 77,14; 99,2; 145,3) sowie hier in V5. ${ }^{639}$ Die Größe der Gottheit zeigt sich im Psalm durch ihre Tatkraft für Israel (V2-3; V6) und durch ihr Wirken in der Natur (V8f; 16-18). Hier wird deutlich, dass JHWHs Größe weniger als Eigenschaft beschrieben und gerühmt wird, sondern vielmehr als ein Tun, ein Ereignis. ${ }^{640}$ Darüber hinaus ist bei den Aussagen über die Größe Gottes erkennbar, dass es um die Größe JHWHs gegenüber anderen Göttern geht (Ps 95,3; $96,4 ; 135,5){ }^{641}$

Die Größe Gottes zeigt sich ebenso an seinem Reichtum an ᄁּ̇, einem Begriff, der zum Wortfeld der Kraft und Stärke gehört. כּ kann die Kraft des Menschen sein, wie etwa die physische Kraft Simsons (Ri 16,5.6.9.15.17.19.30), oder auch die Kraft eines Volkes (Jos 17,17) sowie die Lebenskraft (Ijob 3,17 spricht von »Krafterschöpften«). Beklagt wird häufig des Fehlen der Kraft (Ps 22,16; 1 Sam 2,9). Öfter ist die Rede von Gottes Kraft (Ex 15,6; Jes 40,26), vor allem in Verbindung mit der Schöpfung und mit dem Auszug aus Ägypten. Hier in V5 wird Kraft mit Weisheit bzw. Klugheit kombiniert. ${ }^{642}$ Und so geht es in V4-5 darum, die Größe und Macht Gottes zu demonstrieren. Dabei handelt es sich um »die weder durch andere Götter noch durch politische Mächte begrenzte oder begrenzbare Macht JHWHs bei der Weltenlenkung. « ${ }^{643}$ Mit der Wiederaufnahme von (Zại (Zahl, Anzahl) aus V4, hier in V5 in der Negation, wird die göttliche Klugheit und Einsicht als jene beschrieben, die ohne Maß bzw. unermesslich ist.

639 »In dem Satz: `Groß ist JHWH! dürfte also eine akklamatorische Formel enthalten sein, mit der die feiernde Gemeinde auf dem Zion sich zur Größe ihres Gottes bekannte.« Mosis, לד, 946.

640 Vgl. Risse, Gut ist es, 140.

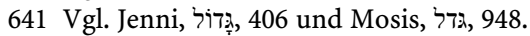

642 Vgl. Ringgren, חָּ, 135.

643 Hossfeld / Zenger, Psalmen 101-150, 831. 
Sie ist grenzenlos und kann nicht ver- bzw. bemessen werden. ${ }^{644}$ Die Verneinung des Bemessungsraumes für Gottes Klugheit wird auch auf die Fülle der göttlichen Weisheit bezogen. ${ }^{645}$ "Die Zahl der Sterne kann der Mensch nicht zählen, nur Gott kennt sie, weil er sie bestimmt [V4]. Die Weisheit JHWHs ist größer; für sie gibt es überhaupt keine Zahl. " ${ }^{66}$ V5 hebt damit "auf die Größe und Bedeutsamkeit Jahwes ab, die sich jedem Zugriff und Begriff entzieht. " ${ }^{647}$

Die bereits in V4 implizit im Leseprozess ausgelösten Emotionen der Bewunderung werden in V5 fortgeführt. Das Gottesbild wird dabei in für Menschen nicht erreichbare Dimensionen entrückt. Dabei beindrucken die Themen der göttlichen Größe und der Unerreichbarkeit, des Reichtums an Stärke, der Klugheit und Einsicht sowie der Einzigartigkeit JHWHs.

\subsection{Vers 6: Göttliches Aufrichten und Erniedrigen}

$6 a$ Aufrichtend JHWH die Gebeugten, $6 b$ erniedrigend die Frevler bis zum Boden.

Der Gegensatz zwischen den Gebeugten bzw. Elenden und Demütigen auf der einen Seite und den Frevlern und Verbrechern auf der anderen Seite ist in V6 dominant. Er steht somit im Vordergrund der Handlungen des Aufrichtens bzw. Aufhelfens (עוד) einerseits und der Erniedrigung (שפל) andererseits, die beide von JHWH ausgeführt werden. שפל bezeichnet entweder den Zustand des Niedrigseins (q.) oder die Tätigkeit des Niedrigmachens (hi.) wie hier in V6. »Dass im AT [...] Gott als Subj. der Handlung des Erniedrigens in den Mittelpunkt rückt, dürfte seinen Grund in der starken personalen Anbindung Israels an den einen Gott JHWH finden, der nicht nur als Garant der Ordnung, sondern auch als individuell eingreifender [...] Gott gilt. ${ }^{648}$

Objekte der Handlung des Niederdrückens sind die רְשִָׁעים (Schuldige, Frevler, Verbrecher, Gottlose), die in den meisten Belegen im Psalter als Gegner der Gerechten gelten und parallel zu den Feinden (Ps 3,8; 17,9; 55,4), Bösewichtern (Ps 26,5; 37,9f), Gewalttätigen (Ps 71,4; 140,5), Übeltätern (Ps 28,3; 92,8; 101,8), רששע Abtrünnigen (Ps 37,38) und Lügnern (Ps 58,4) usw. genannt werden. ${ }^{649}$ So ist »der Ausdruck für das negative Verhalten, für üble Gedanken, Worte und Werke, ein gemeinschaftswidriges Benehmen, das zugleich die innere Disharmonie und

644 Sie ist »beyond measure» bei Stuhlmueller, Psalms 2, 212.

645 Vgl. Sedlmeier, Jerusalem, 253.

646 Risse, Gut ist es, 34.

647 Sedlmeier, Jerusalem, 252.

648 Engelken, שֵָָׁל, 444.

649 Vgl. Ringgren, 679. 
Unruhe (Jes 57,20) eines Menschen verrät. ${ }^{650}$ Klara Butting bezeichnet die ausgehend von Ps 1 als Verbrecher »in Anzügen «, die mitten in der Gesellschaft stehen und sich über die Weisungen, die an Israel überliefert sind, hinwegsetzen. ${ }^{651}$ Gegenbegriffe zu den Frevlern sind, wie bereits erwähnt, die Gerechten, die gemeinschaftstreu handeln, sowie die Redlichen, die Weisen und auch die Armen und Gebeugten wie hier in V6. Viele betrachten V6 als Ausdruck der richterlichen Funktion JHWHs, wodurch den Armen bzw. Rechtlosen Hilfe zukommt, den Frevlern allerdings "ein niederschmetterndes Urteil zuteil wird (Ps 113,7f; 145,14; 146,8f; Jes 40,29; Lk 1,52). ॥ $^{62}$ Auf alle Fälle geht es um göttliche Gerechtigkeit, die für die Armen, die als Opfer der Frevler gelten, geschaffen werden soll. Dies geschieht durch die Befreiung aus Unterdrückung und - in diesem Fall - auch durch die Entmachtung der Gottlosen. ${ }^{653}$ "JHWHs Macht und Sinn richtet sich $[\ldots]$ auf die Durchsetzung von Recht und Gerechtigkeit: den rechtsschwachen `Niedrigen` (den Frommen) wird aufgeholfen, die `Frevler (Gottlosen) werden zu Boden gestoßen $(146,9 ; 20,9)$ - Vorstellungen, die aus der

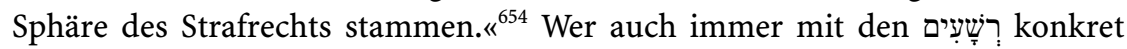
gemeint ist: Wie es in V2-3 um eine Typisierung einer Notsituation geht, so handelt es sich auch hier um einen Begriff, der "transparent [ist] auf die jeweiligen, die Existenz des Jahwevolkes gefährdenden Feinde hin. « $^{655}$ In V6 werden

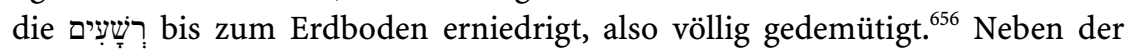
psychosozialen Dimension des Niedrigmachens, die durch das Verb thematisiert wird, klingt mit dem Lokalobjekt »bis zum Boden« auch noch die körperliche Dimension der Erniedrigung im Sinne des Niederdrückens, des Kauerns bzw. Am-Boden-Seins an.

Wenn im Kontrast dazu die Armen als Opfer der Frevler gelten, dann auch deshalb, weil sie von diesen unterdrückt, ausgebeutet und mit Gewalt bedrängt

650 Van Leeuwen, עשר 814.

651 Vgl. Butting, Erbärmliche Zeiten, 22. Ähnlich Sedlmeier, Jerusalem, 219. Er bezeichnet sie als "Opponenten gegen Jahwes Heilswirken und seinen gesellschaftlichen Willen [...].» An manchen Stellen wird versucht, die Frevler bzw. Gottlosen mit konkreten Personengruppen zu identifizieren, z. B. mit Fremdvölkern wie den Babyloniern, Persern oder mit der lokalen Macht, die Juda unterdrückt, oder auch mit innerisraelitischen oppositionellen Gruppen. Vgl. dazu Goldingay, Psalms 3, 721.

652 Kraus, Psalmen, 1137. Ebenso Groß / Reinelt, Das Buch der Psalmen, 432. »Im Hintergrund steht die Erwartung des Gottesgerichts, in dem Gott seine Gerechtigkeit durchsetzt, die für seine Getreuen Hilfe und Heil, für die Gottlosen aber das Ende bedeutet« bei Weiser, Die Psalmen 2, 558.

653 Vgl. Anderson, The Book of Psalms 2, 946; Alonso Schökel / Carniti, Salmos 2, 1652 und Hossfeld / Zenger, Psalmen 101-150, 829. "Yahwe relieves the oppressed« übersetzt Allen, Psalms 101-150, 304 6a.

654 Seybold, Die Psalmen, 540.

655 Sedlmeier, Jerusalem, 214 Anm. 123.

656 Vgl. Risse, Gut ist es, 168. 
werden: »Sie sind verfolgt, verleumdet, unschuldig angeklagt. ${ }^{657}$ Dahinter steht, dass diejenigen als arm bezeichnet werden, die rechtlos und mächtigen Gegnern ausgeliefert sind: "Die Bitte um Befreiung von Feinden ist somit zugleich Bitte um den Rechtsbeistand, der den Armen nach dem Gesetz zusteht, der ihnen aber von den übermächtigen Feinden verwehrt wird. ${ }^{658}$ Norbert Lohfink entdeckt das Armenthema nicht nur hier in V6 mit der Thematisierung der Hilfe für die Armen im Rechtsstreit. Da Krankheit ebenso ins Wortfeld der Armut gehört, findet sich die Armentheologie ${ }^{659}$ bereits in der Nennung der Heilung jener, die gebrochenen Herzens sind, und in der Aussage vom Verbinden der schmerzenden Wunden in V3. Außerdem wird das Armenthema in V9 mit dem Vieh und den jungen Raben mit ihrem Schrei nach Nahrung, der im Dtn als Schrei der Armen (Dtn 15,9; 24,15) seine Entsprechung findet, ausgeweitet. Hier in V9 steht der Aspekt des Hilflosen und Kleinen im Mittelpunkt. Dies ist ebenso in V11 der Fall: Die auf die Güte Gottes warten sind jene, »die keine Macht besitzen, die gewaltlos sind und ganz vom Vertrauen auf ihren Gott leben. ${ }^{660}{ }^{60}$ Wie V11 ist auch V6 gehalten:»Vers 6 ist [...] allgemein und zeitlos formuliert. Er ist Ausdruck der Überzeugung, dass JHWH zu allen Zeiten auf Seiten der Armen und Gebeugten steht - gegen ihre Gegner und Unterdrücker. ${ }^{661}$ Das Aufrichten der Armen und Gebeugten durch JHWH dürfte neben gesellschaftlichen Aspekten auch ökonomische besitzen. ${ }^{62}$ Die Personengruppe der Armen erfährt also im Text eine Erweiterung, sodass das ganze Volk Israel bezeichnet werden kann: »Mit einiger Sicherheit kann $[\ldots]$ angenommen werden, dass das hier vorgestellte Israel als ganzes mit den >Armen zu identifizieren ist. Dieses Israel kann sich auf seinen Gott verlassen und soll sich für ihn entscheiden. ${ }^{663}$

Bezüglich der Emotionen kann auch in V6 durch die kontrastive Darstellung des göttlichen Handelns im Sinne des Aufrichtens der Erniedrigten einerseits und der Erniedrigung der Verbrecher andererseits von einer doppelten Emotionalität gesprochen werden: Den Beginn prägt die Erleichterung, die Rettung und Befreiung, das Durchatmenkönnen und Aufgerichtetwerden, am Schluss ist eindrucksvoll und verstärkt von totaler Demütigung ${ }^{664}$ und Erniedrigung und somit von den Emotionen der Kränkung und Herabwürdigung die Rede. Durch

657 Sedlmeier, Jerusalem, 178.

658 Sedlmeier, Jerusalem, 178.

$659 \mathrm{Zu}$ Entwicklungslinien armentheologischer Aussagen im Psalter und besonders zur Armentheologie im 5. Psalmenbuch vgl. Bremer, Wo Gott sich auf die Armen einlässt, $408 \mathrm{f}$. 447-454.

660 Lohfink, Lobgesänge, 119.

661 Risse, Gut ist es, 168.

662 Vgl. Hossfeld / Zenger, Psalmen 101-150, 832.

663 Ballhorn, Telos, 312. Vgl. ebd. S. 314.

664 "Hasta el polvo« [bis zum Staub - Übersetzung S. E.] bei Alonso Schökel / Carniti, Salmos 2, 1646. 
die verwendeten Begriffe werden ebenso die Themen der göttlichen Gerechtigkeit, der Hilflosigkeit, Ausbeutung und Unterdrückung zur Sprache gebracht, die vor allem mit den Armen/Unterdrückten verbunden sind, wie auch das gemeinschaftswidrige Verhalten und die Gewalttätigkeit und Ausbeutung, die mit den Frevlern assoziiert werden. Im V6 wird das Verhalten der Verbrecher nun auf diese selbst angewandt. Die Allmacht (oder auch Willkür) sowie Stärke Gottes und dessen richterliches Tun stehen dabei im Zentrum.

\subsection{Vers 7: Aufruf zum Lobpreis}

7a Besingt JHWH mit einem Danklied,

$7 b$ spielt unserem Gott auf der Leier.

Mit den beiden Imp.pl. und damit der direkten Anrede an eine Öffentlichkeit endet die Rede über JHWH in der 3.P. (V2-6). Hier beginnt der zweite Teil des Psalms, in dem das lyrische Wir mit der Bezeichnung »unser Gott « wieder stärker in den Vordergrund tritt.

Die Wurzel ענה bezieht sich in 7a auf das seltene ענה IV (besingen, ein Lied anstimmen, einen Wechselgesang singen). ענה I ענה (antworten) übersetzen an dieser Stelle nur wenige; diese Bedeutung kann aber mitklingen. ${ }^{666}$ Mit dem Begriff תרוֹדָה (Dankopferlied, Dankpsalm; siehe auch die Analyse zu Ps 30) wird auf die Haltung der Dankbarkeit verwiesen. Der Vers vermittelt somit durch den Lobaufruf Freude und Dankbarkeit, die nicht nur vokal, sondern auch instrumental, und zwar mit der Handleier, ihren Ausdruck suchen. ${ }^{667}$ Auf der Ebene der Syntax ist durch den parallelen Aufbau der Halbverse sowie durch die Wiederholung der gleichen syntaktischen Form ein größerer Nachdruck auf dem Aufruf zum Gotteslob auszumachen. ${ }^{668}$ So gilt für Ps 147 insgesamt: „Der Dichter will Gefühle der Dankbarkeit erwecken, ohne aber eine leise Mahnung zur Treue gegen Jahve zu unterlassen (V. 6. 10f.). « ${ }^{69}$

Analog zum Lobaufruf in 1a sind in V7 der zeitdeckende Aspekt der Anreden sowie die Emotionen der Freude und der Dankbarkeit zentral. Das vokale und instrumentale זמר (singen, spielen) aus 1a (vgl. auch die Analyse zu Ps 30) wird

665 Vgl. GES 989f; Hossfeld / Zenger, Psalmen 101-150, 832. Vgl. Ps 88,1; 119,172.

666 Z. B. ZUR; Weiser, Die Psalmen 2, 557; Allen, Psalms 101-150, 304 und Hupfeld, Die Psalmen, 671.

667 »Im Lobpreis des Höchsten weitet sich der Blick und das Herz, Danken macht froh und beim lieblichen Klang der Harfen (V.7), von dem der Lobpreis begleitet ist, geschieht's, dass sich `Leib und Seele freuen in dem lebendigen Gott $\iota($ Ps 84,3). « So bei Lamparter, Das Buch der Psalmen 2, 374.

$668 \mathrm{Vgl}$. Risse, Gut ist es, 35.

669 Herkenne, Das Buch der Psalmen, 450. Ähnlich Lamparter, Das Buch der Psalmen 2, 374. 
hier wieder aufgegriffen. Mittels der Imperative wird zur Freude aufgefordert. Es soll also in erster Linie diese Emotion hervorgerufen werden.

\subsection{Vers 8: Gott und die Schöpfung}

8 a Er bedeckend den Himmel mit Wolken, $8 b$ er bereitend der Erde Regen

$8 c$ er wachsen lassend auf Bergen Gras.

Mit V8 beginnt der nächste Abschnitt, in dem JHWH charakterisiert wird (V8-11). Dieses synthetische Trikolon fällt mit seinen drei Stichen aus der Reihe der sonst gleichmäßig gestalteten Bikola des Psalms heraus. Im Zentrum des Verses steht Gottes Schöpfungshandeln durch den Regen. 8a führt als indirektes Objekt die Wolken an. עָ bezieht sich prinzipiell auf eine dichte Regenwolke, die - metaphorisch verwendet etwa im Kontext von Theophanien - auch als Kleid Gottes erscheint (2 Sam 22,12 par. Ps 18,12). Die Wolken bewegen sich mit Leichtigkeit fort. Außerdem sind sie schnell. Meteorologisch betrachtet führen die Wolken zum Regen, der hier als göttliche, lebenserhaltende Segensgabe gilt. ${ }^{670}$ So beschreibt $8 \mathrm{a}$ die meteorologische Vorbereitung und Entstehung des Regens (Wolken), 8b den Regen selbst und 8c das Ergebnis des Regens (Gras auf den Bergen entspricht dem Wachstum) ${ }^{671}$ Von zentraler Bedeutung ist dabei, dass JHWH - und nicht etwa Baal - den Regen spendet, wodurch Fruchtbarkeit entsteht und im kahlen Gebirge Gras wachsen kann. ${ }^{672}$ Der Regen ist insbesondere für die Berge wichtig, die von den Menschen nicht kultiviert werden, da es hier weder künstliche Formen der Bewässerung noch Flüsse gibt. ${ }^{673}$ So ist der intensive Regen (מָָָָ), der nach Monaten der Trockenheit einen grünen Mantel über den bloßen Erdboden legt, das Werk JHWHs. ${ }^{674}$ An anderen Stellen tritt er, wie auch die bereits erwähnten Wolken, zusammen mit Blitz und Donner als Begleiter JHWHs auf (Ex 9,33f). Regen ist

670 Vgl. Staubli, Begleiter, 18. Es könnte sich hier um den Frühregen im Herbst handeln und deshalb in V15-18 um die Winterkälte und den Regen im Frühjahr. Vgl. Lohfink, Lobgesänge, 116 .

671 Vgl. Limburg, Psalms, 497.

672 Vgl. Kraus, Psalmen, 1137 und Anderson, The Book of Psalms 2, 946. »An seiner Macht, Regen zu spenden, zeigt Jahwe seine Überlegenheit über Baal (1 Kön 18,1.35f), die Götzen und deren Bilder (Jes 30,22f). «Sedlmeier, Jerusalem, 265. Und weiter: »Neben den `Wolken und dem $>$ Regen standen in alttestamentlicher Zeit auch die fruchtbaren Berge und die strotzenden Höhen mit dem Baalskult in Verbindung. So könnte auch hier noch einmal die umfassende und alleinige Wirksamkeit Gottes im Bereich der Natur affirmiert sein. Die in der Umwelt Israels Baal oder Hadad zugeschriebene, überschwängliche Fruchtbarkeit des Landes ist demnach ausschließlich das Werk Jahwes, der Schöpfer und Ernährer zugleich ist.« Sedlmeier, Jerusalem, $271 \mathrm{f}$.

673 Vgl. Hossfeld / Zenger, Psalmen 101-150, 833.

674 Vgl. Allen, Psalms 101-150, 310. 
im hier untersuchten Vers ein Symbol der Lebensfülle (siehe dazu auch Ps 72,6) und des Wachstums; ohne Regen ist Leben nicht möglich (Gen 2,5). Die Ambivalenz von potenziell zerstörerischem $($ Gen 7,4$)$ Wolkenbruch und Dauerregen und dem Ausbleiben des Regens in Form der Dürre kommt hier nicht zur Sprache. ${ }^{675}$ JHWH als Geber des Regens gilt hier also vor allem als Quelle des Lebens. ${ }^{676}$ Mit dem Verb כון klingt außerdem die Festigkeit des Schöpfungswerkes und JHWHs Zuverlässigkeit an. ${ }^{677}$

Das Gras, das durch den gottgewirkten Regen wächst, dient dann als Nahrung für die Tiere (9a) ${ }^{678}$ Hier klingt bereits JHWHs Fürsorge an, die in V9 entfaltet wird: »Er spendet der Erde Regen, und durch den Regen schafft er Nahrung für die Tiere, bis hin zu den geringsten, die am meisten der Fürsorge bedürfen. « ${ }^{679}$

Neben den Themen der Schnelligkeit und Leichtigkeit (Wolken), der Verlässlichkeit Gottes (כון) und dessen Größe in der Natur, der Segensgabe, Fruchtbarkeit und Lebensfülle wird auf der Ebene der Emotionen die Zuwendung JHWHs zur Schöpfung betont. Wachstum wird durch Gott ermöglicht; von der möglichen Bedrohung etwa in Form von zu geringer oder zu großer Regenmenge ist nicht die Rede.

\subsection{Vers 9: Göttliches Füttern}

9a Gebend dem Tier seine Nahrung

$9 b$ den jungen Raben, wonach sie rufen.

9a nimmt mit (Vָּהָמָה (Vieh, Getier) ${ }^{680}$ allgemein sowohl wilde als auch domestizierte Tiere in den Blick, wohingegen 9b mit dem Ausdruck »Jungen der Raben« konkreter und spezifischer wird. ${ }^{681}$ Es handelt sich hier um die Tiere, die am

675 Vgl. Risse, Gut ist es, 146.

676 Vgl. Sedlmeier, Jerusalem, 277.

677 »In Ps 147,8 wird mit dem Verb die Verlässlichkeit von JHWHs Handeln betont: Dass er der Erde Regen bereitet und dadurch den Tieren Nahrung, darauf ist Verlass." Risse, Gut ist es, 147.

678 Vgl. Risse, Gut ist es, 22.

679 Risse, Gut ist es, 145.

680 GES 127f. Der Begriff wird dabei häufiger für domestizierte als für wilde Tiere verwendet. Vgl. Anderson, The Book of Psalms 2, 946.

681 Der Relativpartikel אֶׁשֶׁ kann in diesem Vers in dreierlei Weise wiedergegeben werden. Erstens als Subjektsatz: ... Rabenjungen, die schreien; so z. B. bei Weber, Werkbuch 2, 373; Herkenne, Das Buch der Psalmen, 451; Weiser, Die Psalmen 2, 557; Stuhlmueller, Psalms 2, 213; »die zu ihm rufen « bei Lamparter, Das Buch der Psalmen 2, 373 und Hossfeld / Zenger, Psalmen 101-150, 824. Zweitens als Objektsatz: ... Rabenjungen, wonach sie schreien; so z. B. bei Sedlmeier, Jerusalem, 18; Kraus, Psalmen, 1134; Groß / Reinelt, Das Buch der Psalmen, 432. Drittens als Temporalsatz: ... Rabenjungen, wenn sie schreien; so z. B. bei Miller, Die Psalmen, 252; Seybold, Die Psalmen, 538; Limburg, Quoth, 102 und Goldingay, Psalms 3, 716. 
bedürftigsten und hilflosesten sind ${ }^{682}$ Nicht alleine, dass sich ihre Nester an desolaten Orten befinden, sondern ihr Futter ist karg und nur spärlich vorhanden, und es muss über weite Gebiete hinweg gesucht und beschafft werden. ${ }^{63}$ Parallele Verwendungen finden sich etwa in Ijob 38,41, wo die jungen Raben zu Gott schreien, sowie bei der Wiederaufnahme des Motivs in Lk 12,24. Das Schreien, Rufen (קרא) oder Krächzen der Rabenjungen, das nur vereinzelt von Tieren in der Subjektposition ausgesagt wird und im Sinne der Kommunikationsaufnahme zu verstehen ist (vgl. Analyse Ps 30,9), wird hier neben dem Ausdruck als Hunger auch als »Gebet « der Rabenjungen zu Gott verstanden. ${ }^{684}$ "Das קרא in dieser Stelle entspricht dem 4. Beide Male steht es betont am Versende. In Vers 4 ruft JHWH seine Geschöpfe, in 9 rufen seine Geschöpfe zu ihm. Dass die jungen Raben zu JHWH rufen, wird zwar in Ps 147,9 nicht ausdrücklich gesagt, ist aber durch die Bezugsstelle Ijob 38,41 gegeben. Damit schimmert wieder das eigentliche Anliegen durch: JHWHs Fürsorge für die Gottesfürchtigen, die zu ihm rufen. ${ }^{685}$ Mit Hilfe dieses Bildwortes wird die äußerst gütige Fürsorge JHWHs deutlich gemacht: Die Rabenjungen gelten als unreine Tiere (Lev 11,15; Dtn 14,14), und unter anderem wegen ihrer krächzenden, unangenehmen Stimmen werden sie wenig geschätzt und gelten zudem als nutzlos. Gerade diesen Tieren wendet sich die Gottheit in behutsamer Weise $\mathrm{zu}^{686}$ Der Vers will damit »JHWH als großzügigen Geber und Ernährer darstellen [...], der umsonst gibt. ${ }^{687}$ Als Brotgebender (נוֹתֵן לֶחֶם) gilt JHWH bereits in den Erzelternerzählungen und in den Erzählungen über den Auszug aus Ägypten (Ex 16,8.15.29; Ps 78,20.25; 105,40); darin spiegelt sich die kollektive Erfahrung eines lebenserhaltenden Gottes wider. ${ }^{688}$ Von JHWH als Geber von לֶ für Tiere ist allerdings im AT selten die Rede (Spr 6,8; 30,25; Jes 65,25; Ps 136,25). Deshalb stellt sich die Frage, ob der Gebrauch von לֶֶ in diesem Zusammenhang nicht bereits auf die menschliche Sphäre verweist. In diesem Vers könnte sich somit eine Steigerung verbergen: Wenn Gott schon für die geringsten unter den Tieren sorgt, wieviel mehr dann für sein Volk ${ }^{689}$ Mit den Raben klingt daher ein Bildwort

Als Anschluss im Sinne sowohl des Subjekts als auch des Objekts übersetzt Schlögl, Die Psalmen, 227: "Den jungen Raben, die darum schreien.» Aber auch die folgende Form der Wiedergabe lässt sich finden: » ... Raben, wenn sie zu ihm schreien.« Ketter, Die Psalmen, 195. Aufgrund der parallelen Konstruktion in 9a mit לֶ? (Nahrung) als indirektem Objekt gebe ich אֶֶׁׁ ebenso als Objekt (wonach) wieder, also auf die zweite der genannten Weisen.

682 Vgl. Limburg, Quoth, 104.

683 Vgl. Cohen, The Psalms, 473.

684 Vgl. Anderson, The Book of Psalms 2, 946.

685 Risse, Gut ist es, 94.

686 Vgl. Hossfeld / Zenger, Psalmen 101-150, 833.

687 Hossfeld / Zenger, Psalmen 101-150, 833.

688 Vgl. Sedlmeier, Jerusalem, 273.

689 Vgl. Grogan, Psalms, 226; Hossfeld / Zenger, Psalmen 101-150, 833 und Risse, Gut ist es, 388. 
für die Menschen an, auf die sich V6 zurückbezieht und im Folgenden auf V10f verweist: Die auf Hilfe angewiesenen Rabenjungen sind ein Bild für die Armen (V6). Im Kontrast dazu stehen die mächtigen Schlachtrosse in V10. ${ }^{690} "$ In ihrem Krächzen nach Futter spiegelt sich der Hilfeschrei der JHWH-Fürchtigen [V11]. ${ }^{691}$ Der Schrei der Rabenjungen wird damit auch analog zum Schrei Israels nach Hilfe betrachtet. ${ }^{692}$ Innerhalb des Psalms kann mittels zwischen den Rabenjungen (Tieren) und den Kindern bzw. Nachkommen (Menschen) in 13b hergestellt werden. ${ }^{693}$ Zusammenfassend lässt sich festhalten:

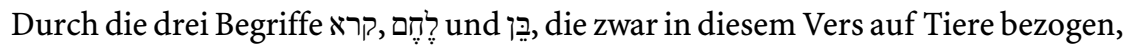
jedoch meist von Menschen ausgesagt werden, klingt bereits JHWHs fürsorgliches Handeln an den Menschen an, das in den folgenden Versen entfaltet wird.

Hinter den Emotionen der göttlichen Fürsorge, Zuwendung und behutsamen Versorgung klingen vor allem durch das Bildwort der jungen Raben die Aspekte der Bedürftigkeit, Hilflosigkeit sowie die Emotion der Verachtung an. Die wenig geschätzten Rabenjungen können sich nicht selbst versorgen und sind auf $\mathrm{Zu}$ wendung angewiesen.

\subsection{Vers 10: Göttliche Ablehnung}

10a Nicht an der Stärke des Pferdes hat er Gefallen, $10 b$ nicht an den Schenkeln des Mannes hat er Wohlgefallen.

V10 thematisiert die göttliche Ablehnung irdischer, menschlicher Macht und Stärke, die sich vor allem in der Macht zur Verteidigung, in militärischer Macht und in der Kraft des Helden zeigt. Dabei kommt vor allem in der Negation des finiten Verbs חתפ, durch das »die ganze Emotionalität der göttlichen Zuwendung zur Sprache komm[t] «"694, eine starke Ablehnung zum Ausdruck. Scharf abge-

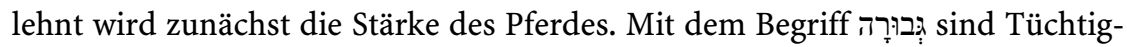
keit, Stärke und Überlegenheit gemeint: »Als besonderer Anwendungsbereich ist der Krieg zu nennen, in dem die eigene Überlegenheit betont oder die der Feinde zugestanden wird. « ${ }^{65}$ Das Pferd steht für militärische Fähigkeit und wird als

Es könnte auch sein, dass die Annahme bzw. die sogenannte »Rabenelternfabel«, wonach die Rabeneltern ihre Jungen hungern lassen bzw. verlassen (was faktisch aber nicht der Fall ist), auch in Palästina gegolten hat: Die Rabenjungen sind von ihren Eltern verlassen, aber Gott kümmert sich um sie. Vgl. Rogerson / McKay, Psalms 101-150, 182.

690 Vgl. Weber, Werkbuch 2, 375.

691 Weber, Werkbuch 2, 376.

692 Vgl. Mays, Psalms, 442.

693 Vgl. Brodersen, Schöpfungsaussagen, $61 \mathrm{f}$.

694 Sedlmeier, Jerusalem, 229.

695 Sedlmeier, Jerusalem, 223. 
Kampfmittel zur menschlichen Machtentfaltung eingesetzt. ${ }^{696}$ Neben dem Kriegspferd in 10a sind mit den Schenkeln des Mannes in 10b, die unter anderem auf Schnelligkeit, Kraft und Standfestigkeit hindeuten, ${ }^{697}$ die Schenkel des Kriegers sowie die Rüstung der Kriegsreiter und der Soldaten angesprochen. ${ }^{698}$ "JHWH hat kein Gefallen an arroganter, terrorisierender Macht, als deren Paradigmen die Kriegsrosse $[\ldots]$ und die prachtvoll gerüsteten Soldaten $[\ldots]$ genannt werden. ${ }^{699}$ Auch wenn im Text von der prachtvollen Rüstung der Soldaten nicht die Rede ist - diese in V10 thematisierte Macht ist nicht nur für den Krieg von Bedeutung, sondern soll den Glanz der staatlichen Macht repräsentieren. ${ }^{700}$ Von all dem will JHWH nichts wissen - im Gegenteil: „Seine Fürsorge gilt denen, die gottesfürchtig sind und im Gefühl des eigenen Unvermögens und im Anerkennen ihrer Abhängigkeit vertrauensvoll seine Huld erwarten. $\aleph^{701}$ Das Bildwort von den Rabenjungen aus V9 wird hier in V10 aufgenommen und in V11 weitergeführt. ${ }^{702}$ Menschliche rohe Kraft und Stärke sowie militärische Machtapparate und Schnelligkeit sind also zu verneinen. Vielmehr geht es, wie der folgende Vers beschreibt, um die "geistige Macht der Gottesfurcht u. des Gottvertrauens. ${ }^{703}$

Auf der Ebene der Emotionen ist hier die Ablehnung zu nennen, die durch eine zweimalige Verneinung verstärkt wird. Menschliche Überlegenheit, Macht, Stärke und Schnelligkeit spielen in diesem Vers thematisch eine wichtige Rolle.

\subsection{Vers 11: Göttliches Wohlgefallen}

11a Wohlgefallen habend JHWH an denen, die ihn fürchten, $11 b$ an denen, die Wartenden auf seine Huld/Güte.

Die Negation in V10 hat eine vorbereitende Funktion für V11, indem sie zu dem hinführen soll, was JHWH nicht ablehnt, sondern mit Wohlgefallen annimmt. ${ }^{704}$

696 Vgl. Goldingay, Psalms 3, 722 und Risse, Gut ist es, 170.

697 Vgl. Hupfeld, Die Psalmen, 676; Sedlmeier, Jerusalem, 228 und Risse, Gut ist es, $170 \mathrm{f}$.

698 Vgl. Hossfeld / Zenger, Psalmen 101-150, 833.

699 Hossfeld / Zenger, Psalmen 101-150, 833.

700 Vgl. Risse, Gut ist es, 171.

701 Groß / Reinelt, Das Buch der Psalmen, 433.

$702 »$ V. 9b enttäuscht die jungen Raben nicht, die ihn um Futter rufen. Der gleiche Gedanke kehrt in V. $10 \mathrm{ff}$ auf die Menschen bezogen wieder: V. 11 Gott enttäuscht die nicht, die auf seine Treue warten (V. 6!). Enttäuschung wird befallen, die auf die Kraft der Pferde bauen (V. 10).« Vosberg, Studien, 95.

703 Hupfeld, Die Psalmen, 676. "Die Erfahrung, dass Pferde und Reiterei letztlich keinen Bestand verleihen, sondern dieser nur in Jahwe zu finden ist, hat sich in vielen biblischen Texten niedergeschlagen.« Sedlmeier, Jerusalem, 225.

704 Vgl. Sedlmeier, Jerusalem, 231. 
Wie die Analyse von Ps 30,6 bereits gezeigt hat, besitzt die Wurzel רצה eine große Bedeutungsvielfalt, die von Gefallen über das wohlgefällige Betrachten bis hin zum Gernhaben und Lieben reicht. JHWH ist also jenen mit Gefallen und Liebe zugewandt, die ihn fürchten und seiner Huld harren. Damit wird explizit eine Emotion Gottes zum Ausdruck gebracht. Dies stellt in Ps 147 eine Seltenheit dar, zumal Emotionen, die Gott zugeschrieben werden können, bisher implizit ausgedrückt wurden.

Mit dem Verbaladjektiv יָרָ m.pl.constr. mit substantivierter Bedeutung kommt ein weiteres Eigenschaftswort ins Spiel, das hier den für die Psalmen typischen Ausdruck der »JHWH-Fürchtigen « markiert und damit jene Gemeinde bzw. Verehrer JHWHs bezeichnet, die auch JHWH-Treue bzw. Fromme genannt werden. ${ }^{705}$ Damit wird in erster Linie die Zugehörigkeit zu JHWH ausgedrückt. ${ }^{706}$

Die Wurzel ירא q. (sich bzw. jem. / etw. fürchten) umspannt die gesamte Bedeutungsbreite der Emotion Angst und reicht "von vitaler Angst angesichts alltäglicher Bedrohungen, Furcht vor numinosen Kräften und Mächten bis hin zur Gottesfurcht in ihrer sehr differenzierten Ausprägung. ${ }^{707}$ Der Gottesfurcht, ohne Zweifel eine zentrale Kategorie des AT, »eignet eine innere Polarität von Erschrecken, Zurückweichen, Flucht und Hinwendung, Vertrauen, Liebe, insofern das Numinose als `tremendum`zwar, zugleich aber als ıfascinosum ‘ [...] erfahrbar wird. [...] Indem das Moment eigentlicher Furcht zurücktritt, wird Gottesfurcht >Äquivalent für Religion und Frömmigkeit` [...], d. h. wird Gottesfurcht zu einem Synonym für Gottesverehrung, Gottesdienst, Gehorsam gegenüber den Weisungen Gottes. ${ }^{708}$

Die Gottesfürchtigen, also jene, die auf Gott vertrauen und an ihn glauben, werden in diesem Vers mit denen parallelisiert, die auf Gottes דֶֶֶ warten. Mit wird ein besonderes zwischenmenschliches Verhalten bezeichnet, das über das Selbstverständliche und Pflichtmäßige hinausgeht, das in konkreten Situationen geschieht und als Voraussetzung dafür gilt, dass eine Gemeinschaft überhaupt zustande kommen kann. Der Begriff hat also sowohl Tat- als auch Gemeinschaftscharakter und steht für Beständigkeit. חֶֶ wird von einem Menschen an einem anderen getan bzw. erwiesen oder auch von einem Menschen erhofft oder erbeten. ${ }^{709}$ bezeichnet »nicht nur eine menschliche Gesinnung, sondern stets

705 Vgl. Stähli, ירא, 775.

706 Vgl. Fuhs, יריז

707 Fuhs, יריר, 874.

708 Fuhs, just a question of worshiping him or having an emotional attachment to him, but of trusting him and obeying him [...].»

709 Vgl. Zobel, 70 , 56. Der Begriff kommt im AT 245x vor, davon 127x in den Psalmen und ist somit hauptsächlich in der Sprache der Psalmen verankert. Laut Jacobson / Jacobson, Invitation, $152 \mathrm{ff}$. ist die göttliche חֶֶ die grundlegende theologische Annahme, die hinter allen 
auch die aus dieser Gesinnung fließende Tat. Sie ist lebenserhaltend oder lebensfördernd. Sie ist Einsatz für einen von Unglück oder Not betroffenen Menschen. Sie ist Freundschafts- oder Pietätserweis. Sie verfolgt das Gute und nicht das Böse. ${ }^{710}$

Die Wiedergabe des Begriffs mit den drei Merkmalen der Gesinnung bzw. inneren Haltung, der Tat und des Gemeinschaftscharakters reicht daher von Gnade, Güte, Freundlichkeit, Huld über den guten Willen, der zur guten Tat wird, bis hin zur Großherzigkeit. In den Psalmen ist meist von der חֶֶ Gottes die Rede. Diese beschreibt die Bereitschaft Gottes, sich für den Menschen einzusetzen, die Zuwendung Gottes (Ps 13,6; 52,10). ${ }^{711}$ Die חֶ Gottes ist eine Tat der Macht, des Heils, der Hilfe, des Rechts und der Gerechtigkeit, in der sich die göttliche Freundlichkeit und das Erbarmen ausdrücken. Diese Handlung Gottes zeugt von Dauerhaftigkeit, Beständigkeit und Verlässlichkeit. ${ }^{72}$ Hier in V11 werden in einem synonymen Parallelismus die Gottesfürchtigen mit denen gleichgesetzt, die auf seine חֶֶ warten. ${ }^{713}$ Hans-Joachim Kraus setzt an dieser Stelle Gottesfurcht und Hoffnung als synonyme Begriffe. ${ }^{714}$ Für den Vers gilt also: „Entscheidend sind Gottesfurcht und unverbrüchliches Vertrauen auf Gottes Eingreifen. [...] Gott hat kein Gefallen an menschlicher Macht, sondern daran, dass Israel auf die Macht Gottes vertraut und auf sein Eingreifen wartet. " $" 15$

Der Vers ist von hoher Emotionalität geprägt, zumal große Gefühle durch explizite Emotionswörter angesprochen werden. Da ist zunächst vom göttlichen Wohlgefallen und der göttlichen Zuwendung und Liebe die Rede. Der Begriff "Gottesfürchtige« impliziert wiederum eine doppelte Emotionalität, wobei die Emotionen des Erschreckens, der Angst und Furcht in den Hintergrund treten und den Emotionen der Ehrfurcht, des Respekts, des Zugehörigkeitsgefühls, der Verehrung und des Vertrauens Platz machen. Daneben werden die Langsamkeit, Geduld und Hoffnung der Wartenden und damit die Emotion der Erwartung, sowie schlussendlich auch die göttliche Zuverlässigkeit, Freundlichkeit und Güte zum Thema gemacht.

Psalmen steht. Der Psalter stellt damit das Bild eines Gottes »of loving faithfulnes (חֶֶָ)《 ins Zentrum (S. 152).

710 Zobel, $70 \pi$ חֶ, 56.

711 Vgl. Stoebe, $70 \pi, 601.617 \mathrm{f}$.

712 Fohrer, Psalmen, 66 übersetzt mit »Verbundenheit«. »Loyalität« bei Sedlmeier, Jerusalem, 232.

713 Vgl. Zobel, 6 , 69.

714 Vgl. Kraus, Psalmen, 1137. Von Hoffnung sprechen ebenso Goldingay, Psalms 3, 716 sowie Limburg, Psalms, 496.

715 Fohrer, Psalmen, 70. Die Gottesfürchtigen aus V11 sind demnach im Gegensatz zu V10 jene "Krieger Gottes«, die in den Augen Gottes Wohlgefallen finden. Vgl. Cohen, The Psalms, 473. 


\subsection{Vers 12: Lobaufforderung an Jerusalem}

12a Rühme, Jerusalem, JHWH,

$12 b$ lobe deinen Gott, Zion.

Mit der Aufforderung an Jerusalem bzw. Zion, Gott zu loben und zu preisen, beginnt der dritte Abschnitt des Psalms. Zion bzw. Jerusalem werden hier synonym verwendet. Die Stadt soll JHWH rühmen und loben (הלל, vgl. dazu V1.20), und zwar grundsätzlich wegen JHWHs Größe, Fürsorge und Güte sowie seiner Hilfe für die Armen und Gebeugten, wovon der Psalm in V1-11 erzählt. Das Lob Gottes gilt hier in V12 ganz speziell dem Aufbau Jerusalems, dem Schutz und Frieden für die heilige Stadt. ${ }^{716}$ Das Loben wird durch den Kausalsatz in V13 und durch die Darstellung in V14 mit JHWHs Schutz, Hilfe und Frieden begründet. ${ }^{717}$

Jerusalem und Zion werden durch die Anrede im Vokativ personifiziert und treten als handelnde Subjekte auf. ${ }^{718}$ Jerusalem bzw. Zion treten vor allem im Jesajabuch als Personifikationen auf (z.B. Jes 40,9; 44,26; 49,14-26; 51,17-23; 52,1-2.7-9; 54; 66; aber auch Zef 3,14-18). Dieses Sprachbild der Vermenschlichung aktiviert in diesem Fall die menschliche Erfahrung des Gotteslobes. Wie bereits in der Analyse zu Ps 30,10 erörtert, ist die Preisung Gottes den lebenden Menschen vorbehalten - Tote können Gott nicht mehr loben - und gehört zu einem lebendigen Dasein unbedingt dazu. Der Lobaufruf erfordert auf Seiten der Angeredeten eine Form von Reaktion und Antwort. Auch dies ist eine Handlung, die nur von Menschen erwartet werden kann. So trägt das Sprachbild der Personifikation aufgrund der Evokation menschlicher Erfahrungen prinzipiell zur Möglichkeit der Identifikation bei (vgl. III Methodik 2.2.3). Im Zentrum des Verses steht der Aufruf zum Lob als Ausdruck dankbarer Freude und Jubels und hat existenzielle Bedeutung. Die Jubelstimmung und die Emotion der Freude sollen entfacht werden.

\subsection{Vers 13: Göttliche Stärke und göttlicher Segen}

13a Denn er hat stark gemacht die Riegel deiner Tore, $13 b$ er hat gesegnet deine Kinder in deiner Mitte.

716 Vgl. Ringgren, הלל, 438.

717 Vgl. Ringgren, הלל 438.

718 "So erscheint Jerusalem / Zion als die Jahwe auf sein Heilshandeln hin antwortende Person.» Sedlmeier, Jerusalem, 292. Ders., Jerusalem, 15 weist darauf hin, dass sich in Ps 147,2.12 die letzten beiden Belege von Jerusalem innerhalb des gesamten Psalters finden lassen. In V12 findet sich das letzte Vorkommen des Doppelausdrucks »Jerusalem» und »Zion« (Ps 51,20). Vgl. ebd., S. 291. 
13a setzt, eingeleitet mit einem kausalen ’ִ̣, formgemäß mit der hymnischen Begründung ein, die der Lobaufforderung aus V12 folgt.

Wie bereits erwähnt, zeichnet sich Ps 147 in Bezug auf seine Emotionen im Speziellen durch die Handlungen JHWHs aus, die emotionalen Gehalt beinhalten. In V13 sind mit den Wurzeln (fest, stark sein / werden q. bzw. starkmachen im pi. und hi.) und ברך (segnen) zwei göttliche Handlungen genannt, deren emotionaler Gehalt im Folgenden genauer betrachtet wird: חז (SK pi.) wird im pi. für die Instandsetzung, für Ausbesserungs- und Renovierungsarbeiten sowie für das Befestigen von Gegenständen verwendet ${ }^{719}$ und gilt auch im hi. unter anderem für das Starkmachen im militärischen Sinn. Es geht dabei um die Stärkung der Herrschaftsgewalt eines Königs oder sonstigen Amtsträgers, oder auch, wie hier in V13, um die Verstärkung einer befestigten Stadt oder von Königreichen (zur Verstärkung von Festungsanlagen vgl. Nah 3,13-14; 2 Chr 11,11-12). Das wirkt sich für die Betroffenen günstig aus, während etwa im Kontrast dazu das Starkwerden einer Hungersnot fatale Folgen nach sich zieht (Gen 41,56f; 2 Kön 25,3).

Die Dinge, die stark gemacht werden können, sind unterschiedlicher Art; so finden sich etwa Zeltpflöcke (Jes 54,2) oder auch Götzenbilder (Jes 41,7) etc. ${ }^{720}$ Stark werden und Stärke ausüben können nicht nur Menschen, sondern auch die Gottheit. Und so bedeutet חז pi. im theologischen Sinn eine Stärkung seitens JHWHs, die sich in erster Linie auf militärische Stärke bezieht. ${ }^{721}$ Wird die Stärke auf die Gottheit übertragen, dann übertrifft sie die menschliche Stärke bei Weitem: "Auch Gegenstände, wie Riegel an Toren, kann JHWH infolge seiner alles menschliche Maß übersteigenden Kraft `stark machen` (Ps 147,13). « ${ }^{722}$ Diese Sicherung der Riegel dient dazu, die Stadt vor feindlichen Angriffen sowie vor wilden Tieren zu schützen. ${ }^{723}$ Die Riegel oder Sperrbalken der Torflügel, die von innen gesichert wurden, waren der letzte Punkt im Sicherheitssystem der altorientalischen Städte, in dem die Stadttore besonders heikle Stellen waren. ${ }^{724}$ Die Stadttore gelten unter anderem als öffentliche Orte der Rechtsprechung. Um Rechtsordnungen geht es vor allem am Ende des Psalms: "Eine stimmige Rechtssprechung und die Erfahrung des Friedens gehören unlöslich zusammen. Wenn mit den wieder funktionierenden Toren [...] auch auf Rechtssprechung angespielt wird, dann tritt ein Bezug zwischen VV. 12-14 und V. 19f umso

719 Vgl. Sedlmeier, Jerusalem, $295 \mathrm{f}$.

720 Vgl. Hesse, prn, 849f.

721 Vgl. Van der Woude, קir, 540.

722 Hesse,

723 Vgl. Cohen, The Psalms, 474 und Hossfeld / Zenger, Psalmen 101-150, 835. Diskutiert wird an dieser Stelle, aus welchem Material die Riegel bestanden. Eventuell handelte es sich um Holzbalken. Vgl. dazu Rogerson / McKay, Psalms 101-150, 182.

724 Vgl. Risse, Gut ist es, 118. 
deutlicher hervor. ${ }^{725}$ Bildlich gesprochen wird mit der erneuten Instandsetzung der Riegel der Tore das Anbrechen der Heilszeit signalisiert. "Sie sind Zeichen der Sicherheit und des Schutzes. Dieser Schutz ist umso wirksamer, als Jahwe selbst der ist, der ihn gewährt. " ${ }^{726}$ JHWH sorgt aber nicht nur für erneuten Schutz und Sicherheit in der Stadt, er wendet sich auch den Nachkommen in spezieller Weise zu.

ברך pi. bedeutet "jemanden zu einem mit heilschaffender Kraft Begabten machen bzw. ihn als solchen erklären. ${ }^{727}$ Überblickt man die Stellen, in denen ברך in dem am häufigsten verwendeten Verbalstamm pi. - wie auch hier in V13 vorkommt, dann gilt, dass »brk pi immer ein Aussprechen feierlicher Worte meint, die demjenigen, dem sie gelten, die Anerkennung, den Dank, die Ehrfurcht, die solidarische Verbundenheit oder das Wohlwollen des Sprechenden bekunden, die das Ansehen des Betreffenden vermehren und, soweit ein Mensch Objekt ist, ihm Glück, Erfolg, Mehrung der Lebensgüter wünschen. ${ }^{728}$ Segnet also JHWH »deine Kinder in deiner Mitte« (V13), ${ }^{729}$ dann will die Gottheit diese Nachkommen mit heilschaffender Lebenskraft ausstatten, ihnen Glück und ברך Wohlstand verleihen sowie ihnen die Fülle des Lebens schenken. Parallel zu pi. steht unter anderem das Geben von שָלוֹם Ausdruck für das Segenshandeln Gottes betrachtet werden kann (vgl. V14). ${ }^{730}$ Mit dem Segnen der Kinder wird das Thema Sicherheit aus 13a in 13b fortgeführt und erweitert: »[...] providing a situation of security in Jerusalem, so that young children can grow up in safety and peace (vv 13-14a). ${ }^{731}$ Mit den Kindern können aber auch einfach die BewohnerInnen der Stadt gemeint sein. ${ }^{732}$ Darüber hinaus können die Kinder auf die Vermehrung der Population hinweisen. ${ }^{733} \mathrm{~V} 12-$ 13 drücken insgesamt aus, dass JHWH »Jerusalem und die Region um die Stadt wieder [...] zu einem Ort von Frieden, d. h. Geborgenheit, Zufriedenheit und Gemeinschaft gemacht [hat] (V 14a), und er hat die Zeit des Hungers und der Not

725 Sedlmeier, Jerusalem, 298.

726 Sedlmeier, Jerusalem, 298.

727 Keller, ברך, 355.

728 Scharbert, ברך, 825.

729 Sedlmeier, Jerusalem, 299; Risse, Gut ist es, 120 u. a. sehen hier Jerusalem/Zion in der Personifikation als Mutter, deren Kinder durch JHWH Segen erfahren.

730 Vgl. Keller, ברך, 362.

731 Limburg, Psalms, 498. Bei den "Kindern« wird häufig an die Nachkommenschaft der nachexilischen Gemeinde gedacht. So z. B. bei Kraus, Psalmen, 1138 und Anderson, The Book of Psalms 2, 947.

732 Vgl. Dahood, Psalms 3, 347. Ähnlich Sedlmeier, Jerusalem, 302, der an die BewohnerInnen Jerusalems und seines Umlandes denkt. (Nachkomme, Kind) bezeichnet seiner Meinung nach die Zugehörigkeit zu jemanden, hier in V13 diejenige zur Gestalt Jerusalem/Zion.

733 Vgl. Cohen, The Psalms, 474. 
durch reiche Ernten beendet (V 14b). ${ }^{734}$ Dabei verweisen die in der SK formulierten Handlungen JHWHs weniger auf ein konkretes vergangenes Ereignis als vielmehr darauf, »den Prozess des Bauens der Größe Jerusalem / Zion als abgeschlossen darstellen [zu] wollen, wobei die Auswirkungen und Folgen dieses Vorgangs die Gegenwart freilich bestimmen und prägen. ${ }^{735}$

Die Analyse zeigt die Fülle von Themen und Emotionen in V13: Göttliche Stärke und (militärische) Macht, Befestigung, Schutz und die Steigerung des Sicherheitsgefühls werden ebenso zu Sprache gebracht wie Wohlbefinden, Lebenskraft, Glück, Heil und Lebensfülle für die Nachkommen bzw. StadtbewohnerInnen. Der Schwerpunkt liegt dabei auf Seiten Gottes weniger auf den Emotionen, sondern auf den Aspekten, die mit seinen Taten verbunden sind, allen voran der Stärke und Macht Gottes sowie dessen Segenskraft. Auf Seiten des Gegenübers haben die göttlichen Handlungen durchaus emotionale Auswirkungen: Für die Betroffenen werden die Emotionen der Geborgenheit, des Sicherheits- und Wohlgefühls sowie des Glücks evoziert.

\subsection{Vers 14: Göttliche Sicherheit und Sättigung}

14a Er verschaffend deiner Grenze Frieden,

$14 b$ mit bestem Weizen sättigt er dich.

Zum Segenshandeln Gottes gehört auch, wie bereits in der Analyse von V13 angekündigt, das Geben von שָׁ. Dieses Wort gilt als »Inbegriff der Wohltaten Jahwes « $^{736}$ und umfasst eine Vielzahl an Inhalten: »Die vielen Aspekte [von שָׁלוֹ], die im weitesten Sinne ungefährdetes Wohlergehen, Glück, Ruhe und Sicherheit umfassen, kommen jedenfalls dem sehr nahe, was im Alten Testament als Inbegriff des Segens verstanden wurde. ${ }^{737}$ Sucht man nach einer Grundbedeutung, so wird שָׁiֹ gewöhnlich als Ganzheit bzw. Unversehrtheit aufgefasst. ${ }^{738}$ Der Begriff markiert zwei miteinander verwandte Vorstellungen, und zwar einerseits die von Frieden und Freundlichkeit - oft im deutlichen Kontrast zu Feindschaft und Krieg -, andererseits jene des Glücks, Gedeihens und Wohlergehens. ${ }^{739}$ Die letztgenannte Vorstellung beinhaltet äußere wie innere Genugtuung, die sich mit den Begriffen Lust, Gefallen und Freude berührt. Die erstgenannte Vorstellung

734 Hossfeld / Zenger, Psalmen 101-150, 835. »Die Verbindung wiedererrichtete Stadt - wiedererrichtetes Volk wird hier aufgenommen.« Vosberg, Studien, 97.

735 Sedlmeier, Jerusalem, 294. »In Vers 13 bezeichnen die Perfektformen vergangene Handlungen mit bleibender Wirkung.« Risse, Gut ist es, 37.

736 Kraus, Psalmen, 1138. Er übersetzt שָׁלוֹ an dieser Stelle mit »Heil«. Kraus, Psalmen, 1134.

737 Liwak, Friede, 2.

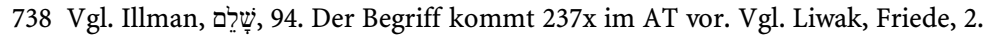

739 Vgl. Gerlemann, שלם 922.927. 
des Friedens als Gegensatz zum Krieg kommt hier in V14 zum Tragen. Es kann sich dabei um einen dauerhaften Zustand oder um einen einmaligen Akt im Sinne einer Vereinbarung handeln, ${ }^{70}$ wobei der Kontext der militärischen Verstärkung und des Ausstattens der Kinder mit lebensförderlicher Kraft aus V13 sowie die Sättigung mit Weizen in 14b auf Dauerhaftes und Beständiges, auf eine politische Ruhevorstellung ${ }^{741}$ schließen lässt. Dies wird in 14a »deiner Grenze« zugesagt. Ob hier גְּבוּל mit Gebiet oder Grenze wiederzugeben ist und damit die Gabe des Friedens innerhalb der Grenze Jerusalems oder, weiter gefasst, innerhalb des Territoriums in und um Jerusalem herum zu denken ist, wird diskutiert. ${ }^{742}$ Parallel zu den Stadttoren in V13, die eine Scharnierstelle zwischen innen und außen markieren, klingt auch hier im Begriff גְּבְּ der Schwellengedanke mit. Innerhalb der Stadttore und des abgegrenzten Gebietes verschafft die Gottheit Frieden als Schutz vor dem, was draußen an feindlicher Bedrohung vorhanden sein könnte.

JHWH verleiht nicht nur Frieden, sondern er sorgt auch für Sättigung. ${ }^{743}$ Die Wurzel שבע mit der Grundbedeutung "sich sättigen, satt werden, satt sein ${ }^{744}$ meint das Stillen des Hungers durch Essen und Trinken und bezieht sich somit auf eine sehr elementare Funktion des tierischen und menschlichen Lebens. ${ }^{745}$ Doch JHWH gibt nicht nur einfache Speise zum Sattwerden; vielmehr wird

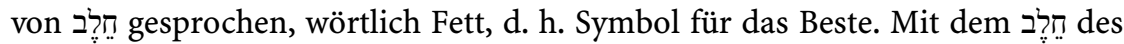
Weizens ist also das Fett als Delikatesse bzw. die "köstliche Gabe der Ernte « ${ }^{746}$ gemeint (Ps 81,17). Es handelt sich damit um »Frieden und Sättigung mit kraftvoller, köstlicher Nahrung (V.13f.) - lauter Güter, die das Volk in der Zeit seiner Not und Trübsal bitter entbehrte (Ps. 85, 9ff). ${ }^{747}$ Mit dem Thema der Sättigung mit dem Besten an Weizen wird der Fokus bereits in Richtung Natur gelenkt, welcher in V15-18 fortgeführt wird. V14 strotzt damit vor Lebensfülle,

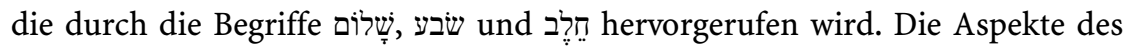
Friedens (nach dem Krieg), der Ruhe und Sicherheit sowie des Heils, der Sättigung und der Köstlichkeit kommen ebenso zur Darstellung wie die Emotionen des Wohlbefindens und Glücksgefühls. Diese Aspekte und Emotionen sind wiederum - wie in V13 - Auswirkungen des göttlichen Handelns für Jerusalem.

740 Vgl. Gerlemann, שלם, 929.

741 Vgl. Liwak, Friede, 5.

742 Für das Verständnis von גָּבְּ als Gebiet argumentieren Fohrer, Psalmen, 66 und Sedlmeier, Jerusalem, 19.306.

743 Vgl. Sedlmeier, Jerusalem, 19, der hier שָׁלוֹ mit »Friedensfülle« wiedergibt.

744 Warmuth, שבע, 693.

745 Vgl. Gerlemann, שבע, 819.

746 Münderlein, חלר, 957. Ebenso Kraus, Psalmen, 1138.

747 Lamparter, Das Buch der Psalmen 2, 376. »mit üppigem Weizen« bei Seybold, Die Psalmen, 538. Seybold, Die Psalmen, 540 spricht davon, dass »ausreichende und beste Nahrungsmittel [...] zur Verfügung stehen.» 


\subsection{Vers 15: Göttliches Wort}

15 a Er sendend seine Rede auf die Erde,

$15 b$ sehr schnell eilt sein Wort.

In V15 finden wir eine weitere Personifikation (vgl. Jerusalem und Zion in V12), die dazu dient, einen abstrakten Begriff in anschaulicher, plastischer Weise darzustellen. Hier wird die Rede (15a) bzw. das Wort (15b) Gottes wie ein Botschafter bzw. Erfüllungsgehilfe dargestellt, der von einem Ort zum anderen in Schnelligkeit läuft und damit diese beiden Orte miteinander verbindet. ${ }^{748} \mathrm{JHWH}$ wird dabei implizit im Himmel verortet, von wo er sein Wort zur Erde sendet. ${ }^{749}$ Dabei gilt das Wort oder Sprechen Gottes als »anthropomorphe Verbildlichung seiner Gedanken und seines Willens, Verbildlichung seiner Wirksamkeit in der Welt. ${ }^{750}$ Die metaphorische Sprache lässt Anklänge an Ps 33,4-9 sowie an Gen 1 $\mathrm{zu}$, wo Gott spricht, woraufhin durch das Wort die Schöpfung erschaffen wird. Das Wort ist effektiv und erreicht sein Ziel. ${ }^{751}$ Mit der Personifikation des Wortes - hier im Speziellen durch die Darstellung eines schnell eilenden Boten - werden durch die menschenähnliche Darstellung die Aspekte der Schnelligkeit, Hast und Eile evoziert. Das Thema der Effektivität in der Kommunikation kommt im Vers ebenso zum Tragen. Die Personifikation und die nun folgenden Vergleiche zielen weniger darauf ab, Emotionen hervorzurufen, sondern vielmehr darauf, die Aussageabsicht des Verses mit Hilfe der bildlichen Rede zu verdeutlichen.

\subsection{Vers 16: Schnee und Asche}

16a Er gebend Schnee wie die Wolle,

$16 b$ Reif wie die Asche zerstreut er.

In V16 wird die metaphorische Sprache aus V15 fortgeführt, allerdings nicht mit einer Personifikation, sondern mit einem Vergleich. V16 eröffnet eine Reihe von drei Vergleichen, die bis V17 eine Steigerung erfahren. Inhaltlich sind dabei die Naturphänomene der winterlichen Regenzeit in Palästina im Blick. Worauf

748 "Both the utterance and the word are personified as something sent like an aide and hastening to fulfill its commission like an aide, as in Ps. 107:20." Goldingay, Psalms 3, 724. Ebenso Anderson, The Book of Psalms 2, 948; Herkenne, Das Buch der Psalmen, 452 und Kraus, Psalmen, 1138: „Das Wort wird wie ein Bote gesehen, der als selbständiges Wesen dahineilt (vgl. Ps 107,20).«

749 Vgl. Risse, Gut ist es, 154.

750 Risse, Gut ist es, 154.

751 Vgl. Anderson, The Book of Psalms 2, 946 mit Verweisstellen auf Jes 45,23; 55,11; Heb 4,12. Gottes Rede (15a) wird auch als Donner gedeutet, der den Regen begleitet. Vgl. Dahood, Psalms 3, 348. Ebenso Seybold, Die Psalmen, 540f. 
zielen nun diese Vergleiche ab? So wie die Wolle (16a) als ein Material gilt, das wie Leinen zur Herstellung von Kleidung verwendet wird (Spr 31,13; Ez 34,3; 44,17) und damit die Hautoberfläche bedeckt, bedeckt der Schnee die Oberfläche des ganzen Landes. Ähnlich sieht das John Goldingay, der allerdings den Vergleich zu einem Schaf zieht (vgl. die frisch geschorene Wolle in Ri 6,37): "Yhwh makes the snow cover the ground in the way a woollen fleece covers a sheep. ${ }^{752}$ Sowohl Wolle als auch Schnee sind weich und weiß. »Im Gebirge fällt in Palästina Schnee, der mit der flockigen, weißen Wolle verglichen wird (vgl. auch Jes 1,18; D[a]n 7,9). ${ }^{753}$ Auf die schützende Funktion dieser weißen Schneedecke, die das Land überzieht, weisen Alonso Schökel und Carniti hin. ${ }^{754}$ So können die Flockenform und die weiße Farbe der Wolle, die zwar nicht unmittelbar nach dem Scheren, jedoch nach einer reinigenden Weiterverarbeitung $\mathrm{zu}$ Tage tritt, als tertium comparationis gelten. ${ }^{755}$ Zudem gilt die Funktion des schützenden Bedeckens einer Oberfläche sowohl für Schnee als auch für Wolle. Schnee schützt Boden und Pflanzen in bestimmtem Maß vor Frost. Eventuell trägt das Bild aber auch ambivalente Züge und lässt daran denken, dass die Gottheit die Erde abkühlt. Auf alle Fälle ist das Schneien in Palästina ein seltenes Phänomen, welches in unregelmäßigen Abständen hauptsächlich im judäischen Bergland stattfindet. ${ }^{756}$

Der zweite Vergleich bezieht sich ebenso auf das Bedecken einer Oberfläche: »Die nach einer Frostnacht bereiften Dächer, Straßen und Felder sehen aus, als wären sie mit weißer Asche bestreut. ${ }^{757}$ Asche und Reif sind sehr feine Materialien. Im Rahmen eines Trauerrituals wird die Asche auf das Haupt gestreut (2 Sam 13,19; Jes 58,5; Est 4,1.3; Dan 9,3; Ijob 2,8). So wie Gott Reif zerstreut, kann Asche aus einer Feuerstelle ausgestreut werden. ${ }^{758}$ Ebenso wie der Schnee kann auch die Asche weiß sein: "Wie weiße Asche schlägt sich der Reif nieder. ${ }^{759}$ Anders sehen dies Charles und Emilie Briggs. Der Vergleichspunkt liegt ihrer Ansicht nach an dieser Stelle in der Quantität. ${ }^{760}$ Somit können die feine Konsistenz, die Häufigkeit und eventuell die weiße bzw. weiß-graue Farbe des Staubs bzw. der Asche als tertium comparationis gelten.

752 Goldingay, Psalms 3, 724.

753 Kraus, Psalmen, 1138. »Den Vergleichspunkt zwischen Schnee und Wolle bilden das Flockige und die weiße Farbe«; Herkenne, Das Buch der Psalmen, 452. Ebenso Allen, Psalms 101-150, 306. Auf die weiße Farbe als Vergleichspunkt weisen auch Briggs / Briggs, Commentary, 536 hin.

754 Vgl. Alonso Schökel / Carniti, Salmos 2, 1650.

755 Vgl. Risse, Gut ist es, 158.

756 Vgl. Keel, Orte 1, 40.

757 Herkenne, Das Buch der Psalmen, 452.

758 Vgl. Goldingay, Psalms 3, 724.

759 Kraus, Psalmen, 1138. Ebenso Allen, Psalms 101-150, 306.

760 Vgl. Briggs / Briggs, Commentary, 536. 
Die metaphorische Sprache dieses Verses bringt mittels der Vergleiche die Aspekte der Oberflächenbedeckung und der Quantität im Sinne des Mengenerweises ans Tageslicht; daneben finden sich die Gemeinsamkeit von Schnee, Wolle, Reif und Asche aufgrund der weißen Farbe und - bei Wolle und Schnee aufgrund des weichen, flockigen Materials. Während die Phänomene des Schnees und Reifs durchweg spielerisch bzw. friedlich gedeutet werden, ${ }^{761} \mathrm{klin}$ gen mit dem folgenden V17 rauere Töne an.

\subsection{Vers 17: Eis und Kälte}

17 a Werfend sein Eis wie Brocken,

$17 b$ vor seiner Kälte - wer kann bestehen?

V17 führt die Reihe der Vergleiche fort und an einen Höhepunkt. 17a lässt viele an Hagel denken, auch wenn der entsprechende hebräische Begriff (꼬ำ dafür hier nicht verwendet wird. ${ }^{762}$ An dieser Stelle ist darauf hinzuweisen, dass Hagel zwar in unseren Breitengraden nicht zu winterlichen Naturvorgängen zählt, in Palästina dagegen schon. Dort gehört auch der intensive Regen aus V8 in die Winterzeit. ${ }^{763}$ "Die Regen sind im allgemeinen heftig und besonders zu Beginn der Regenzeit (Nov./Dez.) und an ihrem Ende (März/April) von Blitz, Donner und gelegentlich von Hagel begleitet. ${ }^{764}$

Der Vergleich liegt hier darin, dass JHWH Eisbrocken wie jemand wirft, der Brotbissen verstreut. ${ }^{765}$ Dabei ist der Vergleichspunkt die Größe des Hagels, die jener von Brotstücken entspricht (Spr 17,1; 28,21), ${ }^{766}$ wodurch an relativ große bzw. übertrieben große Hagelkörner zu denken ist. ${ }^{767}$ Anders sieht das Siegfried Risse, der hier keine bedrohliche Darstellung erkennen kann: „Die Vergleiche: `wie Wolle, wie Staub, wie Brotbissen` haben nichts Erschreckendes an sich. ${ }^{768}$ Drastisch übersetzt hingegen Miller: »Er schleudert hin sein Eis in Stücken, vor

761 "Like a child delighting in the snow, [the psalmist] revels in an excited description of severe winter conditions such as were comparatively rare in Palestine. Snowflakes, frost and hailstones are tossed down to earth like so much confetti.« Allen, Psalms 101-150, 310.

762 »17 schildert den Hagelschlag, der Eisbrocken niederfallen lässt, und den Frost, der das Wasser zu Eis verwandelt." So bei Kraus, Psalmen, 1138. Hagel als Begleiterscheinung des Gewitters kommt in der Bibel öfter vor. Vgl. Ernst, Hagel, 284.

763 Vgl. Staubli, Begleiter, 18. Der Winter gilt im AT als Regenzeit (Hld 2,11; Esra 10,13). Vgl. Keel, Orte 1, 40.

764 Keel, Orte 1, $41 \mathrm{f}$.

765 Vgl. Goldingay, Psalms 3, 724. Ebenso Cohen, The Psalms, 474.

766 Vgl. Anderson, The Book of Psalms 2, 948.

767 Vgl. Briggs / Briggs, Commentary, 536. Allen, Psalms 101-150, 306.

768 Risse, Gut ist es, 194. Vgl. ebd., 160. 
seinem Frost, wer könnte da bestehen? ${ }^{769}$ Kalte, unwirtliche Winter mit Schnee, derartigem Frost und Wetterkapriolen, wie sie in V16f geschildert werden, sind in Palästina eher unüblich und werden daher nicht den individuellen Erfahrungen des Volkes Israels zugeschrieben. ${ }^{770}$ Aufgrund der Seltenheit der Wetterphänomene illustrieren V15-18 noch eindrucksvoller die Macht JHWHs. ${ }^{771}$ Gefürchtete Wetterkapriolen dieser Art, die oft mit schweren Stürmen Hand in Hand gehen, werden biblisch auch mit Theophanien verbunden. ${ }^{772}$

Vor seiner Kälte - wer kann bestehen? Dieser Satz führt zu einer Klimax - es ist eiskalt! Der Hagel kann gefährlich sein und Zerstörung verursachen. ${ }^{773}$ Die in Ps 76,8 und Ps 130,3 ebenso gestellte Frage »Wer kann bestehen? « hat als rhetorische Frage mit der Antwort zu gelten: "Niemand kann vor JHWH bestehen. ${ }^{774}$ Alle Naturvorgänge in Ps 147 werden JHWH zugeschrieben, angefangen von der Kenntnis der Sterne und des Universums in der ersten Szene über die Fürsorge durch Regen, der Gras wachsen lässt, in der zweiten Szene bis hin zu den Naturvorgängen in der winterlichen Regenzeit Palästinas hier in der dritten Szene. ${ }^{775}$ Sind alle bisherigen Naturphänomene in positiver Weise dargestellt worden, kommt mit V17 der Aspekt der Bedrohlichkeit und der Gefahr, die bis zur Wucht und Zerstörung reichen kann, zum Ausdruck, auch wenn diese Inter-

769 Miller, Die Psalmen, 253. Ähnlich Lamparter, Das Buch der Psalmen 2, 373: »schleudert seinen Hagel wie Kiesel.»

770 Vgl. Goldingay, Psalms 3, 724. Die Beschreibungen könnten vielmehr poetischen Quellen entstammen, die Erfahrungen anderer Völker oder Orte reflektieren. Ähnlich Dahood, Psalms 3, 349, der darauf hinweist, dass biblische Dichter sich des Öfteren Metaphern bedienen, die ursprünglich von Poeten aus Kanaan oder Phönizien geprägt wurden. Anders sieht das Thomas Staubli: »Besonders im judäischen Bergland wird es im Winter kalt und feucht. Fast unablässig bläst der Wind. Schneefall, Hagel und Graupeln sind keine Seltenheit.« Staubli, Begleiter, 18. Von kalten palästinensischen Wintern spricht auch Herkenne, Das Buch der Psalmen, 452.

771 Vgl. Anderson, The Book of Psalms 2, 947 und Weiser, Die Psalmen 2, 559.

772 Vgl. Briggs / Briggs, Commentary, 536 mit Verweis auf Theophanien JHWHs im Zusammenhang mit der Befreiung seines Volkes und der Vernichtung der Feinde vgl. Jos 10,11; Ijob $38,22 \mathrm{f}$ : No enemy can resist Him when, in accordance with His command, snow, hail, and frost descend in the face of His enemies."

773 Viviers, Psalm 147, 175 spricht von einem "climactic movement from the previous serene nature depictions to this rather violent exhibition of power through natural forces." Der

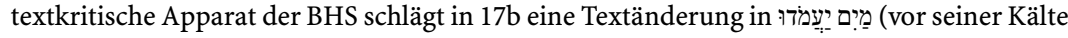
erstarren die Wasser) vor. Anders u. a. Sedlmeier, Jerusalem, 25, der sich gegen eine Textkorrektur ausspricht: ״Die rhetorische Frage מי יעמד unterstreicht die [...] Schöpfermacht, der nichts und niemand Widerstand leisten kann. Insofern stört die Frage den Kontext keineswegs, sie unterstreicht vielmehr die Aussageintention der Verse.»

774 Brodersen, Schöpfungsaussagen, 69.

775 Oeming / Vette, Psalmen, Psalm 90-151, 245f. sehen in der Verteilung der Schöpfungsaussagen in Ps 147 den Verlauf der Jahreszeiten: V8-9: Frühling und Sommer; V15 (Ernte) bzw. V16-18: Herbst und Winter. Dies ist für V18 kritisch zu hinterfragen, nachdem hier mit dem Schmelzen des Eises und dem Rinnen des Wassers Anklänge an den Frühling auszumachen sind. 
pretation nicht von allen KommentatorInnen geteilt wird. Dies stellt einen krassen Gegensatz zu den lebensförderlichen Naturvorgängen dar, die vor allem in der zweiten Szene geschildert werden, zeigt aber gleichzeitig die Macht und Unverfügbarkeit Gottes und zeugt von der starken Theozentrik, die den ganzen Psalm durchzieht: »Die >natürlichen Ereignisse: Gewitter, Schnee, Reif, Hagel, Frost und Hitze werden als Gottes persönliches Wirken begriffen. Sie demonstrieren seine Macht. ${ }^{776}$ V15-18 sind daher "Beispiel der Allmacht Gottes, womit er über die Natur gebietet, u. schnell die grö[ß]ten Wirkungen hervorbringt $u$. wieder aufhebt. ${ }^{777}$ Neben der Bezeugung der Macht JHWHs wird auch die Deutung seines prinzipiellen Wirkens in der Natur sowie die in Regelmäßigkeit stattfindende Reihenfolge des durch JHWH bewirkten Wetters - vgl. dazu auch die Ptz. und PK-Formen, die den andauernden, wiederholenden Aspekt betonen - vertreten. ${ }^{778}$ V17 schildert demnach - im Kontrast zu allen bisherigen Naturvorgängen - die Bedrohung, Wucht, Kälte und Gefährlichkeit der Schöpfung, die auf JHWH zurückgeführt werden. Im Leseprozess kann dies Erschrecken auslösen. Wie bereits konstatiert, evozieren die in V16-17 geschilderten Vergleiche weniger F-emotions, sondern verstärken vielmehr die Aussage der göttlichen (Schöpfer-) Macht. Auf der Ebene der A-emotions sind nach der Bewunderung für die Effizienz des göttlichen Wortes auch die Überraschung und das Erschrecken hinsichtlich der Bedrohung durch die Gefährlichkeit von Eis und Kälte auszumachen.

\subsection{Vers 18: Wort und Geist Gottes}

18 a Er sendet sein Wort und er/es lässt sie schmelzen,

$18 b$ er lässt wehen seinen Wind/Atem - es rinnen die Wasser.

Nachdem in V16f Wasser in allen seinen Formen, d. h. in seinen unterschiedlichen "Aggregatszuständen ${ }^{779}$ wie Reif, Schnee, Eis wie Brocken (Hagel) beschrieben wurde, setzt nun mit der Sendung des Wortes und dem Wehen des göttlichen Windes die Schnee- bzw. Eisschmelze ein, sodass die Wasser rinnen bzw. zu rauschen beginnen. Schnee, Reif und Hagel schmelzen durch den warmen Wind und rinnen als Wasser davon. ${ }^{780}$ Dabei klingt im Rieseln bzw. Fließen (נזל) der Wasser Leben und Fruchtbarkeit an (Num 24,7; Jes 48,21; Ps 78,16; Hld 4,15).

776 Seybold, Die Psalmen, 540.

777 Hupfeld, Die Psalmen, 677.

778 Vgl. Brodersen, Schöpfungsaussagen, 70.

779 Weber, Werkbuch 2, 375.

780 Vgl. Briggs / Briggs, Commentary, 537. Die beiden denken dabei auch an einen theophanen Gebrauch des Windes, der verursacht, dass die Feinde dahinschmelzen und wegfließen. 
18a nimmt wiederum das Wort auf, das als aktive Kraft mit entsprechender Wirkung dargestellt wird. ${ }^{781}$ Syntaktisch ist nicht klar, ob JHWH selbst die Eisbrocken bzw. das Eis schmelzen lässt oder ob das personifizierte Wort das Subjekt der Handlung ist. ${ }^{782}$ Viele KommentatorInnen sehen hier eine Fortführung der Personifikation des Wortes: Das Wort macht sowohl das Fließende fest (V15-17: Schnee, Reif, Hagel) als auch das Feste fließend (V18), indem es Schnee, Reif und Eis in Wasser verwandelt. ${ }^{783} \mathrm{Nach}$ der Winterzeit (Reif, Schnee, Eis) folgt nun der Frühling, in dem das Gefrorene schmilzt. Analog zu Jes 55,8-13, wo das Wort Gottes - mit Regen und Schnee verglichen - den Auszug aus Babylon und die Heimkehr aus dem Exil verheißt, kann das Wort auch hier eine Wende des Erstarrten bewirken und neues Leben in Bewegung setzen. ${ }^{784}$ In Bezug auf die in V16-18 angesprochenen Naturvorgänge fällt auf, dass diese mit dem weichen und kalten Schnee beginnen, mit dem feinen und kalten Reif fortgeführt werden und mit dem harten und kalten Eis ihren Höhepunkt erreichen. Dann löst sich das Eis durch das Schmelzen wieder zu Wasser, das kalt und - im Gegensatz zum Eis - weich ist. Der Aspekt der Kälte zieht sich also durch, der Zustand des Wassers bewegt sich zwischen weich - hart - weich. Dies alles wird durch JHWH bzw. das göttliche Wort bewirkt. Der Machterweis Gottes zeigt sich somit in den Naturphänomenen und in seinem Wort. Wird das Wort in V15 als Personifikation plastisch ins Bild gebracht, so in V16-17 die Naturereignisse mittels der Vergleiche. Hier in V18 holt das Wort die Naturphänomene ein, und sie werden miteinander verbunden.

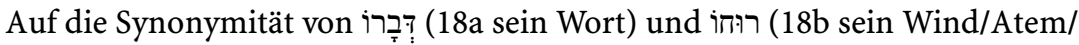
Geist) weist Kraus hin. Dahinter liegt die Vorstellung vom ")Hauch des Mundes [...], der beim Sprechen ausgeht. ${ }^{785}$ Dieser Hauch bzw. Wind verursacht einen Temperaturanstieg. ${ }^{786}$ Zusammenfassend kann festgehalten werden: "Wie in 8-9 JHWH die Wolken und den Regen bewirkt, so schafft er hier die winterlichen Phänomene Schnee, Reif und Eis. Er lässt auch alles wieder schmelzen und die Wasser wieder fließen. Anders aber als in 8-9 kommt in 15-18 sein wirkmächtiges Wort mit ins Spiel. ${ }^{787}$

781 Vgl. Mays, Psalms, 443.

782 Bei Sedlmeier, Jerusalem, 19: »... so lässt er sie schmelzen«.

783 Vgl. Fohrer, Psalmen, 70. Ebenso Limburg, Quoth, 106: "That word causes snow and hail, frost and cold (vv. 16-17), but also times of warmth and thawing (v. 18). These weather phenomena affect all people (cf. Matt 5:45) or no people whatsoever (cf. Job 38:26).« Goldingay, Psalms 3, 724: »Once more Yhwh ssends his word`, and it melts snow, frost, hail and ice."

784 Vgl. Lohfink, Lobgesänge, 119 und Risse, Gut ist es, 163.

785 Kraus, Psalmen, 1139. Ebenso Anderson, The Book of Psalms 2, 948.

786 Vgl. Cohen, The Psalms, 474.

787 Risse, Gut ist es, 154. "God's word, similar to the rain, does not remain in mid-sky to be 
JHWH handelt hier wiederum durch sein Wort (vgl. V15). Das Wort Gottes wird in V19 nochmals aufgenommen und zu einem weiteren Höhepunkt geführt. Hier in V16-18 wird die durch das Wort JHWHs verfügte winterliche Zeit der Kälte und des Eises auch als Erfahrung des Exils gedeutet. Das Schmelzen des Eises und das Rinnen der Wasser werden als Wende nach dem Exil hin zu neuem Leben und zur Heilszeit gedeutet. ${ }^{788}$

V18 zeugt damit nach der Steigerung in der Gefährlichkeit des Wetters (Schnee, Reif, Eis wie Brocken) von einem Wendepunkt. In V15-18 wird nicht nur auf der semantischen und syntaktischen Ebene die Macht Gottes in der Natur ausgedrückt; auch im Leseprozess beeindrucken mich die Mächtigkeit, Zielgerichtetheit und Effizienz des göttlichen Wortes - etwa auch im krassen Unterschied zu so vielen menschlichen Worten und Reden, die wirkungslos bleiben. Die bedrohliche Gefährlichkeit durch Eis und Kälte kann Schrecken auslösen. Im Leseprozess werden damit die A-emotions der Beeindruckung, Faszination, aber auch des Schreckens analog zu V4-5 ausgelöst.

\title{
2.19 Verse 19-20: Göttliches Wort für Israel
}

\author{
19a Verkündend sein Wort Jakob, \\ $19 b$ seine Ordnungen und seine Rechtsbestimmungen Israel. \\ 20a Nicht hat er so gehandelt an jedem Volk, \\ $20 \mathrm{~b}$ und die Rechtsbestimmungen haben sie nicht erkannt. \\ 20c Lobt JH!
}

Auch in den Schlussversen des Psalms steht das göttliche Wort im Zentrum. ${ }^{789}$ Die Wiederaufnahme von דָָָ aus 15b.18a in 19a ist offensichtlich. Dieses göttliche Wort an Jakob in 19a wird mittels eines synonymen Parallelismus mit den Ordnungen und Rechtsbestimmungen (19b), die auch als Satzungen und Gebote be-

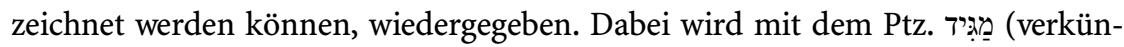
dend) die Kundmachung des Wortes als »fortwährendes Geschehnis bestimmt, das die interpretierende Aktualisierung miteinschließt. ${ }^{790}$ Einige sehen in der Offenbarung des göttlichen Wortes an Israel, womit die meisten die Offenbarung der

admired but soaks the earth and reaches again towards heaven in very earthy forms of life." Stuhlmueller, Psalms 2, 215.

788 Vgl. Sedlmeier, Jerusalem, 321.351.

789 In 19a folge ich dem Ketib רָּר (sein Wort sg.), das gut an V15-18 anschließt, anstatt des Qere דברּרִיו 101-150, 306 und Brodersen, Schöpfungsaussagen, 21. Zur Parallelität der Wirkung des Wortes in 15-18 und 19f bemerkt Hupfeld, Die Psalmen, 678: »Ist nur eine andere Wirkungsart des Wortes Gottes im Reich der Gnade, als vorh. im Reiche der Natur."

790 Sedlmeier, Jerusalem, 352. Ebenso Ballhorn, Telos, 313. 
Tora assoziieren, den Höhepunkt bzw. »eine Spitzenaussage ${ }^{791}$ des Psalms. Der Begriff »Tora « kommt im Psalm allerdings nicht vor. ${ }^{792}$ Mit dem Wort, den Ordnungen und Rechtsbestimmungen, den Entscheidungen und Gesetzen drücken sich der Wille JHWHs bzw. seine religiösen Forderungen für sein Volk Israel aus. ${ }^{793}$

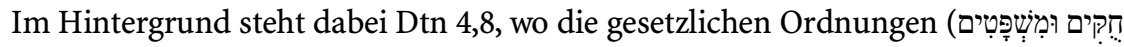
wie hier in V20), die Israel am Horeb gegeben wurden, als jene ausgewiesen werden, die Israel von den anderen Nationen unterscheidet. ${ }^{794}$ Die Offenbarung Gottes zu erhalten, bedeutet nicht nur Verantwortung, sondern ist auch ein Privileg. ${ }^{795}$ "Im Offenbarwerden der göttlichen Sozial- und Lebensordnung wird die Identität der sozialen Größe Jakob / Israel in ihrem radikalen Verwiesen- und Verwurzeltsein im Lebensgrund Jahwe deutlich, ist also als heilsgeschichtlich-theologische Größe unter den Weltvölkern anwesend. ${ }^{796}$

20b drückt unter anderem den generellen Sachverhalt aus, dass die anderen Völker diese Ordnungen (Israels) schlichtweg einfach nicht kennen. ${ }^{797}$ Daneben haben die anderen Nationen auch keinen Zugang zu diesen Rechtsordnungen: »Da Jahwe an keinem anderen Volk so gehandelt hat, dass er sich ihm in gleicher Weise wie Israel bleibend offenbar gemacht hat, können die Völker den Stellenwert und die Bedeutung von משפטים >Rechten einsehen. ${ }^{798}$ Die anderen Völker haben nämlich ihre eigenen Rechtsbestimmungen, die teils aber auch mit denen Israels identisch sind. ${ }^{799}$ Nach dem Motiv

791 Risse, Gut ist es, 182. Vgl. u. a. Dahood, Psalms 3, 350, und Sedlmeier, Jerusalem, 342.

792 Vgl. Ballhorn, Telos, 313.

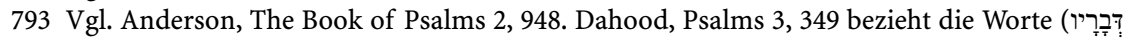
Qere) auf die zehn Gebote.

794 Vgl. Lohfink, Lobgesänge, 119. Er sieht in Ps 147 zwei Themenbereiche verbunden: "Jahwe als der Retter des armen Israel, Jahwes Wort als das Konstitutivum eines neuen, allen Völkern kontrastierenden Israel.« Er verweist dabei auf die Erfahrung der Heimkehr aus Babylon und der Konstituierung einer neuen Gesellschaft in nachexilischer Zeit und sieht dahinter die Struktur des Exodus aus Ägypten und die Gabe des Gesetzes am Horeb. "Rettung von Armen und Wort des Gesetzes gehören also der Sache nach zusammen.« Ebd., S. 120.

795 Vgl. Grogan, Psalms, 227. Das Privileg der Erwählung bedeutet im Umkehrschluss auch Verantwortung. Vgl. Cohen, The Psalms, 474. „Erwählung bedeutet erhöhte Pflicht und Verantwortung vor Gott [...]. Dem viel gegeben ist, von dem wird viel gefordert« bei Weiser, Die Psalmen 2, 559.

796 Sedlmeier, Jerusalem, 341.

797 Bei Hossfeld / Zenger, Psalmen 101-150, 825: »und seine Rechtsvorschriften kennen sie nicht « [20b]; »das Recht, sie kennen es nicht« bei Weiser, Die Psalmen 2, 557. »Sie kennen seine Rechte nicht (M); er hat seine Rechte nicht mitgeteilt« bei Seybold, Die Psalmen, 541. "Seine Rechte hat er ihnen nicht geoffenbart« bei Ketter, Die Psalmen, 195. Anders Sedlmeier, Jerusalem, 19: »Was Rechte sind, sie wissen es nicht.« Der Vers drückt nach Ballhorn, Telos, 313 vielmehr die Besonderheit Israels aus und ist keineswegs als Abqualifizierung anderer Nationen zu betrachten.

798 Sedlmeier, Jerusalem, 338.

799 Vgl. Anderson, The Book of Psalms 2, 948. Die Verben der SK in V20 können hier sowohl 
der Sonderstellung Israels und den Ausführungen zu den Fremdvölkern eröffnet der Psalm mit seinem letzten Wort, dem Lobaufruf, eine für den Vers neue Welt, bringt im Kontext des gesamten Psalms betrachtet jedoch einen bekannten Aspekt ein. Mit dem Halleluja aus 20c wird der Beginn des Psalms (1a) wieder aufgenommen. Eine Inklusion ist festzustellen, der Kreis schließt sich mit den Emotionen der Freude und der Jubelstimmung, die durch den Imperativ evoziert werden sollen.

\section{$3 \quad$ Perspektiven und Textdynamik}

Am Beginn dieses Abschnitts steht die Analyse der Perspektivität des gesamten Psalms. Die Möglichkeit zur Perspektivenübernahme ist ja auschschlaggebend für das Identifikationspotenzial im Text. Danach wird auf Rhythmus und Klang Bezug genommen, um die Identifikationsmöglichkeit aufgrund der Textmelodie zu erheben. Die Textdynamik inklusive der Parallelismen wird anschließend szenenweise analysiert.

\subsection{Perspektivenlenkung}

Aus der Perspektivenlenkung in Ps 147 ergibt sich die Gliederung des Textes in drei Szenen (1-6; 7-11; 12-20) mit jeweils unterschiedlichen Spots. Jede Szene beginnt mit einer AdressatInnenperspektive (1a.7a.12a). Danach wird der Blick auf JHWH gelenkt (Er-Perspektive). Die Fokalisierung wechselt also zwischen AdressatInnenperspektive (1a.V7.V12.20c) und externer Fokalisierung (1b-6.811.13-20b), wobei hier ein lyrisches Wir auf seinen Gott blickt. Das könnte zur Annahme führen, dass die »Kameraführung« des Textes eher distanziert erfolgt. Dem ist aber nicht so. Der Text wechselt nämlich zwischen einer nahen und einer fernen Kameraeinstellung. ${ }^{800}$ Die Nähe zum in der Textwelt Erzählten und damit die Möglichkeit zur Identifikation wird dabei einerseits durch den erzählten Inhalt (Hinwendung JHWHs zu Bedürftigen), andererseits durch die Personaldeixis der Artikel sowie der Possessivpronomen erreicht. Diese beiden Elemente - erstens die Anhäufung deiktischer Elemente und zweitens der Inhalt, der in der Zuwendung und Nähe JHWHs zu seinem Volk besteht - treffen vor allem in der

präsentisch (vgl. z. B. Limburg, Psalms, 496) als auch in der Vergangenheit wiedergegeben werden.

800 Vgl. Hupfeld, Die Psalmen, 672, der davon spricht, dass sich der enge Blick dann zu einem allgemeinen weitet. »Der Dank geht zunächst aus von der Wiederherstellung Jerusalems u. des Volks (nach dem Exil) u. erhebt sich dann zu der allg. Betrachtung des Waltens Gottes im Reich der Natur u. der Gnade.» 
dritten Szene (V12-20) aufeinander. Die erste Szene (V1-6) weist zwar einen »berührenden" Inhalt auf, ist aber nur mit wenigen deiktischen Elementen ausgestatten (lediglich 1b; 3a und 5a). In der zweiten Szene liegt im Possessivpronomen in $7 b$, im viermaligen Vorkommen der Artikel in V8.11 sowie im Relativpronomen in $9 \mathrm{~b}$ eine Deixis vor. Die erzählten Inhalte führen anfangs weg von den Menschen in Richtung Natur.

In der ersten Szene wird deutlich gemacht, dass von "unserem Gott/Adonaj"

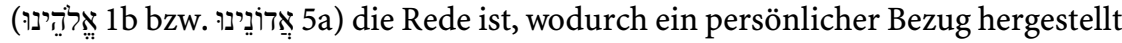
werden kann. Hinsichtlich der Gottesbezeichnungen ist gerade in der ersten Szene eine Häufigkeit festzuhalten: 3x JHWH (1a in Abkürzung; 2a.6a), 1x Elohim (1b) und 1x Adonaj (5a). Nach dem Lobaufruf an die AdressatInnen (1a) und dessen Verstärkung (1b.c) im ersten Spot wird im zweiten Spot JHWH und dessen Eintreten für die Stadt Jerusalem, für das Volk Israel und für die, die Schmerzen leiden müssen (V2.3), geschildert. JHWH und seine Wohltaten stehen dabei im Mittelpunkt der Blickrichtung, die auf Stadt, Volk und Leidende (V2-3) und somit auf das Land und den Boden gelenkt ist. Mit dem dritten Spot in V4.5 stehen zwar wieder JHWH und sein Tun im Zentrum, jedoch wird der Blick gehoben und auf die Sterne - und damit in die Ferne des Weltalls - gerichtet (V4). Mit der Aussage ohne Lokalobjekte über die unermessliche Größe Gottes (V5) bleibt der Blick auf JHWH und im Kosmos, bevor die Perspektive in V6 im

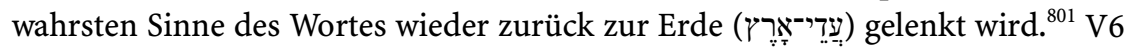
nimmt das Eintreten JHWHs für die Gebeugten und gegen die Gottlosen in den Blick, die die Gottheit bis zum Boden erniedrigt.

\begin{tabular}{|l|l|l|}
\hline Spot & Vers & Fokus \\
\hline 1 & 1 & Ihr $+\mathrm{JH}$ \\
\hline 2 & $2-3$ & JHWH + Jerusalem + Leidende \\
\hline 3 & $4-5$ & Er + Sterne \\
\hline 4 & 6 & JHWH + Gebeugte + Frevler \\
\hline
\end{tabular}

Der Dankaufruf (7a), der die zweite Szene (V7-11) eröffnet, lenkt die Perspektive zunächst auf eine Öffentlichkeit (Imp.m.pl. 7a.b; erster Spot), bevor die Blickrichtung, wie bereits in der ersten Szene, wieder zu JHWH und seinen Aktivitäten zurückkehrt (V8-11). Besonders auffällig ist dabei die Häufigkeit der Artikel in V8, die als deiktische Elemente den Fokus lenken. Alle drei in V8 genannten Partizipien beginnen mit einem Artikel, der auf JHWH verweist. Somit wird die Perspektive auf JHWH verstärkt. Hinsichtlich der Blickrichtungen ist, ähnlich wie in der ersten Szene, eine Bewegung festzustellen: Die Lesenden werden in

801 Auf die Blicklenkung Himmel (V4) - Erde (V6), die sich in V8.9 wiederholt, weist auch Lohfink, Lobgesänge, 116 hin. 


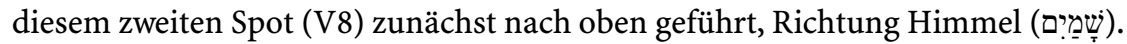
Von JHWHs Tätigkeiten für den Himmel (8a) richtet sich der Blick nach unten auf die Erde (אֶֶץ 8b). Dazwischen steht der Regen (מָּץ 8b), der vom Himmel auf die Erde fällt und die beiden Bereiche verbindet. Zwischen Himmel und Erde sind auch die Berge anzusiedeln (הָ הָרים 8c), auf denen JHWH Gras wachsen lässt. ${ }^{802}$ V8 fällt darüber hinaus durch seine Quantität an Naturbegriffen auf, die die Fülle der Schöpfung sichtbar machen: Himmel, Wolken, Erde, Regen, Berge und Gras.

Mit V9 (dritter Spot) wird der Blick auf die Tiere gelenkt. Die Artikel vor den Verben entfallen. Die Betonung liegt hier auf dem fürsorglichen Tun JHWHs in der Nahrungsbeschaffung für die jungen Raben und weniger auf der Gottheit selbst, wie dies durch die Deixis im vorhergehenden V8 konstruiert wurde. V10 (vierter Spot V10.11) schließt mit der Erwähnung von Tieren (ס 0 Pferd 10a) an V9 (עָרב Rabe 9b) an. Hier in V10 wird das Pferd als domestiziertes Tier in den Blick genommen, dessen Kraft, Stärke und Heldenhaftigkeit (גָּבְּרָה) mit denen des Menschen/Mannes (10b) verglichen werden. Mit der Erwähnung der Pferdestärke in 10a wird der Übergang zum Ausdruck "Schenkel des Mannes« in 10b לא + רצה . לא לא + חפיץ) 10b). Vom Himmel über den Regen und die Berge auf der Erde bei den Tieren und schlussendlich bei den Menschen angelangt, steht nun die Botschaft im Raum, dass JHWH vielmehr an jenen Gefallen findet, die ihn fürchten bzw. auf ihn vertrauen und auf seine Güte, Huld und Zuwendung (חֶֶ) warten (V11). Dass in 11a an betonter Stelle zu Beginn der Gottesname JHWH nach 7a wieder aufgenommen wird, überrascht nicht, da es in V11 um die Gottesfürchtigen geht, die auf JHWHs Huld warten, und damit also um die Gottesbeziehung. Dabei sind

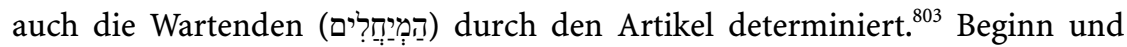
Ende der zweiten Szene werden demnach durch den Gottesnamen verbunden.

\begin{tabular}{|l|l|l|}
\hline Spot & Vers & Fokus \\
\hline 1 & 7 & Ihr + JHWH \\
\hline 2 & 8 & Er + Himmel \\
\hline & & Er + Erde \\
\hline & & Er + Regen \\
\hline & & Er + Berge \\
\hline 3 & 9 & Er + Tiere \\
\hline 4 & $10-11$ & JHWH + Menschen \\
\hline
\end{tabular}

802 Die Besonderheit der Trias Himmel - Erde - Berge, aus der die Schöpfung besteht, hebt Sedlmeier, Jerusalem, 272 mit Verweis auf Jes 44,23; 49,13 hervor.

803 Nach Norbert Lohfink ist, auch wenn nicht explizit genannt, in V10-11 - ebenso wie dann explizit in V19-20 - »der Blick eindeutig auf Israel gelenkt.» Lohfink, Lobgesänge, 117. 
In Verbindung mit der ersten und der zweiten Szene lässt sich folgende Perspektive festhalten: "Zwischen 4-5 und 8-9 lässt sich eine Linie vom Himmel zur Erde erkennen, von den Sternen am Himmel bis hin zu den schreienden Rabenjungen. Zugleich lässt sich eine Linie von JHWHs Macht zu JHWHs Fürsorge feststellen. $"{ }^{804}$ Dahinter steht eine bestimmte Dynamik, deren gesamte Handlungsfolge eben auf das Ziel in $9 \mathrm{~b}$ und die Nahrungsgabe für die Rabenjungen hinausläuft. ${ }^{805}$

In der dritten Szene (V12-20) wird im ersten Spot (V12) wieder - wie bereits in V1.7 - eine AdressatInnenperspektive hergestellt, erstmalig steht jedoch ein Du im Mittelpunkt: Mit den beiden Imp.pi.f.sg. sowie Jerusalem (12a) bzw. Zion (12b) im Vokativ wird Jerusalem, das bereits in V2 (dort allerdings in der Objektposition) genannt wurde, aufgefordert, in das Lob seines Gottes einzustimmen. Der Blick wird also abermals auf eine Öffentlichkeit gelenkt, diese wird jedoch mit Namen angesprochen und damit konkret betitelt. Imperative in der Singularform ( $\mathrm{du})$ dienen ja dazu, vor allem an vertraute (Text-) Personen einen Wunsch oder Befehl zu äußern bzw. einen Willen auszudrücken.

Mit V13 setzt der zweite Spot (V13-14) ein, der die Begründung des Lobaufrufs aus V12 liefert, indem er JHWH und sein Tun für die Stadt Jerusalem und deren BewohnerInnen in den Blick nimmt. Der dritte Spot (V15-18) betrachtet JHWH und sein Handeln durch das Wort und durch die Schöpfung genauer. Anders als in jenen vorhergehenden Spots, die JHWH als mächtigen und fürsorglichen Schöpfer portraitieren (V4-5.8-9), kommt diesmal die Gottheit in ihrer Gefährlichkeit zur Darstellung. Der vierte Spot (V19-20b) stellt JHWH als Leiter Israels dar, indem seine Rechtsbestimmungen und Ordnungen im Speziellen Israel gelten - im Gegensatz zu allen anderen Völkern, für die dies nicht zutrifft. Der fünfte Spot nimmt, analog zu 1a, wieder eine AdressatInnenperspektive auf eine nicht näher bestimmte Öffentlichkeit (pl.) ein (20c).

\begin{tabular}{|l|l|l|}
\hline Spot & Vers & Fokus \\
\hline 1 & 12 & Du + JHWH \\
\hline 2 & $13-14$ & Er + Jerusalem \\
\hline 3 & $15-18$ & Er + sein Wort + Schnee + Reif + Eis wie Brocken \\
\hline 4 & $19-20 \mathrm{~b}$ & Er + Israel \\
\hline 5 & $20 \mathrm{c}$ & Ihr + JH \\
\hline
\end{tabular}

Bezüglich der Blicklenkung fällt hier in der dritten, wie bereits in der zweiten Szene, die Häufung deiktischer Elemente ins Auge. In der zweiten Szene herrscht eine Er-Es bzw. Er-Sie-Perspektive vor. In der dritten Szene nun haben wir es mit

804 Risse, Gut ist es, 27.

805 Vgl. Risse, Gut ist es, 36. 
einer Er-Du-Perspektive zu tun. Innerhalb dieser wird die Deixis, mit V12 beginnend, vor allem durch die Personalsuffixe der 2.P.sg. konstruiert (dein Gott 12b, deiner Tore 13a, deine Kinder 13b, deine Mitte 13b, deine Grenze 14a, dich sättigen 14b). Es wird sehr nahe an das Erzählte herangezoomt, das dadurch eine persönliche Note erfährt. Innerhalb dieser Er-Du-Perspektive werden die für Jerusalem essentiellen und heilbringenden Themen des umfassenden Schutzes und der Sicherheit, besonders auch für die Nachkommenschaft, sowie des Friedens und des Wohlstandes verhandelt. Mit V15 wird die Deixis durch die den Ptz. vorangestellten Artikel (15a.16a) fortgeführt. Diese holen ebenso den Fokus heran und verweisen auf eine bestimmte Figur, im Falle von Ps 147 auf JHWH. Auch wenn in der Diskussion über die Funktion der Personaldeixis in der 3.P.sg. (anaphorisch oder deiktisch vgl. III Methodik 3.2) im Bibelhebräischen bisher kein Konsens gefunden werden konnte, so lässt sich nach den gesicherten deiktischen Elementen in V12-14, die in der Er-Du-Perspektive den Fokus auf ein Du lenken, ab V15-19b eine Häufung an Suffixen der 3.P.sg.m. feststellen (seine Rede 15a, sein Wort 15b.18a.19a, sein Eis 17a, seine Kälte 17b, seinen Wind 18b, seine Ordnungen 19b, seine Rechtsbestimmungen 19b). Diese verweisen zunächst anaphorisch auf JHWH zurück und holen den Fokus nicht näher an die Lesenden heran, wie dies etwa die deiktischen Pronomen ich - du - wir - unser hier - jetzt allgemein und jene aus V13-14 im Besonderen tun. ${ }^{806}$ Die Häufung der Suffixe der 3.P.sg.m. in V15-19b stellt durch die Er-Er-Perspektive eine in sich geschlossene Einheit dar, in der die einzelnen Elemente gegenseitig aufeinander verweisen. Der Fokus ist, im Gegensatz zu V12-14, nun weiter weg, was nicht nur mit der Anaphorik, sondern ebenso mit dem erzählten Inhalt über JHWH als Schöpfer zu tun hat. Der Inhalt bewegt sich damit von der göttlichen Zuwendung zu den Menschen weg, er wird allgemein formuliert und thematisiert die Gefährlichkeit der Natur im Zusammenhang mit Wasser und dessen vielfältigen Erscheinungsformen (Schnee, Reif, Eis).

Insgesamt kann festgehalten werden, dass in Ps 147 der Wechsel zwischen den verschiedenen Spots auffällt, der allerdings gut miterlebt werden kann: Die Lesenden springen, ausgehend von Jerusalem (V2-3), zu den Sternen (V4). Von den Niedergedrückten (V6) steigen die LeserInnen auf zu den Wolken (V8). Diese schauen auf Infanterie und Kavallerie (V10). Ein weiterer Sprung reicht von Jerusalem (V12-14) zu den winterlichen Wetterkapriolen (V16f) und deren Auflösung (V18), bis man am Ende bei den Ordnungen JHWHs (V19f) ankommt. Nach Alonso Schökel und Carniti dient dieser Fokuswechsel dazu, die

806 Die anaphorische Prozedur dient ja zur Aufrechterhaltung eines bereits bestehenden Fokus bzw. einer schon etablierten Fokussierung der Lesenden. Vgl. dazu Ehlich, Prozeduren, 122. 
Macht Gottes, die alle Bereiche des Lebens umfasst, und Gottes universale Herrschaft im Textfluss zu entwickeln. ${ }^{807}$

\subsection{Textdynamik}

Blickt man auf die Verben in Ps 147, dann fällt schon beim ersten Lesen die hohe Anzahl an Partizipien ins Auge. Vor allem jene Ptz. in der Aktivform, welche die Handlungen JHWHs zum Ausdruck bringen, strukturieren die einzelnen Abschnitte bzw. Verse des Psalms und ermöglichen dadurch eine durchgehende Bewegung bzw. Rhythmisierung des Psalms. Grundsätzlich drückt das Partizip, das als Mittelwort zwischen Verb und Nomen steht und an beiden partizipiert, eine andauernde Handlung aus, die auf allen drei Zeitstufen stattfinden kann, meist aber in der Gleichzeitigkeit zum erzählten Sachverhalt steht. ${ }^{808}$ Das Partizip weist zudem Ähnlichkeiten mit dem Adjektiv auf, das in Ps 147 auch mehrmals Verwendung findet. So präsentiert das Partizip - wie das Adjektiv - eine Handlung als einen Status, drückt dabei aber weniger die Aktionen selbst als vielmehr Umstände, Sachverhalte und Tatsachen aus. ${ }^{809}$ Hinsichtlich der Zeitenfolge setzt die PK das Ptz. fort bzw. kann das Ptz. anstelle der PK verwendet werden (vgl. 2b.4b.9b.10a.b.14b.15b.18a.b). Durch diese Konstruktion erhalten die PK-Formen in Ps 147 dieselbe Bedeutung wie die Partizipien. ${ }^{810}$ Hervorzuheben ist der a-temporale, durative Aspekt des Partizips, das - vor allem in der Verwendung als Prädikat - in linearer Weise eine Handlung prolongiert. ${ }^{811}$ In Ps 147 dominiert ein überzeitliches Verständnis der Partizipien. Charakteristisch ist

807 Vgl. Alonso Schökel / Carniti, Salmos 2, 1649.

808 Vgl. Krause, Hebräisch, $124 \mathrm{f}$.

809 Vgl. Waltke / O’Connor, Biblical Hebrew Syntax, 624. Die Autoren unterscheiden vier Funktionen des Partizips im Hebräischen: Es kann als Substantiv, Adjektiv, Relativpronomen oder Prädikat verwendet werden. Vgl. S. $613 \mathrm{f}$.

810 »The actions mentioned by the imperfect forms have repeatedly been done in the past, occur repeatedly in the present, and are to be expected in the future." Brodersen, The End of the Psalter, 175.

811 Vgl. Joüon / Muraoka, Grammar, 383. Dabei ist ein Merkmal von Ps 147 die Abwechslung zwischen mit Artikel determinierten (V2.3.8.14-16) und indeterminierten (V4.6.9.11.17.19) Partizipien. Vgl. Sedlmeier, Jerusalem, 64. Diese Abwechslung hat laut Risse, Gut ist es, 41 weniger semantische Implikationen, sondern ist eher als ein ästhetisches Prinzip der Variation zu betrachten. Ähnlich Waltke / O'Connor, Biblical Hebrew Syntax, 250: »The article is not consistently used even according to the best established patterns. Most often it is somitted,, or not used where it would be expected, in poetry, and this pattern of nonuse is truer of older poetry, though the pattern is found in relatively late poetic passages and in prose." 
die Abfolge: Partizip mit oder ohne Artikel an erster Stelle - PK am Versende (V2.4.9.14.16.17), ein Mal mit Subjekt am Ende von V15. ${ }^{812}$

Ps 147 steht aufgrund der Quantität an Partizipien vor allem in der Gleichzeitigkeit mit dem erzählten Sachverhalt, welcher einer gewissen Zeitlosigkeit entspricht, und weist keine wesentlichen Pro- oder Analepsen auf. Die Imperative des Textes verstärken mit ihrem zeitdeckenden Aspekt die Jetztzeit-Ebene. Diese direkten Anreden passen daher gut zu Form und Inhalt des Textes. Ganz anders stellt sich im Vergleich dazu die Analyse von Ps 30 dar. Dort kann aufgrund der Narrative, der unterscheidbaren Zeitebenen und der Ereignisfolgen von zwei Minierzählungen gesprochen werden. Die Imperative in Ps 30 holen das Geschehen immer wieder in das Jetzt zurück. Diese markante Funktion kommt den Aufforderungen in Ps 147 aufgrund der den gesamten Text prägenden Gleichzeitigkeit nicht zu.

In Bezug auf Zeitebenen können in Ps 147 einzig die SK-Formen in V13.20 als Rückblick verstanden und in der Vergangenheit wiedergegeben werden. ${ }^{813}$ So passt die formale Gestaltung durch die Partizipien und Adjektive, durch die ein anhaltend beschreibender Effekt erzielt wird, zum Inhalt des Psalms, der das Gottesbild zum Thema hat und JHWH in seinem Tun und Sein charakterisiert. ${ }^{814}$

Die im Psalm beschriebenen Sachverhalte werden zusätzlich onomatopoetisch unterstützt: »At the center of this psalm, one hears the cries of a nest full of young ravens. Amid the sounds of musical productions in the temple (vv. 1,7) and of wind, rain and hail in the countryside (vv. 8, 17-18) are those raven cries. $"{ }^{815}$ Der Rhythmus und die Melodie von Ps 147 werden deutlich durch Lautmalerei und Klang bestimmt, wie dies mehrere Kommentatoren betonen. ${ }^{816}$ Unter den in Ps 147 auftretenden literarischen Stilfiguren sticht die Alliteration hervor. Wilfred Watson benennt verschiedene Funktionen der Alliteration, darunter jene, die

812 Vgl. Risse, Gut ist es, $41 \mathrm{f}$. Zur Verwendung von Partizipien und Artikel in Ps 147 siehe ausführlicher Brodersen, The End of the Psalter, 174f.

813 Die Handlungen aus der Vergangenheit wirken in die Gegenwart weiter. Die SK hat damit einen zeitübergreifenden Aspekt. Vgl. Risse, Gut ist es, 43. Nach Brodersen, The End of the Psalter, 176 beziehen sich die SK-Formen ebenso auf Handlungen in der Vergangenheit, die Konsequenzen für die Gegenwart haben. Dies passt auch zu den Lobaufforderungen: JHWH soll für jene vergangene Taten gelobt werden, von denen diejenigen, die zum Lob aufgerufen werden, noch immer profitieren.

814 Viviers, Psalm 147, 174:»[...] form and content complement each other«.

815 Limburg, Psalms, $496 f$.

816 »Vor allem die hymnisch beschreibenden Teile sind klanglich komponiert. Besondere Klangformen finden sich in $4.8(\mathrm{~m}), 5$ ( $a$-o-Sequenz), 8 ( $a$ - $i$-Sequenz), in $18(\mathrm{~s} / z)$, auffallende Klangfiguren in 9.13 (alliteratives $b, k$ im Endreim [...]. 14b.15.16 (besonders die Variation p-r).17.« Seybold, Die Psalmen, 539. Zum Folgenden vgl. Allen, Psalms 101-150, 309; Dahood, Psalms 3, 349; Alonso Schökel / Carniti, Salmos 2, 1651; Anderson, The Book of Psalms 2, 947; Limburg, Psalms, 496f; Weber, Werkbuch 2, 375f; Goldingay, Psalms 3, 718; Fokkelman, Major Poems, 319 und Viviers, Psalm 147, $174 \mathrm{f}$. 
Aufmerksamkeit der Lesenden anschaulich und unverwartet auf die Details eines Objekts, einer Person oder eines Ereignisses zu lenken. ${ }^{817}$ So weisen die beiden

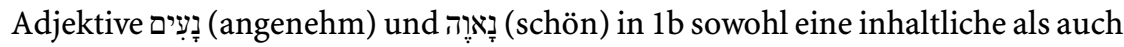
eine klangliche Nähe zueinander auf. »In den Versen 2-3 zeigt sich die Freude des Dichters an Alliteration und Assonanz. In Vers 2 beginnen vier Wörter mit Jod [...]. In Vers 3 haben drei Wörter Lamed als Anfangskonsonanten. Das Sere steht in $2 \mathrm{~b}$ und $3 \mathrm{a}$ in der Endsilbe eines jeden Wortes, außerdem noch im ersten Wort von $2 \mathrm{a}$ und $3 \mathrm{~b}$. Im Wohlklang der Verse zeigt sich die Freude am Gotteslob. ${ }^{818}$ In V4 ist eine Mem- sowie Lamed-Kaph-Alliteration auszumachen, in V6 eine AjinAlliteration. Zwischen 6a und 7a ist mit עַנָוִים (die Gebeugten) und עֶנוּ (besingt) eine Lautparallele auszumachen. Gleich mehrere Assonanzen, Alliterationen und reimende Wörter sind in V8-9 auszumachen, die dadurch sehr klangvoll wirken: „Die Freude am Wortklang spiegelt die Freude an JHWHs Walten in der Schöpfung. ${ }^{819}$ So findet sich z. B. in V9 eine Lamed-Beth-Alliteration. Vier Worte beginnen in V13 mit Beth ${ }^{820}$ und enden mit Kaph, wobei in diesem Vers die

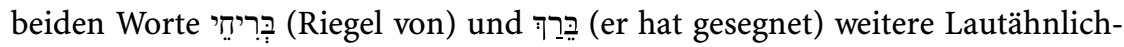
ארָרץ (Erde) und דָרוּץ (es eilt) in V15. In V16 ist eine Kaph-Pe-Resch-Alliteration zu entdecken, wobei Resch vier Mal als Schlusslaut

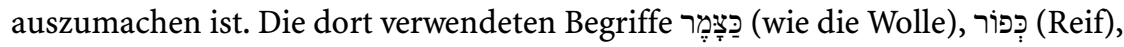
כָּאֵֵָּר (wie die Asche/der Staub) stehen sich dabei nicht nur klanglich, sondern auch inhaltlich nahe. Eine Assonanz mit inhaltlicher Nähe ist ebenso in V17 mit

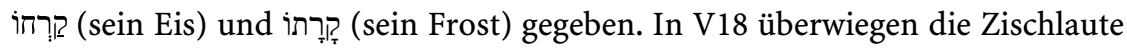
Schin, Samech und Zajin. Wie JHWH in die erstarrte Natur wieder Bewegung hineinbringt, wird in diesem V18 auch lautlich ausgedrückt. ${ }^{821}$ Von V15-18 ist eine Schin-Lamed-Sequenz auszumachen. Laut Viviers wird die Kraft des Wortes Gottes durch die Assonanz in V19 noch zusätzlich verstärkt. ${ }^{822}$ Diese Beispiele zeigen die Vielzahl an Assonanzen, Alliterationen, Wort- und Lautspielen in Ps 147 auf, die das im Psalm Erzählte intensivieren und dadurch die Möglichkeit eröffnen, neben den inhaltlichen Anknüpfungspunkten auch durch die Form des poetischen Textes, durch Klangfarbe, Melodie und Rhythmus in die Bewegung und Bewegtheit der Textwelt einzusteigen und diese mitzuerleben.

817 Vgl. Watson, Classical Hebrew Poetry, 228. Er strukturiert seine Ausführungen über den Klang in der hebräischen Poesie entlang der Kategorien Assonanz, Alliteration, Reim, Lautmalerei sowie Wortspiel und nennt dabei auch die Funktionen der genannten Stilmittel; am Beginn des Kapitels weist er auf die Schwierigkeiten der Aussprache, die ja für den Klang einer Sprache wesentlich ist, im Bibelhebräischen hin (vgl. S. 222).

818 Risse, Gut ist es, 34.

819 Risse, Gut ist es, 36.

820 Watson, Classical Hebrew Poetry, 226 determiniert die Alliteration in 13b als »word-initial alliteration«.

821 Vgl. Risse, Gut ist es, 38.

822 Vgl. Viviers, Psalm 147, 175. 
Wie oben bereits erwähnt, kann in Ps 147 von drei verschiedenen Szenen - und weniger von Minierzählungen wie in Ps 30 - gesprochen werden, die jeweils die drei großen Themen des Psalms - erstens die Handlungen JHWHs an Israel/ Jerusalem (V2-3.13-14.19), zweitens die Handlungen JHWHs an der/in der/ durch die Schöpfung (V4.8-9.16-18) sowie drittens die Handlungen JHWHs an anderen (allgemein formuliert: V6.10-11.20) - in Variationen in den Blick nehmen. Dabei bleiben die Grundthemen konstant, es ändern sich jedoch die Details und die Blickrichtungen.

\subsubsection{Erste Szene V1-6}

Am Beginn jeder Szene wird die Perspektive durch die Sprechrichtung an die AdressatInnen bestimmt. Mit dem Auftakt und der Coda הַלְלוּי-יקיה (lobt JH 1a.20c) wird der Rahmen des Lobes vorgegeben. Der Blick ist auf JHWH gerichtet, um den sich der gesamte Psalm dreht. Eine nicht näher genannte Öffentlichkeit wird aufgefordert, in das Lob Gottes einzustimmen. Durch die refrainartige Wiederaufnahme dieser Lobaufforderung (1a.7.12.20b) nach ungefähr gleichem Versabstand wird der Rhythmus des Psalms nicht unterbrochen. Vielmehr prägen auch diese Verse den Stil des Psalms und tragen zum Gleichmaß bei. Ab V2 fällt die dominante Stellung der Partizipien jeweils am Beginn des Verses (V2-4.6; Ausnahme: V5, Erklärung siehe unten) ins Auge. Da es in dieser ersten Szene nur vier Konjunktionen gibt ( $2 \mathrm{x}$ 'כִ in 1b.c, $2 \mathrm{x}$ ? in $3 \mathrm{~b} .5 \mathrm{~b}$ ), die vor allem die Verbindungen innerhalb der Verse herstellen, ist hinsichtlich der rhythmischen Übergänge, die die Textdynamik in Fluss halten, auf die bereits genannten Partizipien am jeweiligen Versanfang zu verweisen. Durch die Wiederholung der immer gleichen Verbformen am Beginn entsteht bis V6 eine rhythmische Bewegung innerhalb des Psalms. Der mit einem Adjektiv - und nicht wie alle anderen Verse mit einem Partizip - eingeleitete Nominalsatz in V5 fällt deshalb nicht aus dem Rahmen, da an dieser Stelle das Adjektiv, ebenso wie die Partizipien, prädikativ verwendet wird. Das Eigenschaftswort macht, indem es hier als Prädikat fungiert, Aussagen und Behauptungen über ein Subjekt, in diesem Fall über die Gottheit Israels. ${ }^{823} \mathrm{~V} 6$ endet inhaltlich mit einer deutlichen Abwärtsbewegung (bis zum Boden).

Die Subjekt-Verb-Objekt-Verbindungen lassen sich folgendermaßen darstellen: ${ }^{824}$

823 Zur Verwendung des Adjektivs als Prädikat vgl. Waltke / O’Connor, Biblical Hebrew Syntax, 261.

824 Steht das Subjekt in Klammern, so wird damit angezeigt, dass es nicht explizit erwähnt ist, jedoch aus dem Vorhergehenden weitergeführt bzw. in der Verbform enthalten ist. Mit "Er" ist der Artikel angezeigt. Mit »(Er)« wird darauf verwiesen, dass das Ptz. indeterminiert ist. 


\begin{tabular}{|c|c|c|c|}
\hline Vers & Subjekt & Handlung & Objekt \\
\hline la & - & $\begin{array}{l}\text { הללל loben } \\
\text { Imp.pi.m.pl. }\end{array}$ & $\mathrm{JH}$ \\
\hline $1 b$ & - & $\begin{array}{l}\text { spielen, singen זמר } \\
\text { Inf.pi.constr. }\end{array}$ & unser Gott \\
\hline $1 \mathrm{c}$ & Lobgesang & - & - \\
\hline $2 \mathrm{a}$ & JHWH & $\begin{array}{l}\text { bauen בנה } \\
\text { Ptz. q. }\end{array}$ & Jerusalem \\
\hline $2 \mathrm{~b}$ & (JHWH) & $\begin{array}{l}\text { sammeln כנס } \\
\text { PK pi. }\end{array}$ & Verstoßene Israels \\
\hline $3 a$ & Er & $\begin{array}{l}\text { heilen רפא רפ. q. } \\
\text { Ptz. }\end{array}$ & die zerbrochenen Herzens sind \\
\hline $3 \mathrm{~b}$ & (Er) & $\begin{array}{l}\text { verbinden חבש } \\
\text { Ptz. pi. }\end{array}$ & ihre Wunden \\
\hline $4 a$ & (Er) & $\begin{array}{l}\text { מנה מנהhlen } \\
\text { Ptz. q. }\end{array}$ & $\begin{array}{l}\text { eine Anzahl; } \\
\text { für Sterne/ } \\
\text { von Sternen }\end{array}$ \\
\hline $4 \mathrm{~b}$ & (Er) & $\begin{array}{l}\text { קufen קרא } \\
\text { PK q. }\end{array}$ & $\begin{array}{l}\text { für alle; } \\
\text { Namen }\end{array}$ \\
\hline $5 a . b$ & unser Adonaj & - & \\
\hline $5 \mathrm{c}$ & eine Anzahl & - & für seine Klugheit \\
\hline $6 a$ & JHWH & $\begin{array}{l}\text { aufrichten עוד } \\
\text { Ptz. po. }\end{array}$ & Gebeugte \\
\hline $6 \mathrm{~b}$ & $(\mathrm{JHWH})$ & $\begin{array}{l}\text { niederdrücken שפל } \\
\text { Ptz. hi. }\end{array}$ & $\begin{array}{l}\text { Frevler; } \\
\text { bis zum Boden }\end{array}$ \\
\hline
\end{tabular}

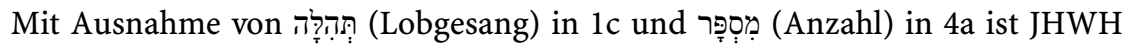
durchgehend Subjekt dieser ersten Szene. JHWH ist einzig und allein derjenige, der aktiv handelt und sich für bzw. gegen bestimmte Menschengruppen bzw. Himmelskörper einsetzt. Die in Objektposition stehenden Gruppen bleiben durchgehend passiv, an ihnen wird gehandelt. Hier kommt nicht nur die Quantität der Handlungsmacht JHWHs und deren Wirkung zum Ausdruck, sondern durch die Unterschiedlichkeit der Handlungen, die JHWH vornimmt, ebenso eine große Qualität. Die daraus resultierenden Themen, die in der ersten Szene zur Darstellung gelangen, lassen sich folgendermaßen benennen:

\begin{tabular}{|l|l|}
\hline Vers & Thema \\
\hline $1 \mathrm{a}$ & Aufruf zum Lob an ein Ihr \\
\hline $1 \mathrm{~b}$ & Begründung und Verstärkung des Lobens und Musizierens für JHWH \\
\hline 2a & JHWH als Bauherrin Jerusalems \\
\hline 2b & JHWH als Hirte \\
\hline 3a.b & JHWH als Ärztin \\
\hline 4 & JHWH als Lenker des Kosmos \\
\hline
\end{tabular}


(Fortsetzung)

\begin{tabular}{|l|l|}
\hline Vers & Thema \\
\hline 5 & Größe, Kraft und unermessliche Klugheit JHWHs \\
\hline 6 & JHWHs Stärkung der Gebeugten und Erniedrigung der Frevler \\
\hline
\end{tabular}

\subsubsection{Parallelismen}

Der Zeitfaktor beim Psalmlesen wird wesentlich von der Art und Anzahl der Parallelismen bestimmt. Diese bewirken, dass die Lesenden den Gedanken in zweifacher Weise präsentiert bekommen und damit länger am Text bleiben. Parallelismen bewirken eine Intensivierung, Konkretisierung und Dynamisierung des Gedankengangs und verhindern damit ein zu hastiges Lesen. Sie verlangsamen den Leseprozess, wodurch eine größere Möglichkeit gegeben ist, sich mit den in der Textwelt präsentierten Inhalten zu identifizieren. Die erste Szene von Ps 147 wird von synonymen und synthetischen Parallelismen dominiert, und zwar vor allem innerhalb der Verse. ${ }^{825}$ So steht $1 \mathrm{c}$ synonym zu 1b, wobei hier auch

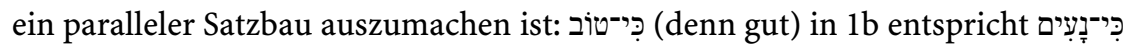

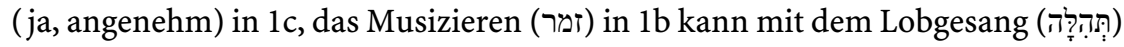
in 1c gleichgesetzt werden. Der Lobaufruf in la wird nicht nur ein Mal kurz getätigt und verschwindet dann wieder, sondern er wird mit der Begründung in $1 \mathrm{~b}$ noch verstärkt. Die Begründung von $1 \mathrm{~b}$ enthält die Aussage, dass es gut, zweckmäßig und nützlich ist, JHWH zu loben. Dieser Zweckmäßigkeit werden in

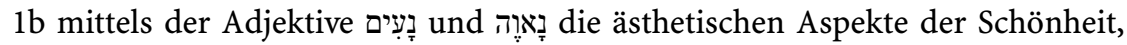
Köstlichkeit und Anmut hinzugefügt, wodurch die Aussage "sinnlicher" und damit intensiviert wird. Danach werden die Handlungen JHWHs an Israel erzählt. Dies geschieht innerhalb von V2 mittels eines synthetischen Parallelismus: Die Zuwendung JHWHs zur (zerstörten) Stadt Jerusalem in Form des (Wieder-) Aufbaus in 2a wird in 2b mit der Zuwendung zu den Vertriebenen des Volkes Israels fortgesetzt. Dabei wird die allgemeine in Partizipialform gehaltene Formulierung des Erbauens Jerusalems von 2a durch das finite Verb des Sammelns und das Objekt der Vertriebenen Israels in 2b konkretisiert und spezifiziert. V3 ist in sich synonym konzipiert: JHWHs heilende Zuwendung zu denen, die zerstörten Herzens sind, wird in zwei Variationen erzählt. Dabei drückt der zweite Halbvers durch die Tätigkeit des Verbindens eine größere Nähe als der erste Halbvers aus. Es kommt damit zu einer Intensivierung der Aussage. Durch die Konjunktion ? in 3 b werden die beiden Stichen miteinander verbunden. Blickt man auf die Versabfolge, so stehen V2 und V3 in einem synthetischen Paralle-

825 »Every line in the psalms involves parallelism, and in most lines, at least in the first two sections, the parallelism involves marked intensifying; the second colon is more concrete or dramatic or vivid." Goldingay, Psalms 3, 718. 
lismus zueinander: V3 führt die Zuwendung JHWHs fort und eine weitere Dimension ein, nämlich die der Heilung. Jerusalem und Israel aus V2 werden in V3 spezifiziert durch jene, deren Herzen zertrümmert sind und die Schmerzen erleiden. Hier kommt die Dimension der Gewalt, die großes Leid verursacht und die auch hinter V2 steckt, deutlicher und detaillierter zum Vorschein, auch wenn nicht berichtet wird, was genau passiert ist. Warum muss Jerusalem aufgebaut werden? Wie kommt es dazu, dass es Verstoßene aus dem Volk Israel gibt? Was genau hat in die Notsituation geführt, die das Zerbrechen der Herzen und das Zufügen von Leid und Schmerzen verursacht hat? Ungeachtet dieser Fragen nimmt die erste Szene mit V4.5 in einem dritten Spot JHWH in den Blick. Es geht nun um die kosmische Dimension und um JHWH in seiner unermesslichen Größe. V4 kann in sich als synthetisch strukturiert bezeichnet werden: In 4a zählt JHWH die Anzahl der Sterne, und in $4 \mathrm{~b}$ kommt der persönliche Bezug der Namensgebung der Sterne hinzu. ${ }^{826}$ Damit ist eine Bewegung vom Allgemeinen ins Konkrete auszumachen. V5a.b sind synonym konzipiert und - wie 1b.c -

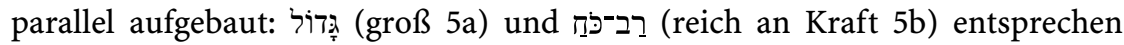
einander. V5 steht zu V4 in einem synthetischen Verhältnis: Die Größe Gottes im Kosmos (V4) wird fortgesetzt durch weitere Eigenschaften, die diese Größe beschreiben (groß; reich an Kraft; unermessliche Klugheit V5). Beide Verse werden durch das Stichwort (מִסָָּּר (Anzahl 4a.5b) chiastisch miteinander verbunden, wobei durch die Verneinung in $5 \mathrm{~b}$ eine Plus-Minus-Verkettung gegeben ist: JHWH zählt die Sterne, seine eigene Klugheit jedoch kann nicht gezählt werden. ${ }^{827}$ Die erste Szene schließt mit einem vierten Spot, der mittels eines antithetischen Parallelismus den Umgang JHWHs mit den Armen in Kontrast setzt zu jenen mit den Frevlern. Diese Gegensätzlichkeit wird durch die klare Bewegung nach oben bzw. nach unten intensiviert: Während JHWH die Armen, Gebeugten aufrichtet, die unten sind, drückt die Gottheit die Gottlosen oder Verbrecher nieder, und zwar bis zum Boden. Die Erniedrigung der Frevler wird damit drastischer dargestellt als das Aufrichten der Armen, sodass eine Dramatisierung der Aussageabsicht festzustellen ist.

\subsubsection{Räume und Zeiten}

Blickt man auf die Räume und Zeitangaben in der ersten Szene, so sind mit dem Boden (ארק 6b) und Jerusalem (2a), das als Stadt - sowie metaphorisch als Gemeinde - aufgebaut wird, zwei Räume auszumachen. Ein weiterer, und zwar

826 Anders Risse, Gut ist es, 34: »Man kann den Vers so verstehen, dass mit Zahl-bestimmen und Mit-Namen-rufen in den beiden Halbversen das gleiche ausgedrückt wird: JHWHs Macht über die Sterne. In diesem Sinne liegt ein synonymer Parallelismus vor.«

827 Vgl. Fokkelman, Major Poems, 318. 
der Himmelsraum bzw. der Kosmos, wird mit der Nennung der Sterne (4a) eingespielt. Ein Temporalobjekt lässt sich in der ersten Szene nicht finden.

\subsubsection{Zweite Szene V7-11}

Wie die erste Szene beginnt auch die zweite mit einem Imp.pl. und damit mit einer AdressatInnenperspektive. Die Gemeinde wird aufgefordert, JHWH mit Dank und Musizieren zu antworten. ${ }^{828}$ Dabei ist das Verb ענה (antworten; hier besingen, zusingen, ein Lied anstimmen ${ }^{829}$ als verbindendes Element zwischen der ersten und der zweiten Szene zu betrachten, zumal sich die Antwort in musikalischer Form inhaltlich auf die in V2-6 geschilderten Wohltaten JHWHs an Jerusalem (2a), Israel (2b) und leidenden sowie gebeugten Menschen (V3.6a) bezieht. Weitere Verknüpfungen zwischen der ersten und der zweiten Szene seien hier kurz erwähnt. Zunächst fallen folgende Stichwortverbindungen ins Auge:

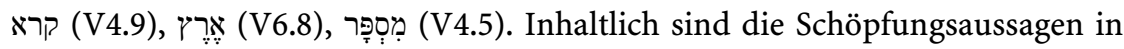
V8f verbunden mit den vorhergehenden Armenaussagen in V6 (Stichwort: Rabenjunge). Der inhaltlichen Opposition von V6 entspricht jene von V10f.

\subsubsection{1 Übergänge und Struktur}

Nun aber zurück zur zweiten Szene: Neben den Imperativen m.pl. in V7 fällt, wie in der ersten Szene, die große Anzahl an Partizipien (5x in Subjektposition 8a.b.c.9a.11a; $1 \mathrm{x}$ in Objektposition 11b) auf, wobei es hier in der zweiten Szene zu einer Abwechslung mit Verben in der PK-Form (3x 9b.10a.b) kommt. Wie bereits erwähnt, kann die PK einem Ptz. folgen bzw. können sich Ptz. und PK abwechseln. Die Gleichzeitigkeit der Handlungen bleibt bei dieser Zeitenfolge bestehen. Der Rhythmus einer gleichförmigen Bewegung wird damit beibehalten. So gestalten sich auch die Übergänge von Szene $1 \mathrm{zu}$ Szene 2 sowie jene innerhalb der zweiten Szene als ebenmäßig und ausgewogen. Wie bereits oben dargestellt, wird in 7a dazu aufgefordert, das, was in der ersten Szene erzählt wird, antwortend zu besingen. V7 stellt also eine mögliche Reaktion auf den ersten Textabschnitt von Ps 147 dar. V8 setzt dann, wie in der ersten Szene, mit Partizipien ein, die bis V9 am Beginn eines jeden Satzes stehen. Die Ptz. können als Verbindungselemente zwischen den einzelnen Sätzen innerhalb von V8 sowie zwischen V8.9 betrachtet werden. Die Wiederholung ein- und derselben Verbform - in V8 verstärkt durch den Artikel - trägt zur Rhythmisierung dieses Textabschnittes bei. Die determinierten Ptz. in V8 dienen dabei der Anbindung an den vorausgehenden Kontext und füllen neben der Leerstelle des Prädikats auch jenes des Subjekts

828 »Der zweite Teil ist mehr auf Dank gestimmt« bei Weiser, Die Psalmen 2, 558.

829 Vgl. Hossfeld / Zenger, Psalmen 101-150, 832. 
aus. ${ }^{830}$ Durch diese formale Struktur wird eine Übereinstimmung mit dem Inhalt von V8 erreicht, d. h. mit dem kontinuierlichen Schöpfungshandeln JHWHs. ${ }^{831}$

Das letzte Element von V10 (רצה PK q. 3.P.m.sg.) wird zu Beginn von V11 רצה Ptz.q.m.sg.) wieder aufgenommen, sodass ein nachvollziehbarer Übergang zwischen den beiden Versen 10 und 11 geschaffen ist. Inhaltlich wirkt - wie in V6 ein Oppositionsverhältnis: Das, was die Gottheit nicht will, wird dem gegenübergestellt, was sie will. ${ }^{832}$ Bleibt noch der Übergang zwischen V9.10 zu klären: V10 setzt mit לא (nicht) betont und vielleicht auch etwas abrupt ein. Dieser Vers steht inhaltlich sowohl im Kontrast zu V11 als auch zu V9. In V9 wird von der sorgsamen Zuwendung JHWHs zu den jungen Raben erzählt, die klein und hilfsbedürftig sind, während davon in V10 durch die Rede von der Mächtigkeit und Stärke des Pferdes nichts mehr zu merken ist. V10 und 11 stehen durch die verschiedenen Menschengruppen, an denen JHWH Gefallen bzw. keinen Gefallen hat, in Opposition zueinander. Dennoch können verbindende Elemente zwischen V9.10 eruiert werden: Es sind dies die Tierthematik einerseits sowie andererseits die Weiterführung der PK, die am Ende von V9 nach einer langen Reihe von Ptz. eingeführt und in V10 prolongiert wird. Mit V10 ist zwar ein Einschnitt gegeben, ein Herausfallen aus der Textdynamik wird aber durch die eben beschriebenen Verbindungsglieder verhindert. ${ }^{833}$ Das beinahe durchgehende Subjekt JHWH (einzige Ausnahme nach V7 ist 9b), dem durch die Textdynamik hindurch gefolgt werden kann, verbindet ebenso die einzelnen Verse miteinander, wie das folgende Schema Subjekt - Handlung - Objekt zeigt:

\begin{tabular}{|l|l|l|l|}
\hline Vers & Subjekt & Handlung & Objekt \\
\hline $7 \mathrm{a}$ & - & $\begin{array}{l}\text { besingen } \text { IV IV } \\
\text { Imp.q.m.pl. }\end{array}$ & mit einem Danklied \\
\hline $7 \mathrm{~b}$ & - & $\begin{array}{l}\text { spielen/musizieren רמ } \\
\text { Imp.pi.m.pl. }\end{array}$ & $\begin{array}{l}\text { unserem Gott; } \\
\text { auf der Harfe }\end{array}$ \\
\hline $8 \mathrm{a}$ & Er & $\begin{array}{l}\text { bedecken } \\
\text { Ptz. pi. }\end{array}$ & $\begin{array}{l}\text { den/die Himmel; } \\
\text { mit Wolken }\end{array}$ \\
\hline $8 \mathrm{~b}$ & Er & $\begin{array}{l}\text { bereiten כון } \\
\text { Ptz. hi. }\end{array}$ & $\begin{array}{l}\text { der Erde; } \\
\text { Regen }\end{array}$ \\
\hline
\end{tabular}

830 Vgl. Sedlmeier, Jerusalem, 262 Anm. 78: „Dass die rhythmische Wiederholung des Artikels und der damit gegebene betonte Rückverweis auf das handelnde Subjekt Jahwe auch für die inhaltliche Aussage wesentlich ist, lässt sich deutlich aufzeigen.»

831 Vgl. Sedlmeier, Jerusalem, 262.

832 Vgl. Fokkelman, Major Poems, 318.

833 Auf den inhaltlichen Konnex zwischen V8f und V10f weist Sedlmeier, Jerusalem, $260 \mathrm{ff}$ hin. Dabei stellt er auf S. 261 folgende Verklammerung vor: »V.9: Positive Wertung des Tieres: Rabe. V.10a: Negative Wertung des Tieres: Streitroß. V.10b: Negative Wertung des Menschen: Krieger. V.11: Positive Wertung des Menschen: Gottesfürchtige, Harrende.» 
(Fortsetzung)

\begin{tabular}{|c|c|c|c|}
\hline Vers & Subjekt & Handlung & Objekt \\
\hline $8 c$ & Er & $\begin{array}{l}\text { wachsen lassen צמח } \\
\text { Ptz. hi. }\end{array}$ & $\begin{array}{l}\text { auf Bergen; } \\
\text { Gras }\end{array}$ \\
\hline $9 \mathrm{a}$ & (Er) & $\begin{array}{l}\text { geben נתן } \\
\text { Ptz. q. }\end{array}$ & $\begin{array}{l}\text { dem Tier; } \\
\text { Nahrung }\end{array}$ \\
\hline $9 b$ & $\begin{array}{l}\text { (Er) } \\
\text { (Sie) }\end{array}$ & $\begin{array}{l}\text { (geben) } \\
\text { schreien קרא } \\
\text { PK q. }\end{array}$ & $\begin{array}{l}\text { den jungen Raben; } \\
\text { das/wonach }\end{array}$ \\
\hline $10 \mathrm{a}$ & (Er) & $\begin{array}{l}\text { nicht Gefallen haben } \\
\text { לא + לא } \\
\text { PK q. } \\
\end{array}$ & an der Stärke des Pferdes \\
\hline $10 \mathrm{~b}$ & (Er) & $\begin{array}{l}\text { nicht Wohlgefallen haben } \\
\text { לא + רצה } \\
\text { PK q. }\end{array}$ & an den Schenkeln des Mannes \\
\hline $11 \mathrm{a}$ & JHWH & $\begin{array}{l}\text { Wohlgefallen haben רצה } \\
\text { Ptz. q. }\end{array}$ & an den Gottesfürchtigen \\
\hline $11 \mathrm{~b}$ & (JHWH) & - & an den auf seine Huld Wartenden \\
\hline
\end{tabular}

Die Darstellung der umfassenden Aktivität Gottes gegenüber der Schöpfung führt in der zweiten Szene die in der ersten Szene erzählte Mächtigkeit Gottes im Universum weiter und konkretisiert sie zugleich. Die Figur Gott wird in dieser Szene als jene dargestellt, die für das Wachsen in der Natur (Flora und Fauna) Verantwortung trägt. Ist in der ersten Szene von der heilenden Zuwendung Gottes zu den Menschen die Rede, so hier in der zweiten stärker von der Charakterisierung Gottes in Bezug zu bestimmten Menschengruppen, wobei das Thema der Zuwendung im Wohlgefallen JHWHs mit anklingt. Zeitangaben lassen sich in dieser Szene nicht auffinden - die Darstellung Gottes als sorgsamer Schöpfer kann somit als zeitlos charakterisiert werden. Analysiert man die Räume, dann werden mit dem Himmel (8a), der Erde (8c) und den Bergen (8c) diejenigen thematisiert, denen sich die Gottheit widmet.

Folgende Themen werden in der zweiten Szene geschildert:

\begin{tabular}{|l|l|}
\hline Vers & Thema \\
\hline 7 & Aufruf, JHWH zu danken und zu musizieren \\
\hline $8-9$ & JHWH als Schöpfer, der Natur und Tiere wachsen lässt und ernährt \\
\hline 10 & Abneigung JHWHs gegenüber militärisch Starken und Schnellen \\
\hline 11 & Vorliebe JHWHs für Gottesfürchtige und auf seine Güte Wartende \\
\hline
\end{tabular}




\subsubsection{Parallelismen}

Zu guter Letzt wird nun in der Analyse der Textdynamik der Zeitfaktor beim Lesen in Bezug auf die zweite Szene genauer betrachtet. Wie bereits in der ersten Szene fallen auch hier die sich zwischen synonymen und synthetischen Konstruktionen abwechselnden Parallelismen ins Auge: Durch die offensichtlich parallel gestalteten Textelemente besingen (ענה 7a) - musizieren (7b); für JHWH (Präp. ? 7a) für unseren Gott (Präp. ’ ? 7b) sowie mit einem Danklied (Präp. רְ 7a) - mit der Harfe (Präp. בุ 7b) beginnt die zweite Szene mit einem synonymen Parallelismus. Dieser intensiviert den Dankaufruf an Gott durch die Aufforderung, dies auch musikalisch - und zwar sowohl vokal als auch instrumental - auszudrücken. Wird in 8a die meteorologische Vorstufe des Regens erwähnt (Wolken am Himmel), so geht es in 8b um die Ausführung (Regen auf der Erde). 8c führt den Gedanken aus 8a.b synthetisch weiter, indem die Folge des Regens beschrieben wird, nämlich das Wachstum, und zwar sogar das auf den Bergen. Für V8 kann somit ein Dreischritt festgehalten werden: (1) Vorbereitung, (2) Durchführung und (3) Folgeeffekt. 9a.b sind ebenfalls synthetisch gestaltet: $9 \mathrm{~b}$ führt den allgemein formulierten Gedanken der Ernährung der Tiere durch die Gottheit weiter, indem dieser mit der göttlichen Zuwendung zu den jungen Raben, die noch dazu eine Stimme erhalten, spezifiziert wird. Dabei ist eine versteckte Wiederholung feststellbar, zumal das Verb (geben) elliptisch weitergeführt wird. V10 kann sowohl als synonymer als auch als synthetischer Parallelismus klassifiziert werden: Während die Versstruktur parallel ist (ל + Objekt mit eingeleitet + synonym. Verb in PK) und das Thema der Kraft und Schnelligkeit sowohl in 10a als auch in 10b zur Darstellung gelangt (synonym), wird nach dem Pferd in 10a nun der Mann/Mensch in 10b in den Blick genommen und damit dem Thema eine Nuance hinzugefügt (synthetisch). Der letzte Vers dieser Szene steht inhaltlich antithetisch zu V10 (Schnelligkeit, Heldenhaftigkeit, Auf-Pferde-und-Menschenstärke-Setzen V10 vs. Geduld, Langsamkeit und AufJHWH-Setzen V11), ist in sich jedoch abermals synonym gestaltet, zumal Subjekt und Prädikat aus 11a in 11b weiterklingen und die Gottesfürchtigen (Adj.) mit den auf Gottes Huld Wartenden (Ptz.) gleichgesetzt bzw. durch diese spezifiziert werden. "JHWH steht auf Seite der Armen gegen die Frevler. Er steht auf der Seite derer, die ihm ganz vertrauen, gegen die Machtprotze. ${ }^{834}$

\subsubsection{Dritte Szene V12-20}

Wie bereits in den vorhergehenden Szenen wird auch diese mit Imp.-Formen eröffnet, die diesmal jedoch im Singular formuliert sind. Hinsichtlich der Thematik lässt sich einerseits eine Wiederaufnahme des Schöpfungsthemas (V1618) sowie jene der Zuwendung zu Jerusalem (V13-14) und die Bezugnahme auf

834 Risse, Gut ist es, 28. 
das Volk Israel (V19) erkennen, andererseits werden mit den Themen des Schutzes und der Sicherheit (V13-14) sowie des Glücks und des Wohlstandes für Jerusalem (14b), der Wortmächtigkeit JHWHs (V15.18) sowie mit dem Einspielen der Völker (V20) neue Akzente gesetzt. Jerusalem wird hier aus V2 wieder aufgenommen. Während in V2 die Dimension der Zerstörung, der Gewalt, der Not und der Trauer mitschwingt und Jerusalem in Objektposition steht, wird Jerusalem hier in V12-14 in seiner Ganzheit als Subjekt angesprochen. Die Wunden (V3) sind verbunden, Jerusalem wird die Fähigkeit, seinen Gott zu loben und $\mathrm{zu}$ preisen (V12), zugestanden, und es ist vom sicheren, gedeihlichen und glücklichen Leben in der Stadt die Rede (V13-14). Damit ist gegenüber der ersten Szene eine deutliche Entwicklung erkennbar: Wird am Beginn von Ps 147 ein notleidendes, verwundetes Bild von Jerusalem gezeichnet, so zeigt hier in der letzten Szene des Psalms das heilende Eingreifen JHWHs seine Wirkung und die Stadt beginnt, erneut in Sicherheit und Wohlstand zu leben. Sowohl Gemeinsamkeiten als auch Unterschiede sind zwischen der ersten und der dritten Szene festzuhalten: In Szene 3 werden die gleichen Themen wie in Szene 1 in den Blick genommen, einzig die Reihenfolge variiert: Jerusalem (V2; V12-14), Schöpfung (V4; V16-18), Israel (2b; V19), kontrastive Allgemeinaussagen (V6; V20). Das Schöpfungsthema zieht sich durch den gesamten Psalm und ist auch in Szene 2 präsent (V8-9). Zwischen der zweiten und der dritten Szene kann insofern eine Dynamik festgestellt werden, als JHWH in V9 den Hunger der jungen Raben stillt und in $14 \mathrm{~b}$ ebenso von Nahrung die Rede ist, allerdings von Sättigung, und zwar mit Köstlichkeiten. Thematisch kann für die dritte Szene Folgendes festgehalten werden:

\begin{tabular}{|l|l|}
\hline Vers & Thema \\
\hline 12 & Aufruf an Jerusalem, JHWH zu loben \\
\hline 13 & $\begin{array}{l}\text { Begründung des Lobaufrufs durch Handlungen der Sicherheit und Stärke } \\
\text { JHWHs für Jerusalem }\end{array}$ \\
\hline 14 & JHWH verschafft Jerusalem Frieden und versorgt es mit Köstlichkeiten \\
\hline 15 & JHWHs Worte und dessen Wirkmacht \\
\hline $16-18$ & $\begin{array}{l}\text { JHWH als Schöpfer in seiner Macht über die Natur und in seiner Gefährlichkeit } \\
\text { (Kälte, Eis) }\end{array}$ \\
\hline $19-20$ & JHWH und ihre Rechtsbestimmungen für Israel, die nicht für alle Völker gelten \\
\hline $20 c$ & Lobaufruf im Imp.pl. \\
\hline
\end{tabular}

\subsubsection{Parallelismen und Struktur}

Bezüglich des Zeitfaktors und der Parallelismen sind, wie bereits in den vorhergehenden Szenen, synonyme und synthetische Parallelismen zu finden. V12 ist synonym konstruiert. In beiden Sätzen geht es um die Lobaufforderung 
Gottes an ein $\mathrm{Du}$, das in 12a mit Jerusalem und in $12 \mathrm{~b}$ mit Zion benannt ist. Der Vokativ mit dem Eigennamen der Gottheit Israels aus 12a wird in 12b durch den Vokativ »deinen Gott « spezifiziert. V13 ist synthetisch gestaltet. ${ }^{835}$ Nacheinander werden zwei in sich abgeschlossene Handlungen JHWHs in der SK erzählt. Inhaltlich baut die Segenshandlung in 13b auf die schutzgebende Handlung in 12a auf: Erst nachdem die Stadt gesichert ist (13a), können die BewohnerInnen und vor allem die Kinder mit Segen ausgestattet werden (13b). Hier geht der Blick zunächst hin zu den Stadttoren, die als Grenze nach außen fungieren, und dann nach innen $\mathrm{zu}$ »deinen Kindern« »in deiner Mitte«. Ähnlich konstruiert ist V14: Erst wenn Friede herrscht (14a), kann es zur Sättigung mit Kostbarem, zu Wohlstand kommen (14b). Dabei ist mit 14b eine Steigerung gegeben. V15 ist ebenso als synthetischer Parallelismus zu bestimmen, auch wenn die Inhalte der beiden Sätze näher beieinander liegen als in V13-14: Beide Male ist vom Wort die Rede, durch welches die Gottheit handelt, indem sie es zunächst auf die Erde schickt (15a), wo sich das Wort schnell fortbewegt (15b). Beide Male werden die Rede bzw. das Wort personifiziert: Ein Mal in der Objektposition eingeführt (15a), führt es dann als Subjekt (15b) eine eigenständige Handlung aus (schnell rennen, eilen רוץ). V16 ist synonym gestaltet: In beiden Sätzen wird ein Vergleich verwendet, der jeweils mit כ̦ eingeleitet wird; mit dem Geben von Schnee und dem Ausstreuen von Reif wird die Erdoberfläche mit einer großen Menge an »Material« zugedeckt. V17 führt das Thema des Wetters weiter. Der synthetisch gestaltete Vers thematisiert den Hagel in 17a und führt den Gedanken weiter, wer vor der Kälte, die ebenso von JHWH kommt, bestehen kann (17b), wodurch eine Steigerung der Dramatik im Text bewirkt wird. V18 ist als synonymer Parallelismus zu charakterisieren. Sowohl das Wort (oder JHWH selbst 18a) als auch dessen Wind (18b) bringen das Eis zum Schmelzen. Ebenso ist V19 als synonym zu betrachten. So wird das Verb נגד aus 19a in 19b prolongiert, "sein Wort « (19a) steht parallel $\mathrm{zu}$ »seinen Ordnungen « und »seinen Rechtsbestimmungen« (19b). Außerdem werden Jakob (19a) und Israel (19b) parallel konstruiert und synonym verwendet. Während V20 antithetisch zu V19 gestaltet ist, ist V20 in sich synthetisch konstruiert. ${ }^{836} \mathrm{JHWH}$ teilt zwar seine Ordnungen und Rechtsbestimmungen dem Volk Israel mit (V19), nicht jedoch allen anderen Nationen (V20). 20a führt das Nicht-Handeln JHWHs - im Gegensatz zum Handeln an Israel - an den Völkern ein (20a), welche dann in 20b als Subjekt des (Nicht-) Erkennens der Rechtsbestimmungen gelten.

Neben den eben analysierten Parallelismen können in Ps 147 weitere parallele Strukturen entdeckt werden. So sehen Alonso Schökel und Carniti Parallelen zwischen der Tatsache, dass Gott Tieren (V9) sowie Menschen (V14) Nahrung

835 Ebenso Viviers, Psalm 147, 175.

836 Anders Risse, Gut ist es, 39, der hier einen synonymen Parallelismus identifiziert. 
zukommen lässt, zwischen dem himmlischen Heer (V4) und den Kämpfern am Boden (V10), zwischen dem Wort, das die Natur lenkt (V15-18) und dem Wort, das das Volk Israel leitet (V19). ${ }^{837}$

Hinsichtlich der Subjekt-Handlung-Objekt-Struktur lässt sich für die dritte Szene Folgendes festhalten:

\begin{tabular}{|c|c|c|c|}
\hline Vers & Subjekt & Handlung & Objekt \\
\hline $12 \mathrm{a}$ & - & $\begin{array}{l}\text { rühmen שבח } \\
\text { Imp.pi.f.sg. }\end{array}$ & JHWH \\
\hline $12 \mathrm{~b}$ & - & $\begin{array}{l}\text { loben הלל Imp.pi.f.sg. } \\
\text { Imp. }\end{array}$ & deinen Gott \\
\hline $13 a$ & (Er) & $\begin{array}{l}\text { stark, fest machen חזק } \\
\text { SK pi. }\end{array}$ & die Riegel deiner Tore \\
\hline $13 \mathrm{~b}$ & (Er) & $\begin{array}{l}\text { ברך segnen } \\
\text { SK pi. }\end{array}$ & $\begin{array}{l}\text { die Kinder; } \\
\text { in deiner Mitte }\end{array}$ \\
\hline $14 \mathrm{a}$ & $\mathrm{Er}$ & $\begin{array}{l}\text { setzen, legen, stellen שים } \\
\text { Ptz. q. }\end{array}$ & $\begin{array}{l}\text { deiner Grenze; } \\
\text { Frieden }\end{array}$ \\
\hline $14 \mathrm{~b}$ & $\mathrm{Er}$ & $\begin{array}{l}\text { sättigen שבע } \\
\text { PK hif. }\end{array}$ & $\begin{array}{l}\text { (dich); } \\
\text { Fett/Bestes des Weizens }\end{array}$ \\
\hline $15 \mathrm{a}$ & $\mathrm{Er}$ & $\begin{array}{l}\text { schicken, senden שלח } \\
\text { Ptz. q. }\end{array}$ & $\begin{array}{l}\text { seine Rede; } \\
\text { auf die Erde }\end{array}$ \\
\hline $15 \mathrm{~b}$ & sein Wort & $\begin{array}{l}\text { rennen, eilen רוץ } \\
\text { PK q. }\end{array}$ & - \\
\hline $16 \mathrm{a}$ & $\mathrm{Er}$ & $\begin{array}{l}\text { geben נתן } \\
\text { Ptz. q. }\end{array}$ & Schnee wie die Wolle \\
\hline $16 \mathrm{~b}$ & (Er) & $\begin{array}{l}\text { שזר פerstreuen } \\
\text { PK pi. }\end{array}$ & Reif wie die Asche \\
\hline $17 \mathrm{a}$ & (Er) & $\begin{array}{l}\text { werfen, schmeißen שלך } \\
\text { Ptz. hi. }\end{array}$ & sein Eis wie Brocken \\
\hline $17 \mathrm{~b}$ & Wer & $\begin{array}{l}\text { bestehen, standhalten } \\
\text { עמד } \\
\text { PK q. }\end{array}$ & vor seiner Kälte \\
\hline $18 \mathrm{a}$ & $\begin{array}{l}(\mathrm{Er}) \\
(\mathrm{Er} ; \mathrm{es})\end{array}$ & $\begin{array}{l}\text { senden שלח } \\
\text { PK q. } \\
\text { schmelzen lassen מסה } \\
\text { W-PK hif. }\end{array}$ & $\begin{array}{l}\text { sein Wort } \\
\text { (sie) }\end{array}$ \\
\hline $18 \mathrm{~b}$ & $\begin{array}{l}\text { (Er) } \\
\text { die Wasser }\end{array}$ & $\begin{array}{l}\text { wehen lassen נשב } \\
\text { PK hif. } \\
\text { rinnen נזל PK q. } \\
\text { Pinn }\end{array}$ & seinen Wind \\
\hline $19 \mathrm{a}$ & (Er) & $\begin{array}{l}\text { erzählen נגד } \\
\text { Ptz. hi. }\end{array}$ & $\begin{array}{l}\text { sein Wort; } \\
\text { für Jakob }\end{array}$ \\
\hline
\end{tabular}

837 Vgl. Alonso Schökel / Carniti, Salmos 2, 1650. 
(Fortsetzung)

\begin{tabular}{|c|c|c|c|}
\hline Vers & Subjekt & Handlung & Objekt \\
\hline $19 \mathrm{~b}$ & - & - & $\begin{array}{l}\text { seine Ordnungen und seine } \\
\text { Rechtsbestimmungen; } \\
\text { für Israel }\end{array}$ \\
\hline $20 \mathrm{a}$ & $(\mathrm{Er})$ & $\begin{array}{l}\text { nicht handeln עש + עשה SK q. } \\
\text { SK }\end{array}$ & für jedes Volk \\
\hline $20 \mathrm{~b}$ & (Sie) & $\begin{array}{l}\text { nבּל + ידע } \text { nicht kennen } \\
\text { SK q. }\end{array}$ & die Rechtsbestimmungen \\
\hline $20 \mathrm{c}$ & - & $\begin{array}{l}\text { Ioben הלל.pl.pl. } \\
\text { Imp.pi.m. }\end{array}$ & $\overline{\mathrm{JH}}$ \\
\hline
\end{tabular}

Die dritte Szene wird durch einen Lobaufruf gerahmt (Imp. von הלל 12b.20c). Bleibt man bei der Analyse der Verbformen, so fällt - im Vergleich mit den vorangegangenen Szenen - eine Vielfalt ins Auge: Zwischen den Imperativen am Beginn und am Ende wechseln sich PK (7x) und Ptz. (5x) ab. Des Weiteren treten erstmalig in diesem Psalm SK-Formen (4x) auf (V13.20). Eine W-PK (18a) ist ebenso auszumachen. Diese ist als deutliche Folgehandlung (das Wasser schmilzt 18a) auf die Wirkmacht JHWHs zu betrachten, die durch das Wort geschieht (Er sendet sein Wort 18a), während vor allem die in der SK erzählten Handlungen aus V13.20 (stark machen, segnen; nicht handeln; nicht erkennen) als in sich abgeschlossene Taten anzusehen sind. Die Abwechslung in den Verbformen bringt deutlich mehr Bewegung in Raum und Zeit in den Psalm, der sich bisher durch seinen in der Gleichzeitigkeit bleibenden beschreibenden Stil ausgezeichnet hatte. Die Handlungen in V13.20 können auch als Rückblende gelesen werden, womit dann eine Bewegung in der Zeitachse festzustellen wäre. Die in der SK geäußerten Handlungen JHWHs an Jerusalem (V13) werden anschließend mit Ptz. und PK (ab V14) weitergeführt. Von V14-19 an dominiert dann wieder die Gleichzeitigkeit. Hier wechseln sich Ptz. und PK ab, wobei in dieser Szene, anders als in den vorangegangenen, die PK mit sieben Vorkommen und einer W-PKForm überwiegt. Mit Ausnahme von 15b (sein Wort), 17b (wer), 18b (die Wasser) und 20b (sie) ist wieder JHWH durchgängig als Subjekt auszumachen; ihm werden ganz unterschiedliche Taten zugestanden. Wiederum geht es, wie bereits vor allem aus der ersten Szene bekannt, um die Zuwendung JHWHs zu Jerusalem (V13-14) und Israel (V19) sowie um JHWH als Schöpfer (V16-18).

\subsubsection{Räume und Zeiten}

Aus dem Vorgenannten ergibt sich eine Vielzahl an Räumen vor allem in den V12-14: Jerusalem (12a), Zion (12b) - beide werden personifiziert und in der Vokativform angesprochen -, Tor (13a), Mitte (13b), Grenze (14a) und Erde (15a). Gerade in V13-14 geht es damit um innen und außen, um das Absichern 
der Stadtgrenzen nach außen hin (Tor), damit im Inneren (Mitte) Leben in Sicherheit und Frieden möglich sind. ${ }^{838}$ "JHWH hat Jerusalem Sicherheit nach außen und Segen im Inneren gegeben. [...] Die Aspekte >nach außen - nach

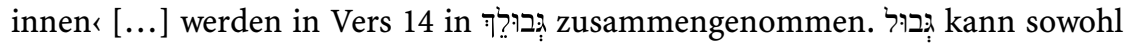
Grenze als auch Gebiet bedeuten. Als ıumgrenztes Gebiet`spielen bei diesem

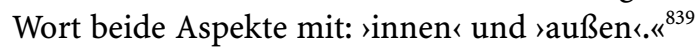

Mit der Darstellung der Naturphänomene Schnee, Reif und Eis, den damit verbundenen Bewegungen des Zerstreuens und Werfens und der Nennung der Erde (ארץ) ist von V15-18 an wieder die Bewegung von oben nach unten fokussiert. Temporalobjekte sind nicht vorhanden. Bezüglich der Figuren im Text treten neben JHWH (V13-15a; 16-17a; 18a; 19-20a) auch sein Wort (15b.18a Wort oder JHWH selbst?), die Wasser (18b) und ein »sie« (20b Fremdvölker) auf.

\subsubsection{3 Übergänge}

Nach dem Lobaufruf an ein Du in V12, das als zeitdeckendes Moment Lesende direkt und unmittelbar an den Text heranholt, wird mit der Konjunktion (denn) ein Kausalsatz eingeleitet (V13), der die Aufforderungen zum Rühmen und Preisen der Gottheit Israels aus V12 begründet und die beiden Verse miteinander verbindet. Die Verknüpfung zwischen V13.14 besteht im gleichen Thema und vor allem in derselben Perspektive (Er-Du): Im Mittelpunkt steht JHWH und sein Handeln an der Stadt Jerusalem und an ihren BewohnerInnen. ${ }^{840}$ V14 kommt eine Brückenfunktion zu: "Mit seiner Aussage expliziert er zum einen noch ganz Jahwes Heilshandeln, das seiner Stadt und deren Gebiet gilt. Zugleich bereitet die Natur- und Schöpfungsthematik von V. 14, die in die Fülle Jerusalems einbezogen erscheint und diese veranschaulicht, bereits Jahwes Schöpfungshandeln in VV. 15-18 vor. ${ }^{841}$ Auch wenn mit V15 ein neues Thema eingespielt wird, werden V14-16 syntaktisch durch den gleichen Satzbeginn zusammengehalten: Alle drei Verse werden mit einem determinierten Ptz. eröffnet. Der Artikel verweist dabei auf JHWH und betont dessen Handlungsmacht. Auf der Ebene der Satzkonstruktion werden die V16-17 durch die drei mit der Präposition כְ konstruierten Vergleiche (Schnee wie die Wolle 16a, Reif wie die Asche 16b, Eis wie Brocken 17a) miteinander verbunden. V17 endet mit einer PK q., mit der auch V18 einsetzt. Die Frage in 17b (vor seiner Kälte - wer kann bestehen?) fällt ein wenig aus dem Rhythmus des Psalms. Diese Frage kann allerdings als Klimax einer Bewegung betrachtet werden, die inhaltlich mit V15

838 Vgl. Sedlmeier, Jerusalem, 299.

839 Risse, Gut ist es, 38.

840 Sedlmeier, Jerusalem, 282 sieht die Zusammengehörigkeit von V12-14 durch die klanglich

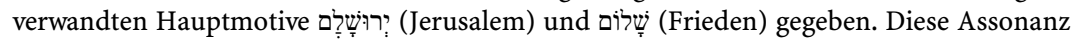
zieht sich bis V18. Vgl. ebd., 279.

841 Sedlmeier, Jerusalem, 282. 
beginnt, in V18 ihren Abschluss findet und eine eigene Dramaturgie aufweist: Die Mächtigkeit der Gottheit Israels erweist sich zunächst in ihrem Wort; dann werden gehäuft Naturelemente genannt (Schnee, Reif, Eis, Kälte), die an Gefährlichkeit zunehmen (Eis wie Brocken); und schließlich wird gefragt, wer diesem ganzen Szenario überhaupt standhalten kann (17b) ${ }^{842}$ Dabei ist auch in den Handlungen JHWHs durch die Schöpfung eine Dramaturgie vorhanden: Von פתן (zerstreuen) bis hin zu שזר (zerfen) wird die Bewegung heftiger, bis sie mit עמד (bestehen, standhalten) angehalten wird: Hier kommt der Spannungsaufbau zu seinem Höhepunkt und wird anschließend mit der wiederholten Sendung des Wortes und dem Wehen des Windes - die beide dazu beitragen, dass das Eis schmilzt - dahingehend abgebaut, dass auf der Ebene der Semantik von der Schneeschmelze und damit vom Ende der winterlichen Frostzeit gesprochen werden kann. Auf der Ebene der Syntax ist mit V18 durch den Wechsel der Satzstruktur und durch die Häufung der PK-Formen ebenso ein Umschwung festzustellen. Durch die vier aufeinanderfolgenden Verbalsätze mit Verben, die Bewegung zum Ausdruck bringen (שלח senden, מסה schmelzen, נשב wehen und נזל rinnen), tritt eine Wende hin zum Tauwetter ein.

Nach diesem Spot kommt ein weiterer in den Blick, der JHWH und seine Ordnungen für Israel thematisiert. V19.20 stehen beide in diesem Spot und

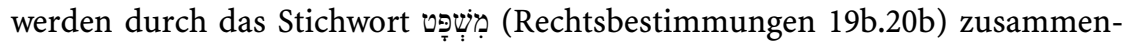
gehalten. Inhaltlich sind die beiden Verse dahingehend voneinander abhängig, dass der in V19 erzählte Inhalt (JHWHs Rechtsbestimmungen für Israel) in V20 kontrastiert wird (kein derartiges Handeln JHWHs für jedes Volk). 20a und 20b werden durch die Konjunktion ? verbunden. Diese ist laut Franz Sedlmeier als Konklusion zu verstehen: "Also haben sie auch nicht erkannt / wissen sie auch nicht, was Rechte sind. ${ }^{843}$ Schlussendlich kann als weiteres Verbindungselement das (beinahe) durchgängige Subjekt JHWH erwähnt werden.

Sedlmeier sieht gerade im letzten Spot von Ps 147 durch die möglichen Querverweise einen deutlichen Rückbezug auf die vorhergehenden Szenen in positiver und negativer Hinsicht. So werden durch die Größen Israel (19b) und Jakob (19a) die Armen (6a), die Gottesfürchtigen (11a) und die auf seine Güte Harrenden (11b) eingespielt. Mit »jedem Volk« aus 20a wird auf die Frevler (6b), die Stärke des Pferdes (10a) und die Schenkel des Mannes (10b) zurückverwiesen. ${ }^{844}$ Zudem wird mit den SK in V20 auf die SK in V13 Bezug genommen, mit den Ordnungen und Rechtsbestimmungen aus V19 werden die Tore als Orte der Rechtsprechung in V13 eingespielt.

842 Ähnlich Sedlmeier, Jerusalem, 318, der von einer Aufsprengung der Geschlossenheit der Bilder durch die Frage in $17 \mathrm{~b}$ spricht.

843 Sedlmeier, Jerusalem, 327.

844 Vgl. Sedlmeier, Jerusalem, 325. 
Bezüglich der Übergänge ist die Szene damit so gestaltet, dass ein Eintauchen in die verschiedenen Spots ermöglicht und dadurch ein Herausfallen aus dem Leseprozess verhindert wird.

\section{$4 \quad$ Zusammenfassung und Auswertung}

\subsection{Inhalt}

Der Hymnus von Ps 147, der durch die Imperative dreigeteilt ist (V1-6; 7-11; 1220), stellt Gottes Fürsorge und Zuwendung zu jenen, die seine Hilfe benötigen, sowie seinen Umgang mit der Schöpfung in den Mittelpunkt seiner Darstellung. Schöpfungs- und Heilshandeln JHWHs sind im Text ineinander verschränkt. »Charakteristisch für die hymnische Botschaft des 147. Psalms ist die innige Wechselwirkung zwischen Jahwes Heilswirken und Schöpfungswalten. [...] Jahwes Heilswirken ist schöpferisch, neuschaffend. Sein schöpferisches Walten ist heilvoll. $\aleph^{845}$ Diese Verwobenheit von Schöpfung und Heilsgeschichte stellt allerdings keine neue Kreation von Ps 147 dar (vgl. Jesajabuch; Psalmen). ${ }^{846}$

Verwobenheit charakterisiert auch das sprechende Wir. Es fällt auf, dass das lyrische Wir durch die subtil gestaltete Rhetorik des Textes als Sprechstimme auch in die Gruppe der Angesprochenen mit hineingenommen wird, seien es nun die AdressatInnen der Aufforderungen oder auch die EmpfängerInnen der Heilstaten Gottes.

Der durch den Partizipialstil sowie durch die Verwendung von Adjektiven und Imperativen in der Gleichzeitigkeit stehende Text illustriert eindrucksvoll folgende Themen:

\begin{tabular}{|l|l|}
\hline Vers & Thema \\
\hline 1 & Lobaufruf inkl. Begründung bzw. Verstärkung \\
\hline 2 & JHWH als Bauherrin Jerusalems und Hirte \\
\hline 3 & JHWH als Ärztin \\
\hline 4 & JHWH als Lenker des Kosmos \\
\hline 5 & Größe, Kraft und unermessliche Klugheit JHWHs \\
\hline 6 & JHWHs Stärkung der Gebeugten und Erniedrigung der Frevler \\
\hline 7 & Zweimaliger Lobaufruf \\
\hline $8-9$ & JHWH als Schöpfer, der Natur und Tiere wachsen lässt und ernährt \\
\hline 10 & Abneigung JHWHs gegenüber militärisch Starken und Schnellen \\
\hline
\end{tabular}

845 Kraus, Psalmen, 1139. Auf das Ineinander von Gottes Geschichts- und Schöpfungshandeln in Ps 147 verweist auch Sedlmeier, Jerusalem, 41.

846 Vgl. Sedlmeier, Jerusalem, 241. 
(Fortsetzung)

\begin{tabular}{|l|l|}
\hline Vers & Thema \\
\hline 11 & Vorliebe JHWHs für Gottesfürchtige und auf seine Güte Wartende \\
\hline 12 & Aufruf an Jerusalem, JHWH zu loben \\
\hline 13 & $\begin{array}{l}\text { Begründung des Lobaufrufs durch Handlungen der Sicherheit und Stärke } \\
\text { JHWHs für Jerusalem }\end{array}$ \\
\hline 14 & JHWH verschafft Jerusalem Frieden und versorgt es mit Köstlichkeiten \\
\hline 15 & JHWHs Worte und deren Wirkmacht \\
\hline $16-18$ & $\begin{array}{l}\text { JHWH als Schöpferin in ihrer Macht über die Natur und in ihrer Gefährlichkeit } \\
\text { (Kälte, Eis) }\end{array}$ \\
\hline $19-20$ & $\begin{array}{l}\text { JHWH und seine Rechtsbestimmungen für Israel, die nicht für alle Völker } \\
\text { gelten }\end{array}$ \\
\hline $20 c$ & Lobaufruf \\
\hline
\end{tabular}

\subsection{Emotionen}

Der Psalm ist geprägt von der Emotion und Atmosphäre der Freude. Diese Jubelstimmung wird in Form von Imperativen von den AdressatInnen eingefordert (1a.V7.12.20c). Die Emotionen der Freude und der Fröhlichkeit sollen also evoziert werden. Mit den aus der Liebessprache stammenden Eigenschaftswörtern in V1 sind die Emotionen der Liebe, der ästhetischen Anmut und des köstlichen Wohlgefühls im Blick, die sich auf den Lobgesang, also auf das Loben und Preisen JHWHs beziehen; allerdings können sie wie in V1 weder dem lyrischen Wir noch der Gottheit eindeutig zugeordnet werden und wirken damit subjektfrei. In V2 treten durch die göttliche Handlung des Versammelns, die das Bild eines Hirten evoziert, die Emotionen der Geborgenheit und des Sich-daheim-Fühlens für Israel zu Tage. Im Gegensatz dazu stehen das Elend und die Not, die hinter dem Ausdruck »Verstoßene Israels« durchschimmern. In V3 ist ein aus der Analyse von Ps 30 bereits bekanntes Phänomen zu entdecken, nämlich das der doppelten Emotionalität. Der Vers stellt durch die Darstellung der göttlichen Zuwendung des Heilens und Verbindens die Emotion der tröstlichen Zuneigung in den Mittelpunkt, während gleichzeitig von schmerzenden Wunden, Verletztsein, Gewalt und Vernichtung sowie von den Emotionen der totalen Niedergeschlagenheit und existenziellen Entmutigung die Rede ist. In V4 sind keine expliziten Emotionswörter zu entdecken, implizit werden aber im Leseprozess Staunen und Bewunderung aufgrund der Darstellung der überirdischen Größe Gottes ausgelöst. Dies wird in V5 fortgeführt. In V6 kann wieder von doppelter Emotionalität gesprochen werden. Mit der Aufrichtung der Gebeugten bzw. Armen und der Befreiung dieser Personengruppen kann die 
Emotion der Erleichterung benannt werden. Im Gegensatz dazu wird die Gruppe der Frevler bzw. Verbrecher von Gott total erniedrigt. Diese Emotion der Kränkung und Herabwürdigung, die bereits im Begriff der »Armen« bzw. »Gebeugten« impliziert ist, fällt nun auf die Gewalttätigen selbst zurück.

Die Emotion der dankbaren Freude soll mittels der Imperative in V7 evoziert werden. V8 besticht durch die Darstellung der Zuwendung JHWHs zu seiner Schöpfung. Die Fürsorge, die Emotion des Mitleids und der Versorgungsaspekt werden in V9 weiter ausgeführt, wo hinter der Erwähnung der Rabenjungen die Emotion der Verachtung mitschwingt. V10 benennt mit der göttlichen Ablehnung eine sehr starke Emotion. Mit V11 erreicht die Emotionalität in Ps 147 ihren Höhepunkt. Der Vers zeichnet sich durch eine einzigartige Dichte an expliziten Emotionswörtern aus: An erster Stelle sind dies Wohlgefallen, göttliche Zuwendung und Liebe, und darauf folgt wieder eine doppelte Emotionalität, hervorgerufen durch den Begriff »Gottesfürchtige«. Hier schwingen die Emotionen des ängstlichen Erschreckens und der Furcht nur hintergründig mit, während das Zugehörigkeitsgefühl und das Vertrauen im Zentrum stehen. Im zweiten Teil des Verses werden die Hoffnung der Wartenden sowie die göttliche Freundlichkeit und Güte thematisiert.

Während V12 wiederum die Freude evoziert, spricht V13 von der Steigerung des Sicherheitsgefühls, von Wohlbefinden, Glück und Lebensfülle. Diese Themen und Emotionen werden in V14 weiter verstärkt und gesteigert: Zum Gefühl des Ganzseins, das Frieden, Sicherheit, Ruhe und Heil, Glück und Wohlbefinden in sich trägt, kommt der Aspekt des Sich-Sättigens mit Köstlichkeiten hinzu. V1516 zeichnen sich durch metaphorische Redeweise aus, die jedoch eher Themen wie etwa jene der Schnelligkeit und Effektivität (Personifikation des Wortes bzw. der Rede) sowie der Oberflächenbedeckung und damit des Mengenbeweises (Schnee und Reif werden mit Wolle und Asche verglichen) benennt, als dass sie Emotionen hervorrufen würde. Mit V17 kommt, anschließend an die bereits in V16 dargestellte Mächtigkeit Gottes in und über die Natur, das Element der gefährlichen Bedrohung ins Spiel, welche in V18 abgewendet wird. Wie bereits V4-5 können V15-18 im Leseprozess Bewunderung und Staunen auslösen (Aemotions), hier im Speziellen ob der Durchschlagskraft und Effektivität des Wortes Gottes, aber auch Erschrecken aufgrund der Bedrohlichkeit. In V19 werden keine Emotionen thematisiert; der Psalm endet in 20c mit dem Lobaufruf und damit mit der Emotion der Freude. 


\subsection{Perspektiven und Textdynamik}

Die Perspektivenlenkung des Textes konnte in der Analyse der einzelnen Spots in der jeweiligen Szene nachgezeichnet werden. Zunächst ist festzuhalten, dass der Text, in dem ein lyrisches Wir als Sprechstimme gilt, mit drei verschiedenen Perspektiven arbeitet (Ihr-Perspektive 1a.7a.b.20c; Du-Perspektive 12a.b; ErPerspektive 1b-6.8-11.13-20b) und damit zwischen einer externen Fokalisierung (1b-6.8-11.13-20b) und einer AdressatInnenperspektive (1a.7a.b.12a.b.20c) wechselt.

Der Psalm arbeitet mit einer nahen und einer fernen "Kameraeinstellung «. Dabei wird die Nähe der Perspektive nicht nur durch die zeitdeckenden Imperative erreicht, sondern ebenso mittels des erzählten Inhalts der Nähe Gottes zu Kosmos, Tier und Mensch sowie mittels der Possessivpronomen (1b.; 5a; 12b; 13a; 13b 2x; 14a.b). Durch diese werden die Inhalte des Psalms näher an die Lesenden herangerückt, während im Falle der Artikel (determinierte Ptz.) sowie der Personaldeixis in der 3.P.sg. (V15-19) durch die Anaphorik ein eher (rück-) verweisender bzw. die einzelnen Elemente verbindender Charakter gegeben ist.

Die Perspektiven und die dadurch erzielten sowie darin erzählten Bewegungsverläufe des Psalms lassen sich am besten mittels der Zusammenschau der Spot-Schemata aus der Detailanalyse darstellen:

\begin{tabular}{|c|c|c|}
\hline \multicolumn{3}{|r|}{ 1. Szene (V1-6) } \\
\hline Spot & Vers & Fokus \\
\hline 1 & 1 & $\mathrm{Ihr}+\mathrm{JH}$ \\
\hline 2 & $2-3$ & JHWH + Jerusalem + Leidende \\
\hline 3 & $4-5$ & Er + Sterne \\
\hline 4 & 6 & JHWH + Gebeugte + Frevler \\
\hline \multicolumn{3}{|r|}{ 2. Szene (V7-11) } \\
\hline 1 & 7 & Ihr + JHWH \\
\hline \multirow[t]{4}{*}{2} & 8 & Er + Himmel \\
\hline & & Er + Erde \\
\hline & & Er + Regen \\
\hline & & Er + Berge \\
\hline 3 & 9 & Er + Tiere \\
\hline 4 & $10-11$ & JHWH + Menschen \\
\hline \multicolumn{3}{|r|}{ 3. Szene (V12-20) } \\
\hline 1 & 12 & $\mathrm{Du}+\mathrm{JHWH}$ \\
\hline 2 & $13-14$ & Er + Jerusalem \\
\hline 3 & $15-18$ & Er + sein Wort + Schnee + Reif + Eis wie Brocken \\
\hline 4 & $19-20 \mathrm{~b}$ & Er + Israel \\
\hline 5 & $20 \mathrm{c}$ & $\mathrm{Ihr}+\mathrm{JH}$ \\
\hline
\end{tabular}


Die Analyse des Fokus lässt erkennen, dass in jeder Szene ${ }^{847}$ eine Bewegung auszumachen ist, die von unten bzw. der Stadt Jerusalem aus (V2-3; 13-14) nach oben Richtung Himmel führt (V4-5; 8a; 15) und danach von oben wieder auf den Boden gelenkt wird (V6; 8b.9; 15a; 16-18). Dieser durchgehende Spotwechsel bzw. diese Auf-und-ab-Bewegung sind nicht sprunghaft, sondern mit- und nachvollziehbar und bestimmen den gesamten Psalm.

Im Gegensatz zur Analyse von Ps 30, in der die klangliche Komponente nur am Rande eine Rolle spielt, ist diese in Ps 147 nicht zu übersehen: Assonanzen, Alliterationen, Lautmalerei und Wortspiel tragen, wie oben gezeigt werden konnte, wesentlich zum Rhythmus und zur melodischen Bewegung des Textes bei und dienen als klangliche Unterstützung bzw. Bekräftigung der erzählten Inhalte und Aussageabsichten. »Der Verfasser zeigt Freude an Wortklang und Wortspiel. Die verschiedenen poetischen Mittel sind nicht um ihrer selbst willen eingesetzt, sondern dienen dazu, die Aussage eindrucksvoller zur Geltung zu bringen. ${ }^{848}$ Diese rankt sich um drei thematische Einheiten: die Heilshandlungen JHWHs an Jerusalem bzw. Israel, die Handlungen JHWHs in und an der Schöpfung und die Handlungen JHWHs an weiteren Personengruppen. Die erzählten Aktionen JHWHs stehen demnach im Mittelpunkt des Psalms. Dieser besticht durch die Darstellung der Diversität, Quantität und Qualität der göttlichen Handlungsmacht. In der Fülle der Handlungen der Gottheit Israels, die nur in 1c, 4a, 9b, 15b, 17b, 18a.b und 20b nicht das Subjekt ist, spiegeln sich die drei Hauptthemen des Psalms wider: Die Heilshandlungen JHWHs (aufbauen 2a, sammeln 2b,

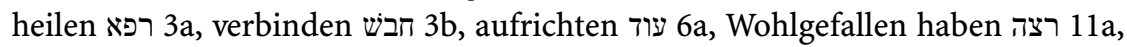

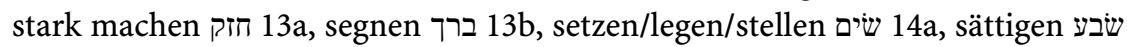
14b, senden שלח 15a.18a, verkünden 19a), die Schöpfungshandlungen JHWHs

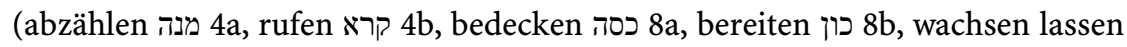

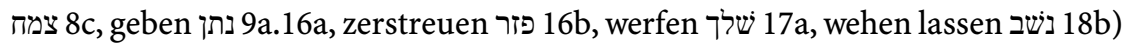
sowie die Handlungen an anderen Personengruppen (erniedrigen שפל 6b, nicht

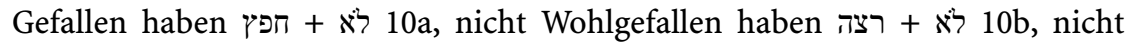
handeln עשה 20a). Die Fülle der Handlungen Gottes schlägt sich auch in Zahlen nieder: So werden von den 39 Verben im Text 27 der Gottheit Israels einschließlich des göttlichen Wortes zugeschrieben, was einen Anteil von fast 70 Prozent für das göttliche Handeln ergibt. Die Handlungsmacht JHWHs wird unterstrichen durch die ihm zugeschriebenen Dispositionen der Größe, des Reichtums an Kraft und der unermesslichen Klugheit (V4-5). Bezeichnet wird die Gottheit Israels im Psalm mit dem Gottesnamen JHWH (1a JH, 2a, 6a, 7a, 11a, 12a, 20c JH), mit Adonaj (5a) und Elohim (1b.12b). »Hervorzuheben ist, dass der Gottesname jeweils die Übergangsverse 6 und 7 sowie 11 und 12 verbindet und

847 In der zweiten Szene klingt V6 noch nach.

848 Risse, Gut ist es, 39. 
damit zusammen mit dem Rahmen von V. 1-2 und 20 den ganzen Psalm zusammenhält. « ${ }^{849}$

Neben der Charakterisierung des Subjekts fällt auf, dass in Bezug auf die weiteren, der Erzähltextanalyse entnommenen Kategorien, die für die Analyse der Textdynamik verwendet wurden, kein einziges Temporalobjekt auszumachen ist. Der Psalm kommt also - etwa im krassen Gegensatz zu Ps 90, wie noch zu zeigen sein wird - ohne Zeitangaben aus. Die Darstellung der Sachverhalte durch Ptz. und PK-Formen sowie das Fehlen der Temporalangaben verstärken die Gleichzeitigkeit und damit die Zeitlosigkeit des Textes.

Nimmt man die Räume gesammelt in den Blick, so können diese einerseits der Natur (Sterne 4a, Himmel 8a, Erde 6b.8c.15a, Berge 8c) und andererseits der Stadt (Jerusalem 2a.12a, Zion 12b, Tor 13a, Mitte 13b, Grenze 14a) zugeordnet werden. Die unterschiedlichen Räume sind für die bereits analysierte Perspektivenlenkung essentiell. Darin hat sich gezeigt, dass für den Psalm die abstrakten Kategorien oben - unten, durch welche die Blicklenkung bewerkstelligt wird, von großer Relevanz sind. ${ }^{850}$ Die abstrakten Kategorien innen - außen sind für die Rede über die Stadt Jerusalem zentral (V13-14). Hier geht es um das Sicherstellen des Schutzes durch die göttliche Stärkung der Tore, damit keine Feinde von außen eindringen können. So kann im Inneren der Stadt ein Leben in Frieden und Sicherheit geführt werden. Der Begriff גבוּר (Gebiet, aber auch Grenze 14a) verbindet in sich die beiden abstrakten Raumkategorien innen - außen.

Von den abstrakten Kategorien des Raumes nun noch einmal zurück zu den konkreten Raumangaben:

אֶרץ (Erde, Boden) kommt in jeder Szene (V6.8.15) vor und kann als Leitwort bezeichnet werden.

Blickt man auf die erzählte Welt in der ersten und in der dritten Szene, so zeigt sich, dass die im Hintergrund mitschwingende Darstellung Jerusalems als zerstörte Stadt mit notleidenden Menschen (V2-3) innerhalb des Textverlaufs eine Wandlung erfährt hin zu einer Stadt, deren Grenzen aufgebaut und stark gemacht wurden und in der Leben in Frieden, Sicherheit und Wohlstand möglich ist (V1214). Blickt man auf die zweite und dritte Szene, so ist auch hier eine Steigerung erkennbar: In V9 stillt JHWH den Hunger der Rabenjungen, während in V14 von der Sättigung der BewohnerInnen Jerusalems nicht nur mit einfachen Nahrungsmitteln, sondern mit dem Kostbarsten an Essen, dem besten Weizen, gesprochen wird. Innerhalb der dritten Szene zeigt sich m. E. die größte Spannung im Text, die mit der Sendung des göttlichen Wortes in V15 beginnt. Daraufhin lässt JHWH in immer heftiger werdenden Bewegungen (geben, zerstreuen,

849 Brodersen, Schöpfungsaussagen, 37.

850 Zur Verwendung der Orientierungsmetaphern »oben - unten« in unserer Kultur bzw. in englischsprachigen Ausdrücken vgl. Lakoff / Johnson, Metaphors We Live By, 14-21. 
werfen) Schnee, Reif und schließlich Eis wie Brocken auf die Erde fallen, bis in V17 dieses Tun JHWHs mit der Frage danach, wer alldem standhalten kann, unterbrochen und damit angehalten wird (Klimax), bevor mit dem erneuten Senden des Wortes in V18 der Wind zu wehen beginnt, die Schmelze einsetzt und die Wasser rinnen. Damit setzt eine erneute Bewegung ein, die die Frostzeit auflöst.

Jeder Vers in Ps 147 besteht aus einem Parallelismus membrorum. Die Analyse hat gezeigt, dass hauptsächlich synonyme (V1.3.5.7.10.11.12.16.18.19) und synthetische (V2.4.8.9.13.14.15.17.20) Parallelismen verwendet werden; nur V6 ist antithetisch gestaltet. Dabei kommt es in V1 zu einer Intensivierung der Aussage, indem $1 \mathrm{~b}$ das Gotteslob ästhetisch beschreibt und damit sinnlicher zu erfassen versucht als in 1a. In V2.4 wird die allgemeine Aussage aus dem ersten Halbvers im zweiten konkretisiert. V3 erzählt im zweiten Halbvers von einer größeren Nähe Gottes als im ersten. Es kommt damit zu einer Intensivierung der Aussage. In V5 wie auch in V10.16.18.19 kann von einer statischen Synonymität gesprochen werden (vgl. III Methodik 3.3.2). Im antithetischen Parallelismus von V6 kommt es durch die drastische Darstellungsweise in $6 \mathrm{~b}$ zu einer Dramatisierung. In $7 \mathrm{~b}$ wird, analog zu $\mathrm{lb}$, die Aussage intensiviert, indem mit dem instrumentalen und vokalen Lobpreis mehr Sinne angesprochen werden als in 7a. In V8 ist ein Dreischritt erkennbar, der von der Vorbereitung über die Durchführung bis zur Folge reicht. Die V9.11.12 tragen eine Spezifizierung der Aussage im zweiten Halbvers in sich. In V13 ist eine Bewegung von außen nach innen auszumachen. 14b.17b sind Steigerungen zum vorhergehenden Halbvers, V15.20 führen jeweils im zweiten Stichos den Gedanken des ersten weiter, insofern das Objekt aus 15a.20a in 15b.20b zum Subjekt wird. Vor allem durch die synonym gestalteten Parallelismen werden also die Aussagen verstärkt und vertieft. Darüber hinaus kommt es vor allem durch die synthetisch gestalteten Parallelismen zu einer Intensivierung, Konkretisierung und Dynamisierung der Inhalte. Insgesamt werden dabei die Lesenden länger am Textgeschehen gehalten und können damit in die jeweilige Aussageabsicht des Verses intensiv einsteigen.

Die Analyse der Szenen und Übergänge hat deutlich gemacht, dass die einzelnen Szenen inhaltlich, in der Bewegung sowie durch Stichwortverbindungen und Querverweise miteinander verwoben sind. Auch die Übergänge innerhalb der einzelnen Szenen sowie zwischen den Szenen sind ausgewogen und nachvollziehbar gestaltet. ${ }^{851}$ Damit kann von Ps 147 als durchdachte Gesamtkompo-

851 »Der Gedankengang ist leicht u. natürlich, aber zwanglos u. ohne strenge Ordnung u. Regel, mit öfterem Wechsel von Aufforderung zum Lob u. Betrachtung v. besonderem u. allgemeinem.« Hupfeld, Die Psalmen, 672. 
sition mit einer "symmetrischen Anordnung des Textmaterials ${ }^{852}$ gesprochen werden.

\section{$5 \quad$ Identifikationspotenziale in Psalm 147}

\section{1 durch Emotionen}

Während in der Analyse von Ps 30 eine hohe Dichte an Emotionen festgestellt werden konnte (beinahe jedes dritte Wort in Ps 30 ist emotional konnotiert), ist dies in Ps 147 weniger der Fall. Dennoch konnten einige Emotionen herausgefiltert werden, die für den Psalm prägend sind, wobei V11 die Spitze an expliziten Emotionswörtern darstellt.

Zunächst ist die Emotion der dankbaren Freude zu nennen, eine Jubelstimmung, die den Psalm rahmt und auch dominiert. Darin eingebettet finden sich die Emotionen der Liebe, der Geborgenheit, des Trostes, der Fürsorge und des Mitleids sowie der Zuwendung Gottes, aber auch jene der göttlichen Ablehnung und des Missfallens. Hinter diesen leuchten daneben jene Emotionen hervor, die der Not sowie Krisen- und Gewalterfahrungen entspringen: Niedergeschlagenheit, Angst, Unsicherheit, Entmutigung, Kränkung und Herabwürdigung. "Das Leid und das Unheil der Welt stehen in Psalm 147 im Hintergrund. Sie kommen nur als prinzipiell überwundene vor: die Zerstörung Jerusalems und die Verschleppung Israels $(2-3 ; 13-14)$, die Existenz der Unterdrückten und ihrer Widersacher der >Frevler` (6), militärische Rüstung und Gewalt (10). Man sollte nicht vorschnell annehmen, dass der Verfasser das noch bestehende Elend und die noch weiter bestehende Ungerechtigkeit einfach übersieht. [...] Er ist dennoch überzeugt, dass Gott letzten Endes das Heil des Menschen will und es auch bewirken kann. ${ }^{853}$ Wie in Ps 30 kann daher auch hier vom Phänomen der doppelten Emotionalität gesprochen werden. Diese zeichnet sich dadurch aus, dass in ein- und demselben Vers sowohl die Emotionen der Freude und Erleichterung, der Geborgenheit, des Trostes und der Liebe geschildert werden wie auch jene der Entmutigung, Angst und Aussichtslosigkeit. Ein Identifikationspotenzial ist damit in jener Hinsicht gegeben, dass die LeserInnen eine große Auswahl haben, sich mit den Emotionen zu identifizieren, je nachdem, was sie in der jeweiligen Lesesituation eher anspricht und ihnen näher ist (Heil oder Unheil). Im Leseprozess können die V4-5.15-18 die Emotionen der Bewunderung, des Staunens, aber auch des Erschreckens hervorrufen und damit die LeserInnen

852 Sedlmeier, Jerusalem, 27. Zur Verbindung der drei Teile des Psalms durch Wortwiederholungen vgl. Brodersen, The End of the Psalter, 178.

853 Risse, Gut ist es, 354. 
in die erzählte Welt des Textes mit hineinnehmen. Ebenso kann die formale Gestaltung des Psalms durch Rhythmus, Klang und Melodie Bewunderung und Staunen (A-emotions) hervorrufen. Gerade Ps 147 zeichnet sich ja durch die klangvolle Unterstreichung der erzählten Welt aus. Davon wird auch im nächsten Abschnitt die Rede sein.

\section{2 durch Perspektivenlenkung und Textdynamik}

Ps 147 gilt als "kunstvoll aufgebaute Komposition. ${ }^{854}$ Der hymnische Partizipialstil, der ein gleichförmiges Metrum bewirkt, Eintönigkeit jedoch durch die unterschiedlichen Bewegungen und Dramatisierungen im Text vermeidet, sowie die inhaltliche Kongruenz $z^{855}$ geben dem Text ein starkes Identifikationspotenzial: »The psalm's balanced structure at macro- and micro-level certainly appeals to our brain's appreciation of symmetry. Our brain orders and categorizes all the time. A well-ordered design is therefore easily detected, easily grasped and also remembered well. Add to this the >right « content, and it is understandable that the psalm 'works well, even today in a modern context. ${ }^{856}$ Die fließend gestalteten Übergänge verhindern dazu ein Herausfallen aus dem Leseprozess. Die Textdynamik nimmt also die Lesenden in mehrerlei Hinsicht mit. Da ist zunächst die klangliche Komponente zu nennen, die für KennerInnen des Bibelhebräischen ein zusätzlicher Anreiz sein kann, mit Hilfe der rhythmischen Gestaltung und der Assonanzen und Alliterationen in die Textwelt einzusteigen. ${ }^{857}$ Darüber hinaus ist die Perspektivenlenkung anzuführen. Dabei steht JHWH im Zentrum, wie die Analyse der Subjekte, der Handlungen und der JHWH zugeschriebenen Fülle an Aktivitäten gezeigt hat. Mittels der verschiedenen Spots, die einer Bewegung von unten nach oben und wieder nach unten folgen, wird ein Fokalisierungsverlauf erzeugt, der menschlichen Bewegungsverläufen ähnelt und damit zur Identifikation einlädt (vgl. III Methodik 3.1). Der Spotwechsel verläuft nicht sprunghaft, sondern fließend. Daher ist ein Mitgehen mit der »Kameraführung» des Textes möglich. Durch die Imperative, die zeitdeckend sind, sowie durch die erzählten Inhalte, die die Nähe Gottes thematisieren, wird ein Zoom-Effekt erzeugt, der die

854 Sedlmeier, Jerusalem, 347 sowie Risse, Gut ist es, 67-97.

$855 »$ Psalm 147 forms a coherent whole which is confirmed by a neat structure.« Viviers, Psalm 147, 183. Dazu Sedlmeier, Jerusalem, 43f: »Die Gesamtkomposition von Ps 147 ist durchdacht $[\ldots . .$. . Der Aufbau des Psalms, die Entsprechungen zwischen seinen Teilen und die Bewegung im Textverlauf machen den Psalm zu einem kunstvollen Gebilde [...].»

856 Viviers, Psalm 147, 183.

857 »Only a mother-tongue speaker of Classical Hebrew would be able to appreciate fully the ancient poetical soundplay that will always be partly the reach of modern scholars." Viviers, Psalm 147, 174. 
Lesenden näher an den Text heranrückt. Dies wird durch die bereits analysierte Deixis verstärkt, die vor allem in V12-14 durch die Anrede und die Possessivpronomen in der 2.P.sg. gegeben ist. Auch werden dort Jerusalem und Zion personifiziert dargestellt. »JHWHs Beziehung zu Jerusalem bzw. Jerusalems Beziehung zu JHWH werden nicht durch lokale, sondern vielmehr durch personale Kategorien ausgedrückt. [...] Diese spersonale` Beziehung zu JHWH ist das zentrale Anliegen des Psalms. ${ }^{858}$ Und in diese personale Beziehung können die LeserInnen durch die genannten Textelemente hineingeholt werden.

Eine weitere Möglichkeit der Identifikation bietet jene mit der Sprechstimme. Analog zum lyrischen Ich, welches das lesende Ich sein kann (vgl. I Einleitung 4.1.4), ist auch hier mit dem offenen lyrischen Wir ein Identifikationspotenzial sowohl für das einzelne Individuum als auch für Gruppen und Gemeinschaften gegeben. Spannend ist in Ps 147 insbesondere, dass das sprechende Wir selbst zu den Angesprochenen und zu den im Text erwähnten HeilsempfängerInnen gehört. Es erzählt also nicht nur von jemandem und etwas oder spricht nicht nur jemanden an, sondern ist selbst mit dabei und hineinverwoben in das, worüber es spricht. Als Lesende kann ich mich daher sowohl mit dem sprechenden Wir als auch mit Jerusalem, Israel, denen, deren Herzen gebrochenen sind, den Zerstreuten, den Gebeugten und den jungen Raben identifizieren. ${ }^{859} \mathrm{Zu}$ guter Letzt ist die hohe Anzahl an synonymen (10x) und synthetischen (9x) Parallelismen zu nennen, die für die Lesezeit wesentlich sind und dazu beitragen, länger am Gedanken des jeweiligen Verses zu bleiben (V6: antithetisch). Durch die Vertiefung der Aussagen, die Intensivierung, Konkretisierung und Dynamisierung ist Zeit für die Imaginationsarbeit und somit Zeit zur Identifikation gegeben.

\section{3 durch Inhalt}

Der Psalm bringt eine Vielfalt von Gottesbildern zur Darstellung, wobei Gottes Zuwendung und Fürsorge für Bedürftige, Gottes machtvolles Handeln für Jerusalem und Israel und Gottes Größe (und Gefährlichkeit) in der Schöpfung im Mittelpunkt stehen sowie die Effizienz und Wirkmacht des göttlichen Wortes. Der Psalm vertritt »die Überzeugung, dass Gott den Geringen und Demütigen, d. h. dem glaubenden Israel, hilft und helfen wird und die Frevler zu Boden wirft; die Überzeugung, dass Gott die Macht zur Hilfe besitzt und dass das glaubende Israel diese Macht anerkennen und - unter Absehen von aller menschlichen Macht - allein auf sie vertrauen soll. ${ }^{860}$ Durch die Botschaft des Textes, auf einen

858 Risse, Gut ist es, $188 \mathrm{f}$.

859 Vgl. dazu Goldingay, Psalms 3, 726.

860 Fohrer, Psalmen, 71. 
Gott zu vertrauen, der Schöpfung und Geschichte lenkt und sich den Notleidenden und Geringsten zuwendet, der Wunden heilt, Schmerzen lindert, Nahrung, Frieden und Sicherheit bis hin zu köstlicher Lebensfülle verleiht, erfährt Ps 147 eine besondere Attraktivität. ${ }^{861}$ Lesende sind daher eingeladen, das je eigene Gottesbild mit dem von Psalm 147 zu identifizieren. Dies wird durch die bereits analysierte Darstellungsform der Gleichzeitigkeit unterstrichen. Der Text wird damit in eine Art Zeitlosigkeit enthoben. ${ }^{862}$ "Worauf es dem Dichter eigentlich ankommt, ist dieses dauerhafte Heilshandeln JHWHs. JHWH baut Jerusalem, er sammelt Israel, er heilt sein Volk. Das hat er in der Vergangenheit bewiesen, das darf Jerusalem/Israel auch in Zukunft von ihm erhoffen. Nicht nur auf Schutz und Sicherheit darf Jerusalem hoffen, sondern auf die Fülle des Heils, die sich in JHWHs Segen und seinem Shalom zeigt und die in der Sättigung mit bestem Weizen symbolisch dargestellt ist. «" ${ }^{863}$

Mit Jerusalem und Israel, die als Heilsempfänger im Text gelten, wird die Geschichte Israels thematisiert, die in der Analyse von Ps 30 keine große Rolle gespielt hat. Die Lesenden sind hiermit eingeladen, an der Geschichte Israels und damit am Beziehungsgeschehen zwischen Gott und seinem Volk zu partizipieren. Es geht darum, die je eigene Heilsgeschichte mit der großen Heilsgeschichte Israels zu verbinden bzw. in der Heils- und Unheilsgeschichte des Volkes die eigenen Heils- und Unheilserfahrungen zu entdecken und dafür Trost, Aufgehobensein bei Gott, Heilung der Wunden und Lebensfülle zu erfahren. Gerade die Psalmen können dafür als Sprachschule gelten, als Sprachschule sowohl für neu Hinzugekommene aus den Völkern als auch für heutige LeserInnen: »Zunächst als Gast- und Nebenhörer, als Forum, dann auch als Mitsprechende lernen sie, ihren Platz, ihre Rolle im Bund zu finden, schließlich mit Israel den Namen des Herrn anzurufen und auszurufen, ihm zu klagen, ihn anzuflehen, seine Nähe,

861 Auf die Aktualität von Ps 147 im Allgemeinen und auf jene des Gottesbildes im Besonderen verweist Viviers in seinem Beitrag mit der Ausgangsfrage: »Why is Ps 147 >catchy८, two and half millenia ago and still today? «(S. 171). Seiner Ansicht nach besticht Psalm 147 »with its universal message of trust in a God who keeps history and nature intact.« (S. 176). Viviers simplifizierende Darstellung bestimmter Richtungen aus der Kognitionsforschung in Bezug auf die Entstehung von Religion, Ritualen und Gottesbildern in unserem Gehirn ist jedoch kritisch zu hinterfragen. Vgl. Viviers, Psalm 147.

862 Auf diese Zeitlosigkeit verweist auch Vosberg mit der folgenden Aussage: »Das Reden vom Schöpfer wird heilvolles Reden von Gott, das den Aussagen letzte Gültigkeit verleiht. Es transzendiert die heilvolle Geschichtserfahrung nach einem `vor der Weltzeit $\iota$ und macht sie gerade so fruchtbar und gültig für Gegenwart und Zukunft (für die von der Zukunft bestimmte Gegenwart). Das Reden vom Schöpfer gibt der Gewissheit Ausdruck, dass Gott, sogar wenn keine Zeit ist, derselbe Gott bleibt (s. Ps 102). "Vosberg, Studien, 116.

863 Risse, Gut ist es, 188. Oder anders gesagt: »Gott ist immer dabei, Jerusalem zu erbauen, die Versprengten zu sammeln, die zerbrochenen Herzen zu heilen, die Armen aufzurichten, sein Wort zu senden, das die Menschen leiten kann, die rechten Schritte zu tun.« Ebd., 355. 
sein Antlitz zu suchen, seine großen Taten zu preisen. ${ }^{864}$ Ereignisse aus der Geschichte Israels werden in Ps 147 zwar zum Thema gemacht, jedoch wird keine eindeutige Zuordnung zu einem bestimmten historischen Ereignis getroffen. »Aber vielleicht soll eine solche Eindeutigkeit ja gerade vermieden werden. Steht doch im Vordergrund die Aussage von Jahwes Handeln [...]. ${ }^{865}$ Es gibt Anklänge an Not- und Gewaltsituationen, an Rettung und Neuanfang. Die Art und Weise der Darstellungsform in Ps 147 wird zu einer Typisierung sowohl der Not- als auch der Rettungssituation und damit zu einem Paradigma für das Heilshandeln Gottes. Zudem können weder die Zerstreuten Israels, die Herzzerbrochenen, die Armen, Gottesfürchtigen, die auf JHWHs Güte Harrenden noch die Frevler, die Schenkel des Mannes oder die Nationen mit konkreten Personengruppen identifiziert werden. Diese Typisierung der Noterfahrung und des Wiederaufbaus in Friede, Heil und Sicherheit sowie die Nicht-Zuordenbarkeit der genannten Gruppen bringen in ihrer Uneindeutigkeit eine zeitübergreifende Offenheit mit sich, die es heutigen LeserInnen möglich macht, sich selbst und ihre eigene Geschichte mit der im Text erzählten zu identifizieren.

Schließlich ist noch auf die brennende Aktualität der im Psalm geschilderten Themen einzugehen, abgesehen vom bereits thematisierten Gottesbild. Wie im Theorieteil ausgeführt, wird Identifikation durch Analogiebildung erreicht. Zur Erinnerung: »Das Identifikationspotential einer Erzählung muss es dem Erzähler wie den Adressaten erlauben, beim Aufnehmen der Erzählung das Erzählte laufend in Beziehung zu setzen mit der eigenen Erfahrungswelt und den Problemkonstellationen ihrer Gegenwart. Auf dem Wege der Analogiebildung muss es für sie möglich sein, in den erzählten Situationen und Personen sowie in den erzählten Komplikationen und deren Auflösungen zumindest teilweise Situationen, Personen und Problemkonstellationen ihrer Gegenwart wiederzuerkennen. $"{ }^{86}$ Auf folgende Themen und Problemkonstellationen des Psalms, die gegenwärtig sehr aktuell sind, weist Siegfried Risse hin: »In Vers 6 geht es um Gottes Option für die Armen. In den Versen 10-11 wird Gott gepriesen als derjenige, der an Rüstung und Krieg keine Freude hat. Die Verse 19-20 führen zu der Frage nach dem Verhältnis von Israel und den übrigen Völkern, von Judentum und Christentum. Ferner geht es um Gottes Umgang mit der Schöpfung; und daraus lassen sich auch Hinweise auf unseren Umgang mit der Schöpfung ableiten. ${ }^{867}$

Der Psalm thematisiert JHWH als Schöpfer und dessen Umgang mit und in der Schöpfung in positiver, fürsorgender wie auch bedrohlicher Weise (Stichwort: Wetterphänomene). Dass in Gegenwart und Zukunft mit der Schöpfung für-

864 Loerbroks, Weisung, 130.

865 Sedlmeier, Jerusalem, 237.

866 Hardmeier, Textwelten, 211.

867 Risse, Gut ist es, 13. 
sorgend und positiv umgegangen werden muss, ist angesichts des jüngst veröffentlichten Klimaberichts ${ }^{868}$ und der Enzyklika "Laudato si'" von Papst Franziskus $^{869}$ ein Gebot der Stunde und eine Pflicht und Verantwortung der Natur und den nachfolgenden Generationen gegenüber. So kommt auch Limburg nach der Analyse von Ps 147 zum Schluss: »The theme of human >solidarity with the rest of creation is sounded clearly. ${ }^{870}$

Mit V6 und der Option für die Armen wird das Thema der Gerechtigkeit eingespielt. Soziale Gerechtigkeit, Verteilungsgerechtigkeit und adäquate Konsequenzen für Gewaltverbrecher sind aktuelle Themen unserer Zeit.

Noch nie hat es seit dem zweiten Weltkrieg so viele kriegerische Auseinandersetzungen ${ }^{871}$ und so viele Menschen auf der Flucht gegeben wie gegenwärtig. V10 spricht davon, dass weder (Kriegs-) Pferde noch Mannesstärke erstrebenswert sind, sondern das Vertrauen auf JHWH. Angesichts der hohen Anzahl kriegerischer Konflikte weltweit und der enormen Zerstörung, die Krieg und Gewalt in unserer Welt anrichten, klingt V10 wie eine Utopie und muss als Mahnung und Aufforderung, den Weg der Gewaltlosigkeit einzuschlagen, hochgehalten werden.

Der atl. Text von Ps 147 bringt damit in einfacher, aber eindrucksvoller Weise brisante Themen zur Sprache, die gerade heute eine hohe Gültigkeit besitzen. Er lädt neben der oben beschriebenen thematischen Aktualität durch die Darstellungsform der doppelten Emotionalität, durch die implizit hervorgerufene Bewunderung im Leseprozess, die Perspektivenlenkung und "Kameraführung" sowie durch das offene lyrische Wir und die Zeitlosigkeit zur LeserInnenidentifikation und zur Identifikation des eigenen Gottesbildes mit jenem von Ps 147 ein.

868 Vgl. http://www.ccca.ac.at/de/apcc/ [abgerufen am 28.5.2015].

869 Vgl. Papst Franziskus: Enzyklika »Laudato si'«. Über die Sorge für das gemeinsame Haus, Rom 2015, besonders S. 20-27.

870 Limburg, Quoth, 110.

871 Vgl. Risse, Gut ist es, 354 . 


\section{Textanalyse Psalm 90}

\section{Inhalt}

Ps 90 stellt als einer von wenigen Texten in der Hebräischen Bibel in expliziter Weise das Zeitthema in den Mittelpunkt seiner Betrachtungen. Das Thema wird ausgespannt zwischen der Zeitdimensionen Gottes und der Menschen (zur Arbeitsübersetzung siehe X Anhang). Die Sprechstimme ist ein lyrisches Wir, das durchgehend im Psalm vorhanden ist und nur in jener Passage in den Hintergrund tritt, in der von der Zeitlosigkeit Gottes im Vergleich zur Vergänglichkeit des menschlichen Lebens im Allgemeinen die Rede ist (V2-6). Das lyrische Wir, das auch die Gottheit mittels direkter Rede zu Wort kommen lässt (3b), zeigt sich demgemäß sowohl als »involviertes als auch distanziertes Subjekt. Dabei verläuft die Entwicklung ab Vers 2 von der Distanz hin zur intensiven Betroffenheit, die in der Bezeichnung Knechte, 13c und 16a, in ihrer Beziehung zu Gott explizit zum Ausdruck kommt. ${ }^{872}$ Textinterne AdressatInnen sind die Gottheit Israels, die in $1 \mathrm{~b}$ mit Adonaj ${ }^{873}$ und in V13 mit JHWH direkt angesprochen wird, sowie die Menschenkinder, die Gott selbst in 3b zur Rückkehr auffordert.

\subsection{Rederichtungen und Themen}

Wie die Zeitthematik sich zwischen Gott und den Menschen bewegt, so ist auch die Beziehungsstruktur des Psalms in ein Du-Wir-Geschehen eingebettet. Diese auf das göttliche Du ausgerichtete Perspektive durchzieht den gesamten Psalm und bestimmt dessen Struktur.

872 Gillmayr-Bucher, Die Psalmen, 264.

873 Liest man die Gottesbezeichung "El« in 2c als Vokativ (»und von Ewigkeit zu Ewigkeit [bist] $\mathrm{du}$, Gott«), dann zählt auch diese zur direkten Anrede. 
Dabei wird mittels einer Vielzahl von Vergleichen und Kontrasten der Gegensatz zwischen menschlicher und göttlicher Zeit zum Ausdruck gebracht. ${ }^{874}$ In diese Zeitthematik hineinverwoben sind die Themen der Vergänglichkeit, Flüchtigkeit und Kürze des menschlichen Lebens, das allgemeine Todesgeschick sowie die Auseinandersetzung mit der eigenen Sterblichkeit. ${ }^{875}$ Die kollektive Leid- und Unheilserfahrung, hinter welcher der Zorn Gottes in seinen vielfältigen Dimensionen steht, ist ein weiteres großes Thema des Psalms. Nach der Thematisierung von Schuld wird in Form von Bitten um Lebensklugheit und positive Lebensgestaltung angesichts der Kürze des menschlichen Lebens um die Zuwendung Gottes, um Sättigung, Freude und ausgleichende Gerechtigkeit zur Zeit des Unheils sowie um das Sichtbarwerden der Herrlichkeit und Anmut Gottes gebeten. Den Schlusspunkt setzt der wiederholte Wunsch nach Beständigkeit und Förderung der menschlichen Arbeit durch Gott.

Der Text kann als eine Mischung zwischen einem Klagelied des Volkes und einer weisheitlichen Reflexion betrachtet werden ${ }^{876}$ oder aber als individuelles Lied, das sich jeder Kategorisierung entzieht. ${ }^{877}$ Er weist eine starke Affinität zur Weisheitsliteratur (z. B. zu Koh 2.3.5.8.9.11; Ijob 3.5.7.14; Spr 8) auf und steht mit Ps 39; 73; 89; 91; 92; 102; 103 in Verbindung. Er lässt sich in zwei große Teile gliedern (V1-12; 13-17), ${ }^{878}$ wobei V11-12 als »Scharnier ${ }^{879}$ bzw. Bindeglied

874 Vgl. Grohmann, Fruchtbarkeit, 92.

$875 \mathrm{Zu}$ den Themenbereichen des Psalms siehe ebenso Gillmayr-Bucher, Die Psalmen, 253. Sie listet die elf semantischen Felder "Zeit", "vergehen«, "Eifer/Zorn«, "Gott«, "Körper", »freuen«, "wahrnehmen«, »Tat«, "wenden«, »elend «, »erkennen« auf.

876 So die meisten KommentatorInnen. »Die beklagte Not ist [dabei] nicht etwa eine Zwangslage Israels, sondern die Sterblichkeit aller Menschen.» Müller, Der 90. Psalm, 267. Anders Terrien, The Psalms, 645: »The psalm is not a lament but praise.« Oder Robertson, Literary Criticism, 49: "It is a hymn of consolation."

877 Vgl. Seybold, Psalm 90, 131.

878 Wie die Unterschiedlichkeit in der Gliederung, so ist auch jene in der Bestimmung der Gattung: Ps 90 wird etwa auch ein hymnischer Charakter zugeschrieben, vor allem aufgrund von V2 und dessen Nähe zum Hymnus der präexistenten Weisheit in Spr 8,22-31. Vgl. dazu z. B. Müller, Der 90. Psalm, 266 und Forster, Begrenztes Leben, 152. Zur Fragestellung nach der Gattung und der Einheitlichkeit siehe die ausführliche Darstellung bei Schnocks, Vergänglichkeit, 133-144. Er kommt nach eingehender literarkritischer Analyse zu folgendem Schluss: »[Es] kann hier von der Einheitlichkeit des Psalms ausgegangen werden. Der Text bildet ein kohärentes Ganzes. «Schnocks, Vergänglichkeit, 144. Ebenso u. a. Kraus, Psalmen, 796; Ernst, Segen, 195 und Schreiner, Erwägungen, 80. Zur Frage der Gattung und der Vielfalt der Stile in Ps 90 siehe Forster, Begrenztes Leben, 151-157.162f. Was die Datierung betrifft, so wird von den meisten AuslegerInnen eine Verortung in nachexilische bzw. spätnachexilische Zeit favorisiert. Hauptargument dafür ist der Begriff עֶֶֶ (V13.16), der beinahe ausschließlich in nachexilischen Texten auftaucht, sowie die Nähe von Ps 90 zur Weisheitsliteratur und die Auseinandersetzung mit der Todesproblematik in einer Situation, in der »die tragende Kraft der geschichtlichen Erfahrungen Israels zu verschwinden droht.» Irsigler, Psalm 90, 61. Vgl. dazu Forster, Begrenztes Leben, 159; Kartje, Wisdom, 123 und Müller, Der 90. Psalm, 279. 
bezeichnet werden und ihnen damit eine Sonderrolle zukommt. Die Strukturierung in zwei große Teile ist aber auch schon der einzige Punkt, über den in der Exegese in Bezug auf die Gliederung Konsens besteht. Es gibt zahlreiche und ganz unterschiedliche Auffassungen über die Feingliederung des Textes. ${ }^{80}$ Ich folge der Gliederung in zwei Teile (V1-12; 13-17), die ich nochmals in je zwei Gedankenspots bzw. Betrachtungen (V1-6; 7-12; 13-15; 16-17) unterteile. ${ }^{881}$ Diese Strukturierung ergibt sich aufgrund der Gliederungskriterien des Themenwechsels, des Sprechrichtungswechsels und des Subjektwechsels. So erfolgt in Teil I die erste Betrachtung von V1-6 über die Zeit Gottes im Gegensatz zur menschlichen Vergänglichkeit. Dabei wird nach der Überschrift in 1a und dem Vokativ in $1 \mathrm{~b}$ (Adonaj) über Gott in der 2.P. gesprochen. Mit V7, der durch ein emphatisches statt (Subjekt in V6 ist das Gras), der die zweite Betrachtung einleitet. Zudem wird mit dem Zorn Gottes ein neues Thema eingespielt. In V7-12 herrscht eine Wir-Du-Perspektive vor. Die dritte Betrachtung in Teil II beginnt mit dem Imperativ in 13a und lässt neben einem Subjektwechsel (in 12b ist Wir das Subjekt) und einem Themenwechsel zur Zuwendung Gottes einen Einschnitt durch den Perspektivenwechsel (direkte Anrede an Gott in Form von Imperativen) erkennen. Diese dritte Betrachtung (V13-15) geht in V16-17 über in die vierte Betrachtung. Die Sprechrichtung (Du-Wir-Perspektive) wird zwar beibehalten, mit 16a ist jedoch ein Subjektwechsel (16a Subjekt: dein Werk; 15b Subjekt: wir) sowie ein Themenwechsel auszumachen: Ist in den V13-15 von der erneuten Zuwendung Gottes und dem Beschenktwerden mit Freude, Güte und ausgleichender Gerechtigkeit die Rede, so treten mit V16 das Werk und Tun Gottes und dessen Glanz und Anmut sowie die Arbeit der Menschen in den Mittelpunkt: Beide mögen sichtbar werden, und das Tun der Menschen möge Bestand haben.

879 Siehe dazu Forster, Begrenztes Leben, 149 sowie Schnocks, Vergänglichkeit, $130 \mathrm{f}$ und die dort angeführten Begriffe für V11.12 als Dreh- und Angelpunkt, Scharnier und Gelenksstelle sowie Mittelpfosten bzw. Kulminations- und Wendepunkt. Ebenso Kartje, Wisdom, 121.

880 Einen Überblick über die vorhandenen Gliederungsvorschläge gibt Forster, Begrenztes Leben, 145, besonders Anm. 36.

881 Ähnlich Alonso Schökel / Carniti, Salmos 2, 1172. Sie gliedern den Psalm in V1-6; 7-11; 1217. 


\section{$1.2 \quad$ Gliederung}

\begin{tabular}{|c|c|c|c|c|}
\hline Vers & Themen & Zeitachse & Sprechstimme & Sprechrichtung \\
\hline $1-6$ & $\begin{array}{l}\text { Ewigkeit Gottes versus } \\
\text { Vergänglichkeit des } \\
\text { Menschen }\end{array}$ & $\begin{array}{l}\text { Vor-Vergangen- } \\
\text { heit (SK); Ver- } \\
\text { gangenheit bzw. } \\
\text { Gegenwart (PK) }\end{array}$ & lyr. Wir & $\begin{array}{l}\text { 1b Wir }-\mathrm{Du} \\
2 \mathrm{Du} \\
3-6 \mathrm{Du}-\mathrm{Sie}\end{array}$ \\
\hline $7-12$ & $\begin{array}{l}\text { Zorn Gottes, Schuld, } \\
\text { Mühsal und Kürze des } \\
\text { Lebens, rhetorische } \\
\text { Frage über die Er- } \\
\text { kenntnis des Zorns, } \\
\text { Bitte um Erkenntnis } \\
\text { der Kürze des Lebens } \\
\text { und um Lebensklugheit }\end{array}$ & $\begin{array}{l}\text { Vergangenheit } \\
\text { bzw. Gegenwart } \\
\text { (SK); Jetzt (Ptz.; } \\
\text { Imp.) }\end{array}$ & lyr. Wir & $\begin{array}{l}\text { 7-10 Wir - Du } \\
11 \text { Wer } \\
12 \mathrm{Du}-\text { Wir }\end{array}$ \\
\hline $13-15$ & $\begin{array}{l}\text { Bitte um Zuwendung } \\
\text { Gottes und um Freude }\end{array}$ & $\begin{array}{l}\text { Jetzt (Imp.); } \\
\text { Zukunft; Rück- } \\
\text { blick (SK) }\end{array}$ & lyr. Wir & $\begin{array}{l}13 \mathrm{Du} \\
14 \mathrm{Du}-\mathrm{Wir} \\
15 \mathrm{Du}-\mathrm{Wir}\end{array}$ \\
\hline $16-17$ & $\begin{array}{l}\text { Bitte um Sichtbarkeit } \\
\text { des Handelns Gottes } \\
\text { und um den Bestand } \\
\text { des Menschenwerkes } \\
\text { durch die Unterstüt- } \\
\text { zung Gottes }\end{array}$ & $\begin{array}{l}\text { Jetzt (Imp.); } \\
\text { Zukunft }\end{array}$ & lyr. Wir & $\begin{array}{l}16 \mathrm{Er}-\mathrm{Sie} \\
17 \mathrm{Er}-\mathrm{Du}-\mathrm{Wir}\end{array}$ \\
\hline
\end{tabular}

\section{Emotionen}

Im Rahmen der Emotionsanalyse von Ps 90 fallen zunächst jene Emotionen und Aspekte ins Auge, die als sogenannte A-emotions (vgl. III Methodik 2.2.2) ausgewiesen werden können und in den bisherigen Analysen nur eine geringe Rolle spielten (vgl. etwa die klangliche Gestaltung von Ps 147 als A-emotions).

So wirkt Ps 90 insgesamt aufgrund seiner Vielzahl an Substantiven ${ }^{882}$ und aufgrund seines Charakters einer weisheitlichen Reflexion auf den ersten Blick eher statisch und behäbig - etwa im Vergleich zu dem aus zwei Minierzählungen bestehenden Ps 30 sowie zu Ps 147 mit seinen vielen Verben, unterschiedlichen Spots und Blickrichtungen. Dennoch sind auf den zweiten Blick auch in Ps 90 auf unterschiedlichen Ebenen (z. B. Zeitdimension, Themen) Elemente der Bewegung auszumachen, wie im Folgenden zu erörtern sein wird.

Der statische Charakter trägt auch einen Zug von Entschlossenheit. Ps 90 ist ein kompakter, in sich feststehender Text. Nimmt man Form und Inhalt des

882 Auf die hohe Anzahl der Abstrakta verweist Ernst, Segen, 195. 
Psalms gemeinsam in den Blick, so wirkt dieser aufgrund der Schwierigkeiten in der Textkonstitution, der Unübersetzbarkeit einiger Textstellen (Form) sowie der Thematik von Vergänglichkeit, Anstrengung und Sinnlosigkeit im Rahmen des kurzen menschlichen Lebens (Inhalt) als ein mühseliger und an manchen Stellen schwer greifbarer Text, der zeitweise in rauen Tönen spricht und eine dumpfe, düstere Stimmung ausstrahlt. ${ }^{883}$ Auch von Pessimismus, Daseinsverdrossenheit, Skepsis und Bedrückung ist dabei die Rede, z. B. bei der Auslegung von V2ff: »Geradezu erdrückend überfällt den Hörer/Leser der Gedanke der Ewigkeit Gottes im Textverlauf [...]. ${ }^{884}$ Umso mehr überrascht V11 mit einer Doppelfrage (je nach Übersetzung), die zum zweiten Teil des Psalms überleitet, der von Hoffnung und Zuversicht getragen ist und dabei immer noch in der Form von Klage und Bitte verharrt. ${ }^{885}$ "In Psalm 90, there is a decided shift from the more somber mood in vv. 3-10 to the more hopeful tone in vv.13-16. ${ }^{886}$ Alles in allem stellt Psalm 90 demnach einen widersprüchlichen, ambivalenten Text dar, der von bedrückender Stimmung, Traurigkeit und Dunkelheit ebenso getragen ist wie von Vertrauen und hoffnungsvoller Freude. ${ }^{887}$ Gemeinsam mit den F-emotions, die in der folgenden Emotionsanalyse dargelegt werden, kann von Psalm 90 als einer Fundgrube von Emotionen gesprochen werden. ${ }^{888}$ Im Hinblick auf die Sprachbilder, die im Rahmen der folgenden Analyse betrachtet werden, wird von den "packenden Bildern ${ }^{889}$ des Psalms gesprochen, und der Psalm insgesamt wird als »ergreifendes Gebet ${ }^{890}$ bezeichnet.

883 Vgl. Seybold, Psalm 90, 130. „Eine ästhetische Betrachtung des Ps 90 wird sich vorwiegend auf die archaischen, schwermütigen und dumpfen Klänge des Gebetsliedes beziehen [...] « bei Kraus, Psalmen, 800. Von Rad, Der 90. Psalm, 273, spricht vor allem im Zusammenhang von V3-10 von »düsteren Überlegungen « bzw. einem »düsteren Horizont.« Von Schwermut und Ernst spricht Duhm, Die Psalmen, 344. Bezüglich des Folgens einer inneren Logik von Ps 90 merken Hossfeld / Zenger, Psalmen 51-100, 603 an: »Es fällt nicht leicht, in seiner Zusammenstellung ungewöhnlicher Sprachbilder die innere Logik zu entdecken." Ähnlich Schnocks, Berge, 164, der von einer "gewisse[n] Mühe, die Struktur des Textes und damit seinen Gedankengang zu erkennen«, spricht.

884 Irsigler, Psalm 90, 62.

885 Für den Abschnitt V13-15 hält Samuel Terrien fest: "The mood changes astonishingly, without transition, to a sapiential prayer.« Terrien, The Psalms, 645.

886 Kartje, Wisdom, 121. Ähnlich McCann, Psalms, 1041. Anders Bruce Vawter, der von Psalm 90 als einem »beautiful prayer» spricht. Vawter, Postexilic Prayer, 461.

887 Jens, Psalm 90, 177:»[...] contradictory and dark, hopeful and somber, merciless and gentle. A song of dying and a word of life - a psalm marked equally by fear and trust, of terrible death and tender friendliness, lament and praise, wrathful judgment and hymnic eucology«.

888 Das zeigt auch die Rezeptionsgeschichte des Textes: »Readers through the ages have found in Psalm 90 a rich and diverse trove of sentiments. [...] The psalm is no less fascinating to modern readers as the continuing stream of scholarly studies makes clear.» Clifford, Psalm 90, 190.

889 Groß / Reinelt, Das Buch der Psalmen, 125.

890 Wahl, Psalm 90,12, 116. 
Wie bereits in den vorangegangenen Analysekapiteln wird auch hier im Rahmen der Emotionsanalyse auf Fragen der Syntax und Semantik des Textes Bezug genommen. Allerdings muss ein kurzer Hinweis auf die inhaltliche Ambivalenz und Übersetzungsproblematik des jeweiligen Verses mit Verweis auf entsprechende Literatur genügen, da ein detailliertes Eingehen auf die vielen Textunsicherheiten den Rahmen dieser Arbeit sprengen würde.

\subsection{Vers 1: Unsere Zuflucht ist Gott}

1a Ein Gebet. Im Geiste Moses, des Mannes Gottes.

$1 b$ Adonaj, Wohnort bist du gewesen für uns von Generation zu Generation.

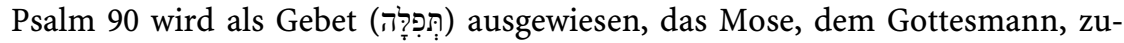
geschrieben wird. Mit der Zuordnung des Gebets wird eine Verbindung zur Erzählfigur Mose im Pentateuch hergestellt. Der Psalm erhält durch die Zuschreibung zu Mose, die im Psalter einzigartig ist, eine besondere Würde und kann damit ebenso als Bittgebet des Mose (Ex 32,11-13 sowie V12-17) wie als sein Segen (Dtn 33,11 und V17, der als Segenswunsch des Psalms betrachtet wird) verstanden werden. ${ }^{891}$ Wie David in den Davidpsalmen dient hier Mose als erste Identifikationsfigur, ${ }^{892}$ die allerdings bereits mit $1 \mathrm{~b}$ hinter das Wir des Psalms zurücktritt.

Nach der Überschrift in 1a wird in 1b JHWH mit Adonaj angesprochen und als מָעזון, d. h. als Wohnung bezeichnet. Unterschlupf von (wilden) Tieren ${ }^{894}$ bezeichnen wie den Aufenthaltsort JHWHs. Mit Letzterem ist meist der Tempel gemeint, es kann sich aber auch um den Himmel als Wohnstatt Gottes handeln. Dem Begriff מָעז liegen damit die beiden folgenden Aspekte zugrunde: Es ist dies einerseits das Element des Schutzes, des Bergens und der Ruhe, sowie andererseits das Aktivwerden in Richtung auf die Eliminierung der Feinde. Der textkritische Apparat der BHS weist an dieser Stelle darauf hin, dass einige wenige Handschriften eine Textänderung in (Festung,

891 Vgl. Hossfeld / Zenger, Psalm 51-100, 609 und Irsigler, Psalm 90, 49. Zur Zuordnung des Gebets zu Mose vgl. ausführlicher Wallace, Psalms, 150; ebenso Terrien, The Psalms, 642; Ballhorn, Telos, 82.84; McCann, Psalms, 1040-1043 und Tate, Psalms, 438. Zu weiteren Bezügen zu Mose außerhalb der Überschrift und innerhalb von Ps 90 siehe Wallace, Narrative Effect, $18-21$.

892 »Der (Nach-)Betende dieses Psalms tritt damit in die Fussstapfen des grossen Fürbitters« bei Weber, Werkbuch 2, 121. Nach Seiler, Text-Beziehungen, 144 kann die Überschrift als Leseanweisung verstanden werden, welche die Erinnerung an Gebetssituationen des Mose in Ex 17,4; 32,11ff; 33,12ff; Num 11,11ff wachruft. Zu David als Identifikationsfigur siehe die Analyse von Ps 30,1 und Ps 64,1 sowie Kuckhoff, Psalm 6, 250.

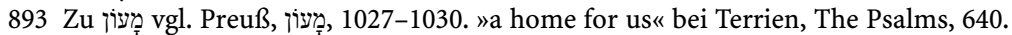

894 Z. B. Jer 9,10; 10,22; 49,33: Wohnung der Schakale; Nah 2,12: Wohnung der Löwen. 
Bollwerk, Burg, Schutz, Zuflucht vor Feinden) ${ }^{895}$ vornehmen. Aber auch ohne diese Textänderung ist der Schutzcharakter der Gottesanrede מָעוֹן ausgewiesen: »Sowohl der Tempel als auch JHWH selbst sind der `Ort`, zu dem der Beter flieht und an dem er Zuflucht und Schutz erfährt. ${ }^{896}$

Mit מָעוֹ als Bleibe, Wohn- und Zufluchtsort sind die Aspekte des Schutzes, der Sicherheit, Zuverlässigkeit und Ruhe sowie der Nähe und heilvollen Gegenwart Gottes angesprochen, in denen die Emotion der Geborgenheit und damit ein Sicherheits- und Wohlgefühl sowie die Emotionen des Vertrauens und der $\mathrm{Zu}$ versicht angesprochen sind. ${ }^{897}$ Allerdings klingt im Begriff מָעוֹ auch ein ambivalenter Zug mit: Als Versteck hat es die Konnotation der Unheimlichkeit, ${ }^{898}$ wobei dahingestellt bleibt, ob damit auch die Gefahr eines Angreifers einhergeht. Im Psalter wird der Begriff jedenfalls in positivem Sinn verwendet, die weiteren Belege im AT könnten aber auch auf folgendes Gottesbild hin gedeutet werden: »But God is also one who hides in his lairs as does the lion or the jackal, ready to come forth in wrath, to spring upon the defenseless and unsuspecting victim. ${ }^{899}$ Auf alle Fälle lässt der Begriff מָָזָ die »Bedrohlichkeit, die es offensichtlich in der Welt gibt, anklingen. ${ }^{900}$

Daneben wird die Zeitdimension der Menschen in den Blick genommen: Adonaj ist Wohnort gewesen für alle Menschengenerationen. Dies zeugt von Beständigkeit und Halt, von Konstanz und Zuverlässigkeit Gottes durch die Zeit hindurch. ${ }^{901}$ Diese Vertrauensäußerung bildet den Ausgangspunkt und die Basis des Psalms und hat für den späteren Verlauf die Funktion, Gott zum Eingreifen zu bewegen. ${ }^{902}$

Auch wird im Hinblick auf V1 darüber diskutiert, wie die SK-Form von הu zu deuten ist: Ist hier gemeint, dass Gott in der Vergangenheit Wohnort und Obdach für die Menschen war, wie dies die in der SK formulierte Handlung mit Vergangenheitsbezug zum Ausdruck bringt, oder zeigt sie einen Zustand an, der bis in die Gegenwart hinein anhält? ${ }^{903}$ Hans-Peter Müller sieht in der SK-Form des Zustandsverbs היה eine zeitlose Funktion und übersetzt mit »bist du«; ${ }^{904}$ laut

895 Vgl. GES $707 \mathrm{f}$.

896 Preuß, מָוֹ, 1030.

897 "Semantisch ist also festzuhalten, dass מָָ als Attribut Gottes vor allem die Geborgenheit im Schutze Gottes konnotiert.« Schnocks, Vergänglichkeit, 45.

898 Vgl. Forster, Begrenztes Leben, 171.

899 Harrelson, Meditation, 186.

900 Hossfeld / Zenger, Psalmen 51-100, 610.

901 Vgl. Oeming / Vette, Psalmen. Psalm 90-151, 20.

902 Vgl. Forster, Begrenztes Leben, 152.

903 Die SK weist einen Vergangenheitsbezug auf. Sie verweist auf Ereignisse, die vor der Topikzeit, also vor der Zeit des Textes liegen. Diese Ereignisse können aber bis in die Topikzeit nachwirken. Vgl. dazu die Ausführungen zur SK im Kapitel III Methodik 3.3.1.

904 Vgl. Müller, Der 90. Psalm, 269. 
Christine Forster, Thomas Krüger u. a. schwingt eine Verunsicherung mit, ob Gott auch gegenwärtig denselben Schutz gewährt wie früher. ${ }^{905}$ Diese führt in den folgenden Versen zu einer weiteren Ambivalenz, nämlich jener zwischen Gott als festem Bestand und sicherem Grund in V1.2 und dessen Kehrseite, nämlich der menschlichen Vergänglichkeit in V3-6.

In $\mathrm{V} 1$ werden die Gott zugeschriebene Emotion der Geborgenheit und die dem lyrischen Wir zugeordnete Emotion des Vertrauens thematisiert. Weitere Aspekte in diesem Zusammenhang sind Schutz, Sicherheit, Zuflucht, Beständigkeit und Halt bei Gott. Eventuell kann beim Gottesattribut »Versteck" auch der Aspekt der Unheimlichkeit und Unberechenbarkeit Gottes mitschwingen, jedenfalls aber die Bedrohlichkeit, die es in der Welt gibt.

\subsection{Vers 2: Gott und Schöpfung}

\section{$2 a$ Bevor Berge geboren wurden}

$2 b$ und $d u$ (unter Wehen) hervorbrachtest Erde und Festland -

$2 c$ und von Ewigkeit zu Ewigkeit (bist) du Gott.

V2 ist jener Vers des gesamten Psalms, der in aller Deutlichkeit die Ewigkeit und Vorzeitigkeit Gottes thematisiert und aufzeigt, dass Gott sprachlich in einer eigenen Zeitdimension verankert ist. Ewigkeit bezeichnet einerseits die entfernteste Zeit und unbegrenzte Dauer, ist aber andererseits, wie hier in V2, mit der Sphäre, dem Wesen und dem Handeln Gottes verbunden und von der Zeit der Menschen unterschieden, ja, mehr noch, "sprengt alle Dimensionen menschlicher Zeiterfahrung. ${ }^{906}$ In der Formulierung "von Ewigkeit zu Ewigkeit» ist Ewigkeit ein begrenzter Zeitraum im Sinne eines Äons (vgl. auch Ps 41,14). Ewigkeit hat die Qualität des Endgültigen sowie die Eigenschaft der Gleichzeitigkeit: »Ewigkeit ist immer Gegenwart göttlicher Essenz im Raum geschichtlicher Kontingenz. ${ }^{907}$ Die Gottheit wird nicht nur mit Ewigkeit verbunden, sondern sie ist sowohl vor der Schöpfung, also vor aller Zeit, als auch Schöpferin, indem sie Berge (pass. divinum 2a), Erde und Welt (2b) hervorbringt. Dabei wird die Entstehung der Welt mittels der meist parallel verwendeten Verben ילד (q. pas. oder pu. geboren werden; q. akt. gebären, zeugen) und (kreißen, unter Wehen hervorbringen) in Geburtsbildern ausgedrückt. Die Metaphorik ist gewaltig und dramatisch und lässt an gigantische Naturphänomene denken wie etwa an sich aufeinanderschiebende Erdplatten, sich hebende Meeresböden oder den Aus-

905 Vgl. Forster, Begrenztes Leben, 138 und Krüger, Psalm 90, 197.205. Laut Ernst, Segen, 196 ist Gott aufgrund der Verbform hier nicht mehr als sicherer Ort zugegen.

906 Feldmeier / Spieckermann, Der Gott der Lebendigen, 413.

907 Feldmeier / Spieckermann, Der Gott der Lebendigen, 407. 
bruch von Erdbeben und Vulkane. Im Geburtsbild bleibend bezeichnet חיל ״den zusammenfassenden Ausdruck für den ganzen Zustand zwischen dem Einsetzen der Geburtswehen und der Geburt selbst [...] - ein Vorgang, der von Angst-

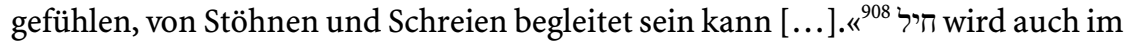
übertragenen Sinn verwendet, dabei auf Länder und Männer bezogen und beschreibt dann einen Zustand, der sich in vibrierenden, unkontrollierbaren Bewegungen äußerst, die mit Hitzegefühlen einhergehen und meist Ausdruck für panische Angst sind. ${ }^{909}$

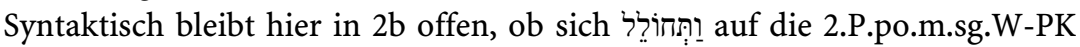
(du) oder auf die 3.P.po.f.sg.W-PK (Erde) bezieht. Liest man die Personalform in der 2.P.sg. als Fortsetzung des Personalpronomens in $1 b$ (אָ אָ du) sowie aufgrund des Fehlens eines Objekts bei der Lesart mit אֶרץ als Subjekt (wen oder was gebiert dann die Erde und der Weltkreis?), dann wäre die Deutung möglich, dass hier Gott als in Wehen gebärend dargestellt wird. ${ }^{910}$ Die Aspekte und Emotionen, die damit verbunden sind, zeugen von Dramatik, Bewegung und Stärke: »Wehen evozieren Heftigkeit, Intensität und Erschütterung im positiven wie im negativen Sinn. Sie weisen auf ein dramatisches Geschehen hin. In ihnen ist die Ambivalenz zwischen Stärke, Freude über neues Leben und Schmerzen, vielleicht auch Angst enthalten. Gott bringt wie eine Frau bei der Geburt Großartiges zustande. [...] Diese Korrelation hat eine besondere Facette darin, dass Gott selbst die Erfahrungen einer gebärenden Frau zwischen Anstrengung und Freude kennt. Wir sehen also den mit-leidenden und sich mit-freuenden Gott. «"11

Neben diesen emotionalen Implikationen auf der Ebene der Semantik ist zu beachten, dass hier bildliche Rede, genauer metaphorische Sprache vorherrscht, die weitere Sinndimensionen zum Ausdruck bringt. So werden zwei Bereiche in Verbindung gebracht, die im Alltagsgebrauch nichts miteinander zu tun haben: die Naturerscheinungen Berge, Erde und Welt einerseits mit dem (menschlichen) Geburtsvorgang andererseits. Zudem sind hier, wie bereits in Ps 30 und Ps 147, Personifikationen $\mathrm{zu}$ finden: "Zwei Motive sind in Ps 90,2 kombiniert: eine personifizierte Rede von Bergen, Erde und Festland und das Bildfeld des gebärenden Gottes. « ${ }^{912}$ Während die Personifikationen in Ps 30 und 147 dazu einladen, menschliche Erfahrungen mit ihnen zu verbinden, ist hier mit der Personifizierung der Naturphänomene (vgl. dazu auch Ps 65,13; 93,3; 96,11) nicht darauf zu schließen, dass die Natur menschenähnlich wird, sondern dass darin eher Gottheiten anklingen. ${ }^{913}$

908 Baumann, חיל, 899.

909 Vgl. Baumann, חיל, 899-900.

910 Vgl. Grohmann, Fruchtbarkeit, 82-83 und Schnocks, Vergänglichkeit, 49.54.

911 Grohmann, Anfang, 385f. Ähnlich Terrien, The Psalms, 643.

912 Grohmann, Fruchtbarkeit, 87.

913 »Im Vorgang der Geburt von Bergen, Erde und Festland aus Gott klingen altorientalische 
Eine weitere Dimension der Bildersprache in diesem Vers wird durch die Begriffe »Berge«, »Erde« und »Festland « zum Ausdruck gebracht. Berge sind das Älteste und Stabilste auf Erden (Ps 36,7; Dtn 33,15). ${ }^{914}$ Sie zeichnen sich durch Unerschütterlichkeit aus. ${ }^{915}$ Indem sie von Gott geboren werden, festigen sie den Ewigkeitsaspekt Gottes. »Im Kontext des Gesamtpsalms haben Berge, Erde und Festland neben ihrer konkreten Bedeutung auch bildlichen Gehalt: Sie symbolisieren Beständigkeit, Dauer, Festigkeit. Diese steht in Parallele zur Existenz Gottes von jeher, aber im Gegensatz zur Kurzlebigkeit der menschlichen Existenz. In ihrer Personifizierung behalten Berge, Erde und Festland eine gewisse Eigenmächtigkeit. Dem präexistenten JHWH als dem, der sie hervorbringt, wird aber größere Macht zugeschrieben. Geburt steht hier im Zusammenhang mit göttlichen Kräften. ${ }^{916}$

Im Hinblick auf die Interaktionstheorie innerhalb der Metapherntheorien (vgl. III Methodik 2.2.3) kann hier Folgendes festgehalten werden: Bringt man - nach der Lesart "du hast hervorgebracht unter Wehen« - das Bild von der menschlichen Geburt mit Gott in Verbindung, dann erhält dadurch die Gottheit die menschlichen Züge der Freude, des Glücks, aber auch des Schmerzes (Gen 3,16 ) und der Anstrengung, die mit dem Geburtsvorgang verbunden sind, ebenso wie die Geburt göttliche Züge erhält. Es stellt sich an dieser Stelle die Frage, ob diese anthropologische Beschreibung bzw. die genannte Metapher die Verwundbarkeit des Schöpfers beschreibt. ${ }^{917}$ Verknüpft man darüber hinaus die Bildbereiche der göttlichen Geburt und der Naturphänomene miteinander, dann erhält die göttliche Geburt Züge der gewaltigen und beständigen Schöpfung sowie die Schöpfung die Züge des Geborenwerdens aus Gott. Folgt man der

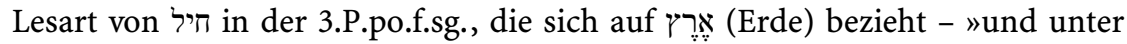
Wehen geboren hat Erde und Festland « - so wird das mythische Bild der »Mutter Erde« generiert, die unter Wehen gebiert. ${ }^{918}$ Dabei geht es um das Herauskom-

Mythen von Gottheiten an, die Berge und Erde gebären." Grohmann, Fruchtbarkeit, 91. Göttliches Gebären wird im AT unter anderem noch in Dtn 32,18 und Jes 42,14 thematisiert und ist in der Mythologie des Alten Orients nichts Außergewöhnliches. Vgl. dazu die Ausführungen bei Grohmann, Fruchtbarkeit, 90.

914 Vgl. Köckert, Zeit, 169.

915 »Sie sind es, die dem Kosmos Bestand und Unerschütterlichkeit geben. Sie tragen den Himmel, und ihre Fundamente reichen tief in das Urmeer und halten so die Erde über dem Chaos. «Zenger, Werk, 19. Vgl. ebenso Forster, Begrenztes Leben, 172. Anders Brandscheidt, "Unsere Tage«, 12, die die Berge als Sitz der Götter und - diesem mythischen Denken folgend - die Geburt der Götterberge als Voraussetzung für das grundsätzliche Geformtwerden der Schöpfung deutet.

916 Grohmann, Fruchtbarkeit, 91.

917 Vgl. Terrien, The Psalms, 643.

918 Vgl. Forster, Begrenztes Leben, 139. 
men der Schöpfung aus der Mutter Erde. Dieses Sprachbild stellt die Schöpfung insgesamt als »einen gewaltigen zum Leben drängenden Prozeß ${ }^{919}$ dar.

Die impliziten Emotionen, die durch die Geburtsmetapher hervorgerufen werden, sind Angst, Freude, Glück und Ekstase. Sie werden Gott zugeschrieben. In der in V2 verwendeten Geburtsmetaphorik verschränken sich die beiden Bildbereiche der Göttlichkeit und der menschlichen Geburt, wodurch die Gottheit menschliche Züge erhält. Weitere Aspekte sind Schmerz, neues Leben, Lebenskraft, göttliche Kraft, Dramatik und Heftigkeit sowie die Gewaltigkeit des Prozesses der Weltenschöpfung. Durch die Personifikationen werden die Aspekte Beständigkeit, Dauer und Festigkeit aufgerufen.

\subsection{Vers 3: Zurück zum Staub?}

3a Du lässt zurückkehren den Menschen zum Staub,

$3 b$ und sprachst: "Kehrt zurück, Menschenkinder!»

Mit V3 wird die Schöpfungsthematik fortgesetzt, allerdings kommen nach der Erschaffung der Natur in V2 nun der Mensch und dessen Zurückkehren zum Staub in den Blick. In jedem Fall ist der Zusammenhang zwischen V2.3 gegensätzlich gestaltet: »War in V. 2 von der erschaffenen bzw. geborenen Welt die Rede, geht es in V. 3 um den Menschen. Die Geburtssprache steht in Kontrast zum Staub, zu dem der Mensch zurückkehren soll: Im Hintergrund der Bezeichnung Tָּ fü Staub steht nicht die Zusammengehörigkeit von Mensch und Ackererde [...], sondern das Zermalmen / Zerschlagen (דכא pi.). Wie in Ps 22 ist also auch hier der Gesamtzusammenhang von Geburt - in urzeitlichem Sinn, noch vor dem Menschen - und Tod - bezogen auf den einzelnen Menschen - im Blick. Die Existenz Gottes von Ewigkeit her steht im Gegensatz zur Vergänglichkeit des Menschen. ${ }^{920}$

Bezüglich des emotionalen Gehalts ist der Begriff דָָּ (Staub) mit den damit verbundenen Assoziationen im Sprachbild des Staubes von Bedeutung. Auch wenn mit V3 Anklänge an Gen 3 gegeben sind, ist hier nicht der Staub (עָָָָר ) aus דכא Gen 3,19 (zermalmen, zertreten, zerschmettern) abgeleitete Substantiv, das auf Gewaltiges und Drastisches schließen lässt, etwa auf einen gewalttätigen Tod. Neben der

919 Zenger, Werk, 19. Vgl. dazu Ijob 38,8.

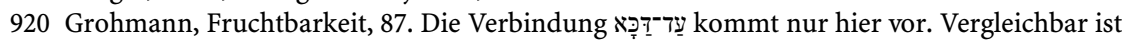

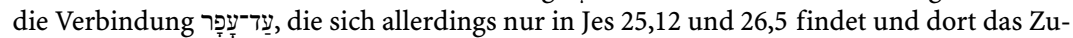
Boden-Stoßen intensiviert. Vgl. Schnocks, Vergänglichkeit, 123, besonders Anm. 392.

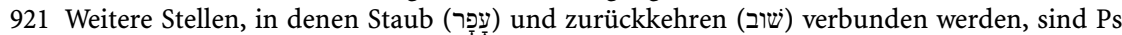
104,29; Ijob 10,9; 34,15 und Koh 3,20. 
Dimension der Flüchtigkeit, die dem Staub inhärent ist, schwingt hier zusätzlich die Dimension der gewalttätigen Zerstörung und der Todesdunkelheit mit. Das Bild vom »zermalmten Staub qualifiziert den Tod als definitives Ende, aus dem es keine Wiederkehr geben kann. ${ }^{922}$ Damit ist hier nicht die Rede vom natürlichen Tod des Menschen, sondern von einem gewaltsamen Tod. Das Sprachbild beschreibt den Tod als Resultat göttlicher Gewalteinwirkung. ${ }^{923}$ Auf spiritueller Ebene wird שוב in in in Vinne eines reuigen Zurückkehrens auch als Zerknirschen und damit nicht als äußere Demütigung, sondern als innere Reue gedeutet. ${ }^{924}$

Das Thema der Todesverfallenheit wird in diesem Vers dadurch unterstrichen, dass hier der Begriff אֶנוֹ für den Menschen verwendet wird (und nicht wָ wie in Gen 2-3). Tritt אנגוֹש im Psalter auf, so ist damit der hinfällige, sterbliche Mensch in seiner Kontingenz gemeint. ${ }^{925}$

Neben der Diskussion um die Wiedergabe der Verbformen steht die Frage im Raum, ob in V3 ein synonymer oder ein synthetischer Parallelismus vorliegt. ${ }^{926}$ Synonym betrachtet sprechen die beiden Halbverse 3a.b jeweils davon, dass Gott die Menschen sterben lässt und damit das Leben der Menschen in der Hand hält und es beenden kann. Synthetisch betrachtet spricht 3a vom Tod der Menschen, $3 \mathrm{~b}$ aber von der Rückkehr der Menschen ins Leben und damit von der Entstehung einer neuen Generation. 3b wäre dann eine Fortführung von 3a in dem Sinn, dass Gott die Menschen wieder ins Dasein ruft, und würde zur Beschreibung des Kreislaufs des Lebens dienen. ${ }^{927}$ Hier wäre Gott auch als Leben schaffend gekennzeichnet.

Neben der Ambivalenz im Bild Gottes, der Leben und Tod des Menschen in der Hand hat sowie - analog zum Schöpfungswerk in V2 - neues Leben im Sinne von neuen Generationen schafft, sind die Themen Vergänglichkeit, Flüchtigkeit, Tod, Gewalt sowie der Kreislauf des Lebens in diesem Vers dominant. Mit Ausnahme der gewalttätigen Dimension und den hinter dem Begriff »Staub« in V3 stehenden Emotionen sind keine Emotionswörter anzutreffen. Die Emotionen bewegen sich auf der Ebene des Leseprozesses (A-emotions). Hier ist von Erschütterung bzw. Ernüchterung in Bezug auf das Gottesbild die Rede; der Vers kann Bedrückung, Wut, Ärger, Verdruss, Angst und Besorgnis aufgrund der

922 Zenger, Werk, 18.

923 Vgl. Zenger, Werk, 20. Ebenso Forster, Begrenztes Leben, 176.

924 Vgl. Goldingay, Psalms 3, 27.

925 Z. B. Ps 73,5; 103,15. Vgl dazu Ijob 25,6; 36,25; Jes $13,7$.

926 Vgl. die Diskussion bei Schnocks, Vergänglichkeit, 62f. Auf die Doppeldeutigkeit des Verses weist auch Forster, Begrenztes Leben, 175 hin. Ebenso Krüger, Psalm 90, 199.205, der die Lesart als synthetischen Parallelismus favorisiert.

927 Vgl. Westermann, Der 90. Psalm, 347. 
Anordnung Gottes auslösen. ${ }^{928}$ Diese Emotionen werden den LeserInnen zugeschrieben und somit als extratextuelle Größe verortet. Es sind dies jedoch Emotionen, die zwar aus der Wahrnehmung der Lesenden heraus entstehen können, aber nicht innerhalb des Textverlaufs aufgebaut werden.

\subsection{Vers 4: Tausend Jahre sind ein Tag}

4a Ja, tausend Jahre in deinen Augen

$4 b$ wie der gestrige Tag, wenn er vorüber geht

$4 c$ und (wie) eine Nachtwache in der Nacht.

Der Vers thematisiert das schnelle Vergehen der Zeit, ein Thema, das in 5b wieder aufgenommen und fortgesetzt wird. Tausend Jahre sind ein Zeitraum, der Menschen zugeschrieben wird, den diese jedoch kaum überblicken und schon gar nicht erfahren können. ${ }^{929}$ Mit dem Ausdruck »in deinen Augen « wird die Perspektive Gottes bzw. das Zeiterleben Gottes thematisiert und ein Jahrtausend als extrem kurze Zeitspanne bzw. als winziger Bruchteil dargestellt: »Die Beschreibung vereint dabei zwei Vorstellungen. Zum einen den göttlich subjektiven Eindruck des Verstreichens von Zeit - 1000 Jahre wie ein Tag, oder wie die wenigen Stunden einer Nachtwache - und zum anderen die Art, wie Zeit erfahren wird. Sowohl der vorüberziehende Tag als auch die Wache in der Nacht bezeichnen Zeitabschnitte, die aktiv und wach erlebt werden. ${ }^{930}$

Für Gott sind also tausend Jahre etwa so wie drei bis vier Stunden, ${ }^{931}$ eine Tatsache, die Staunen hervorrufen kann: "Staunend jedenfalls versucht der Verfasser, sich die unfassbaren Zeitmaße der Ewigkeit klarzumachen. ${ }^{932}$ Es geht hier um eine Zeitraffung, die im darauffolgenden V5 weitergeführt wird im Sinne einer «Schrumpfung der menschlichen Lebenszeit, denn vor ihm sind 1000 Jahre wie der gestrige, schnell verstrichene Tag, wie eine Nachtwache (Ri 7,19). ${ }^{933}$ Der mit ẹִ eingeleitete Konditionalsatz in $4 \mathrm{~b}$ soll die Abgeschlossenheit des gestrigen

928 Vgl. Artner, Emotionen in Psalm 90, 125 mit dem Hinweis, dass an dieser Stelle nicht unterschieden werden kann, ob diese Emotionen auf Seiten der heutigen LeserInnen auch dem lyrischen Wir zugeschrieben werden können.

929 Vgl. Schmidt, Menschen, 122. Ebenso Schreiner, Erwägungen, 82. Die den Vers einleitende Präposition כִ wird hier wie in 7a.9a.10d aufgrund des nicht ersichtlichen kausalen $\mathrm{Zu}$ sammenhangs als emphatisches dazu ausführlicher die Diskussion in der Analyse von Ps 147,1.

930 Gillmayr-Bucher, Die Psalmen, 268.

931 Vgl. McCann, Psalms, 1042. Ebenso Hossfeld / Zenger, Psalmen 51-100, 610. Von der Zeit der Nachtwache als einem Drittel der Nacht spricht Wächter, Psalmstellen, 67.

932 Seybold, Die Psalmen, 358.

933 Kraus, Psalmen, 798. 
Tages hervorheben. ${ }^{934}$ Darüber hinaus wird in metaphorischer Rede ein Subjekt (יוֹם) mit einem Verb (עבר) verbunden, das sich in den meisten Fälle auf menschliches Tun bezieht (vorübergehen, Bund bzw. Gesetze übertreten, jemanden durchs Feuer gehen lassen etc.). עבר wird auch auf die Gottheit und Tiere angewandt, vor allem aber auch auf Naturphänomene, Körperteile und weitere Begriffe, die ebenso vorübergehen können. ${ }^{935}$ Als Zeiteinheiten, die ebenso vorübergehen, werden der Mittag (1 Kön 18,29), Tage wie Schatten (Ps 144,4), der Winter (Hld 2,11), der Neumond (Am 8,5) und die Erntezeit (Jer 8,20) genannt. Aufgrund der vielfältigen Verknüpfung des Verbs mit unterschiedlichen - nicht nur menschlichen - Subjekten ist beim Sprachbild des vorübergehenden Tages nicht eindeutig von einer Personifikation auszugehen. Durch die Betonung des vergangenen gestrigen Tages soll an die Erfahrung erinnert werden, dass "verflossene Zeit kürzer als künftige oder gegenwärtige erscheint.« ${ }^{936}$

Der Begriff der Nachtwache erfährt durch die Zeitangabe רִילָה (Nacht) eine Akzentuierung, zumal die Nacht als Zeit der Finsternis eine besondere Gefahrenzeit darstellt, woraus sich die Notwendigkeit der Nachtwachen ergibt (Neh 4,16; Jdt 7,5). ${ }^{937}$ Es ist an dieser Stelle nicht klar, ob eine verschlafene oder durchwachte Nachtwache gemeint ist. Dabei erscheint die verschlafene Zeit kürzer als die durchwachte..$^{938}$

Im Vers sind weder explizite noch implizite Emotionen auszumachen. Auf Seiten der LeserInnen können im Leseprozess Staunen und Bewunderung ob der unfassbaren Zeitdimensionen Gottes hervorgerufen werden (A-emotions).

\subsection{Verse 5-6: Wie Schlaf und Gras}

$5 a$ Du hast sie hinweggeschwemmt, ein Schlaf sind sie,

$5 b$ am Morgen wie Gras, das wächst/wechselt.

$6 a$ Am Morgen blüht es und wächst/wechselt,

$6 b$ zum Abend hin welkt es und verdorrt.

934 Vgl. Schnocks, Vergänglichkeit, 156, besonders Anm. 503.

935 Naturphänomene: z. B. Wasser Ijob 11,16; Ps 124,4-5; Hab 3,10; Spr 8,29; Wogen/Brandungen Ps 42,8; Flut Jona 2,4; Nah 1,8; Wolke Ijob 30,15; Ps 18,13; Sturm Spr 10,25; Wind/ Geist Ps 103,16; Hab 1,11; Körperteile: z. B. Geist Num 5,14.30; Stimme 2 Chr 36,22; Esra 1,1; 10,7; Neh 8,15; Nefesch Ijob 33,28; Mund Ps 17,3; weitere Begriffe z. B. der Grimm Gottes in Ps 88,17, der Zorn in Jes 26,20, das Übel in Koh 11,10, das Gebet in Klgl 3,44 und der Krieg in 1 Sam 14,23.

936 Schmidt, Menschen, 121. Ebenso Müller, Der 90. Psalm, 272: »Wie kurz eine Zeit war, spürt man erst, wenn sie vorüber ist."

937 Vgl. Brandscheidt, »Unsere Tage«, 17.

938 Vgl. Wächter, Psalmstellen, 67. 
Aufgrund des versübergreifenden Vergleichs des menschlichen Lebens mit Gras, der in $5 \mathrm{~b}$ beginnt und in V6 fortgesetzt wird, werden die beiden Verse gemeinsam analysiert. V5 ist kaum verständlich und bereitet innerhalb der Textkonstitution von Psalm 90 die größten Schwierigkeiten. Aufgrund dieser Problematik werden hier nur die für den Bereich der Emotionen wesentlichen Begriffe benannt und besprochen.

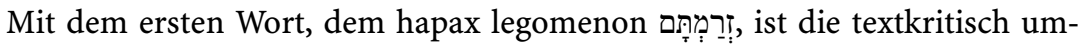
strittenste Stelle in Ps 90 benannt. ${ }^{939}$ Das Verb ist die 2.P.q.m.sg.SK der Wurzel זרם mit Objektsuffix in der 3.P.m.pl. Die Wurzel ist als Verb im AT nur zwei Mal belegt, und zwar hier und in Ps 77,18, wo es im po. mit "regnen, sich ergießen" wiedergegeben wird. Das Substantiv זٓרֶ, das acht Mal im AT vorkommt, ${ }^{940}$ bezeichnet den Regen, das Unwetter sowie den Wolkenbruch, der gefährliche Sturzbäche auslösen kann. Die Wurzel kann demzufolge hier in Ps 90 mit »wegschwemmen, übergießen « wiedergegeben werden. ${ }^{941}$

Es bleibt die Frage, wie der Vers in seinem weiteren syntaktischen Zusammenhang zu verstehen ist, da sowohl die Übersetzung mit »du schwemmst sie hinweg, ein Schlaf sind sie« als auch mit "du überschwemmst sie mit Schlaf» möglich ist. Im übertragenen Gebrauch der Wurzel זרם «zu-«bzw. »bedecken« ist an dieser Stelle ebenso die Übersetzung mit »du hast sie zugedeckt mit Schlaf ${ }^{942}$ möglich. Die Semantik bleibt weiterhin erklärungsbedürftig, zumal neben שְרַמְָּת

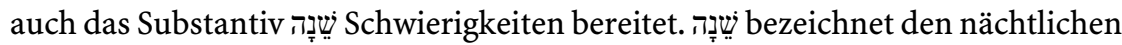
Schlaf ${ }^{943}$ und gilt hier laut Zenger als »Kontrastmetapher zum Leben. ${ }^{944}$ Zenger verweist daneben auf den Schlaf als Tod in Jer 51,39.57; Ijob 14,12 und Ps 76,6 bzw. auf den Schlaf als die »Bezeichnung einer Schattenexistenz im Totenreich ohne Erinnerung. ${ }^{945}{ }$ Wenn nun die Menschen von Gott her mit diesem $>$ nicht Leben überschwemmt werden, so bedeutet das nicht einfach den Tod, sondern das

939 Der schwer verständliche Halbvers gibt große Rätsel auf und hat im Laufe der exegetischen Betrachtung eine Reihe von Konjekturen erfahren. Die bekannteste folgt dem textkritischen Apparat der BHS und Duhm, Die Psalmen, 342 sowie Kraus, Psalmen, 791 und Seybold, Die Psalmen, 356, »du säest sie [aus] Jahr für Jahr«. Mit dieser Konjektur tritt der schöpferische Aspekt im Gottesbild hervor. Für weitere Konjekturen siehe den Überblick bei Howell, Hermeneutical Approach, 178ff. Vgl. ebenso Wächter, Psalmstellen, 65-67. Einen differenzierten und klar strukturierten Überblick über die Lesarten und Deutungsmöglichkeiten von V5 bieten auch u. a. Gillmayr-Bucher, Die Psalmen, 249f; Schnocks, Vergänglichkeit, 6880; Tate, Psalms, 433; Kraus, Psalmen, 795; Booij, Psalm 90,5-6, 393-396 sowie Müller, Sprachliche Beobachtungen, 394-398 mit der Übersetzung: »Du raffst sie hinweg, so dass sie wie ein Schlaf/Traum sind/werden« (S. 397).

940 Jes 4,6; 25,4 (2x); 28,2; 30,30; 32,2; Ijob 24,8; Hab 3,10.

941 Vgl. Schnocks, Vergänglichkeit, 68.70 und Forster, Begrenztes Leben, 141.

942 Schreiner, Erwägungen, 83.

943 Vgl. GES 1393.

944 Zenger, Werk, 21.

945 Zenger, Morgenröte, 209. 
Wissen um den eigenen Weg, der nach Ablauf einer gewissen Zeit ins Vergehen führt. « ${ }^{946}$ Den Schlaf kann man darüber hinaus als »Bild für die Lähmung und Passivität [...] verstehen, die den Menschen ein aktives Gestalten der Lebenszeit verunmöglicht. ${ }^{947}$ Dies ist in Bezug auf die Übersetzung "ein Schlaf sind sie» festzuhalten. Überschüttet Gott in V5 die Menschen mit Schlaf, so bewirkt dieses göttliche Handeln »die Passivität der Menschen, die in der Folge ihr Zeiterleben wesentlich bestimmt. Die den Menschen zur Verfügung stehende Zeit verstreicht, ohne dass ihnen Gestaltungsmöglichkeiten bleiben, vielmehr verbringen sie ihre Zeit wie im Schlaf gefangen. $"{ }^{948}$

Erhält שָָׁנה im AT die Konnotation eines Todesschlafs, dann ist dabei zu beachten, dass jeder Schlaf die Verwundbarkeit des Menschen und die Nähe zum Tod anzeigt, ${ }^{949}$ insofern die Körpertemperatur leicht sinkt und die Kontrolle über das eigene Handeln nicht mehr vorhanden ist. Schlaf ist damit ebenso ein Bild für die Vergänglichkeit und Nichtigkeit. ${ }^{950}$

Hinter dem "Überschwemmen" könnte neben den bereits genannten Möglichkeiten auch der Vergleich zwischen einem plötzlichen Sturm, der eine Hütte oder ein Zelt hinwegschemmt, und dem plötzlichen Ende menschlichen Lebens stehen. ${ }^{951}$ Nachdem die Menschen in 5a also dergestalt überschwemmt werden, kommt in 5b der Gras-Vergleich zur Anwendung. Das Substantiv חִִִָיר (Gras) mit der Grundbedeutung »Grünes« kommt im AT insgesamt $18 \mathrm{Mal}$ vor, wovon sich sechs Belege in den Psalmen finden. In Ps 37,2; 90,5; 103,15; 129,6 wird es im Rahmen von Vergänglichkeitsaussagen verwendet, in Ps 104,14 lässt Gott Gras wachsen für das Vieh und in Ps 147,8 auf den Bergen. Innerhalb der Vergänglichkeitsmotivik wird in bevorzugter Weise auf die Fähigkeit des Grases zum schnellen Wachstum, aber auch auf die Verwundbarkeit des Grases hinsichtlich des raschen Vertrocknens und Verdorrens verwiesen, was meist in Verbindung mit Wind, Hitze und Dürre geschieht. ${ }^{953}$ Die auch in Ps 90,5.6 verwendeten מלל Verben des Absterbens und Zugrundegehens sind in diesem Zusammenhang (verwelken Ps 37,2; 58,8?; 90,6; Ijob 14,2;), יבש (trocken sein, vertrocknen, verdorren Jes 15,6; 40,7f; 42,15; Ps 90,6; 129,6; Ijob 8,12) und כלה (zugrunde gehen Ps 90,7; Jes 15,6). Trockenes ist im AT - mit Ausnahme des Durchzugs auf tro-

946 Schnocks, Vergänglichkeit, 130.

947 Gillmayr-Bucher, Die Psalmen, 249.

948 Gillmayr-Bucher, Die Psalmen, 268. Anders Brandscheidt, »Unsere Tage«, 18, die שָָּׁ als Erholungsschlaf deutet, der die Voraussetzung für die Regeneration der Lebenskraft darstellt, so wie der Schlaf dem Menschen Erholung zukommen lässt. Für die Bedeutung von שָׁנה als Traum vgl. z. B. Müller, Sprachliche Beobachtungen, 397.

949 Vgl. Tsevat, Psalm XC 5-6, 116.

950 Vgl. Gillmayr-Bucher, Die Psalmen, 258.

951 Vgl. Cohen, The Psalms, 298.

952 Vgl. zum Folgenden Barth, חִָָ 137-139.

953 Vgl. Goldingay, Psalms 3, 28. 
ckenem Weg durch das Meer im Exodusereignis - negativ behaftet. ${ }^{954}$ „Wenn Ps 90,6 den Menschen mit dem Gras vergleicht, das doch bald `verdorrt`, so wird hier ein auch an anderen Stellen gängiges Motiv aufgenommen (Ez 17,10; Jes 40,7; Ps 129,6), wonach der Glutwind es ist (vgl. Ez 19,12 hiph), der diese plötzliche Verwandlung bewirkt. «"955

Im Kontrast zum plötzlichen Vertrocknen steht ein ebenso schnelles Wachsen und Emporsprießen, hier in V5-6 ausgedrückt durch חלף (aufeinanderfolgen, vorübergehen, wechseln, vergehen, ändern, neu ausschlagen, wachsen ${ }^{956}$ und צוץ (blühen, glänzen). ${ }^{957}$ Gras sprießt in der Regenzeit im Frühjahr und Herbst rasch auf, vergeht dann aber ebenso schnell im Sommer bei sengender Hitze. Dieses schnell aufsprießende und verdorrende Gras eignet sich daher als Bild für Kurzlebigkeit und Vergänglichkeit. ${ }^{958}$ „Genauso wie das schnell wachsende Gras vergeht, wenn es von der Sonne getroffen wird, genauso unausweichlich ist der Untergang des Menschen. Auch die Begriffe des Vertrocknens und Verdorrens passen sehr gut in den natürlichen Zusammenhang der Pflanze wie des Menschen. Übertragen auf den Menschen umschreiben sie seinen körperlichen Verfall, sein unausweichliches Dahingehen, den Tod. « ${ }^{959}$

Eine Zuspitzung der Vergänglichkeitsmetaphorik ist m. E. in diesem Vers dahingehend gegeben, dass das Wachsen, Blühen und Verdorren des Grases, das - auch wenn der Vorgang als rasch beschrieben wird - doch einige Monate (vom Frühjahr bis zum Sommer etwa) in Anspruch nimmt, hier in nur einen Tag komprimiert wird, beginnend mit dem Aufblühen und Wachsen am Morgen und endend zum Abend hin mit dem Verdorren und Verwelken. Welches Gras lebt nur einen Tag lang? ${ }^{960}$ Zeit wird damit gerafft dargestellt, ${ }^{961}$ und die Bildersprache bringt auch an dieser Stelle des Psalms in überspitzer Weise die totale Kürze des

954 Vgl. Preuß, שיב, 400.

955 Preuß, שיבש, 403.

956 Vgl. Tengström, חל, 999-1001 und Schnocks, Vergänglichkeit, 75.77. Letzterer sieht in der Wurzel חלף den Doppelaspekt von »keinen Bestand haben«, "vergänglich sein« einerseits und »sich regenerieren« andererseits. Ähnlich Forster, Begrenztes Leben, 142.178. Ihrer Meinung nach bleibt unklar, ob חלף das Vergehen des Grases oder das erneute Emporwachsen meint. Ebenso Wächter, Psalmstellen, 68 mit Hinweis auf den Beginn des Wechsels (neu emporwachsen) oder dem Ende des Wechsels (vergehen, verschwinden).

957 Vgl. Steins, ץי, $1028 \mathrm{f}$.

958 Vgl. Riede, »Der Gerechte«, 51.

959 Riede, "Der Gerechte«, 51. Der Vergleich zwischen Menschen und Gras wird auch so gedeutet: »[W]e are like grass, fresh and green in the morning but soon dried up and gone.» Limburg, Psalms, 308.

960 Zenger bringt dazu den Vergleich mit einem Grashalm: »Die Menschen sind kurzlebig und zuletzt wertlos wie ein Grashalm, der am Morgen aufblüht, aber unter der Sonnenglut des aufkommenden Tages rasch umknickt, von oben her verwelkt und schließlich bis in die Wurzel hin trocken und dürr wird.« Zenger, Werk, 21.

961 Vgl. Gillmayr-Bucher, Die Psalmen, 255. 
menschlichen Lebens, zusammengerafft auf einen Tag, zum Ausdruck - im Kontrast zur Ewigkeit und Beständigkeit der Gottheit Israels aus V1-2. ${ }^{962}$ Die Vergänglichkeitsmetaphorik aus V5.6 wird mit den Konnotationen der Zeitbegriffe unterstrichen. Steht der Morgen für die Zeit des Heils, des Aufblühens und der Zuwendung Gottes (siehe dazu vor allem V14 und die Analyse von Ps 30,6), so gilt der Abend als Zeit der herannahenden Finsternis und die Nacht als Zeit der Gefahr und des Chaos. ${ }^{963}$

Die Menschen werden hier mit Gras verglichen, wodurch das Leben der Menschen auch als notwendiger, natürlicher Kreislauf gesehen wird. ${ }^{964}$ Gleichwohl werden durch den Grasvergleich, mit dem ein Standardvorgang in der Natur beschrieben wird, die Menschen anonymisiert und damit wie Gras als undefiniert und unbenannt betrachtet. Daneben ist weder Nutzen noch Ertrag gegeben, worauf Zenger verweist. Das Sprachbild »vom Grashalm, der bis in die Wurzeln hinein verdorrt, evoziert die Ertraglosigkeit und die Nutzlosigkeit, in die der Tod jeden Menschen verwandelt, wenn Gott die Menschen in die Totenexistenz schickt. ${ }^{965}$ Deshalb wird an dieser Stelle von einem $» \operatorname{sinnlosen}$ Sterben ${ }^{966}$ gesprochen.

Mit den Verben des Vertrocknens und Verwelkens in 6b wird die Todesmetaphorik aus V3.5a weitergeführt. Die generellen Betrachtungen über die menschliche Lebenswirklichkeit in ihrer Flüchtigkeit und Vergänglichkeit in V36 werden als Reflexion über menschliches Leben entworfen, als ob jemand von außen auf das Gott-Mensch-Verhältnis in seiner Zeitdimension blickt und dieses reflektiert. Im Leseprozess kann die in diesen Versen geschilderte Thematik Hoffnungslosigkeit erzeugen und ein Gefühl der Ohnmacht hinterlassen: „Die Hoffnungslosigkeit, die sich für eine menschliche Sicht aus der Schilderung ergibt, ist im Text nicht explizit formuliert, diese Deutung wird vielmehr den LeserInnen überlassen. Jedoch wird bei den Lesern/innen, die sich selbst als Menschen in der Schilderung wiederfinden, gerade durch die scheinbar objektive und allgemeingültige Kontrastierung von göttlicher und menschlicher Realität das Ohnmachtsgefühl verstärkt. «"97

Die Analyse der Semantik konnte zeigen, dass die Rede vom »Hinwegschwemmen « eine brutale Dimension aufweist, dass die Rede vom "Schlaf" in Verbindung mit dem Grasvergleich die Todesmetaphorik aus V3 wieder auf-

$962 »$ Der Bereich der Natur setzt sich in V. 5-6 mit dem Gras fort [...]. Hier bildet die Festigkeit und Beständigkeit von Bergen, Erde und Festland in V. 2 einen Kontrast zur Vergänglichkeit des Grases in V. 5-6." Grohmann, Fruchtbarkeit, 87.

963 Vgl. Grund / Janowski, "Solange die Erde steht ...«, 516.

964 Vgl. Gillmayr-Bucher, Die Psalmen, 258.

965 Zenger, Werk, 18.

966 Hossfeld / Zenger, Psalmen 51-100, 611.

967 Gillmayr-Bucher, Die Psalmen, 269. 
nimmt und durch diese Bilderrede die Aspekte der Sinnlosigkeit, Vergeblichkeit, Ertraglosigkeit und Nutzlosigkeit zu Tage treten. Auch kommen hier die Themen der Flüchtigkeit, Kurzlebigkeit und Endlichkeit des Menschen (V3-4), der zur Passivität verdammt ist, wieder zum Tragen.

Emotionen, die außerhalb des Textes auf Seiten der LeserInnen ausgelöst werden können, sind Empörung, Hoffnungslosigkeit sowie ein Ohnmachtsgefühl (A-emotions).

\subsection{Vers 7: Göttlicher Zorn}

$7 a$ Ja, wir sind vergangen durch deinen Zorn,

$7 b$ und durch deine Wut wurden wir verstört.

Mit V7 startet eine Kette von SK-Formen, mit deren Hilfe bis V10 entweder eine Gruppe über eine konkret erlebte Not klagt (Vergangenheit) oder die Reflexion über die allgemein menschliche Erfahrung der Vergänglichkeit aus V3-6 (Gegenwart) fortgesetzt wird. Aufgrund des Vergangenheitsbezugs der SK, die von Ereignissen berichtet, die vor der Topikzeit liegen (vgl. III Methodik 3.3.1), aber auch in diese hineinwirken können, gebe ich die SK mit dem dt. Perfekt wieder. ${ }^{968}$

Das aussagekräftige Verb כלה (aufhören, zu Ende sein/gehen, zugrunde gehen $)^{969}$ folgt auf כִ und steht am Beginn von V7. Es zeigt - neben der zweiten Wurzel בהל 7 7 - an, dass das Leben unter dem Zorn Gottes als unerträglich erlebt wurde und wird. Der Vers weist mit den Begriffen "Zorn « und »Wut « sowie mit dem Verb "verstört« bzw. »schreckensstarr sein« explizite Emotionswörter auf. Wie bereits in der Analyse von Ps 30,6 festgestellt wurde, bezieht sich die Rede vom Zorn Gottes, hier von Gottes entbrannter Nase (אַ) bzw. vom zornigen Schnauben, sowohl auf die Leidenschaft Gottes als auch auf die vernichtende Dimension, die in dieser Rede liegt. Als leidenschaftliche Handlung Gottes, der sich für eine gerechte und faire Schöpfungsordnung einsetzt, ${ }^{970}$ könnte hier der Zorn als Form der Zuwendung ${ }^{971}$ betrachtet werden. Allerdings sehen viele KommentatorInnen im Zorn Gottes gerade die Abwesenheit und Verborgenheit der Nähe Gottes, welche ja ab V13 vehement eingefordert wird. ${ }^{972}$

968 Müller, Der 90. Psalm, 273 Anm. 41 versucht, beide Dimensionen zu vereinen und spricht sich an dieser Stelle für einen zeitlosen Gebrauch der SK-Formen aus. Das konkret erlebte Elend muss nicht auf eine akute Notlage hinweisen, sondern kann auch eine anhaltende Notsituation zum Hintergrund haben. Vgl. Gillmayr-Bucher, Die Psalmen, 270.

969 Vgl. Gerleman, כלה, 831-833.

$970 »$ God's wrath is the wrath of the one who will never be content until there is a just and fair world [...].« Harrelson, Meditation, 190.

971 Vgl. Zenger, Werk, 23 und Strolz, Psalm 90, 153.

972 Vgl. Zenger, Werk, 31. 
Hinter der Zorneserfahrung stehen Leid und Unheil, die im Zusammenhang mit Schuld gesehen werden können, was hier in Ps 90 der Fall ist (vgl. den folgenden V8). Zorn ist daher weder eine Eigenschaft noch eine Haltung JHWHs, sondern eine Handlung. ${ }^{973}$ Die Zornestat, die - wie V8 thematisiert - durch die Schuld des Volkes motiviert ist, wird in $7 \mathrm{~b}$ durch den Begriff חָָּה (Heißsein, Wallung, Erregung, Zorn) $)^{974}$ noch verstärkt. Das Nomen חָמָ wird auf eine Wurzel zurückgeführt, die mit »heiß, brünstig sein« wiedergegeben wird und im $\mathrm{Zu}$ sammenhang mit einem akkadischen Parallelwort mit der Bedeutung "Gift»

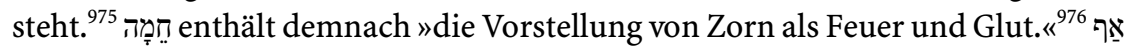
und treten in etwa 40 Fällen gemeinsam im AT auf und werden auch parallel verwendet. Semantisch liegt die Differenz im Detail: »Der Unterschied [...] wäre dann darin zu sehen, dass jener Begriff [אָ] mehr den körperlich sichtbaren erregten Zustand eines im Zorn befindlichen und daher schwer atmenden Menschen bezeichnet, während hẹemā mehr die innere Gemütsbewegung, die innere Zornglut deutlich machen will. $«{ }^{977}$ Hier wird also das Innen und Außen einer Emotion (vgl. III Methodik 2.1) mit zwei verschiedenen Begriffen bezeichnet. Der göttliche Zorn ist dabei gegen das Wir gerichtet, das als EmpfängerIn sowohl verstört bzw. schreckensstarr wird (בהל (בלה) als auch dabei ist, dahinzuschwinden bzw. zugrunde zu gehen (כלה 7). Wie bereits in der Analyse von Ps 30,8 herausgearbeitet werden konnte, bringt die Wurzel בהלד Erschrockensein, Angst, Todesfurcht, Lebensunfähigkeit und Gottverlassenheit zum Ausdruck. In Verbindung mit dem ersten Verb des Verses, כלה, in der Bedeutung "zurückhalten, beenden, aufhören, zu Ende/zugrunde gehen ${ }^{978}$ wird damit ein düsteres Bild für das Wir des Textes gezeichnet: Durch die göttliche Zornesglut wird die Lebensfähigkeit der Menschen derart bedroht, dass ihnen der Untergang bevorsteht. Die Aussage über den vernichtenden göttlichen Zorn ist im Klageteil des Psalms zu verorten. Dem betenden Wir droht der Untergang, und deshalb klagt es. »Und diese Klage gleicht einer Provokation, einer Anklage Gottes, die ihn zum Einschreiten zugunsten des Beters bewegen soll. ${ }^{979}$

Es stellt sich die Frage, welche Erfahrungen dem göttlichen Zornesausbruch (vgl. auch V9) zugeordnet werden. Da die Frage der menschlichen Schuld (V8) ein Randthema des Psalms darstellt, könnte eher »das schnelle Vergehen der mit

973 Vgl. Schnocks, Vergänglichkeit, 145.

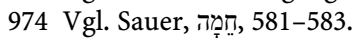

975 Vgl. Schunck, חָזָ, 1032-1033.

976 Forster, Begrenztes Leben, 180.

977 Sauer, 582.

978 Die Wurzel beschreibt eine Handlung, die etwas beendet, bzw. einen Vorgang, in dem etwas aufhört. Dabei liegt die Betonung auf dem Prozess des Zuendebringens bzw. des Erreichens eines Zieles und nicht auf dem Abschließen selbst. Vgl. dazu Helfmeyer, כלה, 167-168.

979 Helfmeyer, כלה, 169. 
Mühsal und Unheil gesättigten Lebenszeit ${ }^{980}$ als Zorneshandeln zu begreifen sein, weniger dagegen der Tod (V3-6) des Menschen. Auf alle Fälle wird die Krise als Auswirkung des göttlichen Zornes interpretiert. ${ }^{981}$ Hinter dem Zorn Gottes kann auch die Erfahrung des unausweichlichen Todes mit der Sinnlosigkeit stehen: "Als Manifestation des Gotteszorns erfahren die Sprecher des Psalms zum einen den Tod als fundamentale Lebensangst (V.7-8) und zum anderen als Lebenslast und Sinnlosigkeit (V.9-10). ${ }^{982}$ In jeden Fall löst der Zornessturm Gottesangst ${ }^{983}$ aus.

V7 weist als erster Vers im Text eine Vielzahl expliziter Emotionswörter auf. Mit dem Zorn und der Wut, die mit Hitze und Glut in Zusammenhang steht, wird Gottes (leidenschaftliche) Emotionalität zur Sprache gebracht. Menschen erleben etwas, und sie schreiben es dem Zorn bzw. der Wut Gottes zu. Das Handeln der Gottheit wird damit als zornig, wutentbrannt, leidenschaftlich, heißblütig und stürmisch dargestellt. Auf Seiten des lyrischen Wir ist mit dem Emotionswort »erstarrt« Angst bzw. Todesfurcht angezeigt.

Implizite Emotionen, die ebenfalls dem lyrischen Wir zugeordnet werden können, sind - ausgelöst durch den Kontext als Klageteil und durch die Anklage an Gott - die im Appell enthaltene Dringlichkeit zum Eingreifen sowie die Betroffenheit. ${ }^{984}$

\subsection{Vers 8: Verborgene Schuld}

$8 a$ Du hast hingestellt unsere Schuld vor dich, $8 b$ unser Verborgenes ins Licht deines Angesichts.

Während 8a mittels des Begriffs עָ eindeutig von ungerechten Handlungen und deren Folgen, von Schuld und Schuldverhängnis ${ }^{985}$ des lyrischen Wir spricht, ist mit dem Ptz.q.pass. von עלם (dem Parallelbegriff zu עָוֹן mit Suffix in der 1.P.pl. "unser Verborgenes « nicht klar, worum es sich hier handelt, zumal das Partizip in dieser Form ein hapax legomenon darstellt. Weitere Belege von עלם im ATund die synonyme Gestaltung des Verses lassen darauf schließen, dass es sich hier um »die dem Täter unbewusste Schuld ${ }^{986}$ bzw. um verborgene Sünden handelt, ${ }^{987}$

980 Schnocks, Vergänglichkeit, 143.

981 Vgl. Forster, Begrenztes Leben, 154.

982 Zenger, Werk, 22f.

983 Vgl. Hossfeld / Zenger, Psalmen 51-100, 611.

984 Vgl. Gillmayr-Bucher, Die Psalmen, 265.

985 Vgl. Forster, Begrenztes Leben, 180.

986 Schnocks, Vergänglichkeit, 143.

987 Vgl. Schnocks, Vergänglichkeit, 86, besonders Anm. 272; Forster, Begrenztes Leben, 143. Siehe Lev 5,2.3; 4,12; Koh 12,14. 
auch wenn nicht geklärt ist, um welche Art von Schuld es sich hier handelt. Die Thematisierung der Schuld des Menschen steht in Ps 90 allerdings nicht im Mittelpunkt, sondern bildet ein Randthema, das die Rede vom Zorn Gottes flankiert. ${ }^{988}$ Interessant ist hier, dass die Verwendung des Ausdrucks »Licht deines Angesichts « nicht wie sonst im AT als Zuwendung Gottes (zum Angesicht vgl. die Analyse zu Ps 30,8), sondern als durchdringender, entlarvender Blick verstanden wird. ${ }^{989} \mathrm{Zu}$ dieser Dimension der Durchleuchtung durch Gott kommt noch jene der Unberechenbarkeit hinzu, die nicht erst im Zusammenhang mit der Wutthematik in V11, sondern bereits hier verortet wird: "Wichtig ist hier das Element der Unberechenbarkeit. Es ist Gott selbst, der nicht nur die (bekannten) Sünden der Beter vor sich stellt, sondern der auch Verborgenes - die Parallelen lassen hier besonders an dem Täter unbewusstes Fehlverhalten denken - ans Licht bringt. Der Vers spricht dann v. a. davon, dass der Mensch auch in seiner Moralität letztlich im Ungewissen bleibt und beklagt den enormen Abstand zu Gott. ${ }^{990}$ Hinsichtlich der Bildersprache wird hier die Personifikation aus V2 und eventuell auch die aus V4 fortgeführt: »In 8a ist es die personifizierte Schuld, die Gott vor sich aufstellt, und in $8 \mathrm{~b}$ gilt alle Aufmerksamkeit dem, was die Menschen zu verbergen trachten - genau das stellt Gott vor das Licht seines Angesichts. «"91

Explizite Emotionswörter können in V8 dann ausgemacht werden, wenn man »Schuld « als Emotionsfeld definiert, wie dies bei Plutchik der Fall ist (vgl. III Methodik 2.1). ${ }^{992}$ Der Vers bringt darüber hinaus die Aspekte des Nichtaufgehobenseins bei Gott sowie das göttliche Durchleuchten und eventuell bereits die Unberechenbarkeit zur Sprache. Dem Kontext entsprechend kann der Vers als Klage und Anklage gedeutet werden. Für die Ebene der impliziten Emotionen gilt, dass sich auf Seiten des lyrischen Wir Unruhe und Furcht breitmachen könnte: »Wenn man davon ausgeht, dass die $\mathrm{Zu}$ - beziehungsweise Abwendung von Gottes Angesicht seine Nähe oder Distanz zu seinen Geschöpfen ausdrücken möchte, kann man schließen, dass das lyrische Wir um die Reaktion Gottes besorgt gewesen sein muss. Wenn alle Schuld, selbst die verborgenen Sünden, vor Gottes Angesicht gestellt werden, muss um eine negative Reaktion Gottes gefürchtet werden. Angst, Panik und Besorgnis könnten hier implizit dem lyrischen Wir der BeterInnen zugeschrieben werden. ${ }^{993}$

988 Vgl. Schnocks, Vergänglichkeit, 143.

989 Vgl. Forster, Vergänglichkeit, 181. Zum Ausdruck »Licht des Angesichts« im AT siehe Num 6,$25 ;$ Ps 4,$7 ; 31,17 ; 44,4 ; 67,2 f ; 80,4.8 .20 ; 89,16$.

990 Schnocks, Vergänglichkeit, 174.

991 Gillmayr-Bucher, Die Psalmen, 270.

992 Den emotionalen Konnotationen der Begriffe »Schuld» bzw. »Verborgenes« im Bibelhebräischen wurde hier nicht nachgegangen.

993 Artner, »Sättige uns«, 88f. 


\subsection{Vers 9: Dahinschwinden}

$9 a$ Ja, alle unsere Tage sind vergangen durch deinen überwallenden Zorn, $9 b$ wir haben unsere Jahre beendet wie einen Seufzer.

Der überwallende Zorn ist in diesem Vers als explizites Emotionswort auszumachen. Das Substantiv f. עֶבְרָה begegnet wie hier in V11 auch in Hos 13,11 gemeinsam mit אֵ als ein weiterer Ausdruck für den Zorn im AT. ${ }^{994}$ Von den 34 Vorkommen im AT bedeuten 30 "Zorn« sowie vier "Überheblichkeit». ${ }^{995} \mathrm{Im}$ Wortfeld des Zornes und der Wut bezeichnet עֶ:ְרָה "speziell das Element des Affektvollen und Unbeherrschten im Zorn, das sich in einem entsprechenden Handeln manifestiert. ${ }^{996}$ Der Begriff schließt damit neben der Emotion des Zorns auch den Affekt mit ein (vgl. III Methodik 2.1). JHWHs עֶבְרָה entflammt als Reaktion auf ein Fehlverhalten der Menschen, hier in Ps 90 als Reaktion auf generelles schuldhaftes Verhalten, wovon V8 spricht. In Ps 90 gilt der Mensch sowohl als Empfänger als auch als Auslöser des Zornes Gottes. Hinter der göttlichen עצבְרָרה steht die Vorstellung vom Ent- bzw. Verbrennen (Hab 3,8; Ps 78,21; Jes 9,18); sie lässt das Menschenleben plötzlich und kurz vergehen (V9) und zeugt von Wucht und Stärke (V11). ${ }^{997}$

Der Vers endet mit dem ungewöhnlichen Vergleich כְמוֹדֶגֶ (wie ein Seufzer, Geseufze). הֶגֶה kommt im AT nur mehr in Ijob 37,2 und in Ez 2,10 vor und hat die Bedeutung eines leisen Tones, nach dem Stille einsetzt. In Verbindung mit der Wurzel הגה I (murmeln, gurren) werden mit dem Begriff das Gurren von Tauben und ähnliche Lautäußerungen von Menschen und Tieren bezeichnet, im übertragenen Gebrauch dann auch das Sprechen, Murmeln, Meditieren und leise Reden. ${ }^{998}$ Mittels des Sprachbildes wird die Vollendung der Lebensjahre mit dem »echolosen und unhörbare[n] Verklingen eines geflüsterten Lauts [verglichen]. Die Beter fühlen, dass ihr Leben bereits abgeschlossen hinter ihnen liegt. $"{ }^{999}$ Die Lebensjahre des lyrischen Wir "verklingen im Nichts. ${ }^{1000}$ Aus dem Vergleich mit einem Seufzer kann implizit die Emotion des Kummers, die dem lyrischen Wir zuzuordnen ist, erhoben werden. ${ }^{1001}$ Das Bild des Seufzers soll wohl neben der Flüchtigkeit der Jahre gleichzeitig die damit verbundene Mühsal und Freudlo-

994 עֶבְרָּ kommt $34 \mathrm{Mal}$ im AT vor und wird zwölf Mal mit der menschlichen und $22 \mathrm{Mal}$ mit

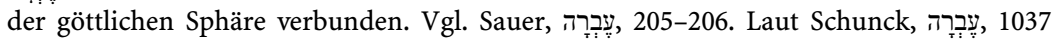
begegnet das Substantiv in der Bezeichnung des göttlichen Zorns $23 \mathrm{Mal}$.

995 Vgl. Schunck, עֶבְרָה 1034. Im Sinne der Überheblichkeit wird das Substantiv in Jes 16,6; Jer $48,29.30$ und Spr 21,24 verwendet.

996 Schunck, עֶבְרָה 1035.

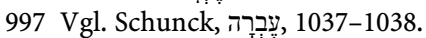

998 Vgl. Schnocks, Vergänglichkeit, 89, besonders Anm. 281.

999 Seybold, Die Psalmen, 359.

1000 Artner, "Sättige uns«, 90.

1001 Vgl. Artner, Emotionen in Psalm 90, 128. 
sigkeit veranschaulichen ${ }^{1002}$ und hat neben der zeitlichen Komponente (ein Seufzer ist kurz und flüchtig) $)^{1003}$ auch eine qualitative, die von Not und Leid, Kummer und Klage gekennzeichnet ist. ${ }^{1004}$

Als explizites Emotionswort ist der Gott zugeschriebene überwallende Zorn auszumachen. Im Sprachbild »wie ein Seufzer« schwingen implizit die Emotionen der Freudlosigkeit, Mühseligkeit, der Klage und des Kummers mit, die dem lyrischen Wir zugeschrieben werden. Der Seufzer bringt auch die Vergänglichkeit und das plötzliche Aufhören von Leben mit danach eintretender Stille zum Ausdruck.

\subsection{Vers 10: Mühevolle Lebenszeit}

10a Die Tage unserer Jahre für sich (sind) 70 Jahre, $10 b$ und wenn in Kraft 80 Jahre, $10 c$ und ihr Stolz ist Mühe und Unheil, 10d ja, schnell ist es vorbeigegangen und wir verflogen.

Der Ausdruck »die Tage unserer Jahre» bezieht sich sinngemäß auf die menschliche Lebenszeit. ${ }^{1005}$ Mit dem in 10a.b genannten Lebensalter von 70 bzw. 80 Jahren sind Zahlen genannt, die nur in seltenen Fällen erreicht werden. ${ }^{1006}$

Das vom Verb רהב abgeleitete nominale Derivat רהַב in 10c ist textlich nicht gesichert. Das hapax legomenon wird, der aramäischen Etymologie folgend, mit

1002 Vgl. Forster, Begrenztes Leben, 183.

1003 Kraus, Psalmen, 795: »im Flug vergangen «.

1004 Vgl. Gillmayr-Bucher, Die Psalmen, 270.

1005 Vgl. Forster, Begrenztes Leben, 143.

1006 Vgl. Schnocks, Vergänglichkeit, 98, besonders Anm. 315. Seybold, Die Psalmen, 359. Man nimmt an, dass das Durchschnittsalter zur damaligen Zeit zwischen 30 und 40 Jahren lag. Vgl. Ernst, Segen, 207. Forster, Begrenztes Leben, 182 spricht von 50 Jahren als Maximalalter. Das biblische Ideal der Höchstnorm und damit die maximale Lebensdauer bzw. Lebensobergrenze wird nach Gen 6,3 und Dtn 31,2; 34,7 mit 120 Jahren beziffert. Vgl. Bührer, Göttersöhne, 511. Forster, Begrenztes Leben, 143 verweis zudem darauf, dass mit der Erwähnung der Zahl 70 eine Anspielung auf die Dauer des Exils verbunden sein kann, die laut Jer 25,11f; 29,10; 2 Chr 36,21 und Dan 9,2 mit 70 Jahren angegeben wird. Vgl. Forster, Begrenztes Leben, 183 und Gillmayr-Bucher, Die Psalmen, 270, Anm. 277. Der kanonischen Lesart folgend »kann dann Ps 90 als Klage über die lange Notzeit des Exils (vgl. V10: >70 Jahre! «) und als Bitte, JHWH möge dem mit dem Werk der Hände seiner Knechte am Ende des Exils versuchten Neuanfang (vielleicht sogar als Anspielung auf den Tempelbau?) mit seiner `Freundlichkeit`Bestand und Lebensförderlichkeit gewähren, gelesen werden « bei Hossfeld / Zenger, Psalmen 51-100, 614. Ebenso Krüger, Psalm 90, 211 und Jens, Psalm 90, 180. Seybold, Zeitvorstellungen, 107 bezieht das "Werk« aus V17 auf den Bau des zweiten Tempels. 
der Bedeutung »Stolz« wiedergegeben. ${ }^{1007}$ Das Substantiv leitet von der Quantität der messbaren Zeit (10a.b) über zu einer qualitativ-wertenden Aussage (10c.d): Das Leben, auch wenn es lange währt, ist mühsam und geht schnell vorbei. Trotz langer Lebensspanne wird das Leben als Last empfunden und als flüchtig erlebt. Der Stolz oder die Herrlichkeit des Lebens ist nur Mühsal und Unheil, der Inhalt der Jahre nur Mühe und Plage.

Mit den Begriffen »Mühsal« sowie »Unheil, Beschwernis« werden hier zwei Termini verwendet, deren emotionaler Gehalt im Folgenden eruiert wird. Hinter dem Substantiv עָ עָמָ wird die Wurzel mit der Grundbedeutung "müde sein/werden« angenommen. Daraus ergeben sich mehrere Bedeutungsvarianten: das, wodurch man müde wird (Arbeit), der Zustand des Ermüdetseins (Mühsal, Elend, Unheil), aber auch der Erfolg der mühsamen Arbeit (Gewinn). bezeichnet also den Vorgang der Arbeit, dann auch die Mühsal, die die Arbeit bereitet, sowie das Ergebnis der Arbeit als Erwerb und Besitz, der erarbeitet wurde. עָָׁ kann im Sprechen zu Gott auch Ausdruck einer konkreten Not sein, in der sich das Volk oder auch ein Einzelner befindet. Diese Not wird in Form der Klage vorgetragen. ${ }^{1009}$ In Ps 90 beschreibt der Begriff das Los des Menschen, »wohl aus der Verallgemeinerungstendenz der Klage (Vergänglichkeitsklage) und der Erkenntnis heraus, dass das Leben von mühsamer Arbeit bestimmt ist (Ps 73,5; 90,10). « ${ }^{1010}$ Vor allem in den Prophetenbüchern und in den Psalmen

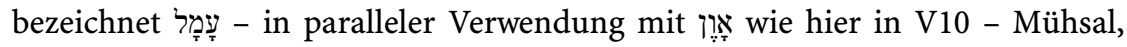
Unheil und Bedrängnis. ${ }^{1011}$ Der Stolz der menschlichen Lebenszeit ist also עָדָל und אָּז Der letztgenannte Begriff beschreibt »nicht nur den Schaden und Verderben bringenden Missbrauch von Macht [...], sondern auch die Nichtigkeit derartigen Frevels ${ }^{1012}$ und wird mit »Unrecht«, »Unheil«, »Übeltat «, »Trug« und »Täuschung« wiedergegeben. אָָ meint aber nicht nur die Unheilsmacht an sich, sondern sowohl die unheilvollen Aktivitäten als auch deren Folgen. ${ }^{1013} \mathrm{Im} \mathrm{Zu-}$

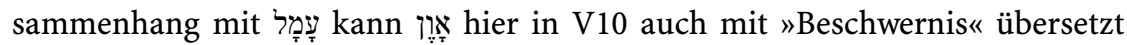
werden. $^{1014}$

Ein weiteres hapax legomenon in diesem Vers ist חיש (schnell), das als Adverb zu גוז (fliegen, verfliegen) gedeutet wird. ${ }^{1015}$ Mit der inhaltlichen Analogie des schnellen Zuendegehens des Lebens in Ijob 7,6 und Jes 38,12 wird von 10a aus-

1007 Vgl. Rüterswörden, רהב, 374.

1008 Vgl. Otzen, עָָָ, 214.

1009 Vgl. Schwertner, עָָָל, 333.

1010 Schwertner, עָעָל, 334.

1011 Vgl. Otzen, עָדָ 215.

1012 Bernhardt, 154.

1013 Vgl. Knierim, אָּ 82 , 82

1014 Vgl. GES, 24.

1015 חִ bedeutet eigentlich »Eile« und wird hier in der adverbiellen Bedeutung "schnell« verwendet. Vgl. Gzella, Lebenszeit, 323. 
gehend (schnelles Vorbeigehen des Lebens und Dahinfliegen) auf »die Vorstellung vom dahineilenden Weberschiffchen bzw. vom 'Schuss` der Garnspule [verwiesen], die sich unaufhaltsam und unumkehrbar abwickelt.« ${ }^{1016}$

Das Sprachbild des Verfliegens spielt auf das Wegfliegen eines Vogels an, der in Sekundenschnelle nicht mehr zu sehen und aufzufinden ist (Ijob 20,8; Spr 23,5; 26,2). "Der Pfeilschuss oder der Vogelflug wird zum Maß der höchsten Geschwindigkeit. « ${ }^{1017}$ Dem plötzlichen Verschwinden des Vogels entspricht das abrupte Verschwinden des Lebens im Augenblick des Todes. ${ }^{1018}$

Die V3-10 sind geprägt von der Vergänglichkeitsklage. Diese hat die Funktion, dass sich Gott der menschlichen Hinfälligkeit und der Flüchtigkeit des Lebens erbarmt sowie im Sinne des Schenkens von Freude und Bestand rettend eingreift, was ab V13 zum Ausdruck kommt. ${ }^{1019}$ V9-10 steigern die Dimensionen der Trostlosigkeit und Ausweglosigkeit angesichts der Vergänglichkeit des Lebens, ${ }^{1020}$ thematisieren daneben die Erschöpfung, die hinter schwerer und ermüdender Arbeit und Mühsal steht, und ebenso Not und Elend als Last des Menschenlebens sowie die Sinnlosigkeit und Absurdität des Lebens, welches sich trotz langer Dauer kurz und flüchtig anfühlt.

Hinter dem Begriff »Mühe/Arbeit/Gewinn« stehen implizit die Erschöpfung, die aufgrund der Ermüdung durch die viele Arbeit hergerufen wird und sich körperlich sowie emotional auswirken kann, sowie jene Emotionen, die mit dieser Erschöpfung verbunden sind. Diese werden dem lyrischen Wir zugeordnet. Aspekte des Verses sind die Mühsal und Schinderei des Lebens, der spärliche Ertrag (was bleibt, ist Mühsal und Unheil) sowie die Unheilsmacht und die Plötzlichkeit des Endes (eilends/schnell; verfliegen).

\subsection{Vers 11: Göttliche Zorneskraft}

11a Wer erkennend die Kraft deines Zorns

$11 b$ und gemäß der Furcht vor dir deinen überwallenden Zorn?

Mit diesem Vers wird die Wende im Duktus des Psalms herbeigeführt. V11 wird als rhetorische Doppelfrage charakterisiert mit dem Inhalt, dass Gott unverfügbar ist und kein Mensch die Macht des göttlichen Zornes erfassen kann. Hinter der Frage in 11a werden ein skeptischer Unterton bzw. eine Erschütterung

1016 Hossfeld / Zenger, Psalmen 51-100, 604. Ebenso Seybold, Zeitvorstellungen, 103.

1017 Seybold, Psalm 90, 137.

1018 Vgl. Zenger, Werk, 25. Seybold, Die Psalmen, 359 weist an dieser Stelle auf den klanglichen Aspekt hin: »10b intoniert den zischenden, dann schwebenden Laut des Davonfliegens eines Vogels oder Pfeils, um die hohe Geschwindigkeit zu veranschaulichen."

1019 Vgl. Forster, Begrenztes Leben, $153 \mathrm{f}$.

1020 Vgl. Hossfeld / Zenger, Psalmen 51-100, 611. 
des sprechenden Wir wie auch eine weisheitlich-resignierte Stimmung konstatiert. $^{1021}$

In Vers 11 bereitet die Syntax Schwierigkeiten: Es ist weder klar, an wen die Frage gerichtet ist, noch, ob $11 \mathrm{~b}$ die Frage aus 11a fortsetzt. Im letztgenannten Fall wäre der gesamte Vers als Doppelfrage anzusehen. Andernfalls müsste er als eigener Nominalsatz betrachtet und damit als Aussagesatz (z. B. BigS: Wie die Furcht vor dir, so dein Grimm) wiedergegeben werden. Ebenso uneindeutig ist

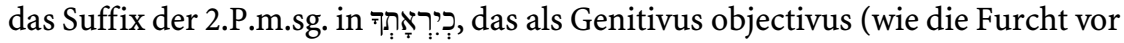
dir) oder als Genitivus subjectivus (wie deine Furcht) gedeutet werden kann. ${ }^{1022}$ Wie die meisten AuslegerInnen schließe ich mich der Deutung als Genitivus objectivus an. Auf alle Fälle wird mit dem Substantiv יִ יְָ (vgl. die Analyse zu Ps 147,11) der Aspekt der elementaren Angst vor der wuchtigen Kraft und Zornesmacht Gottes eingespielt. V11 veranschaulicht damit »die Wucht des göttlichen Zornes ${ }^{1023}$ in eindrücklicher Art und Weise.

Gedeutet wird der Vers unterschiedlich, was wiederum die Ambivalenz durchscheinen lässt, die Ps 90 ausmacht: als Feststellung, dass kaum jemand den Zorn Gottes anerkennen will und sich auch dementsprechend verhält; als Mahnung, den Zorn Gottes in seiner ganzen Macht ernst zu nehmen und - gemäß dem Ideal einer weisheitlichen Lebensführung - diesen Zorn durch entsprechende Gottesfurcht zu vermeiden. Hier wird die Furcht aus $11 \mathrm{~b}$ als Gottesfurcht gedeutet: ${ }^{1024}$ als feststellende Aussage über die Unberechenbarkeit der Wut Gottes und über die Unbegreiflichkeit Gottes, der auf Seiten der Menschen Aussichtslosigkeit gegenübersteht, ${ }^{1025}$ und als Frage danach, ob Gottes Zorn nachvollziehbar und noch dazu verhältnismäßig ist, sowie im Vorblick auf V12.13 als Appell an Gott, wie viel Zeit er noch in seinem Zorn verbringen wird und wann das Maß der Wut endgültig erreicht ist. ${ }^{1026}$

Auf der Ebene der expliziten Emotionswörter wird das Emotionsfeld des Zorns, das durch die Wörter "Zorn« bzw. »überwallender Zorn« wie bereits in V7.9 auch hier zentral ist, durch den Ausdruck »Macht/Kraft « intensiviert. Mit der Furcht bzw. Angst wird ein weiteres Emotionsfeld erschlossen, nämlich das der Angst. Die Gottheit wird als wutentbrannt und zum Fürchten dargestellt. Wiederum stellt sich hier die Frage, welche Erfahrung hinter dieser Beschreibung steht. Interessant ist auch hier - wie in V7.9 - die Tatsache, dass trotz vieler expliziter Emotionswörter kein offensichtliches Identifikationspotenzial gege-

1021 Vgl. Forster, Begrenztes Leben, 187; Kraus, Psalmen, 799 und Müller, Der 90. Psalm, 275.

1022 Vgl. Schnocks, Vergänglichkeit, $100 \mathrm{f}$.

1023 Kraus, Psalmen, 799.

1024 Vgl. Brandscheidt, »Unsere Tage«, 23 und Fokkelman, Major Poems, 247.

1025 Zenger, Werk, 14:»Wer begreift (schon) die Gewalt deines Zornes, und wer sieht (schon) ein den Druck deines Grimms?»

$1026 \mathrm{Zu}$ den genannten Deutungsmöglichkeiten vgl. Forster, Begrenztes Leben, 189. 
ben ist. Die Darstellung derartig geballter Wut der Gottheit kann das eigene Gottesbild vielmehr irritieren und provozieren, wie auch schon die Rede von Gott in V3-6. Zorn, Macht und Furcht werden hier also Gott zugeschrieben, bei der Furcht vor Gott kann auch an die Gottesfurcht und damit an ein Element des Vertrauens und Gehorsams gedacht werden.

Hinsichtlich der impliziten Emotionen ist zu fragen, ob die Angst nicht auch auf Seiten des lyrischen Wir zu finden ist. Die Frage in V11 kann Skepsis und Aussichtslosigkeit zur Sprache bringen und hat, wie die Klagen zuvor und die nachfolgenden Imperative, eine Appellfunktion inne: Die Zeiten mögen sich endlich zum Guten wenden.

\subsection{Vers 12: Weise Zeitbetrachtung}

12a Zu zählen unsere Tage so lehre,

$12 b$ dass wir erlangen ein Herz von Weisheit.

Mit V11.12 sind die Scharnierverse erreicht, die zum zweiten Teil des Psalms überleiten. ${ }^{1027}$ Kennzeichnend für die beiden Verse ist die Verbindung durch die Wurzel ידע, die auf den weisheitlichen Horizont verweist. V12 nimmt innerhalb des Psalms eine Schlüsselstellung ein: ${ }^{1028}$ Ist in V1-9 vom Vergehen und der Flüchtigkeit der Zeit die Rede und erscheint die Lebenszeit unter dem Aspekt der Vergänglichkeit, so »steht in V12 die Bitte um die lebenspraktische Weisheit im Vordergrund, dass das Leben grundsätzlich kurz ist und genutzt werden sollte. ${ }^{1029}$ Es geht darum, die »zählbare» Lebenszeit - die in gewissen Grenzen nun doch einen verfügbaren und gestaltbaren Aspekt erhält - sinnvoll zu gestalten, und zwar in weisheitlicher Art und Weise, d. h. in Kenntnis des Lebens und der Lebenskunst. ${ }^{1030}$ Die ab V14 folgenden Bitten zielen darauf, die Lebenszeit von da an positiv $\mathrm{zu}$ füllen.

Von einer Situation der sich schicksalhaft unter dem Zorn Gottes verflüchtigenden Zeit ohne Bestand wird zum zweiten Teil des Psalms - konträr dazu - zu einer anderen, mit Freude, Sattheit und Bestand gefüllten Zeit übergeleitet. Thematisiert V11 die Nicht-Erkennbarkeit Gottes, so zieht V12 die Konsequenz daraus mit der Bitte um Erkenntnis der Lebenszeit, um realistische Einschätzung der eigenen Vergänglichkeit und darum, diese Kontingenzen zu akzeptieren

1027 »Der erste Teil des Psalms erreicht hier seine Klimax, aus der heraus sich der zweite Teil entwickelt.« Schnocks, Vergänglichkeit, 105.

1028 Vgl. Schnocks, Vergänglichkeit, 131.

1029 Ernst, Segen, 205.

1030 Vgl. Von Rad, Der 90. Psalm, 275. Die Lebenskunst bezeichnen Hossfeld / Zenger, Psalmen 51-100, 612 als »Befähigung, zum Leben Ja zu sagen und dieses Ja zu leben.» 
sowie daraufhin die Kostbarkeit jedes einzelnen Tages zu würdigen. ${ }^{1031}$ Nachdem die Koordinaten des Menschseins und der Geschöpflichkeit in V1-10 ernüchternd und realistisch entfaltet wurden, geht es in diesem Wissen nun darum, etwas Gutes und Sinnvolles aus dem Leben zu machen, damit das menschliche Tun durch göttlichen Glanz (V16) und Beistand (V17) gesegnet wird. Die Erkenntnis als Form der "Bitte um einen weisen Umgang mit der Zeit « ${ }^{1032}$ wird von Gott erbeten und zeigt damit, dass sie sich Gott verdankt und nicht dem Menschen selbst. ${ }^{1033}$ Ort dieser Einsicht ist ein Herz von Weisheit. ${ }^{1034}$ Dass das Herz, das in der Anthropologie der Hebräischen Bibel als Verstandes- und Vernunftherz bezeichnet wird, als »Empfangsorgan« von Weisheit, Erkenntnis und Einsicht gilt, ${ }^{1035}$ ist im AT belegt (z. B. Spr 2,2.10; 14,33; Koh 2,3). Das Herz als Lebenszentrum, das mit Gefühlen, aber viel mehr noch mit Verstehen, Vernunft, Planen, Wissen und Wollen zu tun hat, ist hier in V12 Ort der Weisheit.

Auf der Ebene der Syntax fällt in 12a der erste Imperativ auf, der nach der WerFrage, die in V11 in den offenen Raum hinein gesprochen wurde, nun zielgerichtet und direkt an JHWH gerichtet ist. Dem Imperativ folgt eine "Flut von Bitten ${ }^{1036}$ : »Dem Bereich so dunkler und bitterer Reflexion, in denen sich der Psalm bisher bewegte, war Gott zu fern, um noch angeredet werden zu können. Aber jetzt ist der Bann gebrochen, der Psalm hat endlich wieder das göttliche $\mathrm{Du}$ gefunden, und jetzt ist fast kein Halten mehr mit den Bitten. ${ }^{1037}$ Verbunden mit dem brennenden Anliegen ist das zeitdeckende Element im Imperativ, der als direkte Rede gilt und das Geschehen ins Hier und Jetzt, in die Gleichzeitigkeit holt und es damit den Lesenden ermöglicht, direkt und unmittelbar ins Textgeschehen einzusteigen.

1031 Vgl. Schnocks, Vergänglichkeit, 175; Forster, Begrenztes Leben, 190 und Hossfeld / Zenger, Psalmen 51-100, 612.

1032 Strolz, Psalm 90, 154. Ebenso Liess, Sättigung, 331.

1033 Vgl. Forster, Begrenztes Leben, 191. Ebenso Zenger, Werk, 26: »Der Psalm bittet nicht um Rettung aus der Todesverfallenheit oder gar um die Gabe der Unsterblichkeit. Nein, er bittet um eine (neue) Erkenntnis und eine Unterweisung, die offensichtlich nur Gott geben kann. " Ähnlich Kartje, Wisdom, 131. Irsigler, Psalm 90, 65 hält dazu fest: "Die Einsicht in die eigene so begrenzte Lebenszeit kommt nicht einfach aus der Kraft menschlicher Vernunft, sie ist vielmehr von Gott erbetene Gabe (vgl. Ps 39,5). Nur wer diese Fähigkeit, die eigenen gezählten Lebenstage wahrzunehmen, sich seiner Todesverfallenheit zu stellen, sie nicht zu verdrängen, von Gott erbittet, gewinnt aus dieser Einsicht ein ıweises Herzı. Weise ist dann derjenige, der sich der Tatsache seines begrenzten Lebens stellt, der jeden einzelnen gezählten Tag von Gott her annimmt, weil Gott ihm die Augen für die Wahrheit seines Sterbe-Lebens öffnet."

1034 Vgl. Hossfeld / Zenger, Die Psalmen 51-100, 604.

1035 Vgl. Forster, Begrenztes Leben, 156.

1036 Von Rad, Der 90. Psalm, 276.

1037 Von Rad, Der 90. Psalm, 276. 
Neben den Begriffen »Weisheit« und »Herz«, die emotional konnotiert sein können, aber viel stärker den Bereich des Verstandes und der praktischen Lebensklugheit ansprechen, ist auf der Ebene der impliziten Emotionen durch den ersten Imperativ nach dem Klageteil in V3-10 nun ein deutlicher Appell zu vernehmen. Es wird zunehmend dringlicher, dass sich etwas ändert. Der Vers wird auch als "ardent petition ${ }^{1038}$, als brennende, leidenschaftliche Bitte des lyrischen Wir charakterisiert. Im Leseprozess wirkt der Vers berührend und soll offensichtlich hoffnungsvoll und ermunternd sein (A-emotions). ${ }^{1039}$ "It is moving, entrancing, touching to read how, in the situation of extreme lostness, the psalmist turns not to humans but to God. God alone can teach to count the days and to think not of death which is certain, but of life that is uncertain and requires meaningful order. ${ }^{1040}$

\subsection{Vers 13: Wie lange noch?}

\section{3a Kehre doch zurück/um, JHWH - wie lange noch?}

$13 b$ Und hab Mitleid/Erbarmen mit deinen Knechten.

In 13a ist erstmals und einmalig in Ps 90 der Eigenname Gottes als Gottesbezeichnung in Form des Vokativs vorzufinden. Der Vokativ (vgl. Adonaj in V1) stellt den intensiven Versuch der Kontaktaufnahme des lyrischen Wir mit Gott dar. ${ }^{1041}$ Gemeinsam mit der Bezeichnung »deine Knechte«, durch die das lyrische Wir konkretisiert wird, soll die enge Zugehörigkeit zu Gott hervorgehoben werden. ${ }^{1042}$ "Das >Wir ` in Ps 90 kann ein Doppeltes sein: Es kann die Menschen als solche bezeichnen (`wir als Menschen`), kann aber auch die sprechende Gemeinschaft der `Knechte` als Repräsentanten des Gottesvolks meinen, was in V.13ff. sicher der Fall ist. « ${ }^{1043}$

Mit der Wiederaufnahme der Wurzel שוב aus V3 ist nicht klar, ob sich JHWH hier (1) vom Zorn abkehren und damit (2) seine zornerfüllte Gegenwart vom Volk abwenden ${ }^{1044}$ oder (3) seinen Knechten zuwenden soll. Das Verb impliziert alle drei Möglichkeiten. »Der unmittelbare Parallelismus (die Not des Volkes sehen,

1038 Kartje, Wisdom, 127.

1039 Vgl. McCann, Psalms, 1043.

1040 Jens, Psalm 90, 184.

1041 Vgl. Gillmayr-Bucher, Die Psalmen, 266.

1042 Vgl. Forster, Begrenztes Leben, 193. Sie verweist außerdem auf die unterschiedlichen Konzeptionen des Begriffs »Knechte«. Auf das Vorkommen der »Knechte JHWHs« in den Psalmen (Ps 34,23; 113,1; 134,1; 135,1.14) und deren redaktionelle Provenienz verweisen Hossfeld / Zenger, Psalmen 51-100, 608f.

1043 Seybold, Zeitvorstellungen, 98.

1044 »Denn es ist nicht Gottes Abwesenheit, die seine Knechte bedrückt, sondern seine vernichtende Anwesenheit.« Köckert, Zeit, 178. 
sein Seufzen vernehmen) nötigt dazu, die Aufmerksamkeit nicht auf die Bestrafung [d. h. den Zorn] selbst zu lenken, von der JHWH Abstand nehmen würde, sondern auf die unglückliche Situation des Volkes, vor der JHWH die Augen nicht verschließen kann. ${ }^{1045}$ Die aus den gängigen Klageeröffnungen ${ }^{1046}$ bekannte Frage »Wie lange noch« bzw. »bis wann« bedeutet wahrscheinlich an dieser Stelle: »Wie lange verharrst du noch in deinem Zorn? « ${ }^{1047}$ Der Vers wird damit als ergreifender Ausruf gedeutet, der die Müdigkeit und den Überdruss der lang anhaltenden Bedrängnis zum Ausdruck bringt. ${ }^{1048}$ Eine weitere Variante ist die Deutung mit: "Wie lange dauert es noch, bis du dich uns endlich wieder zuwendest? « ${ }^{1049}$ Oder anders gesagt: "Wie lange noch müssen wir ohne deine Zuwendung auskommen?« In jedem Fall bleibt »der drängende, fordernde Ton aus V. 12 [...] erhalten. ${ }^{1050}$

Die darauffolgende Bitte in 13b wird mit der Wurzel נחם formuliert. נחם im ni. bedeutet »leid tun« im weitesten Sinn, also auch "reuig werden«, "sich etwas reuen lassen «, »etwas bereuen«, »über etwas Leid, Mitleid empfinden«. Daneben birgt es die Bedeutung "sich trösten (lassen) « sowie »Trost finden« und "sich Trost verschaffen « in sich. ${ }^{1051}$ Bezüglich des emotionalen Gehalts kann ein Unterschied zwischen dem Bibelhebräischen und den modernen Sprachen festgehalten werden: »Die zwei umfangreichsten Bedeutungsfelder (`bereuen ‘ für niph, strösten ‘ für pi) schließen in den modernen Sprachen häufig und in erster Linie den emotionalen Bereich (Veränderung in den Empfindungen dessen, der bereut oder tröstet), verbunden mit faktischer Ineffizienz ein: Reue über etwas, was schon geschehen ist oder nicht geändert werden kann: Trost für den, dem man nicht wirksam helfen kann. Diese Bedeutungen sind in der Mehrzahl der at.lichen Belege entweder gar nicht oder nicht primär vorhanden. ${ }^{1052} \mathrm{Ob}$ also die in der Piel-Form (trösten) angenommene Vorstellung der zwischenmenschlichen Nähe auch für die - wie hier in V13 vorliegende - Nifal-Form gilt, ist fraglich: »Ein ausgesprochen emotionales Element fehlt [...]. ${ }^{1053}$ Das Element, das allen Bedeutungen von נחם gemeinsam ist, ist die Einflussnahme auf bzw. die Veränderung einer Situation, z. B. ein Sich-Distanzieren von etwas. Im Falle von Ps 90 ist

1045 Simian-Yofre, נחם 375.

1046 Vgl. z. B. Ps 6,$4 ; 49,5 ; 74,10 ; 82,2 ; 94,3$.

1047 Forster, Begrenztes Leben, 192. Ein deutlicher Sinneswandel wird damit an dieser Stelle von JHWH eingefordert. Vgl. Kuckhoff, Psalm 6, 205.

1048 Vgl. Tate, Psalms, 443.

1049 Vgl. Müller, Der 90. Psalm, 268.

1050 Ernst, Segen, 199. Ähnlich, Nysse, Dark Side, 445, der im Zusammenhang mit den Imperativen von energischen Worten sowie einer kraft- und wirkungsvollen Sprache des Psalms spricht.

1051 Vgl. Simian-Yofre, נחם, 368.

1052 Simian-Yofre, נחם 368.

1053 Stoebe, נחם, 64. 
es - wie bereits besprochen - vorerst nicht möglich zu unterscheiden, ob V13 im Zusammenhang mit dem vorher erzählten Zorn Gottes (V7.9.11) als »etwas bereuen « im Sinne von »eine Strafe zurücknehmen« (vom Zorn Abstand nehmen) bedeutet, oder ob es als Auftakt für die kommenden Verse mit der Bitte um Sättigung mit Güte und Freude (V14-17) mit »Mitleid empfinden« wiedergegeben werden soll. ${ }^{1054}$

V13 drückt neben der Dringlichkeit zur Veränderung der Situation - der Vers wird auch als Aufschrei gedeutet ${ }^{1055}$ - indirekt sowohl eine Klage als auch eine Anklage aus. Letztere besteht aus der "gnadenlosen Anrechnung aller Schuld sowie des daraus resultierende Zorns Gottes, der die BeterInnen bedroht. ${ }^{1056}$ V13 schlägt eine Brücke zurück zu V3-6 und dem Thema der Vergänglichkeit sowie zur Aufforderung in V12, die Lebenszeit aktiv zu gestalten: "Die Vergänglichkeit markiert also die absolute Dringlichkeit, die Zeit zu nutzen, und als Appell an Gott betont sie die Notwendigkeit seines Erbarmens. ${ }^{1057}$

Da das auf den ersten Blick als explizites Emotionswort erscheinende Mitleid, Erbarmen, Reue (hier Gott zugeschrieben) im Bibelhebräischen nicht in dem Maße emotional konnotiert ist wie in modernen Sprachen und in erster Linie auf eine Veränderung einer Situation abzielt, liegt die Emotionalität dieses Verses - wie auch in V12 - auf der Ebene der Syntax. Hier werden durch Imperativ und Frage implizit Dringlichkeit, Bedürftigkeit, Hilflosigkeit, Müdigkeit und Überdruss thematisiert. Diese sind dem lyrischen Wir zuzuschreiben.

\subsection{Vers 14: Lebensfreude}

14a Sättige uns am Morgen mit deiner Güte,

$14 b$ sodass wir jubeln und uns freuen in allen unseren Tagen.

In V14 wird mit בַבּקָר (am (all unsere Tage V 9.14) auf den ersten Teil des Psalms zurückgegriffen und die dort verbundenen Inhalte ins Gegenteil gekehrt. Es kristallisiert sich damit eine Methode des Psalms heraus, an vergangene Verse anzuknüpfen und dabei den negativen Inhalt ins Positive zu kehren (siehe auch V15). ${ }^{1058}$ So werden vor allem die »Tage« in V10 als zu gering und flüchtig beschrieben, während hier in V14 die Fülle von Tagen vor

1054 Vgl. Simian-Yofre, נחם, 375.

1055 Z. B. Schnocks, Vergänglichkeit, 176 und Tucker, Exitus, 151. Goldingay, Psalms 3, 32 spricht von einer drängenden, nachdrücklichen und ausdrücklichen Bitte in V13, Kuckhoff, Psalm 6, 197 mit Ernst Jenni von einer »Bitte um Aktivierung«.

1056 Gillmayr-Bucher, Die Psalmen, 256.

1057 Gillmayr-Bucher, Die Psalmen, 274.

1058 Vgl. Forster, Begrenztes Leben, 195. 
Augen steht. ${ }^{1059}$ Der Rückbezug auf "all unsere Tage« in V9 stellt die Zeit der Zorneserfahrung der Zeit der gottgeschenkten Lebensfreude in V14 gegenüber. Die Last der Vergänglichkeit und Todesverfallenheit aus V3-10 wird von der allgemeinen Lebensfreude in V14.15 abgelöst. ${ }^{1060}$ Lähmende Todesangst und Schwermut angesichts des Todes mögen zugunsten der Freude am Leben weichen. ${ }^{1061}$

Der Vers ist von starken expliziten Emotionswörtern geprägt, die diesmal - im Gegensatz zu V7.9 - positiv gefüllt sind. חֶ meint die Güte, Gnade und Huld Gottes, die vor allem die göttliche Zuwendung und Großherzigkeit thematisiert (vgl. die Analyse zu Ps 147,11). Mit dieser חֶֶֶ sollen die Menschen gesättigt, gefüllt werden (zu שבע vgl. die Analyse zu Ps 147,14). Satt zu sein und sich sattessen zu können gehört zur erhofften Heilszeit. Dies soll am Morgen geschehen, der ebenso "Zeitpunkt der Gottesantwort und Gotteshilfe « ${ }^{1062}$ und Ausdruck »ausgesprochener Heilszeit « ${ }^{1063}$ ist wie ein Bild für die »das nächtliche Unheil und den Tod beendende Lebensmächtigkeit Gottes. « ${ }^{1064}$

Die Verben רנמת (jubeln) und (sich freuen) aus dem Konsekutivsatz 14b, die bereits aus der Analyse von Ps 30 bekannt sind, sind Ausdruck überschwänglicher Freude. Dieser doppelt ausgedrückte Jubel beschreibt den Effekt der erbetenen Güte. ${ }^{1065}$ Nüchtern hält dazu Hans-Peter Müller fest: »Hat man gelernt, seine Tage zu zählen (12), so bleibt die Lebensfreude ohnehin das einzig lohnende Gut. ${ }^{1066}$

Nach V7.9.11 begegnet uns hier wiederum ein Vers, der eine Vielzahl von expliziten Emotionswörtern aufweist. Allerdings sind diese - im Kontrast zu den genannten Versen - dem Emotionsfeld der Freude zuzuordnen: In V14 werden Sattsein, Freude, Jubel, überschwängliche Freude sowie Güte, Zuwendung und Liebe thematisiert. Implizit verweist der Morgen, der anzeigt, dass das nächtliche Unheil vorbei ist, auf eine Zeit des Heils und der Freude. Durch die Bitte bleibt die Appellfunktion erhalten. Zusammenfassend kann festgehalten werden, »dass der Vers in einem Ton des Vertrauens verfasst ist und Freude zum Leitmotiv hat. « ${ }^{1067}$ Die erbetene Freude wird dabei dem lyrischen Wir zugeschrieben, die Güte und Liebe der Gottheit.

1059 Vgl. Gillmayr-Bucher, Die Psalmen, 257.

1060 Vgl. Zenger, Werk, 16.

1061 Vgl. Zenger, Werk, 31.

1062 Kraus, Psalmen, 800.

1063 Grund / Janowski, "Solange die Erde steht ...«, 516.

1064 Hossfeld / Zenger, Psalmen 51-100, 612.

1065 Vgl. Schnocks, Vergänglichkeit, 176.

1066 Müller, Der 90. Psalm, 277.

1067 Artner, »Sättige uns«, 104. 


\subsection{Vers 15: Ausgleichende Gerechtigkeit}

15 a Erfreue uns gleich den Tagen, an denen du uns gebeugt hast, $15 b$ Jahre, in denen wir Unheil gesehen haben.

V15 führt einerseits die Zeitdimensionen aus V14 fort, indem nach dem Morgen in $14 \mathrm{a}$ die Tage aus $14 \mathrm{~b}$ in $15 \mathrm{a}$ aufgenommen und um die Jahre in $15 \mathrm{~b}$ erweitert werden. ${ }^{1068}$ Andererseits wird hier in V15 im Gegensatz zu V14, der vollständig

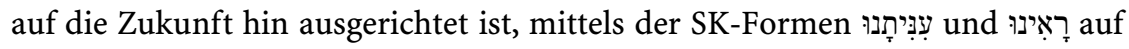
V7-10 und die dort geschilderte Notsituation Bezug genommen.

Mit II wird ein negativ besetzter Erfahrungsbereich thematisiert, der die Grunderfahrung des »Elendseins« in seinen vielfältigen Dimensionen beschreibt. »Das Verb sagt in der Regel aus, dass jemand einen anderen in die Seinsminderung und Bedrohtheit hineinbringt oder sich selbst zeitweise hineinbegibt. Dem >Elenden $>[. .$.$] ist nicht mehr zu helfen. { }^{1069}$ Mit der Wurzel ענה II werden demnach die bedrängte und todesnahe Situation und der degradierte Zustand des Volkes in der in V7-11 geschilderten Notsituation nochmals in drastischer Weise auf den Punkt gebracht. In der Piel-Form, in der ענה II am häufigsten Verwendung findet, wird die Wurzel mit »bedrücken, schlecht behandeln, demütigen, erniedrigen o. ä., auch bezwingen ( $\mathrm{Ri} 16,5 \mathrm{f}$.) und vergewaltigen (Gen 34,2; Dtn 22,24.29) « ${ }^{1070}$ wiedergegeben.

Beugen, demütigen und erniedrigen werden in diesem Vers parallel gesetzt mit Böses/Übles sehen. רָָָ umfasst im Bibelhebräischen das Böse, das Übel sowie das Schlechte und die Unrechtssituation allgemein. ${ }^{1071}$ Dabei liegt der Schwerpunkt darauf, wer im Mittelpunkt steht: Ist es derjenige/diejenige, der/die das Unheil bewirkt (Böses), oder ist es derjenige/diejenige, der/die das Böse erleiden muss (Unheil)? ${ }^{1072}$ "Allerdings, immer ist jemand oder etwas böse. Das Böse erscheint also im Prädikat, als Eigenschaft. Es ist in Ereignissen, Handlungen und deren Wirkungen zu Hause. [...] Das Böse ist ein Relationsbegriff; seine Sache hat mit Handeln und Erleiden, mit menschlichen und sozialen Ordnungen zu tun. Als böse wird erfahren, was bedroht, Ordnungen auflöst, Leben zerstört, Entwicklungen in Katastrophen enden lässt. Es bedeutet im Kern Angriff auf Dasein und Leben. [...] Seine Richtung ist der Tod. ${ }^{1073}$ Auch mit רָעָה wird ebenso wie mit ענה II in eindrücklicher Weise auf die Not-, Elends- und

1068 Hier fallen die ungewöhnlichen femininen Pluralendungen bei שִָָׁה bei שָָָׁ in V10 verwendet wurden.

1069 Gerstenberger, ענה II, 252.

1070 Martin-Achard, ענה II, 342.

1071 Vgl. Dohmen, 589.

1072 Vgl. Lindström, Böse I (AT), 314.

1073 Häring, Problem, 1-2. 
Leidens- sowie Unrechtssituation hingewiesen, in welcher sich das lyrische Wir befand.

Die Bitte in V15 wirkt im Vergleich zu V14 drängender und direkter, ja sogar fordernd ${ }^{1074}$ und kann als »Appell an die Barmherzigkeit Gottes ${ }^{1075}$ verstanden werden.

Neben dem expliziten Emotionswort des Erfreuens wird hier im Rückblick auf die Aspekte der Unterdrückung, Demütigung und des Unheils verwiesen. Die Freude wird von Gott eingefordert, die Demütigung und Unterdrückung Gott zugeschrieben. In diesem einen Vers ist damit kontrastreich einerseits vom Emotionsfeld der Freude, andererseits von den Aspekten der Gewalt und des Niederdrückens und den damit verbundenen Emotionen die Rede. Dadurch zeigt sich der Gegensatz zwischen vergangener Not und erhofftem Heil. Es geht um die Kompensation der Zeit der Demütigung und des Leidens durch eine entsprechende Zeit der Freude. ${ }^{1076}$ Hier kann von einer doppelten Emotionalität gesprochen werden, die aus der Analyse von Ps 30 und 147 bereits bekannt ist.

Auf der Ebene der impliziten Emotionen bleibt die Appellfunktion weiterhin Bestandteil des Textes. Es geht um das Verlangen und Einfordern einer ausgleichenden Gerechtigkeit, um göttliche Gerechtigkeit und die Geschichtsmacht Gottes. ${ }^{1077}$ Die Aufforderung kann auch als Empörung über das Erlebenmüssen von Unheil gedeutet werden und ist dem lyrischen Wir zuzuordnen. ${ }^{1078}$

\subsection{Vers 16: Göttlicher Glanz}

$16 a$ Es soll sich sehen lassen an deinen Knechten dein Werk/dein Handeln $16 b$ und dein Glanz über ihre Kinder.

Die mit V14 eingeschlagene Zukunftsperspektive wird hier in V16 ausgeweitet, und zwar auf die Nachkommenschaft hin (ihre Kinder 16b). Damit wird erstmals im Psalm eine Hoffnung ausgedrückt, die die Generationen umgreift, und das Schicksal des einzelnen Menschen (vgl. V3-6) in den erweiterten Zusammenhang einer sich ablösenden Generationenfolge eingeordnet. ${ }^{1079}$

Mit הָדָר (Pracht, Zierde, Schmuck, Majestät) wird die Pracht der Natur (Lev 23,40; Jes 35,2) ebenso bezeichnet wie die Schönheit des Menschen (Jes 53,2; Ps 8,6) und auch der Schmuck der Alten (Spr 20,29) sowie die Majestät des Königs

1074 Vgl. Forster, Begrenztes Leben, 195.

1075 Forster, Begrenztes Leben, 196.

1076 Vgl. Gillmayr-Bucher, Die Psalmen, 257.

1077 Vgl. Zenger, Werk, 16.

1078 Vgl. Artner, Emotionen in Psalm 90, 134.

1079 Vgl. Forster, Begrenztes Leben, 196. 
auf Erden (Ps 21,6; 45,4.5). Wird der Begriff - wie hier - auf Gott bezogen, so kommt ihm die Bedeutung Erhabenheit, Glanz und Herrlichkeit zu; er ist Ausdruck für die Königswürde JHWHs. ${ }^{1080}$ ist das Gewand, das sich JHWH anzieht, es ist das Königsornat (Ps 104,1; Ijob 40,10) und damit Ausdruck der Hoheit und königlichen Majestät wie auch der Macht und der »theophanen

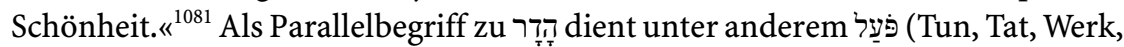
Handeln) wie hier in V16. Der Begriff פַּ bezieht sich in den Psalmen auf das Handeln Gottes, das Gerechtigkeit schafft und Rettung bewirkt. Dieses Handeln gibt in der geschichtlichen Erinnerung Halt in Situationen des Zweifelns und der Not (Ps 44,2; 77,13; 95,9; 143,5) und ist als gegenwärtige Erfahrung Grund dafür, Gott zu loben (Ps 92,5; 111,3). ${ }^{1082}$ Mit der Parallelisierung von wִ הָדָר angezeigt, dass הָדָר auch das Wirken JHWHs in der Geschichte bezeichnet. ${ }^{1083}$

Hinter dem Ausdruck »Glanz Gottes« verbirgt sich auf Ebene der impliziten Emotionen die Zuwendung Gottes. Syntaktisch wird ein Wunsch ausgedrückt, der auf Erfüllung hofft.

\subsection{Vers 17: Segenswunsch}

17a Und es soll sein Anmut Adonajs, unseres Gottes, über uns,

$17 b$ und die Arbeit unserer Hände festige über uns,

$17 c$ und die Arbeit unserer Hände, festige sie!

Der den Psalm abschließende Wunsch wird als "Segenswunsch « ${ }^{1084}$ bezeichnet, der um die Offenbarung der Freundlichkeit bzw. Lieblichkeit und Anmut Gottes bittet.

Das letzte explizite Emotionswort des Psalms ist das Substantiv נגעַם Die Wurzel נעם ist bereits aus der Analyse von Ps 147,1 bekannt und wird in der Liebessprache verortet. נעם wird zur Beschreibung der Attraktivität der Geliebten ebenso verwendet wie für die Bezeichnung der Köstlichkeit im Rahmen erotischer Liebe. Das Substantiv, das nur sieben Mal in der Hebräischen Bibel vorkommt (Spr 3,17; 15,26; 16,24; Ps 27,4; 90,17; Sach 11,7.10), kann mit »Anmut, Wohlergehen, Anmutiges, Gesundheit, Freundlichkeit« wiedergegeben werden. Bildlich gesprochen steht נעם für die Köstlichkeit und Schönheit des Landes (Gen 49,15), auf Gott übertragen bezeichnet נצעם dessen liebevolle Heilszuwendung. ${ }^{1085}$

1080 Vgl. Wehmeier / Vetter, הָדז, 469-471.

1081 Müller, Der 90. Psalm, 278.

1082 Vgl. Forster, Begrenztes Leben, 197.

1083 Vgl. Warmuth, הדז, 359-361. Ebenso Zenger, Werk, 33.

1084 Hossfeld / Zenger, Psalmen 51-100, 612. Ebenso Schmidt, Menschen, 129 mit dem Verweis auf die Segensbitte inmitten der Mühsal.

1085 Vgl. Kronholm, נעם, 500-504. 
Hier »scheint das Wort no'am das wundervolle Eingreifen JHWHs zur Neugründung des menschlichen Lebenswerkes auszudrücken. « ${ }^{1086}$ Oder anders gesagt: »Der Ausdruck נגַעַם, der in tempeltheologischem Kontext die Erfahrung der Lebensfülle im Heiligtum in Gottes Nähe beschreiben kann (vgl. Ps 16,11; 27,4 u. ö.), wird in diesem abschließenden Wunschsatz zum Inbegriff der göttlichen Zuwendung. ${ }^{1087}$

Entsprechend $\mathrm{zu}$ »deine Tat« aus V16 steht nun in V17 »das Werk unserer Hände«. Diesem soll Bestand verliehen werden, es soll gedeihen, gefestigt und gefördert werden (כון po. befestigen, festigen, stärken, etwas fördern ${ }^{1088}$ ), und zwar nicht aus eigener Kraft heraus, sondern durch Gottes Hilfe. ${ }^{1089}$ Die Verbindung und Zusammengehörigkeit zwischen göttlichem Tun und menschlicher Arbeit besteht also darin, dass die Gottheit den Menschen teilhaben lässt an ihrem Wirken und das menschliche Wirken und Tun dadurch beständig wird. ${ }^{1090}$ Außerdem leuchtet das Thema der Vergänglichkeit, das den gesamten Psalm durchzieht, auch am Schluss des Psalms wieder auf: „Gleichzeitig mag bei der Bitte um den Bestand des >Werks unserer Hände` auch mitschwingen, dass über die tägliche Arbeit eine Beziehung des Menschen zu etwas Bleibendem entstehen kann, das wiederum die eigene Vergänglichkeit überdauern mag. « ${ }^{1091}$ Dem Mühevollen, Hoffnungslosen und Flüchtigen der menschlichen Lebenszeit aus V10 wird mit V17 der Gedanke des Bestands der Arbeit und des menschlichen Wirkens entgegengesetzt und damit eine Hoffnungsperspektive entworfen. ${ }^{1092}$

Im Leseprozess verspüren Lesende am Ende des Psalms eine Art Ruhe, ja sogar Frohsinn und Heiterkeit: "Most readers experience a calm at the end, even a kind of exhilaration, tempered, to be sure, by the somber mood of the poem. " ${ }^{1093}$ Dabei wird die Ruhe in der literarischen Anordnung des Textes und nicht in der theologischen Aussagekraft verortet. ${ }^{1094}$

1086 Kronholm, נעם, 505.

1087 Liess, Sättigung, 332.

1088 Vgl. GES 533.

1089 Die drei Bitten in V17.15.12 haben ein gemeinsames Thema, »nämlich die Gestaltung eines erfüllten Lebens und zwar nicht außerhalb, sondern innerhalb der dem menschlichen Leben gesetzten Grenzen. Ebenso können die drei Bitten nur mit Gottes Hilfe Wirklichkeit werden. Die Fähigkeit der Menschen, von sich aus selber etwas zu ihren Gunsten zu unternehmen, kommt in diesem Psalm nicht in den Blick." Gillmayr-Bucher, Die Psalmen, 274.

1090 Vgl. Zenger, Werk, 34.

1091 Schnocks, Vergänglichkeit, 177. Ähnlich Zenger, Werk, 34: »Die Menschen sterben. Was bleibt, ist jenes Tun, in dem Gott durch sie am Werke war.«

1092 Vgl. Hossfeld / Zenger, Psalmen 51-100, 613.

1093 Robertson, Literary Criticism, 47.

1094 »Similarly, as I understand Psalm 90, the thought-emotions we experience when reading this poem are brought about primarily by literary not religious means, and so are neces- 
Mit dem expliziten Emotionswort der Anmut bzw. Lieblichkeit Gottes wird dessen Freundlichkeit und liebevolle Heilszuwendung ausgedrückt. ${ }^{1095}$ Implizit wird durch die Wiederholung und die dadurch hervorgerufene Betonung die Dringlichkeit bzw. Eindringlichkeit der Bitte sichtbar, die dem lyrischen Wir zugeschrieben wird. Schlussendlich sind speziell in diesem Vers auch jene Emotionen zu nennen, die im Leseprozess hervorgerufen werden können: Ruhe, Heiterkeit, Trost und Hoffnung (A-emotions).

\section{$3 \quad$ Perspektiven und Textdynamik}

\subsection{Perspektivenlenkung}

Innerhalb der Überschrift in 1a wird die Perspektive nach Mose durch die Constructus-Verbindung "Mann Gottes« bereits auf Elohim gelenkt. Weitere Gottesbezeichnungen des Psalms sind nach Elohim (1a) Adonaj (1b.17a), El (2c), JHWH (13a) sowie unser Gott/Elohim (17a). ${ }^{1096}$

Der erste Gedankenspot ist $\mathrm{ab} 1 \mathrm{~b}$ in der Du- bzw. Er-Perspektive gehalten: Wird in $1 \mathrm{~b}$ zum göttlichen Du gesprochen, so in 2a-5a $\ddot{u} b e r$ dieses Du. Die erste Betrachtung schließt in 5b-6b mit der Rede in der 3. Person über das allgemein formulierte Thema der menschlichen Vergänglichkeit. Auch wenn hier die Sprechrichtung wechselt, wird die Anrede Gottes in der 2.P.sg. und damit die Gebetssprache beibehalten, wodurch die Redeweise persönlich bleibt. ${ }^{1097}$ In Bezug auf die Blicklenkung lässt sich Folgendes festhalten: In V1 richtet sich der Blick auf Adonaj als Zufluchtsort der Menschengenerationen, in V2 auf die Urzeit, also auf das, was vor der Zeit war. Diese Blicklenkung weitet; sie bietet einen Weitblick zurück vor den Beginn der Zeit. Sodann wird der Blick auf Berge und Erde sowie die Welt als Objekt geworfen. Die Perspektive wird damit auf die Großräume und auf Gott als Subjekt gerichtet. Mit V3 bleibt der Blick bei Gott als Subjekt und wird danach auf die Menschen als Objekt sowie auf den Staub als Lokalobjekt gelenkt. In 3b liegt eine direkte Rede Gottes vor, die an die Menschenkinder als textinterne AdressatInnen gerichtet ist. V4 ist von einer doppelten Fokalisierung geprägt: Die Lesenden sehen auf Gott und nehmen wahr, wie Gott auf die Menschen blickt (in deinen Augen). So wird der Blick mittels dieser doppelten Fokalisierung in V4 durch die Augen Gottes auf tausend Jahre,

sarily independent of religious beliefs. One need be neither Jew nor Christian, nor even a theist, to experience the calm it achieves." Robertson, Literary Criticism, 50.

1095 Vgl. Artner, »Sättige uns«, 110.

1096 Einige AutorInnen weisen auf die unterschiedlichen Konnotationen in den Gottesbezeichnungen hin, z. B. Forster, Begrenztes Leben, $172 \mathrm{f}$.

1097 Vgl. Forster, Begrenztes Leben, 174. 
auf den gestrigen Tag und auf die Nachtwache gerichtet. Wiederum wird die Zeit in allen ihren Dimensionen thematisiert. Zeit ist hier auch als Subjekt auszumachen: tausend Jahre, ein Tag gestern. Es stellt sich an dieser Stelle die Frage, ob von einer Personifikation der Zeit gesprochen werden kann, da der gestrige Tag vorübergeht (vgl. Analyse zu V4). In 5a wird der Blick auf Gott und die Menschen gelenkt, in 5b-6b auf Gras (Erde) und Zeit. Dabei wird das Gras als Subjekt genau beschrieben (wachsen, blühen, sprossen, welken, verdorren), wodurch es im Zentrum der Aufmerksamkeit steht. Es wird von Zeitangaben flankiert (am Morgen 2x; zum Abend hin).

Mit dem Subjektwechsel zum lyrischen Wir in V7 steht im zweiten Gedankenspot der Blick auf das Wir im Beziehungsverhältnis zum göttlichen Du im Mittelpunkt. Auch dieses Wir ist Gegenstand der Betrachtung, was durch die in den Objektpositionen stehenden Begriffe unsere Schuld/Ungerechtigkeiten (8a), unser Verborgenes (8b) und unsere Tage (12a) zum Ausdruck kommt. Die Perspektive wechselt im zweiten Gedankenspot zwischen dem Wir und dem Du. So werden die V7.9.10 in der Wir-Perspektive geschildet, die V8.11b in der DuPerspektive. 11a holt mit dem deiktischen Element des Interrogativpronomens (wer) als Subjekt die Lesenden näher an den Text heran und öffnet die Perspektive auf eine breitere Öffentlichkeit hin. 11a lenkt, auch verstärkt durch das Verb in Partizipialform, das den Aspekt der Gleichzeitigkeit in sich trägt, den Blick weg von dieser dichten Wir-Du-Perspektive. Dadurch beziehen die beiden rhetorischen Fragen in 11a.b die Lesenden mit ein. ${ }^{1098}$

Mit V12 wird ein inhaltlicher Perspektivenwechsel vollzogen: Das lyrische Wir bittet um eine neue Perspektive auf die menschliche Lebenszeit, wodurch der Themenkomplex der Vergänglichkeit, Flüchtigkeit und Begrenztheit des Lebens an ein Ende kommt. ${ }^{1099}$ In V12 kulminiert der zweite Gedankenspot außerdem durch die Abfolge du-unser-wir, indem er das dichte Beziehungsnetz zwischen JHWH und dem lyrischen Wir wieder aufnimmt. Diese Dichte in der Beziehung, ausgedrückt durch die Vielzahl an deiktischen Elementen, wird im zweiten Teil des Psalms (V13-17) weitergeführt und ausgebaut. Zur Deixis in diesem Teil zählen die folgenden Textelemente, die bewirken, dass die Lesenden näher an das Textgeschehen herangeholt und eingeladen werden, dem Text zu folgen und sich mit der erzählten Welt zu identifizieren: Das Fragepronomen »wie« in der Frage "wie lange noch" bzw. »bis wann« (13a) sowie außerdem hauptsächlich Suffixe, die als Personal- bzw. Possessivpronomen wiedergegeben werden: deine Knechte (13b), sättige uns (14a), deine Güte (14a), wir werden jauchzen (14b), uns freuen

1098 »Sie werden aufgefordert, die Überlegungen mitzuvollziehen und sich die Frage nach der Unergründbarkeit des göttlichen Zorns, wie es Vers 11 aufwirft, zu stellen.« GillmayrBucher, Die Psalmen, 266.

1099 Vgl. Gillmayr-Bucher, Die Psalmen, 271. 
(14b), in allen unseren Tagen (14b), erfreue uns (15a), du uns gebeugt hast (15a), wir haben gesehen (15b), an deinen Knechten (16a), dein Werk (16a), dein Glanz (16b), unseres Gottes (17a), über uns (17a.b) und das Tun unserer Hände (17b.c).

Die Blicklenkung erfolgt in V13-17 in abwechselnder Reihenfolge entweder auf das göttliche Du oder auf das lyrische Wir hin: In V13.14a.15a.16a.17b.c wird das Du in den Blick genommen, wobei V16 durch die dreimaligen Suffixe in der 2.P.sg. (deine Knechte; dein Werk; dein Glanz) in der Beschreibung des göttlichen $\mathrm{Du}$ und dessen Wirkmacht durch Werk und Glanz einen Höhepunkt bildet. Interessanterweise wechselt in 16a.b.17a die Rede über das göttliche Du von den Imperativformen in die dritte Person, was als distanzierte Rede aufgefasst werden kann. ${ }^{1100}$ Durch die starke Deixis wird sprachlich jedoch die persönliche Beziehung zwischen dem lyrischen Wir und der Gottheit aufrechterhalten.

14b.15b.V17 stellen das lyrische Wir ins Zentrum. Auch in diesem zweiten Teil des Psalms steht das Beziehungsverhältnis zwischen dem lyrischen Wir und dem göttlichen Du im Mittelpunkt. Das Geschehene wird - ebenso wie die in den Bitten und Wünschen ausgedrückten Inhalte - in diesem Beziehungsnetz geschildert. Die folgende Tabelle fasst die Blicklenkung des Textes und den Fokus des jeweiligen Verses zusammen:

\begin{tabular}{|l|l|l|}
\hline Gedankenspot & Vers & Fokus \\
\hline \multirow{5}{*}{ (V1-6) } & V1 & Gott + Adonaj + Wohnort (Raum) \\
\cline { 2 - 3 } & V2 & Berge + Du + Erde und Welt + Ewigkeit + Gott (Raum und Zeit) \\
\cline { 2 - 3 } & V3 & Du + Mensch + Staub (Raum) \\
\cline { 2 - 3 } & V4 & tausend Jahre + Tag + Nachtwache (Zeit) \\
\cline { 2 - 3 } & V5 & Du + Sie + Schlaf + Gras (Zeit) \\
\cline { 2 - 3 } & V6 & Morgen + wachsen + Abend + welken (Zeit) \\
\hline 2 (V7-12) & V7 & Wir + dein Zorn + deine Wut + wir (Zorn) \\
\cline { 2 - 3 } & V8 & Du + unsere Schuld (Schuld) \\
\cline { 2 - 3 } & V9 & $\begin{array}{l}\text { unsere Tage + dein überwallender Zorn + wir + unsere Jahre } \\
\text { (Zeit und Zorn) }\end{array}$ \\
\cline { 2 - 3 } & V10 & $\begin{array}{l}\text { die Tage unserer Jahre + Mühe und Unheil + schnell verfliegen } \\
\text { wir } \\
\text { (Zeit und Unheil) }\end{array}$ \\
\cline { 2 - 3 } & V11 & Wer + Kraft deines Zorns + deine Furcht (Zorn) \\
\cline { 2 - 3 } & V12 & Du + unsere Tage + wir + Herz von Weisheit (Zeit) \\
\hline
\end{tabular}

$1100 »$ Diese wachsende Distanz, die nach den vehementen Imperativen besonders in v.13 wie ein zur Ruhe Kommen der Beter wirkt, wird in der zweiten Hälfte des Schlußverses durch offenbar an JHWH gerichtete, zuversichtliche Imperative wieder zurückgenommen." Schnocks, Vergänglichkeit, $113 \mathrm{f}$. 
(Fortsetzung)

\begin{tabular}{|l|l|l|}
\hline Gedankenspot & Vers & Fokus \\
\hline \multirow{3}{*}{ 3 (V13-15) } & V13 & JHWH + Mitleid (Zuwendung) \\
\cline { 2 - 3 } & V14 & $\begin{array}{l}\text { Du + sättigen + Güte + wir + Freude + alle unsere Tage } \\
\text { (Zeit und Zuwendung) }\end{array}$ \\
\cline { 2 - 3 } & V15 & $\begin{array}{l}\text { Du + Freude + Tage + niederbeugen + Jahre + Leiden } \\
\text { (Zeit, Zuwendung und Unheil) }\end{array}$ \\
\hline 4 (V16-17) & V16 & Dein Werk + dein Glanz + ihre Kinder (Zuwendung) \\
\cline { 2 - 3 } & V17 & $\begin{array}{l}\text { Freundlichkeit Adonajs + Tun unserer Hände + über uns } \\
\text { (Zuwendung und Beständigkeit) }\end{array}$ \\
\hline
\end{tabular}

Mittels der Tabelle lassen sich neben der Blicklenkung auch die Hauptthemen des Psalms verdeutlichen, die sich um Zeit und Raum, Zorn und Schuld, Unheil, Freude, Zuwendung und Beständigkeit drehen. Deutlich zeigt sich die Verschränkung der einzelnen Themen miteinander, meist mit der Zeitdimension, die den gesamten Psalm durchzieht. Darüber hinaus fällt der Anstieg der Bitten um Zuwendung ab V13 im zweiten Teil des Psalms ins Auge. ${ }^{1101}$

Mit Ausnahme von 1a.5b-6b, die extern fokalisiert werden, und der doppelten Fokalisierung in V4 ist eine durchgehende interne Fokalisierung festzustellen. Textexterne AdressatInnen, wie etwa in Ps 30 und Ps 147, werden nicht genannt. Textintern werden Adonaj (1b), JHWH (13a) und die Menschenkinder (3b) adressiert. Die bereits in den A-emotions konstatierte Kompaktheit des Psalms zeigt sich auch darin, dass der Text perspektivisch in sich geschlossen bleibt und keine Öffentlichkeit einbezieht - im Kontrast etwa zu Ps 30 und vor allem zu Ps 147, wo die Öffnung auf externe Angesprochene, auf eine Gemeinde bzw. auf die weitere Öffentlichkeit der Lesenden hin durch die AdressatInnenperspektive gegeben ist.

\subsection{Textdynamik}

\subsubsection{Erster Gedankenspot V1-6}

Die erste Betrachtung des Psalms (V1-6) widmet sich ganz dem Wesen und Handeln Gottes unter dem Thema »Zeit« im Kontrast zu den Zeitdimensionen des Menschen. So wird mit »Elohim«, dem letzten Wort der Überschrift in 1a, schon auf die göttliche Dimension verwiesen, die in V2-6 näher ausgefaltet wird. Der Auftakt dazu erfolgt in V1: In 1b wird direkt zu Gott gesprochen, indem mit

1101 Zur Differenzierung zwischen göttlicher und menschlicher Perspektive in Ps 90 und zum Zusammenspiel zwischen Thema und Perspektive in der Textdynamik vgl. die Tabelle und die weiteren Ausführungen bei Gillmayr-Bucher, Die Psalmen, 267-273. 
dem Vokativ »Adonaj« die Gottheit Israels angerufen wird. Danach prägt die Rede über das göttliche $\mathrm{Du}$ in der 2. Person, die in $1 \mathrm{~b} .2 \mathrm{c}$ mit dem Personalpronomen אַתָּה (du) verstärkt und damit eigens betont wird, diesen ersten Gedankenspot (2a-5a), der in 5b-6b mit einem Vergleich zwischen den Menschen und dem schnell verwelkenden Gras in der 3.P. schließt. Die nächste direkte Anrede an die Gottheit - die dann als JHWH angesprochen wird - findet sich erst wieder in 13 a.

Die jeweiligen göttlichen und menschlichen Zeitdimensionen werden mit bestimmten Räumen verbunden: So ist Adonaj Wohnort, Versteck und Zuflucht (מָעוֹן) für das lyrische Wir über alle Generationen hinweg. Mit dem Vorzeitlichen und der Ewigkeit Gottes (V2) werden die Räume Berge, Erde und Welt verbunden. Im Gegensatz dazu ist der Staub (3a) als Raum den Menschen zugeordnet. Somit sind die "Riesendimensionen« der Zeit (von Generation zu Generation, bevor Berge geboren wurden, von Ewigkeit zu Ewigkeit) Gott zugeordnet, während die Menschenzeit auf einen Tag beschränkt ist (V5-6: vom Morgen bis zum Abend). Schon hier zeigt sich der enorme Kontrast zwischen der unermesslichen, für Menschen nicht fassbaren Zeit Gottes, in dessen Augen tausend Jahre zu einem Zeitraum von wenigen Stunden der Nachtwache zusammenschrumpfen, und der Zeit der Menschen. ${ }^{1102}$ Die »Riesendimensionen « der Zeit Gottes stehen somit der »Minidimension« der Zeit der Menschen gegenüber.

Ein weiteres Thema des ersten Gedankenspots ist der Kontrast zwischen dem ewigen Sein Gottes (2c) und der Vergänglichkeit des Menschen (V3.5-6). Gott hält Leben und Sterben des Menschen in der Hand. So lässt er den (verletzlichen) Menschen (אֶנוֹש (V3) und überschwemmt die Menschenkinder mit Schlaf (5a), sodass sie zur absoluten Passivität gezwungen sind. Dies birgt eine schwierige Dimension im Gottesbild von Ps 90, die sich im zweiten Gedankenspot weiter verdichten wird. Der Vergleich mit dem Naturvorgang des am Morgen aufblühenden und noch zum selben Abend hin vertrocknenden Grases mit dem Menschenleben, der den Kreislauf des Geborenwerdens und Sterbens thematisiert, schließt die Vergänglichkeits- und Todesmetaphorik im ersten Gedankengang ab. Thematisch ist im ersten Gedankenspot eine deutliche Abwärtsbewegung festzuhalten: Steht am Beginn noch das Vertrauensbekenntnis in Adonaj als Wohn- und Zufluchtsort sowie die Erschaffung der Schöpfung aus göttlicher Geburt, so wird es danach immer düsterer, wenn die Vergänglichkeit und Flüchtigkeit des Menschenlebens bis hin zum Kreislauf von Leben und Sterben zur Sprache kommt. ${ }^{103}$ Der ab-

1102 »Eine in menschlichen Augen unermesslich lange Zeitperiode schrumpft in den Augen Gottes zu einer winzigen Zeitspanne.« Forster, Begrenztes Leben, 177.

1103 Dazu ebenso Schnocks, Vergänglichkeit, 82 mit Bezug auf V6: »[...] der Vergleich der Menschen mit dem Gras erhält den Charakter einer sich von Kolon zu Kolon mit den hinzutretenden Verben steigernden Negativreihe." 
solute Tiefpunkt ${ }^{1104}$ dieser Abwärtsbewegung für den gesamten Psalm ist mit der Rede vom überwallenden Zorn Gottes (עָכברָה $11 \mathrm{~b}$ erreicht. Danach treten eindeutig positivere Themen zu Tage: Herz von Weisheit (12b), Sättigung (14a), Güte (14a), Freude (14b), Jubel (14b) etc., bis mit der zweifachen Bitte um Bestand des Menschenwerkes in V17 die Klimax und der Schluss des Psalms erreicht ist, der den Gegenpart zur Todes- und Vergänglichkeitsthematik aus dem ersten Gedankenspot bildet.

Die Themen des ersten Gedankenspots lassen sich folgendermaßen benennen:

\begin{tabular}{|l|l|}
\hline Vers & Thema \\
\hline 1 & $\begin{array}{l}\text { Überschrift: Gebet, das Mose zugeordnet ist; Gott ist für das lyr. Wir Wohnort } \\
\text { und Versteck seit Menschengenerationen }\end{array}$ \\
\hline 2 & $\begin{array}{l}\text { Gott als Schöpfer und die göttliche Existenz vor der Schöpfung bis in alle } \\
\text { Ewigkeit }\end{array}$ \\
\hline 3 & Gott lässt die Menschen zu Staub zurückkehren \\
\hline 4 & Tausend Jahre sind in den Augen Gottes wie ein Tag bzw. eine Nachtwache \\
\hline 5 & $\begin{array}{l}\text { Gott verursacht in heftiger Weise die Passivität des Menschen; Beginn des } \\
\text { Grasvergleiches }\end{array}$ \\
\hline 6 & $\begin{array}{l}\text { Fortsetzung des Vergleichs zwischen Menschenleben und Gras, das an einem } \\
\text { Tag blüht und welkt }\end{array}$ \\
\hline
\end{tabular}

\subsubsection{Zeiterfahrungen}

Der Blick auf das göttliche Du - das, wie bereits erwähnt, in 1b.2c durch אַ אָ verstärkt wird - bestimmt damit den ersten Gedankenspot. Diesem göttlichen $\mathrm{Du}$ wird in V3 ein eigener Sprechakt zugewiesen. Der Blick ist eingebettet in eine Vielzahl von Zeitbegriffen, wodurch sich dieser erste Gedankenspot durch eine Dichte an Temporaldeixis auszeichnet. Zehn verschiedene Zeitbegriffe werden in V1-6 genannt: Wird mit פִּד וְדר (von Generation zu Generation) in 1b der Blick auf die geschichtliche Heilserfahrung gelenkt, so ist mit טֶרֶם (bevor 2a) festzuhalten, »dass der Blick immer weiter zurückschweift bis zur Weltschöpfung und

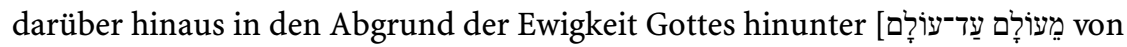
Ewigkeit zu Ewigkeit 2c]. Der Blick wollte die Heilserfahrung in der Geschichte fixieren, aber nun ist es, als wäre er ausgeglitten. $"{ }^{1105}$ Von den mit der Gottheit in Verbindung stehenden Zeitdimensionen wird mit den folgenden Zeitbegriffen auf menschlich erfassbare Zeiträume verwiesen: אֶלֶף שָׁנִים (tausend Jahre 4a); יוֹם

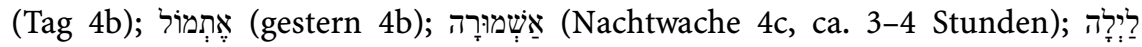

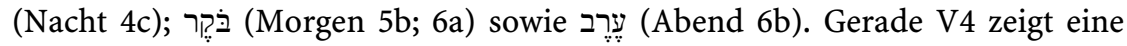

1104 Davon sprechen auch Alonso Schökel / Carniti, Salmos 2, 1177.

1105 Von Rad, Der 90. Psalm, 272. 
Linearität der Zeitdimensionen, die von tausend Jahren über den Tag gestern bis zu den wenigen Stunden einer Nachtwache führt. Innerhalb eines einzigen Verses (V4) sind sowohl die längste (tausend Jahre) als auch die kürzeste (Nachtwache $=$ ca. 3 Stunden) Zeitangabe im AT benannt, die Menschen zugeordnet wird. Dabei stehen diese zeitdeiktischen Ausdrücke jeweils in der Subjektposition. Eine temporale Reihe lässt sich auch in $4 \mathrm{~b}-6 \mathrm{~b}$ erkennen. Sie führt vom gestrigen Tag über die Nacht zum Morgen und schlussendlich zum Abend. Schon hier eröffnet sich jener Horizont, der die Lesenden in Form einer Zeitreise zum Mitgehen mit den Bewegungen und Dynamiken des Textes und dadurch zur Identifikation einlädt.

In den weiteren Versen werden jene Zeiträume erwähnt, die mit Gottes Wirken verbunden sind: von Generation zu Generation, bevor (die Schöpfung entstand), von Ewigkeit zu Ewigkeit. Die Zeitangabe "von Generation zu Generation «1106 bezeichnet dabei die auf Menschen bezogene, von Menschen noch überschaubare geschichtliche Dimension der Zeit, während die Zeitangabe "von Ewigkeit zu Ewigkeit" komplementär dazu die von Menschen nicht mehr fassbare, auBerhalb der Geschichte stehende Dimension fernster Zeit bezeichnet, welche die Existenz Gottes beschreibt. ${ }^{107}$

Die Zeitangaben in diesem ersten Gedankenspot bringen die Unterschiedenheit zwischen göttlicher und menschlicher Dimension nicht nur in der quantitativen Erfahrung von Zeit zur Sprache, sondern besitzen auch eine qualitative Seite: Gott ist ewig, das Vergehen der Zeit, das unaufhaltsam ist, berührt die Gottheit in keinster Weise, die Menschen allerdings schon. Das Vergehen der Zeit wirkt auf die Menschen bedrohlich. ${ }^{1108}$

\subsubsection{Räume und Handlungen}

Die bereits genannten Räume in diesem ersten Gedankenspot sind מָעוֹ (Wohn-

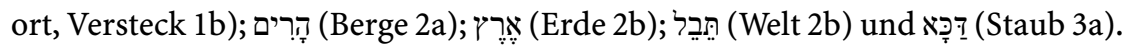
Hier zeigt sich einerseits die Dimension des Festen, der Stabilität und des Bestandes, die durch Berge, Erde und Erdkreis sowie durch den Wohnort gegeben ist, andererseits aber auch die Dimension des Nicht-Festgefügten, die dem Staub als Zermalmtem inhärent ist.

Hinsichtlich der Analyse der Subjekte, Handlungen und Objekte ist kein wesentlicher Ertrag auszumachen. Daher wird an dieser Stelle auf eine Tabelle (Subjekt - Handlungen - Objekt) verzichtet, wie sie der Analyse von Ps 30 und Ps 147 beigefügt wurde. Es zeigt sich, dass die Anwendung dieser narratologischen

1106 Die Zeitspanne »von Generation zu Generation« wird in den Psalmen in Bezug auf eine göttliche Eigenschaft, Tätigkeit oder Existenz verwendet. Vgl. Ps 33,11; 85,6; 100,5; 102,13; 102,$25 ; 119,90 ; 145,13 ; 146,10$.

1107 Vgl. Forster, Begrenztes Leben, 146.

1108 Vgl. Forster, Begrenztes Leben, 177. 
Analysekategorie bei der Betrachtung eines weisheitlich geprägten Gebetes, das hauptsächlich Reflexionen über Gott, die Vergänglichkeit und Mühsal des Menschenlebens sowie die Bitte um Bestand der Arbeit zum Inhalt hat, an ihre Grenzen stößt. Einzig die Zuschreibung der Verben zu Gott (היה q. sein 1b; ילד q.

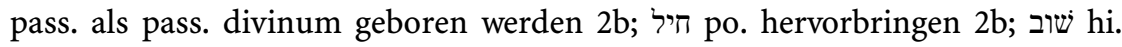
zurückkehren lassen 3a; אמר q. sagen 3b; זרם q. hinwegraffen 5a) und zum Gras bzw. den Menschen (היה q. sein 5a; חלף q. aufsprossen, vorbeigehen 5b.6a; צוץ q צוץ q. blühen 6a; מלל po. welken 6b; יבש q. verdorren 6b) zeigen deutlich den Unterschied zwischen der Aktivität und Aktionsmacht Gottes, der Leben und Tod in der Hand hält, und der Abhängigkeit der Menschen vom göttlichen Handeln. Darüber hinaus wird der Kreislauf des Wachsens und Gedeihens sowie des Welkens und Verdorrens, dem sowohl das Gras als auch die Menschen unterworfen sind, deutlich sichtbar.

\subsubsection{3 Übergänge}

Hinsichtlich der Textdynamik fällt auch auf, dass der Text Übergänge aufweist, die ein Hinausfallen aus dem Leseprozess verhindern. Diese sind in Ps 90 vorhanden, aber subtil in den Text hineinverwoben, sodass sie nicht sofort ins Auge fallen. Die Übergänge werden ebenso durch Verbformen wie durch Konjunktionen und Wiederholungen gestaltet. Am Beginn des Psalms wird durch die beiden Gottesbezeichnungen »Elohim» (1a) und »Adonaj« (1b) eine Verbindung in V1 geschaffen. Es geht also um Gott und dessen Wirken und Handlungen, die beginnend mit 2a zur Darstellung gelangen. Das Personalpronomen אַתָּ (du) aus $1 \mathrm{~b}$ wird in $2 \mathrm{c}$ wieder aufgenommen. $2 \mathrm{a}$.b ist durch die W-PK-Form in $2 \mathrm{~b}$ (unter Wehen hervorbringen), welche die SK-Form (geboren werden) aus 2a fortführt, miteinander verbunden, 2b.c durch die Konjunktion ?: Das Du (אָתָה) Gottes von V1.2 wird in V3 mit den beiden Verbformen in der 2.P.sg. PK bzw. W-PK fortgeführt (du lässt zurückkehren; und du sprachst). V3 ist in sich durch die W-PK verbunden.

Mit dem emphatischen (ִ̣ (ja, fürwahr) in V4 ist zwar auf formaler Ebene ein Neueinsatz markiert, inhaltlich geht das Zeitthema jedoch weiter und erstreckt sich auf V5-6, indem die verschiedenen Zeitangaben weitergeführt werden: von tausend Jahren in V4 über einen Tag gestern und die Nachtwache bis hin zum Morgen und zum Abend in V6. Das Thema der Nacht aus 4c erfährt in 5a mit der Erwähnung des Schlafes eine Fortsetzung bzw. eine Nuancierung. Sowohl die Nacht als auch der Schlaf können als Metaphern des Todes betrachtet werden. 5b und 6a sind sowohl formal durch die Wiederaufnahme derselben Zeitangabe (חלף (חלף am Mechseln, wachsen, aufsprossen) miteinander verbunden als auch durch die Vergänglichkeitsthematik, mit deren Beschreibung in V5 begonnen wird und die in V6 endet. V6 ergibt in sich eine Inklusion (am Morgen - zum Abend hin). 
Sowohl in formaler als auch in inhaltlicher Hinsicht konnten somit Verbindungslinien zwischen den einzelnen Versen sowie die Kohärenz innerhalb der Verse aufgezeigt werden, die die Lesenden in der Textdynamik halten und ein Hinausfallen aus der Textwelt verhindern.

\subsubsection{Parallelismen}

Ebenso ausschlaggebend für das Dranbleiben am Text kann die Zeit sein, die Lesende für die Imagination der Textwelt aufwenden (müssen). Wie bereits in den Analysen von Ps 30 und 147, so ist auch hier ein Blick auf die Parallelismen zu werfen, denn diese sind maßgeblich dafür verantwortlich, dass Lesende die darin ausgedrückten Gedanken von mehreren Seiten beleuchten können, wodurch die Lesezeit entschleunigt und verlangsamt wird. In V1 ist kein Parallelismus auszumachen. V2 ist dann erstmalig parallel gestaltet und wird sowohl als synonymer als auch als synthetischer Parallelismus klassifiziert. ${ }^{1109}$ Wird in 2a noch in einer passiven Formulierung von der Geburt der Berge gesprochen, so wird diese Geburtsmetaphorik in $2 \mathrm{~b}$ weitergeführt, konkretisiert und verstärkt. Dies geschieht, indem ein Subjekt - entweder das göttliche Du oder die Erde - konkret benannt wird und mit der Wurzel חיל n nach 2a das Unter-Wehen-Hervorbringen bzw. Kreißen eine Intensivierung des Geburtsvorgangs darstellt. Es kommt damit $\mathrm{zu}$ einer Steigerung von einer passiven Formulierung $\mathrm{zu}$ einer aktiven. 2c nimmt die Idee der Existenz Gottes vor der Schöpfung (2a) nochmals auf und führt diese Urzeitdimension weiter, indem jener Zeitraum genannt wird, in dem Gott wirkt (von Ewigkeit zu Ewigkeit). V3 ist m. E. als synonymer Parallelismus zu verstehen. ${ }^{1110}$ Beide Sätze (3a.b) sind in der 2.P.m.sg. gestaltet; die

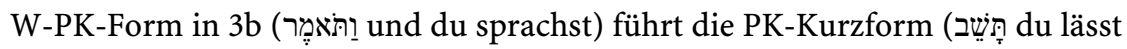
zurückkehren) aus 3a weiter. Die Wurzel שוב wird in beiden Sätzen verwendet. Inhaltlich wird jedes Mal die Vergänglichkeit des Menschen und dessen Rückkehr zum Staub sowie die Abhängigkeit des Menschen von Gott thematisiert und die Todesmetaphorik damit intensiviert. Es kommt auch zu einer Steigerung der Dramatik, da 3b eine erlebte Rede Gottes darstellt, in der die Gottheit die Menschenkinder direkt anspricht. V4 ist synthetisch gestaltet. Der Gedanke der Unterschiedlichkeit der Zeitdimensionen Gottes und der Menschen wird entfaltet und aufgefächert. Dabei beginnt die Ausführung mit dem längsten in der Bibel genannten Zeitraum von tausend Jahren (4a) und endet nach dem gestrigen Tag in $4 \mathrm{~b}$ mit dem kürzesten Zeitraum, der drei bis vier Stunden dauernden

1109 Der dreigliedrige Vers bildet laut Forster, Begrenztes Leben, 147 mit seinen ersten beiden Gliedern einen synonymen Parallelismus.

1110 Ebenso u. a. Müller, Der 90. Psalm, 271 und Von Rad, Der 90. Psalm, 273. V3 kann, wie die Vers-für-Vers-Analyse gezeigt hat, auch als synthetischer Parallelismus gelten. In dieser Deutung ist $3 \mathrm{~b}$ eine Fortsetzung von 3a. Gott lässt in 3a eine Generation sterben und ruft in 3 b die nächste ins Leben. Vgl. Gillmayr-Bucher, Die Psalmen, 248. 
Nachtwache (4c). V5 ist kein Parallelismus. Nach dem schwer verständlichen Teilvers 5a, der als kleinster gemeinsamer Nenner von einer heftigen Handlung Gottes, dem Hinwegschwemmen bzw. Hinwegraffen sowie von der Passivität der Menschen, ausgedrückt durch das Substantiv שָנָ (Schlaf, Traum), spricht - das Hinwegschwemmen und der Schlaf werden auch als Bild für den Tod des Menschen gedeutet -, wird in 5b die Grasmetaphorik eingeführt. Die Menschen werden in $5 \mathrm{~b}$ mit Gras verglichen, das morgens wächst. Dieser Teilvers kann zunächst noch positiv verstanden werden. $5 \mathrm{~b}$ wird in $6 \mathrm{a}$ weitergeführt (siehe Übergänge). V6 ist grammatikalisch gleichmäßig aufgebaut, semantisch allerdings antithetisch gestaltet. ${ }^{1111}$ Erzählt $6 \mathrm{a}$ analog zu 5b vom Vergleich zwischen dem Menschen und dem Gras, das morgens wächst und aufblüht, so ist in $6 \mathrm{~b}$ davon die Rede, dass das Gras bis zum Abend hin welkt, bis es schließlich ganz verdorrt. In V6 zeigt sich also der Kreislauf des Lebens mit dem Gegensatz zwischen dem Wachsen und Aufblühen am Beginn bzw. in Zeiten des Heils - בֶקר (Morgen) steht im AT auch für die Zeit der Freude und des Heils - und dem Verwelken, Sterben und Verdorren zum Abend, also dem Ende hin. Wie die bereits analysierten Kontraste in Ps 30 und Ps 147 lädt auch diese Darstellungsweise der Bipolarität in Ps 90 die Lesenden besonders dazu ein, die Wege zwischen den beiden Polen, zwischen denen sich das Leben abspielt, selbst mit Leben $\mathrm{zu}$ füllen.

Bis auf V1.5 weist jeder Vers einen Parallelismus auf. Durch die fein verwobenen Übergänge, die synonymen und synthetischen Parallelismen, die die Themen und Gedanken des ersten Gedankenspots konkretisieren, intensivieren, steigern und verstärken, sowie durch die räumliche Bewegung und vor allem durch die Zeitreise, die in diesem ersten Gedankenspot beginnt, werden die Lesenden im Lesefluss gehalten und insofern zur Identifikation eingeladen. Inhaltlich stellen die Themen der Vergänglichkeit und Flüchtigkeit des Menschen, die Zeitdimension Gottes im Vergleich zu jener des Menschen sowie das in Gott geäußerte Vertrauen als Wohn- und Zufluchtsort aufgrund ihrer Möglichkeit zur Analogiebildung und ihrer Aktualität ein weiteres Identifikationspotenzial dar.

\subsubsection{Zweiter Gedankenspot V7-12}

Das Thema der Vergänglichkeit und Flüchtigkeit des Menschenlebens, ausgedrückt in Dimensionen der Zeit, wird im zweiten Gedankenspot wieder aufgenommen und durch die Themen der menschlichen Schuld sowie des Zornes Gottes erweitert und vertieft. Damit könnte die Deutung des durchgehend in der SK gehaltenen Gedankenspots - einzige Ausnahmen bilden die W-PK in 10d und

1111 Vgl. Schnocks, Vergänglichkeit, 83. Anders Forster, Begrenztes Leben, 148, die V6 als synonymen Parallelismus bezeichnet. 
die PK in $12 \mathrm{~b}$ - als beschreibende Gegenwart beibehalten werden. ${ }^{1112}$ Viele sehen allerdings die SK-Formen als Ausdruck einer in der Vergangenheit geschehenen und durch das lyrische Wir erlittenen Notsituation. In welcher Zeitform die SK in V7-12 auch immer wiedergegeben werden, die SK-Formen bewirken bzw. suggerieren, dass es sich im zweiten Gedankengang um eine bestimmte Notlage handelt, unterstrichen durch die Tatsache der Rede in der Wir-Du-Perspektive (und nicht etwa in der 3.P.). Herrscht also in V1-6 die abstrakte und allgemeine Rede von der Zeit Gottes im Kontrast zu jener des Menschen vor, so in V7-12 nun die individuelle Rede von der Zeit bzw. vom Zorn Gottes und von der Zeit des Menschen. Die Darstellungsweise der Thematik mittels dieser konkreten Rede, ausgedrückt und eingebettet in die Wir-Du-Perspektive und in eine Reihe von SK-Formen, veranlasst den Rückschluss auf eine etwaige konkrete Notsituation.

Auffallend ist außerdem, dass mit V7 nicht nur durch das empathische eị Neueinsatz markiert ist, sondern dass das lyrische Wir - das gegen Ende des ersten Gedankenspots hinter den allgemeinen, in der 3.P. gehaltenen Formulierungen über die Menschen und ihre Vergänglichkeit zurückgetreten ist - nun wieder in den Vordergrund rückt. Der zweite Gedankenspot ist geprägt durch die Wir-Du-Perspektive, in die hinein die eben genannten Themen in Form von Klage, Anklage, Frage und Bitte verwoben zur Darstellung gebracht werden. Diese Themen lassen sich folgendermaßen benennen:

\begin{tabular}{|l|l|}
\hline Vers & Thema \\
\hline 7 & lyr. Wir wird durch Gottes Zorn verstört \\
\hline 8 & Gott sieht die Schuld des lyr. Wir \\
\hline 9 & Lebenszeit des lyr. Wir wird durch Gottes Zorn beendet \\
\hline 10 & $\begin{array}{l}\text { Lebenszeit des lyr. Wir kann bis zu } 80 \text { Jahre sein, wird aber als mühsam und } \\
\text { kurzlebig empfunden und plötzlich beendet }\end{array}$ \\
\hline 11 & Frage, die die Kraft des Zornes Gottes thematisiert \\
\hline 12 & Bitte an Gott, Lebensklugheit im Umgang mit der Lebenszeit zu erlangen \\
\hline
\end{tabular}

Die Thematik der Vergänglichkeit des Menschen wird - wie in der Tabelle ersichtlich - um jene der Schuld des Menschen und des Zornes Gottes erweitert. Wie bereits im ersten Gedankenspot sind diese Themen mit der Zeitthematik ver-

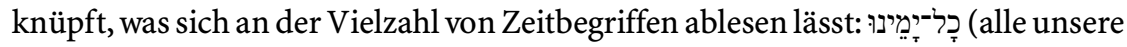

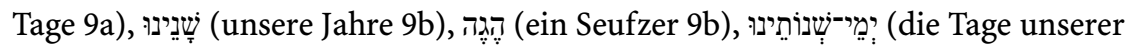

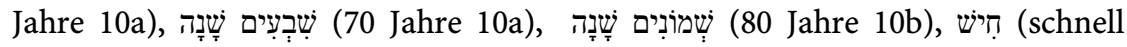
10d), יָינינוּ (unsere Tage 12a).

In Bezug auf die Räume ist einzig und allein das »Licht deines Angesichts « $\mathrm{zu}$ nennen, auch wenn dies eher als Begegnungsraum zu betrachten ist als ein Lo-

1112 So z. B. Michel, Tempora, 21: „Die perfa. bezeichnen gegenwärtige Fakten.« 
kalobjekt im klassisch-grammatikalischen Sinn. Das Herz wird in V12 als Ort der Weisheit thematisiert, ist allerdings auch keine klassische Raumangabe; es steht dort außerdem in Akkusativobjektposition und gilt damit nicht als Lokalobjekt. Der zweite Gedankenspot spannt also die Thematik der menschlichen Lebenszeit, die nicht an (konkrete) Räume gebunden ist, weiter.

\subsubsection{1 Übergänge}

Betrachtet man die Übergänge von V7-12, so ist 7a mit 7b durch die Thematik des

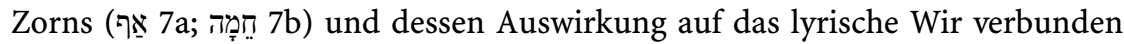
(כלה vergehen, beenden 7a; בהל vert werden 7b) sowie durch die Konjunktion ?. Zwischen V7 und 8 gibt es auf den ersten Blick keinen offensichtlichen Übergang. Mit V8 wird das neue Thema der Schuld eingeführt. Die mit dem Suffix der 2.P.sg. formulierten Objekte aus V7 (durch deinen Zorn; durch deine Wut) werden in V8 (vor dich hin; ins Licht deines Angesichts) fortgesetzt, wodurch auf den zweiten Blick dann doch eine Verknüpfung auszumachen ist. 8a ist durch die synonyme Satzgestaltung und parallele Konstruktion mit $8 \mathrm{~b}$ verbunden. Zudem wirkt das Verb aus $8 \mathrm{a}$ auch in $8 \mathrm{~b}$ weiter. Das emphatische markiert am Beginn von V9 zwar einen Neueinsatz, die Zornesthematik aus V7 wird aber ebenso aufgenommen wie die Wurzel כלה (vergehen 7a.9b) und das deiktische Element כִ̣. V7.9.11 sind durch die Begriffe, die den göttlichen Zorn beschreiben, eng miteinander verknüpft. 9a führt mit dem Suffix in der 2.P.sg. ein Objekt an (durch deinen überwallenden Zorn), das bereits in V7.8 in derselben grammatikalischen Konstruktion genannt wurde. Offensichtlicher ist der Übergang von V9 zu V10: Der Zeitbegriff »Tag« (יוֹ pl. 9a.10a) wird ebenso wieder aufgenommen wie "Jahr« (שָָָׁ pl. 9b.10a). V10 ist in sich ebenso durch die Steigerung der Anzahl der Jahre (von 70 auf 80 ) sowie durch die inhaltliche Ausfaltung des Themas der Mühe des Arbeitsalltags und der empfundenen Kurzlebigkeit des menschlichen Lebens verbunden wie durch eine Vielzahl von Konjunktionen. Mit dem Fragewort מִ in 11a beginnt ein Neueinsatz; das Thema des Zornes aus V7.9 wird hier allerdings wieder aufgegriffen und durch die Entfaltung der Begrifflichkeit intensiviert (Kraft deines Zornes; Furcht; überwallender Zorn). V11 kann dabei sowohl als Abschluss der Klage von V1-10 als auch als Überleitung zur Bitte in V12 verstanden werden. ${ }^{1113}$ 11a.b sind durch die Konjunktion ? miteinander verbunden. Mit V12 kommen neue Themen ins Spiel: Es finden sich ein erster Imperativ sowie Infinitiv und auch das Thema der weisheitlichen Lebensgestaltung angesichts der abzählbaren Tage des menschlichen Lebens. Dies alles leitet zum zweiten Teil des Psalms über, denn V11.12 werden ja als Scharnierverse bezeichnet. Das Thema der Zeit ist allerdings in V12 wie bereits davor in V1-11 und danach in V13-16 ein zentrales. Der zeitdeiktische Ausdruck »unsere

1113 Vgl. Forster, Begrenztes Leben, 149. 
Tage« wird aus V9 wieder aufgenommen. Die Wurzel ידע (q. kennen 11a; hi. lehren 12a) verbindet V11 mit V12. Die Übergänge sind in diesem zweiten Gedankenspot durch den Inhalt und die ähnlichen grammatikalischen Konstruktionen fein gestaltet. Abrupte Einschnitte, die ein Hinausfallen aus dem Leseprozess verursachen könnten, sind nicht auszumachen.

\subsubsection{Verben}

Für die Textdynamik und das Mitgehen mit der erzählenden Stimme des Textes sind neben den Kategorien von Raum und Zeit sowie den Übergängen auch die Verben und deren Einbettung in die jeweiligen Subjekt- und Objektpositionen interessant. Bei der Zuordnung der Verben zeigt sich, dass trotz der Notlage, die als Zorn, Grimm und überwallender Zorn Gottes über das lyrische Wir hereinbricht, dieses Wir mit Ausnahme von 8a.9a.12a immer in eine Subjektposition gestellt wird. Die dem lyrischen Wir zugeschriebenen Handlungen sind folgende: כלה (vergehen, beenden 2x), בהל (verstört werden), עוף (verfliegen) sowie בוא hi. (erlangen). Im Vergleich dazu ist Gott nur zwei Mal in Subjektposition zu finden (V8 mit einem Verb). Das lyrische Wir behält also die Aktivpositionen und bleibt handlungsfähig. Es wird weder als passiv beschrieben noch durch Objektpositionen »hinuntergedrückt «, auch wenn es sich in einer Notsituation befindet. Es kann den Kopf oben lassen. Die Beschreibung dieser extremen Lage könnte beispielsweise auch lauten: „Dein Zorn hat uns dahingerafft." Hier wäre das lyrische Wir in der Objektposition. Ps 90 ist aber nicht in dieser Form gestaltet. Das lyrische Wir bleibt in der Subjektposition; allerdings stellt sich aufgrund der Semantik der dem lyrischen Wir zugeordneten Verben (vergehen, verstört werden, verfliegen, erlangen) die Frage, inwieweit es die Handlungen bewusst aktiv setzen kann oder aber diesen nicht eher ausgeliefert ist.

Hinsichtlich der Verbformen fällt auf, dass in V11 das einzige Partizip des Textes zu finden ist. Dieses Partizip holt aufgrund seines Aspekts der Gleichzeitigkeit und aufgrund der Kombination mit einer rhetorischen Frage (die Interrogativpartikel gilt als deiktisches Element) die Lesenden näher an den Text. Sind in V1-10 Formen in der SK und PK vorherrschend, so geht mit V11 ein Umschwung der Verbformen einher, der sich im zweiten Teil des Psalms (V1317) durch eine Anhäufung von Imperativformen auszeichnet. ${ }^{1114}$ V11.12 fallen demnach durch ihre Verbformen ins Auge. Ist in V11 das einzige Partizip zu finden, so in V12 die einzige Infinitivform (inf. constr.) in betonter Anfangsstellung.

1114 Vgl. Schnocks, Vergänglichkeit, 119. 


\subsubsection{Parallelismen}

Schlussendlich ist wiederum darauf zu achten, wieviel Zeit den Lesenden bei der Betrachtung von Ps 90 zur Verfügung steht. Zu diesem Zweck ist wiederum zu fragen, ob - und wenn ja, in welcher Form - Parallelismen vorhanden sind und wie diese ggf. den jeweiligen Gedanken des Verses gestalten und ausdifferenzieren. V7 ist als synonymer Parallelismus zu benennen. Der Vers ist chiastisch gestaltet und drückt die Irritation der Menschen angesichts einer Erfahrung aus, die sie dem göttlichen Zorn zuschreiben. Dabei wird diese Erfahrung durchweg in einer Dramatik geschildert, die bis hin zur Zerstörung reicht. Beide Versteile

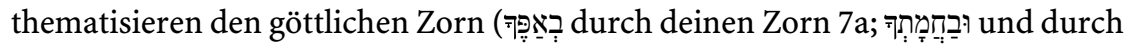

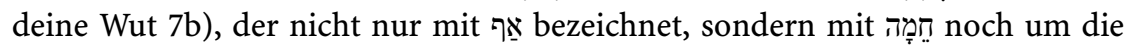
Dimension der Hitze und der inneren Zornesglut erweitert wird. Ebenso synonym ist $\mathrm{m}$. E. V8 gestaltet. Allerdings wird hier überlegt, $8 \mathrm{a}$ als negativ und $8 \mathrm{~b}$ als positiv zu betrachten. Dann würde $8 \mathrm{~b}$ die verborgenen Sünden vor Gottes Angesicht als Zeichen der Nähe und Zuwendung Gottes zum Menschen thematisieren. Gott nähme die Schuld und Ungerechtigkeiten sowie das Verborgene wahr und an. Da aber sonst im AT vom Verborgenen vor JHWH nicht gerade im positiven Sinne die Rede ist (Lev 5,2.3; Koh 12,14), deute ich V8 als synonymen Parallelismus, der das Thema der menschlichen Schuld im Angesicht Gottes zwei Mal thematisiert. ${ }^{1115}$ Das Verb aus 8a wird dabei in $8 \mathrm{~b}$ versteckt wiederholt, indem es elliptisch verwendet wird. Vor Gott ist die menschliche Schuld niemals unsichtbar, selbst wenn sie im Verborgenen geschieht. ${ }^{1116}$

V9 ist als synthetischer Parallelismus gestaltet. Das Thema des Dahinschwindens der Tage durch den überwallenden Zorn Gottes aus 9a wird in 9b zum Beenden der Jahre hin weitergeführt, das wie ein Seufzer erlebt wird, der - kaum hörbar - schnell vergeht. Vom Subjekt »unsere Tage« und dem Objekt des göttlichen Zorns in 9a wechselt der Blick in 9b auf das lyrische Wir als Subjekt und den Zeitbegriff »unsere Jahre« in Objektposition. Mit dem Vergleich »wie ein Seufzer« wird ein Sprachbild verwendet. Die Zeitdimension (9a Tage) wird in 9b erweitert (Jahre), am Versende jedoch mittels des Vergleichs drastisch verkürzt. Es kommt damit zunächst zu einer Erweiterung der Zeitthematik, dann aber zu einer Verkürzung. V10 gilt ebenso als synthetischer Parallelismus. Jeder Teilvers führt den Gedanken des vorhergehenden weiter. 10a beginnt mit der Lebensdauer von 70 Jahren. Diese wird in $10 \mathrm{~b}$ auf 80 verlängert, wenn die Menschen bei Kraft und Gesundheit sind. 10c bringt mit der Bewertung des Erlebens dieser Lebensdauer - nämlich als anstrengend und auch unheilvoll - die Dimension des

1115 Anders Von Rad, Der 90. Psalm, 273, der V8 als synthetischen Parallelismus bezeichnet.

1116 Gott bringt die Ungerechtigkeiten ans Tageslicht, sodass vielleicht auch die Menschen den Mut haben, diese in der Begegnung mit Gott anzuschauen, mit ihnen umzugehen und sie nicht unter der Decke zu halten. 
subjektiven Zeitempfindens des lyrischen Wir hinzu. Neben der Mühe und Anstrengung nennt nun 10d einen weiteren Aspekt, nämlich das Erleben der Flüchtigkeit. Auch wenn das Alter von 80 Lebensjahren erreicht wird, gehen diese Jahre so schnell vorbei, als ob ein Vogel wegflöge. In V10 sind damit eine Steigerung der Thematik sowie eine Intensivierung auszumachen. V11 ist als synthetischer Parallelismus zu kennzeichnen. ${ }^{117}$ Das Thema der Kraft des Zornes aus 11a wird in $11 \mathrm{~b}$ ebenso um die Dimension der Furcht erweitert wie durch die Nennung von עֶבְרָה (überwallender Zorn; siehe bereits 9a). Dies ist ein Begriff, der vor allem das Unkontrollierbare und Affektvolle im Zorneshandeln Gottes benennt. V12 ist wie V11 synthetisch gestaltet. 12b ist als Folge und Konsequenz aus 12a formuliert: Gott wird darum gebeten, dass das lyrische Wir von ihm gelehrt wird, die Tage zu zählen (12a). Erst dann und infolgedessen ist das Erhalten eines weisen Herzens möglich (12b). Hier wird Gott m. E. gebeten, Folgendes zu lehren: Im Wissen um die (kurze) Dauer der Lebenszeit soll man die Tage nutzen bzw. sich die Begrenztheit (und nicht Unendlichkeit) des Lebens bewusst machen, nach dem Motto: Jeder Tag zählt! ${ }^{111}$ Daraus folgt, ganz im Sinne der weisheitlichen Reflexion, das Erhalten eines Herzens voller Weisheit, eines Verstandesoder Vernunftherzens also, das um die rechte Lebensführung und praktische Lebensklugheit weiß.

Das Wortfeld des Zornes Gottes ist in V7-11 dominierend. Fünf Mal wird der göttliche Zorn thematisiert, und flankiert wird er von der Rede über die menschliche Schuld und über die Mühsal des Menschenlebens; dieses wird auch bei entsprechend langer Dauer als kurz sowie voll von Anstrengung und Unheil empfunden und erlebt. Eingebettet ist die Zornesthematik in die Nennung unterschiedlicher Zeitangaben.

\subsubsection{Dritter und vierter Gedankenspot V13-17}

Der zweite Teil des Psalms (V13-17) hat die Bitte um positive Füllung der begrenzten Lebenszeit sowie um Bestand der menschlichen Arbeit zum Inhalt und kann thematisch wiederum in zwei Gedankenspots (V13-15; V16-17) eingeteilt werden. V13-15 sprechen von der Zuwendung Gottes und von der Sättigung mit Freude sowie der ausgleichenden Gerechtigkeit zur Zeit des Leidens. V16-17 rücken das (Heils-) Handeln JHWHs für das Volk und dessen Nachkommen sowie die Förderung der menschlichen Arbeit durch Gott in den Mittelpunkt. Da

1117 Schnocks, Vergänglichkeit, 101 betrachtet V11 als synonymen Parallelismus mit sequentiellen Anteilen. $\mathrm{Zu}$ dieser Art von Parallelismus vgl. Schnocks, Psalmen, 14f. Forster, Begrenztes Leben, 144 sieht in V11 keinen wirklichen Parallelismus.

1118 Ähnlich Zenger, Werk, 27 und ders., Morgenröte, $210 \mathrm{f}$. 
die beiden Gedankenspots sowohl inhaltlich als auch grammatikalisch miteinander verzahnt sind, werden sie gemeinsam analysiert.

Die Themen aus Teil II des Psalms bzw. aus dem dritten und vierten Gedankenspot sind folgende:

\begin{tabular}{|l|l|}
\hline Vers & Thema \\
\hline 13 & $\begin{array}{l}\text { Aufforderung an JHWH zur Umkehr und zur Zuwendung an seine Knechte } \\
\text { inkl. Frage nach der Dauer der Leidenssituation }\end{array}$ \\
\hline 14 & $\begin{array}{l}\text { Bitte um Sättigung durch die Güte Gottes, damit verbleibendes Leben in Jubel } \\
\text { und Freude möglich wird }\end{array}$ \\
\hline 15 & Bitte um ebenso viel Freude wie einst erlittenes Leid \\
\hline 16 & $\begin{array}{l}\text { Wunsch nach Sichtbarwerden der Pracht Gottes für Volk und Nachkommen- } \\
\text { schaft }\end{array}$ \\
\hline 17 & $\begin{array}{l}\text { Doppelter Wunsch um Wahrnehmbarkeit der Anmut Gottes und um Bestand } \\
\text { des Menschenwerkes durch göttliche Förderung }\end{array}$ \\
\hline
\end{tabular}

Atmosphärisch ist dieser zweite Teil des Psalms von Freude und Hoffnung getragen, auch wenn die in den Bitten formulierten hoffungsvollen Aspekte noch nicht in die Tat umgesetzt sind. Beginnend mit dem ersten Imperativ in V12 verbleibt der Psalm in der Situation der Bitte. In dieser endet er auch, und nicht etwa mit einem Lob über die bereits erfahrene Güte und Zuwendung Gottes.

Auffallend ist der starke Schluss des Psalms. Anfang und Schluss eines lyrischen Textes sind ja entscheidend für die Stimmung, die sich auch auf das Identifikationspotenzial auswirkt (vgl. dazu auch VII Textanalyse Psalm 64). So ist es nicht unwesentlich, wie ein poetischer Text endet und was am Schluss betont wird; dies schwingt nämlich weiter und prägt sich den Lesenden stärker ein als etwa der Mittelteil eines Gedichts. Der fast wortgleich wiederholte Satz in 17b.c zeugt von der Dringlichkeit der Bitte, dass angesichts der in Teil I geschilderten Vergänglichkeit und Flüchtigkeit des menschlichen Lebens, das mit einer Ablaufzeit versehen ist, doch wenigstens die Werke, das Tun der Hände Bestand haben mögen. Dieser Bestand kann nur durch die Gottheit bewirkt werden.

Hinsichtlich der Textdynamik wird der 2. Teil durch eine Kette von Imperativen zusammengehalten, die bereits im Scharniervers V12 beginnt und sich in 13a.13b.14a.15a.17b.17c fortsetzt. Die Imperative tragen auch zur zeitlichen Gestaltung des zweiten Teiles bei, wie unten erörtert werden wird. Auffallend ist, dass die Kette von Aufforderungen an JHWH in 16a.b.17a unterbrochen wird. Nun ist nicht mehr die Gottheit selbst das Subjekt des erwünschten Handelns, sondern deren Werk bzw. Handeln (16a) sowie deren Glanz (16b) und Anmut (17a). Im Psalmschluss 17b.c wird die Imperativ-Kette wieder aufgenommen. 
Bei der Analyse der Subjekt-Objekt-Konstellationen ist zunächst hinsichtlich der Subjektposition ${ }^{1119}$ eine Abwechslung zwischen dem lyrischen Wir (14b.15b) und dem göttlichen Du (15a) bzw. deinem Werk (16a), deinem Glanz (16) und der Freundlichkeit Gottes (17a) zu vermerken. Blickt man auf die Objektpositionen, fällt auf, dass im Gegensatz zum zweiten Gedankenspot (V7-12) nun das lyrische Wir häufig in der Objektposition zu finden ist. Es ist hier im zweiten Teil des Psalms als Objekt einerseits Empfänger positiver und heilsamer Gaben Gottes (Freude 15a; Freundlichkeit Adonajs 17a), andererseits wird im Rückblick auf den zweiten Gedankenspot auch auf die negative Dimension und das dort erzählte Unheil verwiesen (du hast uns gebeugt 15a).

\subsubsection{Verben}

Die Verben werden sowohl dem lyrischen Wir als auch dem göttlichen Du zugeordnet, wobei mit Ausnahme des Aussagesatzes in 15a alle mit dem göttlichen Du verbundenen Verben im Imperativ, Jussiv (17a) oder in PK-Form mit jussivischer Bedeutung (16a) stehen. Diese sind folgende: שוב qu (zü̈ckkehren bzw. umkehren 13a), נחם ni. (Mitleid haben 13b), שבע pi. (sättigen 14a), שמח pi. (erfreuen 15a), ענה pi. (beugen 15a), ראה ni. (sich sehen lassen 16a), היה q. (sein 17a), כון po. (Bestand verleihen, festigen 17b.c). Dem lyrischen Wir sind in diesem zweiten Teil des Psalms nur die drei Verben רנן pi. (jubeln, laut rufen 14b), שמון q שרח q (sich freuen 14b) und ראה q. (sehen 15b) zugeordnet, wobei שמח und ראה ebenso von der Gottheit eingefordert werden. Während also die Imperative dazu dienen, sich bittend an Gott zu wenden, drücken die dem lyrischen Wir zugeordneten

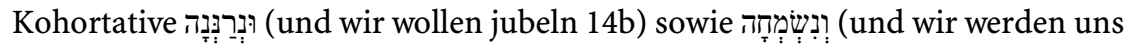
freuen 14b) in der PK + waw die jeweilige Folgehandlung und Konsequenz auf Seiten der Menschen bei Erfüllung der zugesprochenen Bitten aus. ${ }^{1120}$

Bemerkenswert ist die Häufigkeit, mit der Gott um seine Nähe und sein Handeln gebeten wird. Wie im gesamten Psalter, so wird auch hier von Gott in erster Linie die Zuwendung zu seinem Volk (zurückkehren/umkehren, Mitleid haben, sich sehen lassen, Güte, Anmut) eingefordert, die im ersten Teil des Psalms, vor allem in V7-12, als fehlend dargestellt und durch die Rede vom Zorn Gottes, die ja die Abwesenheit der Zuneigung Gottes thematisiert, verdunkelt wird. $^{1121}$

1119 Imperativsätze haben kein Subjekt.

1120 Vgl. Schnocks, Vergänglichkeit, 119.

$1121 \mathrm{Zu}$ den im Psalter an Gott gerichteten Wünschen und Bitten in Form von Imperativen vgl. Eder, »Neige, JHWH«. 


\subsubsection{Zeiten und Räume}

Wie bereits im ersten Teil des Psalms sind auch hier viele Zeitangaben zu fin-

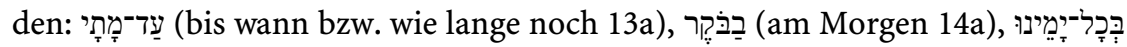

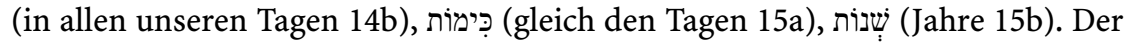
Morgen (5a.6a.14a), der Tag bzw. die Tage (4b.9a.10a.12a) sowie die Jahre (10a) werden aus dem ersten Teil wieder aufgegriffen. Der Abend und die Nacht kommen im zweiten Teil nicht mehr vor. Während also ab V14 die erzählten Inhalte mit Temporalobjekten versehen sind, kommen der Ausblick auf die Zukunft in V16 und die Bitte um Bestand der Arbeit in V17 ohne Zeitangaben aus und werden nicht temporal fixiert. Interessant ist die Beobachtung der Steigerung der Zeitangaben von Morgen und Tag in V14 auf Tag und Jahr in V15. V16 enthält zwar kein Temporalobjekt, lenkt aber mit בִּנִיהֶם (ihre Kinder) den Blick von der Zeiteinheit »Morgen«, »Tag« und »Jahr« aus V14.15 weiter auf die Zeiteinheit »Generation «. ${ }^{1122}$

Die oben genannten Imperative leiten zusammen mit dem Vokativ JHWH (13a) in die - zeitdeckende - direkte Rede über. Sie holen damit die Lesenden in die Gegenwart und sprechen von einer Jetzt-Situation aus. ${ }^{1123}$ Daneben fällt die Häufigkeit der PK-Formen auf, die bereits in 12b beginnen und nur in 15a.b durch zwei SK-Formen kurz unterbrochen werden. Der zweite Teil des Psalms spricht somit von einer Jetzt-Situation aus, lenkt den Blick nach vorne und richtet ihn - nach einem kurzen Rückblick - auf die Zukunft hin aus. »Damit gewinnt die seit dem Imperativ in v.12 durchgehaltene gedankliche Ausrichtung auf die Zukunft die Oberhand, und selbst die srückblickenden ২ Zeitausdrücke in v.15 sind in dieses fortschreitende Schema integriert. « ${ }^{1124}$ Die Tage der Demütigung und die Jahre des Leidens werden rückblickend erwähnt und scheinen somit in der gegenwärtigen Redesituation vorbei zu sein.

Mit Ausnahme der Angabe zur Sprechstimme עָלִינוּ (über uns 17a.b), worin neben der AdressatInnenangabe auch eine zeitliche Perspektive in Hinblick auf den Generationenwechsel beinhaltet ist, ${ }^{1125}$ werden keine Räume erwähnt. Die Bitten, Wünsche und Aufforderungen werden keinem exakten Raum zugeordnet und damit nicht lokalisiert.

\subsubsection{3 Übergänge}

In Bezug auf die Übergänge und Verbindungslinien im zweiten Teil sind neben den Imperativen und der Zeitenlenkung vom Jetzt in die Zukunft wiederum Verknüpfungen auszumachen. So werden V13.14 miteinander durch die Kon-

1122 Vgl. Schnocks, Vergänglichkeit, 111.

1123 »Der Begriff für das Hier und Heute fällt zwar nicht. Doch er ist in den Imperativen implizit enthalten.« Dies hält Seybold, Psalm 90, in Bezug auf den Abschnitt V13-15 fest.

1124 Schnocks, Vergänglichkeit, 111.

1125 Vgl. Schnocks, Vergänglichkeit, 114. 
junktion ?̣ verbunden. Das Thema der Freude schließt V14 eng mit V15 zusammen (שמח 14b.15a). Der Zeitbegriff »Tage« wird nicht nur aus 9a.10a.12a wieder aufgenommen, sondern dient als zusätzliche Nahtstelle zwischen V14 und 15 (יוֹם) pl. 14b.15a). V15 besteht aus zwei synonymen Halbversen (siehe Parallelismen). Die Wurzel ראה aus 15b wird am Beginn von 16a erneut aufgenommen und verbindet die beiden Verse miteinander. V16 schlägt mit עִ עִבְדָ (deine Knechte) den Bogen zurück zu 13b, wo diese Bezeichnung für das Volk bzw. das Wir des Textes erstmalig Erwähnung findet. Verbunden mit der Anrede JHWH, dem Eigennamen Gottes, wird damit die intensive persönliche Beziehung zwischen der Gottheit Israels und den ihr Zugehörigen bzw. Anvertrauten (Knechte, Diener; die dir zugeneigt sind BigS) zum Ausdruck gebracht. V16 ist abermals synonym gestaltet (siehe Parallelismen). V16.17 sind durch die Konjunktion ! in 17 a verbunden. Diese führt den in V16 geäußerten Gedanken des Sehen- und Wahrnehmenkönnens des Wirkens Gottes weiter mit der Bitte, es möge nun nach

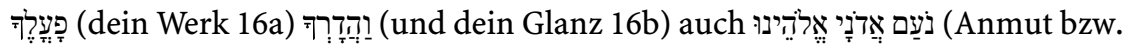
Lieblichkeit Adonajs, unseres Gottes) sichtbar werden. Mit der Gottesbezeichnung "Adonaj« wird der Beginn des Psalms eingespielt, wo in 1b Adonaj mit dem Gottesattribut Wohnort bzw. Versteck angesprochen wird. 17a.b werden durch die Weiterführung des Gedankenganges (siehe Parallelismen) ebenso verbunden wie durch die Konjunktion ? (17b) und die Präposition עַ mit Suffix in der 1.P.pl. 17b.c werden fast wortgleich wiederholt und ebenso durch die Konjunktion ? (17c) zusammengehalten. Damit konnten die Verbindungslinien zwischen den Versen und innerhalb der einzelnen Verse im zweiten Teil des Psalms herausgearbeitet werden. Sie sind sowohl auf der Ebene der Syntax als auch der Semantik zu finden und tragen dazu bei, dass die Lesenden im Textfluss gehalten werden. Zusätzlich zu den genannten Übergängen fällt im zweiten Teil des Psalms auf, dass auch klangliche Verbindungen auszumachen sind (V15.16; 17b.c). Damit nimmt die Klangfarbe von Psalm 90 sukzessive zu, und zudem wird der Psalm gegen Ende hin rhythmischer.

\subsubsection{Parallelismen}

$\mathrm{Zu}$ guter Letzt lädt die Analyse der Parallelismen ein, die differenzierte Gestaltung der darin geäußerten Gedanken im Hinblick auf die Möglichkeit der Entschleunigung des Leseprozesses und der LeserInnenidentifikation wahrzunehmen.

V13 ist als synthetischer Parallelismus zu betrachten, in dem eine Dreistufigkeit zu erkennen ist: Da ist zunächst (1) die Bitte an JHWH, er möge sich in eine andere Richtung bewegen (sich zuwenden bzw. sich vom Zorn abwenden bzw. seinen Zorn vom Volk abwenden), dann folgt (2) die Frage, wie lange das Volk noch leiden soll, und am Schluss (3) wird die Bitte um Zuwendung zu den Knechten geäußert. Die an JHWH adressierte Umkehrbitte wird daher um die Bitte um Zuwendung, 
Mitleid, Erbarmen und Trost erweitert. Hinzu kommt noch das Objekt, an das sich die göttliche Zuwendung richten soll. Es sind dies (עָבָדָיָ (deine Knechte), eine Spezifizierung und Konkretisierung der bis dato als Wir des Textes bezeichneten Gruppe. Diese versteht sich dementsprechend als besonders JHWH-treu. ${ }^{1126}$ V14 ist ebenso ein synthetischer Parallelismus. Auf die Bitte um Sättigung mit der Güte am Morgen folgt die überschwängliche Freude als Konsequenz (»wir werden/wollen jubeln«) sowie die Ausweitung hin auf einen weiten Zeitraum, eventuell bis ans Lebensende ("alle unsere Tage«). In V15 liegt ein synonymer Parallelismus vor. Der

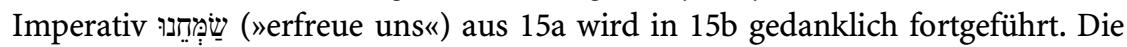
Phrase "gleich den Tagen, an denen du uns gebeugt hast « ist parallel zu "Jahre, in denen wir Unheil gesehen haben« aufzufassen. Beide Male geht es zuerst um das Erfreuen und dann in einem kurzen Rückblick um die Zeit der Not und des Leides. Hier wird auf den zweiten Gedankenspot (V7-12) zurückverwiesen. Inhaltlich drückt der Vers den Wunsch um die ausgleichende Gerechtigkeit für die Zeit der Not aus. In 15b erfolgt eine Ausweitung von »Tage" aus 15a in "Jahre» sowie ein Subjektwechsel (du 15a) zum lyrischen Wir. In 15a wird Gott für die Zeit des Unheils verantwortlich gemacht. Es ist auf alle Fälle nur die Gottheit selbst, die dem Volk nun Freude zuteil werden lassen und für ausgleichende Gerechtigkeit sorgen kann. V16 ist ein synthetischer Parallelismus. Die beiden Stichen drücken den Wunsch nach der Sichtbarkeit des Wirkens Gottes aus; das Werk Gottes aus 16a wird in 16b mit dem Glanz Gottes weitergeführt. Eine Ausweitung des Gedankens zeigt sich in 16b mit der Erwähnung der Nachkommenschaft: Während 16a das Handeln Gottes »an deinen Knechten« thematisiert, das gegenwärtig eintreten soll, führt dies 16b weiter mit Blick auf die Zukunft und בְּנִיהֶם (ihre Söhne/Kinder). Damit ist eine Steigerung mit einer neuen Variante (Glanz; Kinder) auszumachen. Der Schlussvers V17 ist ein synthetischer Parallelismus. 17b.c, die synonym gestaltet sind, führen den Schlussgedanken aus 17a weiter. 17a führt den Wunsch um das Sichtbarwerden des Glanzes Gottes aus 16b weiter in den Wunsch nach Anmut, Freundlichkeit und Lieblichkeit Adonajs (נنֵַِ), die nun über das lyrische Wir kommen mögen. Hat V16 den Blick auf das Handeln Gottes gelenkt, so steht nun am Schluss des Psalms das Tun der Menschen im Mittelpunkt. Zwei Mal wird darum gebeten, dass Gott das Tun der Hände bestärken, fördern und festigen möge (כון), sodass es Bestand hat, wodurch der Schlussbitte des Psalms eine besondere Betonung und großer Nachdruck verliehen wird. ${ }^{1127}$ Hier werden die Themen aus dem ersten (V1-6) und zweiten (V7-12) Gedankenspot nochmals aufgenommen, wo deutlich davon die Rede ist, dass zwar Gott in alle Ewigkeit Bestand hat, im krassen Gegensatz dazu aber die Menschen vergänglich sind, die Menschenzeit von Flüchtigkeit geprägt ist sowie die Mühen der Arbeit zu Lebzeiten sinnlos sind und

1126 Vgl. Brandscheidt, »Unsere Tage«, 26.

1127 Vgl. u. a. Kraus, Psalmen, 796 und Cohen, The Psalms, 300. 
keinen Bestand haben. In auffallender Weise schlägt damit der Schlussvers eine Brücke zurück zum Beginn des Psalms. Hier wird nicht nur auf klanglicher Ebene durch das Palindrom ein Spiegelbild erzeugt - vor allem in der Umkehrung der

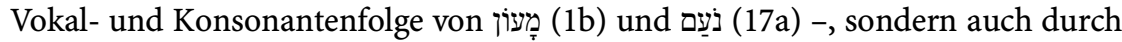

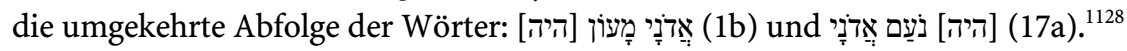
Auf der Ebene der Emotionen wird mit diesem Klang- und Sprachspiel Gottes Zuwendung als thematischer Rahmen um Ps 90 gelegt und damit der Ton des Vertrauens ${ }^{1129}$ aus V1 wieder aufgenommen. Dies wird durch die Semantik verstärkt, indem mit der Bitte, Gottes Freundlichkeit möge »über uns « sein (17a.b), die Zuwendung Gottes in Form der Bleibe und Obhut (מָָעון) »wie ein bergendes Dach ${ }^{1130}$ aus $1 \mathrm{~b}$ eingespielt wird.

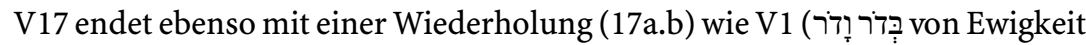
zu Ewigkeit). Die Aufnahme der Gottesbezeichnung "Adonaj« (1b.17a) ist offensichtlich. Der Text bildet mit dieser Verbindung zwischen V1.17 eine große Inklusion und ist damit inhaltlich und grammatikalisch abgerundet. Der trostlose Ton aus dem ersten Teil des Psalms wird im Schlussvers in einen dringlichen Appell verwandelt und findet mit der Wiederaufnahme der Thematik und besonders mit der Wendung zum positiven Bestand der Dinge des Lebens einen versöhnlichen Ausgang.

\section{$4 \quad$ Zusammenschau und Auswertung}

\subsection{Inhalt}

Das Gebet mit weisheitlich-philosophischer Reflexion über die Zeit stellt trotz der Schwierigkeiten der Textkonstitution, der Übersetzung und den daraus folgenden unterschiedlichen Übersetzungsmöglichkeiten klare inhaltliche Linien vor Augen: Je nach Blickwinkel liegt der Interpretationsschwerpunkt entweder auf der Schuld des Menschen und dem Zorn Gottes oder auf dem Unterschied zwischen Gotteszeit und Menschenzeit. Gemeinsam ist allen Auslegungen das Hervorheben der Zeitthematik, die den gesamten Psalm durchzieht. Dies zeigt sich nicht nur an der Fülle und Vielfalt der analysierten Zeitbegriffe, sondern auch an deren inhaltlicher Füllung. Die Themenvielfalt reicht von den Polen der Ewigkeit Gottes bzw. göttlichen Zeitdimension und der Vergänglichkeit des Menschen bzw. der menschlichen Zeitdimension, die »in geradezu erschre-

1128 Vgl. Schnocks, Vergänglichkeit, 129 und Forster, Begrenztes Leben, 146. Auf die Inklusion verweist u. a. auch Wallace, Psalms, 153.

1129 Vgl. Strolz, Psalm 90, 157.

1130 Köckert, Zeit, 159. 
ckender Deutlichkeit ${ }^{1131}$ geschildert wird. Ein weiterer Pol ist die düstere Porträtierung der Kürze des Lebens und der Flüchtigkeit der Zeit sowie der Unberechenbarkeit der Zorneswucht Gottes im Gegensatz zur Vision der Freude und des göttlichen Glanzes, welcher der menschlichen Arbeit Bestand verleiht. ${ }^{1132}$

Thematisch lässt sich die Vielfalt folgendermaßen festhalten:

\begin{tabular}{|l|l|}
\hline Vers & Thema \\
\hline 1 & $\begin{array}{l}\text { Überschrift: Gebet, das Mose zugeordnet ist; Gott ist für das lyr. Wir Wohnort } \\
\text { und Versteck seit Menschengenerationen }\end{array}$ \\
\hline 2 & $\begin{array}{l}\text { Gott als Schöpfer und die göttliche Existenz vor der Schöpfung bis in alle } \\
\text { Ewigkeit }\end{array}$ \\
\hline 3 & Gott lässt die Menschen zu Staub zurückkehren \\
\hline 4 & Tausend Jahre sind in den Augen Gottes wie ein Tag bzw. eine Nachtwache \\
\hline 5 & $\begin{array}{l}\text { Gott verursacht in heftiger Weise die Passivität des Menschen; Beginn des } \\
\text { Grasvergleiches }\end{array}$ \\
\hline 6 & $\begin{array}{l}\text { Fortsetzung des Vergleichs zwischen Menschenleben und Gras, das an einem } \\
\text { Tag blüht und welkt }\end{array}$ \\
\hline 7 & Lyr. Wir wird durch Gottes Zorn verstört \\
\hline 8 & Gott sieht die Schuld des lyr. Wir \\
\hline 9 & Lebenszeit des lyr. Wir wird durch Gottes Zorn beendet \\
\hline 10 & $\begin{array}{l}\text { Lebenszeit des lyr. Wir kann bis zu 80 Jahre erreichen, wird aber als mühsam } \\
\text { und kurz empfunden }\end{array}$ \\
\hline 11 & Frage, welche die Kraft des Zornes Gottes thematisiert \\
\hline 12 & Bitte an Gott, Lebensklugheit im Umgang mit der Lebenszeit zu erlangen \\
\hline 13 & $\begin{array}{l}\text { Aufforderung an JHWH zur Umkehr und zur Zuwendung zu seinen Knechten } \\
\text { inkl. Frage nach der Dauer der Leidenssituation }\end{array}$ \\
\hline 14 & $\begin{array}{l}\text { Bitte um Sättigung durch die Güte Gottes, damit verbleibendes Leben in Jubel } \\
\text { und Freude möglich wird }\end{array}$ \\
\hline 15 & Bitte um ebenso viel Freude wie einst erlittenes Leid \\
\hline 16 & $\begin{array}{l}\text { Wunsch nach Sichtbarwerden der Pracht Gottes für Volk und Nachkommen- } \\
\text { schaft }\end{array}$ \\
\hline 17 & $\begin{array}{l}\text { Doppelter Wunsch um Wahrnehmbarkeit der Anmut Gottes und um Bestand } \\
\text { des Menschenwerkes durch göttliche Förderung }\end{array}$ \\
\hline
\end{tabular}

In Bezug auf die für die erzählte Welt notwendigen Elemente (zu den minimal elements vgl. III Methodik 1) als Basis für Identifikationspotenziale ist die Thematik somit klar erkennbar, ebenso die durchgehende Sprechstimme des lyrischen Wir und die grobe Strukturierung des Psalms in zwei Teile (V1-12; 1317).

1131 Schreiner, Erwägungen, 81.

1132 Vgl. Tate, Psalms, 444. 


\subsection{Emotionen}

Die im Text verorteten und ausgedrückten Emotionen (F-emotions) sind in V1 jene Emotionen, die mit Schutz und Zuflucht verbunden werden, insbesondere Geborgenheit. Ebenso können Unheimlichkeit, Bedrohlichkeit und Unberechenbarkeit im Vers mitschwingen. Beides, Geborgenheit wie Unberechenbarkeit, wird der Gottheit zugeschrieben. V1 spricht auch vom Vertrauen, das auf Seiten des lyrischen Wir verortet werden kann. In den Geburtsbildern von V2 schwingen die Emotionen Freude, Glück und Ekstase ebenso mit wie Angst und Anstrengung. Die genannten Emotionen werden der Gottheit zugeschrieben. Die Ewigkeitsdimension Gottes wird durch die Geburt der Berge verstärkt, mit denen Beständigkeit, Halt und Dauer verbunden sind. V3 wechselt von der Geburtsthematik zur Todesproblematik: Menschliche Hinfälligkeit, gewalttätige, der Gottheit zugeschriebene Zerstörung sowie Todesdunkelheit prägen den Vers. Auf der Ebene des Leseprozesses können Erschütterung, Ernüchterung und Verdruss hervorgerufen werden. V4 kann durch die Darstellung der Zeitschrumpfung der menschlichen Zeit in den Augen Gottes im Leseprozess Staunen und Bewunderung in Bezug auf die unfassbaren göttlichen Zeitdimensionen auslösen. V5.6 sprechen von der Kürze des menschlichen Lebens, vom Hinwegschwemmen durch Gott, vom Todesschlaf, der keine Gestaltungsmöglichkeiten zulässt, von Passivität und Endlichkeit. Dies alles wird den Menschen zugeschrieben. Im Leseprozess können diese Inhalte Ohnmacht, Empörung und Hoffnungslosigkeit auslösen. V7 verstärkt die schwierigen Inhalte durch die Thematik des Zornes. Zorn, Glut, Hitze und Zornessturm werden der Gottheit zugeschrieben, Betroffenheit, Verstörtheit und Angst bis zur Todesfurcht dem lyrischen Wir. V8 bringt das Thema der Schuld zur Sprache sowie jene Emotionen, die mit Schuld im Allgemeinen verbunden sind. Diese werden, wie auch die impliziten Emotionen Angst, Panik und Besorgnis, auf Seiten des lyrischen Wir verortet, Unberechenbarkeit und Durchleuchtetwerden auf Seiten der Gottheit. V9 nimmt die Zornesthematik wieder auf und verstärkt sie durch das explizite Emotionswort des überwallenden bzw. unbeherrschten Zorns, welcher der Gottheit zugeschrieben wird. Auf Seiten des lyrischen Wir sind Todesnähe und Kummer festzustellen. V10 spricht explizit von Mühe und Anstrengung, implizit - vor allem durch Bildersprache - von Trostlosigkeit, Erschöpfung und Ausweglosigkeit auf Seiten des lyrischen Wir. V11 thematisiert ein letztes Mal die Zorneskraft Gottes sowie die Angst bzw. Gottesfurcht auf Seiten des lyrischen Wir. Implizit werden dem lyrischen Wir in diesem Vers Skepsis, Erschütterung und Ausweglosigkeit zugeschrieben. V12 eröffnet mit der direkten Kontaktaufnahme mit Gott und der ersten von mehreren aufeinanderfolgenden Bitten die brennende Leidenschaft und Dringlichkeit, die ab nun bis zum Ende des Psalms auf Seiten des lyrischen Wir zu verorten sind. V13 spricht ebenso von Dringlichkeit, da- 
neben von Bedürftigkeit, Hilflosigkeit, Müdigkeit und Überdruss auf Seiten des lyrischen Wir, das von JHWH vehement eine Situationsänderung (Mitleid, Erbarmen, Hinwendung zum Volk bzw. Abwendung vom Zorn) einfordert. V14 spricht explizit von der göttlichen Zuwendung und Großherzigkeit (Güte) sowie von (überschwänglicher) Freude und Jubel, die von Seiten des lyrischen Wir erbeten wird. Die Dimensionen des Heils (sättigen, Morgen, Güte) werden Gott zugeschrieben, das Emotionsfeld der Freude dem lyrischen Wir. V15 nimmt dieses wieder auf; allerdings wird hier auch explizit von jenen Emotionen gesprochen, die mit Bedrohung, Bedrückung, Erniedrigung und Demütigung durch Gott verbunden sind. Somit werden der Gottheit sowohl Freude als auch Demütigung zugeschrieben, Leben zerstörendes Unheil und Todesnähe hingegen dem lyrischen Wir. In V15 kann von einer doppelten Emotionalität gesprochen werden. V16 spricht implizit von der Zuwendung Gottes und führt die Dimension der Dringlichkeit auf Seiten des lyrischen Wir fort, die - durch die Formulierung als Wunsch auf der Ebene der Syntax - mit Hoffnung erfüllt ist. V17 schließt mit dem letzten expliziten Emotionswort der Lieblichkeit, Anmut oder Freundlichkeit Gottes, das als liebevolle Heilszuwendung charakterisiert werden kann. Die Dringlichkeit, die durch die Wiederholung verstärkt wird, bleibt auf Seiten des lyrischen Wir bestehen. Im Leseprozess werden durch Form und Inhalt des letzten Verses Ruhe, Heiterkeit, Frohsinn und Hoffnung erzeugt.

Durch die implizit und explizit ausgedrückten Emotionen in Ps 90 werden der Gottheit sowohl die Emotionsfelder der Bedrohung (Bedrohlichkeit, Unberechenbarkeit, gewalttätige Zerstörung) und Unterdrückung (Bedrückung, Erniedrigung) als auch jenes des Zornes (Zorn, Wut, überwallender Zorn, Zorneskraft) zugeschrieben. Auffällig ist dabei, dass das Bibelhebräische eine Differenzierung der Emotion Zorn mittels unterschiedlicher Begriffe vornimmt (vgl. dazu die verschiedenen Komponenten einer Emotion in III Methodik 2.1). Es unterscheidet zwischen dem Innen und somit dem subjektiven Gefühl (חמָָה), dem Außen als körperlicher Reaktion bzw. Ausdrucksverhalten (צֵַ) sowie dem Affekt (עֶבר als nicht mehr kontrollierbarer Emotion. Mit der Gottheit werden darüber hinaus die Emotionen der Geborgenheit und des Sicherheitsgefühls verbunden (Beständigkeit, Halt, Dauer) sowie die Emotionen der Freude und der Zuwendung (Erbarmen, Güte, Großherzigkeit, Heil, Anmut, Freundlichkeit), die den Psalm rahmen. Das lyrische Wir ist ebenso durch Angst gezeichnet wie durch Betroffenheit, Schuld, Panik, Besorgnis, Todesnähe, Kummer, Trostlosigkeit, Erschöpfung, Gottesfurcht, Skepsis, Erschütterung, Ausweglosigkeit, Dringlichkeit, Bedürftigkeit, Hilflosigkeit, Müdigkeit, Überdruss und Todesnähe. Neben diesen dunklen Emotionen sind dem lyrischen Wir auch jene der Freude, des Jubels und des Vertrauens zuzuordnen. Wendet man das Modell nach Pluchtik an (vgl. III Methodik 2.1), so kann für Psalm 90 festgehalten werden: »Die Emotionsfelder Ärger, Antizipation, Freude, Vertrauen, Angst und Traurigkeit werden 
im Psalm abgedeckt [...]. Die Emotionsfelder zeigen aber eine deutliche Tendenz. Gott ist es am ehesten, der zornig ist. Angst und Freude hingegen haben vorwiegend die Betenden, sind aber in ihrer Emotion abhängig von Gottes Handlungen. Die Felder Antizipation (vgl. VV 13, 16) und Vertrauen (vgl. VV 1, 14) werden eindeutig göttlich konnotiert, während Traurigkeit (vgl. VV 5, 6, 9) Sache des lyrischen Wir ist. ${ }^{1133}$

Nimmt man die Bildersprache des Psalms genauer in den Blick, dann lässt sich festhalten, dass diese erstens eher versteckt im Psalm aufzufinden ist. Zweitens ist es so, dass die Bezeichnung Adonajs als Wohnort (V1), die Geburtsmetaphorik (V2), die Rede von Staub (V3) und Schlaf (V5) sowie die Vergleiche (V4; V5-6) und Personifikationen (V2.4) weniger Emotionen evozieren, als dass sie vielmehr die Thematik und den Inhalt des Verses unterstreichen, verstärken und vertiefen. Nicht jede metaphorische Rede ist eo ipso emotional konnotiert. Sie kann auch andere Aspekte zu Tage bringen. Dies ist in Psalm 90 der Fall. Interessant ist jedoch, dass der atl. Text von Psalm 90 mit Metaphern arbeitet, die heute sehr aktuell und nachvollziehbar sind und daher zur Identifikation (siehe unten Analogiebildung) einladen. Ps 90 wird von folgenden Metaphern geleitet, die John Kartje in seiner Studie "Wisdom Epistomology in the Psalter" als konzeptuelle Metaphern (conceptual metaphors) ${ }^{1134}$ ausweist: A lifetime is a day ${ }^{1135}$ (V4.5-6.9: Seufzer; V14: Morgen): Die gesamte Lebensspanne eines Menschen wird in einem Tag zusammengefasst; People are plants (V5-6): Das Vergehen des Grases vom morgendlichen Aufblühen bis zum abendlichen Verwelken wird auf die Menschen übertragen; Mensch und Gras teilen dasselbe Schicksal; Time moves (V4.10): Zeit wird als Gefährt dargestellt, das sich entweder dem gegenwärtigen Moment nähert oder sich von diesem wegbewegt.

Schlägt man eine Brücke zum Beginn der Emotionsanalyse, so ist festzuhalten, dass die eingangs dargestellten A-emotions - die sich auf die bedrückende Stimmung beziehen und ebenso von Skepsis, Daseinsverdrossenheit, Traurigkeit und Dunkelheit getragen sind wie von Vertrauen und hoffnungsvoller Freude jene Emotionen sind, die auf Seiten der Lesenden ausgelöst werden. Als diese A-

1133 Artner, »Sättige uns«, 114.

1134 Vgl. Kartje, Wisdom, 124. Der Autor verweist auf den ausführlichen Diskurs über konzeptuelle Metaphern bei Lakoff, George / Turner, Mark: More than Cool Reason: A Guide to Poetic Metaphor, Chicago 1989. Die von G. Lakoff und M. Johnson begründete kognitive Metapherntheorie geht als Teildisziplin der kognitiven Linguistik davon aus, dass Metaphern in der Alltagssprache allgegenwärtig sind und unser Denken, Sprechen und Handeln strukturieren. Metaphorische Ausdrücke werden dabei als sprachliche Phänomene betrachtet, die ein System bilden, das auf zugrundeliegende Denkkonzepte, so genannte konzeptuelle Metaphern, schließen lässt. Aus diesen konzeptuellen Metaphern können Konturen der dahinterstehenden Weltsicht, die sie repräsentieren, abgeleitet werden. Vgl. dazu Lakoff / Johnson: Metaphors We Live By, 3-9.

1135 Auffällig ist, dass hier zwei Zeitbegriffe miteinander in Bezug gesetzt werden. 
emotions können im ersten Teil des Psalms Erschütterung, Ernüchterung, Verdruss, Ohnmacht, Empörung und Hoffnungslosigkeit sowie Bewunderung und Staunen benannt werden, im Schlussvers dagegen Ruhe, Heiterkeit, Frohsinn und Hoffnung.

\subsection{Perspektiven und Textdynamik}

Die Sprechstimme des lyrischen Wir ist durchgehend im Text auszumachen. Eine intensive Wir-Du-Beziehungsstruktur bestimmt den Psalm. Auch wenn in V3-6 in allgemeiner Rede vom Menschen gesprochen wird, ist diese mittels der Rede in der 2.P.sg. persönlich; damit bleibt die Gebetssprache erhalten. Die starke WirDu-Ausrichtung in der Rederichtung zeigt sich auch in einem Netz dichter deiktischer Elemente, das den gesamten Psalm durchzieht und besonders ab dem zweiten Teil noch ausgeprägter zur Darstellung gelangt (vgl. Perspektiven des zweiten Teils). ${ }^{1136}$ Ps 90 ist hauptsächlich textintern fokalisiert (außer 1a.5b-6b: textextern und V4: doppelt). Textexterne AdressatInnen, wie sie in Ps 30 oder Ps $147 \mathrm{zu}$ finden waren, werden nicht angesprochen. Eine AdressatInnenperspektive ist hier also nicht auszumachen. Der kompakte Text bleibt perspektivisch in sich geschlossen und scheint ganz mit sich, der Zeitthematik, dem Ringen um die Grenzen des menschlichen Lebens hinsichtlich der Vergänglichkeits- und Todesproblematik sowie der intensiven Gott-Wir-Beziehung beschäftigt zu sein.

Bezüglich der Textdynamik ist eine Hauptbewegung im Text festzustellen, die bis zum Wendepunkt in V12 ansteigt und dort zur Ruhe kommt sowie von dort weg wieder Aufschwung erhält. ${ }^{1137}$ Des Weiteren lassen sich Textbewegungen hinsichtlich Thema, Raum und vor allem Zeit festhalten.

Die Thematik des Textes lässt sich bis V11 als Negativreihe bestimmen. Sie beginnt mit den positiven Aspekten des Vertrauensbekenntnisses (V1) und der Erschaffung der Natur aus göttlicher Geburt (V2) und führt über die Themen der Vergänglichkeit, Flüchtigkeit und Kürze des menschlichen Lebens (V3-6) sowie der Thematisierung des göttlichen Zornes (V7.9.11) und der menschlichen Schuld (V8) zum Scharniervers V11. Hier erreicht die Negativreihe mit dem Hervorheben der Kraft des überwallenden Zorns Gottes ihren Tiefpunkt. Mit der Wende in V12 und der Rede vom Herz von Weisheit (V12) kehrt sich die The-

1136 Zur Blicklenkung des Textes im Zusammenhang mit dem Fokus des jeweiligen Verses vgl. die Tabelle in der Perspektivenanalyse.

1137 Vggl. Schnocks, Vergänglichkeit, 176. Durch die Strukturierung des Psalms anhand der vier Elemente des Volksklageliedes (1. Anrede Gottes, 2. Klage, 3. Bitte, 4. Ausblick auf die Zukunft) weist Zenger ebenso auf eine Bewegung hin, »in die die Klagenden sich mit ihren Klagegebeten hineinbegeben, um in der von ihnen beklagten Leidenssituation nicht unterzugehen.« Zenger, Werk, 14. 
matik ins Positive. Mit den Themen der Sättigung (V14), Güte (V14) und Freude (V14), des Jubels (V14), Glanzes (V16) und der Anmut Gottes sowie des Bestandes des Menschenwerkes (V17) ist ein deutlicher thematischer Aufwärtstrend auszumachen.

Blickt man auf die Themen des Textes bezüglich der Frage, wen diese Themen betreffen und über wen etwas ausgesagt wird, so ist ebenso eine Entwicklung im Text von Ps 90 festzustellen: »Er lässt vielmehr eine lineare Entfaltung erkennen: von dem, was alle Menschen betrifft, über die konkrete Klage einer Gruppe, zur Hoffnung jener Gottesknechte auf den Erweis der Güte ihres Gottes, obwohl seine erbarmende Zuwendung noch auf sich warten lässt. « ${ }^{1138}$

Hinsichtlich der analysierten Räume können die Dimensionen der Festigkeit, Zuverlässigkeit und des Bestandes im Gegensatz zur Durchlässigkeit des Staubes festgehalten werden. Das Licht deines Angesichts in 8b kann als Begegnungsraum betrachtet werden, das Herz in $12 \mathrm{~b}$ als Ort der Weisheit.

Die anschaulichste Dimension in Ps 90 ist jene der Zeit, auf die bereits mehrmals verwiesen wurde. Ein erster Blick gilt an dieser Stelle den Zeitbegriffen im Text. Es lassen sich folgende auflisten: ${ }^{1139}$ von Generation zu Generation 1b; bevor 2a; von Ewigkeit zu Ewigkeit 2c; tausend Jahre 4a; Tag 4b; gestern 4b; Nachwache 4c; Nacht 4c; am Morgen 5a; am Morgen 6a; zum Abend hin 6b; alle unsere Tage 9a; unsere Jahre 9b; Seufzer 9b; Tage 10a; unsere Jahre 10a; 70 Jahre 10a; 80 Jahre 10b; schnell 10c; unsere Tage 12a; wie lange noch 13a; am Morgen 14a; alle unsere Tage 14b; Tage 15a und Jahre 15b. Aufgrund dieser hohen Anzahl an Zeitbegriffen kann das dominante Thema "Zeit« als Leitwort in Ps 90 betrachtet werden. ${ }^{1140}$ Will man daraus einen Fokus erhalten, so ist mit Johannes Schnocks und Klaus Seybold die Konzentration auf die zeitdeiktischen Ausdrücke »Tag« bzw. »Jahr« festzuhalten: »Es geht Ps 90 nicht um die Reflexion von festgesetzten Fristen oder von Zeiträumen, die durch bestimmte Ereignisse geprägt wären. Stattdessen konzentriert sich der Psalm in seiner Gedankenführung fast ausschließlich auf das Wort יוֹם 1141 (Tag) ist ebenso sechs Mal belegt (V4.9.10.12.14.15) wie שָנזה (Jahr; V4.9.10:3x.15). Dabei stellt der Tag die biblische Basiseinheit für die Zeit dar. ${ }^{1142}$ Inhaltlich geht es jedes Mal um die für das AT charakteristische Dimension der gefüllten Zeit, der qualitativ bestimmten Zeit bzw. Geschehenszeit. ${ }^{1143}$

1138 Köckert, Zeit, 165.

1139 Eine Zusammenstellung aller Wörter für die Zeit Gottes und der Menschen in Psalm 90 bietet Köckert, Zeit, 185. Über die vielfältigen Aspekte der Zeitwahrnehmung im Alten Israel geben Grund / Janowski, "Solange die Erde steht ...«, 506-525 Aufschluss.

1140 Vgl. Watson, Classical Hebrew Poetry, 288.

1141 Schnocks, Vergänglichkeit, 150. Ebenso Seybold, Zeitvorstellungen, 98.

1142 Vgl. Schnocks, Vergänglichkeit, 164.

1143 Vgl. Schnocks, Vergänglichkeit, 147. 
Wesentlich in der Analyse der Zeitangaben ist der immense Kontrast zwischen der Zeit in Bezug auf Menschen und jener in Bezug auf Gott: Menschliche Zeit vergeht (V5.6), göttliche Zeit »steht« (V2.4). Gott steht außerhalb der Zeit und vor der Schöpfung (V2.4) und ist von menschlicher Zeit nicht betroffen. ${ }^{1144}$ Menschliche Lebenszeit verstreicht (V.7.9). In der Beschreibung dieses Verstreichens ist eine Beschleunigung ${ }^{1145}$ erkennbar. Wird in V3 Vergänglichkeit allgemein beschrieben, so wird diese in V7 direkt auf das lyrische Wir bezogen und in V9 mit den Zeiteinheiten der Lebensjahre (70 bzw. 80) versehen. Am Schluss heißt es in 10d, dass wir schnell verfliegen. Interessant ist an dieser Stelle die subjektive Zeitwahrnehmung: Hier wird begrenzte Lebenszeit als Leid und Mühsal erlebt und als schnelllebig empfunden; dabei wird normalerweise die Zeit, die mit schönen Ereignissen gefüllt ist, so empfunden, als ob sie wie im Flug vergeht. Gerade für Ps 90 gilt: »Gottesnähe und Gottesferne ereignen sich für die Beter von Ps 90 auch und gerade in der Wahrnehmung ihrer Lebenszeit. «"146

Blickt man auf die Zeitkonstruktion in Ps 90, so ist ein "streng lineares Fortschreiten von der Vergangenheit in die Zukunft ${ }^{1147}$ festzuhalten. Die "Linearität der Zeitkonstruktion « ${ }^{1148}$ wird mit Elementen der Be- und Entschleunigung verbunden. Diese zeigen sich dadurch, dass bis V10 Zeit immer kürzer bzw. verringert und beschleunigt wird (siehe oben: wir verfliegen schnell). Ab V12.13 wird die zeitliche Perspektive gedehnt, und zwar in Form der Steigerung der Ausdrücke vom Tag (V14.15) über das Jahr (V15) bis hin zu »deine Kinder« (V16), einem Ausdruck, der auf die zukünftigen Generationen verweist. ${ }^{1149} \mathrm{Zu}$ sammenfassend kann daher festgehalten werden: "In der Darstellung der Dimension Zeit zeigt sich in Psalm 90 somit eine Entwicklung von der Kontrastierung ewiger vs. begrenzter Zeiträume über eine Betonung der Flüchtigkeit aller Zeiterfahrung hin zur Konzentration auf die einzelnen Tage des Lebens. « ${ }^{1150}$

Innerhalb der Zeitdimensionen kann nach Alonso Schökel und Carniti eine absteigende bzw. aufsteigende Bewegung hinsichtlich der Dauer erkannt werden: Die absteigende Linie beginnt mit der längsten und nicht fassbaren Zeitdimension der Ewigkeit über die der Generation, dann über die der Jahre und Tage und führt dann über die Zeitausdrücke gestern, Nacht, Nachtwache und Morgen hin bis zum Abend. Aufsteigend ergibt sich folgende Linie: von der Dauer einer

1144 Vgl. Schnocks, Vergänglichkeit, 160.

1145 Vgl. Schnocks, Vergänglichkeit, $164 \mathrm{f}$.

1146 Schnocks, Vergänglichkeit, 158f.

1147 Schnocks, Vergänglichkeit, 164.

1148 Schnocks, Vergänglichkeit, 164.

1149 Vgl. Schnocks, Vergänglichkeit, 165.

1150 Gillmayr-Bucher, Die Psalmen, 257. 
Pflanze über das Leben eines Menschen, über die Geschichte der Menschheit und die kosmische Zeit bis hin zur Ewigkeit Gottes. ${ }^{1151}$

Nimmt man die Verben von Ps 90 in den Blick, so ergibt sich folgende $\mathrm{Zu}$ ordnung: Mit Gott sind verbunden: היה q. sein 1b; ילד q. geboren werden pass. als pass. divinum 2b; שיל po. hervorbringen 2b; שוב hurückkehren lassen 3a; אמר sagen 3b; זרם q. hinwegraffen 5a; שוב q. zurückkehren bzw. umkehren 13a; נחם ni. Mitleid haben 13b; שבע pi. sättigen 14a; שמח pi. erfreuen 15a; ענה pi. beugen 15a; ראה ni. sich sehen lassen 16a; היה q. כון 17a pein 17a bestand verleihen, festigen 17b.c. Dem Gras bzw. Menschen werden folgende Verben zugeordnet:

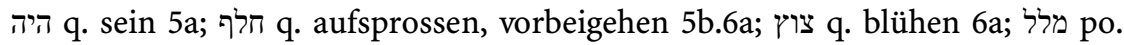
כלה

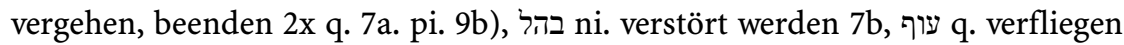
10d, בוא hi. erlangen 12b, רנן pi. jubeln, laut rufen 14b, שממח q. sich freuen 14b und q. sehen 15b zugeordnet werden. Als Erkenntnis aus der Verbanalyse und -zuordnung kann festgehalten werden, dass das Themenfeld der Freude und die positiven Aspekte der erhofften und erbetenen Heilszeit im Text vorwiegend über das Tun und die Verben konstruiert werden, während die Zeiten der Krise und des Zornes mit Substantiven beschrieben werden. Betrachtet man die Verben, die der Gottheit zugeschrieben werden, so ist dadurch keine gewalttätige oder zornige Dimension auszumachen. Im Zusammenhang mit der Gottheit werden keine aggressiven Tätigkeiten genannt.

Die Analyse der Übergänge - die durchgehend vorhanden sind - ${ }^{1152}$ führt zur Erkenntnis einer "mittels Stichwort-Wiederholungen gestaltete[n] Verknüpfungstechnik ${ }^{1153} \mathrm{im}$ Psalm. So ist hier die Konjunktion ?, die nur in V5.8.9.15 nicht vorkommt, $22 \mathrm{Mal}$ belegt. Trotz großer Schwierigkeiten in der inhaltlichen Bestimmung einzelner Lexeme und Verse hat die Analyse der Übergänge gezeigt,

1151 Vgl. Alonso Schökel / Carniti, Salmos 2, 1170.

1152 Zur Wiederholung mehrfach auftauchender Lexeme in benachbarten Versen sowie über Wurzeln und Partikeln, die sich in Ps 90 wiederholen, siehe die Tabellen bei Schnocks, Vergänglichkeit, 122.124-126. 279f. Er eruiert folgende Leseeinheiten, die mittels wiederholter Lexeme eine fortlaufende Anbindung schaffen: V1-2; 5-6; 8-10;11-12; 14-16. Dass auch die übrigen V3.4.7.13.17 mit den vorhergehenden bzw. nachfolgenden verbunden sind, konnte in der Analyse der Übergänge herausgearbeitet werden: Das Du Gottes aus V2 wird durch die Verbformen in der 2.P.m.sg. in V3 fortgeführt. V4 knüpft an das Zeitthema von V1-3 an. V8 führt Suffixe in der 2.P.m.sg. aus V7 weiter, V17 wird mit V16 durch die Konjunktion ! verbunden. Einzig die Verbindung zwischen V12 und V13 ist weniger offensichtlich. Mit V13 beginnt der zweite Teil des Psalms, ein Einschnitt ist ersichtlich, ein Herausfallen aus dem Leseprozess ist dennoch nicht gegeben.

1153 Weber, Werkbuch 2, 120. Auf die Verbindung von jeweils zwei aufeinanderfolgenden Versen bzw. Halbversen mittels einer Wortwiederholung verweisen ebenso Alonso Schökel / Carniti, Salmos 2, 1172. 
dass in Psalm 90 "ein kunstvolles Netz von Stichwortverbindungen « ${ }^{154}$ vorliegt. Wir haben es »in Ps 90 mit einer kunstvoll gestalteten, ästhetisch anspruchsvollen poetischen Komposition zu tun. ${ }^{1155}$ Durch die Wiederholung am Schluss und die inhaltliche sowie klangliche Verknüpfung mit V1 wirkt die Komposition abgerundet und ergibt ein stimmiges Ganzes.

Die Analyse der Parallelismen diente auch in dieser Psalmanalyse - wie bereits in den Kapiteln davor - zur Eruierung des Potenzials der Vertiefung in die jeweilige Thematik des Verses und damit zur Eruierung der Zeit, die Lesende für das Lesen des Textes benötigen. Die meisten Parallelismen in Ps 90 sind als synthetische einzuordnen (V2.4.9.10.11.12.13.14.16.17). Es folgen die synonymen Parallelismen (V3.7.8.15) und der antithetische in V6; V1.5 sind nicht parallel gestaltet. Dabei sind aufgrund der Gestaltung durch den Parallelismus folgende Bewegungen erkennbar: In V2 wechselt die Formulierung von einer passiven zu einer aktiven, wodurch die Geburtsmetaphorik konkretisiert und intensiviert wird. In V3 wird die Todesmetaphorik intensiviert, es kommt zu einer Steigerung von der Rede in der 2.P. in 3a hin zur direkten Rede Gottes in 3b. In V4 manifestiert sich in einem Dreischritt (tausend Jahre - ein Tag gestern - Nachtwache) die Unterschiedlichkeit zwischen göttlicher und menschlicher Zeit. Der antithetische Parallelismus von V6 zeigt den Gegensatz zwischen morgendlichem Wachsen und abendlichem Verdorren auf und lädt die Lesenden ein, die Verbindungslinien zwischen den beiden Polen und das, was sich dazwischen an Leben abspielt, zu füllen. In V7 kann von einer statischen Synonymität gesprochen werden, in der die Konsequenzen für die Menschen aufgrund der göttlichen Zorneserfahrung aufgezeigt werden. V8 thematisiert zwei Mal die Schuld des Menschen vor Gott. In V9 kommt es zu einer Ausweitung und dann zu einer Verkürzung. V10 enthält eine Steigerung und Intensivierung der Thematik der Lebenszeit, indem das subjektive Zeitempfinden hinzutritt (70 Jahre - 80 Jahre - mühsam und unheilvoll - schnell vorbei). V11 bewegt sich von der göttlichen Zorneskraft über die Angst hin zum Affektvollen des Zorns. In V12 ist $12 \mathrm{~b}$ als Folge und Konsequenz des Imperativs aus 12a zu lesen. V13 enthält eine dreistufige Bitte, um Gott zur Richtungsänderung zu bewegen. In V14 ist 14b als Konsequenz und Erweiterung zu 14a zu betrachten. In V15 gibt es in 15b eine Ausweitung der Zeitdimension sowie einen Subjektwechsel. Eine Ausweitung ist auch in V16 zu erkennen: 16b weitet den Blick von der Gegenwart auf die Zukunft. V17 gilt als Inklusion zu V1 und beinhaltet den Wunsch nach göttlichem Segen. Eine Bewegung von der Anmut Adonjas zur Festigung der menschlichen Arbeit ist erkennbar. Der Psalm er-

1154 Forster, Begrenztes Leben, 150 für V13-16. Das Stichwortnetz wird auf den gesamten Psalm ausgedehnt. Vgl. Forster, Begrenztes Leben, 163. Ebenso Krüger, Psalm 90, 203 f.

1155 Schreiner, Erwägungen, 80. 
öffnet aufgrund dieses Befundes den Lesenden die Möglichkeit, bei einem Gedanken $\mathrm{zu}$ verweilen und genug Zeit auf die Imagination $\mathrm{zu}$ verwenden, sodass sich der entsprechende Inhalt auch »setzen « kann. Dadurch erhalten die Lesenden die Möglichkeit, an die Thematik und die Bewegungen des Textes anzuschließen und mit diesen mitzugehen.

Extrem auffällig ist in Psalm 90 die hohe Menge an Kontrasten, die ich im Folgenden zunächst in der Abfolge der Verse aufliste:

\begin{tabular}{|c|c|c|c|}
\hline Vers & \multicolumn{2}{|c|}{ im Gegensatz zu } & Vers \\
\hline $1 b$ & Sicherheit, Hilfe, Schutz & Hinwegraffen, Schlaf & $5 a$ \\
\hline $1 \mathrm{~b}$ & Ewigkeit & kurzes Leben & V6 \\
\hline V2 & Schöpfung & Tod/Gewalt & V3 \\
\hline V3 & $\begin{array}{l}\text { שוב = Rückkehr des Menschen zu } \\
\text { Staub }\end{array}$ & $\begin{array}{l}ש ו ב=\text { Rückkehr JHWHs zu Men- } \\
\text { schen oder Abkehr vom Zorn }\end{array}$ & V13 \\
\hline V3 & $\begin{array}{l}\text { Menschenkinder = vergänglich, } \\
\text { dem Tod geweiht, sterblich }\end{array}$ & $\begin{array}{l}\text { Kinder = auf Bestand aus; Hoff- } \\
\text { nung, dass sich Anmut Gottes } \\
\text { den Knechten und den Kindern } \\
\text { zeigt }\end{array}$ & V16 \\
\hline V3-10 & $\begin{array}{l}\text { Flüchtigkeit des Lebens/Ver- } \\
\text { gänglichkeit }\end{array}$ & Festigkeit/Bestand & V17 \\
\hline $4 a$ & tausend Jahre & eine Nachtwache & $4 \mathrm{c}$ \\
\hline V7.9 & $\begin{array}{l}\text { Erlebnis des göttlichen Zornes = } \\
\text { unheilvolle Zuwendung oder Ab- } \\
\text { wendung }\end{array}$ & Bitte um heilvolle Zuwendung & ab V13 \\
\hline V9 & $\begin{array}{l}\text { dahingeschwundene Tage und } \\
\text { Jahre }\end{array}$ & $\begin{array}{l}\text { Bitte um Freude während ebenso } \\
\text { vieler Tage und Jahre }\end{array}$ & V14f \\
\hline 10a.b & hohes Alter & ohne Ertrag, nichts bleibt & $10 \mathrm{c.d}$ \\
\hline V10 & Mühsal, nichts bleibt & Freude, Bestand & V13-17 \\
\hline V14 & $\begin{array}{l}\text { Morgen = Bild für Zeit der Güte } \\
\text { und Gnade }\end{array}$ & $\begin{array}{l}\text { Morgen = Teil der Vergänglich- } \\
\text { keitsklage }\end{array}$ & V5f \\
\hline
\end{tabular}

Allgemein formuliert sind die kontrastiven Themen des Psalms folgendermaßen zu benennen:

\begin{tabular}{|l|l|}
\hline Unbegrenztheit Gottes & Begrenztheit menschlichen Lebens \\
\hline $\begin{array}{l}\text { Erfahrungen der eigenen Bedeutungslo- } \\
\text { sigkeit, der Last und Sinnlosigkeit des Le- } \\
\text { bens }\end{array}$ & $\begin{array}{l}\text { Hoffnung auf Freude, Beständigkeit und } \\
\text { sinnvolle Lebensgestaltung }\end{array}$ \\
\hline Tod & Leben \\
\hline ewig/unendlich & kurz \\
\hline Gotteszeit & Menschenzeit \\
\hline
\end{tabular}

1156 Vgl. Forster, Begrenztes Leben, 150. 
(Fortsetzung)

\begin{tabular}{|l|l|}
\hline Unbegrenztheit Gottes & Begrenztheit menschlichen Lebens \\
\hline Gott steht außerhalb der Zeit & Mensch steht innerhalb der Zeit \\
\hline Gott handelt aktiv & Menschen sind passiv \\
\hline
\end{tabular}

Die geschilderten Kontraste beziehen jeweils zwei Pole aufeinander. Die analysierten Pole bewegen sich einerseits zwischen dem göttlichen und dem menschlichen Pol, andererseits zwischen positiven und negativen Aspekten. Analog zum antithetischen Parallelismus wird durch die kontrastreiche Schilderung die Plastizität und Mehrdimensionalität der Aussage deutlich. Kontraste machen die Distanzen zwischen den beiden Polen bewusst und eröffnen den Lesenden die Möglichkeit, den Weg dazwischen »mit Leben « zu füllen. Daneben gilt es, diese Ausgespanntheit des Psalms wahrzunehmen und auszuhalten: „So gesehen ist der Psalm von einer starken Spannung bestimmt. Den einen Pol dieser Spannung bildet das nüchterne, kompromisslose Sehen des Menschen in seinem Todesschicksal, den anderen das Sich-Werfen auf Gott angesichts dieses Todesschicksals im Bekenntnis der Zuversicht und der Bitte. So ist der Grundton des Psalms ein starkes, klares Dennoch: ein Sich-Halten an das Erbarmen Gottes angesichts voller Bejahung der Wirklichkeit seines Zornes und dessen Auswirkungen. ${ }^{1157}$

\section{Identifikationspotenziale in Psalm 90}

\section{1 durch Inhalte}

Trotz Ambivalenzen in Textkonstitution, Übersetzungen, Inhalt und Gottesbild ist die erzählte Bühne von Ps 90 klar auszumachen. Die sogenannten minimal elements sind gegeben, ein Mitgehen und Dranbleiben am Text wird damit ermöglicht. Der klare Themenbereich der Zeit, die sich zwischen göttlicher Ewigkeit und menschlicher Vergänglichkeit erstreckt, zieht sich ebenso als roter Faden durch den Text wie das Wir-Du-Beziehungsnetz bzw. die Ausrichtung auf das göttliche Du hin. »Unverändert wird im gesamten Psalm Gott als >Du angesprochen. ${ }^{1158}$ Die Klage wird fortwährend unmittelbar an Gott gerichtet; über andere Verursacher des Leidens (z. B. Feinde, Frevler etc.) wird nicht geklagt. ${ }^{1159}$

Eine Analogiebildung ist für mehrere Themen gegeben: (1) Die im Text genannten Zahlen für das Lebensalter, die in biblischen Zeiten als Idealmaß galten,

1157 Westermann, Der 90. Psalm, 349.

1158 Schnocks, Vergänglichkeit, 130.

1159 Vgl. Forster, Begrenztes Leben, 196. 
treffen das Lebensalter der Menschen, die heutzutage 70 bzw. 80 Jahre und älter werden. ${ }^{1160}$ (2) Menschliches Leben kann damals wie heute von mühevoller Arbeit, Anstrengung, Unheil und Leid sowie von Kürze und Flüchtigkeit gekennzeichnet sein. Dies deckt sich mit einer der Hauptaussagen des Psalms: »Despite momentary joys, human life is mostly difficult and relatively brief. $\aleph^{1161}$ (3) Die Themen Zeit und Vergänglichkeit sowie die oftmalige Vergeblichkeit menschlichen Tuns sind auch heute aktuell. Ps 90 versucht, »auf die drängende Frage zu antworten, wie trotz der Vergänglichkeit allen menschlichen Tuns dennoch menschliches Tun möglich, notwendig und sinnvoll ist [...].. ${ }^{1162}$ Hier schließt sich die Bitte aus dem Psalm an, dass das Tun, die Arbeit und das Abmühen der Menschen endlich Bestand haben möge, dass es nicht vergebens und sinnlos sei, sondern weiter wirke und anderen, nachfolgenden Generationen eine Hilfe sei. Dahinter steht die große, alle Menschen betreffende Frage: Was bleibt, wenn das/ mein Leben zu Ende ist? Was hat Bestand? (4) Die Bitte um ausgleichende Gerechtigkeit, jene Bitte also, dass es im Leben einen Ausgleich gibt zwischen der Zeit des Leidens und der Zeit der Freude, dass es im Leben letztendlich doch eine Belohnung gibt für das, was zu ertragen war, diese Bitte ist damals wie heute sehr aktuell. (5) Ein weiteres, sehr aktuelles Thema ist die Schnelligkeit des Lebens, die im Psalm mit dem Seufzer in 9b und dem Verfliegen in 10d angezeigt wird. Alonso Schökel und Carniti sprechen in diesem Zusammenhang von einer absurden Schnelligkeit in unserer Zeit. ${ }^{1163}$ Dass man angesichts dieser Schnelligkeit und Flüchtigkeit des Lebens mit der eigenen Lebenszeit und der Zeitgestaltung behutsam und weise umgehen sollte, wird bereits im Psalm vermerkt (V12). ${ }^{1164}$

1160 Vgl. Goldingay, Psalms 3, 30.

1161 Kartje, Wisdom, 126.

1162 Zenger, Werk, 17.

1163 Alonso Schökel / Carniti, Salmos 2, 1176: »[...] esa absurda velocidad a nuestros días«.

1164 Dem Thema »Was ist Zeit?» hat sich eine Sonderbeilage zur österreichischen Tageszeitung Der Standard gewidmet. Vgl. Der Standard: Österreichs unabhängige Tageszeitung, hg. von Oscar Bronner, Sa/So/Mo 6./7./8. Dezember 2014. Es geht in dieser Ausgabe um ethische, religiöse, politische, philosophische und kulturelle Dimensionen der Zeit. Folgende Themen decken sich mit denen in Ps 90: 1. subjektives Zeitempfinden (wann vergeht Zeit schnell, z. B. vorm PC, oder langsam, z. B. beim Fahren in öffentlichen Verkehrsmitteln; Ps 90: Seufzer, verfliegen); 2. prinzipielles Empfinden von Zeit: Wird heute Zeit schneller und hektischer erlebt als etwa vor 20 Jahren? Hier spricht das AT generell von erlebter Zeit und gefüllter Zeit sowie davon, dass das Zeitempfinden vom eigenen Erleben geprägt ist. Dies wird auch im Standard festgehalten; 3. das Erleben der Zeit als Grenze macht Handeln endlich und begrenzt Möglichkeiten (V12: zu zählen unsere Tage, so lehre uns); 4. messbare Zeit (Ps 90: Tag, Jahre etc.) versus subjektives Zeitempfinden, das sich in einem Experiment in einer Gletscherhöhle verdeutlicht, in welcher ein Forscher für ein bis mehrere Monate lebte und dabei seinen Tages- und Nachtrhythmus sowie sein subjektives Zeitempfinden schriftlich festhielt. 
Das Thema der Analogiebildung resümierend nimmt Ps 90 also Themen auf, die alle Menschen betreffen, und lädt damit ein, die allgemeinen Beobachtungen und Aussagen über die menschliche Existenz an sich selbst zu überprüfen »[The psalm] conveys an overarching observation on the nature of human existence. Each individual hearer of the psalm is invited to compare her or his own perceptions of life to determine whether or not they cohere with the psalmist's proposition. ${ }^{1165}$

\section{2 durch Emotionen}

Die Emotionsanalyse (F-emotions) hat ergeben, dass Ps 90 zwar eine hohe Quantität an expliziten Emotionswörtern aufweist, diese aber nicht zwingend zu einer LeserInnenidentifikation führen. Vielmehr werden Identifikationspotenziale in Ps 90 durch die impliziten Emotionen eröffnet - vor allem durch jene, die dem lyrischen Wir zugeordnet werden können - sowie auch durch die A-emotions. Die düstere, dumpfe Stimmung des Psalms könnte man als negative Emotionen bezeichnen, die nach Suzanne Keen (vgl. II Methodologische Grundlagen 4.3) stärker zur Empathielenkung beitragen als positive. An dieser Stelle ist mit Hans-Peter Müller zu fragen: »Spricht er uns, ohne dass wir uns dessen bewusst wären, gerade wegen seiner düsteren Gestimmtheit [...] an? « ${ }^{1166}$ $\mathrm{Zu}$ unterstreichen sind die Emotionen, die im Leseprozess hervorgerufen werden und damit zum Mitgehen und Dranbleiben an Text und Thema beitragen: Erschütterung, Ernüchterung, Verdruss, Ohnmacht, Empörung und Hoffnungslosigkeit wie auch Bewunderung, Staunen und schlussendlich Heiterkeit, Frohsinn und Hoffnung. Auf der Ebene der F-emotions ist vor allem V15 mit seiner doppelten Emotionalität hervorzuheben, die Freude und Not gleichzeitig im Blick hat.

Die Analyse der Sprachbilder in Ps 90 hat ergeben, dass diese nicht so sehr Emotionen hervorrufen, sondern eher die Inhalte und Themen des jeweiligen Verses verstärken. Aufgrund der Tatsache, dass durch die breite, alle Menschen betreffende Thematik des Psalms ein hohes Identifikationspotenzial gegeben

1165 Kartje, Wisdom, 126. Der Sitz von Ps 90 im Leben heute ist die Begräbnisfeier, in der uns der Text mit unserer Endlichkeit konfrontiert: »Because Psalm 90 moves from despair to hope, it is quite appropriate for what is probably its most frequent contemporary setting in life: funeral services. To be sure, these services of worship confront us starkly with our finitude, as does Psalm 90.« McCann, Psalms, 1045. Auf den Sitz im Leben bei Begräbnissen verweisen ebenso Mays, Psalms, 289 und Goldingay, Psalms 3, 21.

1166 Müller, Der 90. Psalm, 282. 
ist, ${ }^{1167}$ kann das auch für die metaphorische Sprache, welche die Themen ja verstärkt, festgehalten werden: »Ps 90 [...] hat Formularcharakter und dient in der Offenheit seiner Metaphern der Identifikation des Beters mit dem Text. « ${ }^{1168}$ An dieser Stelle sei an die konzeptuellen Metaphern (siehe oben) erinnert, die der Psalm verwendet und die heute ebenso gängig sind: Die Lebenszeit ist ein Tag; Menschen sind Pflanzen; die Zeit schreitet voran.

\section{3 durch Perspektivenlenkung und Textdynamik}

Das lyrische Wir von Ps 90 kann als offenes Wir ${ }^{1169}$ charakterisiert werden. Es lädt die Lesenden ein, sich selbst sowohl als einzelneR als auch als Gruppe mit dem Wir des Psalms zu identifizieren. ${ }^{1170}$ Als Meditationstext ist "Ps 90 designed precisely to assist in the meditations of other individuals or of groups who are wrestling with the issues of life explored in them. ${ }^{1171}$ So kann er auch gerade einer Gruppe in einer Zeit der Krise dienen. ${ }^{1172}$ Trotz der Offenheit des lyrischen Wir bedarf es einer größeren "Anstrengungsleistung ", sich als Einzelperson mit dem Wir des Textes zu identifizieren, als sich - wie etwa in Ps 30 - als Einzelperson mit einem lyrischen Ich in Verbindung zu bringen. Erleichtert wird die Identifikation in Ps 90 jedoch durch das dichte Beziehungsgeschehen und das hervorstechende Netz an Deixis (du - wir - unser).

Die direkten Reden, die sich in Ps 90 vor allem in den Vokativen und Imperativen zeigen, sind zeitdeckend und ermöglichen damit eine LeserInnenidentifikation, was bereits für Ps 30 gezeigt werden konnte. Durch die Perspektivenlenkung in Zusammenhang mit Textdynamik und Inhalt ist in allen Teilen des Textes ein Mitvollzug bzw. eine LeserInnenidentifikation gegeben: In V1-10 gilt: »Die LeserInnen sind in diesem ersten Abschnitt aufgefordert, die reflektierende Darstellung mitzuverfolgen. Die Verknüpfung von allgemeinen und erfahrbaren Dimensionen menschlichen Lebens, Vergleichen aus der Natur sowie der Darstellung göttlichen Handelns und göttlicher Perspektive entwerfen ein überzeugendes Bild, das sie mitvollziehen können. ${ }^{1173}$ V11-12 involvieren die Lesenden durch die Imperative und die Deixis, die sich in V13-17 fortsetzt: »Die

1167 Generell kann für die Psalmenlektüre festgehalten werden: Die Vielfalt der Themen in einem Text (vgl. z. B. auch Ps 35) erhöht die Möglichkeit zur Identifikation.

1168 Ballhorn, Telos, 84.

1169 Auf das Wir des Psalms als Gruppe, die auf Kontinuität angelegt ist, verweisen Alonso Schökel / Carniti, Salmos 2, $1172 \mathrm{f}$.

1170 Vgl. Wallace, Psalms, 150.

1171 Harrelson, Meditation, 182.

1172 Vgl. Clifford, Psalm 90, 205.

1173 Gillmayr-Bucher, Die Psalmen, 265 f. 
von der Gesprächssituation zwischen dem lyrischen Subjekt und Gott dominierten Verse 13-17 erlauben den Leser/innen keine distanzierte Sicht auf die vorgebrachten Äußerungen. Vielmehr sind sie hier stärker aufgefordert, sich mit dem lyrischen Subjekt zu identifizieren und sich dem wir anzuschließen. ${ }^{1174}$

Die LeserInnenidentifikation wird durch die Textkohärenz gesteigert. Trotz Unebenheiten im Textverständnis sind offensichtliche und subtile Verbindungen zwischen den Versen und damit eine kunstvolle Struktur an Stichwortverknüpfungen ${ }^{1175}$ auszumachen, die dazu beitragen, die Lesenden im Textgeschehen $\mathrm{zu}$ verankern und sie nicht aus dem Leseprozess herausfallen zu lassen. Dazu tragen ebenso die synthetischen und synonymen Parallelismen sowie der antithetische Parallelismus bei.

Der Psalm weist in thematischer und zeitlicher Hinsicht Bewegungen auf, die es den Lesenden ermöglichen, die Dynamik des Textes aufzunehmen und in sie einzusteigen. So nimmt der Psalm zuallererst die Lesenden mit auf eine Zeitreise. Dabei führt er, beginnend mit der dauerhaften, vorzeitigen Existenz der Gottheit Israels (V1-2) über die Klage über die Vergänglichkeit der Menschen (V3-6), die Kurzlebigkeit und Mühsal des vom Zorn Gottes geprägten Menschenlebens in Vergangenheit und Gegenwart (V7-10) zu einem Jetzt-Zeitpunkt (V11-12) hin, von dem aus mittels Appell, Wünschen und hoffnungsvollen Bitten der Blick in die freudvolle Zukunft (V13-17) gerichtet ist. ${ }^{1176}$

Und das Gottesbild? Psalm 90 weist der Gottheit Israels durchweg ambivalente Züge zu. ${ }^{177}$ Müller spricht in diesem Zusammenhang von »ärgerlichen Gottesvorstellungen. ${ }^{1178}$ Ps 90 beschreibt zunächst Gott als Zuflucht und Wohnort, als ewigen Bestand, der Halt gibt und Unterschlupf gewährt. Gott ist vor der Schöpfung und zugleich Schöpfer. Die Gottheit steht über der menschlichen Zeit. Gottes Zuwendung ist heilsam. Gott gibt dem Menschenwerk Bestand und kann Lebenstage mit Freude füllen. Bis hierher ist es kein Problem, das je eigene Gottesbild mit jenem des Psalms zu identifizieren, dann wird es allerdings schwieriger. Ps 90 beschreibt Gott als distanziert und unerreichbar. ${ }^{1179}$ Intensi-

1174 Gillmayr-Bucher, Die Psalmen, 266.

1175 Stichwortverbindungen konstatieren u. a. Gillmayr-Bucher, Die Psalmen, 262.

1176 Ähnlich Seybold, Die Psalmen, 356: »Beginnend bei der `Zeit Gottes`, der Ewigkeit, schreitet er fort zur Zeit der Menschen, zur Zeit des Einzellebens, zur gefährdeten und verwirkten Zeit, um - in seiner Gegenwart angekommen (13) - von den Möglichkeiten zukünftiger Zeit zu sprechen.« Den Begriff »Reise« (engl. itinerary, journey) verwendet auch Tucker, Exitus, 154 in seiner Beschreibung für die dem Psalm inhärente Bewegung: »The itinerary of Ps 90 moves the reader along, suggesting that exitus, while experienced along the way, is not the final movement in the work of God. To be more precise, in the journey toward God, exitus is always trumped by anticipated reditus."

1177 Vgl. Weber, Werkbuch 2, 122.

1178 Müller, Der 90. Psalm, 285.

1179 Vgl. Robertson, Literary Criticism, 45. 
viert wird dieses Bild durch die Rede vom Zorn Gottes in allen seinen Dimensionen. Gott hält Leben und Tod in der Hand, bestimmt den Kreislauf des Lebens, lässt Menschen zum Staub zurückkehren, beschränkt und beendet damit menschliches Leben, wird als wutentbrannt und zornglühend dargestellt, als furchterregend und angsteinflößend, ist Bedrücker (V15) und Verursacher der Sterblichkeit (V3-6) sowie verantwortlich für die aktuell erfahrene Not (V7-9). Gerade die zornerfüllte Darstellungsweise Gottes evoziert die Frage, welche tiefgreifenden und dramatischen Erfahrungen dem zugrunde liegen, dass der Gottheit so viel Zorn und Wut zugeschrieben wird. An dieser Stelle kann das eigene Gottesbild irritiert, gesprengt und erweitert werden. Wichtig ist festzuhalten, dass der Zorn keine göttliche Eigenschaft ist, sondern eine Tat Gottes. Dies nimmt der wiederholten Nennung des göttlichen Zornes jedoch keineswegs den Schrecken: »Es zeigt sich vielmehr, dass das Widerfahrnis des Gotteszorns im Zusammenhang von Ps 90 nur einer der Aspekte ist, unter denen das Verhältnis zwischen Gott und Mensch angesichts der menschlichen Vergänglichkeit reflektiert wird. Es steht hier für einen Bereich der Existenz, der sich der Verfügung und dem Verständnis des Menschen gänzlich entzieht. «1180

Als faszinierend erachte ich den Text in Bezug auf seine Ehrlichkeit. Ps 90 verschleiert die Vergänglichkeits- und Todesproblematik nicht, die alle Menschen betrifft, sondern stellt sie Gott klagend, anklagend und bittend gegenüber. »Der Wert des 90 . Psalms liegt ja in der Verweigerung jedes Selbstbetruges, [...] er überzeugt durch seine Ehrlichkeit gegenüber einer religiösen Ungeborgenheit ${ }^{1181}$ und hat gleichzeitig die Funktion, Hoffnung zu generieren. ${ }^{1182}$

Ps 90 ermöglicht durch die Aktualität der Thematik, die Analogiebildung zu heutigen Themen, die expliziten, impliziten und im Leseprozess hervorgerufenen Emotionen, durch Perspektivenlenkung (offenes lyrisches Wir, Wir-Du-Beziehungsnetz, Deixis), Textstruktur und Textdynamik sowie Bewegung in thematischer und vor allem zeitlicher Hinsicht LeserInnenidentifikation. Diese ist dort am größten, wo sich eine hohe Dichte an Deixis, doppelte Emotionalität, dynamische Erzählweise, aktuelle Themen sowie ein positives Gottesbild ineinander verschränken, wie dies in V12-15 der Fall ist.

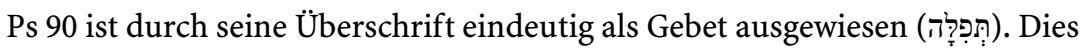
kann dazu beitragen, den Formularcharakter des Textes als Angebot anzunehmen und die eigene Betroffenheit hinsichtlich der im Psalm zur Sprache kommenden Themen und Anliegen in den Text hineinzulegen - mit dem letztlich

1180 Schnocks, Vergänglichkeit, 145.

1181 Müller, Der 90. Psalm, 282. Vgl. ebenso Zenger, Werk, 29. Auf die Provokation der Aussagen des Psalms und die Fragen, die er für die Gegenwart vor allem in Hinsicht auf die Todesproblematik aufwirft, auf die Zweifel und die Anklage Gottes heute verweist Greinacher, Psalm 90, 374ff.

1182 Vgl. Wallace, Psalms, 154. 
allen Psalmen zugrunde liegenden Ziel, sich durch das "Gott [L]ernen ${ }^{1183}$ auf eine Reise zu begeben, auf der man sich der Begrenztheit des menschlichen Lebens bewusst wird und sich gleichzeitig Stück für Stück dem Geheimnis des göttlichen $\mathrm{Du}$ annähert. ${ }^{1184}$

$1183 »$ Von den Psalmen zu sprechen bedeutet immer auch `Gott lernen`, seine Offenbarung lernen, die sich in den Psalmen vermittelt.« Deselaers, Wiederentdeckung, 17.

1184 Tucker, Exitus, 146:»[...] the Psalms are in fact organized along structures of manuduction, guiding community and individual alike, along an itinerary $[. .$.$] of exit and return, to their$ journey to God.» 
Open-Access-Publikation im Sinne der CC-Lizenz BY-NC-ND 4.0

(c) 2019, V\&R unipress GmbH, Göttingen 


\section{Textanalyse Psalm 64}

\section{Inhalt}

Ps 64 schildert im Rückblick die durch gefährlich agierende Feinde hervorgerufene Not sowie das Einschreiten Gottes und die nachfolgende Reaktion (zur Arbeitsübersetzung siehe X Anhang). ${ }^{185}$ Die Darstellung lässt die Worte und Taten von damals als gegenwärtig erscheinen (vgl. Textdynamik und Perspektivenlenkung). ${ }^{1186}$ Eine/ein von Feinden Bedrängte/r bittet Gott um dessen Schutz. Die Feinde gelten als jene, die mit scharfer Zunge durch ihr Wort den Unschuldigen gleichsam mit einem Pfeil beschießen. Sie tun dies unvermittelt und ohne Furcht - weder Gott noch den Menschen gegenüber. Ihre Waffen sind böse Worte und schlechte, unheilvolle Gedanken. Doch dies alles kommt auf sie zurück. Gott schießt nämlich einen Pfeil auf sie, woraufhin unvermittelt Wunden vorhanden sind. Die Feinde straucheln durch ihre eigene Zunge. Alle Menschen, die dies sehen, geraten in (Gottes)Furcht, verkünden und begreifen endlich die Taten Gottes. Der Psalm endet mit dem Fazit, dass sich der Gerechte freuen und

1185 »Ein Stoßgebet aus schwerer Sorge!« bei Schmidt, Die Psalmen, 120. Kraus, Psalmen, 605 zählt den Psalm zu den Gebetsliedern. Gerstenberger, Der bittende Mensch, 116 bezeichnet Ps 64 als echten Bitttext. Als Schutzpsalm (Protective Psalm/prayer for protection) bezeichnen ihn - zufolge Mowinckel - Anderson, The Book of Psalms 1, 460 und Goldingay, Psalms 2, 265. Es gibt keinen Hinweis im Text auf eine mögliche Datierung. Vgl. Groß / Reinelt, Das Buch der Psalmen, 341; Anderson, The Book of Psalms 1, 460; Rogerson / McKay, Psalms 51-100, 69; Tate, Psalms, 133 und Schlögl, Die Psalmen, 91. Ebenso Kraus, Psalmen, 606: „Für die Erklärung der Abfassungszeit fehlt jeder eindeutige Anhaltspunkt.» Anders Terrien, The Psalms, 468, der in der Verbindung von $7 \mathrm{c}$ mit Jer 17,9f als mögliche Abfassungszeit die des Propheten Jeremia (spätes 7. bzw. frühes 6. Jh. v.Chr.) angibt. Briggs / Briggs, Commentary, $76 \mathrm{f}$ lesen den Psalm kollektiv als Hilfeschrei Israels zu Gott um Schutz vor den Feinden, die das Volk verleumden und sich gegen Israel verschwören, und verweisen dabei auf den persischen Hof. Kittel, Die Psalmen, 239 denkt bei der Abfassung an die nachexilische, vor allem an die griechische Zeit, räumt aber ein, dass der Psalm auch früher entstanden sein könnte.

1186 Vgl. Weber, Werkbuch 1, 285. 
bei JHWH bergen kann, sowie mit einem Ausblick auf alle Herzgeraden, die sich rühmen sollen.

\subsection{Sprechstimme und Struktur}

Als Sprechstimme ist durchgehend ein lyrisches Ich anzunehmen, das zu Beginn des Psalms (V2-3) seine Stimme erhebt, im weiteren Verlauf jedoch hinter eine »Erzählstimme« zurücktritt. Angesprochen wird die Gottheit (Elohim) als textinterne Adressatin mittels des Vokativs in 2a. In $6 \mathrm{c}$ wird eine offene Frage gestellt (wer wird sie sehen?), die als Zitat der Feinde gilt. Der Text zeichnet sich durch eine Vielzahl von Rederichtungen und Sprechrichtungswechseln aus (vgl. Perspektivenlenkung).

Ps 64 kann in zwei große Teile gegliedert werden: V1-7 und V8-12, ${ }^{1187}$ wobei als Gliederungskriterium neben dem Subjekts- und Themenwechsel auch jener in die Narrativformen angeführt werden kann. Teil I besteht nach der Überschrift in V1, die den Psalm David zuordnet, aus zwei Gedankenspots: V2-3 beschreibt die Bitte des lyrischen Ich an Gott um Schutz vor den Feinden, während V4-7b die Charakterisierung der Feinde zum Inhalt hat. Der erste Teil wird durch eine weisheitlich geprägte Aussage über das Innere des Menschen abgeschlossen (7c). Die Bewegung des Texts kommt vorerst zur Ruhe. Teil II erzählt zunächst von der Tat Gottes an den Feinden und deren Auswirkungen (V8-9) als Gegenbewegung zu Teil I sowie anschließend von der Konsequenz des göttlichen Eingreifens für die Menschen, den Gerechten und die Herzgeraden (V10-11). ${ }^{188}$ Ps 64 weist eine große Nähe zur Feindpsalmkomposition 52-64 auf. ${ }^{1189}$

1187 Vgl. z. B. Weiser, Die Psalmen 1, 311; Botha, Strategy, 69; Clifford, Psalms 1-72, 298 u. v. a. m. Dahood, Psalms 2, 154 spricht von zwei Bewegungen des Textes: (1) die Bitte um göttlichen Schutz und die Beschreibung der Feinde V1-7; (2) die göttliche Intervention und die Reaktion der Gläubigen (V8-11).

1188 Dieser Gliederung folgen auch u. a. Hossfeld / Zenger, Psalmen 51-100, 204 und Riede, Netz, 365. Auf die besondere Versarchitektur und die kunstvolle Anlage des Psalms verweist Seybold, Poetik der Psalmen, 74.

1189 Vgl. Hossfeld / Zenger, Psalmen 51-100, 205. Parallele Gedanken und gleichlautende sprachliche Ausdrücke wie in Ps 64 lassen sich in Ps 5.7.10-12.14.26.52.55.57 finden. Vgl. Kirkpatrick, Psalms, 357. 


\subsection{Gliederung}

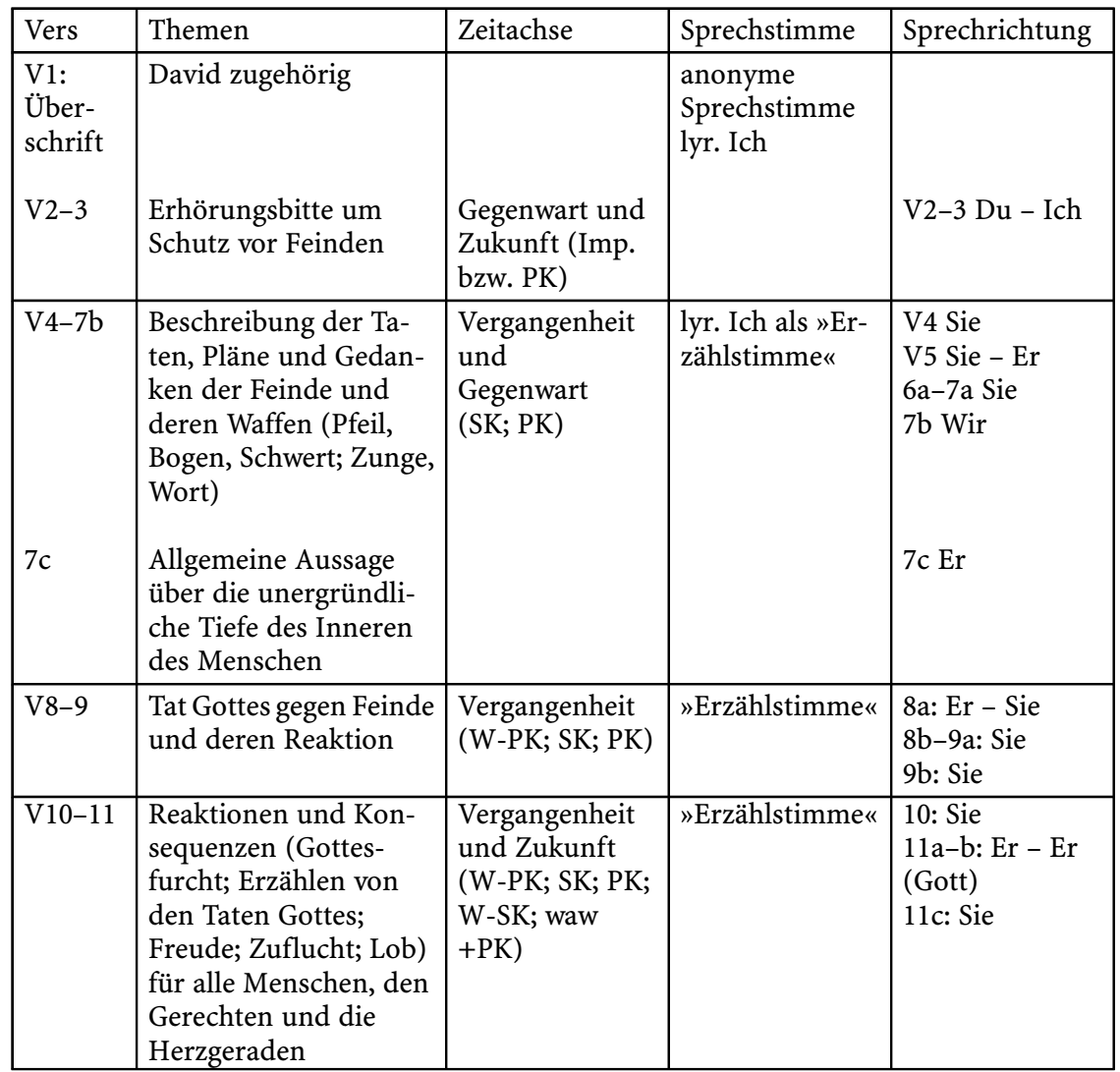

Die inhaltliche Ausrichtung des Psalms verläuft in mehrere Richtungen. So thematisiert der Text die große Wirkmacht von bösartigen Worten, ${ }^{1190}$ verschiebt aber gleichzeitig durch die Intervention Gottes (V8) den Fokus auf den Glauben an einen Gott, der helfend gegen die Wortmächtigen eingreift. ${ }^{1191}$ Eine Botschaft des Psalms lautet daher: "Wo die Gefahr am größten, da ist Gottes Hilfe am nächsten, daher verzage nicht. $"{ }^{192}$ Trotz der immensen Bedrohung durch die Feinde geht es im Psalm nicht um deren Vernichtung, sondern einfach um Schutz vor ihnen. ${ }^{1193}$ Der Text weist einen klaren Aufbau auf und endet mit Zuversicht

1190 »Der Psalm schildert die abgründigen, unheimlichen Wirkungen, die durch tödliche Wünsche und Worte auf einen unschuldigen Menschen ausgeübt werden.« Kraus, Psalmen, 607.

1191 Vgl. Botha, Strategy, 79.

1192 Thalhofer, Erklärung, 364.

1193 Vgl. Goldingay, Psalms 2, 266. 
und Freude. Trotz der Kürze ist Ps 64 von großer Dichte und Dramatik (siehe Textdynamik) gekennzeichnet.

\section{Emotionen}

Wie in den Analysen zuvor liegt hier der Schwerpunkt auf der Analyse expliziter und impliziter Emotionen. Weitere semantische, syntaktische und textkritische Überlegungen, die zu einem besseren Textverständnis beitragen, fließen in die Exegese ein.

\subsection{Vers 1: Auf David hin}

\section{Für den Chorleiter. Ein Psalm. Im Geiste Davids}

Durch die Überschrift wird Psalm 64 nach der Angabe »für den Chormeister« bzw. "Vorsänger" mit David verbunden. Eine konkrete innerbiblische Verknüpfung mit Erzählungen aus dem Leben Davids ist dabei nicht auszumachen. ${ }^{1194}$ Martin Kleer verweist darauf, dass die Lesenden durch die Überschrift angehalten sind, bei der Lektüre und Meditation des Textes an David zu denken. Er bezeichnet die Überschriftennotiz לְְִָו als Identifikationsangebot für Betende, die sich in einer ähnlichen Situation befinden wie die, welche im Psalm geschildert wird: „Der Beter kann sich etwa in vergleichbarer Notlage über das Psalmengebet mit David, dem exemplarisch Leidenden, identifizieren. [...] Die Leseanweisung לדוד lädt den Psalmbeter ein, in eine Schicksalsgemeinschaft mit David zu treten. ${ }^{1195}$ Durch die Zuordnung zu David ${ }^{1196}$ ist damit die Möglichkeit gegeben, den Psalm in seinem Geist und aus seinen Erlebnissen der Bedrängnis, Flucht und Errettung heraus zu lesen und sich mit ihm zu identifizieren. ${ }^{1197}$

1194 Auf die Verfolgung Davids - allerdings ohne Anhaltspunkt in der Überschrift - verweist an dieser Stelle Thalhofer, Erklärung, 364.

1195 Kleer, Sänger, 81. In Bezug auf das Bild Davids in den Psalmen hält er fest: »David ist hier noch nicht der Dichter und Sänger der Psalmen. Stattdessen ist er aber für die Psalmbeter die große Identifikationsfigur « (S. 82).

1196 Vgl. dazu die unterschiedlichen Wiedergabemöglichkeiten von לִ לָזְד bei Kleer, Sänger, 80: »auf David hin«; »in bezug auf David» oder »hinsichtlich Davids«.

1197 Zur LeserInnenlenkung durch die Überschrift siehe auch die Analyse von Ps 30 und Ps 90 sowie Bail, Gendering Laments, 177: »Durch die Psalmüberschriften wird das Lesen und Verstehen des Psalms in eine bestimmte Richtung gelenkt." 


\subsection{Vers 2: Erhörungsbitte}

2a Höre, Gott, meine Stimme in meinem Klagen.

$2 b$ Vor dem Schrecken des Feindes sollst du beschützen mein Leben.

Bereits mit dem ersten inhaltlich bestimmten Vers des Psalms zeigt sich eine Dichte an Emotionalität, die den Beginn des Psalms prägt und auf den Ebenen der Syntax und der Semantik angesiedelt ist. Letztere zeichnet sich in ihrem emotionalen Gehalt durch die Substantive שִיַָ (Klage, Unruhe, Sorge 2a) und (Schrecken, Beben 2b) sowie durch das Verb נצר (beschützen, bewahren 2b) aus. שִיָ bezeichnet eine Emotion im Zusammenhang mit einer inneren Bewegung des Bedenkens, Nachsinnens und Meditierens. Diese äußert sich laut in Form der Freude oder - wie hier in Ps 64 - der Klage: „śjh beinhaltet zwar im Wesentlichen ein Empfinden von bedrückenden wie erfreulichen Erfahrungen und deren Meditieren, doch bleibt dieses Empfinden bzw. Meditieren nicht auf das Seelenleben des Menschen beschränkt, ist keine allein innerliche Angelegenheit. Es zielt vielmehr auf Äußerung durch Verbalisierung. ${ }^{1198}$ Laut Erhard Gerstenberger schildert das Bittelement hier in V2 »das eigene, erbärmliche Schreien, Weinen, Seufzen [...]. ${ }^{1199}$ Das Emotionsfeld der Unruhe und Besorgnis findet hierin einen deutlichen Ausdruck.

Nach der Bitte um Erhörung ${ }^{1200}$ wird jene bedrückende Empfindung artikuliert, welche die Situation des von Feinden bedrängten lyrischen Ich in drastischer Weise beschreibt. Dies tut ebenso das nächste Substantiv auf den Feind bezogen und bezeichnet sowohl den Vorgang des Erschreckens als auch das ausgelöste Beben und Zittern sowie den Gegenstand des Schreckens, also das, was den Schrecken, das Zittern und Beben auslöst. ${ }^{1201}$ Der oder das Schreckenerregende wird entweder durch ein Pronominalsuffix am Nomen oder - wie hier - durch eine entsprechende Genitivkonstruktion spezifiziert. Es handelt sich demnach in Ps 64 um den Schrecken, der vom Feind ausgeht und durch diesen ausgelöst wird. Der stark emotionsbesetzte Begriff gilt als Vergegenständlichung jener Gefahr, die den Schrecken auslöst und damit die Betroffenen in Angst, Zittern und Beben sowie große Sorge und Unruhe versetzt. ${ }^{1202}$ Die Gründe für den Schrecken und für die bösartigen Anfeindungen insgesamt

1198 Hausmann, שִ, 761.

1199 Gerstenberger, Der bittende Mensch, 122.

1200 Gerstenberger, Der bittende Mensch, 120 zählt die Bitte in V2 zu den einleitenden Bitten. $\mathrm{Zu}$ den verschiedenen Bitttypen im individuellen Klagelied vgl. ebd.

1201 Zum Folgenden vgl. Müller, דֵַٍ, 554-557.

1202 Vgl. Anderson, The Book of Psalms 1, 461. Er ergänzt, dass sich פֵַ auch auf jene Erfahrung beziehen kann, die Menschen derart in Schrecken versetzt, dass sie vor Angst gelähmt sind (2 Chr 17,10; 20,29; Ijob 13,11). Ähnlich Rogerson / Mc Kay, Psalms 51-100, 69: »He feels more than threatened; he is alarmed.« 
werden im Psalm nicht genannt. ${ }^{1203}$ Damit diese Bedrohung nicht auf das lyrische Ich trifft, wird mittels der Wurzel נצר um Schutz und Bewahrung gebeten. נצר bezeichnet zunächst konkret das Bewachen, Bewahren und Behüten, etwa des Feldes (Ijob 27,18; 2 Kön 17,9) oder von Obstbäumen (Spr 27,18). Im übertragenen Sinn wird damit z. B. die Bewahrung vor Schwert und Pest $(E z 6,12)$ oder vor dem Bösen (Spr 2,11f; 4,6) zum Ausdruck gebracht. Hier in Ps 64 wird mit der Bitte um נצ' die Fürsorge Gottes für den Einzelnen thematisiert (ebenso Jes 42,6; Ps 32,7; 40,12; 140,2.5; Spr 2,8). ${ }^{1204}$ bezeichnet nicht nur die »sinnliche Wahrnehmung (wozu auch >Hören ‘ gehört), sondern das Tun des zu Bewahrenden. « ${ }^{1205}$ Dieses Achthaben auf das Leben wird in Teilen der Dank- und Klagelieder des Einzelnen ausschließlich auf die Gottheit bezogen; so erscheint JHWH als derjenige, der sowohl willens als auch imstande ist, die bedrängte oder in Not geratene Person zu schützen und zu retten. Die mit נצר ausgedrückte erhaltende und bewahrende Zuwendung JHWHs zum Einzelnen und auch zum Volk Gottes kann in der Fürsorge für das Aufgefundene, das z. B. wie ein Augapfel (Dtn 32,10) bewahrt werden muss, beinahe emotionale Züge annehmen. ${ }^{1206}$ Damit werden die Emotionsfelder der Umsicht und Wachsamkeit sowie der Zuneigung thematisiert.

Auf der Ebene der Syntax ist durch den Imperativ שִׁמַ (höre 2a), durch die direkte Anrede Gottes im Vokativ (2a) sowie durch die Personalform der PK 2.P.sg. in $2 \mathrm{~b}$, die durchweg als Imperativ wiedergegeben wird, ein deutlicher Appell auszumachen, der auf eine große Dringlichkeit des Wunsches nach Änderung der Situation verweist. Diese Dringlichkeit wird dadurch verstärkt, dass das zweite Kolon (2b) nicht die Bitte um Erhörung des Gebets wiederholt (z. B. Ps $61,2)$, sondern sofort zum Thema des Feindesschreckens übergeht. Der Wechsel vom ersten (2a) zum zweiten Kolon (2b) wird also schnell vollzogen. ${ }^{1207}$

Damit werden Emotionen in V2 explizit durch die Klage als lauten Ausdruck (Seufzen, Weinen, Schreien) von innerer Unruhe Sorge und Bedrängnis thematisiert. Der Schrecken lässt auf Gefahr, Bedrohung und die elementare Lebensäußerung der Angst schließen. Das Bewahren enthält die Emotion der Wachsamkeit und Umsicht, die sinnliche Wahrnehmung sowie die heilsam zugewandte Tätigkeit Gottes (Fürsorge). ${ }^{1208}$ Durch die syntaktische Gestaltung des

1203 Groß / Reinelt, Das Buch der Psalmen, 343 sehen in der Schuldlosigkeit des lyr. Ich (vgl. תָт 5a) den Grund der Verfolgung: »Vielleicht liegt gerade darin der tiefste Grund dafür, dass sich die Ungerechten feindlich gegen ihn stellen. Seine Schuldlosigkeit ist ihnen ein Dorn im Auge."

1204 Vgl. Sauer, נצ, $100 \mathrm{f}$.

1205 Wagner, 579.

1206 Vgl. Wagner, נצי, 587.

1207 Vgl. Goldingay, Psalms 2, 266.

1208 Dabei verweist Goldingay, Psalms 2, 266 darauf, dass es beim Terror, vor dem der Psalm 
Verses werden implizit jene Emotionen zum Ausdruck gebracht, die in Verbindung mit Hetze, Bedrängnis und Dringlichkeit stehen. ${ }^{1209}$

\subsection{Vers 3: Versteck erbeten}

$3 a$ Du sollst mich verstecken vor der Gemeinschaft der Übeltäter, $3 b$ vor dem Tumult derer, die Böses tun.

Wie in V2 werden auch hier auf der Ebene der Semantik Emotionen mittels dreier hebräischer Begriffe thematisiert. Mit סתר in der Grundbedeutung "verbergen" ist sowohl das Entziehen einer Person oder Sache aus der Wahrnehmung eines anderen im Sinne des Verhüllens gemeint als auch das sich daraus ergebende Schützen, die Zufluchtnahme. ${ }^{1210}$ Dabei geht es stets um eine personale Beziehung, in der das Subjekt beinahe immer eine Person und das andere Beziehungselement entweder ein Sachverhalt oder auch eine Person ist. In den Psalmen, in denen סתר gehäuft anzutreffen ist, ${ }^{1211}$ wird - wie hier - in den Klagen um den Schutz Gottes gebeten, während in den Vertrauensäußerungen der Schutz, den JHWH gewährt, gerühmt wird (Ps 27,5; 31,21; 32,7; 91,1; 119,114).

Das zweite Wort, das Emotionen thematisiert, ist mit מִרֵצִים (Übeltäter) gegeben. Das Ptz.hi.m.pl. der Wurzel רעע wurde bereits in der Analyse von Ps 90,15 genauer betrachtet. Demnach ist hier in 3a von all jenen die Rede, die sich in einer Versammlung bzw. Gemeinschaft zusammenrotten und Böses tun. Die Feinde agieren also gemeinsam, einer Horde gleich, während das lyrische Ich alleine dasteht. $^{1212}$

Das Tun des Bösen zielt auf diejenigen, welche die soziale Ordnungen auflösen, Dasein und Leben bedrohen, Entwicklungen in Katastrophen enden lassen und das Leben zerstören. Das angestrebte Ziel dieser Aktionen ist der Tod. Parallel zu den Übeltätern werden jene genannt, die Unheil stiften bzw. böse

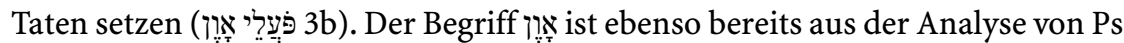
90,10 bekannt und bezeichnet neben dem Machtmissbrauch auch die Unheilsmacht an sich sowie deren Aktivitäten und unheilvolle Konsequenzen. In der

Zuflucht sucht, nicht um das subjektive Gefühl der Furcht und des Grauens geht, sondern um den objektiven Schrecken der Bedrohung, mit dem das betende Ich konfrontiert ist.

1209 Auf die Dringlichkeit in der Aussage verweist auch Firth, Retribution, 97.

1210 Vgl. Wagner, 7 ת 968.

$121117 \mathrm{Mal}$ im hi., fünf Mal im ni. und ein Mal im hit. Vgl. Wehmeier, רת, 174.

1212 Vgl. Clifford, Psalms 1-72, 302: "It is not one but many enemies who are engaged in the destruction, and they operate anonymously with a complete disregard for justice.« Dass die Feinde nicht als Einzelgänger auftreten, sondern pluralisch bezeichnet werden, ist für die Psalmen nichts Ungewöhnliches. Eher selten treten die Feinde wie hier in sogenannten strukturierten Gruppen (Bande, Schar, Versammlung) auf. Vgl. Gerstenberger, Der bittende Mensch, 159f mit Verweis auf Ps 22,17; 26,5; 55,15; 86,14 u. ä. 
Übersetzung ist die Wiedergabe mit "Unrecht", "Unheil«, "Übeltat" sowie »Trug« und »Täuschung« üblich. Die Übeltäter und Unheilstifter können durch ihr auf Unheil und Zerstörung ausgerichtetes Handeln bei den Betroffenen Panik, Angst und Besorgnis, eventuell auch Wut und Verachtung auslösen. Hier in Ps 64 wird durch die Präzisierung der Feinde in V2-3 die Angst und Hilflosigkeit des betenden Ich weiter gesteigert. ${ }^{1213}$ "Sie drohen und üben Terror aus (פחד 'Schrecken`), sie agieren als `kriminelle Vereinigung` und sintrigierende Cliquen ( 710 >vertrauliche Besprechung, Kreis von Vertrauten $\triangleleft$ HAL 703f.) und sie liegen buchstäblich als bedrohlicher >Dauerlärm ^ (רגשה >Unruhe, Erregung`, HAL 1140) über der Welt. ${ }^{1214}$

Mit dem dritten Begriff, der emotional konnotiert ist - dem expliziten Emotionswort אָָ -, wird der Eingangsteil des Psalms beschlossen, der als Hilfeschrei aus tiefster Not gestaltet ist ${ }^{1215}$. Syntaktisch verstärkt die Personalform in der PK 2.P.sg. in 3a, die wie in $2 b$ durchgehend als Imperativ wiedergegeben wird, die aus V2 bereits eruierte Dringlichkeit und den Appellcharakter des Verses. ${ }^{1216}$ Die PKFormen verweisen laut Frank Matheus auf die Zukunft des deiktischen Zentrums, das hier im lyrischen Ich besteht. ${ }^{1217}$

Der emotionale Gehalt von V3 lässt sich somit durch die in expliziten Emotionswörtern ausgedrückten Emotionen der Geborgenheit in der Bitte um Schutz und Zuflucht sowie durch die mit den bedrohlichen und zerstörerischen Taten der Übeltäter und Unheilstiftenden verbundenen Emotionen der Panik, Angst, Besorgnis, Ohnmacht und Hilflosigkeit zusammenfassen. Implizit wird durch die Syntax, die an den Appellcharakter von V2 anschließt, sowohl die Dringlichkeit ausgedrückt als auch die Angst, die durch die Bedrohung und Gefahr der Feinde ausgeht. Zur Zuschreibung der Emotionen: Die Emotion der Geborgenheit und des Schutzes ist mit Gott und dessen bewahrender Hin- und Zuwendung verbunden, die Emotionen der Angst und Panik sind an das lyrische Ich geknüpft, und die mit der Lebenszerstörung verbundenen Emotionen (Schreck, eventuell auch Hass) mit den Feinden.

1213 Darauf, dass sich der Psalmist vor Sorge und Angst ohne den Hilferuf nach Schutz und Zuflucht bei Gott richtiggehend verzehren könnte, verweist Weiser, Die Psalmen 1, 312.

1214 Hossfeld / Zenger, Psalmen 51-100, 207.

1215 Vgl. Kraus, Psalmen, 606.

1216 Auf die durch »äußere Merkmale des Vortrags« erzeugte Dringlichkeit der Bitte verweist ebenso Gerstenberger, Der bittende Mensch, 121.

1217 Vgl. Matheus, Zeit, 435. 


\subsection{Vers 4: Lebensgefährliche Worte}

4a Die geschärft haben wie das Schwert ihre Zunge,

$4 b$ sie haben angelegt ihren Pfeil - ein bitteres Wort,

Die in der SK formulierten Handlungen dienen zur Beschreibung dessen, was die Übeltäter und Unheilstifter getan haben, um zu ebensolchen zu werden. ${ }^{1218}$ Die Beschreibung erfolgt mittels metaphorischer Rede, die sich durch die Verschränkung von Kriegs- (Schwert 4a; Pfeil und Bogen 4b) sowie Jagdmotivik auszeichnet (ebenso Pfeil und Bogen 4b; Fallstricke/Klappnetze 6b). Die Bildbereiche aus Krieg und Jagd werden auf das Sprechen der Feinde (Zunge 4a.9a, bitteres bzw. böses Wort 4b.6a) übertragen. Zunächst wird die Zunge mit einem Schwert verglichen (Ps 57,5). Dieses gilt als Nahkampfwaffe ${ }^{1219}$ und besteht aus einer Klinge und einem Griff mit dem Heft. Die zwei Schneiden des Schwertes wurden geschärft bzw. gewetzt, um ein spitzes bzw. scharfes Schwert zu erhalten, ${ }^{1220}$ was hier in Ps 64 als kriegsvorbereitende Maßnahme geschildert wird. Mit diesem Vergleich wird die verletzende Dimension von Worten, die wie eine schneidend scharfe Klinge des Schwertes Wunden zufügen können, drastisch dargestellt. Die Feinde werden zu Kriegern, die im Kampf das Schwert zücken. Während das Schärfen des Schwertes Bestandteil der Kriegsvorbereitung ist, wird mit dem Treten des Bogens und Anlegen des Pfeiles auf die unmittelbare Nähe der Kampfhandlung verwiesen. Pfeil und Bogen sind Fernkampfwaffen und sowohl Kriegs- als auch Jagdinstrumente. Der Bogen (קֶֶׁ), der hier in V4 nicht erwähnt wird, wohl aber im Treten (דרך) (T) $^{1221}$ impliziert ist (siehe unten), dient dabei als Abschnellgerät. Er wird vor dem Schuss mit der Hand oder - wie hier durch Aufstemmen des Fußes gegen die Rundung des Bogens gespannt (Jes 5,28; Ps 7,13; 11,2; 37,14 u. a.). Die eigentliche Waffe ist dann der Pfeil, dessen Spitze tödliche Verletzungen bewirken soll und mit den entsprechenden Materialien (Feuerstein, Metall etc.; auch Gift) ausgestattet sein kann. Die Feinde schießen auf den Unschuldigen mit Worten, wie Pfeilschützen in einer Schlacht ihre Pfeile zum Abschuss bringen. Der Pfeil steht hier als Bild für die Gefährlichkeit der

1218 Zur Erinnerung: Die x-SK sowie SK-x-Formen verweisen laut Matheus, Zeit, 435 auf die Vergangenheit des deiktischen Zentrums (vgl. III Methodik 3.3.1).

$1219 \mathrm{Zu}$ diesen zählen neben dem Schwert bzw. Dolch noch Speer bzw. Lanze und Keule. Vgl. Riede, Netz, 123.

1220 Vgl. zu den folgenden Ausführungen über Schwert, Pfeil und Bogen Riede, Netz, 124-126. Siehe dazu die Übersetzung bei Miller, Die Psalmen, 116: "Sie wetzen ihr Zunge wie ein Schwert, zu bittrer Rede spannen sie den Bogen, und zielen heimlich auf den Frommen." Ähnlich Kittel, Die Psalmen, 236: »die da wetzen wie ein Schwert ihre Zunge, ihren Pfeil spannen zu bitterer Rede.»

1221 Kraus, Psalmen, 605 stellt die Frage, ob die Wurzel דרך in diesem Kontext die Bedeutung "schussfertig machen« in sich trägt. 
Zunge und die tödliche Gefahr, die von ihren Worten ausgehen kann. ${ }^{122}$ Die tödlichen Worte der Feinde schneiden und durchbohren. ${ }^{1223}$ V4 berichtet von Fern- und Nahkampfwaffen der Feinde und zeigt damit »die Überlegenheit der Gegner, die den Beter mit ihren Worten und Handlungen angreifen und ihn wie mit >echten` Waffen so verletzen bzw. in der Ehre treffen können, dass sein Leben und seine Existenz ernsthaft in Gefahr sind. ${ }^{1224}$ Durch die metaphorische Rede, die mit Worten die Plastizität und Tiefendimension des Kampfes verdeutlicht, wird den Lesenden ein Einblick in die hohe Relevanz der Bedrohung verschafft, die von den Übeltätern ausgeht. ${ }^{1225}$ "Dass diese >Waffen Hinterhalt, aus der Distanz und vor allem, wenn sie von einer Gruppe gemeinsam und gezielt eingesetzt werden, tödlich sind, ist eine Erfahrung, die bis heute gilt. Wo das Opfer sich weder verteidigen noch falschem Gerede widersprechen kann [...], hat gerade der >Unschuldige keine Chance. ${ }^{1226}$

Das bittere Wort trifft den Unschuldigen wie ein Pfeil (V5). Dabei ist das Adjektiv teren Geschmack, der eine negative Gefühlsreaktion hervorruft. ${ }^{1227}$ Demzufolge wird מِ bildlich verwendet, z. B. für Gemütszustände (Rut 1,13) oder wie hier für die nähere Beschreibung der Worte. So wird in V4 »das Schärfen des Schwertes, das Treten des Pfeils verglichen mit bösen, bitteren Reden, die verwunden und wehtun «, ${ }^{1228}$ sowie mit zerstörerischen, verletzenden und bösartigen Worten. ${ }^{1229}$ Um welche Worte es sich hier genau handelt, bleibt offen. Die Vermutungen gehen in Richtung (falsche) Anklage, Lüge, Verleumdung, Beschimpfung, Diffamierung, Beleidigung, üble Nachrede, Kränkung, Intrige, Fluch oder Zauberwort. $^{1230}$

4b ist durch ein Stilmittel gekennzeichnet, durch das ein Verb (hier: דרך gehen, treten) nicht mit dem adäquaten Objekt (קֶֶֶ Bogen; dieser ist hier eben ausgelassen), sondern mit dem nächsten Objekt - wie hier mit dem Pfeil - verbunden wird (vgl. auch Ps 58,8). Das Treten bzw. Anspannen des Bogens und das Pfeil-Anlegen wird damit als einziges Geschehen geschildert anstatt, wie üblich,

1222 Der Vergleich böser Worte mit Pfeilen ist im Psalter bekannt (Ps 7,13f; 11,2; 37, 14; 52,4; 57,5; 59,8). Vgl. Keel, Feinde, 171.

1223 Vgl. Wilson, Psalms, 899.

1224 Riede, Netz, 140.

1225 Vgl. Botha, Strategy, 71.

1226 Hossfeld / Zenger, Psalmen 51-100, 208.

1227 Vgl. Ringgren, מרר, 17.

1228 Riede, Netz, 366.

1229 Vgl. Alonso Schökel / Carniti, Salmos 1, 840.

1230 Vgl. Keel, Feinde, 171f; Riede, Netz, 366; Anderson, The Book of Psalms 1, 461; Tate, Psalms, 133 und Alonso Schökel / Carniti, Salmos 1, 839. 
mit zwei Verben (treten; anlegen) und zwei Objekten (Bogen; Pfeil). ${ }^{1231}$ Wie bereits erwähnt kann der Pfeil neben Bronze- und Eisenspitzen auch spezielle Brand- und Giftpfeilspitzen (Ijob 6,4) tragen, die in der nachfolgenden Phrase »bitteres Wort« anklingen, was vielfach mit "giftiges Wort« übersetzt wird. ${ }^{1232}$ In V4 kann der Pfeil sowohl Teil der Aussage »sie haben getreten ihren Pfeil« als auch Teil der nachfolgenden Phrase »ihr Pfeil ein bitteres Wort « gewertet werden. In der Übersetzung ist es entsprechend schwierig bis schier unmöglich, dies adäquat wiederzugeben.

Worte können wie die scharfe Klinge eines Schwertes Wunden zufügen und wie ein Giftpfeil treffen. Die in diesem Vers verwendeten Vergleiche verstärken die Verletzungsgefahr und die tödliche Bedrohung, die auf das lyrische Ich einwirken, das sowohl von Ferne als auch in der Nähe gejagt wird. Dieses kriegsähnliche Bedrohungsszenario ist existenzgefährdend und ohne Möglichkeit zur Verteidigung. Auf der Ebene der Emotionen kommen in diesem Vers jene zum Tragen, die mit der von den Übeltätern ausgehenden Bedrohung und Verletzungsgefahr im Zusammenhang stehen, in der metaphorischen Rede implizit vorhanden sind und für das lyrische Ich gelten: Da sind zunächst Angst, Panik und Schreck zu nennen und daneben jene Emotionen, die mit tödlicher Bedrohung, der Gefahr durch Beschuss mit Pfeilen bzw. Worten verbunden werden. Das Adjektiv »bitter« verweist auf einen negativen Gefühlszustand, der nicht näher definiert wird, hier im Kontext aber auf giftige Worte bezogen wird.

\subsection{Vers 5: Unvermuteter Beschuss}

5 a um zu schießen in dem Versteck auf den Unschuldigen.

$5 b$ Plötzlich schießen sie auf ihn und fürchten sich nicht.

Die in 5b und V6 in der PK formulierten Handlungen sind Umstandsangaben, die als Folge der SK-Handlungen aus V4 und als deren Kommentierung betrachtet werden können. Die Feinde werden so beschrieben, dass sie im Geheimen agieren und vom Versteck aus schießen, womit nun nach den Kriegsvorbereitungen aus V4 die eigentliche Kampfaktion erreicht ist. Einerseits klingt durch das Auflauern im Geheimen eher eine Jagd als ein Kriegsgeschehen an, andererseits wird das Bild eines Heckenschützen evoziert, der in den Büschen mit gespannter Bogensehne wartet, sowie das Bild des Opfers, das den Pfad entlang

1231 Vgl. Weber, Werkbuch 2, 285; Schmidt, Die Psalmen, 120 und Alonso Schökel / Carniti, Salmos 1, 840 .

1232 Vgl. Hossfeld / Zenger, Psalmen 51-100, 203; Kirkpatrick, Psalms, 358; Cohen, The Psalms, 199; Botha, Strategy, 67; Tate, Psalms, 130f; Ketter, Die Psalmen, 85 und Dahood, Psalms 2, 104. 
kommt, woraufhin der Pfeil abgeschossen wird. (Versteck) wird die Wurzel רת aus 3a wieder aufgenommen. Hier steht die Dimension des Verhüllens im Zentrum, die aus der Perspektive der Angreifenden zugleich die Dimension des Schutzes aufweist. Beide Ebenen klingen in der Wurzel an (V3). Die Übeltäter und Unheilstifter scheuen sich vor einer direkten Begegnung mit dem Betroffenen, was durchweg als Feigheit und Hinterlist im Kampf (mit Worten und/oder Waffen) kommentiert wird. ${ }^{1234}$

Ein emotionaler Gehalt ist durch das Adjektiv (ữ (unschuldig, aufrichtig, untadelig) und das explizite Emotionswort ירא (fürchten) gegeben. Das Adjektiv תמם (vollständig, fertig sein/werden; zu einem Abschluss bringen) ab, die in $7 \mathrm{~b}$ abermals aufgenommen wird und sich dort auf die Tatsache bezieht, dass etwas zu Ende ist bzw. gebracht wurde (inkl. negativer Konnotation), während hier mit dem Adjektiv die positive Eigenschaft der Rechtschaffenheit gemeint ist: "Der hebr. Begriff von >Vollständigkeit, Abgerundetsein eines Verhaltens oder einer Lebensweise meint zuerst die Übereinstimmung zwischen Wort, Absicht und Tat, die dann darüberhinaus mit den im Gemeinschaftsleben der Menschen geltenden Normen im Einklang stehen. [...] Die Wortgruppe tmm bezeichnet das Richtige, Gutartige, Gerade, Rechte, wie dies in einer einmaligen Handlung oder in der gesamten Lebensführung seinen Ausdruck findet. $\aleph^{1235}$ Der Unschuldige bzw. Redliche, auf den in 5a geschossen wird, steht demnach semantisch mit denjenigen in Verbindung, die aufrichtigen bzw. geraden Herzens sind (11c). Der Schuss auf den Unschuldigen erfolgt unvermittelt: »Wie von einem plötzlich abgeschossenen Pfeil soll er durch die unerwarteten heimlichen Verleumdungen getroffen und erledigt werden. ${ }^{1236}$ Wie das Rüsten der Waffen aus V4 löst dieses plötzliche Schießen aus dem Versteck Unsicherheit auf Seiten des lyrischen Ich aus. ${ }^{1237}$

Eine weitere Emotion wird durch das Temporaladverb פְִּ zum Ausdruck gebracht. Diesem dürfte das Nomen »Augenblick« zugrunde liegen. Mit פְְִּאָם wird im AT überwiegend ein unheilvolles Ereignis qualifiziert, was auch hier in V5 der Fall ist. ${ }^{1238}$ Das Wort wird auch mit »unvermutet, sofort, jählings, ur-

1233 Vgl. Limburg, Psalms, 212.

1234 Vgl. Lamparter, Das Buch der Psalmen 1, 308 und Nötscher, Die Psalmen, 137. Ähnlich Ketter, Die Psalmen, 85:»Die Feinde Gottes haben zu allen Zeiten lieber aus dem Hinterhalt mit den giftigen Waffen der Lüge und Verleumdung als in ehrlichem, offenem Kampfe ihre Ziele zu erreichen gesucht. [...] Aber mit all ihrer Hinterlist gewinnen sie nur kurze Scheinerfolge."

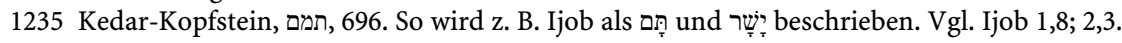

1236 Riede, Netz, 366.

1237 Vgl. Keel, Feinde, 195. Er hält dazu fest: „Die Fülle von Bildern weist nicht auf einen konkreten Vorgang, sondern auf ein unsagbares Grauen, das den Beter erfasst hat. Diesem versucht er Ausdruck zu geben."

1238 Jes 29,5; Jer 6,26; $15,8 \mathrm{f}$. 
plötzlich « ${ }^{1239}$ wiedergegeben und trägt den Überraschungseffekt und damit die Emotion der Überraschung in sich. Im Psalter kommt das Temporaladverb nur in Ps 64 vor. Diese mit Plötzlichkeit hereinbrechende Begebenheit, die in 5b von den Feinden ausgeht, trifft allerdings in $8 \mathrm{a}$ die Feinde selbst durch die (überraschende) Tat Gottes. Diesbezüglich ist von einer Entsprechungsstrafe die Rede, die im Zusammenhang mit dem Tun-Ergehen-Zusammenhang steht, der dem Psalm zugrunde liegt: »Wie die Feinde des Beters unversehens Denunziationen wie einen Pfeil gegen ihn schleudern (v. 5), so trifft sie Gott plötzlich mit seinem Pfeil der Strafe (v. 8). «"1240

Abschließend wird mit der Verneinung וְלא יירָאו gerade darauf verwiesen, dass die Feinde keine Angst haben, weder vor den Menschen, noch ist ihnen Gottesfurcht (vgl. 10a) eigen. ${ }^{1241}$

Explizit wird in diesem Vers die Emotion der Angst - allerdings verneint thematisiert und den Feinden zugeschrieben. Während Letztere also offensichtlich und explizit keine Angst haben, lässt sich dies für den Unschuldigen implizit aus dem Inhalt des Verses erschließen. Dieser hat wohl Angst, wenn heimlich und unvermutet auf ihn geschossen wird. Die Emotion der Überraschung (explizites Emotionswort) spielt dabei eine große Rolle. Mit dem Unschuldigen sind ferner jene Emotionen verknüpft, die mit dessen Gutsein und Aufrichtigkeit sowie Geradlinigkeit in Verbindung stehen, während mit den Feinden jene impliziten Emotionen verbunden sind, die mit Hinterlist, Tücke durch Agieren aus dem Versteck heraus einschließlich der Scheu vor einer Konfrontation zusammenhängen.

6a Sie machen sich stark mit bösem Wort, $6 b$ sie erzählen davon, Klappnetze zu verstecken. $6 c$ Sie haben gesagt: »Wer wird sie sehen?»

1239 Vgl. dazu z. B. Thalkamp, Erklärung, $363 \mathrm{f}$ und Wutz, Die Psalmen, 159.

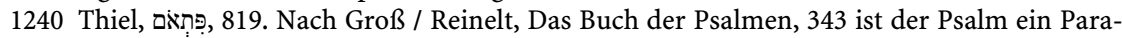
debeispiel für den Tun-Ergehen-Zusammenhang: »Pläne und Vorhaben der Gegner sind von Gott dazu bestimmt, sich schließlich gegen die Urheber selbst zu wenden. Das ist Gott sich selbst schuldig. Denn in dem Verfolgten treffen die Gegner eigentlich Gott und dessen Ratschluss mit den Menschen." Auf den Tun-Ergehen-Zusammenhang verweist auch Beyerlin, Rettung, 30. Daneben hält er fest: „Von einem Strafgericht Gottes ist fraglos die Rede.» (S. 29) Beyerlin denkt dabei nicht an ein kultisches Verfahren, sondern, basierend auf der Hörbitte von V2-3, eher an einen Antrag auf Tempelasyl. Ob dieses tatsächlich angestrebt wurde und dem betenden Ich zuteil geworden ist, bleibt allerdings fraglich. Vgl. dazu auch McCann, Psalms, 930.

1241 Vgl. Hupfeld, Die Psalmen, 112; Cohen, The Psalms, 199 und Delitzsch, Psalmen, 428. 
Wie die Analyse von Ps 147,13 gezeigt hat, wird mim pi. für das Starkmachen, Befestigen und Instandsetzen von Gegenständen verwendet. Hier in Ps 64 zeigt sich, dass durch bösartige Worte Stärke ausgeübt werden kann. Gedeutet wird der Vers in Richtung Festhalten, Beharrlichkeit und Entschlossenheit. ${ }^{1242}$ Marvin Tate sieht in 6a die Idee ausgedrückt, dass sich die Feinde entweder selbst für ihr Streben und Bemühen stärken, den Feind zu fangen, oder dass sie sich an ihren Plänen festhalten. ${ }^{1243}$ Im Sinne der Selbststärkung und Selbstbeeinflussung könnte hier auch an Autosuggestion gedacht werden. Die Stärke wird hier mit Bosheit in Zusammenhang gebracht. Mit dem Adjektiv רֵ (böse) wird die Wurzel רע aus 3b (bzw. Ps 90,15) wieder aufgenommen, welche die Unheilstifter und die, die Böses tun, charakterisiert. Damit ist in V6 neben חז ein weiteres explizites Emotionswort vorhanden, das hier auf das Wort bezogen wird. Die Stärke der Feinde liegt damit in bösen, bedrohlichen, lebenszerstörenden Worten, die als Angriff auf Dasein und Leben gelten. Das Tun der Feinde, das bereits in V5 als heimlich beschrieben wird, wird hier durch ihre Heimlichtuerei weitergeführt, indem zunächst mit dem Verstecken der Fallstricke bzw. Klappnetze ein Jagdmotiv eingespielt wird. Das Motiv des Verborgenen kommt durch die rhetorische Frage nach dem Sehen mit der zu erwartenden Antwort »Niemand « abermals zur Darstellung. Das Nicht-Sehen, das die vor Selbstsicherheit strotzende Frage der Feinde impliziert, bezieht sich sowohl auf Menschen als auch darauf, dass auch die Gottheit ihr Tun und Denken nicht wahrnimmt und daher nicht in ihre Pläne eingreift. ${ }^{1244}$ Die Feinde vertrauen ihrer eigenen Arroganz und Verschlagenheit und nehmen an, dass sie weiterhin im Geheimen agieren können. ${ }^{1245}$ Dies wird mit dem Bild der Klappnetze (מוֹקi) zum Ausdruck gebracht. Diese werden im Vogelfang eingesetzt und so angebracht, dass die Vögel diese nicht als Fallen erkennen. ${ }^{1246}$ Die Wiedergabe mit "geheime Schlingen $" ~{ }^{1247}$ weist auf die Eigenschaft der Unsichtbarkeit der Fallen hin. Die geheimen Fallen könnten sich auch auf verbale Attacken beziehen - analog zur metaphorischen Rede über Schwert und Pfeil. ${ }^{1248}$

V6 thematisiert Emotionen, die im Zusammenhang mit dem Tun und Reden der Feinde stehen. Es sind dies jene, die mit deren Entschlossenheit und (ver-

1242 »Sie sind fest entschlossen zu bösem Tun.« Groß / Reinelt, Das Buch der Psalmen, 342. Ähnlich Hupfeld, Die Psalmen, 113:»[S]ie machen sich fest [...] sie nehmen ihn sich fest vor, womit das Beharren gegeben ist."

1243 Vgl. Tate, Psalms, 131.

1244 Vgl. Anderson, The Book of Psalms 1, 462. Er folgert: »They trust in their own arrogance and shrewdness."

1245 Vgl. Brueggemann / Bellinger, Psalms, 281.

1246 Vgl. Hossfeld / Zenger, Psalmen 51-100, 208 und Riede, Netz, 342f.

1247 Bonkamp, Die Psalmen, 299.

1248 Vgl. Herkenne, Das Buch der Psalmen, 217, der die Fallen als ein Bild für die geheimen Nachstellungen der Feinde betrachtet. 
meintlicher) Stärke verbunden sind, sowie auch die Emotionen des Stolzes und der Selbstsicherheit.

\subsection{Vers 7: Verkehrte Gedanken}

7a Sie planen Schlechtigkeiten:

$7 b »$ Wir haben es vollendet. Der Plan ist durchdacht."

$7 c$ Und das Innere eines Menschen, das Herz (ist) unergründlich.

Die Charakterisierung der Feinde durch böse Taten (V3) und böse Worte (V6) wird hier durch schlechte Gedanken fortgesetzt. Die Feinde denken sich Schlechtigkeiten, Ungerechtigkeiten, Verkehrtheiten und Bosheiten aus (עוֹלו).

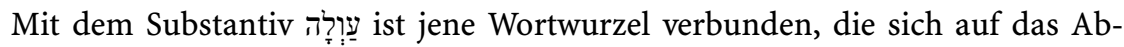
weichen vom rechten Weg, auf das Sichvergehen bzw. Verkehrthandeln bezieht. Im Gegensatz dazu stehen das Richtige und Redliche, der Untadelige bzw. Unschuldige (V5) sowie der Gerechte (V11). ${ }^{1249}$

Während $7 \mathrm{~b}$ schwer wiederzugeben ist und teilweise als unübersetzbar gilt, ${ }^{1250}$ wird in $7 \mathrm{c}$ darüber diskutiert, welcher Stimme im Text dieses Kolon zuzuordnen ist. Einige Übersetzungen und KommentatorInnen zählen $7 c$ zum Zitat der Feinde und legen ihnen diesen allgemein formulierten Satz in den Mund. ${ }^{1251}$ Andere betrachten ihn als weisheitliche Aussage der Sprechstimme des Textes. ${ }^{1252}$ Inhaltlich bezeichnet die Wurzel עמק Tiefe im wörtlichen oder abgeleiteten Sinn. So kann eine Fallgrube tief sein (Hos 5,2; 9,9). Das hier gebrauchte Adjektiv עָמסק bezeichnet nur in seltenen Fällen eine feststellbare Tiefe. Es wird hauptsächlich bildlich verwendet. So sind die Worte bzw. Vorhaben aus dem Mund eines Mannes tiefe Wasser (Spr 18,4; 20,5), also unergründlich bzw. eventuell auch gefährlich. Auch die Unterwelt kann tief und damit unzugänglich und unerforschlich sein (Ijob 11,8). Diese Unergründbarkeit wird hier auf das menschliche

1249 Vgl. Schreiner, עָָ, $1136 \mathrm{f}$.

1250 »Der Text ist entstellt. « Kraus, Psalmen, 605. »The text of v 7 is extremely difficult and no translation should be treated with confidence.« Tate, Psalms, 131. "The whole verse is obscure.« Kissane, Psalms, 273.

1251 Vgl. z. B. EÜ und Goldingay, Psalms 2, 265.268. Hupfeld, Die Psalmen, 114 bringt den Vers ebenso mit den Feinden in Verbindung und verweist auf das Herz als tiefe und unerschöpflich Quelle sowie als "Vorrat, woraus sie ihre Anschläge nehmen." Laut Kraus, Psalmen, 607 könnte die Aussage in Anlehnung an Jer 17,9 auf ein weisheitliches Sprichwort zurückgehen, das die Unergründlichkeit des Inneren eines Menschen thematisiert. Er ordnet den Satz den Feinden zu und hält fest (ebd.): »Doch diese Erkenntnis dient den Verfolgern nur als Beleg für die Unerreichbarkeit ihres Frevels und als Ausdruck verstocktester Sicherheit."

1252 Siehe dazu meine Wiedergabe und z. B. Delitzsch, Psalmen, 429; Ketter, Die Psalmen, 85 sowie Schlögl, Die Psalmen, 91. 
Innenleben bezogen (vgl. inhaltlich auch Spr 25,3). ${ }^{1253}$ Auch wenn das Adjektiv "tief" an keiner Stelle im AT mit »schlecht « verbunden wird, so wird doch im AT vom Herzen des Menschen als Sitz böser Gedanken und Auslöser furchtbarer Taten gesprochen. ${ }^{1254}$ Eine positive Deutung im Sinne der Aussage über die Tiefe bzw. den Tiefgang des menschlichen Herzens lässt sich hier auch vom Kontext her nicht erheben, der vom Heimlichen und Verstecken (3a; 5a; 6b) sowie von schlechten Gedanken und Plänen im Inneren der Feinde (7a) erzählt. Es geht an dieser Stelle vielmehr um die letztendliche Unergründbarkeit und Unerforschlichkeit des menschlichen Innenlebens. ${ }^{1255}$

Die in diesem Vers thematisierten Emotionen hängen einerseits mit der Ungerechtigkeit, Schlechtigkeit und Bosheit der feindliche Pläne zusammen, und andererseits sind sie mit der Tiefe, Unergründlichkeit und eventuell auch Unheimlichkeit des menschlichen Inneren verbunden.

\subsection{Vers 8: ... und Gott greift ein}

8 a Und dann schoss Gott einen Pfeil auf sie.

$8 b$ Plötzlich waren ihre Wunden da.

Mit V8 setzt eine Kette von Narrativen (8a; 9a; 10a.b) ein, die den Handlungsfortschritt und Progress in der erzählten Welt einleiten und ausbauen. Mit den W-PK-Formen ist außerdem angezeigt, dass die Sprechstimme in den Modus des Erzählens und damit die Gesprächshaltung wechselt. ${ }^{1256}$ In dieser Haltung gehören die Ereignisse zum Äußerungszeitpunkt der Vergangenheit an. ${ }^{1257}$ Die Kommunikationsrichtung ist passiv-einseitig. Viele KommentatorInnen sehen die W-PK-Formen als Problem und übersetzen präsentisch, mit jussivischer Bedeutung oder zukünftig. Dabei liegt das Verständnis zugrunde, dass Gott eingreifen wird. Dahinter steht die Argumentation, dass ansonsten die Eingangsbitte um Schutz bedeutungslos wäre, denn wozu sollte man Gott um etwas bitten, das er bereits getan hat? ${ }^{1258}$ An dieser Stelle stellen sich grundsätzliche Fragen zur

1253 Vgl. Beyse, עִמק, $225 \mathrm{f}$.

1254 Gen 6,5; 8,21; Koh 7,24; 8,11; 9,3; Jer 17,9.

1255 Herz und Innenleben sind »tief verhüllt« bei De Wette, Commentar, 345. Negativer übersetzt z. B. Lamparter, Das Buch der Psalmen 1, 306: »ein Abgrund ist eines jeden Sinn und Herz.« Ähnlich Groß / Reinelt, Das Buch der Psalmen, 342: »Ihr Inneres ist heillos verdorben, ihr Herz ist ein Abgrund."

1256 Vgl. Matheus, Zeit, 435. Ebenso Seybold, Poetik der erzählenden Literatur, 33.

1257 So z. B. in der Übersetzung von Goldingay, Psalms 2, 265.

1258 Vgl. Firth, Retribution, 99. Er führt vier mögliche Lesarten an: als Optativ (Wunsch), als Beschreibung vergangener Taten, als prophetisches Perfekt (vgl. z. B. Cohen, The Psalms, 200) oder als Futur. So liest z. B. Schmidt, Die Psalmen, 120 diesen Vers als Gegenfluch, der den Wunsch ausdrückt, dass Gottes Pfeil die Feinde treffen möge: „So schieße sie Gott mit 
Hermeneutik der Psalmen, welche ja als kunstvoll gestaltete (vgl. z. B. das Stilmittel in V4) literarische Texte immer bereits eine Reflexion auf bestimmte Erfahrungen darstellen. Eine/ein von solch einer Gefahr und Horde von Feinden Bedrängte/r wie in Ps 64 muss zunächst aus der Situation entkommen, bevor er/ sie diese schriftlich festhalten kann. Daher verstehe ich, wie eingangs erwähnt, den Text als Reflexion auf eine Erfahrung. Jenseits der Frage nach dem Tempus stellt der Psalm klar, dass diese Aktionen - unabhängig davon, ob sie nun vergangen, gegenwärtig oder zukünftig übersetzt werden - tatsächlich stattfinden, und dass nicht nur die Feinde die ihnen zugeschriebenen Handlungen ausführen, sondern vor allem auch Gott fähig ist und über die Macht verfügt, aktiv einzugreifen. Das lyrische Ich wird hier nicht aktiv. Es ist die Gottheit, die durch die Entmachtung der Übeltäter der feindlichen Bedrohung ein Ende setzt. Die Darstellung der einen Pfeil abschießenden Gottheit setzt die Kriegsmetaphorik aus V4-5 fort. Dort werden die Feinde als Krieger und Jäger porträtiert, hier Gott. ${ }^{1259}$ Auch mythische Anklänge an Pfeile abschießende Gottheiten im Kampf gegen den Chaosdrachen können an dieser Stelle durchscheinen. ${ }^{1260}$ Wie auch immer das Bild zu deuten ist: "[Es] kommt die Zuversicht, ja Gewißheit zum Ausdruck, dass Gott diese lebenszerstörerische Unheilsmacht der Bösen bricht, um seine Welt als einen Ort des Lebens und als >Werk Gottes`(V10) zu verteidigen. ${ }^{1261}$ In $4 \mathrm{~b}$ ist es das Wort, das gleich einem Pfeil tödliche Verletzungen zufügen kann. Hier in 8a ist zwar nicht vom Wort die Rede; da aber eine Analogie zwischen den beiden Stichen herrscht, könnte angenommen werden, dass auch die Gottheit mittels des Wortes eingreift: Dieses ist so wirksam, dass es die Feinde trifft und schwächt, sie verwundet und zu Fall bringt.

Das aus 5 b bekannte Temporaladverb "plötzlich«, das wiederum das Überraschungsmoment und damit die Emotion der Überraschung in den Psalm einträgt, sowie die Verbformen tragen dazu bei, dass der Vers zeitraffend gestaltet ist. V8 »beschleunigt als >verbaler Zeitraffer` das Tempo des Pfeils, in dem sich gleichsam das Gottesgericht manifestiert. Die Feinde werden verwundet. ${ }^{1262}$ Marvin Tate weist an dieser Stelle auf die extreme Kürze des zweiten Kolon (8b)

dem Pfeil; plötzlich seien da ihre Wunden!« Dagegen Lamparter, Das Buch der Psalmen 1, 308: "Nicht als Bitte, sondern als fraglose Gewißheit spricht der Psalmist diesen Gedanken aus. « Hupfeld, Die Psalmen, 111 übersetzt im Futur: »Aber schießen wird sie Gott mit dem Pfeil.« Ebenso Delitzsch, Psalmen, 429: »Die folgenden impf. consec. stellen das Künftige mit der Gewißheit einer gesch. Thatsache als aus der Tücke der Feinde hervorgehende Vergeltung dar. «Auch Tate, Psalms, 130 und Botha, Strategy, 68 übersetzen zukünftig: »But God will shoot his arrow at them; suddenly they are hit.« Botha führt an dieser Stelle weitere Übersetzungs- und Interpretationsvarianten an.

1259 Zur Darstellung Gottes als Krieger im Psalter vgl. u. a. Ps 17,13; 35,2f; 38,3.

1260 Vgl. Hossfeld / Zenger, Psalmen 51-100, 209.

1261 Hossfeld / Zenger, Psalmen 51-100, 209.

1262 Riede, Netz, 368. 
hin, welche die Plastizität der Darstellung der plötzlich zugefügten Wunden erhöht, ${ }^{1263}$ verursacht durch Pfeile, die ihr Ziel ohne Vorwarnung treffen. ${ }^{1264}$ Auch im Kontrast zur ausführlichen Darstellung der Aktivitäten der Feinde (V4-7) fällt die Darstellung von deren Straucheln und Fallen hier in V8 kurz aus. ${ }^{1265}$

Die in diesem Vers vorhandenen Emotionen beziehen sich im Gegensatz zu V4-7 auf die Gefährlichkeit und Verletzungsmacht Gottes, die nun auf Seiten der Feinde - im Kontrast zum lyrischen Ich und zum Unschuldigen in V2-5 - Bedrohung und Angst auslösen und zu Verwundung und Schmerz führen könnten.

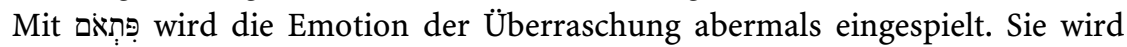
diesmal auf die Feinde bezogen.

\subsection{Vers 9: Straucheln}

9a Und man brachte ihn zu Fall, gegen sie ihre Zunge.

$9 b$ Alle, die das sahen, schüttelten sich.

Die mit 8 a einsetzenden Narrative werden in 9a weitergeführt. Dabei wirft die

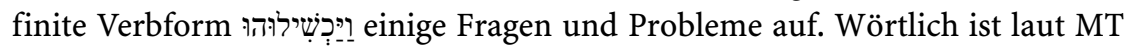
die Form mit "und sie brachten ihn zu Fall« (כשל hi.3.P.m.pl. + Suffix 3.P.sg.WPK) wiederzugeben. Bezieht man die Pluralform auf ein unbestimmtes "man« sowie das Singularsuffix in der 3.P.m. auf den Feind (2b), so ergibt sich die Übersetzung mit: "Man/er ließ jeden einzelnen stürzen. « ${ }^{1266}$ Inhaltlich geht es demnach darum, dass die Feinde selbst zu Fall kommen bzw. straucheln, und zwar durch ihre eigene Waffe (Zunge). ${ }^{1267}$ Die Wurzel כשל bezieht sich auf das Stürzen bzw. Fallen eines Gehenden, häufig verbunden mit der Vorstellung, dass ein Hindernis oder Anstoß den Sturz verursacht hat. Im Kontrast dazu stehen Verben des Stärkens und Festmachens, wie etwa die Wurzel rin, die sich in 6a auf die Feinde bezieht. ${ }^{1268}$ Hierin zeigt sich eine kontrastive Gegenüberstellung: Die Genannten empfinden sich zunächst als stark, straucheln dann aber und kom-

1263 מַּ (Wunde) kommt in den Psalmen nur hier vor, an anderen Stellen beschreibt der Begriff das Tun Gottes gegen Israels Gegner (Jos 10,10; Ri 11,33; 1 Sam 4,8.10).

1264 Vgl. Tate, Psalms, 131.

1265 Vgl. Brueggemann / Bellinger, Psalms, 282.

1266 Vgl. Hossfeld / Zenger, Psalmen 51-100, 202. Ähnlich Riede, Netz, 365. Kirkpatrick, Psalms, 359 und Herkenne, Das Buch der Psalmen, 53 denken bei der Pluralform an geheimnisvolle göttliche Vermittler bzw. himmlische Mächte. Auch Delitzsch, Psalmen, 430 spricht an dieser Stelle mit Verweis auf Ps 63,11; Ijob 4,19 und Lk 12,20 von »unbenannt bleibende[n], Gotte dienstbare[n] Gewalten.« Barrè, Proposal, 115 führt sieben verschiedene Übersetzungsvarianten an und kommt durch Emendation zu folgender Wiedergabe: »(And) may Yahwe(h)/Yahu make (them) trip (and fall) on their own (sword-) ttongue'« (S. 116).

1267 Vgl. dazu z. B. Kittel, Die Psalmen, 237 sowie Tate, Psalms, 130 und Barth, כשל 372.

1268 Vgl. Barth, כשל, 368.370. 
men zu Fall, und zwar durch die eigenen Waffen. Haben die Feinde erst aus dem Verborgenen heraus gewirkt, so wird ihr Scheitern nun in der Öffentlichkeit ausgetragen: Jeder, der das sieht, flieht bzw. schüttelt den Kopf. Wird die finite

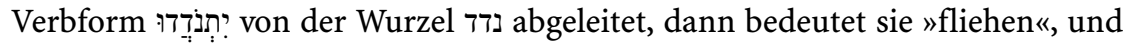
zwar vor Angst, Horror oder Ekel. ${ }^{1269}$ Meist wird die Form allerdings auf die Wurzel נוד zurückgeführt mit der Bedeutung »den Kopf hin und her schütteln. ${ }^{1270}$ Das Kopfschütteln wird als Gestus der Schadenfreude und von Spott und Hohn (Ps 22,8; 44,15; 109,25; Jer 18,16; 48,27; Mt 27,39) gedeutet, kann aber auch Ausdruck der Erleichterung sein. ${ }^{1271}$ Dieser Gestus ist sichtbarer Ausdruck eines Gemütszustandes. ${ }^{1272}$

Die mit der Reaktion auf die Tat Gottes verbundenen Emotionen, die auf alle Menschen bezogen werden, sind als körperlicher Ausdruck (Kopfschütteln) der Abscheu und des Ekels, der Angst und Furcht sowie der Schadenfreude, die in Hohn und Spott liegt, zu betrachten. Auf der anderen Seite könnte für die hier nicht erwähnten Feinde aufgrund ihres öffentlichen Scheiterns implizit die Emotion der Scham bzw. Peinlichkeit gelten.

\subsection{Vers 10: Reaktion und Erkenntnis}

10a Da fürchteten sich alle Menschen, $10 b$ und sie verkündeten das Tun Gottes, 10c und sein Werk haben sie begriffen.

V10 führt die Narrative aus 8a und 9a in 10a.b weiter und endet mit der abschließenden Handlung der Erkenntnis bzw. des Begreifens der Werke Gottes in der SK. Hier kommt der in der Gesprächshaltung des Erzählens verfasste Abschnitt V8-10 zu einem Ende. Die Reaktion auf die Tat Gottes wird in V10 universal, also alle Menschen betreffend, beschrieben. Demgegenüber nimmt V11 auf den Gerechten und die Herzgeraden Bezug. Dies ist eine Figurengruppe, zu der auch der Unschuldige (5a) und das lyrische Ich des Psalms zu rechnen sind. ${ }^{1273}$ Entscheidend ist in V10 die Gottesfurcht: Mit der Wurzel ירא wird auf 5b rückverwiesen. Dort wird erzählt, dass sich die Übeltäter und Unheilstifter nicht fürchten, während hier die Wurzel auf alle Menschen bzw. jeden Menschen

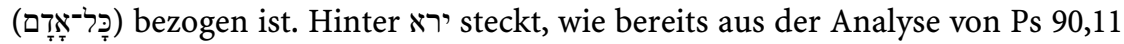
und 147,11 ersichtlich wurde, sowohl das Faszinosum als auch das Tremendum,

1269 Vgl. dazu z. B. die Übersetzung bei Herkenne, Das Buch der Psalmen, 52: „Und zu Falle bringen sie die Tücken ihrer Zunge; es flüchtet sich Jeder, so sie erblickt.»

1270 Vgl. Tate, Psalms, 132.

1271 Vgl. Hossfeld / Zenger, Psalmen 51-100, 202.210.

1272 Vgl. Gillmayr-Bucher, Rauchende Nase, 22.

1273 Vgl. Hossfeld / Zenger, Psalmen 51-100, 210. 
das mit dem Göttlichen in Verbindung steht. Damit sind ebenso die Emotionen der Angst sowie des Erschreckens und das Zurückweichen gemeint wie das Emotionsfeld des Respekts sowie die Hinwendung zu und das Vertrauen in Gott. Gottesfurcht bedeutet auch Gottesverehrung und Gehorsam gegenüber den göttlichen Weisungen. ${ }^{1274}$ "Weil das Treiben der Bösen die Störung der Weltordnung als Lebensordnung bedeutet und aus dem Fehlen von Gottesfurcht (vgl. V5b) entspringt, zielt das Eingreifen Gottes auf die Gottesfurcht als jene grundlegende Haltung, die die Welt als von Gott geschaffenes und gegen das anstürmende Chaos verteidigtes lebensförderliches Ganzes (`Kosmos`) wahrnimmt und lobpreisend annimmt. « ${ }^{1275}$

Mit dem expliziten Emotionswort ירא werden in V10 Angst, Gottesfurcht, Ehrfurcht und Vertrauen als Emotionen thematisiert, die allen Menschen zugeschrieben werden können.

\subsection{Vers 11: Freude und Zuflucht}

11a Der Gerechte kann sich freuen an JHWH,

$11 b$ und er findet Zuflucht bei ihm,

$11 c$ und es sollen sich rühmen alle Herzgeraden.

Mit dem Schlussvers wird das Fazit aus der Handlung Gottes und der Reaktion der Menschen für den Gerechten und für alle Herzgeraden formuliert. Dabei wird die gerade aus V2.3 (aber auch V5.6.7.9b) bekannte PK wieder aufgenommen und hier im Sinne der Folge bzw. Quintessenz aus dem vorher Erzählten verwendet. Die drei in der PK (11a), W-SK (11b) und waw+PK (11c) gesetzten Verben des Schlussverses verweisen auf die Zukunft des deiktischen Zentrums. ${ }^{1276}$ Weil der Gottheit die in 8a geschilderte Handlung zugetraut wird, kann in V11 folgendes Fazit gezogen werden: Der Gerechte, der wohl mit dem Unschuldigen (5a) und dem betenden Ich aus V2-3 parallel zu setzen ist, kann sich nun dementsprechend freuen und sich in JHWH bergen. Mit dem Gottesnamen JHWH ist eine Inklusion gegeben (vgl. V2 Elohim). Die Hörbitte an Gott und der Aufruf zur Freude an JHWH dienen als Rahmung des Psalms. ${ }^{1277}$ Der Schlussvers ist sowohl ein Aufruf zum Vertrauen in Gott als Zufluchtsort als auch einer zur Danksagung an den Gott, der befreit. ${ }^{1278}$

1274 Auf die Dimension des Respekts im Rahmen der Gottesfurcht verweist Limburg, Psalms, 212.

1275 Hossfeld / Zenger, Psalmen 51-100, 210.

1276 Vgl. Matheus, Zeit, 435.

1277 Vgl. Weber, Werkbuch 2, 286.

1278 Vgl. Brueggemann / Bellinger, Psalms, 282. 
Das explizite Emotionswort der Freude (Wurzel שממח) wurde bereits in den vorangegangenen Analysen beschrieben und dient als Ausdruck neu erworbener Lebensfreude (Ps 30,12). Vom Verstecken im Sinne von "Zuflucht suchen« war bereits in 3a die Rede (סתר); hier in 11b wird die Wurzel חסרה verwendet. Dabei handelt es sich um Schutz im Sinne eines geschützten Raumes bzw. bergenden Lebensraumes, meist aus aktueller Gefahr heraus und in Verbindung mit der Bewegung des Fliehens oder Suchens. Das schutzlose lyrische Ich aus V3 findet nun als Gerechter diesen bergenden Raum. Ziel der Zuflucht ist in den Psalmen immer Gott, nie ein Ort, Gegenstand oder Mensch. ${ }^{1279}$ »hat in den Psalmen das Physische und Psychologische der `Flucht` abgelegt, dafür ist ihm die ausschließliche Ausrichtung auf JHWH zugewachsen, und zwar im Sinne einer Grundentscheidung für diesen gegen alles andere und alle anderen, sei sie einfür allemal gefällt oder in Gefahren und Versuchungen jeweils zu aktualisieren. ${ }^{1280}$

Der Vers endet mit dem Sich-Rühmen der Herzgeraden. Die Wurzel הלל ist bereits aus der Analyse von Ps 147,1 bekannt, dort allerdings als Gotteslob im Imp.pi.m.pl. formuliert, hier im hitp. waw+PK 3.P.m.pl. in jussivischer Bedeutung. Mit der Wurzel ist der Vorgang des Rühmens zwischen Menschen sowie jener des Preisens Gottes gemeint. Rühmen sollen sich die druck ist gerade für die Psalmen charakteristisch (Ps 7,11;11,2; 32,11;36,11; $94,15 ; 97,11 ; 125,4)$ und bezieht sich auf jene, die aufrichtigen Herzens sind. Die Wurzel ישר bedeutet "gerade sein«, im übertragenen Sinn auch »recht sein« und steht damit im Gegensatz zu »krumm»bzw. "schlecht» und »falsch sein«. Die Herzgeraden sind jene, "die ehrlichen Herzens sind. $"{ }^{1281}$ Es sind die Menschen, "die sich an der Rechtsordnung Gottes orientieren [und] darauf vertrauen können, dass er diese aktiv durchsetzt. ${ }^{1282}$ Häufig wird יָָָּ wie hier in Ps 64

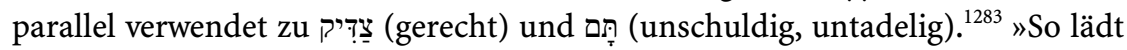
der Psalm von seinem Schluss her dazu ein, durch ein Leben der Gerechtigkeit und der Rechtschaffenheit sich in das Tun und Werk Gottes aktiv einzugliedern und so ihn selbst als schützende und rettende Zuflucht zu erfahren. " ${ }^{1284}$ Insgesamt drückt der Schlussvers neben dem Fazit auch eine Hoffnung aus, die Zuversicht gibt: „Gott hat vor aller Welt erwiesen, dass er die Frevler richtet, dem Gerechten aber hilft und ihm Zuflucht gewährt. Dieses Tun wird einerseits Gegenstand der Verkündigung und zugleich Ermutigung für alle die, die geraden

1279 Vgl. Gamberoni, הoח, 82.

1280 Gamberoni, הסח, 83.

1281 Wutz, Die Psalmen, 159.

1282 Hossfeld / Zenger, Psalmen 51-100, 204.

1283 Vgl. Liedtke, ישר, 791-793.

1284 Hossfeld / Zenger, Psalmen 51-100, 211. 
Herzens sind. ${ }^{1285}$ Auf die Ermutigung des Schlussverses weist auch Kraus hin: »Der Psalm schließt mit einem ermutigenden Wunsch an alle, die schuldlos verfolgt werden und den Triumph des Eingreifens Jahwes erleben. “ ${ }^{1286}$ Und zu guter Letzt bringt die Dimension der Freude (vgl. auch Ps 32,11; 58,11; 63,12) einen versöhnlichen Abschluss nach der bedrohlichen Darstellung der Gefahr, die von den Feinden und von deren Worten und Taten ausgeht. »Aber, als schüttle der Betende die Schatten dieser Angst mit einem Ruck von sich, so erheben sich seine Worte zum Schluss (11a. 10. 11b) in die Freude und Stille, die das in Gott geborgene Herz in sich aufnehmen. Er weiß sich in dieser Freude nicht allein. Viele teilen sie mit ihm. ${ }^{1287}$

Analog zum Beginn des Psalms weist der Schluss eine hohe Emotionalität auf. Im Kontrast zu den anfangs dargestellten Emotionen der Angst, Panik, Bedrohung und Gefahr gelangen allerdings hier die Emotionen der Freude und des Rühmens zur Darstellung, die mit dem Gerechten und den Herzgeraden in Verbindung gebracht werden. Daneben ist die Emotion des Vertrauens (bergender Lebensraum, Schutz und Sicherheit) zu finden, die der Gottheit zugeschrieben wird. Zuversicht, Ermutigung und Erleichterung prägen den Schlussvers.

\section{Perspektiven und Textdynamik}

Im Gegensatz zu den vorangegangenen Analysen der Perspektiven und Textdynamik in Ps 90 und 147 wird diese nicht in Szenen bzw. Gedankenspots strukturiert. Ps 64 wird aufgrund seiner Kürze sowie seiner durchgehenden Dynamik und des Spannungsaufbaus als gesamter Text in den Blick genommen.

\subsection{Perspektivenlenkung}

Der Text beginnt in V2-3 mit einer starken Du-Ich-Perspektive, welche die Erhörungsbitte um Schutz vor der drohenden Gefahr, die von den lärmenden Übeltätern und Unheilstiftern ausgeht, zum Inhalt hat. Der Beginn des Psalms ist durch ein dichtes Netz an Deixis geprägt, das sich durch Personalpronomen sowie vor allem in der Quantität der Possessivpronomen zeigt: meine Stimme in meinem Klagen (2a); sollt $d u$ beschützen mein Leben (2b); $d u$ sollst mich verstecken. Durch diese Dichte an deiktischen Elementen und durch den Imperativ

1285 Riede, Netz, 368.

1286 Kraus, Psalmen, 607.

1287 Schmidt, Die Psalmen, 120. 
»höre" am Beginn, der zeitdeckend ist (siehe Analyse zu Ps 30; 90 und 147), werden die LeserInnen ganz an das in der Textwelt erzählte Geschehen herangeholt. In V3 wird der Blick auf das göttliche Du, auf das lyrische Ich in seiner Sorge und Klage sowie auf die Feinde gelenkt. Diese Perspektive auf die Feinde wird bis V7 beibehalten. Mit V8 wird der Blick auf die Gottheit (8a), danach auf die Feinde (8b-9a) sowie schließlich auf alle Menschen (9b-10c) gelenkt. Der Psalm endet mit der Perspektive auf den Gerechten, der sich nun in Freude JHWH zuwenden kann sowie auf alle, die aufrichtigen Herzens sind. Die Hauptperspektive ist jene auf ein »Sie« in der 3.P.pl., weshalb dieser Psalm auch zur Analyse gewählt wurde. Einmal betrifft dieses »Sie« die Feinde (3b-7a.8b.9a), ein anderes Mal sind damit die Gesamtheit der Menschen (9b-10c) sowie die Herzgeraden (11c) gemeint.

Ps 64 lebt nicht nur vom Perspektivenwechsel und vor allem von der Textdynamik, wie noch zu zeigen sein wird, sondern auch von den unterschiedlichen Rederichtungen. So setzt er nach der Überschrift in V1 mit der Rede in der 2.P.sg. ein (V2-3), fährt dann in der Rede der 3.P.pl. fort (V4-7a; Ausnahme: 6c) und wechselt dann in eine Wir-Rede (7b) und in eine Er-Es-Rede (Nominalsatz 7c). 8a gilt als Er-Rede (Gottheit) in der 3.P.sg., 8b-V10 sind in der Rede der 3.P.pl. gestaltet. 11a-b ist eine Er-Rede in der 3.P.sg. Der Psalm endet mit der Rede in der 3.P.pl. (11c). Diese Vielzahl an Sprechrichtungswechseln wirkt nicht sprunghaft, sondern ist im Leseprozess gut nachvollziehbar. Sie trägt zur Lebendigkeit des Textes bei und dient dem Spannungsaufbau. Dieser lebt unter anderem vom Wechsel zwischen unterschiedlichen Innensichten und dem Erzählverlauf, der in der Außensicht formuliert ist. Im Text wird also zwischen externer (3b-6b; 7a.7c.8-11) und interner (2-3a.6c.7b) Fokalisierung gewechselt. Die Innensicht wird durch mehrere Textelemente erzeugt: Da sind an erster Stelle die direkten Reden der Feinde im sogenannten Feindzitat (6c.7b) zu nennen. Im Feindzitat lässt das Sprecher-Ich die Feinde selbst zu Wort kommen und gibt damit den Gedanken der Frevler einen öffentlichen Raum: »Im Feindzitat holt das Ich des Psalms die Gedanken der Frevler aus dem Bereich des Verborgenen heraus und schafft damit eine breite Öffentlichkeit: die Versammlung derer, die Gott ins Recht setzt. Gott wird aufgerufen, nicht länger untätig zu sein. Das Zitat erlaubt dem Beter, seiner Bitte Nachdruck zu verleihen. Es dient dazu, Gott von der Notwendigkeit des Eingreifens zu überzeugen. ${ }^{1288}$ Das Stilmittel der direkten Rede gilt als eines der stärksten für die Charakterisierung von Figuren in literarischen Texten. ${ }^{1289}$ Paradoxerweise herrscht hier allerdings die Eigentümlich-

1288 Erbele-Küster, Lesen, $122 \mathrm{f}$.

1289 Vgl. Keel, Feinde, 176. Auf die durch die wörtliche Rede erzeugte Lebendigkeit in der Darstellung des Feindporträts verweisen an dieser Stelle Oeming / Vette, Psalmen, Psalm 42-89, 137. Die Stimme der Feinde ist auch jene, die im Psalter am häufigsten in direkter 
keit vor, dass die Zitate im Nachgesprochenwerden aufgrund der Verletzungsmacht, die der Sprache selbst inhärent ist, selbst verletzen können. Deshalb »stellt sich die Frage, wie verletzende Rede so wiederholt werden kann, dass dabei zugleich deren Macht gebrochen wird. « ${ }^{1290}$

Die Innensicht der Feinde wird darüber hinaus durch die Schilderung der Gedanken der Feinde mittels des Wortfeldes des Sprechens bzw. Denkens (6c) und des Planens (7a.b) sowie mit Hilfe des Wortfeldes des Inneren bzw. Herzens (7c.11c) dargestellt. Doch nicht nur von den Feinden werden innere Vorgänge beschrieben, sondern auch von "allen Menschen«, die sich fürchten (ירא 10a) und begreifen (שכל 10c). Das Innenleben des lyrischen Ich kommt durch die in der Du-Ich-Rede implizit geschilderte Unruhe und Sorge sowie die Angst vor der drohenden Gefahr der Übeltäter und Unheilstifter zum Ausdruck. Außer der Blicklenkung in Bezug auf Innen- und Außensicht lässt der Text noch ein Wechselspiel zwischen Nähe und Distanz erkennen. Wie bereits erwähnt, zeichnet sich der Beginn des Psalms (V2-3; Imperativ und Dichte an Deixis) durch eine besondere Nähe zu den Lesenden aus, auch wenn die Klage des lyrischen Ich, dessen Situation sowie die Beschreibung der Feinde allgemein gehalten sind. In V4-7 stehen die Feinde im Fokus; der Blick wird auf diese hin geschärft durch die Detailbeschreibung ihrer einzelnen Handlungen und die konkretisierende Darstellung ihrer Vorhaben und Gedanken. Auch wenn hier nicht Deixis, sondern Anaphorik vorherrscht, werden die Lesenden durch die detaillierte Beschreibung der feindlichen Aktionen nahe an das Textgeschehen herangerückt. Diese Kameraeinstellung wird bis 8 a beibehalten. Dann allerdings wird durch die Anaphorik und die allgemein gehaltenen Aussagen, die von den Wunden und dem Straucheln der Feinde über die Reaktion aller Menschen sowie das Fazit daraus für den Gerechten und die Herzgeraden erzählen, der Blick weg von den konkreten Taten der Feinde und Gottes in Richtung Ferne gelenkt. In V10-11 werden allerdings sehr positive Inhalte geschildert (Gottesfurcht; Verkündigung und Begreifen des Tuns Gottes; Freude an JHWH; Zuflucht bei Gott und Lobpreis der Herzgeraden), die aufgrund ihrer emotionalen Komponenten die Möglichkeit in sich bergen, die Lesenden trotz der allgemein gehaltenen Rede (3.P.pl./sg.; Anaphorik) an die Textwelt heranzuholen.

Rede zitiert wird (34 Mal in 26 verschiedenen Psalmen). Vgl. dazu Jacobson, »Many are Saying", 27.

1290 Erbele-Küster, Lesen, 121. 


\subsection{Textdynamik}

Hinsichtlich des Spannungsaufbaus ist nach V2-3, in denen das gemeinsame Thema des Schutzes vor den Feinden behandelt wird, eine Steigerung in der Beschreibung der Aktionen der Feinde auszumachen, die mit dem Nominalsatz in 7c zunächst einmal an ein Ende kommt. Diese Steigerung kann in die zwei Ebenen (1) der Aktionen im Zusammenhang mit Jagd und Kampf sowie (2) in jene der inneren Vorgänge und der Kommunikation eingeteilt werden. ${ }^{1291}$ Im Zusammenhang mit der ersten Ebene treffen die Feinde zunächst Vorbereitungen für die Jagd bzw. den Kampf, indem sie ihre Zunge wie das Schwert schärfen (4a), dann den Bogen treten und den Pfeil anlegen (4b) sowie daraufhin unvermittelt und aus dem Verborgenen heraus schießen (5b.6b). Die zweite Ebene der inneren (planen) und äußeren (erzählen, sagen) Kommunikation führt von der Beschreibung der Sicherheit im Sinne des Sich-Nicht-Fürchtens (5b), der Gewissheit, nicht entdeckt zu werden (6c), der Stärke durch böses Worte (6a) und durch unheilvolle Gedanken (7a) bis hin zu einem vollendeten und durchdachten Plan (7b). Nach dem Ruhepol in 7c, der, an das Planen der Ungerechtigkeiten aus 7a.b anschließend, die Thematik der Unerforschlichkeit des menschlichen Innenlebens expliziert, folgt der zweite Teil des Psalms. Die Feinde haben ihre Pläne nun durchdacht. Bei den Lesenden wird eine Erwartungshaltung aufgebaut, die auf die Umsetzung der Feindespläne gerichtet ist. Auf der Figurenebene erwarten die Feinde wahrscheinlich einen Triumph. ${ }^{1292}$ Es geht jedoch überraschenderweise ganz anders weiter: Gott ist es, der aktiv und zielgerichtet in das Geschehen eingreift und den Triumph der Feinde verhindert. Mit dem Narrativ in 8a und der Thematik des Schießens Gottes sowie mit dem Stolpern der Feinde durch ihre eigene Waffe in 9a wird die Schilderung von Handlungen wieder aufgenommen und dies noch dazu in dramatischer Art und Weise. Die Dramatik wird einerseits thematisch erzeugt, indem unerwartet und überraschend die Gottheit ins Spiel kommt und in einer einzigen, zielführenden Aktion die Feinde zu Fall bringt.

1291 Dementsprechend sind die den Psalm bestimmenden Wortfelder (1) Verstecken: beschützen V2; verstecken V3; im Versteck $5 \mathrm{a}$; verstecken 6b; unerforschlich, unergründlich $7 c$; Verstecken im Gegensatz zum Sehen bzw. öffentlichen Sehen: indirekt soll Gott wahrnehmen, hören und sehen in V2-3; Feindzitat: wer wird sie sehen $6 c$; alle sehen es 9b; (2) Kommunikation: hören 2a, Klage 2a, bitteres bzw. böses Wort 4b.6a, Zunge 4a.9a, erzählen/abzählen $6 \mathrm{~b}$, sagen $6 c$, verkünden $10 \mathrm{~b}$, sich rühmen 11c. Dieses semantische Feld der Kommunikation wird von Botha, Strategy, 73 eigens betont. (3) Kampf/Jagd: schärfen 4a; Schwert 4a; [den Bogen] treten, den Pfeil anlegen 4b; schießen 5b.8a, sich stark machen 6a; Fallstricke/Klappnetze 6b; Pfeil 8a; Wunden 8b; (4) Schutz: bewahren 2b; Zuflucht suchen 11b; (5) Innere Vorgänge: meine Unruhe 2a; sich (nicht) fürchten 5b. 10a; erforschen/planen 7a; Plan durchplanen bzw. durchdenken $7 \mathrm{~b}$; das Innere und das Herz eines Menschen $7 \mathrm{c}$; begreifen 10c, sich freuen 11a.

1292 Vgl. Thalhofer, Erklärung, 365. 
Noch dazu wird dies mit jener Handlung und jenen Waffen erzählt, die bereits zuvor auf Seiten der Feinde genannt wurden (schießen 5b.6a; Pfeil 4b; ihre Zunge 4a). Grammatikalisch wird die Dramatik durch die Kürze des Verses (siehe Analyse zu V8), durch das Temporaladverb "plötzlich « und damit durch das dem Adverb inhärente Überraschungsmoment (unvermutet, sofort) erzeugt sowie durch die Narrative in $8 \mathrm{a} .9 \mathrm{~b}$, die den Handlungsverlauf wieder aufnehmen und fortführen. Mit V8-9 ist die Klimax des Psalms erreicht: Unvermuteterweise hat Gott eingegriffen, die Feinde wurden zu Fall gebracht. Der Text endet, die Spannung abflachend, mit der Beschreibung der Reaktion darauf und einem Fazit.

\subsubsection{Charakterisierung}

Im Gegensatz etwa zu Ps 90 oder Ps 147 lassen sich in Ps 64 unterschiedliche Figuren und entsprechende Charakterisierungen ausmachen. Nach Jens Eder (vgl. III Methodik 3.3) ist es ja gerade das Teilen derselben Situation und des Wahrnehmungsraums eines Lesenden mit einer Figur in der Textwelt, das Möglichkeiten zur Identifikation bietet. Hier in Ps 64 wird die imaginative Nähe zu einer Figur durch kognitive Nähe (Verstehen und Perspektivenübernahme) sowie die emotionale Nähe vor allem für das lyrische Ich ausschlaggebend. Neben dem lyrischen Ich werden im Folgenden alle Figuren hinsichtlich ihrer Charakterisierung besprochen.

Auffallend sind in Ps 64 die unterschiedlichen Figurenkonstellationen und in welchem Verhältnis sie zueinander stehen (parallel oder kontrastiv). So sind acht verschiedene Figuren auszumachen, die jeweils in verschiedener Weise interagieren: Das lyrische Ich (1) tritt mit der Gottheit (2) in Kontakt (V2-3), der Feind (3), der als Übeltäter und Unheilstifter ausgewiesen ist (V3), schießt auf den Unschuldigen (4), Gott wiederum schießt auf die Feinde (V8). Alle, die das sehen, also die Beobachtenden (5) der Aktion Gottes (V9), reagieren darauf mit Kopfschütteln (V9). Alle Menschen (6) aus V10 verhalten sich ebenso dazu. Schlussendlich freut sich der Gerechte (7) und birgt sich in JHWH (V11), und die Herzgeraden (8) rühmen sich (V11). Das lyrische Ich tritt mit den Feinden nicht in Kontakt; würde es allerdings mit dem Unschuldigen aus V5 gleichgesetzt, wäre es hier in einer Objektposition gegenüber den Feinden zu finden. Die Gottheit tritt sehr wohl mit den Feinden in Kontakt, nicht aber mit dem betenden Ich. Alle Menschen reagieren auf das Tun Gottes, aber nicht auf die Gottheit selbst. Der Gerechte wird in direkter Verbindung mit JHWH (sich freuen an ihm; Zuflucht suchen und finden bei ihm) gezeichnet. Dies geschieht in V11, der als Fazit und Ausblick gestaltet ist.

Innerhalb dieser Figurendarstellung kristallisieren sich drei Figurengruppen heraus: (1) die Feinde, (2) der Unschuldige, der später als Gerechter bezeichnet 
wird und Teil der Herzgeraden ist, zu denen auch das lyrische Ich zählt, sowie (3) eine dritte und eher neutrale Gruppe, zu der alle Sehenden bzw. alle Menschen gehören. $^{1293}$

\subsubsection{Feindliche Übeltäter}

Einen Schwerpunkt des Psalms bildet die Charakterisierung der Übeltäter und Unheilstifter. Was macht einen Übeltäter und Unheilstifter zu einem ebensolchen? Die Feinde werden in Ps 64 mittels dreier verschiedener Bezeichnungen eingeführt: אוֹיב (Feind, 2b, substantiviertes Ptz.sg., vgl. die Analyse zu Ps

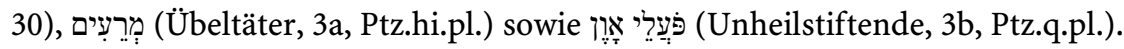
Diese Aufzählung der unterschiedlichen Begrifflichkeiten kann auch als Steigerung verstanden werden: "Sie sind `Feinde` (אויב), insofern sie als Gegner und Widersacher stören, behindern und bedrohen; sie sind >Bösewichter` (מרעים), insofern sie rücksichtslos und brutal machen, was sie wollen, also keinerlei ethische Maßstäbe kennen; sie sind >Übeltäter (פעלי און), insofern sie gezielt und geplant Unrecht, Unheil und Vernichtung wirken wollen. ${ }^{1294}$ Die Lesenden erfahren also viel über die Feinde, und zwar nicht nur durch die gerade erwähnten Bezeichnungen, sondern sowohl durch die sie beschreibende Sprechstimme in der Rederichtung der 3.P.pl. als auch durch die Sprechakte, die den Feinden zugestanden werden, und darüber hinaus auch durch die Perspektive der Innensicht. Dadurch wird es den Lesenden ermöglicht, tiefe Einblicke in das Wesen der Feinde zu erhalten. Gleichzeitig zeigt dies, dass das lyrische Ich ein sehr klares Bild von seinen Angreifern hat. Die Feinde versammeln sich und agieren als Gruppe bzw. Haufen oder Horde. Hinzu kommt, dass sie als lärmende Menge auftreten. Sie verbreiten Unruhe und Schrecken, verletzen durch böse Worte und machen sich durch Worte stark. »Aus dem Hinterhalt agieren sie, überraschend, kaltblütig, tödlich. ${ }^{1295}$ Sie treten selbstsicher auf, fürchten sich nicht, erzählen von ihrem Vorhaben, Fallen zu stellen, und hegen schlechte Gedanken und dunkle Pläne. ${ }^{1296}$ David Firth spricht davon, dass die Feinde sowohl psychische als auch physische Gewalt gegenüber dem lyrischen Ich ausüben. Zunächst fügen sie ihm durch die Drohung psychische Qual zu, sie suchen aber im Endeffekt seinen physischen Tod. ${ }^{1297}$ Bezeichnenderweise werden die Feinde selbst durch einen

1293 Vgl. Botha, Strategy, 73f.

1294 Hossfeld / Zenger, Psalmen 51-100, 207.

1295 Oeming / Vette, Psalmen, Psalm 42-89, 137.

1296 Die unheimliche und finstere Beschaffenheit der feindlichen Handlungen kann bei den Lesenden den Eindruck erwecken, hier seien übermenschliche Kräfte am Werk. Vgl. Tate, Psalms, 133. Er verweist in diesem Zusammenhang auf mögliche dämonische Kräfte (S. 134).

1297 Vgl. Firth, Retribution, 98: »The imagery of ambush and stalking of the psalmist contribute to the psalm by developing the reader's awareness of the fact that there is a continued process of hunting going on in which the strophy< is the death of the psalmist." 
Pfeil getroffen, verwundet und ins Stolpern gebracht. Dabei ist ihre Zunge gegen sie selbst gerichtet. Gott schlägt sie mit ihren eigenen Waffen (Pfeil, Zunge). »Die Jäger werden zu Gejagten. « ${ }^{1298}$ Vieles von dem, was die Feinde tun, fällt also auf sie selbst zurück: ${ }^{1299}$ Nach dem Pfeil, den sie angelegt haben (4b) und der sie dann selbst trifft (8a), schießen sie unvermutet (plötzlich 5b), um ebenso unvermutet und überraschend (plötzlich $8 b$ ) selbst verwundet zu werden. Sie erzählen davon, Fallstricke auszulegen (6b), und geraten danach ebenfalls zu Fall (9a). Sie wollen mit ihren Machenschaften im Verborgenen bleiben (5a.6c), ihr Straucheln wird aber öffentlich wahrgenommen (9b). Sie zeigen keine Furcht (5b), Gott allerdings gebührt Furcht (10a).

Die Feinde können für die persönliche Bedrohung des lyrischen Ich durch eine Gruppe von Menschen stehen, die ihm mit Wort und Tat Unheil antun möchten, sie können aber auch, über das Einzelschicksal hinausgehend, generell die bedrohliche Macht des Todes repräsentieren. Dann ginge es im Ps 64 »letztlich um die Bekämpfung der im gezielten Vernichtenwollen sich manifestierenden Todesmacht durch den Leben (vgl. V2b) schützenden Gott. « ${ }^{1300}$

\subsubsection{Gottheit Israels}

Die Gottheit kommt fünf Mal im Text vor, wobei sie nur ein einziges Mal in der Subjektposition ist und eine Handlung setzt. Diese jedoch genügt, um die Wende im Textgeschehen zu bewirken. Gott wird als Elohim mittels eines Vokativs angerufen (2a) und schießt in $8 \mathrm{a}$ einen Pfeil auf die Feinde. Auf dieses Tun Elohims wird in 10b Bezug genommen (Constructus-Verbindung bzw. Genitivkonstruktion). Als Objekt, an dem sich der Gerechte freut und bei dem er sich birgt, steht im letzten Vers des Psalms der Eigenname Gottes, JHWH. Das in Ps 64 gezeichnete Gottesbild ist demnach zunächst geprägt von der Bitte um Zuwendung (Hören) und um Schutz. ${ }^{1301}$ Gott kann also die Lage des betenden Ich wahrnehmen, sich ihm zuwenden und ihm Schutz gewähren. Auch ist es die Gottheit, die als Bogenschütze die Feinde mit ihren eigenen Waffen besiegt. Hier

1298 Oeming / Vette, Psalmen, Psalm 42-89, 138.

1299 Ps 7,17; 9,16; 35,8; 57,7; 141,10; Spr 26,27 sowie Weiser, Die Psalmen 1, 312. Ähnlich Riede, Netz, 367. Dahood, Psalms 2, 155 spricht an dieser Stelle von einem Bumerangeffekt des Bösen und verweist auf Ps 7,16. Ähnlich Brueggemann / Bellinger, Psalms, 282.

1300 Hossfeld / Zenger, Psalmen 51-100, 204. Bezugnehmend auf Ps 59; 64; 73 und 94 verweist auch Keel, Feinde, 172 auf die Wirkmacht Gottes: »Immer wieder führt bei diesen Pss, die nicht mehr nur ein Einzelschicksal im Auge haben, die Klage über die Unterdrückung der Armen zur Frage nach der Geschichtsmächtigkeit Jahwes, die der Frevler in Wort und Tat leugnet, und die der Beter glaubt und glauben will, und um deren Erweis er mit ganzem Herzen bittet."

1301 Zum Gottesbild im Psalter aufgrund der an Gott gerichteten Imperative vgl. ausführlicher Eder, »Neige, JHWH.» 
wird auch der Gottheit eine gewalttätige Tat zugeschrieben. ${ }^{1302}$ Nach David Firth gehört das Recht zu reagieren und damit das Recht zur Gewaltausübung im Namen des unschuldig Verfolgten alleine der Gottheit. Hinter dieser Tat steht die Erwartung, dass sie vom Talionsprinzip geleitet ist. ${ }^{1303} \mathrm{Zu}$ guter Letzt wird die Gottheit in Ps 64 als Ort der Zuflucht und des Sich-Bergens dargestellt. ${ }^{1304}$ Die Dimensionen der Wahrnehmung, des Schutzes, der Geborgenheit und der Zuflucht werden hier ebenso der Gottheit Israels zugeschrieben wie jene der Aktions- und Verletzungsmacht gegenüber den Feinden. Die letztgenannte Macht ירה wird in paralleler Weise zu den Feinden selbst dargestellt, zumal das Verb (schießen) sowohl mit den Feinden (5a.b) als auch mit der Gottheit (8b) als Subjekt verbunden wird.

\subsubsection{Lyrisches Ich}

Betrachtet man das lyrische Ich aus V2-3, den Unschuldigen aus V5 und den Gerechten sowie die Herzgeraden aus V11 als eine Figurengruppe, so ist diese dadurch gekennzeichnet, dass die Lesenden zunächst durch die in V2-3 an Gott gerichtete direkte Rede Einblick in die düstere Lage und drastische Situation der Bedrohung und Angst erhalten. Das betende Ich bittet inständig darum, dass Gott sein Leben bewahren möge. Als Unschuldiger mit ethisch und moralisch tadelloser Lebensführung wird er von den Feinden heimlich beschossen (V5). Letztlich wird seine eingangs gestellte Bitte erfüllt: Der Gerechte kann sich an JHWH erfreuen und bei ihm Zuflucht, Schutz und Sicherheit finden, und die Herzgeraden rühmen sich. Das Thema der Ausweglosigkeit, die Bitte um Bewahrung des Lebens, die Bitte um Schutz sowie die Freude bei und durch JHWH sind sehr deutlich mit dem lyrischen Ich verbunden, das als Unschuldiger, Gerechter und Teil der Gruppe der Herzgeraden im krassen Gegensatz zu den Feinden mit ihren hinterlistigen und schlechten Gedanken und Taten steht. Durch die ausführliche Darstellung der Aktivitäten und Pläne der Feinde wird die Identifikation mit diesen geradezu verstellt und zur Abgrenzung ihnen gegenüber eingeladen. »[D]ie >Feinde` des Psalmisten [...] werden als Antigruppe gesehen, von der man sich zum eigenen Besten, zur Bewahrung der eigenen Identität abgrenzt. ${ }^{1305}$ Im Gegensatz dazu wird durch die in der Analyse dargelegte Präsentation des lyrischen Ich, des Unschuldigen und des Gerechten die

1302 Zur Hermeneutik von biblischen Texten, die (göttliche) Gewalt thematisieren siehe u. a. Zenger, Ein Gott der Rache?; Brandtscheidt, Gott; Eder, Gewalt und Grohmann, Gott.

1303 Vgl. Firth, Retribution, 101. Cohen, The Psalms, 200: »[...] there is a God Who judges the world «. Ähnlich Clifford, Psalms 1-72, 299: „God must act for the sake of justice.»

1304 Weiser charakterisiert die Gottheit in Ps 64 als »Richter des Bösen und Helfer und Zuflucht der >Gerechten`.« Weiser, Die Psalmen 1, 311.

1305 Gerstenberger, Der bittende Mensch, 160. 
Identifikation mit dieser Figurengruppe nahegelegt. ${ }^{1306}$ Dieses Denken in Bipolarität ist den Psalmen nicht fremd, vor allem, was den bereits in Ps 1 grundgelegten Diskurs über Gerechte und Frevler angeht. Die einfache Schwarz-weißStruktur hilft, was z. B. Ps 1 betrifft, sich selbst einzuordnen; sie wird unter anderem als pädagogisches Mittel betrachtet, sich für den Weg zu entscheiden, der mit JHWH gegangen wird und zu ihm hinführt. Die Gegensätze zwischen Gerechten und Frevlern können daneben gegensätzliche Haltungen bezeichnen, die jeder Mensch im Laufe seines Lebens mehrfach einnimmt; jeder Mensch handelt manchmal frevlerisch und dann auch wieder gerecht. Die Distanzen zwischen den beiden Polen werden durch Kontraste bewusst gemacht, zwischen den Polen schwarz und weiß werden keine Grautöne angeboten. Lesende müssen sich klar einer Seite zuordnen.

\subsubsection{Alle Menschen}

Betrachtet man alle Sehenden (V9) und alle Menschen (V10), die durch das Nomen diesen Menschen Handlungen verknüpft, die allesamt als Reaktionen auf die Tat Gottes gegen die Feinde zu betrachten sind: Sie schütteln den Kopf, sie fürchten sich, und sie erzählen und verkünden die Taten Gottes, die sie begreifen. Wie schon bei der Charakterisierung des lyrischen Ich gezeigt werden konnte, ist auch hier die kontrastive Gegenüberstellung zu den Feinden erkennbar: Während diese sich sicher sind, dass niemand ihre Fallen sieht (ראה) 6 ), sind es nun alle (פ), die sehen (ראה), und zwar gerade das Fallen und Stolpern der Feinde (9a). Die Übeltäter und Unheilstifter fürchten sich nicht (לרא + לא 5 b), während sich alle Menschen fürchten (ירא 10a), womit wohl die Gottesfurcht gemeint ist. ${ }^{1307}$ Die Feinde üben sich in bösen Worten (6a) und erzählen (ספר) von schlechten Taten (Fallstricke verstecken $6 \mathrm{~b}$ ), die Menschen hingegen erzählen und verkünden das Tun Gottes (נ10b).

Im Rahmen der Charakterisierung fällt auf, dass diese immer wieder entweder von Wiederholungen (Feinde - Gottheit), stärker aber noch von Kontrasten (lyr. Ich/Unschuldiger/Gerechter/Herzgerade vs. Feinde; alle vs. Feinde) dominiert wird. Phil Botha spricht an dieser Stelle davon, dass die literarische Technik der antithetischen Struktur den Psalm bestimmt. Dabei verweist er nicht nur auf die Gegenüberstellung zwischen den Übeltätern auf der einen Seite und Gott und den Gerechten (alle Menschen, Herzgeraden) auf der anderen Seite, sondern unter anderem auch auf die antithetische Inklusion des Psalms, der mit der dreifachen Beschreibung der Feinde beginnt und mit der Erwähnung des Ge-

1306 Vgl. dazu ausführlicher Erbele-Küster, Lesen, $114 \mathrm{ff}$.

1307 Das Wortspiel mit den ähnlich klingenden Wurzeln ראה (sehen 6c.9b), ירא (fürchten 5b.10a) und ירה (schießen 5a.b. 8a) ist in Ps 64 offensichtlich. 
rechten und der Herzgeraden endet. Beginn und Ende des Psalms sind auch durch den Kontrast zwischen den negativ konnotierten Nomen »Klage« (2a) und »Schrecken« (3a) und den positiv konnotierten Verben »sich freuen « (11a), »sich bergen « (11b) und »sich rühmen « (11c) gekennzeichnet. ${ }^{1308}$ Dies hat bereits die Vers-für-Vers-Analyse der Emotionen erbracht.

\subsubsection{Handlungen}

Für die Untersuchung und Charakterisierung der Figuren sind die Zuordnung der Handlungen zu den jeweiligen Subjekten sowie die Analyse der Objekte bedeutsam. Aufgrund der Komplexität wird hier auf die aus den bisherigen Analysen bekannte Tabelle zu Subjekten, Handlungen und Objekten verzichtet und gleich auf die Erkenntnisse und Ergebnisse aus der Analyse eingegangen. Zunächst zeigen sich der Abwechslungsreichtum, die Lebendigkeit und die Buntheit des Textes durch fünfzehn Subjektpositionen, ${ }^{1309}$ die sich vom göttlichen »Du« über das "Sie« der Übeltäter bis hin zur Gottheit und auf alle Menschen, den Gerechten und alle Herzgeraden erstrecken. Während der Gottheit vier Verben zugeordnet sind - שמע (hören 2a), נצר (bewahren/beschützen 2b), סתר (verstecken/verbergen 3a) und ירה (schießen 8a) -, hat das lyrische Ich keine Subjektposition inne. Es wird folglich mit keiner aktiven Handlung betraut, sondern ist durch Objektpositionen gekennzeichnet (meine Stimme 2a; in meinem Klagen/in meiner Unruhe 2a; mein Leben 2b; mich 3a). Durch das Sprechen und Klagen zu Gott ist es allerdings dahingehend initiativ, als es die Stimme an Gott richtet, um aus der Situation zu entkommen. Auch der Unschuldige befindet sich in einer Objektposition (5a.b), der Gerechte allerdings in Subjektpositionen, die - im Kontrast zum bisher im Psalm Geschilderten - mit den äußerst positiven Handlungen des Sich-Freuens an JHWH (שמח 11a) und des Sich-Bergens bei der Gottheit (11b) verbunden sind. Der Hauptteil der Aktionen im Text wird mit zwölf verschiedenen Verben den Feinden zugeschrieben, ${ }^{1310}$ die somit auch die meisten Subjektpositionen im Text innehaben. Blickt man auf die Zeitwörter, die mit den Feinden in Verbindung stehen, so ist durch

1308 Vgl. Botha, Strategy, 71-73.77. Eine Zusammenstellung von Entsprechungen, Übereinstimmungen und korrespondierenden Phrasen präsentieren auch Alonso Schökel / Carniti, Salmos 1, 839; Dahood, Psalms 2, 155 und Clifford, Psalms 1-72, 299.

1309 Göttliches Du (2b, 3a), die/welche (4a), sie (4b, 5b, 6a.b.c, 7a, 9a), wer (6c), wir (7b), der Plan (7b), das Innere und das Herz (7c), Gott (8a), ihre Wunden (8b), ihre Zunge (9a), jeder/alle (9b), jeder Mensch (10a), sie (alle Menschen 10b.c), der Gerechte (11a.b), alle Herzgeraden (11c).

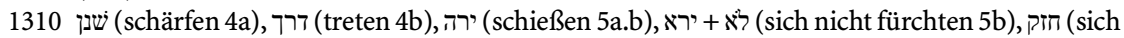
stark machen 6a), ספר (zählen/erzählen 6b), טמן (verstecken 6b), המר ליר (sagen 6c), שפש (erforschen/planen 7a), תמם (wir vollenden 7b), היה (ihre Wunden waren da 8b), כשל (stolpern/ straucheln 9a). 
das Schießen die einzige gefährliche Handlung der Feinde auszumachen, die bedrohlich ist und zu Verletzung und Tod führen kann. Demnach lässt sich das negative Bild der Feinde im Text nicht alleine aus den ihnen zugeschriebenen Handlungen ableiten. Hierfür müssen auch die vielen Objekte hinzugezogen werden, die mit den Feinden verbunden werden: Zunächst sind jene zu nennen, die mit der Präposition Feindes 2b; vor der Gemeinschaft der Übeltäter 3a; vor dem Tumult derer, die Böses tun 3b. Die Feinde werden damit als jene gezeichnet, die Schrecken und Panik verursachen, die sich versammeln bzw. sich in Horden zusammenrotten, also gemeinsam üble Pläne hegen und dies in Aufruhr und Lärm in die Tat umsetzen. Die negative und zerstörerische Dimension der Feinde zeigt sich in ihren weiteren Objekten: ihre Zunge, die sie wie das Schwert schärfen (4a); ihr Pfeil, der als bitteres Wort gilt (4b); ihr Handeln mit bösem Wort (6a). Daneben agieren sie im Versteck bzw. aus dem Verborgenen heraus (5a), sie reden von Fallstricken bzw. Klappnetzen und denken sich Ungerechtigkeiten bzw. Schlechtigkeiten aus. Durch diese Vielzahl an Objekten, die mit den Feinden syntaktisch verbunden sind, wird ihre gefährliche Absicht offenbar. Faszinierend erscheint es mir hingegen, dass die Gottheit diese Feindesmacht, die ja einen Großteil des Psalms dominiert, durch eine gezielte Handlung zu Fall bringt. Addiert man die acht verbleibenden Verben, die sich auf alle (נדד ; ראל sich schütteln 9b), alle Menschen (ירא sich fürchten 10a; ניאד vä verkünden 10b; begreifen 10c), den Gerechten (שמח sich freuen 11a; חסה sich bergen 11b) und alle Herzgeraden (הלל sich rühmen 11c) beziehen, und jene vier der Gottheit, so stehen sich die Feinde mit ihren zwölf Handlungen und alle Menschen (acht Verben) inklusive der Gottheit (vier Verben) mit ihren insgesamt zwölf Handlungen sozusagen 1:1 gegenüber. Der Psalm zeichnet also - wie bereits mehrmals erwähnt - einen deutlichen Kontrast. Dabei stehen auf der einen Seite die Gottheit und alle Menschen inklusive des Gerechten, des Unschuldigen und des lyrischen Ich, die zu JHWH halten und die durch die Syntax (Objekte im Zusammenhang mit Gott) ganz auf die Gottheit bezogen sind. Auf der anderen Seite steht der Feind, der als Übeltäter und Unheilstifter Bedrohung, Verletzung, Unruhe und Bedrängnis evoziert.

\subsubsection{Zeiten und Räume}

Zum Abschluss der narratologischen Analyse sei noch auf die Raum- und Zeitangaben im Text verwiesen: Der Text zeichnet sich dadurch aus, dass er nur jeweils ein einziges Lokal- und Temporalobjekt besitzt. ${ }^{1311}$ Letzteres liegt im

1311 Vgl. im Gegensatz dazu die Vielzahl an Temporalobjekten in Ps 90 und an Lokalobjekten in Ps 147. 


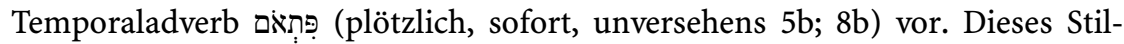
mittel, das Spannung erzeugt, beschreibt die Unvermitteltheit und das Überraschungsmoment des Eintretens einer unheilvollen Begebenheit (5b für den Unschuldigen; 8b für die Feinde). Das Lokalobjekt ist mit im Verborgenen 5a) gegeben und steht einerseits symptomatisch für die Taten der Feinde, welche - statt die Konfrontation face to face zu suchen - heimlich agieren, andererseits aber auch für die Wünsche des lyrischen Ich nach Schutz und Geborgenheit (3a).

\subsubsection{Parallelismen}

Nach Ps 30, 147 und 90 ist auch Ps 64 daraufhin zu untersuchen, wie der Parallelismus membrorum ausgestaltet ist und ob er dazu beiträgt, dass die Lesenden die Zeit besitzen, sich in ihrer Imagination der Textwelt anzunähern und sich mit dieser zu identifizieren. Auf die Dimension des zeitlichen Verweilens soll an dieser Stelle ebenso das Augenmerk gelenkt werden wie auf die Entfaltung und Konkretisierung der Thematik und Dramatik des jeweiligen Verses.

Ps 64 ist hauptsächlich durch synthetische Parallelismen gekennzeichnet. Dies zeigt auch, dass der Text in dem Sinn dynamisch gestaltet ist, dass er eine fortschreitende Handlung und einen Spannungsaufbau aufweist. Dennoch ist dieser Handlungsfortschritt nicht sprunghaft konstruiert, sondern so, dass im Leseprozess genug Zeit bleibt, beim Gedanken des jeweiligen Verses zu bleiben. Im jeweils nächsten Halbvers wird eine Nuance bzw. ein weiteres Detail hinzugefügt. So wird die Erhörungsbitte aus 2a expliziert, indem sie mit dem dringenden Wunsch nach Bewahrung des Lebens vor dem Schrecken der Feinde in 2b fortgesetzt wird. In V2 wird also nach dem Appell an Gott (2a) im zweiten Kolon der Grund für diesen Appell benannt. V3 ist ebenso wie V2 synthetisch gestaltet. Die Gemeinschaft der Übeltäter aus 3a wird in $3 \mathrm{~b}$ dahingehend spezifiziert, dass von רִגְשָׁה (Tumult, Unruhe, Aufruhr) die Rede ist und damit das neue Element des

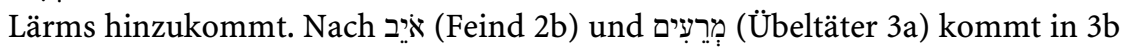

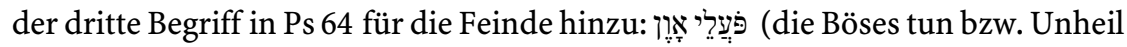
stiften). Nach diesen drei Bezeichnungen werden die Feinde nun mittels neun verschiedener Handlungen charakterisiert, die in V4-7 mit Hilfe von synthetischen Parallelismen geschildert werden. Für V3 sind damit drei Elemente festzuhalten: Es kommt zunächst zu einer (1) versteckten Wiederholung, indem in 3b das Verb aus 3a elliptisch fortgeführt wird. Zudem ist (2) eine Spezifizierung festzustellen: Die Gemeinschaft der Übeltäter aus 3a ist jene, die in 3b Böses tut. $\mathrm{Zu}$ guter Letzt wird (3) ein neues, weiterführendes Element eingeführt, nämlich der Lärm bzw. Tumult (3b). V4 erzählt von den vorbereitenden Handlungen zur Jagd mit Worten, die mit Hilfe eines synthetischen Parallelismus nach dem Schärfen des Schwertes (4a) und dem Treten des Bogens bzw. Anlegen des Pfeiles 
(4b) zum eigentlichen Beutezug führen (V5). In V4 werden damit zwei Aktionen hintereinander erzählt. In 5a.b wird jeweils das Verb »schießen « verwendet, allerdings kommt mit der Furcht in 5b ein neues Thema hinzu, das erst in 10a wieder aufgenommen wird. V5 zeichnet sich insofern einerseits durch die Wiederholung sowie andererseits durch ein neues, weiterführendes Element aus. V6 ist ebenso synthetisch gestaltet: 6a bezieht sich allgemein auf die Stärke der Feinde durch böse Wörter, welche in $6 \mathrm{~b}$ ausgestaltet (davon erzählen, Fallstricke bzw. Klappnetze zu verstecken) und in $6 \mathrm{c}$ sogar wörtlich zitiert werden. Hier ist ein Dreischritt vom Allgemeinen zum Konkreten festzustellen: Von der allgemeinen Rede über das Wort in 6a geht es zu den Wörtern, die von den Feinden indirekt erzählt werden, bis hin zu der direkten Rede der Feinde im Feindzitat. Indem $7 \mathrm{~b}$ die Vollendung des Erforschens und Nachdenkens über Ungerechtigkeiten benennt, führt es diese Eigenschaft der Feinde, nämlich das Planen von Schlechtigkeiten aus 7a, weiter. 7c setzt den Gedanken der inneren Vorgänge, des Planens und Nachdenkens dergestalt fort, als er eine allgemeine Aussage über die Unergründbarkeit des menschlichen Inneren zum Inhalt hat. Auch hier sind drei Stufen auszumachen: Beginnend mit der allgemeinen Rede über die Schlechtigkeiten der Feinde in 7a über das direkte Feindzitat in 7b schließt der Vers in 7c mit einer allgemeinen Reflexion im Nominalsatz. V8 erzählt von der Tat Gottes (Pfeilschuss 8a) und der Konsequenz daraus (Wunden 8b). Mit V8 beginnt der zweite Teil des Psalms, der in jedem Halbvers eine Handlung nennt, die die vorangehende weiterführt. Auf das Straucheln der Feinde (9a) folgt als Konsequenz und mit Blickwechsel auf alle, die das sehen, eine Reaktion des Kopfschüttelns (9b). Die V8-9 folgen damit dem Tat-Folge-Schema, wobei die jeweilige Konsequenz in $8 \mathrm{~b}$ und $9 \mathrm{~b}$ von außen wahrnehmbar ist. V10 lädt innerhalb des Abschnitts am längsten zum Verweilen ein. Hier werden die Reaktionen aller Menschen in einem Dreischritt geschildert, beginnend beim (1) Fürchten, wohl in Form der Gottesfurcht und des Vertrauens zu Gott gemeint, über (2) das Erzählen, Reden und Verkünden der Tat Gottes bis hin zum (3) Verstehen und Begreifen des göttlichen Tuns. Nach der Kürze der Verse 8 und 9 scheinen nun die Menschen in V10 länger zu brauchen, um auf die Tat Gottes zu reagieren und diese zu verstehen. Anders gesagt: Das, was auf einmal passiert (Gottesfurcht; verkünden und verstehen), wird in drei Stufen entfaltet. Durch diese zeitdehnende Darstellungsweise wird vor allem den Lesenden Zeit zugestanden, diesen mehrstufigen Prozess mitzuvollziehen. In V11 kommt es zu einer Wiederholung, indem auch in 11b das Subjekt aus 11a gilt. 11b führt das Subjekt aus 11a weiter (Gerechter) und verstärkt dessen Freude an JHWH durch das Thema der Zuflucht (vgl. V2-3). 11c öffnet den Psalm gegen Ende hin auf alle Herzgeraden und das Lobthema. Die in V8-11 erzählten elf Handlungen sind als ein durchgängiger Handlungsfortschritt zu betrachten. Hier ist, etwa im Vergleich zum ersten Teil, weniger Zeit vorhanden, im Leseprozess bei einem Vers zu bleiben (Ausnahme: 
V10). Die Dynamik des Textes in Form der in den synthetischen Parallelismen geschilderten aufeinanderfolgenden Handlungen nimmt gerade im zweiten Teil die Lesenden mit hinein in die Spannung des Textgeschehens bis zum versöhnlichen Ende und feierlichen Abschluss in 11c. ${ }^{1312}$ Die parallele Gestaltung in Ps 64 ist damit von einer Dynamisierung geprägt. Inhaltlich wird der Text bestimmt durch das Schema Wiederholung - Weiterführung ${ }^{1313}$ (V3.5.11) einerseits sowie Tat - Folge (V2.8.9) andererseits. V4 enthält zwei aneinandergereihte Aktionen. Die Trikola V6.7 führen vom Allgemeinen ins Konkrete, das zeitdehnende Trikolon in V10 entfaltet einen Erkenntnisprozess, damit dieser für die Lesenden nachvollziehbar wird.

\subsection{5 Übergänge}

Für die Textdynamik ist neben den bereits analysierten Elementen auch die Gestaltung der Übergänge innerhalb des Psalms relevant: Sind die Verse miteinander verbunden, und wenn ja, wie geschieht das? Die Überschrift, die den Psalm David zuordnet, steht unverbunden am Beginn des Textes. ${ }^{1314}$ Die Verbindung zwischen V2 und V3 ist durch die Konstruktion der beiden Halbverse 2b.3a gegeben, die chiastisch aufeinander bezogen und inhaltlich parallel ausgerichtet sind. $3 \mathrm{~b}$ führt $3 \mathrm{a}$ weiter, indem die Übeltäter näher charakterisiert werden. In 2b.3a.3b ist dieselbe Präposition p̣ zu finden. Mit dem Relativpro-

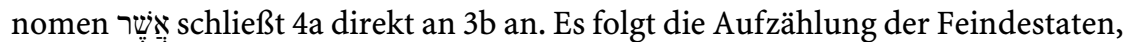
die mit dem Feindzitat in 7b endet. Dabei wird der Begriff דָָָ (Wort) aus 4b in 6a wieder aufgenommen. Die im Nominalsatz allgemein gehaltene Aussage über die Unergründlichkeit des menschlichen Inneren in $7 \mathrm{c}$ wird durch die Konjunktion ? mit $7 b$ verbunden. Mit $8 a$ setzen Narrative ein (8a; 9a; 10a.b), die bis V10 fortgesetzt werden und den Abschnitt zusammenhalten. $10 \mathrm{c}$ ist wiederum durch die Konjunktion ? mit 10b verbunden. Auch wenn auf den ersten Blick der Eindruck vorherrscht, dass mit dem Gerechten und dessen Freude an JHWH gerade im Schlussvers des Psalms ein neues Thema eingespielt wird, so zeigt ein zweiter Blick Verbindungslinien $\mathrm{zu}$ bereits geschilderten Figuren und Themen des Psalms: So wird mit dem Gerechten aus 11a der Unschuldige (5a) und das klagende lyrische Ich (V2-3) wieder aufgenommen und ebenso das Thema des Schutzes und der Zuflucht (11b), das in V2-3 eine große Rolle spielt. V11 beginnt wie 2b.3a mit einer PK-Form (11a). Die folgenden Halbverse sind durch die Verbformen in der W-SK (11b) und in der waw+PK (11c) miteinander verbun-

1312 Nötscher, Die Psalmen, 138 bezeichnet das Psalmenende als »einen freundlichen Ausklang nach der düsteren Klage.«

1313 Vgl. dazu das Schema »Echoing and Extending« bei Jacobson / Jacobson, Invitation, 17.

1314 Vgl. dazu im Gegensatz Ps 90, der in seiner Überschrift mit Elohim (1a) bereits auf den ersten inhaltlichen Vers und den dortigen Gottesnamen Adonaj (1b) verweist. 
den. In $11 \mathrm{c}$ wird das Nomen ţ $_{\text {aus }} 9 \mathrm{~b} .10 \mathrm{a}$ wieder aufgenommen. Damit sind in Ps 64 Übergänge zwischen den einzelnen Versen vorhanden. Sie werden durch die Konjunktion !̣, durch das Relativpronomen inhaltliche Gemeinsamkeiten, durch die Wiederaufnahme von Stichworten sowie durch die Zeitenfolge der Verben konstruiert.

\section{$4 \quad$ Zusammenfassung}

\subsection{Inhalt und Emotionen}

Psalm 64 schildert nach der Überschrift in V1, durch die der Psalm mit David in Beziehung gesetzt wird, die Ausgangslage des lyrischen Ich: Es benötigt dringend Schutz vor einer Ansammlung von Übeltätern. Diese werden daraufhin in V4-7 in ihrem Tun beschrieben. In V8-9 tritt unvermittelt die Gottheit in Aktion und setzt eine Verletzungstat gegen die Feinde. Mit den Konsequenzen dieses Tuns für die Feinde (8b-9a) und für alle Menschen (9b-10c) sowie mit dem daraus folgenden Fazit für den Gerechten (11a.b) und die Herzgeraden (11c) endet der Psalm. Das lyrische Ich wird als durchgehende Sprechstimme angenommen. Der Psalm ist hauptsächlich in der Sie-Rede gestaltet, lebt aber vom Wechsel der verschiedenen Rederichtungen und Perspektiven (siehe Perspektivenlenkung). In Anbetracht der Kürze des Textes ist eine erstaunlich hohe Dichte an Emotionalität auszumachen. Sie findet sich vor allem zu Beginn (V2-3) und am Ende des Psalms (V10-11). Die Dichte wird sowohl durch explizite Emotionswörter als auch durch implizit vorhandene Emotionen in Syntax und Metaphorik sowie Inhalt bzw. Kontext erzeugt. Dabei hat sich gezeigt, dass die Emotionen, die hauptsächlich in expliziter Weise für das lyrische Ich thematisiert und vor allem durch die Bedrängnis und Bedrohung der Feinde ausgelöst werden (Schwerpunkt: Emotion der Angst), dann implizit auch bei den Feinden vorhanden sind. So sind die Emotionen der Angst, Panik, der Sorge und Unruhe, der Ohnmacht und Hilflosigkeit sowie die Emotionen, die auf die Dringlichkeit der Situationsänderung hinweisen und mit Bedrohung und Gefahr von außen verbunden sind, dem lyrischen Ich zuzuordnen (V2-5). Die Emotionen der Freude, Zuversicht, Erleichterung und Ermutigung werden mit dem Gerechten und den Herzgeraden in Verbindung gebracht (V11). Betrachtet man das lyrische Ich, den Unschuldigen, Gerechten und die Herzgeraden als eine Figurengruppe und nimmt Beginn und Ende des Psalms gemeinsam in den Blick, so kann hier durch die Emotionen der Angst, Sorge und Hilflosigkeit einerseits sowie jener der Freude, Zuversicht und Erleichterung andererseits im weitesten Sinne von der bereits bekannten doppelten Emotionalität gesprochen werden. 
Mit der Gottheit sind jene Emotionen verbunden, die Fürsorge ausdrücken (V2), Geborgenheit und Schutz (V3) sowie Vertrauen (11). Die Darstellung der Feinde wird von Emotionen begleitet, die mit Erschrecken, Gewalt und Lebenszerstörung verknüpft sind (V3-5). Daneben sind den Feinden die Emotionen der Überraschung (V8), des Stolzes und der Selbstsicherheit (V6) ebenso zuzuordnen wie diejenigen, die mit Entschlossenheit und Stärke verbunden sind (V6). Emotionen, die mit Ungerechtigkeiten, Schlechtigkeiten und Bosheiten der feindlichen Pläne (V7) zusammenhängen, kommen ebenso zur Darstellung wie die Emotion der Angst (V8) und die der Peinlichkeit bzw. Scham (V9). Es bleiben noch jene Emotionen zu nennen, die mit allen Menschen verbunden sind: Abscheu und Ekel, Angst und Furcht sowie Schadenfreude (V9) und die in der Gottesfurcht liegende Dimension des Vertrauens (V10).

\subsection{Textdynamik}

Die narratologischen Analysekriterien haben sich für die Analyse der Textdynamik von Ps 64 als hilf- und aufschlussreich erwiesen. Die Perspektivenlenkung des Textes zeichnet sich durch externe (3b-6b; 7a.c; 8-11) und interne (23a.6c.7b) Fokalisierung sowie durch den Wechsel von Nähe (V2-3; V10-11) und Ferne (V8-9; V4-7: Anaphorik schafft Ferne, der Fokus auf die Aktivität der Handlungen und Pläne der Feinde allerdings Nähe) aus. Dabei sind V2-3 durch eine hohe Zahl an deiktischen Textelementen bestimmt. Im Text können zwei Bewegungen (1. Bewegung: V2-7: lyr. Ich und Feinde; 2. Bewegung als Gegenbewegung: V8-11: Eingreifen Gottes, Reaktion und Fazit) ausgemacht werden. Dabei finden sich im ersten Teil Steigerungen sowie ein Spannungsaufbau im Hinblick auf die Vorbereitung von Jagd und Kampf und deren Durchführung sowie bezüglich der Kommunikation und der inneren Vorgänge der Feinde. Auf der Figurenebene wird die Erwartungshaltung des Sieges über das lyrische Ich aufgebaut bzw. generell die Frage aufgeworfen, wie es nun weitergeht, nachdem die Feinde ihm so hart zusetzen. Damit ist auf der Ebene der Lesenden der Wunsch verbunden, das lyrische Ich möge seiner misslichen Lage entkommen. Hier treffen die im Methodenteil ausgeführten Elemente einer emotionalen Reaktion auf literarische Texte zusammen, nämlich in Gestalt einer Kombination aus einem vorfokussierten Text, der eine bestimmte Situation darstellt, sowie Interessen, Bedenken und Einstellungen gegenüber dem lyrischen Ich, die sich in Wünschen manifestieren.

Der Höhepunkt in V8-9 wird durch das unvermutete Eingreifen Gottes und damit durch das Brechen der Erwartungshaltung auf Figurenebene bestimmt. Der Spannungsaufbau erreicht in V8 eine Klimax und flacht gegen Ende des Psalms wieder ab. 
Hinsichtlich der Figurenkonstellationen ist festzuhalten, dass das lyrische Ich mit der Gottheit in Kontakt tritt, die Gottheit mit den Feinden und die Feinde mit dem lyrischen Ich. Dieses Beziehungssystem zeigt auf, dass die Gottheit weder mit dem lyrischen Ich direkt in Kontakt tritt noch die Feinde mit der Gottheit. Das lyrische Ich setzt auch keine Handlung gegen die Feinde. Über die Verletzung der Feinde kommt dem lyrischen Ich (als Gerechtem und Teil der Herzgeraden in V11) göttliche Wirkmacht zu. Deutlich hat sich bei der Charakterisierung der Figuren eine Kontrastierung herauskristallisiert: So steht das lyrische Ich (inkl. Unschuldiger, Gerechter und Herzgerader) in deutlichem Gegensatz zu den Feinden. Auch alle Menschen werden im Kontrast zu den Feinden dargestellt. Vor allem hier zeigt sich, dass Ps 64 eine antithetische Struktur besitzt. Ebenso sind parallele Züge auszumachen. So sind die Feinde und die Gottheit durch die gemeinsame Handlung des Schießens verbunden. Die Charakterisierung zeichnet sich daneben vor allem durch die Möglichkeit aus, dass die Lesenden Einblicke in das Innenleben der Figuren (lyr. Ich und Feinde) erhalten. Die durchgehende Gestaltung des Textes mittels synthetischer Parallelismen bewirkt ein Fortschreiten des Plots. Jeder Halbvers ergänzt den Gedanken des vorangegangenen Stichos um ein weiteres Detail. Der weitergeführte Gedanke entfaltet thematisch eine neue Nuance, ohne sich dabei vom Gedanken des vorangegangenen Halbverses völlig abzuheben. So wird es den Lesenden ermöglicht, mit dem Handlungsfortschritt des Textes mitzugehen und gleichzeitig Zeit zu haben, die jeweiligen Inhalte des Verses zu imaginieren. Zu guter Letzt verhindern die Übergänge, die durch Konjunktion, Relativpronomen, Wortwiederholungen, Parallelen in Thema und Inhalt sowie durch die Zeitenfolge der Verben ausgestaltet sind, ein Hinausfallen aus dem Leseprozess.

\section{$5 \quad$ Identifikationspotenziale in Psalm 64}

\section{1 durch Emotionen, Aufbau, Textdynamik und Perspektivenlenkung}

Bereits ganz zu Beginn (V1) bietet die Überschriftennotiz mit David eine Identifikationsfigur an und lädt die Lesenden dazu ein, sich in der Psalmlektüre mit David und dessen Schicksal zu identifizieren.

Die klare Struktur ${ }^{1315}$ des Psalms und das Vorhandensein der sogenannten minimal elements der Bühne der erzählten Welt schaffen die Basis dafür, dass sich die Lesenden in den Text einfinden können. Dabei zeichnet sich der Anfang des Psalms (V2-3) durch eine hohe Emotionalität aus, die durch explizite Emotionswörter und implizite Emotionen hervorgerufen wird. Eine Häufung

1315 Vgl. Stuhlmueller, Psalms 1, 290; Botha, Strategy, 69 und Kraus, Psalmen, 606. 
deiktischer Elemente ist ebenso festzustellen. Dieser "starke Beginn" (hohe Emotionalität, Deixis) mit einem klaren Inhalt, der den Lesenden genug Raum lässt, die je eigene Situation der Bedrängnis darin zu lesen, ist als erstes Identifikationspotenzial in Ps $64 \mathrm{zu}$ nennen. Nimmt man Beginn und Schluss gemeinsam in den Blick, so ist mit der doppelten Emotionalität ein Identifikationspotenzial dahingehend gegeben, als den Lesenden zwei Möglichkeiten der Identifikation - jene mit der Situation der Bedrohung und Angst, aber auch jene der Freude, Erleichterung und Zuflucht bei Gott - eröffnet werden.

Die literarische Einheit und Kohärenz des Textes einerseits sowie der Mangel an offensichtlichen Bezügen zum altorientalischen Kontext andererseits tragen zur LeserInneninteraktion mit dem Text bei, sodass das Identifikationspotenzial erhöht wird. "In any case, the psalm is a literary unity, apparently without any strong ties to a specific ancient context. The text generates its own context in interaction with the reader. ${ }^{1316}$

Durch Lebendigkeit in der Darstellung (Sprechrichtungswechsel; interne und externe Fokalisierung, Nähe und Ferne), Bewegung und Gegenbewegung im Text und Charakterisierung der Figuren (Schwerpunkt: Innensicht) sowie einen deutlichen Spannungsaufbau ist ein Mitgehen mit den Figuren und ein Dranbleiben an der Textwelt gegeben. Die Kombination aus Spannungsaufbau und dem Aufbau von LeserInnenerwartungen und -wünschen kann zusätzlich emotionale Reaktionen auf Seiten der Lesenden hervorrufen.

Das Dranbleiben an der Textwelt wird durch die vorhandenen Übergänge und synthetischen Parallelismen verstärkt. Ein Mitgehen mit der Sprechstimme und mit deren Bewegungen wird dadurch ebenso ermöglicht. "The speaker has moved to a very different place at the conclusion of the psalm. The movement is from the oppression of the enemies [...] to refuge in the shelter of divine protection. That movement leads to rejoicing. ${ }^{1317}$ Das Identifikationspotenzial mit der Sprechstimme (lyrisches Ich) wird durch die antithetische Struktur des Psalms und die Gegenüberstellung zwischen dem lyrischen Ich und den Feinden erhöht (siehe unten Analogiebildung).

\section{2 durch Inhalt, Analogiebildung und Kontraste}

Ps 64 hat eine breite Palette an Themen zu bieten, die für heutige Lesende anschlussfähig sind und damit als Identifikationspotenziale ausgewiesen werden können. "This psalm can touch our modern lives at a number of points. « ${ }^{1318}$

1316 Tate, Psalms, 133.

1317 Brueggemann / Bellinger, Psalms, 281.

1318 Limburg, Psalms, 212. 
Schwerpunkte bilden dabei die Macht der Worte ${ }^{1319}$ und der Kampf mit Worten, die dunklen Kräfte der Feinde, die Unerforschlichkeit des menschlichen Inneren sowie das Vertrauen auf das Eingreifen Gottes in Gestalt des Erzählens von Gott nach der Erfahrung der göttlichen Befreiung und der Reflexion darüber, was an die Anfänge von Theologie heranreicht. ${ }^{1320}$

Ein großer Teil des Psalms wird von der Darstellung der Bedrohung und Gefährdung durch Worte sowie der Verletzungsmacht von Worten bestimmt. »Words can hurt deeply; words like 'We're downsizing, and the company won't really be needing you anymore from now on! or 'I'm sorry, but I just don't love you anymore. « $^{1321}$ Die verletzenden Worte können in der Nähe artikuliert werden oder ohne offene Konfrontation aus der Ferne. Letzteres wird gegenwärtig von Manfred Oeming und Joachim Vette als »Mobbing« bezeichnet: »Der Hilfeschrei von Ps 64 macht deutlich, dass `das böse Wort‘, heute würde man sagen, das Mobbing (wörtlich übersetzt das verbale über jemanden `Herfallen`), eine außerordentliche Macht besitzt. Verleumdung ist eine dämonische Macht, die einen Menschen fertig machen und in den Untergang treiben kann. Das Gebet kann eine gute Hilfe sein, in diesem Konflikt zu überleben. . $^{1322}$ Die Verletzungsmacht von Worten wird ganz aktuell auch in der Hetze im Internet und in Hasspostings sichtbar. ${ }^{1323}$ Die bösartigen Worte in Ps 64 gehen von einer Gruppe von Feinden aus (vgl. Pluralformen 3a.b bzw. Versammlung/Gemeinschaft/ Horde 3a). Wilson spricht in diesem Zusammenhang von der Macht des Mobs ${ }^{1324}$ und nennt im Gegensatz zu Ps 64 positive Beispiele für die Macht einer Gruppe: »There can be good moments of solidarity, as in moments of mass civil disobedience in protest against racial injustice or against unjust wars. The kind of strength to stand our ground against impossible odds has great moral power - as Gandhi's nonviolent resistance showed in India and the best of civil-rights protests did in the United States. «"1325

Einen weiteren Schwerpunkt des Psalms bildet die Darstellung der Aktivitäten und Gedanken der Feinde, die als dunkle Kräfte wirken. Durch diese Darstellung hält uns der Psalm einen Spiegel vor hinsichtlich der destruktiven Kräfte, die in

$1319 »$ Words are powerful in contemporary culture, both for good and ill. Some reflect the depth and power of human evil; others commend grace and care. The power of words provides a connection between Psalm 64 and today's culture. Evil and its words continue to be pervasive and powerful - words such as racism, cancer, or poverty. People continue to suffer under the power of such words, which become the slings and arrows of chaos knocking at the door." Brueggemann / Bellinger, Psalms, 283.

1320 Vgl. Limburg, Psalms, 213.

1321 Limburg, Psalms, 211.

1322 Oeming / Vette, Psalmen, Psalm 42-89, 138.

1323 Man bedenke hier etwa die beleidigenden Äußerungen im Rahmen von Shitstorms.

1324 Vgl. Wilson, Psalms, 901.

1325 Wilson, Psalms, 901. 
heutigen Gesellschaften vorhanden sind. ${ }^{1326}$ Der Psalm verweist damit mit erbarmungsloser Aktualität auf die zerstörenden Kräfte in uns und in unserer Gesellschaft: »In a real sense, Psalm 64 calls us to recognize and to confess the evil within ourselves and our society. ${ }^{1327}$ Der Text thematisiert also die zerstörerischen Mächte, gleichzeitig vermeidet der Text aber durch die antithetische Darstellungsweise die Identifikation mit den Feinden und legt vielmehr die Abgrenzung zu diesen nahe. Vor allem Erbele-Küster betont in ihrer Dissertation die Funktion der Feindbeschreibungen und -zitate als Negativfolie einerseits sowie als Identifikationspotenzial mit dem Gerechten auf der anderen Seite: »In ausführlichen Schilderungen des Treibens der Feinde, in der Klage und in den Zitaten ihrer lästerlichen Reden [...] wird dem Leser eine Negativfolie vorgeführt und damit die Identifikation verstellt [...]. Durch die Abgrenzung gegenüber den Feinden wird dem Beter die Identifikation mit dem Gerechten nahegelegt. « ${ }^{1328}$

Ein weiteres Identifikationspotenzial - insbesondere für jene, die von der Verletzungsmacht der Worte und von versteckter Böswilligkeit betroffen sind - ${ }^{1329}$ ist die im Psalm geschilderte Erfahrung, dass Gott in lebensbedrohlichen Situationen eingreift, dass die Waffen der Feinde auf diese selbst zurückfallen und dass der Tun-Ergehen-Zusammenhang wirkt. Mit anderen Worten: Dass man im Leben einen Ausgleich bekommt für die Zeiten, in denen man der Bedrohung ausgesetzt war. Oder mit Blick auf die Feinde: Ungerechte Taten müssen Konsequenzen haben; die Täter bekommen, was sie verdienen. $^{1330}$

Schließlich ist noch der Gebetscharakter des Psalms hervorzuheben. Im Gebet ist es möglich, die eigenen Erfahrungen, Ängste und Zweifel auszudrücken und

1326 Ps 64 hilft uns dabei, dass wir uns mit diesen destruktiven Kräften auseinandersetzen:»[...] we need these psalms to help us grapple with the real presence of threat, hurt, and anger in human relationships. «Steussy, Enemy, 5. Tate, Psalms, 135 hält darüber hinaus fest: »The psalm communicates a sense of anxiety and perplexity about the nature of human society that is at home in every generation. The supposed sophistication of modern society is not immune to deep awareness of destructive forces which threaten to reduce our semi-ordered world to chaos. The power of viral disease, resistant to all known drugs, is an example from the area of medicine. Political and economic forces which seem to paralyze leaders and elude the grasp of government in the face of the threat of war or internal disorder are others. The demonic is a part of our way of life, and we are all subject to the danger of the poison arrow shot from hiding places.« Tate, Psalms, 135.

1327 McCann, Psalms, 931.

1328 Erbele-Küster, Lesen, 114. Müllner, Gewalt, 68: »Auf dem Hintergrund einer Negativfolie kann ein anderer Charakter umso positiver hervortreten." Siehe auch Wenham, Psalms, 167: »Modern readers have little difficulty identifying with the [righteous].»

1329 Nach Clifford, Psalms 1-72, 301 eignet sich gerade Ps 64 für diese Personengruppe.

$1330 »$ You get what you deserve« bei Wilson, Psalms, 902. „Ein Handeln, das das Leben anderer und die Gemeinschaft zerstört, führt zur Selbstzerstörung, wird zum Fluch. Ein Handeln hingegen, das andern hilft und die Gemeinschaft stärkt, wird zur Lebensmacht, zum Segen.» Marti, Die Psalmen, 186. 
diese vor Gott zu bringen. Der Gebetstext von Ps 64 bietet dafür den entsprechenden Kontext, indem er auch davon erzählt, was JHWH getan hat und was daher von Gott erwartet werden kann. Hierin besteht auch die Möglichkeit, durch die Identifikation mit der Sprechstimme (siehe oben) den Weg des Textes mitzugehen und den Gebetsweg an einem anderen Ort zu verlassen als dort, wo man begonnen hat: »Worship appropriately gives opportunity to express our experience, our laments, and our longings, but if we stop at that, we have hardly moved forward. Worship makes it possible to express our fears and longings because it provides a context in which we can also be reminded of what God has done and therefore can be expected to do again. That is what can make it possible to leave worship in a different place from the one we occupied when we arrived. « $^{1331}$

Ps 64 zeichnet das Bild einer Gottheit, die zuhören sowie Schutz bieten kann, die Geborgenheit und Zuflucht gewährt und bei der Menschen sich erfreuen können. Mit ihrer die Feinde verletzenden Tat stellt sie Gerechtigkeit für den Bedrängten her und zeigt damit, dass mit ihrem tatkräftigen und befreienden Eingreifen zu rechnen ist und Menschen solches Eingreifen nicht aus eigener Kraft und Initiative heraus bewerkstelligen müssen. ${ }^{1332}$ Die genannten Dimensionen, die mit dem Gottesbild verbunden sind, laden durchweg dazu ein, das je eigene Gottesbild mit dem von Psalm 64 zu identifizieren.

1331 Goldingay, Psalms 2, 271.

1332 McCann, Psalms, 931 bezeichnet Ps 64 dementsprechend als Aufruf, die eigenen Fähigkeiten und das eigene Schicksal Gott anzuvertrauen: »It is also a call to faith - not to trust our own inclinations or capacities but to entrust our abilities and destiny to God." 


\section{Ergebnisse}

Die Analysen haben gezeigt, dass die vier in verschiedenen Perspektiven ausgerichteten Psalmen Identifikationspotenziale in unterschiedlicher Intensität und Ausprägung anbieten. Diese werden im Folgenden unter "3. Identifikationspotenziale« nochmals differenziert dargestellt. Davor kommen in der folgenden Zusammenschau und Auswertung weitere Analyseergebnisse konzentriert zur Darstellung. Sie werden dabei entlang der in der Einleitung ausgewiesenen Forschungsdesiderate aufgefächert.

\section{$1 \quad$ Narratologische Analysekriterien und Psalmen}

Welcher Ertrag ist nach der Analyse von Ps 30; 64; 90 und 147 mittels narratologischer Analysekriterien im Allgemeinen und hinsichtlich der Frage nach Identifikation im Besonderen festzuhalten? Durch die Analyse von Figuren und deren Handlungen, von Zeiträumen und zeitlichen Abfolgen, von Räumen und Bewegungen sowie von Blick, Perspektivenlenkung und Art und Weise der »Kameraführung" des Textes werden Analysierende näher an den Text herangeholt, da sie sich im Detail mit der Textstruktur und Textoberfläche beschäftigen müssen. Dabei sind die klare Nachzeichnung von Bewegungen und die Charakterisierung der Figuren im Text hervorzuheben, vor allem des lyrischen Ich/Wir.

\subsection{Bewegungen in Raum und Zeit}

Durch die Analyse von Räumen, Bewegungen sowie Zeiten und Ereignisfolgen innerhalb dieser Zeiträume in Verbindung mit der Analyse narrativer Impulse innerhalb der Parallelismen kommen die Bewegungen des Psalms klarer zum Ausdruck, sodass diese für die Lesenden besser nachvollziehbar werden und die Lesenden dadurch leichter in die Bewegung des Textes einsteigen und mit dieser mitgehen können. So erhält in Ps 30 die wellenartige Auf- und Abwärtsbewegung, 
das Aus-der-Tiefe-Herausgezogenwerden als Rettungsbewegung von unten nach oben sowie die Bewegung nach oben hin zu Gott eine klare Kontur. Daneben kann der Text als ein Nacheinander von zwei Minierzählungen betrachtet werden, von denen die erste das göttliche Rettungshandeln aus tiefer existenzieller Not von außen beschreibt und die zweite durch den zeitlichen Rückblick und die Binnenperspektive des lyrischen Ich die innere Dimension des Geschehens aufrollt. Die Geschichte, die in Ps 30 erzählt wird, tritt somit durch die Analyse der Bewegungen in Raum und Zeit klarer hervor. In Ps 147 zeichnet jede Szene mittels des durchgehenden Spotwechsels eine Auf-und-ab-Bewegung, und zwar von unten nach oben und danach wieder von oben nach unten. Gerade für diesen Psalm gilt, dass Lautmalerei, Alliterationen, Assonanzen und Wortspiele die melodische Bewegung des Textes verstärken. In Ps 90 eröffnen die Zeitdimensionen eine Reise bzw. Bewegung in der Zeit, beginnend mit der Ewigkeit Gottes und dessen Sein vor aller Zeit über die Vergangenheit der leidvollen Erlebnisse des lyrischen Wir bis hin zum gegenwärtigen Aufruf an Gott mit der Bitte um seine Zuwendung. Die Bitte beinhaltet einen Ausblick in die Zukunft. In dieser Zeitreise sind Elemente der Zeitraffung und der Zeitbeschleunigung im ersten Teil des Psalms sowie der Zeitdehnung im zweiten Teil enthalten. Thematisch ist im Text zunächst eine Abwärtsbewegung auszumachen, die mit den positiven Aspekten des Vertrauens in Gott und der Erschaffung der Schöpfung aus göttlicher Geburt beginnt und über die Themen der Hinfälligkeit, Vergänglichkeit und Kürze des Menschenlebens über Zorn und Schuld letztlich bei der Kraft des überwallenden Zornes Gottes im Scharniervers (V11) den Tiefpunkt erreicht. Mit V12, der Bitte um besonnenen Umgang mit der Lebenszeit und der Rede vom Herz von Weisheit, wird die Wende hin zur positiven Thematik vollzogen, die über Sättigung, Güte, Freude und Jubel bis zum Glanz und zur Anmut Gottes sowie dem Bestand des Menschenwerks reicht. In Ps 64 können zwei Bewegungen ausgemacht werden. Die erste Bewegung konzentriert sich auf die Notsituation des lyrischen Ich und die Handlungen sowie die Gesinnung der Feinde, die zweite gilt mit dem Eingreifen Gottes als Rettungshandlung für das lyrische Ich und der göttlichen Verletzungstat gegenüber den Feinden sowie der Reaktion und Schlussfolgerung daraus als Gegenbewegung zur ersten. In der ersten Bewegung ist der Spannungsaufbau offensichtlich: Es kommt zu einer Steigerung der Dramatik, durch die bei den Lesenden eine Erwartungshaltung aufgebaut wird. Der Spannungsaufbau erreicht in V8 und damit zu Beginn der zweiten Bewegung seinen Höhepunkt und flacht gegen Ende des Psalms ab. Der Psalm ist mittels der synthetischen Parallelismen, die einen Handlungsfortschritt bewirken, durchgehend dynamisch gestaltet. 


\subsection{Charakterisierung}

Nach der Darlegung der Bewegungen innerhalb der Texte sticht im Rahmen der Analyse der Handlungen durch Verbanalyse und Analyse der Subjekt-ObjektPositionen die Charakterisierung der Figuren hervor. Je mehr die Lesenden von den Textpersonen erfahren, desto leichter ist Identifikation (z. B. mit dem lyrischen Ich) oder auch Abgrenzung möglich, wie beispielsweise gegenüber den Feinden. Dabei sind Vokative und direkte Reden, etwa in Form der Introspektion, wichtige zeitdeckende Elemente, die die Lesenden unmittelbar ins Textgeschehen hineinholen. Auch die Auseinandersetzung mit dem je eigenen Gottesbild wird durch die Möglichkeit der Charakterisierung der Gottheit gefördert und herausgefordert, indem durch die Narratologie Gott als Figur ernst und in den Blick genommen wird. ${ }^{1333}$ Die Gottheit zeichnet sich in Ps 30 durch ihr tatkräftiges Eingreifen, ihr heilendes Rettungs- und Befreiungshandeln, durch Wohlgefallen, Zuneigung und berührende Nähe, aber auch durch Abwendung, Distanz, Zorn sowie die Handlungen des existenziellen Wandelns aus und verfügt in diesem Text über den höchsten Anteil an Handlungen. Dies ist ebenso in Ps 147 der Fall, wo der Gottheit 70 Prozent des Anteils an Handlungen zukommen. Diese erweisen sich einerseits als Heilshandlungen an Jerusalem und Israel, als Handlungen an anderen Menschengruppen, etwa den (gerechten) Umgang mit den Unterdrückten und Unterdrückern, sowie als widersprüchliches, einerseits fürsorgliches und anderseits gefahrvolles Handeln mit und in der Schöpfung. Ps 90 zeichnet ein ambivalentes Bild von Gott. JHWH ist Schöpfer und hat vor allen Zeiten Bestand. Er gilt als Zuflucht und Wohnort, gibt damit Halt und Unterschlupf. Zudem werden ihm mittels einer Reihe von Substantiven Zorn und Wut zugeschrieben. JHWH gilt in Ps 90 als leidenschaftlich-machtvoller Gott, der Leben und Tod des Menschen in der Hand hat, sowie als eine Gottheit, die sich erbarmen, den Menschen zuwenden, Freude, Glanz und Bestand gewähren kann. Die Nüchternheit des Textes in Bezug auf die göttlichen und menschlichen Dimensionen fordert die Auseinandersetzung mit dem eigenen Gottes- und Menschenbild stets aufs Neue heraus. In Ps 64 schließlich steht die Gottheit, die sich durch Zuhören und Wahrnehmen auszeichnet und Schutz, Zuflucht sowie Freude gewährt, über den Feinden, und sie befreit durch gewaltvoll-mächtiges Eintreten mit nur einer einzigen Handlung aus der Situation der Verfolgung und Bedrängnis.

In dieser Arbeit konnte auch aufgezeigt werden, wo die Analyse mit Hilfe narratologischer Kategorien an ihre Grenze stößt. Dies ist dann der Fall, wenn die Ereignisfolge ausfällt, wenn es also keine zwei aufeinanderfolgenden Ereignisse

1333 Vgl. dazu den Sammelband von Eisen, Ute E. / Müllner, Ilse (Hg.): Gott als Figur. Narratologische Analysen biblischer Texte und ihrer Adaptionen, HBS 82, Freiburg u. a. 2016. 
gibt, und stattdessen Reflexionen oder durchgehende direkte Rede Einzug halten bzw. dominieren, was im Fall von Ps 90 in Form von Aufforderungen geschieht. Narrativität, also das, was das Erzählende ausmacht, tritt dadurch in den Hintergrund, sodass die narratologischen Analysekategorien nicht mehr greifen.

Im Hinblick auf die Anwendung narratologischer Analysekategorien für lyrische Texte im Rahmen der Charakterisierung ist das Wahrnehmen des lyrischen Ich als Figur zu nennen. Dieses erhält deutlichere Konturen dahingehend, wer es ist und was es mit welcher Intention tut, wodurch es sich stärker präzisieren lässt. Durch die Analyse poetischer Texte mit Hilfe der Narratologie ist diese nähere Bestimmung des lyrischen Ich als besonders gewinnbringend hervorzuheben. ${ }^{1334}$ So ist das lyrische Ich in Ps 30 mit Kommunikationsverben des Lobens, Dankens, Rufens und Bittens ausgestattet, und es wird durch Introspektion, Rückblick und Selbstzitat als einst selbstsicher und selbstbezogen, als von Gottes Abwendung erschrocken, als mit Gott verhandelnd und hadernd und als Gott flehentlich bittend dargestellt. Es erfährt durch das göttliche Rettungshandeln und dessen Wandlungskraft neues Leben angesichts der erfahrenen Todesnähe und ruft aus dieser Erfahrung heraus zum Lobpreis Gottes auf. Das lyrische Ich in Ps 64 zählt gemeinsam mit dem Unschuldigen, dem Gerechten und den Herzgeraden zu einer Figurengruppe. Es zeichnet sich dadurch aus, dass es die Gottheit um Schutz und Beschütztwerden bittet und dies in eindringlicher Art und Weise tut. Als Unschuldiger wird es durch die Feinde beschossen, als Gerechter erfährt es schlussendlich Zuflucht bei Gott und als Teil der Herzgeraden bringt es Freude und Lob Gottes zum Ausdruck. Das lyrische Wir in Ps 147 ist dadurch gekennzeichnet, dass es einerseits die Sprechinstanz darstellt, andererseits sowohl zu den Angesprochenen (AdressatInnenperspektive) als auch zu den durch Gottes Heilstaten Begünstigten gehört (Jerusalem; Israel; jene, deren Herz zerbrochen ist; Unterdrückte). Das lyrische Wir in Ps 90 thematisiert ebenso die leidvolle kollektive Erfahrung einer Notsituation wie die allgemein menschlichen Koordinaten der Vergänglichkeit und Sterblichkeit angesichts einer Gottheit, die sowohl Neubeginn, Schöpfung und Leben als auch Ende und Tod bestimmt. Das Wir wird im ersten Teil zwar mit Verben ausgestattet, diese lassen allerdings keine aktiv gesetzten Handlungen erwarten. Im zweiten Teil des Psalms wird das lyrische Wir als Sprechstimme dahingehend charakterisiert, dass es mittels einer Reihe von Imperativen um die Nähe, Zuneigung und das gerechte Eingreifen Gottes ringt und diesen die erwünschten positiven Aspekte der Freude, der heilvollen Zuwendung und des Bestandes der menschlichen Werke den Zeiten des Unheils gegenüberstellt.

Neben der Nähe zum Text und zu den Details der Textstruktur sind somit als Erkenntnisse aus der narratologischen Analyse der Psalmen das klare Hervor-

1334 Vgl. dazu Bleumer / Emmelius, Generische Transgressionen, 16. 
treten der Konturen in der Bewegung des Textes sowie die Charakterisierung des Gottesbildes und vor allem des lyrischen Ich/Wir festzuhalten.

\section{Emotionen}

\subsection{Bildersprache und Emotionen}

Die Identifikation mit literarischen Texten ist eng verknüpft mit im Text thematisierten sowie durch Sprachbilder evozierten Emotionen. Die in Ps 30; 64; 90 und 147 analysierten Sprachbilder können in metaphorische Rede, Metaphern, Personifikationen und Vergleiche eingeteilt werden. Sie werden im Folgenden nochmals Psalm für Psalm wiedergegeben mit dem Schwerpunkt darauf, ob und welche Emotionen sie beinhalten bzw. ob sie Emotionen auslösen.

$\mathrm{Zu}$ Beginn von Psalm 30 eröffnet die metaphorische Rede vom Heraufziehen bzw. Heraufwinden das Bild eines Schöpfeimers, der aus einem tiefen Brunnen heraufgeholt wird (V2). Damit in Verbindung stehende Emotionen sind Unsicherheit, Todesangst, das Schweben über dem dunklen, tiefen Abgrund einerseits sowie die kraftvolle, verlässliche, Sicherheit gebende Dimension Gottes andererseits. Diese metaphorische Rede wird fortgesetzt mit dem Heraufholen der Nefesch aus der Scheol im Gegensatz zum Hinabsteigen in die Zisterne (V4). Auch hier werden die Emotionen der Angst, ja Todesfurcht, der Ausweglosigkeit, Einsamkeit und Gefährlichkeit sowie die Aspekte der Enge und Kraftlosigkeit thematisiert, die im Kontrast zur Erleichterung und Freude über die Rettung der Nefesch stehen, wodurch neues, erfülltes Leben ermöglicht wird. An dieser Stelle kann, wie in den Analysen bereits mehrmals erwähnt, von einer doppelten Emotionalität gesprochen werden. Im Erzählverlauf des Psalms werden danach die Personifikationen des übernachtenden Weinens und des lobenden Staubes angeführt. Beide zeugen von einer Dynamik, im Falle des übernachtenden und gegen Morgen hin weiterziehenden Weinens wird die Statik des Verses aufgebrochen und die Analogiemöglichkeit der menschlichen Erfahrung so manch durchweinter Nächte eröffnet (V6). Gerahmt wird diese Personifikation von den Zeitangaben "am Abend" und "für den Morgen«, die wiederum selbst ein Sprachbild sind für die Zeit des Heils (Morgen) und des Unheils (Abend, Nacht). Der lobende und erzählende Staub von V10 zeigt den Kontrast zwischen Leben bzw. Lebendigkeit - loben und erzählen können nur Lebende - und Todesnähe, Morast sowie absoluter Stille. Lobt der Staub und erzählt dieser von der Treue Gottes, dann endet dies im zerbröselnden Staub und totalen Schweigen. Im Gegensatz dazu steht am Schluss des Psalms die besingende Ehre, die nicht verstummt (V13). Vor dem Psalmende wird in der Klimax (V12) der Wandel von der Trauer zur Freude durch Gott mittels der Metapher des Umgürtens mit 
Freude intensiviert und konkretisiert, der die anthropologische Schilderung des göttlichen Öffnens des Trauergewandes vorausgeht. Die Metapher des Umgürtens mit Freude verstärkt nicht nur die Dimension des Wandels von der Klage, der Dunkelheit und dem Trauern hin zu neuem Leben, zu Lebendigkeit und Buntheit, sondern sie eröffnet auch die Dimension der Sicherheit, Beständigkeit, des Halts und des Schutzes. Der innere Prozess der Verwandlung hin zur überschäumenden Lebensfreude wird durch die Metapher nach außen hin sichtbar gemacht.

Die erste metaphorische Rede in Ps 147 thematisiert mit dem göttlichen Aufbauen Jerusalems und der göttlichen Hirten-Aktivität des Sammelns die Emotionen der Geborgenheit sowie das Sicherheitsgefühl (V2). Die darauffolgende Metapher derer, die zerbrochenen bzw. zerschmetterten Herzens sind (V3), hebt durch das Zermalmen und Zu-Boden-Ringen die destruktive Dimension und deren Konsequenzen hervor, die mit dem totalen Am-Boden-Sein in physischer und psychischer Hinsicht einhergehen. Es geht hier um ein Zerbrochensein, das die Existenzmitte betrifft und das neben den Emotionen der Entmutigung, der Niedergeschlagenheit und des Kummers auch Vernichtung und Gewalt thematisiert. Eingebettet ist diese Metapher in die Rede von der heilenden Gottheit, die sich in einem ganzheitlichen Sinn denen, die zerbrochenen Herzens sind, zuwendet und ihre schmerzenden Wunden verbindet. So sind die Emotionen der Niedergeschlagenheit und der totalen Entmutigung, die aus der existenziellen Notsituation des Zerschmettertseins hervorgehen, eingebunden in jene der Geborgenheit, des heilenden Zuneigens Gottes und des Aufgehobenseins bei ihm, wodurch wiederum von einer doppelten Emotionalität gesprochen werden kann.

Das Bildwort von den jungen Raben (V9) kann aufgrund des Textzusammenhangs - dies ist der Rückbezug auf die Gebeugten in V6 und der Vorausblick auf die JHWH-Fürchtigen und die auf dessen Güte Wartenden in V11 - auf die Bedürftigsten unter den Menschen bezogen werden. Aus der bildlichen Rede von den Rabenjungen können die Emotionen der Hilflosigkeit, Bedürftigkeit und Verachtung implizit erschlossen werden. Danach folgen die Personifikationen Jerusalems und Zions (V12), die die menschliche Erfahrung des Gotteslobes aktivieren, sowie die Personifikation des eilenden Wortes (V15), das in Analogie zu einem schnellen Boten die Wirkmacht Gottes verstärkt und die Dimensionen der Hast und Schnelligkeit sowie der Effektivität in der Kommunikation hervortreten lässt. Die Naturvergleiche Reif wie Asche sowie Schnee wie Wolle (V16) haben als tertium comparationis die Quantität im Sinne des Mengenerweises, die Oberflächenbedeckung sowie das Weiß der Farbe gemeinsam, der Vergleich des Eises mit Brocken (V17) lässt überdimensional große Hagelkörner dahinter vermuten und verweist auf die Gefährlichkeit und Macht Gottes, der auch die Natur in seiner Gewalt hat. Aufgrund der Rarität der Wetterphänomene Schnee 
und Eis in Palästina dienen die Vergleiche dazu, die Macht und Unverfügbarkeit der Gottheit zu demonstrieren, und sie tragen zur Theozentrik des Psalms bei.

In der Geburtsmetaphorik am Beginn von Ps 90 wird Gott als in Wehen gebärend dargestellt (V2). In dieser metaphorischen Rede tritt die Ambivalenz zwischen Freude über neues Leben einerseits und Schmerz, Angst und Anstrengung andererseits zum Vorschein. Die Verschmelzung von Personifikation und metaphorischer Rede, in der die Gottheit menschliche Züge und die menschliche Geburtsdimension göttliche Züge erhält, eröffnet gleichzeitig die Emotionen von Angst und Ekstase und lässt dahinter Anklänge an personifizierte gebärende Gottheiten im Alten Orient vermuten. Dass die Gottheit in Ps 90 Berge und Erdkreis gebiert, impliziert nicht nur das gewaltige Hervorbringen der Schöpfung, sondern auch hohe Beständigkeit, zumal die Berge als das Älteste und Stabilste auf Erden gelten und für Unerschütterlichkeit, Dauer und Beständigkeit sowie Festigkeit stehen. Auf den nicht eindeutig als Personifikation ausweisbaren vorübergehenden Tag (V4) folgt in V5-6 die Vergänglichkeits- und Todesmetaphorik. Die metaphorische Rede vom Hinwegschwemmen der Menschen und der Erwähnung, dass sie ein Schlaf sind - beides ist in V5 allerdings weder textkritisch noch syntaktisch oder semantisch gesichert -, zielt vermutlich auf die Passivität und Handlungsunfähigkeit sowie das Ausgeliefertsein des Menschengeschlechts ab. Das Hinwegschwemmen trägt eine brutale Dimension in sich und impliziert ein plötzliches Ende. Die Hinfälligkeit und Vergänglichkeitsthematik wird mit dem Grasvergleich verstärkt, der das rasche Aufblühen, Wachsen und Verdorren eines Grashalms mit dem Menschenleben in Verbindung setzt (V5-6). Die Ertrag- und Nutzlosigkeit sowie Anonymität und das rasche Vorübergehen des menschlichen Lebens, die in den vorhergehenden Versen bereits thematisiert wurden, werden dadurch intensiviert, neben der totalen Kürze des menschlichen Lebens im Kontrast zur Ewigkeit und Beständigkeit Gottes. Die metaphorische Rede vom schnellen Verfliegen (V10) sowie der Vergleich mit dem Seufzer (V9) verstärken das rasche Vorübergehen des Menschenlebens und implizieren die Emotionen der Mutlosigkeit und Hoffnungslosigkeit. Der Seufzer verklingt im Nichts, ist kurz und wird von Kummer und Klage bestimmt. Er steht für die Flüchtigkeit der Jahre, für Mühe und Freudlosigkeit. Mit dem Sprachbild des Verfliegens, das auf einen blitzschnellen Pfeilschuss bzw. auf einen in Sekundenschnelle davonfliegenden Vogel anspielt, wird das plötzliche, abrupte Verschwinden des Lebens thematisiert (V10).

In Ps 64 verstärken der Vergleich der Zunge mit dem Schwert und die metaphorische Rede vom Bogenanlegen und Pfeilspannen im Zusammenhang mit dem bitteren Wort die Gefährlichkeit und todbringende Wirkung der feindlichen Worte (V4). Dabei werden Bilder aus der Kriegsmotivik (Schwert; Pfeil und Bogen V4) mit jenen aus der Jagdmotivik (Pfeil und Bogen; Klappnetze V6) verschränkt und auf das Sprechen der Feinde übertragen. Die verletzende Di- 
mension von Worten kann demnach wie die schneidend scharfe Klinge eines Schwertes große Wunden zufügen. Mit dem Schärfen des Schwertes ist die Kriegsvorbereitung angesprochen, mit dem Treten des Bogens und Anlegen des Pfeils die unmittelbare Nahkampfhandlung. Der Pfeil steht für die Gefährlichkeit der Zunge und die tödliche Gefahr, die von den Worten ausgehen kann. Emotionen der Panik, der Angst und des Schreckens werden in diesem Bildwort ebenso evoziert wie der Aspekt der Bedrohung und der Gefahr. Die metaphorische Rede vom Sich-Stärken mit bösen Worten (V6) kann als Festhalten am eigenen Plan, als Beharrlichkeit und Entschlossenheit gedeutet werden, ebenso als Selbststärkung bis hin zur Autosuggestion der Feinde, die auf verbale Attacken abzielen. Als Beitrag zur Erforschung metaphorischer Sprache in den Psalmen kann als Ergebnis festgehalten werden, dass Sprachbilder vielschichtige und vielfältige Emotionen beinhalten und auslösen sowie die im Vers bzw. im Kontext des Psalms thematisierten Inhalte verstärken und intensivieren können.

\subsection{Emotionsfelder}

Die Emotionsanalyse erfolgte entlang der Begrifflichkeiten von A- und F-emotions, wobei innerhalb letzterer sowohl explizite Emotionswörter als auch implizite Emotionen eruiert wurden, die in allen sprachlichen Formen auftreten können. Blickt man auf die vier analysierten Psalmen, so treten folgende explizite Emotionswörter auf:

\begin{tabular}{|c|c|}
\hline Psalm & Explizites Emotionswort \\
\hline $30,2.12$ & sich nicht freuen = Schadenfreude \\
\hline 30,6 & 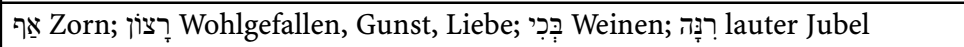 \\
\hline 30,7 & שֶָberheblichkeit, Stolz, Selbstsicherheit \\
\hline 30,8 & רצוֹ Wohlgefallen \\
\hline 30,8 & בהל verstört, erschreckt sein \\
\hline 30,12 & מְְִפַּT Trauerklage \\
\hline 30,12 & 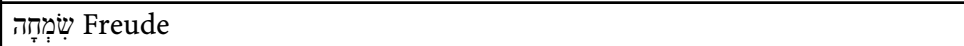 \\
\hline 147,1 & lieblich, wonnig, angenehm; נָעִִים anmutig, schön, lieblich \\
\hline 147,10 & 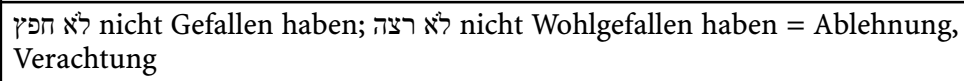 \\
\hline 147,11 & $\begin{array}{l}\text { יזרא die Fürchtenden (JHWH-Fürchtigen); חֶֶ Güte, Freundlichkeit, Gnade, } \\
\text { Zuwendung Gottes, Großherzigkeit }\end{array}$ \\
\hline 90,7 & 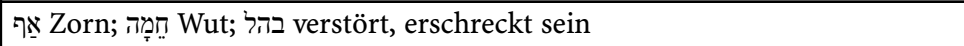 \\
\hline 90,9 & עֶבְרָה überwallender Zorn \\
\hline 90,11 & 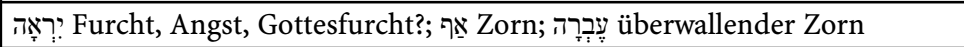 \\
\hline 90,14 & חסֶֶ Güte; שֶמן jubeln; sich freuen \\
\hline
\end{tabular}


(Fortsetzung)

\begin{tabular}{|c|c|}
\hline Psalm & Explizites Emotionswort \\
\hline 64,2 & 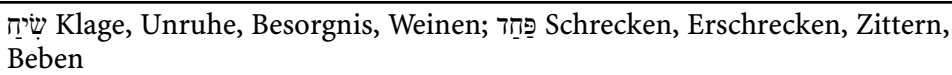 \\
\hline 64,5 & sich nicht fürchten \\
\hline 64,10 & ירא sich fürchten \\
\hline 64,11 & שממח sich freuen; הלל sich rühmen \\
\hline
\end{tabular}

Ordnet man diese expliziten Emotionswörtern den Listen von Emotionen aus dem Methodenkapitel zu, so sind dadurch die acht Emotionsfelder (1) des Zorns, (2) der Liebe und Zuneigung, (3) der Freude, (4) der Angst, (5) der Traurigkeit und Trauer, (6) der Verstörtheit, (7) des Stolzes und (8) der Verachtung abgedeckt. ${ }^{1335}$ Damit sind also hauptsächlich die sogenannten Basisemotionen Freude, Furcht, Wut und Trauer (Ekel ausgenommen) benannt. Nimmt man alle F-emotions in den Blick - also neben den eben genannten expliziten Emotionswörtern auch die implizit eruierten Emotionen -, so ergibt sich ein weit umfassenderes Bild der emotionalen Welt der Ps 30; 64; 90 und 147. Die Fülle der darin eruierten Emotionen können den folgenden 16 Emotionsfeldern zugeordnet werden, die sich bei Plutchik, Wagner u. a. finden lassen (vgl. III Methodik 2.1). Die ersten drei Emotionsfelder der Freude, Angst und Zuneigung stechen dabei durch eine hohe Anzahl an Belegen hervor.

\section{Ekstase / Freude / Glück / Gelassenheit}

Ps 30,2.4 (Freude, Erleichterung, Lebensfreude); Ps 30,5 (Freude verbreiten, musizieren); Ps 30,6 (Jubel); Ps 30,12 (Freude, Tanz, Leichtigkeit); Ps 30,13 (immerwährende Freude); Ps 147,1.12.20 (Aufruf zum Lob); Ps 147,7 (dankbare Freude); Ps 147,13-14 (Glück); Ps 90,2 (Ekstase, Freude); Ps 90,14-15 (Freude, Jubel); Ps 64,11 (Freude, Erleichterung, sich rühmen).

\section{Panik / Angst / Furcht / Besorgnis / Unruhe}

Ps 30,2-4 (Furcht, Todesangst); Ps 30,8 (Angst); Ps 30,10 (Todesangst); Ps 147,11 (Gottesfurcht); Ps 90,2 (Angst); Ps 90,7-8 (Angst, Panik, Besorgnis); Ps 90,11 (Angst, Gottesfurcht); Ps 64,2-5 (Angst, Panik, Sorge, Unruhe); Ps 64,8-9 (Angst, Furcht); Ps 64,10 (Gottesfurcht).

\section{Liebe / Zuneigung / Lust}

Ps 30,3 (Zuneigung); Ps 30,6.8 (Wohlgefallen, Gernhaben); Ps 30,11 (Zuneigung, Zuwendung); Ps 30,12 (Nähe, Zuwendung); Ps 147,1 (Liebe, ästhetische Anmut,

1335 Die Reihenfolge dieser und der folgenden Auflistungen von Emotionen richtet sich nach der Häufigkeit der Vorkommen. 
köstliches Wohlgefühl); Ps 147,8 (Zuwendung); Ps 147,11 (Wohlgefallen, Zuwendung); Ps 147,11 (göttliche Freundlichkeit und Güte); Ps 90,14 (Güte); Ps 90,16 (Zuneigung); Ps 90,17 (Lieblichkeit, Anmut, liebevolle Zuwendung).

4 Wut / Zorn / Ärger bzw. Groll / Verdruss

Ps 30,6 (Zorn); Ps 90,7 (Zorn, Glut, Hitze, Zornessturm); Ps 90,11 (Zorneskraft).

5 Verwunderung / Überraschung / Empörung / Verstörtheit

Ps 30,8 (erschrecken, verstört bzw. erstarrt sein); Ps 30,10 (Empörung); Ps 90,7 (Verstörtheit); Ps 64,3-5 (Schreck); Ps 64,8 (Überraschung).

6 Mitleid / Sympathiegefühle

Ps 30,3 (Mitgefühl); Ps 147,2 (tröstliche Zuneigung); Ps 147,9 (Mitleid, Fürsorge); Ps 90,13 (Zuwendung, Erbarmen, Mitleid); Ps 64,2 (Fürsorge).

\section{Verehrung / Vertrauen / Akzeptanz}

Ps 147,11 und Ps 64,10 (Gottesfurcht als Vertrauen); Ps 90,1; Ps 64,11 (Vertrauen).

\section{Trauer / Niedergeschlagenheit}

Ps 30,3 (Trauer); Ps 30,12 (Trauerklage); Ps 147,2 (Niedergeschlagenheit).

9 Verachtung / Achtung / Respekt

Ps 147,10 (Ablehnung, Verachtung); Ps 90,15 (Erniedrigung, Kränkung, Demütigung), Ps 147,6 (Erniedrigung).

10 Kummer / Traurigkeit / Schwermütigkeit

Ps 30,3 und Ps 90,9 (Kummer).

\section{Stolz}

Ps 30,7 und Ps 64,6 (Selbstsicherheit, Überheblichkeit, Stolz).

12 Scham / Peinlichkeit

Ps 64,9 (Peinlichkeit).

\section{Schuld}

Ps 90,8 (Schuld).

14 Abscheu / Ekel / Abneigung / Langeweile Ps 64,9 (Abscheu, Ekel). 
Das Emotionsfeld Hass, Eifersucht und Neid wurde in den Texten nicht thematisiert, und das Emotionsfeld Umsicht bzw. Wachsamkeit, Erwartung und Interesse ist am ehesten innerhalb der A-emotions anzusiedeln. ${ }^{1336}$ Des Weiteren thematisieren die Psalmen eine Reihe von zusätzlichen Emotionen und erweitern dadurch die vorgegebene Klassifizierung mit folgenden zehn Emotionsfeldern, in denen der Übergang von Emotion zur Nicht-Emotion fließend ist:

(1) Emotionen und Zustände, die mit Notsituationen, existenziellem Leid, Schmerz und Elend (Ps 30,3-4.6; Ps 147,2) verbunden sind:

Todesdunkelheit (Ps 90,3); Todesnähe (Ps 90,9; Ps 30,10); Am-Boden-Sein (Ps 30,2); Ausweglosigkeit (Ps 90,10-11); Kraftlosigkeit, existenzielle Entmutigung (Ps 147,2); Hoffnungslosigkeit (Ps 90,5-6); Trostlosigkeit (Ps 90,10); Isolation, Einsamkeit (Ps 30,4.8) und Unsicherheit (Ps 30,2).

(2) Emotionen, die im Zusammenhang mit Schutz, Zuflucht und Sicherheit (Ps 30,2.12; Ps 90,1; Ps 64,3.11) stehen: Geborgenheit, Sich-daheim-Fühlen (Ps 147,2); Sicherheitsgefühl, Wohlbefinden (Ps 147,13-14; Ps 64,2; Ps 90,1).

(3) Emotionen im Zusammenhang mit der Dringlichkeit, die Situation zu ändern (Ps 30,3.11; Ps 90,12-13; Ps 90,16-17; Ps 64,2-5).

(4) Emotionen, die in Zusammenhang mit Gewalt, Verletzung und Lebenszerstörung stehen (Ps 147,2; Ps 64,3-5; Ps 90,5).

(5) Emotionen, die von Hoffnung und Zuversicht geprägt sind (Ps 147,11; Ps 90,16-17; Ps 64,11).

(6) Emotionen, die mit Lebensfülle, Sättigung und Heil zu tun haben (Ps 147,1314 ; Ps 90,14).

(7) Emotionen rund um das Thema Bedürftigkeit und Hilflosigkeit (Ps 90,13; Ps 147,9 , Ps 64,2-5).

(8) Emotionen, die aus Gefahr, Bedrohung, Unheimlichkeit, Gefährlichkeit und Unberechenbarkeit heraus entstehen (Ps 147,17; Ps 90,1.15; Ps 64,2-5).

(9) Emotionen, die im Zusammenhang mit dem Bösen, mit Unheil und Unglück, mit Ungerechtigkeiten, Schlechtigkeiten und Übeltätern stehen (Ps 64,3.6-7; Ps 90,10.15).

1336 Für beide Emotionsfelder siehe die Liste bei Plutchik (vgl. III Methodik 2.1). 
(10) Emotionen, die verbunden sind mit Anstrengung, Mühe, Erschöpfung, Müdigkeit und Überdruss (Ps 90,2; Ps 90,10; Ps 90,13).

Eine Analyse von Emotionen, die allein explizite Emotionswörter in den Blick nimmt, erfasst damit nur einen kleinen Ausschnitt der emotionalen Welt, die vor allem in lyrischen Texten zu finden ist. Von den 24 Emotionsfeldern, die durch die Analyse der explizit genannten und impliziten Emotionen ermittelt werden konnten, gehen nur acht Emotionsfelder - also ein Drittel - aus expliziten Emotionswörtern hervor. Diese Erkenntnis kann für das methodische Vorgehen zukünftiger Analysen von Emotionen in biblischen Texten hilfreich sein.

\subsection{Zuordnung der Emotionen}

Schließlich ist noch die Zuordnung der Emotionen von Interesse. So gehören in die Gruppe der Artefact-Emotions, zu welchen jene Emotionen zählen, die im Leseprozess ausgelöst werden und damit den Lesenden zugeordnet werden können: Staunen, Bewunderung, Faszination (Ps 90,4; 147,4-5; 147,15-18), Erschütterung, Ernüchterung, Verdruss (Ps 90,3), Ohnmacht, Empörung, Hoffnungslosigkeit (Ps 90,5-6), Erschrecken (Ps 147,17) sowie Ruhe, Heiterkeit und Frohsinn (Ps 90,17) sowie Interesse (Ps 30,7-12; Ps 64). Blickt man auf die Femotions, so ist die überwältigende Mehrheit der Emotionen, die der Gottheit Israels zugeordnet werden, jene der Zuneigung, Fürsorge und liebevollen Heilszuwendung, die einerseits erlebt, andererseits vermisst und daher vehement eingefordert werden. Die Emotionsfelder der Zuneigung und Liebe sowie des Mitgefühls (siehe oben) sind damit eindeutig mit Gott verbunden. Weit abgeschlagen sind die Emotionsfelder des Zorns, der Geborgenheit und des Schutzes, danach jene des Sicherheitsgefühls und Halts, der Bedrohung und Gefährlichkeit sowie der Erniedrigung. An nur einer Stelle wird jeweils implizit die Freude, Angst, Anstrengung und Todesdunkelheit thematisiert, die von JHWH ausgeht bzw. mit ihm verbunden ist. ${ }^{1337}$

Neben der Charakterisierung der Figur Gott durch die Zuordnung der Emotionen werden den Feinden in Ps 64 Überheblichkeit, Entschlossenheit, Gewalt und Lebenszerstörung, Ungerechtigkeiten sowie die Emotionen der Überraschung, der Angst und Peinlichkeit zugeordnet. "Alle Menschen« in Ps 64 empfinden Abscheu und Ekel, Angst und Gottesfurcht. Alle übrigen Emotions-

1337 Vgl. dazu die Auswertung der Emotionen Gottes in den Psalmen nach den Emotionsfeldern Zorn, Reue, Erbarmen, Gnade, Liebe und Hass/Abneigung bei Kumpmann, Schöpfen, 395439. Sie hält auf S. 436 fest: »Insgesamt ist deutlich, mit wie starkem Übergewicht von Gottes Zuneigung gesprochen wird - ein deutlicher Widerspruch zum Vorurteil vom salttestamentlichen Gott des Zornsı." 
felder (siehe oben) werden dem lyrischen Ich bzw. Wir zugeordnet. Dabei stehen die Freude bzw. der Aufruf zur Freude an erster Stelle, gefolgt von den Emotionen der Angst und Panik, der Empörung und Verstörtheit, des Vertrauens, der Trauer und Niedergeschlagenheit, des Kummers und der Traurigkeit, des Stolzes und der Schuld. Von den erweiterten Emotionsfeldern sind jene mit dem lyrischen Ich bzw. Wir verbunden, die aus Leid und Schmerz im Zusammenhang mit existenzieller Not hervorgehen, daneben die Dringlichkeit, diese Notsituation zu ändern, sowie jene Emotionen, die mit Gewalt, Hoffnung, Lebensfülle, Bedürftigkeit, Gefahr, Mühe und Erschöpfung verknüpft sind.

\subsection{Doppelte Emotionalität}

Die Zusammenschau der Emotionsanalyse abschließend konnte als weitere Erkenntnis gewonnen werden, dass sich in den Texten das Phänomen der doppelten Emotionalität beobachten lässt. Dabei werden innerhalb eines Verses, eines Begriffs oder aber in der Zusammenschau von Anfang und Ende eines Psalms einerseits sowohl die Emotionen der Freude, Erleichterung bzw. der heilvollen Zuwendung und des Vertrauens als auch andererseits jene der Angst, Ausweglosigkeit, Trauerklage, Erniedrigung und des Unheils thematisiert. So werden mittels metaphorischer Rede in Ps 30,4 in die Perspektive der Erleichterung, Leidenschaft und Lebensfreude die Emotionen der Todesangst, Isolation, Einsamkeit, Gefährlichkeit, Ausweglosigkeit und Kraftlosigkeit eingebettet. Ps 30,12 bringt den Gegensatz zwischen Trauerklage, Leid, Traurigkeit, Dunkel und Schwere und der Freude über die innere Wandlung und Wende hin zur Lebensfülle, die unter anderem durch Halt, Leichtigkeit und Buntheit gekennzeichnet ist, mittels einer Metapher zum Ausdruck. In Ps 147,3 ist von Verletzungen, schmerzenden Wunden, existenziellem Leid und Elend, Entmutigung und Niedergeschlagenheit durch die Metapher "die zerbrochenen Herzens sind " die Rede. Im Gegensatz dazu stehen davor und danach die Hinwendung und Zuwendung Gottes, das Verbunden- und Geheiltwerden durch die Gottheit sowie deren Achtsamkeit und Fürsorge. In Ps 147,6 steht die Aufrichtung der Gebeugten durch die Gottheit und die damit verbundene Erleichterung, Befreiung und neue Lebenswürde im Gegensatz zur Kränkung und totalen Erniedrigung der Frevler durch Gott. Der Begriff »Gottesfürchtige» in Ps 147,11 impliziert ebenso eine doppelte Emotionalität. Hier treten die Emotionen der Angst und des Erschreckens in den Hintergrund und machen den Emotionen der Ehrfurcht, des Zugehörigkeitsgefühls, der Verehrung und des Vertrauens Platz. In Ps 90,15, in dem es um die Kompensation der Zeit der Demütigung und der Not durch eine Zeit der Freude und des Heils geht, ist kontrastreich vom Emotionsfeld der Freude einerseits sowie andererseits von Aspekten der Gewalt und des Nieder- 
drückens und den damit verbundenen Emotionen die Rede. Nimmt man in Ps 64 das lyrische Ich, den Unschuldigen, den Gerechten und die Herzgeraden zu einer Figurengruppe zusammen und gleichzeitig Anfang und Ende des Psalms in den Blick, so kann auch hier von einer doppelten Emotionalität gesprochen werden. Werden zu Beginn die Emotionen der Panik und Furcht, der Unruhe und Besorgnis, der Ohnmacht und Hilflosigkeit sowie jene thematisiert, die mit der Dringlichkeit der Situationsänderung, mit Bedrohung und Gefahr verbunden sind, so kommen am Ende die Emotionen der Freude, Zuversicht, Erleichterung und Ermutigung in den Blick.

Die genannten Psalmstellen tragen ein hohes Identifikationspotenzial, und zwar dergestalt, dass sich die Lesenden durch die Vielschichtigkeit der hier zum Schwingen kommenden Emotionen je nach biographischer Situation auf unterschiedliche Weise mit dem Text verbinden können. Es stehen damit beide Möglichkeiten der Identifikation offen, sowohl jene mit der Situation der Bedrohung und Angst, aber auch jene mit der Freude und Erleichterung über das befreiende Heilshandeln Gottes, womit wir beim nächsten Punkt angelangt sind.

\section{Identifikationspotenziale}

Ausgehend von der Darlegung der geschichtlichen Entwicklung des Identifikationsbegriffs ist es in dieser Arbeit gelungen, aus den Gemeinsamkeiten der Bestimmung von Identifikation eine Definition für die Identifikation mit literarischen Texten abzuleiten und damit den Identifikationsbegriff für literarische - in diesem Fall: poetische - Texte methodisch zu operationalisieren sowie danach in der Textanalyse anzuwenden. Das Identifikationsphänomen konnte dabei mit unterschiedlichen Methodenschritten erfasst werden. Die Ergebnisse aus den Textanalysen sollen nun nach dem fünfstufigen Verfahren von Uri Margolin zur LeserInnenbindung (vgl. II Methodologische Grundlagen 4.5) sowie nach den vier Ebenen der Emotionen beim Lesen nach David Miall und Don Kuiken (vgl. III Methodik 2.2.2) nochmals differenziert dargestellt werden. Dadurch werden die unterschiedlichen Formen von Identifikation, denen laut der Forschungsfragen (vgl. I Einleitung 3) nachgegangen wurde, fokussiert und gebündelt aufgezeigt.

\subsection{Einsteigen}

Zunächst geht es um den Einstieg in die Textwelt, der nach Uri Margolin die erste Ebene darstellt. Zur Erinnerung: Suzanne Keen spricht hier vom Vorhandensein einer Bühne der erzählten Welt in Form von minimal elements (vgl. II Metho- 
dologische Grundlagen 4.3). Diese liegen in allen vier analysierten Psalmen vor. In Ps 30 sind dies die beinahe durchgehende Sprechstimme des lyrischen Ich, eindeutige Themen der existenziellen Notsituation und die Errettung daraus sowie Klarheit in Aufbau (zwei Minierzählungen) und Darstellung. Ps 147 zeichnet sich diesbezüglich durch die Sprechstimme des lyrischen Wir sowie durch einen gleichförmigen, rhythmischen Stil, durch die wohlgeordnete dreiteilige Gestaltung und eine ausgewogene Struktur sowie durch inhaltliche Kongruenz (Handlungen JHWHs an Jerusalem/Israel; an und in der Schöpfung sowie an anderen Gruppen) aus. In Ps 90 lässt sich die klare Thematik der Zeit finden, die sich zwischen göttlicher Ewigkeit und göttlichem Sein außerhalb der Zeit sowie menschlicher Vergänglichkeit und des Seins innerhalb der Zeit erstreckt. Eine durchgehende Sprechstimme des lyrischen Wir ist gegeben. Die Ausrichtung auf das göttliche Du und das dichte Wir-Du-Beziehungsnetz zieht sich wie ein roter Faden durch den Psalm, der grob in zwei Teile gegliedert werden kann. Ps 64 ist klar strukturiert (zwei Teile: Bewegung und Gegenbewegung). Ein lyrisches Ich ist als Sprechstimme vorhanden. Der Psalm weist einen starken Beginn auf, der sich durch hohe Emotionalität, Deixis sowie die inhaltliche Komponente der Bedrängnissituation auszeichnet, deren Darstellung genug Raum lässt, die je eigene Notsituation darin wiederzufinden. Der Einstieg in die Textwelt ist hier besonders leicht und intensiv.

\subsection{Dranbleiben}

Die zweite Ebene ist nach Uri Margolin die emotionale Antwort auf Figuren und Situationen im Text, nach David Miall und Don Kuiken sind dies die A-emotions. Diese A-emotions werden im Folgenden angeführt sowie auch das Interesse und Dranbleiben am Text, das mit Textdynamik und Spannungsaufbau zu tun hat. Es gilt, dass die Lesenden, nachdem sie in die Textwelt eingestiegen sind, in dieser bleiben und nicht herausfallen. In Ps 30 sind diesbezüglich eine aufsteigende Dynamik und ein Spannungsaufbau durch narrative Strukturen und durch den Wechsel zwischen erzählendem Ich und direkter Rede gegeben, vor allem in der zweiten Minierzählung. Durch die Konjunktionen sind fließende Übergänge vorhanden, es gibt im Text aber auch Asyndesen. Diese abrupten Übergänge ereignen sich jedoch nicht so plötzlich und unverständlich, dass Lesende aus dem Textgeschehen herausfallen könnten. Es ist im Leseprozess möglich, selbst Verbindungslinien und Zusammenhänge herzustellen. Dazu tragen auch die Parallelismen bei, die es ermöglichen, länger am Text zu verweilen und damit am Textgeschehen dranzubleiben. Die Parallelismen dienen in Ps 30 darüber hinaus zur Vertiefung der Gedanken, zu Konkretisierung und Intensivierung bis hin zur Dynamisierung und Dramatisierung. 
In Ps 147 lösen die A-emotions in V4-5.15-18 Bewunderung, Staunen, aber auch Erschrecken aus. Die klangliche Komponente stellt für KennerInnen des Bibelhebräischen ein zusätzliches Potenzial dar, mit Hilfe dieser rhythmischmelodischen Gestaltung im Textgeschehen zu bleiben. Die fließend gestalteten Übergänge verhindern ein Hinausfallen aus dem Leseprozess und damit aus dem Textgeschehen. Wie bereits für Ps 30 konstatiert, so dienen auch hier die Parallelismen zur Vertiefung der Aussagen, zur Intensivierung, Konkretisierung und Dynamisierung. Sie eröffnen einen Zeitraum für Imaginationsarbeit und fördern damit den Identifikationsprozess.

Ps 90 hebt sich durch seine Verknüpfungstechnik mittels Stichwort-Wiederholungen und der häufigen Verbindung durch die Konjunktion ? hervor. Dieses Netz von Stichwortverbindungen prägt die kunstvoll gestaltete, ästhetisch anspruchsvolle Komposition des Textes, dessen Parallelismen entsprechend Zeit geben, dass sich der Inhalt auch setzen kann. Hinsichtlich der A-emotions ist die düstere, dumpfe Stimmung des Psalms festzuhalten. Im Lesen des Psalms können sich auf Seiten der Lesenden Erschütterung, Ernüchterung, Verdruss, Ohnmacht, Empörung, Hoffnungslosigkeit sowie Bewunderung, Staunen, Heiterkeit und letztendlich Frohsinn einstellen. Unter den vier analysierten Psalmen konnte in Ps 90 der höchste Anteil an A-emotions ausgemacht werden.

Ps 64 besticht durch seine literarische Einheit und Kohärenz. Das Fehlen von offensichtlichen Bezügen zum altorientalischen Kontext verstärkt die LeserInneninteraktion mit dem Text. Die Lebendigkeit in der Darstellung der Bewegung und Gegenbewegung des Textes (Sprechrichtungswechsel, interne und externe Fokalisierung, Nähe und Ferne) und der deutliche Spannungsaufbau, der gleichzeitig einen Aufbau von LeserInnenerwartungen bewirkt, prägen den Text, in dem Übergänge vorhanden sind. Ps 64 ist durchgehend mit synthetischen Parallelismen gestaltet, durch die der Handlungsverlauf vorangetrieben wird.

\subsection{Identifikation}

Die dritte Stufe nennt Uri Margolin Identifikation. Es geht dabei um die aktive Übernahme von im Text vorgezeichneten Perspektiven. Identifikation ist gegeben, wenn die Übernahme, die sich aus der Kombination von (1) Analogiebildung, Aktualität der Themen und Interesse (in thematischer Hinsicht Perspektiven übernehmen), (2) Fokalisierung bzw. Deixis (durch Fokuslenkung Perspektiven übernehmen) und (3) Emotionalität sowie Emotionalisierung (durch Emotionen, emotionale Erzählweise, doppelte Emotionalität und metaphorische Sprache Perspektiven übernehmen) zusammensetzt, gelingt.

In Ps 30 führt das lyrische Ich durch den Text (siehe oben VIII 1.2). Es erzählt dynamisch. Diese dynamische Wahrnehmungssituation zeichnet sich durch den 
Wechsel zwischen Jetztsituation, Rück- und Ausblicken (verschiedene Zeitachsen) sowie den Wechsel zwischen den unterschiedlichen Räumen aus. Ein Mitgehen mit den Bewegungen des lyrischen Ich in Zeit und Raum wird durch die vorfokussierte und emotionale Erzählweise sowie durch die klare Darlegung von Interessen, Zielen und Wünschen des lyrischen Ich erleichtert. Die deutlich geschilderten Aufund Abwärtsbewegungen des lyrischen Ich können mit dem eigenen Auf und $\mathrm{Ab}$ des Lebens verknüpft werden. Die direkten Anreden an die Gottheit sind zeitdeckend, holen ins Hier und Jetzt und dienen der Unmittelbarkeit der Darstellung, ebenso das dichte Netz an Deixis (Du-Ich-Beziehung), das die Lesenden näher an den Text heranholt. Diese erfahren viel vom lyrischen Ich, sodass sie sich nicht nur von diesem durch den Text führen lassen, sondern sich auch mit ihm identifizieren können (siehe oben VIII 1.2 und VIII 2.3). Zudem zeichnet sich der Psalm durch die im Rahmen der analysierten Psalmen höchste Dichte an Emotionen, eine große Vielfalt und Bandbreite an Emotionen sowie die doppelte Emotionalität (siehe oben VIII 2.4) aus, sodass die Emotionen der Lesenden darin sowohl aufgehoben sind und sich Lesende darin wiederfinden können als auch Emotionen hervorgerufen werden können. Eine bestimmte Unschärfe durch Sprache und poetische Ausdrucksweise des Psalms, vor allem durch die Bildersprache (metaphorische Sprache, Metaphern, Personifikationen) macht den Reiz von Ps 30 aus: Dieser liegt in der Offenheit ${ }^{1338}$ hinsichtlich der Beschreibung der Notsituationen und der Todesbedrohung, der Feinde, des Rettungshandelns und des Wandels durch Gott. Durch diese unbestimmt-offene Darstellungsweise entstehen Leerstellen, die den vielschichtigen Erfahrungen des lyrischen Ich ebenso gerecht werden wie jenen der Lesenden, die sich durch den so eröffneten Auslegungsspielraum leichter in die Textwelt einbringen können. Wer kann sich in Ps 30 mit welchen Themen wiederfinden? Notleidende, von existenziellem Leid Betroffene, die ihren eigenen Schmerz und ihr Elend mit den Worten des Psalms vor Gott bringen und damit vom Formularcharakter des Psalms Gebrauch machen; jene, die aus dem Leid entkommen sind, die erlöst und gerettet wurden und dafür Gott danken und loben möchten; jene, die den existenziellen Wandel von der Trauerklage zum Freuden$\tan z$ Gott zuschreiben, sowie jene, die die Nähe Gottes erfahren durften. Die aktuellen Themen des Psalms sind, neben den Dimensionen der Not, Todesnähe und Errettung, vermeintliche Selbstsicherheit, Hadern mit Gott, Klage und Anklage, totale Verwandlung und immerwährendes Lob. Das höchste Identifikationspotenzial weist Ps 30 dort auf, wo (1) hohe bzw. doppelte Emotionalität, hervorgerufen durch metaphorische Sprache, (2) Dichte an Deixis bzw. Beziehungsgeschehen zwischen dem göttlichen Du und dem lyrischen Ich, (3) aktueller Inhalt

1338 Auf die Strategie der Offenheit, derer sich das Hld bedient, um bei den Lesenden Emotionen auszulösen, weist Peetz, Emotionen, 360 hin. 
und (4) spannende Erzähldynamik aufeinandertreffen, wie dies in $2 b-4 b$ sowie in $8 \mathrm{c}-12 \mathrm{c}$ der Fall ist.

In Ps 147 kann zwar auch von einer doppelten Emotionalität (V3.6.11) gesprochen werden. Allerdings ist hier der Fokalisierungsverlauf der verschiedenen Spots, die einer Bewegung von unten nach oben und von oben nach unten folgen und damit menschlichen Bewegungsverläufen ähneln, für das Identifikationsphänomen relevanter. Dieses stellt sich zudem durch die Sprechinstanz des offenen lyrischen Wir ein, das gleichzeitig zu denen gehört, von denen im Text gesprochen wird. Das Identifikationspotenzial für Lesende stellt sich damit dergestalt dar, dass diese sich sowohl mit dem lyrischen Wir als auch mit Jerusalem, Israel, mit denen, deren Herz zerbrochen ist, mit den Zerstreuten, Gebeugten sowie den jungen Raben identifizieren können. Die Gleichzeitigkeit (Partizipien) und Zeitlosigkeit sowie die Imperative und Inhalte, welche die Nähe Gottes thematisieren, holen die Lesenden ebenso an den Text heran (Fokalisierung) wie der Zoom-Effekt der Deixis (vor allem in V12-14).

Ps 147 thematisiert unter anderem eine Not- wie auch eine Rettungssituation Israels. Dabei wird eine eindeutige Zuordnung zu historischen Ereignissen in der Geschichte Israels vermieden. So wird der Psalm zu einer Typisierung sowohl der Not- als auch der Rettungssituation und damit zu einem Paradigma für das Heilshandeln Gottes. Durch diese Typisierung der Noterfahrung und des Wiederaufbaus sowie durch die Unmöglichkeit, die unterschiedlichen Figurengruppen im Text zuzuordnen, wird eine zeitübergreifende Offenheit des Texts erzeugt, der den Lesenden die Möglichkeit gibt, an der Heils-(und Unheils-) Geschichte Israels zu partizipieren und die eigene Geschichte mit der im Text erzählten zu identifizieren. Der Psalm wird damit zur Sprachschule. Ps 147 zeugt von einem vielschichtigen und bis heute attraktiven Gottesbild (siehe oben VIII 1.2) und spricht von Gottes Zuwendung, Fürsorge und Mitgefühl, von heilendem und tröstendem Handeln, dem machtvollen Einsatz für Jerusalem und Israel. Der Psalm thematisiert ebenso die Größe, Macht und Gewalt einschließlich der Gefährlichkeit der Gottheit in der Schöpfung wie auch die Effizienz und Wirkmacht des göttlichen Wortes. Gerade dieser Psalm legt es ganz besonders nahe, das eigene Gottesbild mit dem des Textes zu identifizieren. Ja, an solch einen Gott möchte ich glauben: Er/Sie wendet sich zu, nimmt Not wahr, heilt, verbindet, tröstet, sammelt ein, sucht zusammen, ist gerecht gegenüber Gebeugten und Frevlern gleichermaßen, lehnt menschliche Machtdemonstration und militärische Stärke (Krieg) ab, sorgt sich um die Schöpfung einerseits, kann aber andererseits durch eben diese Schöpfung bedrohlich wirken und gibt Regeln zum Zusammenleben vor (Rechtsvorschriften).

Weitere aktuelle Themen des Psalms sind der Umgang mit der Schöpfung, die Option für die Armen und das Eintreten für Gerechtigkeit. Hier kann an soziale Gerechtigkeit, Verteilungsgerechtigkeit und Konsequenzen für Gewaltverbrecher 
gedacht werden. V10-11 thematisieren militärische Macht im Gegensatz zum Vertrauen auf Gott. V10 ähnelt heute der Vision, angesichts der hohen Anzahl an kriegerischen Auseinandersetzungen und so vielen Menschen auf der Flucht den Weg der Gewaltlosigkeit einzuschlagen. Das höchste Identifikationspotenzial ist in den Versen 2-3 durch die Kombination aus einem attraktiven Gottesbild, einem berührenden Inhalt und der doppelten Emotionalität gegeben, in den Versen 12-14 aufgrund der Deixis, des Inhalts, der von Heil und Frieden spricht, der Thematisierung freudvoller Emotionen und der direkten Anrede an eine Personifikation.

In Ps 90 verstärken die Kontraste und Gegensätze die Plastizität und Mehrdimensionalität der Aussagen und eröffnen den Lesenden die Möglichkeit, den Weg und die Distanzen zwischen den Polen mit "Leben« zu füllen, Verbindungslinien selbst herzustellen oder aber die Ausgespanntheit des Psalms auch auszuhalten. Das offene lyrische Wir lädt sowohl Einzelne als auch Gruppen ein, sich mit dem sprechenden Wir zu identifizieren. Der Text zeichnet sich durch ein dichtes Netz an Deixis (du - wir - unser), welches das Beziehungsgeschehen zwischen dem lyrischen Wir und Gott ins Zentrum stellt, sowie durch direkte Reden in Form von Vokativen und vor allem Imperativen aus; dies alles sind Elemente, welche die Lesenden nahe an den Text heranholen. Der Psalm nimmt die Lesenden daneben mit durch die Bewegungen in der Zeit und der Thematik (siehe oben VIII 1.1).

In V15 ist eine doppelte Emotionalität auszumachen. Hervorzuheben ist in Ps 90 die breite, alle Menschen betreffende Thematik des Vergehens der Lebenszeit angesichts der Ewigkeit Gottes. In V1-10 sollen die Lesenden das Dargestellte reflektieren, ab V12 werden sie durch Imperative, Deixis, Beziehungsnetz sowie dem Wechsel hin zu positiven Themen (siehe oben VIII 1.1) involviert und eingeladen, sich dem sprechenden Wir anzuschließen. Weitere aktuelle Themen, die zur Analogiebildung anregen, sind das im Text thematisierte Lebensalter von 70 oder 80 Jahren, das mit dem heutigen Lebensalter in unserem Kontext vergleichbar ist. Die Beschreibung des menschlichen Lebens, das von mühevoller Arbeit, Unheil, Anstrengung, Leid und Kürze geprägt ist, bleibt auch heute aktuell. Der Psalm thematisiert daneben die stets aktuelle Frage danach, was bleibt und was Bestand hat. Die Bitte, dass angesichts der Sterblichkeit des Menschen die Früchte der Arbeit und des Abmühens Bestand haben und weiter wirken mögen, zeugt damit von großer Aktualität, ebenso die Bitte um ausgleichende Gerechtigkeit zwischen der Zeit des Leidens und der Zeit der Freude und damit der Wunsch nach einer Belohnung für das, was es zu ertragen gab. Die Schnelligkeit des Lebens und die Bitte, mit der Zeitgestaltung behutsam und weise umzugehen sowie diese allgemeinen Beobachtungen über das Menschenleben bei sich selbst zu prüfen, bestimmen den Psalm, der sich durch seine absolute Ehrlichkeit in Bezug auf die Darstellung der Koordinaten des Menschseins im 
Unterschied zu Gott auszeichnet. Hier wird nichts beschönigt oder verharmlost, der Psalm erzählt nüchtern, eindrucksvoll und doch mit Hoffnung. Er ist durch seine Überschrift als Gebet ausgewiesen und verweist damit explizit auf den Formularcharakter und die Möglichkeit, ein Gebrauchstext zu sein. Das Identifikationspotenzial ist in Ps 90 dort am größten, wo eine hohe Dichte an Deixis, doppelte Emotionalität, eine dynamische Erzählweise und aktuelle Thematik sowie positive Züge im Gottesbild verschränkt sind, was in V12-17 der Fall ist.

Ps 64 zeichnet sich durch einen starken Beginn und ein Happy-End aus, wodurch eine doppelte Emotionalität ausgemacht werden kann. Die Identifikation mit dem lyrischen Ich legt sich in diesem Psalm aufgrund einiger Möglichkeiten ganz besonders nahe: Das lyrische Ich kann das lesende Ich sein (vgl. I Einleitung 4.1.4); das lyrische Ich kann sich mit David und die Lesenden können sich mit ihm als Identifikationsfigur verbinden; und die antithetische Struktur des Psalms fördert durch die Abgrenzung gegenüber den Feinden die Identifikation mit dem lyrischen Ich, dem Unschuldigen und Gerechten sowie den Herzgeraden. Die Identifikation mit der Sprechstimme kann auch dazu führen, den Gebetsweg im Text mitzugehen und damit am Ende des Psalms an einen anderen biographischen Ort zu gelangen, als man sich am Anfang befunden hat. Der Gebetscharakter des Psalms als individuelles Klage- und Bittgebet eröffnet zudem die Möglichkeit, den Psalm als Gebrauchstext zu nutzen und mit den Worten des Psalms die eigenen Anliegen vor Gott zu bringen. Mittels Ps 64 ist auch zu erfahren, was JHWH getan hat und was von der Gottheit erwartet werden kann. Der Psalm besticht durch drei aktuelle Themenfelder. Da ist zunächst (1) die Macht der Worte, die Verletzungsmacht und Gefährdung durch Worte sowie der Kampf mit Worten zu nennen. Heute kann dabei an Mobbing, Verleumdung oder Hetze im Internet gedacht werden. Der Psalm schildert, wie böse und verletzend Worte sein können und wie tatkräftig und effektiv die Gottheit gegen jene einschreiten kann, die mit solchen Worten hantieren. Mit den Feinden werden (2) dunkle und destruktive Kräfte thematisiert. Diese können als Spiegel der destruktiven und zerstörenden Kräfte betrachtet werden, die heute in uns und in unseren Gesellschaften vorhanden sind. Und schlussendlich spricht der Psalm von der Erfahrung, dass es (3) Gott gibt, dass Gott in lebensbedrohlichen Situationen eingreift, dass die Taten der Feinde auf sie selbst zurückfallen, sich die Waffen gegen sie selbst richten und dass ungerechte Taten adäquate Konsequenzen haben. Durch das Mitgehen mit dem lyrischen Ich und das Sich-Hineindenken und -fühlen in dieses lädt der gesamte Text zur Identifikation mit dem lyrischen Ich ein, wobei das Identifikationspotenzial durch den starken Beginn und das positive Ende verstärkt wird. 


\subsection{Aneignung}

Die dritte Ebene der Identifikation bei Uri Margolin, nämlich die des Auslösens autobiographischer Erinnerungen, die vierte Ebene bei Margolin, Miall und Kuiken, welche die persönlichkeitsverändernd wirkenden Emotionen betreffen, sowie die fünfte Ebene bei Margolin, die den Transfer in die Lebenswelt benennt, können mittels einer Textanalyse nicht eruiert werden, denn sie verbleiben auf der LeserInnenseite. Dieser Punkt ist wohl der provokanteste in der Literatur über Identifikation: Hierbei geht es um das Ausmaß, in dem das Lesen und die dabei hervorgerufenen Emotionen sich der realen Welt entziehen sowie die Frage, ob diese Emotionen die Lesenden möglicherweise in irgendeiner Art und Weise verändern. ${ }^{1339}$

\section{Standpunktbestimmung und Ausblick}

Das generell durch die Rezeptionsgeschichte hindurch konstatierte Phänomen der Identifikationskraft der Psalmen (vgl. I Einleitung 1) konnte methodisch reflektiert an einzelnen Psalmen und innerhalb differenzierter Textanalysen festgemacht und exemplarisch aufgezeigt werden. Dabei hat sich das Zusammenspiel zwischen hermeneutischen Prämissen und der Kombination unterschiedlicher Methoden- und Arbeitsschritte, die aus der Ableitung der Begrifflichkeit (vgl. II Methodologische Grundlagen und III Methodik) heraus entwickelt wurden, als adäquat und bereichernd erwiesen. Um eine Aussage über das Identifikationspotenzial für den gesamten Psalter treffen zu können, muss an jedem einzelnen Psalm überprüft werden, ob dort hohe bzw. doppelte Emotionalität, hervorgerufen durch metaphorische Sprache, Dichte an Deixis, aktueller Inhalt und spannende Erzähldynamik aufeinandertreffen. Die Vermutung liegt nahe, dass dies in den meisten individuellen und kollektiven Klage-, Bitt- und Dankliedern der Fall ist, die den Großteil des Psalmenbuches ausmachen. Es trifft, wie die Analyse von Ps 90 deutlich machen konnte, auch auf jene durch eine weisheitliche Reflexion geprägten Psalmen $\mathrm{zu}$, die generelle Themen der Schöpfung und des Menschseins thematisieren, was z. B. bei Ps 1; 8; 19; 104; 119 und 144 der Fall ist. Das jeweilige textuelle Identifikationspotenzial ist allerdings im Einzelnen herauszuarbeiten.

Die Arbeit stellt innerhalb der Psalmenforschung einen Beitrag zur textuellen Identifikation dar, dessen Schwerpunkt auf Perspektivenlenkung bzw. Deixis, Emotionen und Textdynamik bzw. Narratologie liegt. Die Forschungsfrage nach Identifikationspotenzialen eröffnet mir die Möglichkeit, mich als Forschende

1339 Vgl. Oatley / Gholamain, Emotions, 277. 
explizit in den Forschungsprozess mit hineinzunehmen, der sich zwischen Involviertsein und Distanz zum Text, zwischen Faszination und den Mühen der analytischen Auseinandersetzung sowie zwischen Identifikation und Aneignung bewegt.

Mittels der Begriffsbestimmung von literarischer Identifikation, methodischer Operationalisierung und den daraus abgeleiteten Arbeitsschritten konnte das äußerst komplexe Identifikationsphänomen auf Seiten der Texte erfasst werden. Hinsichtlich der Komplexität von Identifikation, die im Leseprozess auf die drei Säulen (1) Text, (2) LeserInnen und (3) Kontext aufbaut, wurde damit ein Drittel des Gesamtprozesses in den Blick genommen. Ein umfassendes Bild des Identifikationsprozesses würde sich dann ergeben, wenn zusätzlich zur textanalytischen Komponente aktuelle Lesende dahingehend befragt werden, wo, wie und warum sie sich mit dem Psalm bzw. einzelnen Stellen daraus identifizieren (empirische Bibelforschung), sowie die entsprechenden Kontexte der Psalmenrezeption dahingehend erforscht würden, wie in diesen die in dieser Arbeit analysierten Psalmen und bestimmte Verse daraus ausgelegt wurden und welche Diskurse in der jeweiligen Epoche vorherrschend gewesen sind. Die Untersuchung dieser beiden Elemente - der Lesenden und der Rezeptionsgeschichte - war nicht Thema der vorliegenden Arbeit und hätte ihren Rahmen überschritten, wobei es sich als Folgeprojekt nahelegen würde. Beispiele aus der Auslegungstradition sollen aber im Folgenden einen kurzen Einblick in die Rezeptionsgeschichte der vier analysierten Psalmen geben, um zu eruieren, ob die in der Analyse erarbeiteten Identifikationspotenziale in der Rezeption Aufnahme gefunden haben. Begonnen wird dabei mit Ps 147.

Siegfried Risse widmet sich im Rahmen seiner umfassenden Dissertation zu Ps 147 auch der Rezeption des Psalms in jüdischer (Talmud, Liturgie der Synagoge, Midrasch Tehillim, Kommentar des David Kimchi und Chassidismus) und christlicher Tradition (NT, Zeit der Kirchenväter, Mittelalter, Reformation und Liturgie). ${ }^{1340}$ Als interessant erweist sich die Tatsache, dass sich neben der Macht Gottes in der Natur (V4-5) und seiner Fürsorge für die Schöpfung, hier vor allem für die jungen Raben (V8f), die V2-3 sowie V12-14, die sich in der hier vorliegenden Textanalyse als primäre Identifikationspotenziale herauskristallisiert haben, sowie die V15-18 (Personifikation des Wortes und Naturvergleiche) intensiver Auslegung und Aktualisierung erfreuen. Einige Beispiele sollen dies im Folgenden veranschaulichen:

In der jüdischen Tradition sind im Midrasch Tehillim die Verstoßenen bzw. Zerstreuten aus V2 die zehn Stämme Israels, und in V3 wird festgestellt, dass das Herz Israels gebrochen ist. Im Kommentar des David Kimchi werden Schnee und

$1340 \mathrm{Zu}$ den folgenden Ausführungen vgl. Risse, Gut ist es, 244-340. 
Raureif aus V16-17 als Wasser- und Feuchtigkeitsspender gleich dem Regen interpretiert.

Innerhalb der christlichen Tradition ist bei den Kirchenvätern eine Auslegungstradition zu finden, die sich zum einen allegorisch (wobei hier Jerusalem für die Kirche oder die einzelne Seele steht), zweitens im historischen Sinn (wobei es um die Heimkehr aus dem Exil geht), sowie drittens auch im eschatologischen Sinn (Jerusalem entspricht hier dem himmlischen Jerusalem) mit dem Psalm auseinandersetzt. So interpretiert etwa Origenes den Psalm allegorisch. Die Riegel der Tore in V13, die Gott fest und sicher macht, sind entweder jene Tugenden, die dem bösen Feind den Eintritt in die Seele (= Jerusalem) verwehren, oder auch die himmlischen Satzungen und der rechte Glaube an die Dreifaltigkeit. Der beste Weizen aus V14 bzw. das Getreidekorn ist der Erlöser. V16-17 interpretiert Origenes so, dass Schnee, Eis und Kälte die vernünftige Natur umschließen. Diesen Schnee hat der ausgesandte Logos Gottes geschmolzen.

Nach Hieronymus wird in V2-3 Jerusalem erbaut, indem die zerknirschten Herzen geheilt werden. Der fette Weizen in V14 wird mit Christus bzw. seiner göttlichen Botschaft gleichgesetzt. Das schnell laufende Wort in V15 bezieht Hieronymus auf die Menschwerdung des Logos bzw. die Verkündigung des Evangeliums. In V16-17 steht die Asche für den Schmutz und alles, was lasterhaft ist, der Schnee allerdings für die Reinheit. Das Wort Gottes aus V18 löst aus der Starre und Kälte.

Cassiodorus sieht in Jerusalem die himmlische Stadt und bezieht V3 auf das Ende der Welt, wenn die Zerstreuten Israels zu einem Volk gesammelt werden, auf dass eine Herde und ein Hirte werde. V3 ist für ihn auch eine Metapher von den Heilkundigen: Wenn sie gebrochene Knochen zusammenfügen wollen, umbinden sie sie fest mit Leinenbinden, damit die Glieder wieder $\mathrm{zu}$ ihrer einstigen Festigkeit zusammenwachsen. Ebenso verbindet und festigt der himmlische Arzt die Herzen der Büßenden, die durch schwere Betrübnis gebrochen sind. In V14 werden die Gläubigen durch den Anblick Christi gesättigt, der beste Weizen ist somit die schaubare Gottheit. Schnee, Eis und Frost aus V16-17 stehen für die Übel dieser Welt, die mit dem Eis der Sünden die sterblichen Herzen einschließen und sie in Felsstarre verharren lassen, wenn sie nicht durch die Wärme Gottes gelöst werden. In V15 bezieht sich die Schnelligkeit des Wortes auf die Botschaft, die so schnell laufen kann, dass eine rasche Anerkennung der Heiligen Dreifaltigkeit die Welt erfüllt.

In der Zeit der Reformation hält Martin Luther in seiner ersten Psalmenvorlesung (1512-1515) unter Bezug auf Ps 147 fest, dass Gott Jerusalem, d. h. die Kirche, die in Jerusalem entstanden ist und ihren Namen von ihm hat, mit geistlicher Erbauung bauen wird. V3 deutet er dahingehend, dass Gott durch Wort und Sakrament die Schmerzen der Kirche, d. h. die Pein ihrer Sünden und die Schwachheit, verbindet. Die Tore Zions in V13 sind die Heiligen Schriften. In 
V14 geht es um den Frieden des Geistes mit Gott; der beste Weizen ist der Geist. V15 handelt davon, dass das Evangelium durch die Apostel auf die Erde gesendet wird; es läuft schnell. Gut 20 Jahre später deutet Martin Luther den Psalm im Rahmen des Literalsinns und bezieht Jerusalem auf das städtische und dörfliche Leben zu seiner Zeit (1532). Er sieht im Psalm fünf zeitliche Wohltaten Gottes thematisiert - hier bezogen auf das gesellschaftliche Zusammenleben in Stadt/ Dorf und Staat: (1) Schutz und Sicherheit, (2) Glück und Segen, (3) Friede, (4) das liebe tägliche Brot, (5) dass Gott uns auch im Winter Sommer gibt. Die Torriegel von V13 sieht er als Sinnbild für alles, was neben den eisernen Riegeln Schutz gewährt, z. B. das gute Stadtrecht und die gute Ordnung. Der Friede aus V14 gilt nicht nur der Stadt, sondern auch dem Land ringsum. Die Wolle, Asche und Bissen aus V16-17 geben nach Luther einen Hinweis auf Wärme, Feuerstätte und Nahrung im Winter. Er spricht infolgedessen von zwei Arten von Winter: erstens von einem geistlichen Winter, der sich dann einstellt, wenn der inwendige Mensch in Sünde erfroren und in Kälte erstorben ist. Der Wind aus V18 wird dann zum heiligen Geist, der das Evangelium unter solch erkaltete Sünder weht, der die Sünden vergibt und die Sünder tröstet; und zweitens von jenem Winter, der dann vorherscht, wenn der äußerliche Mensch unter dem Kreuz liegt und in Trübsal ist.

Diese Beispiele aus der Rezeptionsgeschichte von Ps 147 zeigen, dass neben den in der Analyse von Identifikationspotenzialen herausgearbeiteten Versen 23 und 12-14 vor allem die in bildlicher Rede gestalteten Abschnitte des Psalms ein hohes Rezeptionspotenzial in sich tragen (V15-18). Dadurch bestätigt sich das, was in der Methodik (vgl. III Methodik 2.2.3) ausgewiesen wurde, dass nämlich gerade metaphorische Rede einen großen Auslegungs- und Interpretationsraum eröffnet, weil sie die Mitarbeit der Lesenden ermöglicht und geradezu erfordert.

Ein Blick in die Rezeptionsgeschichte konstatiert für Ps 90: "Biblische Psalmen, die unseren Blick auf allgemeinmenschliche Erfahrung hin weiten, haben sich in der Rezeptionsgeschichte allem Anschein nach als besonders attraktiv erwiesen. Das gilt [...] auch für Ps 90, der aus dem Lebensgefühl einer skeptischkritischen Weisheit spricht. ${ }^{1341}$ Auf die breite Rezeption aufgrund der Tatsache, dass der Psalm zentrale Aussagen und Botschaften zum menschlichen Leben in seiner zeitlichen Dimension bereithält, verweist auch Klaus Seybold. ${ }^{1342}$ Auf-

1341 Irsigler, Psalm 90, 49.

1342 Vgl. Seybold, Psalm 90, 129.»The text travels through history, including our own, and only becomes meaningful as it communicates and generates meaning in particular contexts.« So Boring, Psalm 90, 126, der der Rezeption von Ps 90 in der LXX und im Jubiläenbuch nachgeht. Anklänge von Ps 90 im Jubiläenbuch 23,13.15 erarbeitet ebenso Kugel, The Jubilees Apocalypse. James Comer Howell widmet sich in seiner Dissertation der Rezeptionsgeschichte von Ps 90 in jüdischer und christlicher Perspektive bis hinauf ins 19. und 20. Jh. Vgl. Howell, Hermeneutical Approach. 
grund der alle Menschen betreffenden Erfahrung der Vergänglichkeit, Sterblichkeit und Todesproblematik ist der Text heute unter anderem in der Begräbnisliturgie verankert. ${ }^{1343}$

Psalm 64 wird in christlicher Rezeption indirekt messianisch gedeutet und auf den leidenden Christus bezogen. ${ }^{1344}$ Die katholische Kirche legt den Psalm neben dem leidenden Heiland auch der Schmerzensmutter, die von den Pfeilen der Feinde schwer getroffen wurde, sowie den Aposteln und Märtyrern, die aufgrund des Evangeliums verfolgt wurden, in den Mund. ${ }^{1345}$ In der jüdischen Auslegungstradition des Midrasch wird das lyrische Ich mit Daniel in der Löwengrube identifiziert. ${ }^{1346}$ Die Identifikation mit der Figurengruppe rund um das lyrische Ich des Psalms (Unschuldiger, Gerechter, Herzensgeraden), die als Analyseergebnis festgehalten werden konnte, ist damit auch in der Rezeptionsgeschichte belegt. $^{1347}$

Ps 30 wird unter anderem kollektiv gelesen. ${ }^{1348}$ Bei der jährlichen Verwendung am Chanukka-Fest wird das Ich des Psalms zum Volk Israel, wobei hier die Geschichte Israels vom Exil bis zur Errettung von den Seleukiden im 2. Jh. v. Chr. erzählt wird: »Die überlieferte Psalmüberschrift, sein Lied zur Tempelweihe`

1343 Vgl. Kartje, Wisdom, 126; McCann, Psalms, 1045; Mays, Psalms, 289; Goldingay, Psalms 3, 21 und Oeming / Vette, Psalmen, Psalm 90-151, 18. Siehe dazu u. a. die Predigt von Pfarrer Hans-Christoph Meier zu Ps 90,12 unter http://www.predigten.de/predigt.php3?predigt= 6691 oder die Predigt zu Ps 90 am Ewigkeitssonntag unter http://www.trauernetz.de/beglei ten/13342.html.

1344 Eine christologische Deutung findet sich auch bei Augustinus, der die Vulgata-Fassung des Psalms auf die Passion Christi und ihre Stationen anwendet und den Text auch den Märtyrern in den Mund legt. Vgl. Alonso Schökel / Carniti, Salmos 1, 842.

1345 Vgl. Thalhofer, Erklärung, 366.

1346 Vgl. Delitzsch, Die Psalmen, 428.

1347 Auf eine kollektive Lesart des Psalms verweisen Oeming und Vette: »In der jüdischen Tradition ist Ps 64 ein Spiegel der Situation Israels inmitten einer feindlichen und verleumderischen Umwelt. Antijüdische Pogrome fingen mit solchen gezielten Verleumdungen an. Aus der Rhetorik der Gewalt wurde oft reale Gewalt, aus der Rhetorik/Terminologie der Tierjagd brutale Menschenhatz.« Oeming / Vette, Psalmen, Psalm 42-89, $138 \mathrm{f}$.

1348 "Das `Ich<, das mit ganz allgemeinen Formulierungen die Phase der Krankheit und Unterdrückung beschreibt, wird als Israel interpretiert, das unter der Verfolgung und Bekämpfung durch den aufgeklärten Monarchen Antiochus IV. gelitten hat, dann aber wieder zur Gesundheit, d. h. zur Eigenstaatlichkeit gelangte und nun bei der Wiedereinweihung des entweihten Tempels im Jahre 164 v. Chr. (vgl. 1 Makk 4,36-61; 2 Makk 10,1-8) seine Restituierung dankbar besingt und feiert. «Oeming, Das Buch der Psalmen, 182. Er verweist auch auf die christliche Tradition, in der Psalm 30 aufgrund der Schilderung des Herausziehens aus der Todessphäre und des völligen Wandelns vom Tod zum Leben als klassischer Osterpsalm gilt. Dass die frühe Kirche den Psalm in der Osternacht verwendet hat, ist für Jerusalem bezeugt. Die Belege reichen bis an den Anfang des 5. Jh. n. Chr. zurück. Vgl. dazu Zenger, Mit meinem Gott, 93. Ausführlicher dazu Witzenrath, Am Abend Weinen, 488-492. Er geht auch auf die Rezeption von Ps 30 in der Liturgie der christlichen Kirchen ein; vgl. ebd., 471-488. 
zeigt, dass der Psalm in einer bestimmten geschichtlichen Situation von der Kultgemeinde als Gebet rezitiert worden ist. Das Ich des Psalms wird auf das Groß-Ich der Gemeinde übertragen. Wenn Ps 30 am Tempelweihfest von der Gemeinde gebetet worden ist, so ist das das Ergebnis einer Adaption. Im Midrasch Tehillim ${ }^{1349}$ wird eine Adaption greifbar, bei der das ganze Volk Israel als Beter des Psalms verstanden wird. Die Gefangenschaft in Babylon, aus der das Volk herausgezogen wurde $(30,2)$, die Gefangenschaft in Griechenland, in der es um Hilfe schrie $(30,3)$, die Rettung durch die Hasmonäer, die das Volk heilte $(30,3)$, sind unterschiedliche geschichtliche Situationen, auf die einzelne Psalmverse angewandt werden. ${ }^{1350}$ So können sich im lyrischen Ich des Textes, wie die Rezeption von Ps 30 in jüdischer Tradition eindrucksvoll zeigt, auch Gemeinschaften wiederfinden: „Die verschiedenen Trägergruppen der Rezeption müssen in dem Psalm etwas gefunden haben, was ihrer augenblicklichen notvollen Lage entsprach und daher eine Aneignung des Psalms ermöglichte. So war eine Erfahrungskonformität zwischen Psalm und Rezipienten die Voraussetzung für seine Aneignung. Unterschiedliche Ereignisse mit neuen Erfahrungen ermöglichen also eine je neue Rezeption. « ${ }^{1351}$

Die kollektive Lesart in der jüdischen Tradition zeigt, dass das offene lyrische Ich auch als das Wir einer Gruppe gelesen wird. Mit der Textdynamik und dem Auf und $\mathrm{Ab}$ an Bewegungen, die in der Analyse von Ps 30 als Identifikationspotenzial ausgewiesen werden konnten, werden Stationen der Heils- und Unheilsgeschichte Israels identifiziert.

Mit dieser kurzen Darstellung einzelner ausgewählter Stationen aus der Rezeptionsgeschichte von Ps 30; 64; 90 und 147 konnte gezeigt werden, dass die aus der Textanalyse erhobenen Elemente auch in der Auslegungstradition zu finden sind.

1349 Laut Goldingay, Psalms 1, 425 bezieht der Midrasch Tehillim 1:390-91 die Überschrift auf drei Ereignisse: auf die Einweihung des Tempels von David (1 Kön 8,63; vgl. dazu $1 \mathrm{Chr} 21$ ), auf die Wiedereinweihung des Tempels nach dem Exil (vgl. Esr 6,16-17) sowie auf die Wiedereinweihung nach der Entweihung durch Antiochus Epiphanes (vgl. 1 Makk 4,52$59)$.

1350 Witzenrath, Am Abend Weinen, 472. Auch Loader weist auf die auf eine Gemeinschaft bezogene Lesart mit der Zuordnung zu David hin: »Therefore a reinterpretation [...] of Psalm 30 from an individual to a collective song is not only quite possible, but also attested in the text itself. For the identification with David was an identification by the whole people or the faith community with the person of the sinful yet beloved king. What could be said of such an individual could also be said of Israel. And, consequently, what could be said by him, could also be said by the whole people. Therefore the psalm `of >of , the faith community." Loader, Psalm 30, 302. Er stellt eine kollektive bzw. historische Lesart vor, indem er den einzelnen Strophen konkrete Ereignisse aus der Geschichte Israels zuordnet, die er mit den entsprechenden biblischen Belegstellen verbindet.

1351 Witzenrath, Am Abend Weinen, 472. 
Die Forschungsfrage nach textuellen Identifikationspotenzialen ist nicht nur Teil der Psalmenforschung bzw. der Analyse biblischer Texte, sondern berührt die Frage nach Textwirkungen generell. Auch die Grundintention der Bibelauslegung insgesamt, die ja auf Aktualisierung angelegt ist, ist dabei berührt. Welche Anknüpfungspunkte in den Texten für die Identifikation und Aktualisierung gegeben sind, ist eine ständig herausfordernde Frage an alle, die daran interessiert sind, dass biblische Texte auch heute noch etwas zu sagen haben. Dazu ist meiner Ansicht nach Exegese unter anderem auch da, will sie nicht im theologieleeren Raum verharren und zum Selbstzweck werden, sondern sich für die an der Begegnung mit biblischen Texten interessierten Menschen als fruchtbringend erweisen. 
Open-Access-Publikation im Sinne der CC-Lizenz BY-NC-ND 4.0

(c) 2019, V\&R unipress GmbH, Göttingen 


\section{Literatur}

Die Abkürzungen folgen Siegfried M. Schwertner: Internationales Abkürzungsverzeichnis für Theologie und Grenzgebiete. Zeitschriften, Serien, Lexika, Quellenwerke mit bibliographischen Angaben, Berlin / Boston ${ }^{3} 2014 .{ }^{1352}$

\section{Bibelausgaben}

Bibel in gerechter Sprache, hrsg. von Bail, Ulrike / Crüsemann, Frank u. a., Gütersloh ${ }^{4} 2011$. (BigS)

Biblia Hebraica Stuttgartensia, hrsg. von Elliger, Karl / Rudolph, Wilhelm, Stuttgart ${ }^{4} 1990$. (BHS)

Die Bibel. Elberfelder Übersetzung, revidierte Fassung, Wuppertal ${ }^{8} 2000$. (ELB)

Die Bibel. Nach der Übersetzung Martin Luthers. Mit Apokryphen, hrsg. von der Evangelischen Kirche in Deutschland und vom Bund der Evangelischen Kirchen in der DDR, Bibeltext in der revidierten Fassung von 1984. Sonderdruck für die Österreichische Bibelgesellschaft, Wien 1990. (LUT)

Die Bibel. Vollständige Ausgabe des Alten und Neuen Testaments in der Einheitsübersetzung, hrsg. im Auftrag der Bischöfe Deutschlands u. a., Stuttgart 1991. (EÜ)

Die Schrift. Verdeutscht von Martin Buber gemeinsam mit Franz Rosenzweig. Die Schriftwerke, Heidelberg ${ }^{7} 1994$. (BUBER)

Elberfelder Studienbibel mit Sprachschlüssel und Handkonkordanz. Deutsche Bearbeitung des AT von Klement, Herbert u. a.; deutsche Bearbeitung des NT von Maier, Philippus u. a., Witten ${ }^{3} 2012$.

Holy Bible. New International Version, hrsg. von der International Bible Society, London 2011. (NIV)

Zürcher Bibel, hrsg. vom Kirchenrat der Evangelisch-Reformierten Landeskirchen des Kantons Zürich, Zürich 2008. (ZUR)

1352 Die gesamte in dieser Bibliographie verzeichnete Literatur ist in der vorliegenden Arbeit verwendet worden; sie wird in den Anmerkungen als Kurzzitat angegeben. Weiterführende Literatur wird in den entsprechenden Anmerkungen als Vollzitat ausgewiesen. Die Angabe der hebräischen Verbwurzeln erfolgt ohne Vokale. Die Zitate werden den aktuellen Rechtschreibregeln angepasst. 


\section{Sekundärliteratur und Hilfsmittel}

Abart, Christine: Lebensfreude und Gottesjubel. Studien zu physisch erlebter Freude in den Psalmen, WMANT 142, Neukirchen-Vluyn 2015.

Ackermann, Irmgard: Psalmendichtung aus der Außenperspektive, in: Stimmen der Zeit 226 (2008) 185-196.

Allen, Leslie C.: Psalms 101-150, WBC 21, Waco / Texas 1983.

Alonso Schökel, Luis / Carniti, Cecilia: Salmos 1 (Salmos 1-72). Traducción, introducciones y comentario, Nueva Biblia Española, Estella / Navarra ${ }^{2} 1994$.

Alonso Schökel, Luis / Carniti, Cecilia: Salmos 2 (Salmos 73-150). Traducción, introducciones y comentario, Nueva Biblia Española, Estella / Navarra 1993.

Alter, Robert: The Art of Biblical Poetry. Revised and Updated, New York 2011.

Anderson, Arnold A.: The Book of Psalms. Volume 1-2. New Century Bible, London 1977.

Anderson, Gary A.: A Time to Mourn, a Time to Dance. The Expression of Grief and Joy in Israelite Religion, Pennsylvania 1991.

Andringa, Els: Wandel der literarischen Identifikation, in: Siegener Periodicum zur internationalen empirischen Literaturwissenschaft 3 (1984) 27-65.

Anz, Thomas: Kulturtechniken der Emotionalisierung. Beobachtungen, Reflexionen und Vorschläge zur literaturwissenschaftlichen Gefühlsforschung, in: Eibl, Karl u. a. (Hg.): Im Rücken der Kulturen, Poetogenesis 5, Paderborn 2007, 207-239.

Artner, Sarah J.: „Sättige uns am Morgen mit deiner Güte, dass wir jubeln und uns freuen an all unseren Tagen!« (Ps 90,14). Emotionen in Psalm 90, Dipl. Linz 2014.

Artner, Sarah J.: Emotionen in Psalm 90, in: PZB 25 (2016) 119-137.

Baader, Fritz H.: Wortkunde der Bibel und Etymologie über die Herkunft der europäischen Sprachen, Schömberg 2000.

Bader, Günter: Psalterspiel. Skizze einer Theologie des Psalters, HUTh 54, Tübingen 2009.

Bail, Ulrike: Gegen das Schweigen klagen. Eine intertextuelle Studie zu den Klagepsalmen Ps 6 und Ps 55 und der Erzählung von der Vergewaltigung Tamars, Gütersloh 1998.

Bail, Ulrike: On Gendering Laments. Eine genderorientierte Lektüre der Klagepsalmen, in: Maier, Christl / Calduch-Benages, Nuria (Hg.): Schriften und spätere Weisheitsbücher, Die Bibel und die Frauen. Altes Testament 1.3, Stuttgart 2013, 169-184.

Bail, Ulrike / Crüsemann, Frank u. a.: Einleitung, in: Bibel in gerechter Sprache, hrsg. von Bail, Ulrike / Crüsemann, Frank u. a., Gütersloh ${ }^{4} 2011$, 9-22.

Ballhorn, Egbert: Zum Telos des Psalters. Der Textzusammenhang des Vierten und Fünften Psalmenbuches (Ps 90-150), BBB 138, Berlin u. a. 2004.

Ballhorn, Egbert: Zur Pragmatik des Psalters als eschatologisches Lehrbuch und Identitätsbuch Israels, in: Gerhards, Albert u. a.: Identität durch Gebet. Zur gemeinschaftsbildenden Funktion institutionalisierten Betens in Judentum und Christentum, Studien zu Judentum und Christentum 534, Paderborn u. a. 2003, 241-259.

Barré, Michael L.: A Proposal on the Crux of Psalm 649 A, in: VT 66 (1996) 115-118. Barstad, Hans M.: רצה, in: ThWAT 7 (1993) 640-652.

Barth, Christoph: Die Errettung vom Tode in den individuellen Klage- und Dankliedern des Alten Testaments, hrsg. von Bernd Janowski, Stuttgart 1997.

Barth, Christoph: זמר, in: ThWAT 2 (1977) 603-612.

Barth, Christoph: iָצִיר: ThWAT 3 (1982) 137-140. 
Barth, Christoph: כשל, in: ThWAT 4 (1984) 368-375.

Baumann, Arnulf: חיל, in: ThWAT 2 (1977) 898-902.

Baumann, Gerlinde: Das göttliche Geschlecht. JHWHs Körper und die Gender-Frage, in: Hedwig-Jahnow-Forschungsprojekt (Hg.): Körperkonzepte im Ersten Testament. Aspekte einer Feministischen Anthropologie, Bonn 2003, 220-250.

Baumgart, Norbert C.: Vom Tod mitten im Leben zum Leben nach dem Tod. Zu einer Grenzüberschreitung im Psalter, in: ThG 56 (2013) 98-118.

Beckmann, Susanne: Die Grammatik der Metapher. Eine gebrauchstheoretische Untersuchung des metaphorischen Sprechens, Linguistische Arbeiten 438, Münster 1997.

Beilfuß, Wilfried: Der literarische Rezeptionsprozeß. Ein Modell, EHS.DS 989, Frankfurt am Main 1987.

Bender, Andrea: Heiliger Zorn im »Paradies«? Emotionen im Kulturvergleich, in: Wagner, Andreas (Hg.): Anthropologische Aufbrüche. Alttestamentliche und interdisziplinäre Zugänge zur historischen Anthropologie, FRLANT 232, Göttingen 2009, 297-318.

Bernhardt, Karl-Heinz: in: ThWAT 1 (1973) 151-159.

Berry, Donald K.: The Psalms and their Readers. Interpretative Strategies for Psalm 18, JSOTS 153, Sheffield 1993.

Bester, Dörte: Körperbilder in den Psalmen. Studien zu Psalm 22 und verwandten Texten, FAT.2/24, Tübingen 2007.

Bester, Dörte: Weinen (AT), in: Bauks, Michaela / Koenen, Klaus (Hg.): Das wissenschaftliche Bibellexikon im Internet, Stuttgart 2011. [http://www.bibelwissenschaft.de/ stichwort/34647/]

Beyerlin, Walter: Die Rettung der Bedrängten in den Feindpsalmen der Einzelnen auf institutionelle Zusammenhänge untersucht, FRLANT 99, Göttingen 1970.

Beyse, Karl-Martin: נאה, in: ThWAT 5 (1986) 117-119.

Beyse, Karl-Martin: עָָּ in: ThWAT 6 (1989) 220-226.

BibleWorks 9. Software for Biblical Exegesis \& Research, Norfolk / Virginia 2011.

Black, Max: Die Metapher, in: Haverkamp, Anselm (Hg.): Theorie der Metapher, Darmstadt $^{2} 1996,55-79$.

Bleumer, Hartmut / Emmelius, Caroline (Hg.): Lyrische Narrationen - narrative Lyrik. Gattungsinterferenzen in der mittelalterlichen Literatur, Trends in Medieval Philo$\operatorname{logy} 16$, Berlin u. a. 2011.

Bleumer, Hartmut / Emmelius, Caroline: Generische Transgressionen und Interferenzen. Theoretische Konzepte und historische Phänomene, in: dies. (Hg.): Lyrische Narrationen - narrative Lyrik. Gattungsinterferenzen in der mittelalterlichen Literatur, Trends in Medieval Philology 16, Berlin u. a. 2011, 1-39.

Bloomfield, Morton W.: A Grammatical Approach to Personification Allegory, in: Modern Philology 60 (1963) 161-170.

Booij, Thijs: Psalm 90,5-6: Junction of Two Traditional Motifs, in: Bib. 68 (1987) 393-396.

Bonkamp, Bernhard: Die Psalmen nach dem hebräischen Grundtext, Freiburg 1949.

Bons, Eberhard: Psalm 31 - Rettung als Paradigma. Eine synchron-leserorientierte Analyse, FTS 48, Frankfurt am Main 1994.

Boring, M. Eugene: Psalm 90 - Reinterpreting Tradition, in: Midstream 40 (2001) 119-128. Borkowski, Jan / Winko, Simone: Wer spricht das Gedicht? Noch einmal zum Begriff lyrisches Ich und zu seinen Ersetzungsvorschlägen, in: Bleumer, Hartmut / Emmelius, 
Caroline (Hg.): Lyrische Narrationen - narrative Lyrik. Gattungsinterferenzen in der mittelalterlichen Literatur, Trends in Medieval Philology 16, Berlin u. a. 2011, 43-77.

Botha, Phil J.: The Textual Strategy and Social Background of Psalm 64 as Key to its Interpretation, in: JSem 11 (2002) 64-82.

Brandtscheidt, Renate: Der Gott des Alten Testaments und die Gewalt, in: TThZ 118 (2009) 1-15.

Brandscheidt, Renate: »Unsere Tage zu zählen, so lehre du« (Psalm 90,12). Literarische Gestalt, theologische Aussage und Stellung des 90. Psalms im vierten Psalmenbuch, in: TTZ 112 (2004) 1-33.

Braulik, Georg: Rezeptionsästhetik, kanonische Intertextualität und unsere Meditation des Psalters, in: ders. / Lohfink, Norbert: Liturgie und Bibel. Gesammelte Aufsätze, ÖBS 28, Frankfurt am Main u. a. 2005, 523-547.

Bremer, Johannes: Wo Gott sich auf die Armen einlässt. Der sozio-ökonomische Hintergrund der achämenidischen Provinz Yəhūd und seine Implikationen für die Armentheologie des Psalters, BBB 174, Göttingen 2016.

Briggs, Charles A. / Briggs, Emilie G.: A Critical and Exegetical Commentary on the Book of Psalms. Volume 2, ICC, Edinburgh 1907.

Brodersen, Alma: Die Bedeutung der Schöpfungsaussagen für die Theologie von Psalm 147, BThSt 134, Neukirchen-Vluyn 2013.

Brodersen, Alma: The End of the Psalter. Psalms 146-150 in the Masoretic Text, the Dead Sea Scrolls, and the Septuagint, BZAW 505, Berlin / Boston 2017.

Brown, M. L.: רפ, in: ThWAT 7 (1993) 618-625.

Brown, William P.: Seeing the Psalms. A Theology of Metaphor, Louisville u. a. 2002.

Brueggemann, Walter / Bellinger, William: Psalms, NCBC, New York 2014.

Bühler, Karl: Sprachtheorie. Die Darstellungsfunktion der Sprache, Ullstein u. a. 1978 (Erstausgabe 1934).

Bühlmann, Walter / Scherer, Karl: Sprachliche Stilfiguren der Bibel. Von Assonanz bis Zahlenspruch, Göttingen ${ }^{2} 1994$.

Bühlmann, Walter: Vom rechten Reden und Schweigen. Studien zu Proverbien 10-31, OBO 12, Göttingen 1976.

Bührer, Walter: Göttersöhne und Menschentöchter: Gen 6,1-4 als innerbiblische Schriftauslegung, in: ZAW 123 (2011) 495-515.

Butting, Klara: Erbärmliche Zeiten - Zeit des Erbarmens. Theologie und Spiritualität der Psalmen, Erev-Rav-Hefte Biblische Erkundungen 15, Uelzen 2013.

Carroll, Noël: Art, Narrative, and Emotion, in: Hjort, Mette / Laver, Sue (Hg.): Emotion and the Arts, New York / Oxford 1997, 190-211.

Charney, Davida H.: Persuading God. Rhetorical Studies of First-Person Psalms, HBM 73, Sheffield 2015.

Clifford, Richard J.: Psalms 1-72, Abingdon Old Testament Commentaries, Nashville 2002.

Clifford, Richard J.: Psalm 90: Wisdom Meditation or Communal Lament?, in: Flint, Peter W./ Miller, Patrick D. (Hg.): The Book of Psalms. Composition and Reception, VTSup 99, Leiden 2005, 190-205.

Clines, David J. A.: A World Established on Water (Psalm 24): Reader-Response, Deconstruction and Bespoke Interpretation, in: Exum, Cherly J. / ders. (Hg.): The New Literary Criticism and the Hebrew Bible, JSOTS 143, Sheffield 1993, 79-90. 
Cohen, Abraham: The Psalms. Hebrew Text and English Translation with an Introduction and Commentary, SBBS, London u. a. ${ }^{12} 1977$.

Collins, Terence: The Physiology of Tears in the Old Testament. Part 1 and 2, in: CBQ 33 (1971) 18-28.185-197.

Cook, Ryan: Prayers That Form Us: Rhetoric and Psalm Interpretation, in: JSOT (2015) 451-467.

Cottrill, Amy C.: A Reading of Ehud and Jael through the Lens of Affect Theory, in: BibInt 22 (2014) 430-449.

Craigie, Peter C.: Psalms 1-50, WBC 19, Waco 1983.

Curtis, Robin: Einführung in die Einfühlung, in: ders. / Koch, Gertrud (Hg.): Einfühlung. Zur Geschichte und Gegenwart eines ästhetischen Konzepts, München 2009, 10-29.

Dahood, Mitchell: Psalms 1-3, AncB, New York 1965. 1968. 1970.

Dawes, Stephen: The Psalms, SCM Studyguide, London 2010.

Delitzsch, Franz: Die Psalmen, BK 4/1, Leipzig ${ }^{5} 1894$.

Deselaers, Paul: Die Wiederentdeckung der Psalmen. Eine Anregung für die Predigtpraxis, in: PThI 29 (2009) 10-19.

De Wette, Wilhelm M. L.: Commentar über die Psalmen, nebst beigefügter Übersetzung, Breslau ${ }^{5} 1885$.

Diedrich, Friedrich / Scholtissek, Klaus: Gnade, in: NBL 1 (1991) 859-867.

Dietrich, Walter / Arnet, Samuel (Hg.): Konzise und aktualisierte Ausgabe des Hebräischen und Aramäischen Lexikons zum Alten Testament, Leiden 2013. (KAHAL)

Dodson, Joseph R.: The >Powers` of Personification. Rhetorical Purpose in the Book of Wisdom and the Letter to the Romans, BZNW 161, Berlin u. a. 2008.

Dohmen, Christoph: רעע, in: ThWAT 7 (1993) 582-611.

Domin, Hilde: Gesammelte Gedichte, Frankfurt am Main ${ }^{13} 2015$.

Duden. 5. Das Fremdwörterbuch, hrsg. vom Wissenschaftlichen Rat der Dudenreaktion, Mannheim u. a. ${ }^{6} 1997$. (Duden)

Duhm, Bernhard: Die Psalmen, KHC 14, Tübingen ${ }^{2} 1922$.

Dürr, Michael / Schlobinski, Peter: Deskriptive Linguistik. Grundlagen und Methoden, Göttingen ${ }^{3} 2006$.

Ebach, Jürgen: Gottes Name(n) oder: Wie die Bibel von Gott spricht, in: BiKi 65 (2002) 6267.

Eberhardt, Gönke: JHWH und die Unterwelt. Spuren einer Kompetenzausweitung JHWHs im Alten Testament, FAT 23, Tübingen 2007.

Eder, Jens: Die Figur im Film. Grundlagen der Figurenanalyse, Marburg 2008.

Eder, Sigrid: Do Justice and Peace Really Kiss Each Other? Personifications in the Psalter and an Exemplary Analysis of Ps 85:11, in VT 67 (2017) 387-402.

Eder, Sigrid: Gewalt in der Bibel. Begrifflichkeit - Verstehenshilfen - Perspektiven, in: PZB 19 (2010) 1-20.

Eder, Sigrid: »Neige, JHWH, dein Ohr! Antworte mir!« (Ps 86,1). Gott als Adressat in den Psalmen, in: Eisen, Ute E. / Müllner, Ilse (Hg.): Gott als Figur. Narratologische Analysen biblischer Texte und ihrer Adaptionen, HBS 82, Freiburg u. a. 2016, 187-216.

Eder, Sigrid: Sehnsucht nach dem Gott des Lebens - eine Spurensuche in den Psalmen des Alten Testaments, in: Pernkopf, Elisabeth / Schaupp, Walter (Hg.): Sehnsucht Mystik, Theologie im kulturellen Dialog 22, Innsbruck u. a. 2011, 71-93. 
Eder, Sigrid: Wie Frauen und Männer Macht ausüben. Eine feministisch-narratologische Analyse von Ri 4, HBS 54, Freiburg u. a. 2008.

Ehlich, Konrad: Deixis, in: Glück, Helmut (Hg.): Metzler Lexikon Sprache, Stuttgart ${ }^{4} 2010$, 132-133.

Ehlich, Konrad: Deiktische und phorische Prozeduren beim literarischen Lesen, in: Lämmert, Eberhard (Hg.): Erzählforschung. Ein Symposion, Germanistische Symposien Berichtsbände 4, Stuttgart 1982, 112-129.

Ehlich, Konrad: Verwendungen der Deixis beim sprachlichen Handeln. Linguistischphilologische Untersuchungen zum hebräischen deiktischen System. Teil 1 und 2, Forum Linguisticum 24, Frankfurt am Main u. a. 1979.

Eisen, Ute E. / Müllner, Ilse (Hg.): Gott als Figur. Narratologische Analysen biblischer Texte und ihrer Adaptionen, HBS 82, Freiburg u. a. 2016.

Elliott, Raymond K.: Aesthetic Theory and the Experience of Art, in: Osborne, Harold (Hg.): Aesthetics, Oxford 1972, 145-157.

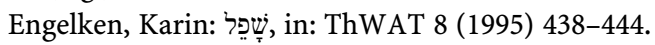

Erbele-Küster, Dorothea: Lesen als Akt des Betens. Eine Rezeptionsästhetik der Psalmen, Eugene / Oregon 2013. (Erstauflage WMANT 87, Neukirchen-Vluyn 2001).

Ernst, Michael: Hagel, in: HNBL (2009) 284.

Ernst, Stephanie: Segen - Aufgabe - Einsicht. Aspekte und Bilder des Alterns in den Texten des Alten Israel, ATSAT 93, St. Ottilien 2011.

Fabry, Heinz-Josef: לב, in: ThWAT 4 (1984) 413-451.

Feldmeier, Reinhard / Spieckermann, Hermann: Der Gott der Lebendigen. Eine biblische Gotteslehre, Topoi Biblischer Theologie 1, Tübingen 2011.

Feagin, Susan L.: Imagining Emotions and Appreciating Fiction, in: Hjort, Mette / Laver, Sue (Hg.): Emotion and the Arts, New York / Oxford 1997, 50-62.

Ficker, R.: רנן, in: THAT 2 (1976) 781-786.

Firmage, E. / Milgrom, Jacob / Dahmen, Ulrich: in: ThWAT 7 (1993) 425-431.

Firth, David G.: Surrendering Retribution in the Psalms. Responses to Violence in Individual Complaints, Paternoster Biblical Monographs, Carlisle 2005.

Fischer, Irmtraud: Über »die Liebe« in hierarchischen Gesellschaftsformen. Sozialgeschichtliche Voraussetzungen zum Verständnis von Liebe in der Hebräischen Bibel, in: Gielen, Marlies / Kügler, Joachim (Hg.): Liebe, Macht und Religion. Interdisziplinäre Studien zu Grunddimensionen menschlicher Existenz. FS H. Merklein, Stuttgart 2003, 64-81.

Fischer, Stefan: Das Hohelied Salomos zwischen Poesie und Erzählung. Erzähltextanalyse eines poetischen Textes, FAT 72, Tübingen 2010.

Fix, Ulla: Zugänge zu Textwelten. Linguistisch-literaturwissenschaftliche Möglichkeiten, in die Geschlossenheit eines Erzähltextes einzudringen, in: Hermanns, Fritz / Holly, Werner (Hg.): Linguistische Hermeneutik. Theorie und Praxis des Verstehens und Interpretierens, Germanistische Linguistik 272, Tübingen 2007, 323-356.

Fohrer, Georg: Psalmen, De Gruyter Studienbuch, Berlin u. a. 1993.

Fokkelman, Jan P.: Major Poems of the Hebrew Bible at the Interface of Prosody and Structural Analysis. Volume 2: 85 Psalms and Job 4,1-14, SSN, Assen 2000.

Fokkelman, Jan P.: The Psalms in Form. The Hebrew Psalter in its Poetic Shape, Tools for Biblical Study Series 4, Leiden 2002. 
Fontius, Martin: Einfühlung / Empathie / Identifikation, in: Ästhetische Grundbegriffe 2 (2001) 121-142.

Forster, Christine: Begrenztes Leben als Herausforderung. Das Vergänglichkeitsmotiv in weisheitlichen Psalmen, Zürich 2000.

Freedman, David N. / Lundbom, Jack: חנן, in: ThWAT 3 (1982) 23-40.

Fritz, Martin: Von der heiligen Poesie der Hebräer. Eine Relektüre des schrifthermeneutischen Klassikers von Robert Lowth (1710-1783), in: KuD 57 (2011) 90-111.

Fuhs, Hans: ירא: in: ThWAT 3 (1982) 869-893.

Fuhs, Hans: עלה, in: ThWAT 6 (1989) 84-106.

Füglister, Notker: Das Psalmengebet, München 1965.

Furrow, Melissa: Listening Reader and Impotent Speaker: The Role of Deixis in Literature, in: Language and Style 21 (1988) 365-378.

Gamberoni, Johann: הסח, in: ThWAT 3 (1982) 72-83.

Gerlemann, Gillis: Der »Einzelne« der Klage- und Dankpsalmen, in: VT 32 (1982) 33-49.

Gerleman, Gillis: כלה, in: THAT 1 (1971) 831-833.

Gerlemann, Gillis: שִשָi, in: THAT 2 (1976) 837-841.

Gerlemann, Gillis: שבע, in: THAT 2 (1976) 819-821.

Gerlemann, Gillis: שלם in: THAT 2 (1976) 919-935.

Gerstenberger, Erhard S.: Arbeitsbuch Psalmen, Stuttgart 2015.

Gerstenberger, Erhard S.: Der bittende Mensch. Bittritual und Klagelied des Einzelnen im Alten Testament, WMANT 51, Neukirchen-Vluyn 1980.

Gerstenberger, Erhard S.: ענה II, in: ThWAT 6 (1989) 247-270.

Gesenius, Wilhelm: Hebräisches und Aramäisches Handwörterbuch über das Alte Testament, Berlin u. a. ${ }^{18} 2013$. (GES)

Gillmayr-Bucher, Susanne: Body Images in the Psalms, in: JSOT 28 (2004) 301-326.

Gillmayr-Bucher, Susanne: Die Psalmen im Spiegel der Lyrik Thomas Bernhards, SBB 48, Stuttgart 2002.

Gillmayr-Bucher, Susanne: Emotion und Kommunikation, in: Frevel, Christian (Hg.): Biblische Anthropologie. Neue Einsichten aus dem Alten Testament, QD 237, Freiburg u. a. 2010, 279-290.

Gillmayr-Bucher, Susanne: Erzählte Welten im Richterbuch. Narratologische Aspekte eines polyfonen Diskurses, BiInS 116, Leiden u. a. 2013.

Gillmayr-Bucher, Susanne: »Meine Zunge - ein Griffel eines geschickten Schreibers«. Der kommunikative Aspekt der Körpermetaphern in den Psalmen, in: Van Hecke, Pierre (Hg.): Metaphor in the Hebrew Bible, BETL 187, Leuven 2005, 197-213.

Gillmayr-Bucher, Susanne: Rauchende Nase, bebendes Herz. Gefühle zur Sprache bringen, in: BiKi 67 (2012) 21-25.

Goldingay, John: Psalms. Volume 1-3, Baker Commentary on the Old Testament Wisdom and Psalms, Grand Rapids / Michigan 2006-2008.

Greinacher, Norbert: Psalm 90, in: Degenhardt, Johannes (Hg.): Die Freude an Gott unsere Kraft. FS für Otto Bernhard Knoch zum 65. Geburtstag, Stuttgart 1991, 366-377.

Greule, Albrecht: Empor die Herzen! Emotionen in der deutschen Sakralsprache, in: Wagner, Andreas (Hg.): Anthropologische Aufbrüche. Alttestamentliche und interdisziplinäre Zugänge zur historischen Anthropologie, FRLANT 232, Göttingen 2009, 319-328. 
Groeben, Norbert / Vorderer, Peter: Leserpsychologie. 2. Lesemotivation - Lektürewirkung, Münster 1988.

Grogan, Geoffrey W.: Psalms, Two Horizons Old Testament Commentary, Grand Rapids / Cambridge 2008.

Grohmann, Marianne: Der Anfang des Lebens. Anthropologische Aspekte der Rede von Geburt im Alten Testament, in: Janowski, Bernd / Liess, Kathrin: Der Mensch im Alten Israel. Neue Forschungen zur alttestamentlichen Anthropologie, HBS 59, Freiburg u. a. 2009, 365-399.

Grohmann, Marianne: Ein Gott der Rache? Feindpsalmen in jüdischen und christlichen Auslegungen, in: Rossmanith, Nadja u. a. (Hg.): Sprachen heiliger Schriften und ihre Auslegung, Ethica Themen. Institut für Religion und Frieden, Wien 2015, 35-48.

Grohmann, Marianne: Fruchtbarkeit und Geburt in den Psalmen, FAT 53, Tübingen 2007.

Groß, Heinrich / Reinelt, Heinz: Das Buch der Psalmen. Teil 1 (Ps 1-72), GSL.AT 9/1, Düsseldorf 1978.

Grund, Alexandra: »Die Himmel erzählen die Herrlichkeit Gottes.« Psalm 19 im Kontext nachexilischer Toraweisheit, WMANT 103, Neukirchen-Vluyn 2004.

Grund, Alexandra / Janowski, Bernd: »Solange die Erde steht ...«Zur Erfahrung von Zeit und Raum im alten Israel, in: Janowski, Bernd / Liess, Kathrin (Hg.): Der Mensch im Alten Israel. Neue Forschungen zur alttestamentlichen Anthropologie, HBS 59, Freiburg u. a. 2009, 487-535.

Grübel, Rainer / Kowalski, Edward u. a.: Michail M. Bachtin. Autor und Held in der ästhetischen Tätigkeit, Stw 1878, Frankfurt am Main 2008.

Gunn, George S.: God in the Psalms, Edinburgh 1956.

Gzella, Holger: Althebräisch, in: ders. (Hg.): Sprachen aus der Welt des Alten Testaments, Darmstadt 2009, 65-88.

Gzella, Holger: Lebenszeit und Ewigkeit. Studien zur Eschatologie und Anthropologie des Septuaginta-Psalters, BBB 134, Berlin u. a. 2002.

Hardmeier, Christof: Systematische Elemente der Theo-logie in der Hebräischen Bibel. Das Loben Gottes - ein Kristallisationsmoment biblischer Theo-logie (1995), in: ders.: Erzähldiskurs und Redepragmatik im Alten Testament. Unterwegs zu einer performativen Theologie der Bibel, FAT 46, Tübingen 2005, 339-354.

Hardmeier, Christof: Textwelten der Bibel entdecken. Grundlagen und Verfahren einer textpragmatischen Literaturwissenschaft der Bibel, Textpragmatische Studien zur Hebräischen Bibel 1/2, Gütersloh 2004.

Harrelson, Walter: A Meditation on the Wrath of God: Psalm 90, in: Merrill, Arthur L. / Overholt, Thomas W. (Hg.): Scripture in History \& Theology: Essays in Honor of J. Coert Rylaarsdam, PThMS 17, Pittsburgh / Pennsylvania 1977, 181-191.

Hartenstein, Friedhelm: Das Angesicht JHWHs. Studien zu seinem höfischen und kultischen Bedeutungshintergrund in den Psalmen und in Exodus 32-34, FAT 55, Tübingen 2008.

Hartvigsen, Kirsten M.: Prepare the Way of the Lord. Towards a Cognitive Poetic Analysis of Audience Involvement with Characters and Events in the Markan World, BZNW 180, Berlin u. a. 2012.

Hausmann, Jutta: רנן, in: ThWAT 7 (1993) 538-545.

Hausmann, Jutta: שִיָׁ, in: ThWAT 7 (1993) 757-761.

Hausmann, Jutta: שוע, in: ThWAT 7 (1993) 1187-1191. 
Häring, Hermann: Das Problem des Bösen in der Theologie, Grundzüge 62, Darmstadt 1985.

Helfmeyer, Franz-Josef: כלה, in: ThWAT 4 (1984) 166-174.

Herkenne, Heinrich: Das Buch der Psalmen, HSAT 5, Bonn 1936.

Hermanns, Fritz: Empathie. Zu einem Grundbegriff der Hermeneutik, in: ders. / Holly, Werner (Hg.): Linguistische Hermeneutik. Theorie und Praxis des Verstehens und Interpretierens, Germanistische Linguistik 272, Tübingen 2007, 127-172.

Hesse, Franz: חז, in: THAT 2 (1976) 846-857.

Höge, Holger: Emotionale Grundlagen ästhetischen Urteilens. Ein experimenteller Beitrag zur Psychologie der Ästhetik, Frankfurt am Main u. a. 1984.

Höver-Johag, Ingeborg: טil, in: ThWAT 3 (1982) 315-339.

Horn, András: Theorie der literarischen Gattungen. Ein Handbuch für Studierende der Literaturwissenschaft, Würzburg 1998.

Horst, Friedrich: Kennzeichen der hebräischen Poesie, in: ThR 21 (1953) 97-121.

Hossfeld, Frank-Lothar / Kindl, Eva-Martina: קרא, in: ThWAT 7 (1993) 117-125.

Hossfeld, Frank-Lothar / Zenger, Erich: Die Psalmen 1. Psalm 1-50, NEB 29, Würzburg 1993. (Hossfeld / Zenger, Die Psalmen 1)

Hossfeld, Frank-Lothar / Zenger, Erich: Psalmen 51-100, HThKAT, Freiburg u. a. 2000. Hossfeld, Frank-Lothar / Zenger, Erich: Psalmen 101-150, HThKAT, Freiburg u. a. 2008. Howell, James C.: A Hermeneutical Approach to Psalm 90, Durham 1984.

Hupfeld, Hermann: Die Psalmen. Band 1.2. Für die dritte Auflage bearbeitet von Wilhelm Nowack, Gotha 1888.

Hühn, Peter: Geschichten in Gedichten. Ansätze zur narratologischen Analyse von Lyrik, mit einem Ausblick auf die Lyrik Shakespeares und den Petrarkismus, in: Bleumer, Hartmut / Emmelius, Caroline (Hg.): Lyrische Narrationen - narrative Lyrik. Gattungsinterferenzen in der mittelalterlichen Literatur, Trends in Medieval Philology 16, Berlin u. a. 2011, 79-101.

Hühn, Peter / Sommer, Roy: Narration in Poetry and Drama, in: Hühn, Peter u. a. (Hg.): The Living Handbook of Narratology, Hamburg 2011, 1. [http://www.lhn.uni-hamburg.de]

Ibita, Maricel S.: »O Israel I will testify against you«. Intensification and Narrativity in the Lament-Lawsuit of the "Unsilent» God in Psalm 50, in: Zenger, Erich (Hg.): The Composition of the Book of Psalms, BETL 238, Leuven 2010, 537-549.

Illman, Karl-Johann: שֵָׁם in: ThWAT 8 (1995) 93-101.

Irsigler, Hubert: Psalm 90. Der vergängliche Mensch vor dem ewigen Gott, in: ders.: Vom Adamssohn zum Immanuel. Gastvorträge Pretoria 1996, ATSAT 58, St. Ottilien 1997, 71-100.

Iser, Wolfgang: Der Akt des Lesens. Theorie ästhetischer Wirkung, München ${ }^{4} 1994$.

Jacobson, Rolf A.: »Many are Saying«. The Function of Direct Discourse in the Hebrew Psalter, JSOTS 397, London u. a. 2004.

Jacobson, Rolf A. / Jacobson, Karl N.: Invitation to the Psalms. A Reader's Guide for Discovery and Engagement, Grand Rapids / Michigan 2013.

Janowski, Bernd: Konfliktgespräche mit Gott. Eine Anthropologie der Psalmen, Neukirchen-Vluyn 2003.

Janowski, Bernd: Rettungsgewissheit und Epiphanie des Heils: das Motiv der Hilfe Gottes "am Morgen« im alten Orient und im Alten Testament. 1. Alter Orient, WMANT 59, Neukirchen-Vluyn 1989. 
Janssen, Claudia, »Ich ermutige euch, Geschwister ...« Zum Brief an die Gemeinde in Rom, Schlangenbrut 96 (2006) 5-8.

Jauß, Hans R.: Ästhetische Erfahrung und literarische Hermeneutik, Frankfurt am Main 1982.

Jeffries, Lesley: The Role of Style in Reader-Involvement: Deictic Shifting in Contemporary Poems, in: Journal of Literary Semantics 37 (2008) 69-85.

Jenni, Ernst: Psalm 30,6a - eine ungewöhnliche Sentenz, in: ders. / Jenni, Hanna (Hg.): Studien zur Sprachwelt des Alten Testaments 3, Stuttgart 2012, 105-120.

Jenni, Ernst: לוֹ in: THAT 1 (1971) 402-409.

Jens, Walter: Psalm 90. On Transience, in: LuthQ 9 (1995) 177-189.

Joüon, Paul / Muraoka, Takamitsu: A Grammar of Biblical Hebrew, SubBi 27, Rom 2006. Kampling, Rainer: Blut, in: BThW (1994) 82-85.

Kartje, John: Wisdom Epistemology in the Psalter. A Study of Psalms 1, 73, 90, and 107, BZAW 472, Berlin u. a. 2014.

Kazen, Thomas: Emotions in Biblical Law. A Cognitive Science Approach, HBM 36, Sheffield 2011.

Kedar-Kopfstein, Benjamin: תמם, in: ThWAT 8 (1995) 688-701.

Keitel, Evelyn: Von den Gefühlen beim Lesen. Zur Lektüre amerikanischer Gegenwartsliteratur, American Studies 71, München 1996.

Keel, Othmar: Die Welt der altorientalischen Bildsymbolik und das Alte Testament. Am Beispiel der Psalmen, Göttingen ${ }^{5} 1996$.

Keel, Othmar: Gott weiblich. Eine verborgene Seite des biblischen Gottes, Gütersloh ${ }^{2} 2010$.

Keel, Othmar: Feinde und Gottesleugner. Studien zum Image der Widersacher in den Individualpsalmen, SBM 7, Stuttgart 1969.

Keel, Othmar u. a.: Orte und Landschaften der Bibel. Ein Handbuch und Studienreiseführer zum Heiligen Land. Band 1: Geographisch-geschichtliche Landeskunde, Zürich 1984.

Keen, Suzanne: Empathy and the Novel, Oxford 2007.

Keen, Suzanne: Narrative Empathy, in: Hühn, Peter u. a. (Hg.): The Living Handbook of Narratology, Hamburg 2012, 1. [http://www.lhn.uni-hamburg.de]

Keller, Carl-A.: ברך, in: THAT 1 (1971) 353-376.

Ketter, Peter: Die Psalmen, Stuttgart ${ }^{4} 1949$.

Kittel, Rudolf D.: Die Psalmen, KAT 13, Leipzig ${ }^{2} 1914$.

Kirkpatrick, Alexander F.: The Book of Psalms, Grand Rapids / Michigan 1982.

Kissane, Edward J.: The Book of Psalms. Translated from a Critically Revised Hebrew Text. With a Commentary, Volume 1 (Psalms 1-72), Dublin 1953.

Kleer, Martin: »Der liebliche Sänger der Psalmen Israels«, BBB 108, Bodenheim 1996.

Kneepkens, E.W.E.M / Zwaan, Rolf A.: Emotions and Literary Text Comprehension, in: Poetics 23 (1994) 125-138.

Knierim, Rolf P.: wָוֹ, in: THAT 1 (1971) 81-84.

Knipping, Burkhart: שבר: in: ThWAT 7 (1993) 1027-1040.

Koenen, Klaus: Wasserversorgung, in: Bauks, Michaela / Koenen, Klaus (Hg.): Das wissenschaftliche Bibellexikon im Internet, Stuttgart 2010. [http://www.bibelwissenschaft. de/stichwort/14617]

Kohler-Spiegel, Helga: Emotionen - Schlaglichter auf ein schillerndes Phänomen, in: KatBl 132 (2007) 8-12. 
Koppe, Franz: Sprache und Bedürfnis. Zur sprachphilosophischen Grundlage der Geisteswissenschaften, problemata 56, Stuttgart 1977.

Köckert, Matthias: Zeit und Ewigkeit in Psalm 90, in: Kratz, Reinhard G. (Hg.): Zeit und Ewigkeit als Raum göttlichen Handelns. Religionsgeschichtliche, theologische und philosophische Perspektiven, BZAW 390, Berlin u. a. 2009, 155-185.

Koehler, Ludwig / Baumgartner, Walter: Hebräisches und Aramäisches Lexikon zum Alten Testament, Leiden ${ }^{3} 1967 \mathrm{ff}$. (HALAT 1-4)

Köller, Wilhelm: Perspektivität und Sprache. Zur Struktur von Objektivierungsformen in Bildern, im Denken und in der Sprache, Berlin 2004.

Kraft, Charles F.: The Strophic Structure of Hebrew Poetry. As Illustrated in the First Book of the Psalter, Chicago 1938.

Kraus, Hans-Joachim: Psalmen. 1. und 2. Teilband, BKAT 15/1.2, Neukirchen-Vluyn ${ }^{5} 1978$.

Krause, Martin: Hebräisch. Biblisch-hebräische Unterrichtsgrammatik, hrsg. von Michael Pietsch und Martin Rösel, Berlin 2008.

Krinetzki, Leo: Psalm 30 (29) in stilistisch-exegetischer Betrachtung, in: ZKTh 83 (1961) 345-360.

Kronholm, Tryggre: נדח, in: ThWAT 5 (1986) 254-260.

Kronholm, Tryggre: נעם , in: ThWAT 5 (1986) 500-506.

Kruger, Paul A.: A Cognitive Interpretation of the Emotion of Fear in the Hebrew Bible, in: JNSL 27 (2001) 77-89.

Kruger, Paul A.: On Emotions and the Expression of Emotions in the Old Testament: A Few Introductory Remarks, in: BZ 48 (2004) 213-228.

Krüger, Thomas: Psalm 90 und die »Vergänglichkeit des Menschen«, in: Bib. 75 (1994) 191219.

Kuckhoff, Antonius: Psalm 6 und die Bitten im Psalter. Ein paradigmatisches Bitt- und Klagegebet im Horizont des Gesamtpsalters, BBB 160, Göttingen 2011.

Kugel, James: The Jubilees Apocalypse, in: DSD 1 (1994) 322-337.

Kumpmann, Christina: Schöpfen, Schlagen, Schützen. Eine semantische, thematische und theologische Untersuchung des Handelns Gottes in den Psalmen, BBB 177, Göttingen 2016.

Kuntz, J. Kenneth: Continuing the Engagement: Psalms Research Since the Early 1990s, in: CBR 10 (2012) 321-378.

Labahn, Antje: Wild Animals and Chasing Shadows. Animal Metaphors in Lamentations as Indicators for Individual Threat, in: Van Hecke, Pierre (Hg.): Metaphor in the Hebrew Bible, BETL 187, Leuven 2005, 67-97.

Labuschagne, Casper J.: קרא, in: THAT 2 (1976) 666-674.

Lakoff, George / Johnson, Mark: Metaphors We Live By, Chicago / London 1980.

Lamparter, Helmut: Das Buch der Psalmen 1-2, BAT 14.15, Stuttgart ${ }^{2} 1961 .{ }^{2} 1965$.

Lämmlin, Georg: Die Lust am Wort und der Widerstand der Schrift. Homiletische ReLektüre des Psalters, Heidelberger Studien zur Praktischen Theologie 4, Münster u. a. 2002.

Leuenberger, Martin: Konzeptionen des Königtums Gottes im Psalter. Untersuchungen zu Komposition und Redaktion der theokratischen Bücher IV-V im Psalter, AThANT 83, Zürich 2004.

Levinson, Jerrold: Emotion in Response to Art. A Survey of the Terrain, in: Hjort, Mette / Laver, Sue (Hg.): Emotion and the Arts, New York / Oxford 1997, 20-34. 
Liebert, Wolf-Andreas: Metaphernforschung, in: Fix, Ulla u. a. (Hg.): Rhetorik und Stilistik: ein internationales Handbuch historischer und systematischer Forschung, HSK 31/1, Berlin u. a. 2008, 743-757.

Liedke, Gerhard: ישר, in: THAT 1 (1971) 790-794.

Liess, Kathrin: Sättigung mit langem Leben. Vergänglichkeit, Lebenszeit und Alter in den Psalmen 90-92, in: Bauks, Michaela u. a. (Hg.): Was ist der Mensch, dass du seiner gedenkst? (Psalm 8,5). Aspekte einer theologischen Anthropologie. FS für Bernd Janowski zum 65. Geburtstag, Neukirchen-Vluyn 2008, 329-342.

Limburg, James: Psalms, WeBC, Louisville / Kentucky 2000.

Limburg, James: Quoth The Raven: Psalm 147 and the Environment, in: Strawn, Brent A. / Bowen, Nancy R. (Hg.): A God so Near. Essays on Old Testament Theology in Honor of Patrick D. Miller, Winona Lake / Indiana 2003, 101-111.

Lindström, Fredrik: Böse I (AT), in: NBL 1 (1991) 314-316.

Link, Christian: Die Theologie vor der »linguistischen Wende«, in: ders.: In welchem Sinne sind theologische Aussagen wahr? Zum Streit zwischen Glaube und Wissen, ThSt(B) 2, Neukirchen-Vluyn 2003, 131-139.

Linke, Angelika u. a.: Studienbuch Linguistik, Germanistische Linguistik 121, Tübingen ${ }^{4} 2001$.

Lipps, Theodor: Grundlegung der Ästhetik. Erster Teil, Hamburg 1903.

Lisowsky, Gerhard: Konkordanz zum hebräischen Alten Testament, Stuttgart ${ }^{3} 1993$.

Liwak, Rüdiger: Friede / Schalom, in: Bauks, Michaela / Koenen, Klaus (Hg.): Das wissenschaftliche Bibellexikon im Internet, Stuttgart 2011. [http://www.bibelwissenschaft. de/stichwort/26245/]

Loader, Alfred J.: Psalm 30 Read Twice and Understood Two Times, in: OTEs 16 (2003) 291308.

Lobsien, Eckhard: Theorie literarischer Illusionsbildung, Stuttgart 1975.

Loch, Wolfgang / Prinz, Wolfgang: Identifikation, in: HWPh 4 (1976) 138-144.

Loerbroks, Matthias: Weisung vom Zion. Biblisch-theologische Orientierungen für eine Kirche neben Israel, SKI 19, Berlin 2000.

Lohfink, Norbert: Lobgesänge der Armen. Studien zum Magnifikat, den Hodajot von Qumran und einigen späten Psalmen, SBS 143, Stuttgart 1990.

Lüdtke, Jana: Eine Frage der Empirie: Zum emotionalen Erleben bei der Rezeption von Stimmungsgedichten, in: Reents, Friederike / Meyer-Sickendiek (Hg.): Stimmung und Methode, Tübingen 2013, 119-138.

MacCormac, Earl R.: A Cognitive Theory of Metapher, Cambridge 1985.

Macrae, Andrea: You and I, Past and Present. Cognitive Processing of Perspective, in: DIEGESIS. Interdisciplinary E-Journal for Narrative Research 5 (2016) 64-80. [https:// www.diegesis.uni-wuppertal.de/index.php/diegesis/article/view/214/305; abgerufen am 22.8.2016]

Marböck, Johannes: Bilder und Psalmen, in: Linzer Bibelsaat 94 (2005) 21-24.

Marböck, Johannes: Psalmen / Psalmenbuch, in: HNBL (2009) 606-609.

Margolin, Uri: From Predicates to People like Us. Kinds of Readerly Engagement with Literary Characters, in: Eder, Jens / Jannidis, Fotis (Hg.): Characters in fictional worlds, Berlin 2010, 400-415.

Marti, Kurt: Die Psalmen. Annäherungen, Stuttgart ${ }^{2} 2010$.

Martin-Achard, Robert: ענה II in: THAT 2 (1976) 341-360. 
Matheus, Frank: Ein jegliches hat seine Zeit. Tempus und Aspekt im biblisch-hebräischen Verbalsystem, Kleine Untersuchungen zur Sprache des Alten Testaments und seiner Umwelt Beihefte 1, Kamen 2011.

Mayordomo-Marín, Moisés: Den Anfang hören. Leserorientierte Evangelienexegese am Beispiel von Matthäus 1-2, FRLANT 180, Göttingen 1998.

Mays, James L.: Psalms, Interp., Louisville 1994.

McCann, Clinton J.: The Book of Psalms. Introduction, Commentary, and Reflections, NIB 4, Nashville 1996.

McConville, Gordon: Happiness in the Psalms, in: De Villiers, Pieter G. / Pietersen, Lloyd K. (Hg.): The Spirit that Inspires. Perspectives on Biblical Spirituality, AcT(V) 15, Bloemfontein 2011, 81-100.

Mehling, Karin: Heute hier, morgen dort - Deixis und Anaphorik in der Deutschen Gebärdensprache (DGS). Analyse und Vergleich mit der deutschen Lautsprache, Nödlingen 2010.

Mellmann, Katja: Emotionalisierung - von der Nebenstundenpoesie zum Buch als Freund. Eine emotionspsychologische Analyse der Literatur der Aufklärungsepoche, Poetogenesis 4, Paderborn 2006.

Mellmann, Katja: Gefühlsübertragung? Zur Psychologie emotionaler Textwirkungen, in: Kasten, Ingrid (Hg.): Machtvolle Gefühle, Trends in Medieval Philology 24, Berlin u. a. 2010, 107-119.

Miall, David S. / Kuiken, Don: A Feeling for Fiction: Becoming What We Behold, in: Poetics 30 (2002) 221-241.

Michel, Diethelm: Tempora und Satzstellung in den Psalmen, Müllheim 1960.

Miller, Athanasius: Die Psalmen. Neu bearbeitet nach der 10. Auflage der Ecclesia Orans, Klosterneuburg 1934.

Mosis, Rudolf: גיל, in: ThWAT 1 (1973) 928-956.

Müller, Hans-Peter: Der 90. Psalm. Ein Paradigma exegetischer Aufgaben, in: ZThK 81 (1984) 265-285.

Müller, Hans-Peter: Formgeschichtliche und sprachliche Beobachtungen zu Psalm 30, in: ZAH 12 (1999) 192-201.

Müller, Hans-Peter: Sprachliche Beobachtungen zu Ps. XC 5F, in: VT 50 (2000) 394-400.

Müller, Hans-Peter:

Müller, Lutz: Identifikation, in: Wörterbuch der Analytischen Psychologie (2003) 186-187.

Müller-Zettelmann, Eva: Lyrik und Narratologie, in: Nünning, Vera / Nünning, Ansgar (Hg.): Erzähltheorie transgenerisch, intermedial, interdisziplinär, WVT-Handbücher zum literaturwissenschaftlichen Studium 5, Trier 2002, 129-153.

Müllner, Ilse: Gewalt im Hause Davids. Die Erzählung von Tamar und Amnon (2 Sam 13,122), HBS 13, Freiburg u. a. 1997.

Müllner, Ilse: Wie sind wir gemeint? Überlegungen zur identifikatorischen Lektüre biblischer Texte, in: BiKi 71 (2016) 17-23.

Müllner, Ilse: Zeit, Raum, Figuren, Blick. Hermeneutische und methodische Grundlagen der Analyse biblischer Erzähltexte, in: PZB 15 (2006) 1-24.

Münderlein, Gerhard: חבש:, in: ThWAT 3 (1982) 726-730.

Münderlein, Gerhard: חלֶ, in: ThWAT 2 (1977) 957-958.

Nasatu, Harry P.: Historical Narrative and Identity in the Psalms, in: HBT 32 (2001) 132153. 
Nielsen, Kirsten: The Variety of Metaphors about God in the Psalter: Deconstruction and Reconstruction?, in: SJOT 16 (2002) 151-159.

Nötscher, Friedrich: Die Psalmen, EB, Würzburg 1962.

Nünning, Vera / Nünning, Ansgar: Produktive Grenzüberschreitungen: Transgenerische, intermediale und interdisziplinäre Ansätze in der Erzähltheorie, in: dies. (Hg.): Erzähltheorie transgenerisch, intermedial, interdisziplinär, WVT-Handbücher zum literaturwissenschaftlichen Studium 5, Trier 2002, 1-21.

Nysse, Richard: The Dark Side of God: Considerations for Preaching and Teaching, in: WorWor 17 (1997) 437-446.

Oatley, Keith: A Taxonomy of the Emotions of Literary Response and a Theory of Identification in Fictional Narrative, in: Poetics 23 (1994) 53-74.

Oatley, Keith / Gholamain, Mitra: Emotions and Identification. Connections between Readers and Fiction, in: Hjort, Mette / Laver, Sue (Hg.): Emotion and the Arts, New York / Oxford 1997, 263-281.

Oeming, Manfred: Das Buch der Psalmen: Psalm 1-41, NSK.AT 13/1, Stuttgart 2000.

Oeming, Manfred / Vette, Joachim: Das Buch der Psalmen. Psalm 42-89, NSK.AT 13/2, Stuttgart 2010.

Oeming, Manfred / Vette, Joachim: Das Buch der Psalmen. Psalm 90-151, NSK.AT 13/3, Stuttgart 2016.

Oikonomou, E. B.: לין, in: ThWAT 4 (1984) 562-567.

Otzen, Benedikt: בהלו, in: ThWAT 1 (1973) 520-523.

Otzen, Benedikt: inמָ in: ThWAT 6 (1989) 213-220.

Patrick, Dale / Diable, Kenneth: Persuading the One and Only God to Intervene, in: Foster, Robert / Howard, David (Hg.): »My Words are Lovely«. Studies in the Rhetoric of the Psalms, LHB 467, New York 2008, 19-32.

Petsch, Robert: Einleitung, in: ders. (Hg.): Lessings Briefwechsel mit Mendelsohn und Nicolai über das Trauerspiel, Leipzig 1910, 9-55.

Peetz, Melanie: Emotionen im Hohelied. Eine literaturwissenschaftliche Analyse hebräischer Liebeslyrik unter Berücksichtigung geistlich-allegorischer Auslegungsversuche, HBS 81, Freiburg u. a. 2015.

Pohl-Patalong, Uta: Zugänge zur Bibel, Bibel verstehen, Freiburg u. a. 2013.

Plutchik, Robert: Plutchiks Rad der Emotionen in: http://de.wikipedia.org/wiki/Robert Plutchik [abgerufen am 30.4.2015].

Pragglejaz Group: A Practical and Flexible Method for Identifying Metaphorically Used Words in Discourse, in: Metaphor and Symbol 23 (2007) 1-39.

Preuß, Horst-Dietrich: מעוֹע, in: ThWAT 4 (1984) 1027-1030.

Preuß, Horst-Dietrich: יבש

Pusch, Luise F.: Weibliches Schicksal aus männlicher Sicht. Über Syntax und Empathie, in: dies.: Deutsch als Männersprache. Aufsätze und Glossen zur feministischen Linguistik, Frankfurt am Main 1984, 109-128.

Radebach-Huonker, Christiane: Opferterminologie im Psalter, FAT2./44, Tübingen 2010.

Rapp, Ursula: Vom Mut, das Schweigen auszuhalten. LeserInnen als Co-KonstrukteurInnen von Sinn, in: Österreichisches Religionspädagogisches Forum 20 (2012) 13-16.

Reemts, Christiana: Schriftauslegung. Die Psalmen bei den Kirchenvätern, NSK.AT 33/6, Stuttgart 2000. 
Reif, Stefan C. / Egger-Wenzel, Renate (Hg.): Ancient Jewish Prayers and Emotions. Emotions Associated with Jewish Prayer in and around the Second Temple Period, DCLS 26, Berlin / Boston 2015.

Richter, Matthias: Wirkungsästhetik, in: Arnold, Heinz Ludwig / Deternig, Heinrich (Hg.): Grundzüge der Literaturwissenschaft, München ${ }^{3} 1999$, 517-535.

Richter, Wolfgang: Biblia Hebraica transcripta, 11. Psalmen, ATSAT 33/11, St. Ottilien 1993. (BHt 11)

Ricœur, Paul: Stellung und Funktion der Metapher in der biblischen Sprache, in: ders. I Jüngel, Eberhard: Metapher. Zur Hermeneutik religiöser Sprache, München 1974, 4570.

Ridderbos, Nic. H.: Die Psalmen. Stilistische Verfahren und Aufbau. Mit besonderer Berücksichtigung von Ps 1-41, BZAW 117, Berlin u. a. 1972.

Riede, Peter: »Der Gerechte wird wachsen wie eine Zeder auf dem Libanon« (Ps 92,13) Pflanzenmetaphorik in den Psalmen, in: Mell, Ulrich (Hg.): Pflanzen und Pflanzensprache der Bibel. Erträge des Hohenheimer Symposions vom 26. Mai 2004, Frankfurt am Main u. a. 2006, 39-64.

Riede, Peter: Im Netz des Jägers. Studien zur Feindmetaphorik der Individualpsalmen, WMANT 85, Neukirchen-Vluyn 2000.

Riede, Peter: Jenseitsvorstellungen (AT), in: Bauks, Michaela / Koenen, Klaus (Hg.): Das wissenschaftliche Bibellexikon im Internet, Stuttgart 2014. [http://www.bibelwissen schaft.de/stichwort/33830/]

Rilke, Rainer M.: Briefe an seinen Verleger, Leipzig 1934.

Ringgren, Helmer: היב, in: ThWAT 1 (1973) 228-235.

Ringgren, Helmer: הלב in: ThWAT 2 (1977) 43-441.

Ringgren, Helmer: פַּ, in: ThWAT 4 (1984) 130-137.

Ringgren, Helmer: מרת, in: ThWAT 5 (1986) 16-20.

Ringgren, Helmer: רשער, in: ThWAT 7 (1993) 675-684.

Risse, Siegfried: »Gut ist es, unserem Gott zu singen. «Untersuchungen zu Psalm 147, seiner Einbindung in das Schluß-Hallel und seinem Verständnis in der jüdischen und christlichen Tradition, MThA 37, Altenberge 1995.

Robertson, David: Literary Criticism of the Bible: Psalm 90 and Shelley's »Hymn to Intellectual Beauty«, in: Semeia 8 (1977) 35-50.

Rogerson, John W./ McKay, John W.: Psalms 1-50; 51-100 und 101-150, CNEB, Cambridge u. a. 1977.

Ruprecht, Eberhard: שמשח, in: THAT 2 (1976) 828-835.

Ruwe, Andreas: Die Psalmen zum Betrachten, Studieren und Vorlesen. Eine textanalytische Übersetzung von Andreas Ruwe, Zürich 2012.

Rüterswörden, Udo: רהב, in: ThWAT 7 (1993) 372-378.

Sandig, Barbara: Sprachliche Perspektivierung und perspektivierende Stile, in: Zeitschrift für Literaturwissenschaft und Linguistik 102 (1996) 36-63.

Sarna, Nahum M.: Halleluja, in: EJ $8^{2}$ (2007) 280.

Sauer, Georg: §ֵ, in: THAT 1 (1971) 220-224.

Sauer, Georg: in: in: THAT 1 (1971) 581-583.

Sauer, Georg: נצר , in: THAT 2 (1976) 99-101.

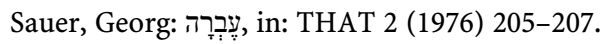

Scharbert, Josef: ברך, in: ThWAT 1 (1973) 808-841. 
Scharbert, Josef: ספד, in: ThWAT 5 (1986) 901-906.

Schlaffer, Heinz: Die Aneignung von Gedichten. Grammatisches, rhetorisches und pragmatisches Ich in der Lyrik, in: Poetica 27 (1995) 38-57.

Schlaffer, Heinz: Geistersprache. Zweck und Mittel der Lyrik, München 2012.

Schlimm, Matthew R.: From Fratricide to Forgiveness. The Language and Ethics of Anger in Genesis, Siphrut 7, Winona Lake / Indiana 2011.

Schlögl, Nivard: Die Psalmen. Hebräisch und Deutsch mit einem kurzen wissenschaftlichen Kommentar, Graz / Wien 1911.

Schmid, Wolf: Elemente der Narratologie, Berlin u. a. ${ }^{2} 2008$.

Schmidt, Hans: Die Psalmen, HAT 1/15, Tübingen 1934.

Schmidt, Uta: Zentrale Randfiguren. Strukturen der Darstellung von Frauen in den Erzählungen der Königebücher, Gütersloh 2003.

Schmidt, Werner H.: »Der Du die Menschen lässest sterben«. Exegetische Anmerkungen zu Ps 90, in: Crüsemann, Frank u. a. (Hg.): Was ist der Mensch ...? Beiträge zur Anthropologie des Alten Testaments, München 1992, 115-130.

Schneider, Ralf: Grundriß zur kognitiven Theorie der Figurenrezeption am Beispiel des viktorianischen Romans, Zeitschrift für Anglistik und Amerikanistik Studies 9, Tübingen 2000.

Schneider, Wolfgang: Grammatik des Biblischen Hebräisch. Völlig neue Bearbeitung der »Hebräischen Grammatik für den akademischen Unterricht» von Oskar Grether. Ein Lehrbuch, München 1974.

Schnocks, Johannes: »Ehe die Berge geboren wurden, bist du. « Die Gegenwart Gottes im 90. Psalm, in: BiKi 54 (1999) 163-169.

Schnocks, Johannes: Psalmen, UTB 3473 Grundwissen Theologie, Paderborn 2014.

Schnocks, Johannes: Vergänglichkeit und Gottesherrschaft. Studien zu Psalm 90 und dem vierten Psalmenbuch, BBB 140, Berlin 2002.

Scholz, Manfred G. / Burgdorf, Dieter: Identifikation, in: Metzler Lexikon Literatur ${ }^{3}$ (2007) 339.

Schönau, Walter / Pfeiffer, Joachim: Einführung in die psychoanalytische Literaturwissenschaft, Stuttgart u. a. ${ }^{2} 2003$.

Schönert, Jörg u. a.: Lyrik und Narratologie. Text-Analysen zu deutschsprachigen Gedichten des 16. bis zum 20. Jahrhundert, Narratologia 11, Berlin 2007.

Schouten, Sabine: Sinnliches Spüren. Wahrnehmung und Erzeugung von Atmosphären im Theater, Theater der Zeit Recherchen 46, Berlin ${ }^{2} 2011$.

Schram, Dick H.: Norm und Normbrechung. Die Rezeption literarischer Texte als Gegenstand empirischer Forschung. Aus dem Niederländischen übersetzt von Harry Verschuren, Konzeption Empirische Literaturwissenschaft 13, Braunschweig 1991.

Schreier, Margit: Textwirkungen, in: Anz, Thomas (Hg.): Handbuch Literaturwissenschaft. Bd. 1: Gegenstände und Grundbegriffe, Stuttgart 2007, 193-202.

Schreiner, Stefan: Erwägungen zur Struktur des 90. Psalms, in: Bib. 59 (1978) 80-90.

Schreiner, Josef: עָּו in: ThWAT 5 (1986) 1135-1144.

Schroer, Silvia: Tanz, in: NBL 3 (2001) 779-781.

Schroer, Silvia / Staubli, Thomas: Biblische Emotionswelten, in: KatBl 132 (2007) 44-49. Schroer, Silvia / Staubli, Thomas: Die Körpersymbolik der Bibel, Darmstadt 1998.

Schunck, Klaus-Dietrich: חָָדָ, in: ThWAT 2 (1977) 1032-1036.

Schunck, Klaus-Dietrich: עִבְרָה in: ThWAT 5 (1986) 1033-1039. 
Schweizer, Harald: Biblische Texte verstehen. Arbeitsbuch zur Hermeneutik und Methodik der Bibelinterpretation, Stuttgart u. a. 1986.

Schwertner, Siegfried: iָָָׁ in: THAT 2 (1976) 332-335.

Sedlmeier, Franz: Jerusalem - Jahwes Bau. Untersuchungen zu Komposition und Theologie von Psalm 147, FB 79, Würzburg 1996.

Seiler, Stefan: Text-Beziehungen. Zur intertextuellen Interpretation alttestamentlicher Texte am Beispiel ausgewählter Psalmen, BWANT 202, Stuttgart 2013.

Seebass, Horst J., נֶֶֶ, in: ThWAT 5 (1986) 532-555.

Seybold, Klaus: Die Psalmen, HAT 1/15, Tübingen 1996.

Seybold, Klaus: Poetik der erzählenden Literatur im Alten Testament, Poetologische Studien zum Alten Testament 2, Stuttgart 2006.

Seybold, Klaus: Poetik der Psalmen, Poetologische Studien zum Alten Testament 1, Stuttgart 2003.

Seybold, Klaus: Psalm 90 und die Theologie der Zeit (Zeiten), in: ders.: Studien zu Sprache und Stil der Psalmen, BZAW 415, Berlin u. a. 2010, 129-143.

Seybold, Klaus: Zu den Zeitvorstellungen in Psalm 90, in: ThZ 53 (1997) 97-108.

Seybold, Klaus: Zur neueren Psalmenforschung, in: ders.: Studien zur Psalmenauslegung, Stuttgart u. a. 1998, 9-74.

Sieben, Hermann Josef: Athanasius über den Psalter. Analyse seines Briefes an Marcellinus, in: ThPh 48 (1973) 157-173.

Sieben, Hermann Josef: Schlüssel zum Psalter. Sechzehn Kirchenväter-Einführungen, Paderborn u. a. 2011.

Simian-Yofre, Horacio: נחם, in: ThWAT 5 (1986) 366-384.

Smith, Mark: The Heart and Innards in Israelite Emotional Expressions: Notes from Anthropology and Psychobiology, in: JBL 117 (1998) 427-436.

Sommer, Roy: Erzählung/Erzählen/Erzähler. V. Literaturwissenschaftlich, in: LBH (2013) 162-163.

Sommer, Roy: Funktionsgeschichten. Überlegungen zur Verwendung des Funktionsbegriffs in der Literaturwissenschaft und Anregungen zu seiner terminologischen Differenzierung, in: LWB 41 (2000) 319-341.

Spieckermann, Hermann: Heilsgegenwart. Eine Theologie der Psalmen, FRLANT 148, Göttingen 1989.

Staubli, Thomas: Begleiter durch das Erste Testament, Düsseldorf ${ }^{2} 1999$.

Stähli, Hans-Peter: ריא, in: THAT 1 (1971) 765-778.

Stähli, Hans-Peter: רום, in: THAT 2 (1976) 753-761.

Steen, Gerard: From Linguistic Form to Conceptual Structure in Five Steps: Analyzing Metaphor in Poetry, in: Brône, Geert / Vandaele, Jeroen (Hg.): Cognitive Poetics: Goals, Gains and Gaps, Applications of Cognitive Linguistics 10, Berlin u. a. 2009, 197-226. Steins, Georg: ציץ: ThWAT 6 (1989) 1028-1034.

Steussy Marti J.: The Enemy in the Psalms, in: WorWor 28 (2008) 5-12.

Stoebe, Hans Joachim: חסק, in: THAT 1 (1971) 600-621.

Stoebe, Hans Joachim: נחם in: THAT 2 (1976) 59-66.

Stoebe, Hans Joachim: רפא, in: THAT 2 (1976) 803-809.

Stolz, Fritz: בכה, in: THAT 1 (1971) 313-316. 
Strolz, Walter: Psalm 90. Gabe und Last der Zeit, in: ders. (Hg.): Aus den Psalmen leben. Das gemeinsame Gebet von Kirche und Synagoge neu erschlossen, Freiburg u. a. 1979, 146160.

Stuhlmueller, Carroll: Psalms 1-2, OTMes 21.22, Wilmington / Delaware 1983.

Tan, Ed S.-H.: Film-Induced Affect as Witness Emotion, in: Poetics 23 (1994) 7-23.

Tanaka, Shin: Deixis und Anaphorik. Referenzstrategien in Text, Satz und Wort, Linguistik - Impulse und Tendenzen 42, Berlin u. a. 2011.

Tate, Marvin E.: Psalms 51-100, WBC 20, Dallas 1990.

Tengström, Sven: in: ThWAT 2 (1977) 999-1002.

Terrien, Samuel: The Psalms. Strophic Structure and Theological Commentary, ECCo 4, Grand Rapids / Cambridge 2003.

Thalhofer, Valentin: Erklärung der Psalmen und der im römischen Brevier vorkommenden biblischen Cantica, mit besonderer Rücksicht auf deren liturgischen Gebrauch, Regensburg ${ }^{9} 1923$.

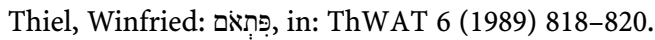

Thiel, Winfried:

Thöne, Yvonne Sophie: Stay in the Desert, Prowl in the City. A Narratological Analysis of Psalm 55, in: Ólason, Kristinn u. a. (Hg.): Mótun Menningar. Shaping Culture (Festschrift Gunnlaugur A. Jónsson), Reykjavík 2012, 55-73.

Thöne, Yvonne Sophie: Liebe zwischen Stadt und Feld. Raum und Geschlecht im Hohelied, Exegese in unserer Zeit 22, Berlin u. a. 2012.

Titchener, Edward: Lectures on the Experimental Psychology of the Thought-Processes, New York 1909.

Tsevat, Matitiahu: Psalm XC 5-6, in: VT 35 (1985) 115-116.

Tucker, W. Dennis: Exitus, Reditus, and Moral Formation in Psalm 90, in: Burnett, Joel S. u. a. (Hg.): Diachronic and Synchronic. Reading the Psalms in Real Time: Proceeding of the Baylor Symposium on the Book of Psalms, LHB 488, New York u. a. 2007, 143154.

Turner, Mark: Death is the Mother of Beauty: Mind, Metaphor, Criticism, Chicago 1987. Utzschneider, Helmut: Zur vierfachen Lektüre des Alten Testaments. Bibelrezeption als Erfahrung von Diskrepanz und Perspektive, in: Bartelmus, Rüdiger u. a. (Hg.): Konsequente Traditionsgeschichte. Festschrift für Klaus Baltzer zum 65. Geburtstag, OBO 126, Freiburg / Schweiz 1993, 383-401.

Urbanz, Werner: Gebet im Sirachbuch. Zur Terminologie von Klage und Lob in der griechischen Texttradition, HBS 60, Freiburg u. a. 2009.

Van Alphen, Ernst: Affective Operations of Art and Literature, in: Res: Anthropology and Aesthetics 53/54 (2008) 21-30.

Van der Woude, Adam S.: קזr, in: THAT 1 (1971) 538-541.

Van Dyke Parunak, H.: A Semantic Survey of NHM, in: Bib. 56 (1975) 512-532.

Van Grol, Harm: Emotions in the Psalms, in: Egger-Wenzel, Renate / Corley, Jeremy (Hg.): Emotions from Ben Sira to Paul, Deuterocanonical and Cognate Literatur. Yearbook 2001, Berlin u. a. 2011, 69-102.

Van Hecke, Pierre (Hg.): Metaphor in the Hebrew Bible, BETL 187, Leuven 2005.

Van Hecke, Pierre / Labahn, Antje (Hg.): Metaphors in the Psalms, BETL 231, Leuven 2010. Van Leeuwen, Raymond C.: רשע, in: THAT 2 (1976) 813-818. 
Van Wolde, Ellen: Sentiments as Culturally Constructed Emotions: Anger and Love in the Hebrew Bible, in: BibInt 16 (2008) 1-24.

Vanoni, Gottfried: שמח, in: ThWAT 7 (1993) 808-822.

Vawter, Bruce: Postexilic Prayer and Hope, in: CBQ 37 (1975) 460-470.

Vellusig, Robert: Die Sinnenhaftigkeit der Poesie. Eine Wahrnehmungspsychologie literarischer Texte, in: Sprachkunst: Beiträge zur Literaturwissenschaft 31 (2001) 361-367.

Vischer, Robert: Ueber das optische Formgefühl. Ein Beitrag zur Aesthetik, Leipzig 1873.

Viviers, Hennie: Why is Psalm 147 still »Cathy«?, in: Foster, Robert L. / Howard, David M. (Hg.): »My Words are Lovely«. Studies in the Rhetoric of the Psalms, LHB 467, New York 2008, 171-186.

Von Rad, Gerhard: Der 90. Psalm, in: Steck, Odil Hannes (Hg.): Gottes Wirken in Israel. Vorträge zum Alten Testament, Neukirchen 1974, 268-283.

Vosberg, Lothar: Studien zum Reden vom Schöpfer in den Psalmen, BEvTh 69, München 1975.

Wächter, Ludwig: Drei umstrittene Psalmstellen (Ps 26,1; 30,8; 90,4-6), in: ZAW 78 (1966) 61-69.

Wächter, Ludwig: שַָָׁ, in: ThWAT 7 (1993) 1245-1248.

Wagner, Andreas: Der Parallelismus membrorum zwischen poetischer Form und Denkfigur, in: ders.: Beten und Bekennen. Über Psalmen, Neukirchen-Vluyn 2008, 235-261.

Wagner, Andreas: Emotionen, Gefühle und Sprache im Alten Testament. Vier Studien, Kleine Untersuchungen zur Sprache des Alten Testaments und seiner Umwelt 7, Waltrop 2006.

Wagner, Andreas: Emotionen in alttestamentlicher und verwandter Literatur - Grundüberlegungen am Beispiel des Zorns, in: Egger-Wenzel, Renate / Corley, Jeremy (Hg.): Emotions from Ben Sira to Paul, Deuterocanonical and Cognate Literatur. Yearbook 2001, Berlin u. a. 2011, 27-68.

Wagner, Andreas: Gottes Konturen in der Sprache. Körper und Emotionen Gottes in Psalmen und Kirchenliedern, in: ders.: Beten und Bekennen. Über Psalmen, Neukirchen-Vluyn 2008, 266-287.

Wagner, Andreas: Sprechakte und Sprechaktanalyse im Alten Testament. Untersuchungen im biblischen Hebräisch an der Nahtstelle zwischen Handlungsebene und Grammatik, BZAW 253, Berlin u. a. 1997.

Wagner, Andreas: Sprechen zu Gott - Sprechen über Gott, in: ders.: Beten und Bekennen. Über Psalmen, Neukirchen-Vluyn 2008, 3-20.

Wagner, Siegfried: נצר, in: ThWAT 5 (1986) 577-587.

Wagner, Siegfried: סתר, in: ThWAT 5 (1986) 967-977.

Wahl, Harald-Martin: Psalm 90,12: Text, Tradition und Interpretation, in: ZAW 106 (1994) 116-123.

Wahl, Heribert: Empathie und Text. Das selbstpsychologische Modell interaktiver Texthermeneutik, in: ThQ 169 (1989) 201-222.

Wallace, Howard N.: Psalms, Sheffield 2009.

Wallace, Robert E.: The Narrative Effect of Psalms 84-89, in: JHS 11 (2011) 1-15. (Wallace, The Narrative Effect)

Wallace, Robert E.: The Narrative Effect of Book IV in the Hebrew Bible, Studies in Biblical Literature 112, New York u. a. 2007. (Wallace, Narrative Effect) 
Wälchli, Stefan H.: Gottes Zorn in den Psalmen. Eine Studie zur Rede vom Zorn Gottes in den Psalmen im Kontext des Alten Testaments und des Alten Orients, OBO 244, Fribourg / Göttingen 2012.

Waltke, Bruce K. / O’Connor, Michael P.: An Introduction to Biblical Hebrew Syntax, Winona Lake 1990.

Walton, Kendall: Thoughtwriting - in Poetry and Music, in: New Literary History 42 (2001) 455-476.

Warmuth, Georg: הדזָד, in: ThWAT 2 (1977) 357-363.

Warmuth, Georg: שבע:, in: ThWAT 7 (1993) 693-704.

Watson, Wilfred G. E.: Classical Hebrew Poetry. A Guide to its Techniques, JSOTS 26, Sheffield 1984.

Watson, Wilfred G. E.: Hebrew Poetry, in: Mayes, Andrew D. H. (Hg.): Text in Context. Essays by Members of the Society for Old Testament Study, Oxford 2000, 253-285.

Weber, Beat: Bibliographie zu Psalmen und Psalter, in: https://bienenberg.academia.edu/ BeatWeber [abgerufen am 18.06.2015].

Weber, Beat: Psalm 30 als Paradigma für einen heutigen »Kasus der Wiederherstellung«. Überlegungen zu einer Schnittstelle zwischen Altem Testament und kirchlichem Handeln im Blick auf eine Theologie und Praxis der Dankbarkeit, in: JETh 21 (2007) 3150 .

Weber, Beat: Werkbuch Psalmen 1. Die Psalmen 1 bis 72, Stuttgart u. a. 2001.

Weber, Beat: Werkbuch Psalmen 2. Die Psalmen 73 bis 150, Stuttgart 2003.

Weber, Beat: Werkbuch Psalmen 3. Theologie und Spiritualität des Psalters und seiner Psalmen, Stuttgart 2010.

Wehmeier, Gerhard: עלה, in: THAT 2 (1976) 272-290.

Wehmeier, Gerhard: סתרה, in: THAT 2 (1976) 174-181.

Wehmeier, Gerhard / Vetter, Dieter: הָדָר: in: THAT 1 (1971) 469-472.

Weiser, Artur: Die Psalmen. 1. Teil. ATD 14, Göttingen ${ }^{9} 1979$.

Weiser, Artur: Die Psalmen. 2. Teil. ATD 15, Göttingen 1950.

Wenham, Gordon J.: Psalms as Torah. Reading Biblical Song Ethically, Grand Rapids 2012. Westermann, Claus: Der 90. Psalm, in: ders.: Forschung am Alten Testament. Gesammelte Studien 1, München 1964, 344-350.

Westermann, Claus: הלל, in: THAT 1 (1971) 493-502.

Westermann, Claus: ידה: in: THAT 1 (1971) 674-682.

Westermann, Claus: נֶפטּה in: THAT 2 (1976) 71-95.

Willenberg, Heiner: Zur Psychologie literarischen Lesens. Wahrnehmung, Sprache und Gefühle, Informationen zur Sprach- und Literaturdidaktik 15, Paderborn 1978.

Wilson, Gerald H.: Psalms - Volume 1. The NIV Application Commentary, Grand Rapids / Michigan 2002.

Winko, Simone: Kodierte Gefühle. Zu einer Poetik der Emotionen in lyrischen und poetologischen Texten um 1900, Allgemeine Literaturwissenschaft - Wuppertaler Schriften 7, Berlin 2003.

Witte, Markus: Schriften, in: Gertz, Jan Ch. (Hg.): Grundinformation Altes Testament. Eine Einführung in Literatur, Religion und Geschichte des Alten Testaments, UTB 2745, Göttingen ${ }^{2} 2007,404-508$. 
Witzenrath, Hagia: Am Abend Weinen - doch am Morgen Jubel. Ps 30 - ein alter Osternachtspsalm der Kirche, in: Becker, Hans Jakob u. a. (Hg.): Liturgie und Dichtung. Ein interdisziplinäres Kompendium 2, PiLi 2, St. Ottilien 1983, 447-495.

Wolf, Werner: Ästhetische Illusion und Illusionsdurchbrechung in der Erzählkunst. Theorie und Geschichte mit Schwerpunkt auf englischem illusionsstörenden Erzählen, Buchreihe der Anglia Zeitschrift für Englische Philologie 32, Tübingen 1993.

Wolff, Hans Walter: Anthropologie des Alten Testaments, Gütersloh ${ }^{6} 1994$.

Wutz, Franz: Die Psalmen. Textkritisch untersucht, München 1925.

Yoder, Christine R.: The Objects of our Affections: Emotions and the Moral Life in Proverbs 1-9, in: dies. / O'Connor, Kathleen M. (Hg.): Shaking Heaven and Earth, Westminster 2005, 73-88.

Zenger, Erich: »Dem vergänglichen Werk unserer Hände gib du Bestand!«. Ein theologisches Gespräch mit dem 90. Psalm, in: Panikkar, Raimundo (Hg.): Die Verantwortung des Menschen für eine bewohnbare Welt im Christentum, Hinduismus und Buddhismus, Weltgespräch der Religionen 12, Freiburg u. a. 1985, 11-36.

Zenger, Erich: Der Psalter - Das Gebetbuch der Bibel, in: Communio 37 (2008) 547-559.

Zenger, Erich: Die Nacht wird leuchten wie der Tag. Psalmenauslegungen, Freiburg u. a. 1997.

Zenger, Erich: Die Psalmen, in: ders. (Hg.): Stuttgarter Altes Testament. Einheitsübersetzung mit Kommentar und Lexikon, Stuttgart ${ }^{3} 2005$, 1036-1219.

Zenger, Erich: »Du thronst auf den Psalmen Israels« (Ps 22,4). Von der Unverzichtbarkeit der jüdischen Psalmen im christlichen Gottesdienst, in: Kranemann, Benedikt / Sternberg, Thomas (Hg.): Wie das Wort Gottes feiern? Der Wortgottesdienst als theologische Herausforderung, QD 194, Freiburg u. a. 2002, 16-40.

Zenger, Erich: Ein Gott der Rache? Feindpsalmen verstehen, Freiburg u. a. 1994.

Zenger, Erich: Ich will die Morgenröte wecken. Psalmenauslegungen, Freiburg u. a. 1991.

Zenger, Erich: Mit meinem Gott überspringe ich Mauern. Einführung in das Psalmenbuch, Freiburg u. a. ${ }^{2} 1988$.

Zenger, Erich: Psalmenexegese und Psalterexegese - eine Forschungsskizze, in: ders. (Hg.): The Composition of the Book of Psalms, BETL 238, Leuven 2010, 17-65.

Zenger, Erich: Theophanien des Königsgottes JHWH: Transformationen von Psalm 29 in den Teilkompositionen Ps 28-30 und Ps 93-100, in: Flint, Peter W. / Miller, Patrick D. (Hg.): The Book of Psalms. Composition and Reception, VTSup 99, Leiden u. a. 2005, 407-442.

Zillmann, Dolf: Empathy: Affect from Bearing Witness to the Emotions of Others, in: Bryant, Jennings / Zillmann, Dolf (Hg.): Responding to the Screen. Reception and Reaction Processes, Hillsdale 1991, 135-167.

Zimmermann, Ruben: Metapherntheorie und biblische Bildersprache. Ein methodologischer Versuch, in: ThZ 56 (2000) 108-133.

Zobel, Hans-Jürgen: 


\section{Internetadressen}

http://de.wikipedia.org/wiki/Geborgenheit [abgerufen am 18.5.2015].

http://en.wikipedia.org/wiki/Contrasting_and_categorization_of_emotions [abgerufen am 30.4.2015].

http://www.ccca.ac.at/de/apcc/ [abgerufen am 28.5.2015].

http://www.predigten.de/predigt.php3?predigt=6691 [abgerufen am 9.7.2015].

http://www.trauernetz.de/begleiten/13342.html [abgerufen am 9.7.2015]. 


\section{Anhang}

\section{Arbeitsübersetzung Psalm 30 353}

1 Ein Psalm. Ein Lied zur Einweihung des Hauses. Im Geiste Davids.

2a Ich will dich hochheben, JHWH,

$2 \mathrm{~b}$ denn du hast mich herausgeschöpft

2c und hast meine Feinde sich nicht freuen lassen über mich.

3a JHWH, mein Gott, ich schrie um Hilfe zu dir,

3b und du hast mich geheilt.

4a JHWH, du hast heraufgeholt aus dem Totenreich meine Lebenskraft,

$4 \mathrm{~b}$ du hast mich zum Leben gebracht weg von meinem Hinabsteigen zur Zisterne.

5a Singt/spielt für JHWH, ihr seine Getreuen,

$5 b$ und lobt zum Gedenken seiner Heiligkeit.

6a Denn ein Augenblick in seinem Zorn -

$6 \mathrm{~b}$ (ein) Leben (lang) in seinem Wohlgefallen.

6c Am Abend übernachtet Weinen,

6d aber zum Morgen hin (gilt): lauter Jubel.

7a Ich aber, ich habe gesagt in meiner Sicherheit:

7b Nicht werde ich ins Wanken gebracht auf ewig.

8a JHWH, in deinem Wohlgefallen

$8 \mathrm{~b}$ hast du aufgestellt für meinen Berg eine Kraft.

8c Du hast dein Angesicht verborgen,

8d ich war erschrocken.

9a Zu dir, JHWH, rief ich,

9b und zu Adonaj flehte ich um Erbarmen:

10a »Was für ein Gewinn (ist) an meinem Blut,

$10 \mathrm{~b}$ wenn ich in die Grube hinabsteige?

10c Wird dich loben Staub,

1353 Den Übersetzungen liegt der MT zugrunde, wie er in der BHS vorzufinden ist. Die Gliederung der Äußerungseinheiten folgt, ausgenommen von V3, Fokkelman, The Psalms in Form, 41 und - bis auf drei minimale Abweichungen in V1.10.11 - Richter, BHt 11, 98-100. 
10d wird er erzählen von deiner Treue?

11a Höre, JHWH, und sei mir gnädig,

11b JHWH, sei mir Hilfe.«

12a Verwandelt hast du meine Trauerklage in einen Tanz für mich,

$12 \mathrm{~b}$ geöffnet hast du mein Trauergewand

12c und mich umgürtet mit Freude.

13a Damit dich besinge Ehre

$13 \mathrm{~b}$ und nicht verstumme,

13c JHWH, mein Gott, auf ewig will ich dich loben.

\section{Arbeitsübersetzung Psalm 147-1. Variante ${ }^{1354}$}

1a Lobt JH!

1b Denn gut ist es, zu singen/spielen unserem Gott.

1c Ja, angenehm ist ein schöner Lobgesang.

2a Aufbauend JHWH Jerusalem,

$2 \mathrm{~b}$ die Verstoßenen Israels sammelt er.

3a Er heilend die zerbrochenen Herzens sind

$3 \mathrm{~b}$ und verbindend ihre schmerzenden Wunden.

4a Bestimmend eine Anzahl von Sternen,

$4 \mathrm{~b} \quad$ sie alle ruft er mit Namen.

5a Groß ist unser Adonaj

$5 b$ und reich an Stärke,

5c für seine Klugheit gibt es keine Anzahl.

6a Aufrichtend JHWH die Gebeugten,

$6 \mathrm{~b}$ erniedrigend die Frevler bis zum Boden.

7a Besingt JHWH mit einem Danklied,

$7 \mathrm{~b}$ spielt unserem Gott auf der Leier.

8a Er bedeckend den Himmel mit Wolken,

$8 \mathrm{~b}$ er bereitend der Erde Regen,

$8 \mathrm{c}$ er wachsen lassend auf Bergen Gras.

9a Gebend dem Tier seine Nahrung,

$9 \mathrm{~b}$ den jungen Raben, wonach sie rufen.

10a Nicht an der Stärke des Pferdes hat er Gefallen,

10b nicht an den Schenkeln des Mannes hat er Wohlgefallen.

11a Wohlgefallen habend JHWH an denen, die ihn fürchten,

$11 \mathrm{~b}$ an denen, die Wartenden auf seine Huld/Güte.

12a Rühme, Jerusalem, JHWH,

$12 \mathrm{~b}$ lobe deinen Gott, Zion.

13a Denn er hat stark gemacht die Riegel deiner Tore,

$13 \mathrm{~b}$ er hat gesegnet deine Kinder in deiner Mitte.

1354 Die Gliederung der Äußerungseinheiten folgt Fokkelman, The Psalms in Form, 152. 
14a Er verschaffend deiner Grenze Frieden,

14b mit bestem Weizen sättigt er dich.

15a Er sendend seine Rede auf die Erde,

15b sehr schnell eilt sein Wort.

16a Er gebend Schnee wie die Wolle,

16b Reif wie die Asche zerstreut er.

17a Werfend sein Eis wie Brocken,

17b vor seiner Kälte - wer kann bestehen?

18a Er sendet sein Wort und er/es lässt sie schmelzen,

$18 \mathrm{~b}$ er lässt wehen seinen Wind/Atem - es rinnen die Wasser.

19a Verkündend sein Wort Jakob,

19b seine Ordnungen und seine Rechtsbestimmungen Israel.

20a Nicht hat er so gehandelt an jedem Volk,

$20 \mathrm{~b}$ und die Rechtsbestimmungen haben sie nicht erkannt.

20c Lobt JH!

\section{Arbeitsübersetzung Psalm 147-2. Variante}

1a Lobt JH!

1b Denn gut ist es, zu singen/spielen unserem Gott.

1c Ja, angenehm ist ein schöner Lobgesang.

2a Aufbauend JHWH Jerusalem,

$2 \mathrm{~b}$ die Verstoßenen Israels sammelt sie.

3a Sie heilend die zerbrochenen Herzens sind

$3 \mathrm{~b}$ und verbindend ihre schmerzenden Wunden.

4a Bestimmend eine Anzahl von Sternen,

$4 \mathrm{~b}$ sie alle ruft sie mit Namen.

5a Groß ist unser Adonaj

$5 b$ und reich an Stärke,

5c für ihre Klugheit gibt es keine Anzahl.

6a Aufrichtend JHWH die Gebeugten,

$6 \mathrm{~b}$ erniedrigend die Frevler bis zum Boden.

7a Besingt JHWH mit einem Danklied,

$7 \mathrm{~b}$ singt/spielt unserem Gott auf der Leier.

8a Sie bedeckend den Himmel mit Wolken,

$8 \mathrm{~b}$ sie bereitend der Erde Regen,

8c sie wachsen lassend auf Bergen Gras.

9a Gebend dem Tier seine Nahrung,

$9 \mathrm{~b}$ den jungen Raben, wonach sie rufen.

10a Nicht an der Stärke des Pferdes hat sie Gefallen,

$10 \mathrm{~b}$ nicht an den Schenkeln des Mannes hat sie Wohlgefallen.

11a Wohlgefallen habend JHWH an denen, die sie fürchten,

$11 \mathrm{~b}$ an denen, die Wartenden auf ihre Huld/Güte. 
12a Rühme, Jerusalem, JHWH,

12b lobe deinen Gott, Zion.

13a Denn sie hat stark gemacht die Riegel deiner Tore,

$13 \mathrm{~b}$ sie hat gesegnet deine Kinder in deiner Mitte.

14a Sie verschaffend deiner Grenze Frieden,

14b mit bestem Weizen sättigt sie dich.

15a Sie sendend ihre Rede auf die Erde,

15b sehr schnell eilt ihr Wort.

16a Sie gebend Schnee wie die Wolle,

16b Reif wie die Asche zerstreut sie.

17a Werfend ihr Eis wie Brocken,

17b vor ihrer Kälte - wer kann bestehen?

18a Sie sendet ihr Wort und sie/es lässt sie schmelzen,

$18 \mathrm{~b}$ sie lässt wehen ihren Wind/Atem - es rinnen die Wasser.

19a Verkündend ihr Wort Jakob,

19b ihre Ordnungen und ihre Rechtsbestimmungen Israel.

20a Nicht hat sie so gehandelt an jedem Volk,

20b und die Rechtsbestimmungen haben sie nicht erkannt.

20c Lobt JH!

\section{Arbeitsübersetzung Psalm 90 1355}

1a Ein Gebet. Im Geiste Moses, des Mannes Gottes.

1b Adonaj, Wohnort bist du gewesen für uns von Generation zu Generation.

2a Bevor Berge geboren wurden

$2 \mathrm{~b}$ und du (unter Wehen) hervorbrachtest Erde und Festland -

2c und von Ewigkeit zu Ewigkeit (bist) du Gott.

3a Du lässt zurückkehren den Menschen zum Staub,

3b und sprachst: »Kehrt zurück, Menschenkinder!»

4a Ja, tausend Jahre in deinen Augen

$4 \mathrm{~b}$ wie der gestrige Tag, wenn er vorüber geht,

4c und (wie) eine Nachtwache in der Nacht.

5a Du hast sie hinweggeschwemmt, ein Schlaf sind sie,

$5 b$ am Morgen wie Gras, das wächst/wechselt.

6a Am Morgen blüht es und wächst/wechselt,

$6 \mathrm{~b}$ zum Abend hin welkt es und verdorrt.

7a Ja, wir sind vergangen durch deinen Zorn,

7b und durch deine Wut wurden wir verstört.

8a Du hast hingestellt unsere Schuld vor dich,

$8 \mathrm{~b}$ unser Verborgenes ins Licht deines Angesichts.

1355 Die Gliederung der Äußerungseinheiten folgt Fokkelman, The Psalms in Form, 100. 
9a Ja, alle unsere Tage sind vergangen durch deinen überwallenden Zorn,

$9 \mathrm{~b}$ wir haben unsere Jahre beendet wie einen Seufzer.

10a Die Tage unserer Jahre für sich (sind) 70 Jahre,

$10 \mathrm{~b}$ und wenn in Kraft 80 Jahre,

10c und ihr Stolz ist Mühe und Unheil,

10d ja, schnell ist es vorbeigegangen und wir verflogen.

11a Wer erkennend die Kraft deines Zorns

$11 \mathrm{~b}$ und gemäß der Furcht vor dir deinen überwallenden Zorn?

12a Zu zählen unsere Tage so lehre,

$12 \mathrm{~b}$ dass wir erlangen ein Herz von Weisheit.

13a Kehre doch zurück/um, JHWH - wie lange noch?

13b Und hab Mitleid/Erbarmen mit deinen Knechten.

14a Sättige uns am Morgen mit deiner Güte,

$14 \mathrm{~b}$ sodass wir jubeln und uns freuen in allen unseren Tagen.

15a Erfreue uns gleich den Tagen, an denen du uns gebeugt hast,

15b Jahre, in denen wir Unheil gesehen haben.

16a Es soll sich sehen lassen an deinen Knechten dein Werk/dein Handeln

16b und dein Glanz über ihre Kinder.

17a Und es soll sein Anmut Adonajs, unseres Gottes, über uns,

17b und die Arbeit unserer Hände festige über uns,

17c und die Arbeit unserer Hände, festige sie!

\section{$5 \quad$ Arbeitsübersetzung Psalm $64^{1356}$}

1 Für den Chorleiter. Ein Psalm. Im Geiste Davids.

2a Höre, Gott, meine Stimme in meinem Klagen.

2b Vor dem Schrecken des Feindes sollst du beschützen mein Leben.

3a Du sollst mich verstecken vor der Gemeinschaft der Übeltäter,

3b vor dem Tumult derer, die Böses tun.

4a Die geschärft haben wie das Schwert ihre Zunge,

$4 \mathrm{~b}$ sie haben angelegt ihren Pfeil - ein bitteres Wort,

5a um zu schießen in dem Versteck auf den Unschuldigen.

5b Plötzlich schießen sie auf ihn und fürchten sich nicht.

6a Sie machen sich stark mit bösem Wort,

$6 \mathrm{~b}$ sie erzählen davon, Klappnetze zu verstecken.

6c Sie haben gesagt: "Wer wird sie sehen?»

7a Sie planen Schlechtigkeiten:

7b «Wir haben es vollendet. Der Plan ist durchdacht.»

7c Und das Innere eines Menschen, das Herz (ist) unergründlich.

8a Und dann schoss Gott einen Pfeil auf sie.

8b Plötzlich waren ihre Wunden da.

1356 Die Gliederung der Äußerungseinheiten folgt Fokkelman, The Psalms in Form, 72. 
9a Und man brachte ihn zu Fall, gegen sie ihre Zunge.

9b Alle, die das sahen, schüttelten sich.

10a Da fürchteten sich alle Menschen,

$10 \mathrm{~b}$ und sie verkündeten das Tun Gottes,

10c und sein Werk haben sie begriffen.

11a Der Gerechte kann sich freuen an JHWH,

$11 \mathrm{~b}$ und er findet Zuflucht bei ihm,

11c und es sollen sich rühmen alle Herzgeraden. 
Bibelstellenregister

\begin{tabular}{|c|c|}
\hline \multirow[t]{2}{*}{ a) Altes Testament } & $42,24 \quad 121$ \\
\hline & $43,30 \quad 121$ \\
\hline GEN & $45,2 \quad 121$ \\
\hline $2-3 \quad 264$ & 45,14f. 121 \\
\hline $2,5 \quad 199$ & $49,15 \quad 185,288$ \\
\hline $3,16 \quad 262$ & $50,10 \quad 134$ \\
\hline $3,19 \quad 130,263$ & \\
\hline $4,10 \quad 150$ & EX \\
\hline $6,3 \quad 276$ & $2 \quad 108$ \\
\hline $6,5 \quad 344$ & $2,5 \quad 115$ \\
\hline $7,4 \quad 199$ & $2,16 \quad 108$ \\
\hline $8,21 \quad 344$ & $2,19 \quad 108$ \\
\hline $9,4 \quad 150$ & 9,33f. 198 \\
\hline $9,5 \quad 150$ & $11,8 \quad 119$ \\
\hline $11,1-9 \quad 24$ & $12,41 \quad 192$ \\
\hline $12,10 \quad 115$ & $12,51 \quad 192$ \\
\hline $15,5 \quad 192$ & $13,18 \quad 114$ \\
\hline $18,1-16 \quad 24$ & $15,2 \quad 107$ \\
\hline 19,19f. $\quad 113$ & $15,6 \quad 193$ \\
\hline $23,2 \quad 121,134$ & $16,8 \quad 200$ \\
\hline $24,16 \quad 115$ & $16,15 \quad 200$ \\
\hline $24,45 \quad 115$ & $16,29 \quad 200$ \\
\hline $26,2 \quad 115$ & $17,4 \quad 258$ \\
\hline $27,38 \quad 121$ & $32,7 \quad 114$ \\
\hline $29,11 \quad 121$ & $32,11-13 \quad 258$ \\
\hline $30,2 \quad 119$ & $33,1 \quad 114$ \\
\hline $31,27 \quad 110$ & 33,12 ff. $\quad 258$ \\
\hline $32,23-33 \quad 24$ & \\
\hline $34,2 \quad 286$ & LEV \\
\hline $35,18 \quad 113$ & $5,2 \quad 303$ \\
\hline $37,26 \quad 129$ & $5,3 \quad 303$ \\
\hline 41,56f. $\quad 206$ & $11,15 \quad 200$ \\
\hline $42,2 \quad 115$ & $17,11 \quad 150$ \\
\hline $42,21 \quad 128$ & $17,14 \quad 150$ \\
\hline
\end{tabular}


$20,32 \quad 113$

$23,30 \quad 113$

$23,40 \quad 287$

NUM

$5,14 \quad 266$

$5,30 \quad 266$

$6,25 \quad 274$

$7,10 \quad 105$

$7,11 \quad 105$

$7,84 \quad 105$

$7,88 \quad 105$

$11,11 \mathrm{ff} . \quad 258$

$13,17 \quad 114$

$14,13 \quad 114$

$14,45 \quad 115$

$20,19 \quad 114$

$24,7 \quad 214$

$26,12 \quad 120$

$32,11 \quad 114$

DTN

$1,21 \quad 114$

$1,26 \quad 114$

$1,41 \quad 114$

$3,23 \quad 128$

$4 \quad 182$

$4,8 \quad 217$

$6,5 \quad 113$

$12,23 \quad 150$

$14,14 \quad 200$

$15,9 \quad 196$

$20,5 \quad 105$

$22,24 \quad 286$

$22,29 \quad 286$

23,6 134

$24,15 \quad 196$

26,1-11 106

$30,1 \quad 187$

$31,2 \quad 276$

$32,10 \quad 334$

$32,18 \quad 262$

$33,11 \quad 258$

$33,15 \quad 262$

$34,7 \quad 276$
JOS

$2,19 \quad 150$

5,13-15 24

$10,10 \quad 346$

$10,11 \quad 213$

$17,17 \quad 193$

RI

3-5 42

524,25

$5,19 \quad 129$

$5,20 \quad 192$

$6,37 \quad 211$

$7,13 \quad 133$

$7,19 \quad 265$

$9,30 \quad 119$

$11,13 \quad 114$

$11,16 \quad 114$

$11,33 \quad 346$

$11,37 \quad 121$

$16,5 \quad 193$

16,5 f. $\quad 286$

$16,6 \quad 193$

$16,9 \quad 193$

$16,15 \quad 193$

$16,17 \quad 193$

$16,19 \quad 193$

$16,30 \quad 193$

$19,30 \quad 114$

$20,23 \quad 121$

$20,26 \quad 121$

RUT

$1,13 \quad 338$

$3,3 \quad 115$

$3,6 \quad 115$

1 SAM

$1,7 \mathrm{f} . \quad 121$

$1,10 \quad 121$

$2,4 \quad 135$

$2,9 \quad 193$

$4,8 \quad 346$

$4,10 \quad 346$

$8,3 \quad 129$

$9,27 \quad 115$ 
$10,9 \quad 133$

$14,23 \quad 266$

$18,6 \quad 110$

$22 \quad 25$

\section{SAM}

$1,12 \quad 121$

$1,20 \quad 110$

$1,23 \quad 185$

$1,24 \quad 121$

$3,31 \quad 134$

$11,2 \quad 84$

1341

$13,19 \quad 211$

15f. 106

22,12 198

$22,40 \quad 135$

$24 \quad 106$

24,25 106

\section{$1 \mathrm{KÖN}$}

$1,13 \quad 128$

$1,39 \quad 110$

$8,33 \quad 128$

$8,47 \quad 128$

$8,63 \quad 396$

$13,29 \quad 134$

18,29266

2 KÖN

$1,13 \quad 128$

$17,9 \quad 334$

21,13 133

25,3206

$1 \mathrm{CHR}$

21 106, 396

21-22 106

21,28-30 106

22,1 106

22,2 187

$2 \mathrm{CHR}$

$6,37 \quad 128$

$7,9 \quad 105$

11,11-12 206
$17,10 \quad 333$

$20,29 \quad 333$

$36,21 \quad 276$

$36,22 \quad 266$

ESRA

$1,1 \quad 266$

$4,22 \quad 125$

$6,9 \quad 125$

6,16-17 396

$10,7 \quad 266$

$10,13 \quad 212$

$\mathrm{NEH}$

4,16266

8,15266

$12,44 \quad 187$

JDT

$7,5 \quad 266$

\section{EST}

$4,1 \quad 211$

$4,3 \quad 121$

$4,16 \quad 187$

$9,1 \quad 134$

1 MAKK

4,52 ff. $\quad 105$

4,52-59 396

4,36-61 395

2 MAKK

$10,1 \mathrm{ff} . \quad 105$

10,1-8 395

IJOB

$1,8 \quad 340$

$2,3 \quad 340$

$2,8 \quad 211$

$2,12 \quad 121$

3254

$3,17 \quad 193$

4,19346

$5 \quad 254$

$6,4 \quad 339$ 


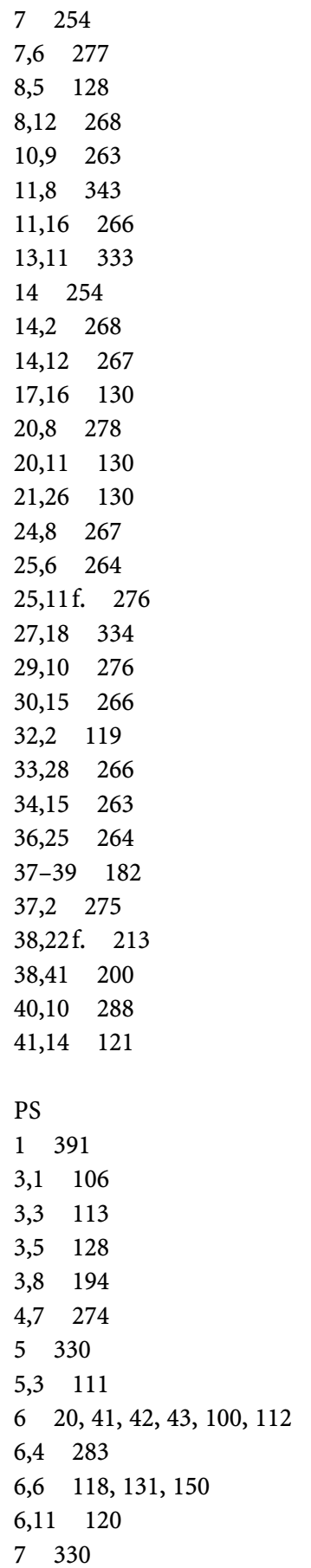

$7,11 \quad 349$

$7,13 \quad 337$

7,13f. $\quad 338$

$7,17 \quad 356$

$8 \quad 391$

$8,6 \quad 287$

$9,16 \quad 356$

10-12 330

$10,6 \quad 125$

$11,2 \quad 337,338,349$

$13,3 \quad 109$

$13,6 \quad 204$

$14 \quad 330$

$16,8 \quad 149$

$16,11 \quad 289$

$17,1 \quad 123$

$17,3 \quad 266$

$17,9 \quad 194$

$17,13 \quad 345$

$1824,41,100$

$18,3 \quad 79$

$18,12 \quad 198$

$18,13 \quad 266$

$18,18 \quad 108$

$18,33 \quad 136$

$18,40 \quad 135$

$18,41 \quad 108$

$19 \quad 391$

$19,9 \quad 110$

$21,6 \quad 288$

$21,9 \quad 108$

$22 \quad 263$

22,2f. $\quad 144$

$22,3 \quad 128$

$22,8 \quad 347$

$22,16 \quad 193$

$22,17 \quad 335$

$22,25 \quad 133$

$22,30 \quad 130$

$23 \quad 167$

$25,13 \quad 121$

$26 \quad 330$

$26,5 \quad 194,335$

$27,2 \quad 108$

$27,4 \quad 288,289$

$27,5 \quad 107,335$ 


\begin{tabular}{|c|c|}
\hline $28,1 \quad 128$ & $41,12 \quad 109$ \\
\hline $28,2 \quad 111$ & $41,14 \quad 260$ \\
\hline $28,3 \quad 194$ & $42,4 \quad 121$ \\
\hline $28,6 \quad 133$ & $42,8 \quad 266$ \\
\hline $3022,24,38,96,99-175,179,224,226,247$, & $44,2 \quad 288$ \\
\hline $256,261,293,315,324,371-375,378-$ & $44,4 \quad 274$ \\
\hline $383,385-387,395-396$ & $44,15 \quad 347$ \\
\hline $30,2 \quad 80,114$ & $45,4 \quad 288$ \\
\hline $30,4 \quad 80$ & $45,5 \quad 288$ \\
\hline $30,591,184$ & $47,2 \quad 117$ \\
\hline $30,6 \quad 203$ & $48,2 \quad 193$ \\
\hline $30,6 \quad 80$ & $49,5 \quad 283$ \\
\hline $30,9 \quad 200$ & $49,16 \quad 115$ \\
\hline $30,10 \quad 80,205$ & $51 \quad 106$ \\
\hline $30,12 \quad 80,349$ & $51,11 \quad 127$ \\
\hline 3141,100 & $51,20 \quad 205$ \\
\hline $31,17 \quad 274$ & $52-64 \quad 330$ \\
\hline $31,21 \quad 335$ & $52 \quad 330$ \\
\hline $31,23 \quad 133$ & $52,4 \quad 338$ \\
\hline $32,7 \quad 334,335$ & $52,10 \quad 204$ \\
\hline $32,11 \quad 349,350$ & $54,4 \quad 133$ \\
\hline 33169,182 & $5541,45,330$ \\
\hline $33,4-9 \quad 210$ & $55,4 \quad 194$ \\
\hline $33,7 \quad 187$ & $55,15 \quad 335$ \\
\hline $33,11 \quad 296$ & $55,23 \quad 149$ \\
\hline $34,3 \quad 107$ & $55,24 \quad 130$ \\
\hline $34,23 \quad 282$ & $56,9 \quad 121$ \\
\hline $35 \quad 324$ & $57 \quad 330$ \\
\hline 35,2 f. $\quad 345$ & $57,2 \quad 93$ \\
\hline $35,8 \quad 356$ & $57,5 \quad 337,338$ \\
\hline $35,19 \quad 110$ & $57,7 \quad 356$ \\
\hline $35,24 \quad 110$ & $58,4 \quad 194$ \\
\hline $35,26 \quad 110$ & $58,8 \quad 268,338$ \\
\hline $36,7 \quad 262$ & $58,11 \quad 350$ \\
\hline $36,11 \quad 349$ & 59356 \\
\hline $37,2 \quad 268$ & $59,8 \quad 338$ \\
\hline 37,9f. $\quad 194$ & $60,10 \quad 117$ \\
\hline $37,14 \quad 337,338$ & $61,2 \quad 123,334$ \\
\hline $37,38 \quad 194$ & $62,3 \quad 149$ \\
\hline $38,3 \quad 345$ & $62,7 \quad 125,149$ \\
\hline $38,17 \quad 110$ & $63,11 \quad 346$ \\
\hline $39,13 \quad 111$ & $63,12 \quad 350$ \\
\hline $40,2-5 \quad 24$ & $6422,25,93,99,100,144,329-370,371-$ \\
\hline $40,9 \quad 120$ & $375,377,379-382,384-386,390,395,396$ \\
\hline $40,12 \quad 334$ & $64,4 \quad 80$ \\
\hline $41,4 \quad 134$ & $64,8 \mathrm{ff} . \quad 93$ \\
\hline
\end{tabular}


$65,7 \quad 136$

$65,13 \quad 261$

$66,6 \quad 134$

67,2f. $\quad 274$

$69 \quad 24,38$

$71,4 \quad 194$

$72,6 \quad 199$

$73 \quad 356$

$73,5 \quad 264,277$

$74,10 \quad 108,283$

$76,6 \quad 267$

$\begin{array}{ll}76,8 & 213\end{array}$

$77,13 \quad 288$

$77,14 \quad 193$

$77,18 \quad 267$

$78 \quad 24$
78,16

$78,16 \quad 214$

$78,20 \quad 200$

$78,21 \quad 275$

$78,25 \quad 200$

$78,44 \quad 134$

$80,4 \quad 274$

$80,6 \quad 121$

$80,8 \quad 274$

$80,20 \quad 274$

$81 \quad 182$

$81,2 \quad 117$

$81,8 \quad 128$

$81,15 \quad 108$

$81,17 \quad 209$

$82,2 \quad 283$

$83,2 \quad 129$

84-89 45

$85,6 \quad 296$

85,9 ff. $\quad 209$

$86,14 \quad 335$

$88 \quad 112$

$88,2 \quad 144$

$88,3 \quad 123$

$88,11 \quad 118$

88,11 f. $\quad 131$

88,11-13 131, 150

$88,17 \quad 266$

$89,16 \quad 274$
$9022,38,93,94,96,99,100,245,253-327$, 354, 363, 371-375, 377-383, 385, 386, 389-391, 394-396

$90,3-6 \quad 124$

$90,4-5 \quad 80$

$90,4 \quad 80$

90,7-10 94

$90,9 \quad 80$

$90,15 \quad 342$

$90,17 \quad 288$

$91,1 \quad 335$

$92,5 \quad 288$

$92,8 \quad 194$

$93,1 \quad 135$

$93,3 \quad 261$

$94 \quad 356$

$94,3 \quad 283$

$94,15 \quad 349$

$95,3 \quad 193$

$95,9 \quad 288$

$96,4 \quad 193$

$96,11 \quad 261$

$97,11 \quad 349$

$99,2 \quad 193$

$99,5 \quad 107$

$99,9 \quad 107$

$100,5 \quad 296$

$101,8 \quad 194$

$102,13 \quad 296$

$102,25 \quad 296$

$103,15 \quad 264,268$

$103,16 \quad 266$

$104 \quad 182,391$

$104,1 \quad 288$

$104,14 \quad 268$

$104,29 \quad 127,263$

$105 \quad 24$

$105,29 \quad 134$

$105,40 \quad 200$

$106 \quad 24$

$106,44 \quad 123$

107-150 43

$107,25 \quad 107$

$107,30 \quad 136$

$107,32 \quad 107$

$109 \quad 24$ 


\begin{tabular}{|c|c|}
\hline $109,25 \quad 347$ & $145,14 \quad 195$ \\
\hline $111,3 \quad 288$ & $145,19 \quad 120$ \\
\hline $113,1 \quad 282$ & $146,1 \quad 183$ \\
\hline $113,7 \quad 131$ & 146,8f. $\quad 195$ \\
\hline 113,7f. 195 & $146,10 \quad 296$ \\
\hline $114,8 \quad 134$ & $14722,38,96,99,100,140,177-252,256$, \\
\hline $115,17 \quad 131$ & $261,293,315,354,371-376,378-383$ \\
\hline $116,2 \quad 128$ & $385,386,388,392-394,396$ \\
\hline $116,3 \quad 162$ & $147,1 \quad 91$ \\
\hline $116,8 \quad 162$ & $147,2 \quad 205$ \\
\hline $116,9 \quad 162$ & $147,3 \quad 112$ \\
\hline $116,19 \quad 162$ & $147,4-5 \quad 74$ \\
\hline $118,5 \quad 128$ & $147,7 \quad 91$ \\
\hline $118,28 \quad 107$ & $147,8 \quad 268$ \\
\hline 119182,391 & $147,12 \quad 80,205$ \\
\hline $119,36 \quad 129$ & $147,13 \quad 206$ \\
\hline $119,90 \quad 296$ & $147,15 \quad 80$ \\
\hline $119,114 \quad 335$ & $147,16-17 \quad 80$ \\
\hline $119,169 \quad 123$ & $147,20 \quad 91$ \\
\hline $124,3 \quad 119$ & \\
\hline $124,4 \mathrm{f} . \quad 266$ & SPR \\
\hline $125,2 \quad 126$ & $1,32 \quad 125$ \\
\hline $125,4 \quad 349$ & $2,2 \quad 281$ \\
\hline 126,5 f. $\quad 121$ & $2,8 \quad 334$ \\
\hline $129,6 \quad 268$ & $2,10 \quad 281$ \\
\hline $130,3 \quad 213$ & $2,11 \mathrm{f} . \quad 334$ \\
\hline $134,1 \quad 282$ & $3,17 \quad 288$ \\
\hline $135 \quad 24$ & $4,6 \quad 334$ \\
\hline $135,1 \quad 282$ & $6,8 \quad 200$ \\
\hline $135,5 \quad 193$ & $8 \quad 254$ \\
\hline $135,14 \quad 282$ & $8,22-31 \quad 254$ \\
\hline 13624,182 & $8,29 \quad 266$ \\
\hline $136,25 \quad 200$ & $8,35 f . \quad 113$ \\
\hline $137,3 \quad 110$ & $10,25 \quad 266$ \\
\hline $138,3 \quad 128$ & $14,33 \quad 281$ \\
\hline $140,2 \quad 334$ & $15,26 \quad 288$ \\
\hline $140,5 \quad 194,334$ & $15,30 \quad 110$ \\
\hline $141,10 \quad 356$ & $16,24 \quad 288$ \\
\hline $142,2 \quad 128$ & $17,1 \quad 212$ \\
\hline $142,7 \quad 123$ & $17,5 \quad 110$ \\
\hline $143,5 \quad 288$ & $18,4 \quad 343$ \\
\hline $144 \quad 391$ & $20,5 \quad 108,343$ \\
\hline $144,4 \quad 266$ & $20,29 \quad 287$ \\
\hline $145,1 \quad 107$ & $21,24 \quad 275$ \\
\hline $145,3 \quad 193$ & $23,5 \quad 278$ \\
\hline $145,13 \quad 296$ & $25,3 \quad 343$ \\
\hline
\end{tabular}




\begin{tabular}{|c|c|}
\hline $26,2 \quad 278$ & $4,6 \quad 267$ \\
\hline $26,7 \quad 108$ & $5,28 \quad 337$ \\
\hline $26,27 \quad 356$ & $8,22 \quad 187$ \\
\hline $27,7 \quad 113$ & $9,18 \quad 275$ \\
\hline $27,18 \quad 334$ & $11,12 \quad 182,187$ \\
\hline $28,16 \quad 129$ & $13,7 \quad 264$ \\
\hline $28,21 \quad 212$ & $13,14 \quad 187$ \\
\hline $30,25 \quad 200$ & 14,7 f. $\quad 268$ \\
\hline $31,10-31 \quad 39$ & $14,29 \quad 110$ \\
\hline $31,13 \quad 211$ & $15,6 \quad 268$ \\
\hline & 16,3f. 187 \\
\hline $\mathrm{KOH}$ & $16,6 \quad 275$ \\
\hline $2 \quad 254,281$ & $25,1 \quad 107$ \\
\hline $2,8 \quad 187$ & $25,4 \quad 267$ \\
\hline $2,26 \quad 187$ & $25,8 \quad 121$ \\
\hline $3 \quad 254$ & $25,12 \quad 263$ \\
\hline $3,4 \quad 134$ & $26,5 \quad 263$ \\
\hline $3,5 \quad 187$ & $26,19 \quad 130$ \\
\hline $3,20 \quad 130,263$ & $26,20 \quad 266$ \\
\hline $5 \quad 254$ & $27,13 \quad 187$ \\
\hline $6,9 \quad 113$ & $28,2 \quad 267$ \\
\hline $7,24 \quad 344$ & $29,5 \quad 340$ \\
\hline $8 \quad 254$ & $30,19 \quad 121$ \\
\hline $8,11 \quad 344$ & $30,30 \quad 267$ \\
\hline $9 \quad 254$ & $32,2 \quad 267$ \\
\hline $9,3 \quad 344$ & $35,2 \quad 287$ \\
\hline $11 \quad 254$ & 38100,112 \\
\hline $11,10 \quad 266$ & $38,8 \quad 263$ \\
\hline $12,7 \quad 130$ & $38,12 \quad 277$ \\
\hline $12,14 \quad 303$ & $38,18 \mathrm{f} . \quad 118,131$ \\
\hline & $40-66 \quad 182$ \\
\hline HLD & $40,9 \quad 205$ \\
\hline $1,5 \quad 185$ & $40,26 \quad 192,193$ \\
\hline $1,10 \quad 185$ & $40,28 \quad 192$ \\
\hline $1,16 \quad 185$ & $40,29 \quad 195$ \\
\hline $2,11 \quad 212,266$ & $41,7 \quad 206$ \\
\hline $4,3 \quad 185$ & $42,6 \quad 334$ \\
\hline $4,15 \quad 214$ & $42,14 \quad 262$ \\
\hline & $42,15 \quad 268$ \\
\hline SIR & $44,23 \quad 220$ \\
\hline $17,27 \mathrm{f} . \quad 131$ & $44,26 \quad 205$ \\
\hline & $45,23 \quad 210$ \\
\hline JES & $48,21 \quad 214$ \\
\hline $1,14 \quad 113$ & $49,13 \quad 220$ \\
\hline $1,18 \quad 211$ & $49,14-26 \quad 205$ \\
\hline $1,21 \quad 121$ & $51,17-23 \quad 205$ \\
\hline
\end{tabular}


52,1-2 205

52,7-9 205

$53,2 \quad 287$

$54 \quad 205$

$54,2 \quad 206$

55,8-13 215

$55,11 \quad 210$

$56,8 \quad 187$

$58,5 \quad 211$

$61,3 \quad 135$

$65,19 \quad 121$

65,25200

66205

JER

$3,21 \quad 121$

$6,26 \quad 340$

$8,3 \quad 187$

$8,20 \quad 266$

$9,10 \quad 258$

$10,22 \quad 258$

15,8f. $\quad 340$

$16,15 \quad 187$

$17,9 \quad 343,344$

$17,14 \quad 112$

$18,16 \quad 347$

23,2-3 187

$23,8 \quad 187$

$24,9 \quad 187$

27,10 187

$30,13 \quad 112$

$30,17 \quad 112$

$31,13 \quad 134$

$31,15 \quad 121$

$33,6 \quad 112$

$48,5 \quad 121$

$48,27 \quad 347$

48,29f. 275

$49,33 \quad 258$

$50,11 \quad 136$

$51,39 \quad 267$

$51,57 \quad 267$

KLGL

2,16 109

$2,17 \quad 109$
$3,44 \quad 266$

$3,46 \quad 109$

$5,15 \quad 134$

BAR

2,17f. 131

EZ

$2,10 \quad 275$

$4,13 \quad 187$

$6,12 \quad 334$

22,21 187

25,6 110, 136

$31,4 \quad 107$

$34,3 \quad 211$

$35,15 \quad 110$

36,5110

$39,28 \quad 187$

$44,17 \quad 211$

DAN

$6,5 \quad 125$

$7,9 \quad 211$

$9,2 \quad 276$

$9,3 \quad 211$

HOS

$5,2 \quad 343$

$5,13 \quad 112$

$9,9 \quad 343$

$13,11 \quad 275$

JOËL

$1,19 \quad 128$

225

AM

8,5266

$8,10 \quad 134$

JONA

224,100

$2,4 \quad 266$

MI

$7,8 \quad 110$ 
$\mathrm{NAH}$

$1,8 \quad 266$

$2,12 \quad 258$

3,13-14 206

$27,39 \quad 347$

$\mathrm{HAB}$

$1,11 \quad 266$

$3,8 \quad 275$

$3,10 \quad 266,267$

ZEF

3,14-18 205

HAG

$2,22 \quad 133$

\section{$\mathrm{SACH}$}

$11,7 \quad 288$

$11,10 \quad 288$

\section{b) Neues Testament}

MT

$11,17 \quad 134$

LK

$1,52 \quad 195$

$7,32 \quad 134$

10,25-37 21

$12,20 \quad 346$

$12,24 \quad 200$

$15,11-32 \quad 21$

$\mathrm{JOH}$

$10,22 \quad 105$

EPH

$5,19 \quad 17$

HEBR

$4,12 \quad 210$ 